

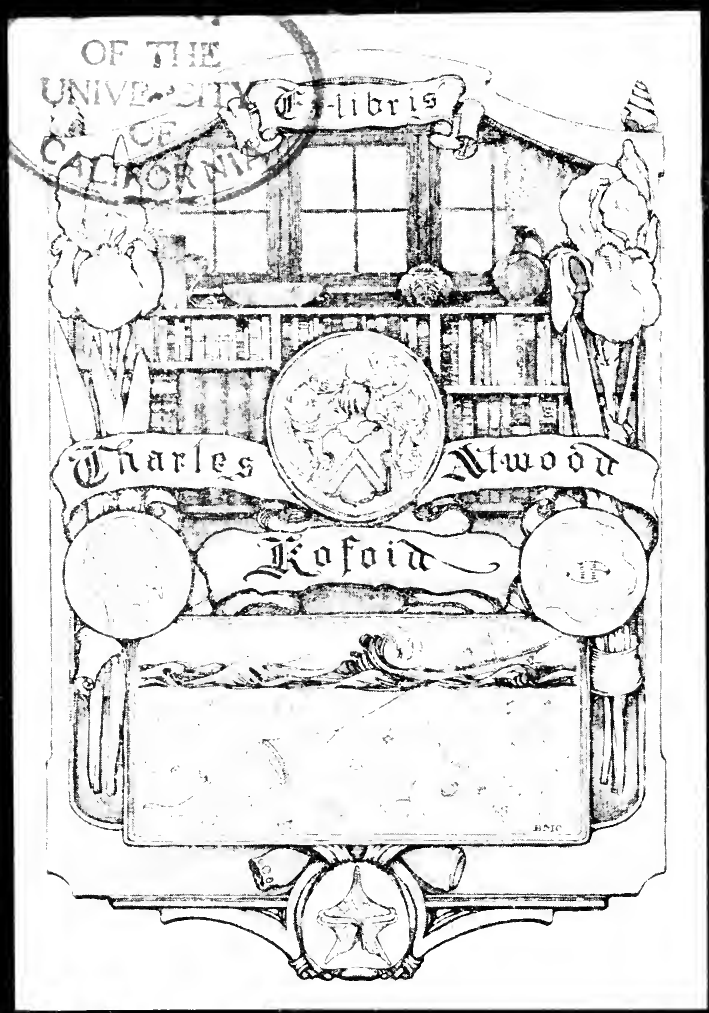




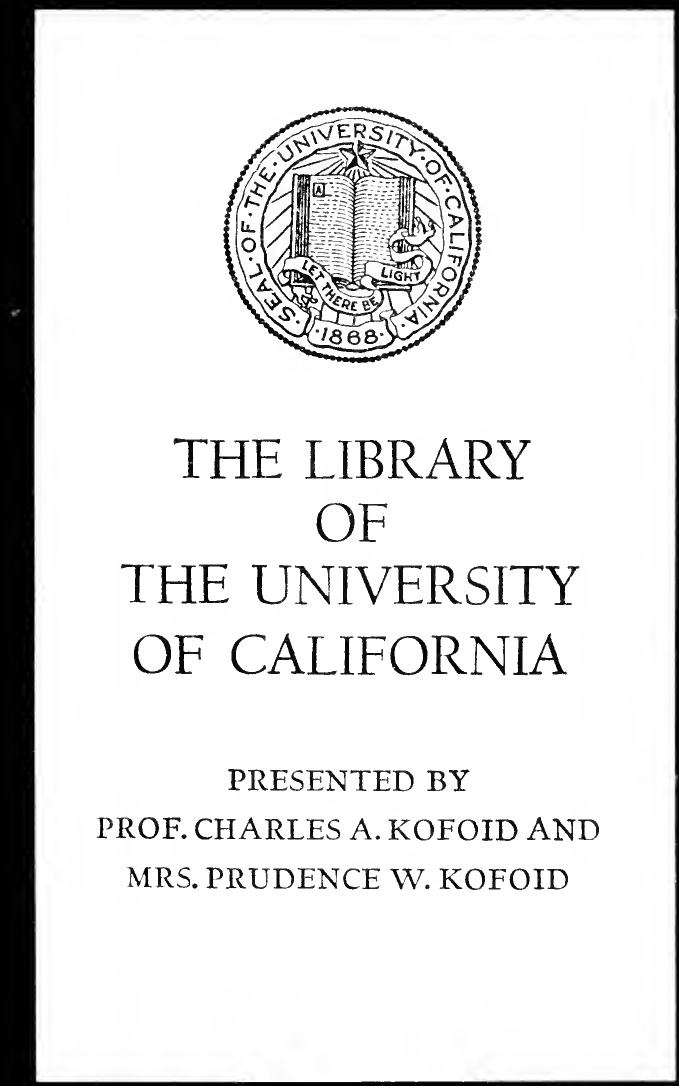




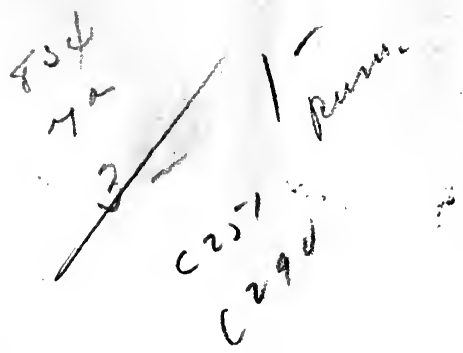




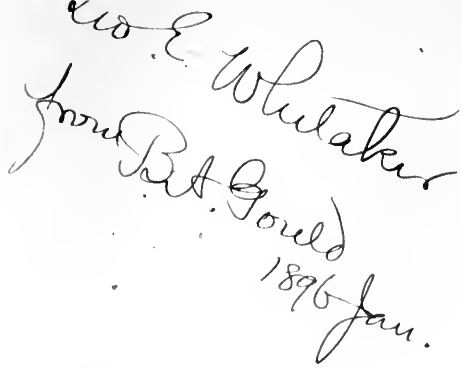

HISTORY OF ASTRONOMY 




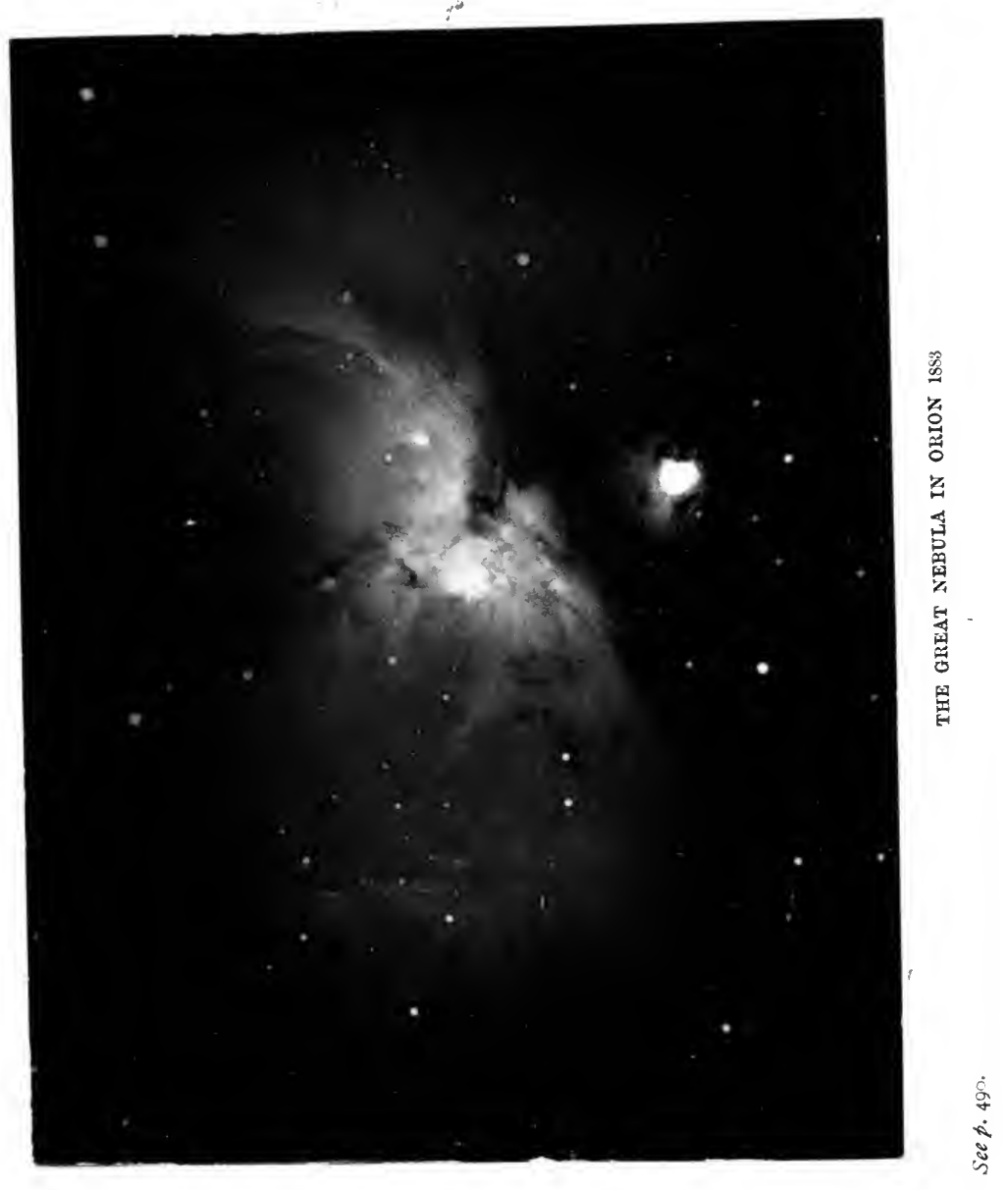




\section{$\because \quad$ A POPULAR \\ HISTORY OF ASTRONOMY \\ DURING}

\section{THE NINETEENTH CENTURY}

BY

AGNES M. COLERKE

JUPITER 1879

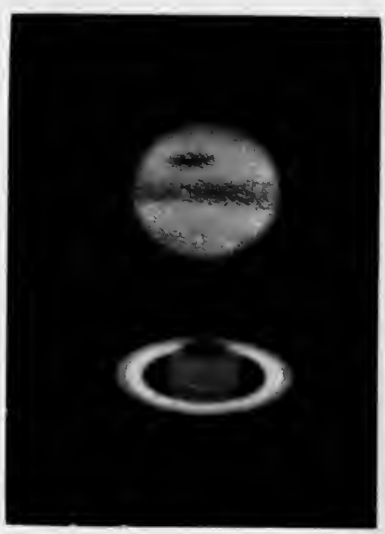

SATURN 1885

THIRD EDITION

LONDON: ADAM \& CHARLES BLACK 1893 



\section{PREFACE TO THE THIRD EDITION.}

The interval of six years since the publication of the Second Edition of the present work has been marvellously fruitful of astronomical discoveries. Hence a searching revision was called for, and has been executed without stint of care or pains. Additions and substitutions have been freely made; and it has been the aim of the writer, not only to furnish the large amount of requisite new information, but to incorporate it so completely with the pre-existing text as to leave no gaps in the narrative suggesting "interpolations" to the refined critical sense. The book has thus grown, and been brought down to date, by a process of assimilation, rather than of mere accretion. Its adjuncts, too, have been renovated. The foot-note references have been multiplied; the Index has been rendered more copious; the Chronological Table has been considerably extended; and several new Tables of data, likely to be useful, while not everywhere accessible to students, have been appended. Besides the Frontispiece and Vignette, retained from the Second Edition, for which the writer renews her thanks to Dr. Common and the MM. Henry, five Plates have been prepared, with the most kind assistance of Mr. Ranyard, especially for the Third. Their availability is due to the courtesy of the Council of the Royal Astronomical Society, of Professor George E. Hale, of Professor 
Barnard, and of Dr. and Mrs. Huggins, to all of whom the writer offers grateful acknowledgments. She ventures to hope that the remodelled work will enjoy no less favour with the public than was shown to its earlier issues.

LoNdon, Ma!! I893. 


\section{PREFACE TO THE FIRST EDITION.}

The progress of astronomy during the last hundred years has been rapid and extraordinary. In its distinctive features, moreover, the nature of that progress has been such as to lend itself with facility to untechnical treatment. To this circumstance the present volume owes its origin. It embodies an attempt to enable the ordinary reader to follow, with intelligent interest, the course of modern astronomical inquiries and to realise (so far as it can at present be realised) the full effect of the comprehensive change in the whole aspect, purposes, and methods of celestial science introduced by the momentous discovery of spectrum analysis.

Since Professor Grant's invaluable work on the History of Physical Astronomy was published, a third of a century has elapsed. During the interval, a so-called "new astronomy" has grown up by the side of the old. One effect of its advent has been to render the science of the heavenly bodies more popular, both in its needs and in its nature, than formerly. More popular in its needs, since its progress now primarily depends upon the interest in, and consequent efforts towards its advancement of the general public; more popular in its nature, because the kind of knowledge it now chiefly tends to accumulate is more easily intelligible-less remote from ordi- 
nary experience-than that evolved by the aid of the calculus from materials collected by the use of the transit-instrument and chronograph.

It has thus become practicable to describe in simple language the most essential parts of recent astronomical discoveries; and being practicable, it could not be otherwise than desirable to do so. The service to astronomy itself would be not inconsiderable of enlisting wider sympathies on its behalf; while to help one single mind towards a fuller understanding of the manifold works which have, in all ages, irresistibly spoken to man of the glory of God, might well be an object of no ignoble ambition.

The present volume does not profess to be a complete or exhaustive History of Astronomy during the period covered by it. Its design is to present a view of the progress of celestial science, on its most characteristic side, since the time of Herschel. Abstruse mathematical theories, unless in some of their more striking results, are excluded from consideration. These, during the eighteenth century, constituted the sum and substance of astronomy; and their fundamental importance can never be diminished, and should never be ignored. But, as the outcome of the enormous development given to the powers of the telescope in recent times, together with the swift advance of physical science, and the inclusion, by means of the spectroscope, of the heavenly bodies within the domain of its inquiries, much knowledge has been acquired regarding the nature and condition of those bodies, forming, it might be said, a science apart, and disembarrassed from immediate dependence upon intricate, and except to the initiated, unintelligible formulæ. This kind of knowledge forms the main subject of the book now offered to the public.

There are many reasons for preferring a history to a formal treatise on astronomy. In a treatise, what we know is set 
forth. $\bar{A}$ history tells us, in addition, how we came to know it. It thus places facts before us in the natural order of their ascertainment, and narrates instead of enumerating. The story to be told leaves the marvels of imagination far behind, and requires no embellishment from literary art or high-flown phrases. Its best ornament is unvarnished truthfulness, and this at least may confidently be claimed to be bestowed upon it in the ensuing pages.

In them unity of treatment is sought to be combined with a due regard to chronological sequence by grouping in separate chapters the various events relating to the several departments of descriptive astronomy. The whole is divided into two parts, the line between which is roughly drawn at the middle of the present century. Herschel's inquiries into the construction of the heavens strike the keynote of the first part; the discovery of sun-spot and magnetic periodicity and of spectrum analysis determine the character of the second. Where the nature of the subject required it, however, this arrangement has been disregarded. Clearness and consistency should obviously take precedence of method. Thus, in treating of the telescopic scrutiny of the various planets, the whole of the related facts have been collected into an uninterrupted narrative. A division, elsewhere natural and helpful, would here have been purely artificial, and therefore confusing.

The interests of students have been consulted by a full and authentic system of references to the sources of information relied upon. Materials have been derived, as a rule with very few exceptions, from the original authorities. The system adopted has been to take as little as possible at second-hand. Much pains have been taken to trace the origin of ideas, often obscurely enunciated long before they came to resound through the scientific world, and to give to each individual discoverer, strictly and impartially, his due. Prominence has 
also been assigned to the biographical element, as underlying and determining the whole course of human endeavour. The advance of knowledge may be called a vital process. The lives of men are absorbed into and assimilated by it. Inquiries into the kind and mode of the surrender in each separate case must always possess a strong interest whether for study or for example.

The acknowledgments of the writer are due to Professor Edward S. Holden, director of the Washburn Observatory, Wisconsin, and to Dr. Copeland, chief astronomer of Lord Crawford's Observatory at Dunecht, for many valuable communications.

LoNDON, September 1885. 


\section{CONTENTS.}

\section{INTRODUCTION.}

Three Kinds of Astronomy-Progress of the Science during the Eighteenth Century-Popularity and Rapid Advance during the Nineteenth Century . . . . . . . . Page I

\section{PART I.}

PROGRESS OF ASTRONOMY DURING THE FIRST HALF OF THE NINETEENTH CENTURY.

\section{CHAPTER I.}

FOUNDATION OF SIDEREAL ASTRONOMY.

State of Knowledge regarding the Stars in the Eighteenth CenturyCareer of Sir William Herschel-Constitution of the Stellar System -Double Stars-Herschel's Discovery of their Revolutions-His Method of Star-Gauging-Discoveries of Nebulæ-Theory of their Condensation into Stars-Summary of Results . . . Page ro

\section{CHAPTER II.}

PROGRESS OF SIDEREAL ASTRONOMY.

Exact Astronomy in Germany-Career of Bessel-His Fundamenta Astronomice-Career of Fraunhofer-Parallaxes of Fixed StarsTranslation of the Solar System-Astronomy of the InvisibleStruve's Researches in Double Stars-Sir John Herschel's Exploration of the Heavens-Character of Fifty Years' Progress . . Page 32 
CHAPTER JII.

PROGRESS OF KNOWLEDGE REGARDING THE SUN.

Early Views as to the Nature of Sun-Spots-Wilson's Observations and Reasonings-Herschel's Theory, of the Solar Constitution-Sir John Herschel's Trade-Wind Hypothesis-Baily's Beads-Total Solar Eclipse of 1842-Corona and Prominences-Eclipse of I851 Page

\section{CHAPTER IV.}

PLANETARY DISCOVERIES.

Bode's Law-Search for a Missing Planet-Its Discovery by Piazzi-

Further Discoveries of Minor Planets-Unexplained Disturbance of Uranus-Discovery of Neptune-Its Satellite-An Eighth Saturnian Moon-Saturn's Dusky Ring-The Uranian System . . Page

\section{CHAPTER V.}

COMETS.

Predicted Return of Halley's Comet-Career of Olbers-Acceleration of Encke's Comet-Biela's Comet-Its Duplication-Faye's CometComet of I8II-Electrical Theory of Cometary Emanations-The Earth in a Comet's Tail-Second Return of Halley's Comet-Great Comet of 1843-Results to Knowledge . . . . Page 109

CHAPTER VI.

INSTRUMENTAL ADVANCES.

Two Principles of Telescopic Construction-Early Reflectors-Three Varieties-Herschel's Specula-High Magnifying Powers-Invention of the Achromatic Lens-Guinand's Optical Glass-The Great Rosse Reflector-Its Disclosures-Mounting of Telescopes-Astronomical Circles-Personal Equation . . . . . . . Page I34

\section{PART II.}

RECENT PROGRESS OF ASTRONOMY.

\section{CHAPTER I.}

FOUNDATION OF ASTRONOMICAL PHYSICS.

Schwabe's Discovery of a Decennial Sun-Spot Period-Coincidence with Period of Magnetic Disturbance-Sun-Spots and Weather-Spectrum Analysis-Preliminary Inquiries-Fraunhofer Lines-Kirchhoff's Principle-Anticipations-Elementary Principles of Spectrum AnalysisUnity of Nature . . . . . . . . . Page 


\section{CHAPTER II.}

SOLAR OBSERVATIONS AND THEORIES.

Black Openings in Spots-Carrington's Observations-Rotation of the Sun-Kirchhoff's Theory of the Solar Constitution-Faye's ViewsSolar Photography-Kew Observations-Spectroscopic MethodCyclonic Theory of Sun-Spots-Volcanic Hypothesis-A Solar Outburst-Sun-Spot Periodicity-Planetary Influence-Nasmyth's Willow Leaves . . . . . . . . . . . Page 178

\section{CHAPTER III.}

\section{RECENT SOLAR ECLIPSES.}

Expeditions to Spain-Great Indian Eclipse-New Method of Viewing Prominences-Total Eclipse Visible in North America-Spectrum of the Corona-Eclipse of 1870-Young's Reversing Layer-Eclipse of 1871-Corona of 1878-Varying Types-Egyptian Eclipse-ExtraEclipse Coronal Photography-Observations at Caroline IslandDiffraction Theory of Corona-Photographs of Corona in 1886 and I889-Mechanical Theory-Mathematical Theory-Nature of Corona

Page 207

\section{CHAPTER IV.}

\section{SPECTROSCOPIC WORK ON THE SUN.}

Chemistry of Prominences-Study of their Forms-Two Classes-Distribution of Prominences-Structure of the Chromosphere-Spectroscopic Measurement of Movements in Line of Sight-Spectroscopic Determination of Solar Rotation-Velocities of Transport in the Sun -Lockyer's Theory of Dissociation-Solar Constituents-Absence of Oxygen .

Page 24I

\section{CHAPTER V.}

\section{TEMPERATURE OF THE SUN.}

Thermal Power of the Sun-Radiation and Temperature-Estimates of Solar Temperature-Rosetti's Result-Zöllner's Method-Langley's Experiment at Pittsburg-The Sun's Atmosphere-Selective Absorption by our Air-The Sun Blue-The Solar Constant . . . 


\section{CHAPTER VI.}

THE SUN'S DISTANCE.

Difficulty of the Problem-Oppositions of Mars-Transits of Venus-

Lunar Disturbance-Velocity of Light-Transit of 1874-Inconclusive Result-Opposition of Mars in 1877-Measurements of Minor Planets -Transit of I882-Newcomb's Determination of the Velocity of Light -Combined Result . . . . . . . . . Page 280

\section{CHAPTER VII.}

PLANETS AND SATELLITES.

Schröter's Life and Work-Luminous Appearances during Transits of Mercury-Mountains of Mercury-Rotation-Intra-Mercurian Planets - Schiaparelli's Conclusion as to the Rotation of Venus-Mountains and Atmosphere of Venus - Ashen Light - Illusory Satellite Solidity of the Earth-Secular Changes of Climate-Figure of the Globe-Study of the Moon's Surface-Lunar Atmosphere-New Craters-Thermal Effects of Moonlight-Tidal Friction . Fage 299

\section{CHAPTER VIII.}

PLANETS AND SATELlites (continued).

Analogy between Mars and the Earth-Martian Snowcaps, Seas, and Continents-Climate and Atmosphere-Schiaparelli's Canals-Discovery of Two Martian Satellites-Distribution of the Minor Planets -Their Collective Mass and Estimated Diameters-Condition of Jupiter-His Spectrum-Transits of his Satellites-Their Mode of Rotation-Discovery of an Inner Satellite-The Great Red SpotConstitution of Saturn's Rings-Period of Rotation of the Planet -Variability of Japetus-Equatorial Markings on Uranus-His Spectrum-Rotation of Neptune-Trans-Neptunian Planets Page 336

\section{CHAPTER IX.}

THEORIES OF PLANETARY EVOLUTION.

Origin of the World according to Kant-Laplace's Nebular HypothesisMaintenance of the Sun's Heat-Meteoric Hypothesis-Radiation the Result of Contraction-Regenerative 'Theory-Faye's Scheme of Planetary Development-Origin of the Moon-Effects of Tidal Friction 


\section{CHAPTER $\mathrm{X}$.}

RECENT COMETS.

Donati's Comet-The Earth again Involved in a Comet's Tail-Comets of the August and November Meteors-Star Showers-Comets and Meteors-Biela's Comet and the Andromedes-Orbits of Meteorites -Meteors with Stationary Radiants-Spectroscopic Analysis of Cometary Light .. . . . . . . . . Page

\section{CHAPTER XI. \\ RECENT COMETS (continued).}

Forms of Comets' Tails-Electrical Repulsion-Bredichin's Three TypesGreat Southern Comet-Supposed Previous Appearances-Tebbutt's Comet and the Comet of I807-Successful Photographs-Schaeberle's Comet-Comet Wells-Sodium Blaze in Spectrum-Great Comet of 1882-Transit Across the Sun-Relation to Comets of 1843 and 1880 -Cometary Systems-Origin of Comets-Rediscovery of Lexell's Comet-Swift's Comet-Holmes's Comet . . . . Page

\section{CHAPTER XII.}

STARS AND NEBULA.

Stellar Chemistry-Four Orders of Stars-Their Relative Ages-Gaseous Stars-Spectroscopic Star-Catalogues-Stellar Chemistry-The Draper Catalogue-Velocities of Stars in Line of Sight-Spectroscopic Binaries-Eclipses of Algol-New Stars-Outbursts in NebulæNova Aurigæ-Gaseous Nebulæ-Variable Nebulæ-Movements of Nebulæ-Stellar and Nebular Photography-Nebulæ in the Pleiades -Photographic Star-Charting-Stellar Parallax-Double StarsStellar Photometry-Status of Nebulæ-Photographs and Drawings of the Milky Way-Star Drift . . . . . . Page 450

\section{CHAPTER XIII.}

\section{METHODS OF RESEARCH.}

Development of Telescopic Power-Silvered Glass Reflectors-Giant Refractors-Comparison with Reflectors-The Lick Telescope-Atmospheric Disturbance-Mechanical Difficulties-The Equatoreal Coudé -The Photographic Camera-Retrospect and Conclusion . Page 5 I2 
$\because=\quad$ 


\section{LIST OF ILLUSTRATIONS.}

Photograph of the Great Nebula in Orion (1883) . . Frontispiece Photographs of Jupiter (1879) and of Saturn (1885) . V Vignette

Plate I. Photographs of the Solar Chromosphere and Proninences . . . . . . . To face $p .246$

"II. The Great Comet of September I882 photographed at the Cape . . . . . $\quad$, 434

, III. Photographs of Swift's Comet (1892) • . . , 446

, IV. Photographic and Visual Spectrum of Nova Aurigæ . . . • . • . " " " 478

"V. Photograph of the Milky Way in Sagittarius " 508 


\title{
HISTORY OF ASTRONOMY
}

\author{
DLRING THE NINETEENTH CENTURY.
}

\section{INTRODLCCTION.}

WE can distinguish three kinds of astronomy, each with a different origin and histors, but all mutually dependent, and composing, in their fundamental unity, one science. First in order of time came the art of observing the returns and measuring the places of the hearenly bodies. This was the sole astronomr of the Chinese and Chaldeans; but to it the vigorous Greet mind added a highly complex geometrical plan of their morements. for which Copernicus substituted a more harmonious svstem. without as ret any idea of a compelling cause. The planets revolred in circles because it was their nature to do so, just as laudanum sets to sleep because it possesses a virtus lormitica. This first and oldest branch is known as "observational." or "practical astronomy." Its business is to note facts as accurately as possible: and it is essentially unconcerned with schemes for connecting those facts in a manner satisfactory to the reason.

The second kind of astronomy was founded by Newton. Its nature is best indicated by the term "gravitational"; but it is also called "theoretical astronomy." I It is based on the idea of cause; and the whole of its elaborate structure is reared according to the dictates of a single law, simple in itself, but the

1 The denomination "phrsical astronomy," first used by Kepler, and long appropriated to this branch of the science, has of late been otherwise applied. 
tangled web of whose consequences can be unravelled only by the subtle agency of an elaborate calculus.

The third and last division of celestial science may properly be termed "physical and descriptive astronomy." It seeks to know what the heavenly bodies are in themselves, leaving the How? and the Wherefore? of their movements to be otherwise answered. Now such inquiries became possible only with the invention of the telescope, so that Galileo was, in point of fact, their originator. But Herschel was the first to give them a prominence which the whole progress of science during the nineteenth century has served to confirm and render more exclusive. Inquisitions begun with the telescope have been extended and made effective in unhoped-for directions by the aid of the spectroscope and photographic camera; and a large part of our attention in the present volume will be occupied with the brilliant results thus achieved.

The unexpected development of this new physical-celestial science is the leading fact in recent astronomical history. It was out of the regular course of events. In the degree in which it has actually occurred it could certainly not have been foreseen. It was a seizing of the prize by a competitor who had hardly been thought qualified to enter the lists. Orthodox astronomers of the old school looked with a certain contempt upon observers who spent their nights in scrutinising the faces of the moon and planets rather than in timing their transits, or devoted daylight energies, not to reductions and computations, but to counting and measuring spots on the sun. They were regarded as irregular practitioners, to be tolerated perhaps, but certainly not encouraged.

The advance of astronomy in the eighteenth century ran in general an even and logical course. The age succeeding Newton's had for its special task to demonstrate the universal validity, and trace the complex results of the law of gravitation. The accomplishment of that task occupied just one hundred years. It was virtually brought to a close when Laplace explained to the French Academy, November 19, I787, the cause of the moon's accelerated motion. As a mere machine, the solar system, so far 
as it was then known, was found to be complete and intelligible in all its parts ; and in the Mécanique Céleste its mechanical perfections were displayed under a form of majestic unity which fitly commemorated the successive triumphs of analytical genius over problems among the most arduous ever dealt with by the mind of man.

Theory, however, demands a practical test. All its data are derived from observation; and their insecurity becomes less tolerable as it advances nearer to perfection. Observation, on the other hand, is the pitiless critic of theory; it detects weak points, and provokes reforms which may be the beginnings of discovery. Thus, theory and observation mutually act and react, each alternately taking the lead in the endless race of improve.ment.

Now, while in France Lagrange and Laplace were bringing the gravitational theory of the solar system, to completion, work of a very different kind, yet not less indispensable to the future welfare of astronomy, was being done in England. The Royal Observatory at Greenwich is one of the few useful institutions which date their origin from the reign of Charles II. The leading position which it still occupies in the science of celestial observation was, for near a century and a half after its foundation, an exclusive one. Delambre remarked that, had all other materials of the kind been destroyed, the Greenwich records alone would suffice for the restoration of astronomy $;^{1}$ and the establishment was indeed absolutely without a rival. Systematic observations of sun, moon, stars, and planets were during the whole of the eighteenth century made only at Greenwich. Here materials were accumulated for the secure correction of theory, and here refinements were introduced by which the exquisite accuracy of modern practice in astronomy was eventually attained.

The chief promoter of these improvements was James Bradley. Few men have possessed in an equal degree with him the power of seeing accurately, and reasoning on what they see. He let nothing pass. The slightest inconsistency between what appeared and what was to be expected roused his keenest attention;

${ }^{1}$ Histoire de l'Astronomie au xviiie Siecle, p. 267. 
and he never relaxed his mental grip of a subject until it had yielded to his persistent inquisition. It was to these qualities that he owed his discoveries of the aberration of light and the nutation of the earth's axis. The first was announced in I729. What is meant by it is that, owing to the circumstance of light not being instantaneously transmitted, the heavenly bodies appear shifted from their true places by an amount depending upon the ratio which the velocity of light bears to the speed of the earth in its orbit. Because light travels with enormous rapidity, the shifting is very slight; and each star returns to its original position at the end of a year.

Bradley's second great discovery was finally ascertained in I748. Nutation is a real "nodding" of the terrestrial axis produced by the dragging of the moon at the terrestrial equatorial protuberance. From it results an apparent displacement of the stars, each of them describing a little ellipse about its true or " mean" position, in a period of eighteen years and about seven months.

Now an acquaintance with the fact and the laws of each of these minute irregularities is vital to the progress of observational astronomy; for without it the places of the heavenly bodies could never be accurately known or compared. So that Bradley, by their detection, at once raised the science to a higher grade of precision. Nor was this the whole of his work. Appointed Astronomer-Royal in I742, he executed during the years I75062 a series of observations which formed the real beginning of exact astronomy. Part of their superiority must, indeed, be attributed to the co-operation of John Bird, who provided Bradley in I 750 with a measuring instrument of till then unequalled excellence. For not only was the art of observing in the eighteenth century a peculiarly English art, but the means of observing were furnished almost exclusively by British artists. John Dollond, the son of a Spitalfields weaver, invented the achromatic lens in 1758 , removing thereby the chief obstacle to the development of the powers of refracting telescopes; James Short, of Edinburgh, was without a rival in the construction of reflectors; the sectors, quadrants, and circles of Graham, Bird, 
Ramsden, and Cary were inimitable by Continental workmanship.

Thus practical and theoretical astronomy advanced on parallel lines in England and France respectively, the improvement of their several tools-the telescope and the quadrant on the one side, and the calculus on the other-keeping pace. The whole future of the science seemed to be theirs. The cessation of interest through a too speedy attainment of the perfection towards which each spurred the other, appeared to be the only danger it held in store for them. When, all at once a rival stood by their side-not, indeed, menacing their progress, but threatening to absorb their popularity.

The rise of Herschel was the one conspicuous anomaly in the astronomical history of the eighteenth century. It proved decisive of the course of events in the nineteenth. It was unexplained by anything that had gone before; yet all that came after hinged upon it. It gave a new direction to effort; it lent a fresh impulse to thought. It opened a channel for the widespread public interest which was gathering towards astronomical subjects, to flow in.

Much of this interest was due to the occurrence of events calculated to arrest the attention and excite the wonder of the uninitiated. The predicted return of Halley's comet in I759 verified, after an unprecedented fashion, the computations of astronomers. It deprived such bodies for ever of their portentous character; it ranked them as denizens of the solar system. Again, the transits of Venus in I76I and I769 were the first occurrences of the kind since the awakening of science to their consequence. Imposing preparations, journeys to remote and hardly accessible regions, official expeditions, international communications, all for the purpose of observing them to the best advantage, brought their high significance vividly to the public consciousness; a result aided by the facile pen of Lalande, in rendering intelligible the means by which these elaborate arrangements were to issue in an accurate knowledge of the sun's distance. Lastly, Herschel's discovery of Uranus, March I3, I78I, had the surprising effect of utter novelty. Since the 
human race had become acquainted with the company of the planets, no addition had been made to their number. The event thus broke with immemorial traditions, and seemed to show astronomy as still young and full of unlooked-for possibilities.

Further popularity accrued to the science from the sequel of a career so strikingly opened. Herschel's huge telescopes, his detection by their means of two Saturnian and as many Uranian moons, his piercing scrutiny of the sun, picturesque theory of its constitution, and sagacious indication of the route pursued by it through space; his discovery of stellar revolving systems, his bold soundings of the universe, his grandiose ideas, and the elevated yet simple language in which they were conveyedformed a combination powerfully effective to those least susceptible of new impressions. Nor was the evoked enthusiasm limited to the British Isles. In Germany, Schröter followedlongo intervallo-in Herschel's track. Von Zach set on foot from Gotha that general communication of ideas which gives life to a forward movement. Bode wrote much and well for unlearned readers. Lalande, by his popular lectures and treatises, helped to form an audience which Laplace himself did not disdain to address in the Exposition du Systeme du Monde.

This great accession of popularity gave the impulse to the extraordinarily rapid progress of astronomy in the nineteenth century. Official patronage combined with individual zeal sufficed for the elder branches of the science. A few wellendowed institutions could accumulate the materials needed by a few isolated thinkers for the construction of theories of wonderful beauty and elaboration, yet precluded, by their abstract nature, from winning general applause. But the new physical astronomy depends for its prosperity upon the favour of the multitude whom its striking results are well fitted to attract. It is, in a special manner, the science of amateurs. It welcomes the most unpretending co-operation. There is no one "with a true eye and a faithful hand" but can do good work in watching the heavens. And not unfrequently prizes of discovery which the most perfect appliances failed to grasp have fallen to the share of ignorant or ill-provided assiduity. 
Observers, accordingly, have multiplied; observatories have been founded in all parts of the world; associations have been constituted for mutual help and counsel. A formal astronomical congress met in I789 at Gotha-then, under Duke Ernest II. and Von Zach, the focus of German astronomy-and instituted a combined search for the planet suspected to revolve undiscovered between the orbits of Mars and Jupiter. The Astronomical Society of London was established in 1820 , and the similar German institution in I863. Both have been highly influential in promoting the interests, local and general, of the science they were organised to serve; while functions corresponding to theirs have been discharged elsewhere by older or less specially constituted bodies, and new ones of a more popular character are springing up on all sides.

Modern facilities of communication have helped to impress more deeply upon modern astronomy its associative character. The electric telegraph gives a certain ubiquity which is invaluable to an observer of the skies. With the help of a wire, a battery, and a code of signals, he sees whatever is visible from any portion of our globe, depending, however, upon other eyes than his own, and so entering as a unit into a widespread combination of intelligence. The press, again, has been a potent agent of co-operation. It has mainly contributed to unite astronomers all over the world into a body animated by the single aim of collecting "particulars" in their special branch for what Bacon termed a History of Nature, eventually to be interpreted according to the sagacious insight of some one among them gifted above his fellows. The first really effective astronomical periodical was the Monatliche Correspondenz, started by Von Zach in the year I 800 . It was followed in 1822 by the Astronomische Nachrichten, later by the Memoirs and Monthl? Notices of the Astronomical Society, and by the host of varied publications which now, in every civilised country, communicate the discoveries made in astronomy to divers classes of readers, and so incalculably quicken the current of its onward flow.

Public favour brings in its train material resources. It is represented by individual enterprise, and finds expression in an 
ample liberality. The first regular observatory in the Southern Hemisphere was founded at Paramatta by Sir Thomas Makdougall Brisbane in I82I. The Royal Observatory at the Cape of Good Hope was completed in I829. Similar establishments were set to work by the East India Company at Madras, Bombay, and St. Helena, during the first third of the nineteenth century. 'The organisation of astronomy in the United States of America was due to a strong wave of popular enthusiasm. In I825 John Quincy Adams vainly urged upon Congress the foundation of a National Observatory; but in I843 the lectures of Ormsby MacKnight Mitchel on celestial phenomena stirred an impressionable audience to the pitch of providing him with the means of erecting at Cincinnati the first astronomical establishment worthy the name in that great country. On the Ist of January r 882 no less than one hundred and forty-four were active within its boundaries.

The apparition of the great comet of 1843 gave an additional fillip to the movement. To the excitement caused by it the Harvard College Observatory-called the "American Pulkowa" -directly owed its origin; and the example was not ineffective elsewhere. Corporations, universities, municipalities, vied with each other in the creation of such institutions ; private subscriptions poured in; emissaries were sent to Europe to purchase instruments and to procure instruction in their use. In a few years the young Republic was, in point of astronomical efficiency, at least on a level with countries where the science had been fostered since the dawn of civilisation.

A vast widening of the scope of astronomy has accompanied, and in part occasioned, the great extension of its area of cultivation which our age has witnessed. In the last century its purview was a comparatively narrow one. Problems lying beyond the range of the solar system were almost unheeded, because they seemed inscrutable. Herschel first showed the sidereal universe as accessible to investigation, and thereby offered to science new worids-majestic, manifold, "infinitely infinite" to our apprehension in number, variety, and extentfor future conquest. Their gradual appropriation has absorbed, 
and will long continue to absorb, the powers which it has served to develop.

But this is not the only direction in which astronomy has enlarged, or rather has levelled, its boundaries. The unification of the physical sciences is perhaps the greatest intellectual feat of recent times. The process has included astronomy; so that, like Bacon, she may now be said to have "taken all knowledge" (of that kind) "for her province." In return, she proffers potent aid for its increase. Every comet that approaches the sun is the scene of experiments in the electrical illumination of rarefied matter, performed on a huge scale for our benefit. The sun, stars, and nebulæ form so many celestial laboratories, where the nature and mutual relations of the chemical "elements" may be tried by more stringent tests than sublunary conditions afford. The laws of terrestrial magnetism can be completely investigated only with the aid of a concurrent study of the face of the sun. The positions of the planets will perhaps one day tell us something of impending droughts, famines, and cyclones.

Astronomy generalises the results of other sciences. She exhibits the laws of Nature working over a wider area, and under more varied conditions, than ordinary experience presents. Ordinary experience, on the other hand, has become indispensable to her progress. She takes in at one view the indefinitely great and the indefinitely little. The mutual revolutions of the stellar multitude during tracts of time which seem to lengthen out to eternity as the mind attempts to traverse them, she does not admit to be beyond her ken; nor is she indifferent to the constitution of the minutest atom of matter that thrills the ether into light. How she entered upon this vastly expanded inheritance, and how, so far, she has dealt with it, is attempted to be set forth in the ensuing chapters. 


\section{PART I.}

\section{PROGRESS OF ASTRONOMY DURING THE FIRST HALF OF THE NINETEENTH CENTURY.}

\section{CHAPTER I. \\ FOUNDATION OF SIDEREAL ASTRONOMY.}

UNTIL nearly a hundred years ago the stars were regarded by practical astronomers mainly as a number of convenient fixed points by which the motions of the various members of the solar system could be determined and compared. Their recognised function, in fact, was that of milestones on the great celestial highway traversed by the planets, as well as on the byways of space occasionally pursued by comets. Not that curiosity as to their nature, and even conjecture as to their origin, were at any period absent. Both were from time to time powerfully stimulated by the appearance of startling novelties in a region described by philosophers as "incorruptible," or exempt from change. The catalogue of Hipparchus probably, and certainly that of 'Tycho Brahe, some seventeen centuries later, owed each its origin to the temporary blaze of a new star. The general aspect of the skies was thus (however imperfectly) recorded from age to age, and with improved appliances the enumeration was rendered more and more accurate and complete; but the secrets of the stellar sphere remained inviolate.

In a qualified, though very real sense, Sir William Herschel may be called the Founder of Sidereal Astronomy. Before his time some curious facts had been noted, and some ingenious 
speculations hazarded, regarding the condition of the stars, but not even the rudiments of systematic knowledge had been acquired. The facts ascertained can be summed up in a very few sentences.

Giordano Bruno was the first to set the suns of space in motion, but in imagination only. His daring surmise was, however, confirmed in I7I8, when Halley announced $^{1}$ that Sirius, Aldebaran, Betelgeux, and Arcturus had unmistakably shifted their quarters in the sky since Ptolemy assigned their places in his catalogue. A similar conclusion was reached by J. Cassini in 1738 , from a comparison of his own observations with those made at Cayenne by Richer in 1672; and Tobias Mayer drew up in 1756 a list showing the direction and amount of about fifty-seven proper motions, ${ }^{2}$ founded on star-places determined by Olaus Römer fifty years previously. Thus the stars were no longer regarded as "fixed," but the question remained whether the movements perceived were real or only apparent; and this it was not yet found possible to answer. Already, in the previous century, the ingenious Robert Hooke had suggested an "alteration of the very system of the sun," 3 to account for certain suspected changes in stellar positions; Bradley in 1748 , and Lambert in $176 \mathrm{I}$, pointed out that such apparent displacements (by that time well ascertained) were in all probability a combined effect of motions both of sun and stars; and Mayer actually attempted the analysis, but without result.

On the I3th of August I596, David Fabricius, an unprofessional astronomer in East Friesland, saw in the neck of the Whale a star of the third magnitude, which by October had disappeared. It was, however, visible in 1603 , when Bayer marked it in his catalogue with the Greek letter o, and was watched through its phases of brightening and apparent extinction by a Dutch professor named Holwarda in 1638-39. ${ }^{4}$ From

1 Phil. Trans., vol. xxx., p. 737. 2 Out of eighty stars compared, fiftyseven were found to have changed their places by more than 10". Lesser discrepancies were at that time regarded as falling within the limits of observational error. Tobice Mayeri up. Inedita, t. i., pp. 80-81, and Herschel in Phil. Trans., vol. Ixxiii., pp. 275-278. ${ }^{3}$ Postlumous Works, p. 7or. 4 Arago in Annuaire du Bureau des Longitudes, I842, p. 313. 
Hevelius this first-known periodical star received the name of "Mira," or the Wonderful, and Boulliaud in I667 fixed the length of its cycle of change at 334 days. It was not a solitary instance. A star in the Swan was perceived by Janson in 1600 to show fluctuations of light, and Montanari found in 1669 that Algol in Perseus shared the same peculiarity to a marked degree. Altogether the class embraced in I782 half-a-dozen members. When it is added that a few star-couples had been noted in singularly, but it was supposed accidentally, close juxtaposition, and that the failure of repeated attempts to find an annual parallax pointed to distances for the stars at least 400,000 times that of the earth from the sun, ${ }^{1}$ the picture of sidereal science, when the last quarter of the eighteenth century began, is practically complete. It included three items of information: that the stars have motions, real or apparent; that they are immeasurably remote; and that a few shine with a periodically variable light. Nor were the facts thus scantily collected ordered into any promise of further development. They lay at once isolated and confused before the inquirer. They needed to be both multiplied and marshalled, and it seemed as if centuries of patient toil must elapse before any reliable conclusions could be derived from them. The sidereal world was thus the recognised domain of far-reaching speculations, which remained wholly uncramped by systematic research until Herschel entered upon his career as an observer of the heavens.

The greatest of modern astronomers was born at Hanover, November $\mathbb{1} 5$, I738. He was the fourth child of Isaac Herschel, a hautboy-player in the band of the Hanoverian Guard, and was early trained to follow his father's profession. On the termination, however, of the disastrous campaign of 1757 , his parents removed him from the regiment, there is reason to believe, in a somewhat unceremonious manner. Technically, indeed, he incurred the penalties of desertion, remitted-according to the Duke of Sussex's statement to Sir George Airy-by a formal pardon handed to him personally by George III. on his presenta-

1 Bradley to Halley, Phil. Trans., vol. xxxv. (1728), p. 66o. His observations were directly applicable to only two stars, $\gamma$ Draconis and $\eta$ Ursæ Majoris, but iome lesser ones were included in the same result. 
tion in $1782 .^{1}$ At the age of nineteen, then, his military service having lasted four years, he came to England to seek his fortune. Of the life of struggle and privation which ensued little is known beyond the circumstances that in 1760 he was engaged in training the regimental band of the Durham Militia, and that in 1765 he was appointed organist at Halifax. This post he exchanged a year later for the more distinguished one of organist at the Octagon Chapel in Bath. The tide of prosperity now began to flow for him. The most brilliant and modish society in England was at that time to be met at Bath, and the young Hanoverian quickly found himself a favourite and the fashion in it. Engagements multiplied upon him. He became director of the public concerts; he conducted oratorios, engaged singers, organised rehearsals, composed anthems, chants, choral services, besides undertaking private tuitions, at times amounting to thirty-five or even thirty-eight lessons a week. He in fact personified the musical activity of a place then eminently and energetically musical.

But these multifarious avocations did not take up the whole of his thoughts. His education, notwithstanding the poverty of his family, had not been neglected, and he had always greedily assimilated every kind of knowledge that came in his way. Now that he was a busy and a prosperous man, it might have been expected that he would run on in the deep professional groove laid down for him. On the contrary, his passion for learning seemed to increase with the diminution of the time available for its gratification. He studied Italian, Greek, mathematics ; Maclaurin's Fluxions served to "unbend his mind"; Smith's Harmonics and Optics and Ferguson's Astronomy were the nightly companions of his pillow. What he read stimulated without satisfying his intellect. He desired not only to know, but to discover. In 1773 he hired a small telescope, and through it caught a preliminary glimpse of the rich and varied fields in which for so many years he was to expatiate. Henceforward the purpose of his life was fixed : it was to obtain " a knowledge of the construction of the heavens;" 2 and to this sublime ambition he remained true until the end.

${ }^{1}$ Holden, Sir William Herschel, his Life and Works, p. I7.

${ }_{2}$ Phil. Trans., vol. ci., p. 269. 
A more powerful instrument was the first desideratum; and here his mechanical genius came to his aid. Having purchased the apparatus of a Quaker optician, he set about the manufacture of specula with a zeal which seemed to anticipate the wonders they were to disclose to him. It was not until fifteen years later that his grinding and polishing machines were invented, so the work had at that time to be entirely done by hand. During this tedious and laborious process (which could not be interrupted without injury, and lasted on one occasion sixteen hours), his strength was supported by morsels of food put into his mouth by his sister, ${ }^{1}$ and his mind amused by her reading aloud to him the Arabian Nights, Don Quixote, or other light works. At length, after repeated failures, he found himself provided with a reflecting telescope-a $5 \frac{1}{2}$-foot Gregorianof his own construction. A copy of his first observation with it, on the great Nebula in Orion-an object of continual amazement and assiduous inquiry to him-is preserved by the Royal Society. It bears the date March $4,1774 .^{2}$

In the following year he executed his first " review of the heavens," memorable chiefly as an evidence of the grand and novel conceptions which already inspired him, and of the enthusiasm with which he delivered himself up to their guidance. Overwhelmed with professional engagements, he still contrived to snatch some moments for the stars; and between the acts at the theatre was often seen running from the harpsichord to his telescope, no doubt with that "uncommon precipitancy which accompanied all his actions." 3 He now rapidly increased the power and perfection of his telescopes. Mirrors of seven, ten, even twenty feet focal length, were successively completed, and unprecedented magnifying powers employed. His energy was unceasing, his perseverance indomitable. In the course of twenty-one years no less than 430 parabolic specula left his

1 Caroline Lucretia Herschel, born at Hanover, March 16, 1750, died in the same place, January 9, 1848. She came to England in 1772, and was her brother's devoted assistant, first in his musical undertakings, and afterwards down to the end of his,life, in his astronomical labours. ${ }^{2}$ Holden, op cit. p. 39. 3 Memoir of Caroline Herschel, p. 37. 
hands. He had entered upon his forty-second year when he sent his first paper to the Philosophical Transactions; yet during the ensuing thirty-nine years his contributions-many of them elaborate treatises-numbered sixty-nine, forming a series of extraordinary importance to the history of astronomy. As a mere explorer of the heavens his labours were prodigious. $\mathrm{He}$ discovered 2500 nebulæ, 806 double stars, passed the whole firmament in review four several times, counted the stars in 3400 "gauge-fields," and executed a photometric classification of the principal stars, founded on an elaborate (and the first systematically conducted) investigation of their relative brightness. He was as careful and patient as he was rapid; spared no time and omitted no precaution to secure accuracy in his observations; yet in one night he would examine, singly and attentively, up to 400 separate objects.

The discovery of Uranus was a mere incident of the scheme he had marked out for himself-a fruit, gathered as it were by the way. It formed, nevertheless, the turning-point in his career. From a star-gazing musician he was at once transformed into an eminent astronomer; be was relieved from the drudgery of a toilsome profession, and installed as Royal Astronomer, with a modest salary of $£ 200$ a year; funds were provided for the construction of the forty-foot reflector, from the great space-penetrating power of which he expected as yet unheard-of revelations; in fine, his future work was not only rendered possible, but it was stamped as authoritative. ${ }^{1}$ On Whit-Sunday i 782, William and Caroline Herschel played and sang in public for the last time in St. Margaret's Chapel, Bath; in August of the same year the household was moved to Datchet, near Windsor, and on April 3, I786, to Slough. Here happiness and honours crowded on the fortunate discoverer. In I788 he married Mary, only child of James Baldwin, a merchant of the city of London, and widow of Mr. John Pitt-a lady whose domestic virtues were enhanced by the possession of a large jointure. The fruit of their union was one son, of whose work-the worthy sequel of his father's-we shall have to.

1 See Holden's Sir William Herschel, p. 54. 
speak further on. Herschel was created a Knight of the Hanoverian Guelphic Order in 1816 , and in 1821 he became the first President of the Royal Astronomical Society, his son being its first Foreign Secretary. But his health had now for some years been failing, and on August 25, 1822, he died at Slough, in the eighty-fourth year of his age, and was buried in Upton churchyard.

His epitaph claims for him the lofty praise of having " burst the barriers of heaven." Let us see in what sense this is true.

The first to form any definite idea as to the constitution of the stellar system was Thomas Wright, the son of a carpenter living at Byer's Green, near Durham. With him originated what has been called the "Grindstone Theory" of the universe, which regarded the Milky Way as the projection on the sphere of a stratum or disc of stars (our sun occupying a position near the centre), similar in magnitude and distribution to the lucid orbs of the constellations. ${ }^{1}$ He was followed by Kant, ${ }^{2}$ who transcended the views of his predecessor by assigning to nebulæ the position they long continued to occupy, rather on imaginative than scientific grounds, of "island universes," external to, and co-equal with the Galaxy. Johann Heinrich Lambert, ${ }^{3}$ a tailor's apprentice from Mühlhausen, followed, but independently. The conceptions of this remarkable man were grandiose, his intuitions bold, his views on some points a singular anticipation of subsequent discoveries. The sidereal world presented itself to him as a hierarchy of systems, starting from the planetary scheme, rising to throngs of suns within the circuit of the Milky Way-the "ecliptic of the stars," as he phrased itexpanding to include groups of many Milky Ways; these again combining to form the unit of a higher order of assemblage, and so onwards and upwards until the mind reels and sinks before the immensity of the contemplated creations.

1 An Original Theory or New Hypothesis of the Universe, London, 1750. See also De Morgan's summary of his views in Philosophical Magazine, April 1848. 2 Allgemeine Naturgeschichte und Theorie des Himmels, i 755. I Cosmo. logische Briefe, Augsburg, I76I. 
"Thus everything revolves-the earth around the sun; the sun around the centre of his system; this system round a centre common to it with other systems; this group, this assemblage of systems, round a centre which is common to it with other groups of the same kind; and where shall we have done?"1

The stupendous problem thus speculatively attempted, Herschel undertook to grapple with experimentally. The upshot of this memorable inquiry was the inclusion, for the first time, within the sphere of human knowledge, of a connected body of facts, and inferences from facts, regarding the sidereal universe; in other words, the foundation of what may properly be called a science of the stars.

Tobias Mayer had illustrated the perspective effects which must ensue in the stellar sphere from a translation of the solar system, by comparing them to the separating in front and closing up behind of trees in a forest to the eye of an advancing spectator $;^{2}$ but the appearances which he thus correctly described he was unable to detect. By a more searching analysis of a smaller collection of proper motions, Herschel succeeded in rendering apparent the very consequences foreseen by Mayer. He showed, for example, that Arcturus and Vega did, in fact, appear to recede from, and Sirius and Aldebaran to approach, each other by very minute amounts; and, with a striking effort of divinatory genius, placed the "apex," or point of direction of the sun's motion, close to the star $\lambda$ in the constellation Hercules, ${ }^{3}$ within a few degrees of the spot indicated by later and indefinitely more refined methods of research. $\mathrm{He}$ resumed the subject in $1805,{ }^{4}$ but though employing a more vigorous method was scarcely so happy in his result. In $1806,{ }^{5}$

1 The System of the World, p. 125, London, 1800 (a translation of the lastmentioned work). Lambert regarded nebulæ as composed of stars crowded together, but not as external universes. In the case of the Orion nebula, indeed, he throws out such a conjecture, but afterwards suggests that it may form a centre for that one of the subordinate systems composing the Milky Way to which our sun belongs. $\quad 2$ Opera Inedita, t. i., p. 79. ${ }^{3}$ Phil Trans., vol. Ixxiii. (1783),p. 273. It is worthy of remark that Prévost, almost simultaneously with Herschel, executed an investigation similar to his with very considerable success. Klugel confirmed Herschel's result by an analytical inquiry in 1789. " Phil. Trans., vol. xcv., p. 233. '5 1bid., voi. zevi., p. 205. 
he made a preliminary attempt to ascertain the speed of the sun's journey, which he no doubt greatly under-estimated in fixing it at about three miles a second. Yet the validity of his general conclusion as to the line of solar travel, though long doubted, has been triumphantly confirmed. The question as to the "secular parallax" of the fixed stars was in effect answered.

With their annual parallax, however, the case was very different. The search for it had already led Bradley to the important discoveries of the aberration of light and the nutation of the earth's axis; it was now about to lead Herschel to a discovery of a different, but even more elevated character. Yet in neither case was the object primarily sought attained.

From the very first promulgation of the Copernican theory the seeming immobility of the stars had been urged as an argument against its truth; for if the earth really travelled in a vast orbit round the sun, objects in surrounding space should appear to change their positions, unless their distances were on a scale which, to the narrow ideas of the universe then prevailing, seemed altogether extravagant. ${ }^{1}$ The existence of such apparent or "parallactic" displacements was accordingly regarded as the touchstone of the new views, and their detection became an object of earnest desire to those interested in maintaining them. Copernicus himself made the attempt; but with his "Triquetrum," a jointed wooden rule with the divisions marked in ink, constructed by himself, he was hardly able to measure angles of ten minutes, far less fractions of a second. Galileo, a more impassioned defender of the system, strained his ears, as it were, from Arcetri, in his blind and sorrowful old age, for news of a discovery which two more centuries had still to wait for. Hooke believed he had found a parallax for the bright star in the Head of the Dragon; but was deceived. Bradley convinced himself that such effects were too minute for his instruments to measure. Herschel made a fresh attempt by a practically untried method.

It is a matter of daily experience that two objects situated at

1 "Ingens bolus devorandus est," Kepler admitted to Herwart in May 1603. 
different distances seem to a beholder in motion to move relatively to each other. This principle Galileo, in the third of his Dialogues on the Systems of the World, ${ }^{1}$ proposed to apply to the determination of stellar parallax; for two stars, lying apparently close together, but in reality separated by a great gulf of space, must shift their mutual positions when observed from opposite points of the earth's orbit; or rather, the remoter forms a virtually fixed point, to which the movements of the other can be conveniently referred. By this means complications were abolished more numerous and perplexing than Galileo himself was aware of, and the problem was reduced to one of simple micrometrical measurement. The "double-star method" was also suggested by James Gregory in 1675, and again by Wallis in $1693 ;^{2}$ Huygens first, and afterwards Dr. Long of Cambridge (about I750), made futile experiments with it; and it eventually led, in the hands of Bessel, to the successful determination of the parallax of 6I Cygni.

Its advantages were not lost upon Herschel. His attempt to assign definite distances to the nearest stars was no isolated effort, but part of the settled plan upon which his observations were conducted. He proposed to sound the heavens, and the first requisite was a knowledge of the length of his sounding-line. Thus it came about that his special attention was early directed to double stars.

"I resolved," he writes, ${ }^{3}$ " to examine every star in the heavens with the ntmost attention and a very high power, that I might collect such materials for this research as would enable me to fix my observations upon those that would best answer my end. The subject has already proved so extensive, and still promises so rich a harvest to those who are inclined to be diligent in the pursuit, that I cannot help inviting every lover of astronomy to join with me in observations that must inevitably lead to new discoveries."

The first result of these inquiries was a classed catalogue of 269 double stars presented to the Royal Society in 1782 , followed,

1 Opere, t. i., p. 415. $\quad 2$ Phil. Trans., vol. xvii., p. 848.

3 Phil. Trans., vol. Ixxii., p. 97. 
after three years, by an additional list of 434 . In both these collections the distances separating the individuals of each pair were carefully measured, and (with a few exceptions) the directions with reference to a celestial meridian, of the lines joining their centres (technically called "angles of position") were determined with the aid of a "revolving-wire micrometer," specially devised for the purpose. Moreover, an important novelty was introduced by the observation of the various colours visible in the star-couples, the singular and vivid contrasts of which were now for the first time described.

Double stars were at that time supposed to be a purely optical phenomenon. Their components, it was thought, while in reality indefinitely remote from each other, were brought into fortuitous contiguity by the chance of lying nearly in the same line of sight from the earth. Yet Bradley had noticed a change of $30^{\circ}$, between I7I8 and 1759, in the position-angle of the two stars forming Castor, and was thus within a hair's breadth of the discovery of their physical connection. ${ }^{1}$ While the Rev. John Michell, arguing by the doctrine of probabilities, wrote as follows in I767:- "It is highly probable in particular, and next to a certainty in general, that such double stars as appear to consist of two or more stars placed very near together, do really consist of stars placed near together, and under the influence of some general law." 2 And in $1784::^{3}$ "It is not improbable that a few years may inform us that some of the great number of double, triple stars, \&c., which have been observed by Mr. Herschel, are systems of bodies revolving about each other."

This remarkable speculative anticipation had a practical counterpart in Germany. Father Christian Mayer, a Jesuit astronomer at Mannheim, set himself, in January I776, to collect examples of stellar pairs, and shortly afterwards published the supposed discovery of "satellites" to many of the principal stars. ${ }^{4}$ His observations, however, were neither exact nor prolonged enough to lead to useful results in such an inquiry.

${ }^{1}$ Doberck, Observatory, vol. ii., p. I Io. 2 Phil. Trans., vol. lvii., p. 249. 3 Ibid., vol. lxxiv., p. $56 .{ }_{4}^{4}$ Beabuchtungen von Fixsterntrabanten, 1778; and De Novis in Coelo Sidereo Phanomenis, 1779. 
His disclosures were derided; his planet-stars treated as results of hallucination. On n'a point cru à des choses aussi extraordinaires, wrote Lalande ${ }^{1}$ within one year of a better-grounded announcement to the same effect.

Herschel at first shared the general opinion as to the merely optical connection of double stars. Of this the purpose for which he made his colllection is in itself sufficient evidence, since what may be called the differential method of parallaxes depends, as we have seen, for its efficacy upon disparity of distance. It was " much too soon," he declared in 1782,2 "to form any theories of small stars revolving round large ones;" while in the year following, ${ }^{3}$ he remarked that the identical proper motions of the two stars forming, to the naked eye, the single bright orb of Castor could only be explained as both equally due to the "systematic parallax" caused by the sun's movement in space. Plainly showing that the notion of a physical tie, compelling the two bodies to travel together, had not as yet entered into his speculations. But he was eminently open to conviction, and had, moreover, by observations unparalleled in amount as well as in kind, prepared ample materials for convincing himself and others. In 1802 he was able to announce the fact of his discovery, and in the two ensuing years to lay in detail before the Royal Society proofs, gathered from the labours of a quarter of a century, of orbital revolution in the case of as many as fifty double stars, henceforth, he declared, to be held as real binary combinations, "intimately held together by the bond of mutual attraction." 4 The fortunate preservation in Dr. Maskelyne's note-book of a remark made by Bradley about I759, to the effect that the line joining the components of Castor was an exact prolongation of that joining Castor with Pollux, added eighteen years to the time during which the pair were under scrutiny, and confirmed the evidence of change afforded by more recent observations. Approximate periods were fixed for many of the revolving sunsfor Castor, 342 years; for $\gamma$ Leonis, I 200, $\delta$ Serpentis, 375,

1 Bibliographie, p. 569. 2 Phil. Trans., vol. 1xxii., p. 162. 3 Ibid., vol. lxxiii., p. 272. $\quad$ Phil. Trans., vol. xciii., p 340. 
ع Bootis, I68 I years ; ء Lyræ was noted as a "double-double-star," a change of relative situation having been detected in each of the two pairs composing the group; and the occultation of one star by another in the course of their mutual revolutions, was described as having been exemplified in 1795 by the rapidly circulating system of $\zeta$ Herculis.

Thus, by the sagacity and perseverance of a single observer, a firm basis was at last provided upon which to raise the edifice of sidereal science. The analogy long presumed to exist between the mighty star of our system and the bright points of light spangling the firmament was shown to be no fiction of the imagination, but a physical reality; the fundamental quality of attractive power was proved to be common to matter so far as the telescope was capable of exploring, and law, subordination, and regularity to give testimony of supreme and intelligent design no less in those limitless regions of space than in our narrow terrestrial home. The discovery was emphatically (in Arago's phrase) "one with a future," since it introduced the element of precise knowledge where more or less probable conjecture had previously held almost undivided sway; and precise knowledge tends to propagate itself and advance from point to point.

We have now to speak of Herschel's pioneering work in the skies. To explore with line and plummet the shining zone of the Milky Way, to delineate its form, measure its dimensions, and search out the intricacies of its construction, was the primary task of his life, which he never lost sight of, and to which all his other investigations were subordinate. He was absolutely alone in this bold endeavour. Unaided, he had to devise methods, accumulate materials, and sift out results. Yet it may safely be asserted that all the knowledge we possess on this sublime subject was prepared, and the greater part of it anticipated, by him.

The ingenious method of "star-gauging," and its issue in the delineation of the sidereal system as an irregular stratum of evenly-scattered suns, is the best-known part of his work. But it was, in truth, only a first rude approximation, the principle of 
which maintained its credit in the literature of astronomy a full half-century after its abandonment by its anthor. This principle was the general equality of star distribution. If equal portions of space really held equal numbers of stars, it is obvious that the number of stars visible in any particular direction would be strictly proportional to the range of the system in that direction, apparent accumulation being produced by real extent. The process of "gauging the heavens," accordingly, consisted in counting the stars in successive telescopic fields, and calculating thence the depths of space necessary to contain them. The result of 3400 such operations was the plan of the Galaxy familiar to every reader of an astronomical text-book. Widely-varying evidence was, as might have been expected, derived from an examination of different portions of the sky. Some fields of view were almost blank, while others, in or near the Milky Way, blazed with the radiance of many hundred stars compressed into an area about one-fourth that of the full-moon. In the most crowded parts I 6,000 were stated to have been passed in review within a quarter of an hour. Here the "length of his sounding-line" was estimated by Herschel at about 497 times the distance of Sirius - in other words, the bounding orb, or farthest sun of the system in that direction, so far as was revealed by the 20-foot reflector, was thus inconceivably remote. But since the distance of Sirius, no less than of every other fixed star, was as yet an unknown quantity, the dimensions inferred for the Galaxy were of course purely relative; a knowledge of its form and structure might (admitting the truth of the fundamental hypothesis) be obtained, but its real or absolute size remained altogether undetermined.

Even as early as I785, however, Herschel perceived traces of a tendency which completely invalidated the supposition of any approach to an average uniformity of distribution. This was the action of what he called a "clustering power" in the Milky Way. "Many gathering clusters" 1 were already discernible to him even while he endeavoured to obtain a "true mean result" on the assumption that each star in space was separated from

1 Phil. 'Trans., vol. lxxv., p. 255. 
its neighbours as widely as the sun from Sirius. "It appears," he wrote in I789, "that the heavens consist of regions where suns are gathered into separate systems"; and in certain assemblages he was able to trace " a course or tide of stars setting towards a centre," denoting, not doubtfully, the presence of attractive forces. ${ }^{1}$ Thirteen years later, he described our sun and his constellated companions as surrounded by "a magnificent collection of innumerable stars, called the Milky Way, which must occasion a very powerful balance of opposite attractions to hold the intermediate stars at rest. For though our sun, and all the stars we see, may truly be said to be in the plane of the Milky Way, yet I am now convinced, by a long inspection and continued examination of it, that the Milky Way itself consists of stars very differently scattered from those which are immediately about us." "This immense aggregation," he added, " is by no means uniform. Its component stars show evident signs of clustering together into many separate allotments." 2

The following sentences, written in I8I I, contain a definite retractation of the view frequently attributed to him :-

"I must freely confess," he says, "that by continuing my sweeps of the heavens my opinion of the arrangement of the stars and their magnitudes, and of some other particulars, has undergone a gradual change; and indeed, when the novelty of the subject is considered, we cannot be surprised that many things formerly taken for granted should on examination prove to be different from what they were generally but incautiously supposed to be. For instance, an equal scattering of the stars may be admitted in certain calculations; but when we examine the Milky Way, or the closely compressed clusters of stars of which my catalogues have recorded so many instances, this supposed equality of scattering must be given up." ${ }^{3}$

Another assumption, the fallacy of which he had not the means of detecting since become available, was retained by him to the end of his life. It was that the brightness of a star afforded an approximate measure of its distance. Upon this

1 Phil. Trans., vol. Ixxix., pp. 214, 222. 2 Ibid., vol. xcii., pp. 479, 495.

3 Ibid., vol. ci., p. 269. 
principle he founded in I8I7 his method of "limiting apertures," ${ }^{1}$ by which two stars, brought into view in two precisely similar telescopes were "equalised" by covering a certain portion of the object-glass collecting the more brilliant rays. The distances of the orbs compared were then taken to be in the ratio of the reduced to the original apertures of the instruments with which they were examined. If indeed the absolute lustre of each were the same, the result might be accepted with confidence; but since we have no warrant for assuming a "standard star" to facilitate our computations, but much reason to suppose an indefinite range, not only of size but of intrinsic brilliancy, in the suns of our firmament, conclusions drawn from such a comparison are entirely worthless.

In another branch of sidereal science besides that of stellar aggregation, Herschel may justly be styled a pioneer. He was the first to bestow serious study on the enigmatical objects known as "nebulæ." The history of the acquaintance of our race with them is comparatively short. 'The only one recognised before the invention of the telescope was that in the girdle of Andromeda, certainly familiar in the middle of the tenth century to the Persian astronomer Abdurrahman Al-Sûfi; and marked with dots on an old Dutch chart of the constellation, presumably about I5OO A.D. ${ }^{2}$ Yet so little was it noticed that it might practically be said-as far as Europe is concerned-to have been discovered in I6r 2 by Simon Marius (Mayer of Genzenhausen), who aptly described its appearance as that of a "candle shining through horn." The first mention of the great Orion nebula is by a Swiss Jesuit named. Cysatus, who succeeded Father Scheiner in the chair of mathematics at Ingolstadt. He used it, apparently without any suspicion of its novelty, as a term of comparison for the comet of December I6I8. ${ }^{3}$ A novelty, nevertheless, to astronomers it still remained in 1656 , when Huygens discerned, "as it were, an hiatus in the sky, affording

1 Phil. Trans., vol. cvii., p. 31 r. ${ }^{2}$ Bullialdus, De Nebulosâ Stellâ in Cingulo Andrumeda (1667); see also G. P. Bond, Mem. Am. Ac., vol. iii., p. 75, and Holden's Monograph on the Orion Nebula, Washington Observations, vol. xxv., I878 (pub. 1882). 3 Mathemata Astronomica, p. 75. 
a glimpse of a more luminous region beyond." ${ }^{1}$ Halley in 1716 knew of six nebulæ, which he believed to be composed of a "lucid medium".diffused through the ether of space. ${ }^{2}$ He appears, however, to have been unacquainted with some previously noticed by Hevelius. Lacaille brought back with him from the Cape a list of forty-two-the first-fruits of observation in Southern skiesarranged in three numerically equal classes; ${ }^{3}$ and Messier (nicknamed by Louis XV. the "ferret of" comets"), finding" such objects a source of extreme perplexity in the pursuit of his chosen game, attempted to eliminate by methodising them, and drew up a catalogue comprising, in I78I, IO3 entries. ${ }^{4}$

These preliminary attempts shrank into insignificance when Herschel began to "sweep the heavens" with his giant telescopes. In 1786 he presented to the Royal Society a descriptive catalogue of 1000 nebulæ and clusters, followed, three years later, by a second of an equal number; to which he added in I 802 a further gleaning of 500 . On the subject of their nature his views underwent a remarkable change. Finding that his potent instruments resolved into stars many nebulous patches in which no signs of such a structure had previously been discernible, he naturally concluded that "resolvability" was merely a question of distance and telescopic power. He was (as he said himself) led on by almost imperceptible degrees from evident clusters, such as the Pleiades, to spots without a trace of stellar formation, the gradations being so well connected as to leave no doubt that all these phenomena were equally stellar. The singular variety of their appearance was thus described by him :-

"I have seen," he says "double and treble nebulæ variously arranged; large ones with small, seeming attendants; narrow, but much extended lucid nebulæ or bright dashes; some of the shape of a fan, resembling an electric brush, issuing from a lucid point; others of the cometic shape, with a seeming nucleus in the centre, or like cloudy stars surrounded with a nebulous

1 Systema Saturnium, p. 9. 2 Phil. Trans., vol. xxix., p. 390. 3 Mém. Ac. des Sciences, 1755. 4 Conn. des Temps, I784 (pub. 178r), p. 227. A previous list of forty-five had appeared in Mém. Ac. d. Sc. I77 I. 
atmosphere; a different sort, again, contain a nebulosity of the milky kind, like that wonderful, inexplicable phenomenon about $\boldsymbol{\theta}$ Orionis; while others shine with a fainter, mottled kind of light, which denotes their being resolvable into stars." 1

"These curious objects" he considered to be "no less than whole sidereal systems," 2 some of which might "well outvie our Milky Way in grandeur." He admitted, however, a wide diversity in condition as well as compass. The system to which our sun belongs he described as "a very extensive branching congeries of many millions of stars, which probably owes its origin to many remarkably large as well as pretty closely scattered small stars, that may have drawn together the rest." 3 But the continued action of this same "clustering power" would, he supposed, eventually lead to the breaking up of the original majestic Galaxy into two or three hundred separate groups, already visibly gathering. Such minor nebulæ, dne to the "decay "of other "branching nebulæ" similar to our own, he recognised by the score, lying, as it were, stratified in certain quarters of the sky. "One of these nebulous beds," he informs us, "is so rich that in passing through a section of it, in the time of only thirty-six minutes, I detected no less than thirtyone nebulæ, all distinctly visible upon a fine blue sky." The stratum of Coma Berenices he judged to be the nearest to our system of such layers; nor did the marked aggregation of nebulæ towards both poles of the circle of the Milky Way escape his notice.

By a continuation of the same process of reasoning, he was enabled (as he thought) to trace the life-history of nebulæ from a primitive loose and extended formation, through clusters of gradually increasing compression, down to the kind named by him "Planetary" because of the defined and uniform discs which they present. These he regarded as "very aged, and drawing on towards a period of change or dissolution." 4

"This method of viewing the heavens," he concluded, "seems to throw them into a new kind of light. They now are seen to

1 Phil. Trans., vol. lxxiv., p. 442. 2 Ibid., vol. lxxix., p. 213. 3 lbid., vol. lxxv., p. 254.

4 Ibid., vol. Ixxix., p. 225. 
resemble a luxuriant garden which contains the greatest variety of productions in different flourishing beds; and one advantage we may at least reap from it is, that we can, as it were, extend the range of our experience to an immense duration. For, to continue the simile which I have borrowed from the vegetable kingdom, is it not almost the same thing whether we live successively to witness the germination, blooming, foliage, fecundity, fading, withering, and corruption of a plant, or whether a vast number of specimens, selected from every stage through which the plant passes in the course of its existence, be brought at once to our view?" 1

But already this supposed continuity was broken. After mature deliberation on the phenomena presented by nebulous stars, Herschel was induced, in I79I, to modify essentially his original opinion.

"When I pursued these researches," he says, "I was in the situation of a natural philosopher who follows the various species of animals and insects from the height of their perfection down to the lowest ebb of life; when, arriving at the vegetable kingdom, he can scarcely point out to us the precise boundary where the animal ceases and the plant begins; and may even go so far as to suspect them not to be essentially different. But, recollecting himself, he compares, for instance, one of the human species to a tree, and all doubt upon the subject vanishes before him. In the same manner we pass through gentle steps from a coarse cluster of stars, such as the Pleiades . . . till we find ourselves brought to an object such as the nebula in Orion, where we are still inclined to remain in the once adopted idea of stars exceedingly remote and inconceivably crowded, as being the occasion of that remarkable appearance. It seems, therefore, to require a more dissimilar object to set us right again. A glance like that of the naturalist, who casts his eye from the perfect animal to the perfect vegetable, is wanting to remove the veil from the mind of the astronomer. The object I have mentioned above is the phenomenon that was wanting for this purpose. View, for instance, the I9th cluster of my 6th class, and afterwards cast

1 Phil. Trans., vol. lxxix., p. 226. 
your eye on this cloudy star, and the result will be no less decisive than that of the naturalist we have alluded to. Our judgment, I may venture to say, will be, that the nebulosity about the star is not of a starry nature." 1

The conviction thus arrived at of the existence in space of a widely diffused "shining fluid" (a conviction long afterwards fully justified by the spectroscope) led him into a field of endless speculation. What was its nature? Should it "be compared to the coruscation of the electric fluid in the aurora borealis ? or to the more magnificent cone of the zodiacal light?" Above all, what was its function in the cosmos? And on this point he already gave a hint of the direction in which his mind was moving by the remark that this self-luminous matter seemed " more fit to produce a star by its condensation, than to depend on the star for its existence." 2

This was not a novel idea. Tycho Brahe had tried to explain the blaze of the star of $\mathrm{I} 572$ as due to a sudden concentration of nebulous material in the Milky Way, even pointing out the space left dark and void by the withdrawal of the luminous stuff; and Kepler, theorising on a similar stellar apparition in I604, followed nearly in the same track. But under Herschel's treatment the nebular origin of stars first acquired the consistency of a formal theory. He meditated upon it long and earnestly, and in two elaborate treatises, published respectively in I8II and 1814, he at length set forth the arguments in its favour. These rested entirely upon the "principle of continuity." Between the successive classes of his progressive assortment of objects there was, as he said, "perhaps not so much difference as would be in an annual description of the human figure, were it given from the birth of a child till he comes to be a man in his prime." 3 From diffused nebulosity, barely visible in the most powerful light-gathering instruments, but which he estimated to cover nearly ${ }^{5} 52$ square degrees of the heavens, ${ }^{4}$ to planetary nebulæ, supposed to be already centrally solid, instances were alleged by him of every stage and

1 Phil. Trans., vol. lxxxi., p. 72. $\quad 2$ Ibid., p. $85 . \quad{ }^{3}$ Ibid., vol. ci., p. 27 I. 4 Ibid., p. 277. 
phase of condensation. The validity of his reasoning, however, was evidently impaired by his confessed inability to distinguish between the dim rays of remote clusters and the milky light of true gaseous nebulæ.

It may be said that such speculations are futile in themselves, and necessarily barren of results. But they gratify an inherent tendency of the human mind, and, if pursued in a becoming. spirit, should be neither reproved nor disdained. Herschel's theory still holds the field, the testimony of recent discoveries with regard to it having proved strongly confirmatory of its principle, although not of its details. Strangely enough, it seems to have been propounded in complete independence of Laplace's nebular hypothesis as to the origin of the solar system. Indeed, it dated, as we have seen, in its first inception, from I791, while the French geometrician's view was not advanced until r 796.

We may now briefly sum up the chief results of Herschel's long years of "watching the heavens." The apparent motions of the stars had been disentangled; one portion being clearly shown to be due to a translation towards a point in the constellation Hercules of the sun and his attendant planets; while a large balance of displacement was left to be accounted for by real movements, various in extent and direction, of the stars themselves. By the action of a central force similar to, if not identical with, gravity, suns of every degree of size and splendour, and sometimes brilliantly contrasted in colour, were seen to be held together in systems, consisting of two, three, four, even six members, whose revolutions exhibited a wide range of variety both in period and in orbital form. A new department of physical astronomy was thus created, ${ }^{1}$ and rigid calculation for the first time made possible within the astral region. The vast problem of the arrangement and relations of the millions of stars forming the Milky Way was shown to be capable of experimental treatment, and of at least partial solution, notwithstanding the variety and complexity seen to prevail, to an extent previously undreamt of, in the arrangement of that

1 Sir J. Herschel, Phil. 'Trans., vol. cxvi., part iii., p. I. 
majestic system. The existence of a luminous fluid, diffused through enormous tracts of space, and intimately associated with stellar bodies, was virtually demonstrated, and its place and use in creation attempted to be divined by a bold but plausible conjecture. Change on a stupendous scale was inferred or observed to be everywhere in progress. Periodical stars shone out and again decayed; progressive ebbings or flowings of light were indicated as probable in many stars under no formal suspicion of variability; forces were everywhere perceived to be at work, by which the very structure of the heavens themselves must be slowly but fundamentally modified. In all directions groups were seen to be formed or forming; tides and streams of suns to be setting towards powerful centres of attraction; new systems to be in process of formation, while effete ones hastened to decay or regeneration when the course appointed for them by Infinite Wisdom was run. And thus, to quote the words of the observer who "had looked farther into space than ever human being did before him," 1 "the state into which the incessant action of the clustering power has brought the Milky Way at present, is a kind of chronometer that may be used to measure the time of its past and future existence; and although we do not know the rate of going of this mysterious chronometer, it is nevertheless certain that, since the breaking-up of the parts of the Milky Way affords a proof that it cannot last for ever, it equally bears witness that its past duration cannot be admitted to be infinite." 2

1 His own words to the poet Campbell, cited by Holden, Life and Works, p. 109. 2 Phil. Trans., vol. civ., p. 283 . 


\section{CHAPTER II.}

\section{PROGRESS OF SIDEREAL ASTRONOMY.}

WE have now to consider labours of a totally different character from those of Sir William Herschel. Exploration and discovery do not constitute the whole business of astronomy; the less adventurous, though not less arduous, task of gaining a more and more complete mastery over the problems immemorially presented to her, may, on the contrary, be said to form her primary duty. A knowledge of the movements of the heavenly bodies has, from the earliest times, been demanded by the urgent needs of mankind; and science finds its advantage, as in many cases it has taken its origin, in condescension to practical claims. Indeed, to bring such knowledge as near as possible to absolute precision has been defined by no mean authority ${ }^{1}$ as the true end of astronomy.

Several causes concurred about the beginning of the present century to give a fresh and powerful impulse to investigations having this end in view. The rapid progress of theory almost compelled a corresponding advance in observation ; instrumental improvements rendered such an advance possible; Herschel's discoveries quickened public interest in celestial inquiries; royal, imperial, and grand-ducal patronage widened the scope of individual effort. The heart of the new movement was in Germany. Hitherto the observatory of Flamsteed and Bradley had been the acknowledged centre of practical astronomy; Greenwich observations were the standard of reference all over Europe; and the art of observing prospered in direct proportion

1 Bessel, Populäre Vorlesungen, pp. 6, 4c8. 
to the fidelity with which Greenwich methods were imitated. Dr. Maskelyne, who held the post of Astronomer Royal during forty-six years (from I765 to I8I I), was no unworthy successor to the eminent men who had gone before him. His foundation of the Nautical Almanac (in I767) alone constitutes a valid title of fame; he introduced at the Observatory the important innovation of the systematic publication of results; and the careful and prolonged series of observations executed by him formed the basis of the improved theories, and corrected tables of the celestial movements, which were rapidly being brought to completion abroad. His catalogue of thirty-six "fundamental" stars was besides excellent in its way, and most serviceable. Yet he was devoid of Bradley's instinct for divining the needs of the future. He was fitted rather to continue a tradition than to found a school. The old ways were dear to him; and, indefatigable as he was, a definite purpose was wanting to compel him, by its exigencies, along the path of progress. Thus, for almost fifty years after Bradley's death, the acquisition of a small achromatic $^{1}$ was the only notable change made in the instrumental equipment of the Observatory. The transit, the zenith sector, and the mural quadrant, with which Bradley had done his incomparable work, retained their places long after they had become deteriorated by time and obsolete by the progress of invention; and it was not until the very close of his career that Maskelyne, compelled by Pond's detection of serious errors, ordered a Troughton's circle, which he did not live to employ.

Meanwhile, the heavy national disasters with which Germany was overwhelmed in the early part of the present century, seemed to stimulate rather than impede the intellectual revival already for some years in progress there. Astronomy was amongst the first of the sciences to feel the new impulse. By the efforts of Bode, Olbers, Schröter, and Von Zach, just and elevated ideas on the subject were propagated, intelligence was diffused, and a firm ground prepared for common action in mutual sympathy and disinterested zeal. They were powerfully seconded by the

${ }^{1}$ Fitted to the old transit instrument, July I I, 1772. 
foundation, in 1804 , by a young artillery officer named Von Reichenbach, of an Optical and Mechanical Institute at Munich. Here the work of English instrumental artists was for the first time rivalled, and that of English opticians-when Fraunhofer entered the new establishment-far surpassed. The development given to the refracting telescope by this extraordinary man was indispensable to the progress of that fundamental part of astronomy which consists in the exact determination of the places of the heavenly bodies. Reflectors are brilliant engines of discovery, but they lend themselves with difficulty to the prosaic work of measuring right ascensions and polar distances. A signal improvement in the art of making and working flint-glass thus most opportunely coincided with the rise of a German school of scientific mechanicians, to furnish the instrumental means needed for the reform which was at hand. Of the leader of that reform it is now time to speak.

Friedrich Wilhelm Bessel was born at Minden, in Westphalia, July 22, I784. A certain taste for figures, coupled with a still stronger distaste for the Latin accidence, directed his inclination and his father's choice towards a mercantile career. In his fifteenth year, accordingly, he entered the house of Kuhlenkamp \& Sons, in Bremen, as an apprenticed clerk. He was now thrown completely upon his own resources. From his father, a struggling Government official, heavily weighted with a large family, he was well aware that he had nothing to expect; his dormant faculties were roused by the necessity for self-dependence, and he set himself to push manfully forward along the path that lay before him. The post of supercargo on one of the trading expeditions sent out from the Hanseatic towns to China and the East Indies was the aim of his boyish ambition, for the attainment of which he sought to qualify himself by the industrious acquisition of suitable and useful knowledge. He learned English in two or three months; picked up Spanish with the casual aid of a gunsmith's apprentice; studied the geography of the distant lands which he hoped to visit; collected information as to their climates, inhabitants, products, and the courses of trade. He desired to add some acquaintance with the art (then 
much neglected) of taking observations at sea; and thus, led on from navigation to astronomy, and from astronomy to mathematics, he groped his way into a new world.

It was characteristic of him that the practical problems of science should have attracted him before his mind was as yet sufficiently matured to feel the charm of its abstract beauties. His first attempt at observation was made with a sextant, rudely constructed under his own directions, and a common clock. Its object was the determination of the longitude of Bremen, and its success, he tells us himself, ${ }^{1}$ filled him with a rapture of delight, which, by confirming his tastes, decided his destiny. He now eagerly studied Bode's Jahrbuch and Von Zach's Monatliche Correspondenz, overcoming each difficulty as it arose with the aid of Lalande's Traité d'Astronomie, and supplying, with amazing rapidity, his early deficiency in mathematical training. In two years he was able to attack a problem which would have tasked the patience, if not the skill, of the most experienced astronomer. Amongst the Earl of Egremont's papers Von Zach had discovered Harriot's observations on Halley's comet at its appearance in 1607, and published them as a supplement to Bode's Annual. With an elaborate care inspired by his youthful ardour, though hardly merited by their loose nature, Bessel deduced from them an orbit for that celebrated body, and presented the work to Olbers, whose reputation in cometary researches gave a special fitness to the proffered homage. The benevolent physician-astronomer of Bremen welcomed with surprised delight such a performance emanating from such a source. Fifteen years before, the French Academy had crowned a similar performance; now its equal was produced by a youth of twenty, busily engaged in commercial pursuits, self-taught, and obliged to snatch from sleep the hours devoted to study. The paper was immediately sent to Von Zach for publication, with a note from Olbers explaining the circumstances of its author, and the name of Bessel became the common property of learned Europe.

$\mathrm{He}$ had, however, as yet no intention of adopting astronomy

1 Briefwechsel mit Olbers, p. xvi. 
as his profession. For two years he continued to work in the counting-house by day, and to pore over the Mécanique Céleste and the Differential Calculus by night. But the post of assistant in Schröter's observatory at Lilienthal having become vacant by the removal of Harding to Göttingen in I 805, Olbers procured for him the offer of it. It was not without a struggle that he resolved to exchange the desk for the telescope. His reputation with his employers was of the highest; he had thoroughly mastered the details of the business, which his keen practical intelligence followed with lively interest; his years of apprenticeship were on the point of expiring, and an immediate, and not unwelcome prospect of comparative affluence lay before him. The love of science, however, prevailed; he chose poverty and the stars, and went to Lilienthal with a salary of a hundred thalers yearly. Looking back over his life's work, Olbers long afterwards declared that the greatest service which he had rendered to astronomy was that of having discerned, directed, and promoted the genius of Bessel. ${ }^{1}$

For four years he continued in Schröter's employment. At the end of that time the Prussian Government chose him to superintend the erection of a new observatory at Königsberg, which after many vexatious delays caused by the prostrate condition of the country, was finished towards the end of 1813 . Königsberg was the first really efficient German observatory. It became, moreover, a centre of improvement, not for Germany alone, but for the whole astronomical world. During two-andthirty years it was the scene of Bessel's labours, and Bessel's labours had for their aim the reconstruction, on an amended and uniform plan, of the entire science of observation.

A knowledge of the places of the stars is the foundation of astronomy. ${ }^{2}$ Their configuration lends to the skies their distinctive features, and marks out the shifting tracks of more mobile objects with relatively fixed, and generally unvarying points of light. A more detailed and accurate acquaintance with the stellar multitude, regarded from a purely uranographical point of view, has accordingly formed at all times a

${ }^{1}$ R. Wolf, Gesch. der Astron., p. 518. " $\quad$ Bessel, Pop. Vorl., p. 22. 
primary object of celestial science, and has, during the present century, been cultivated with a zeal and success by which all previous efforts are dwarfed into insignificance. In Lalande's Histoire Céleste, published in I80I, the places of no less than 47.390 stars were given, but. in the rough, as it were, and consequently needing laborious processes of calculation to render them available for exact purposes. Piazzi set an example of improved methods of observation, resulting in the publication, in 1803 and 1814 , of two catalogues of about 7600 stars-the second being a revision and enlargement of the first-which for their time were models of what such works should be. Stephen Groombridge at Blackheath was similarly and most beneficially active. But something more was needed than the diligence of individual observers. A systematic reform was called for; and it was this which Bessel undertook and carried through.

Direct observation furnishes only what has been called the "raw material" of the positions of the heavenly bodies. ${ }^{1}$ A number of highly complex corrections have to be applied before their mean can be disengaged from their apparent places on the sphere. Of these, the most considerable and familiar is atmospheric refraction, by which objects seem to stand higher in the sky than they in reality do, the effect being evanescent at the zenith, and attaining, by gradations varying with conditions of pressure and temperature, a maximum at the horizon. Moreover, the points to which measurements are referred are themselves in motion, either continually in one direction, or periodically to and fro. The precession of the equinoxes is slowly progressive, or rather retrogressive; the nutation of the pole oscillatory in a period of about eighteen years. Added to which, the noninstantaneous transmission of light, combined with the movement of the earth in its orbit, canses a minute displacement known as aberration.

Now it is easy to see that any uncertainty in the application of these corrections saps the very foundations of exact astronomy. Extremely minute quantities, it is true, are concerned; but the life and progréss of modern celestial science depends upon the 
sure recognition of extremely minute quantities. In the early years of this century, however, no uniform system of "reduction" (so the complete correction of observational results is termed) had been established. Much was left to the individual caprice of observers, who selected for the several "elements" of reduction such values as seemed best to themselves. Hence arose much hurtful confusion, tending to hinder united action and mar the usefulness of laborious researches. For this state of things, Bessel, by the exercise of consummate diligence, sagacity, and patience, provided an entirely satisfactory remedy.

His first step was an elaborate investigation of the precious series of observations made by Bradley at Greenwich from I750 until his death in I762. The catalogue of 3222 stars which he extracted from them, gave the earliest example of the systematic reduction on a uniform plan of such a body of work. It is difficult, without entering into details out of place in a volume like the present, to convey an idea of the ardnous nature of this task. It involved the formation of a theory of the errors of each of Bradley's instruments, and a difficult and delicate inquiry into the true value of each correction to be applied before the entries in the Greenwich journals could be developed into a finished and authentic catalogue. Although completed in I8I3, it was not until five years later that the results appeared with the prond, but not inappropriate title of Fundamenta Astronomia. The eminent value of the work consisted in this, that by providing a mass of entirely reliable information as to the state of the heavens at the epoch 1755 , it threw back the beginning of excact astronomy almost half a century. By comparison with Piazzi's catalogues the amount of precession was more accurately determined, the proper motions of a considerable number of stars became known with certainty, and definite prediction-the certificate of initiation into the secrets of Nature-at last became possible as regards the places of the stars. Bessel's final improvements in the methods of reduction were published in I830 in his Tabulce Regiomontance. They not only constituted an advance in accuracy, but afforded a vast increase of facility in application, and were at once and everywhere adopted. Thus 
astronomy became a truly universal science; uncertainties and disparities were banished, and observations made at all times and places rendered mutually comparable. ${ }^{1}$

More, however, yet remained to be done. In order to verify with greater strictness the results drawn from the Bradley and Piazzi catalogues, a third term of comparison was wanted, and this Bessel undertook to supply. By a course of 75,0r I observations, executed during the years I82I-33, with the utmost nicety of care, the number of accurately known stars was brought up to above 50,000, and an ample store of trustworthy facts laid up for the use of future astronomers. In this department Argelander, whom he attracted from finance to astronomy, and trained in his own methods, was his assistant and successor. The great "Bonn Durchmusterung," ${ }^{2}$ in which 324, I98 stars visible in the northern hemisphere are enumerated, and the corresponding "Atlas" published in 1857-63, constituting a picture of our sidereal surroundings of heretofore unapproached completeness, may be justly said to owe their origin to Bessel's initiative, and to form a sequel to what he commenced.

But his activity was not solely occupied with the promotion of a comprehensive reform in astronomy; it embraced special problems as well. The long-baffled search for a parallax of the fixed stars was resumed with fresh zeal as each mechanical or optical improvement held out fresh hopes of a successful issue. Illusory results had for some time abounded. Piazzi in 1805 perceived, as he supposed, considerable annual displacements in Vega, Aldebaran, Sirius, and Procyon ; the truth being that his instruments were worn out with constant use, and could no longer be depended upon. ${ }^{3}$ His countryman, Calandrelli, was similarly deluded. The celebrated controversy between the Astronomer Royal and Dr. Brinkley, director of the Dublin College Observatory, turned on the same subject. Brinkley, who was in possession of a first-rate meridian circle, believed himself to have discovered relatively large parallaxes for four of the brightest stars; Pond, rely-

1 Durège, Ressel's Leben und Wirken, p. 2 .

2 Bonner Beobachtungen, Bd. iii.-v., 1859-62. ${ }^{3}$ Bessel, Pop. Vorl., p. 238. 
ing on the testimony of the Greenwich instruments, asserted their nullity. The dispute was protracted for fourteen years, from I8IO to I824, and was brought to no definite conclusion; but the strong presumption on the negative side was abundantly justified in the event.

There was good reason for incredulity in the matter of parallaxes. Announcements of their detection had become so frequent as to be discredited before they were disproved; and Struve, who investigated the subject at Dorpat in I8I8-2 I, had clearly shown that the quantities concerned were so small as to lie beyond the reliable measuring powers of any instrument then in use. Already, however, the means were being prepared of giving to those powers a large increase.

On the 2ist July I80I, two old houses in an alley of Munich tumbled down, burying in their ruins the occupants, of whom one alone was extricated alive, though seriously injured. This was an orphan lad of fourteen named Joseph Fraunhofer. The Elector Maximilian Joseph was witness of the scene, became interested in the survivor, and consoled his misfortune with a present of eighteen ducats. Seldom was money better bestowed. Part of it went to buy books and a glass-polishing machine, with the help of which young Fraunhofer studied mathematics and optics, and secretly exercised himself in the shaping and finishing of lenses; the remainder purchased his release from the tyranny of one Weichselberger, a looking-glass maker by trade, to whom he had been bound apprentice on the death of his parents. A period of struggle and privation followed, during which, however, he rapidly extended his acquirement; and was thus eminently fitted for the task awaiting him, when, in I806, he entered the optical department of the establishment founded two years previously by Von Reichenbach and Utzschneider. He now zealously devoted himself to the improvement of the achromatic telescope ; and, after a prolonged study of the theory of lenses, and many toilsome experiments in the manufacture of flint-glass, he succeeded in perfecting, December I2, I8I7, an object-glass of exquisite quality and finish, $9 \frac{1}{2}$ inches in diameter and of fourteen feet focal length. 
This (as it was then considered) gigantic lens was secured by Struve for the Russian Government, and the "great Dorpat refractor"- the first of the large achromatics which have played such an important part in modern astronomy-was, late in 1824, set up in the place which it still occupies. By ingenious improvements in mounting and fitting, it was adapted to the finest micrometrical work, and thus offered unprecedented facilities both for the examination of double stars (in which Struve chiefly employed it), and for such subtle measurements as might serve to reveal or disprove the existence of a sensible stellar parallax. Fraunhofer, moreover, constructed for the observatory at Königsberg the first really available heliometer. The principle of this instrument (termed with more propriety a "divided object-glass micrometer") is the separation, by a strictly measurable amount, of two distinct images of the same object. If a double star, for instance, be under examination, the two half-lenses into which the object-glass is divided are shifted until the upper star (say) in one image is brought into coincidence with the lower star in the other, when their distance apart becomes known by the amount of motion employed. ${ }^{1}$

This virtually new engine of research was delivered and mounted in 1829, three years after the termination of the life of its deviser. The Dorpat lens had brought to Fraunhofer a title of nobility and the sole management of the Munich Optical Institute (completely separated since I8I4 from the mechanical department). What he had achieved, however, was but a small part of what he meant to achieve. He saw before him the possibility of nearly quadrupling the light-gathering capacity of the great achromatic acquired by Struve; he meditated improvements in reflectors as important as those he had already effected in refractors; and was besides eagerly occupied with investigations into the nature of light, the momentous character of

1 The heads of the screws applied to move the halves of the object-glass in the Königsbery heliometer are of so considerable a size that a thousandth part of a revolution, equivalent to $\frac{{ }_{2}^{1} \sigma}{2}$ of a second of arc, can be measured with the utmost accuracy. Main, in R. A. S. Mem., rol. xii., p. 53. 
which we shall by-and-by have an opportunity of estimating. But his health was impaired, it is said, from the weakening effects of his early accident, combined with excessive and unwholesome toil, and, still hoping for its restoration from a projected journey to Italy, he died of consumption, June 7, I 826, aged thirty-nine years. His tomb in Munich bears the concise eulogy, Approximavit sidera.

Bessel had no sooner made himself acquainted with the exquisite defining powers of the Königsberg heliometer, than he resolved to employ them in an attack upon the now secular problem of star-distances. But it was not until 1837 that he found leisure to pursue the inquiry. In choosing his test-star he adopted a new principle. It had hitherto been assumed that our nearest neighbour in space must be found amongst the brightest ornaments of our skies. The knowledge of stellar proper motions afforded by the critical comparison of recent with earlier star-places, suggested a different criterion of distance. It is impossible to escape from the conclusion that the apparently swiftest-moving stars are, on the whole, also the nearest to us, however numerous the individual exceptions to the rule. Now, as early as $1792,{ }^{1}$ Piazzi had noted, as an indication of relative vicinity to the earth, the unusually large proper motion $\left(5.2^{\prime \prime}\right.$ annually) of a double star of the fifth magnitude in the constellation of the Swan. Still more emphatically in $1812^{2}$ Bessel drew the attention of astronomers to the fact, and 6I Cygni became known as the "flying star." The seeming rate of its flight, indeed, is of so leisurely a kind, that in a thousand years it will have shifted its place by less than $3 \frac{1}{2}$ lunar diameters, and that a quarter of a million would be required to carry it round the entire circuit of the visible heavens. Nevertheless, it has few rivals in rapidity of movement, the apparent displacement of the vast majority of stars being, by comparison, almost insensible.

This interesting, though inconspicuous object, then, was chosen by Bessel to be put to the question with his heliometer, while Struve made a similar and somewhat earlier trial with the bright

1 Specola Astronomica di Palermo, lib. vi., p. Io, note. 2 Monatliche Correspondenz, vol. xxvi., p. 162 . 
gem of the Lyre, whose Arabic title of the "Falling Eagle" survives as a time-worn remnant in "Vega." Both astronomers agreed to use the "differential" method, for which their instruments and the vicinity to their selected stars of minute, physically detached companions offered special facilities. In the last month of 1838 Bessel made known the result of one year's observations, showing for 6r Cygni a parallax of about a third of a second (0.3136"). ${ }^{1}$ He then had his heliometer taken down and repaired, after which he resumed the inquiry, and finally terminated a series of 402 measures in March $1840 .^{2}$ The resulting parallax of $0.3483^{\prime \prime}$ (corresponding to a distance about 600,000 times that of the earth from the sun), seemed to be ascertained beyond the possibility of cavil, and is memorable as the first published instance of the fathom-line, so industriously thrown into celestial space, having really and indubitably touched bottom. It was confirmed in 1842-43 with curious exactness by C. A. F. Peters at Pulkowa; but later researches showed that it required increase to nearly half a second. ${ }^{3}$

Struve's measurements inspired less confidence. They extended over three years (1835-38), but were comparatively few, and were frequently interrupted. The parallax, accordingly, of about a quarter of a second (0.261 $3^{\prime \prime}$ ) which he derived from them for $\boldsymbol{a}$ Lyræ, and announced in $1840,{ }^{4}$ has proved considerably too large. ${ }^{5}$

Meanwhile a result of the same kind, but of a more striking character than either Bessel's or Struve's, had been obtained, one might almost say casually, by a different method and in a distant region. Thomas Henderson, originally an attorney's clerk in his native town of Dundee, had become known for his astronomical attainments, and was appointed in I83 I to direct

1 Astronomische Nachrichten, Nos. 365-366. It should be explained that which is called the "annual parallax" of a star is only half its apparent displacement. In other words, it is the angle subtended at the distance of that particular star by the radius of the earth's orbit. ${ }^{2}$ Astr. Nach., Nos. 40r402. ${ }^{3}$ Sir R. Ball's measurements at Dunsink give to 6r Cygni a parallax of $0.47^{\prime \prime}$; Professor Pritchard has obtained, by photographic determinations, one of $0.43^{\prime \prime}$ " Additamentum in Mensuras Micrometricas, p. 28.5 Elkin's corrected result (in 1892) for the parallax of Vega is $0.092^{\prime \prime}$. 
the recently completed observatory at the Cape of Good Hope. He began observing in April 1832, and, the serious shortcomings of his instrument notwithstanding, executed during the thirteen months of his tenure of office a surprising amount of first-rate work. With a view to correcting the declination of the lustrous double star a Centauri (which ranks after Sirius and Canopus as the third brightest orb in the heavens), he, effected a number of successive determinations of its position, and on being informed of its very considerable proper motion (3.6" annually), he resolved to examine the observations already made for possible traces of parallactic displacement. This was done on his return to Scotland, where he filled the office of Astronomer Royal from I 834 until his premature death in I844. The result justified his expectations. From the declination measurements made at the Cape and duly reduced, a parallax of about one second of arc clearly emerged (diminished by Gill's and Elkin's observations, I882-I883, to $0.75^{\prime \prime}$ ), but, by perhaps an excess of caution, was withheld from publication until fuller certainty was afforded by the concurrent testimony of Lieutenant Meadows' determinations of the same star's right ascension. ${ }^{1}$ When at last, January 9, I 839, Henderson communicated his discovery to the Astronomical Society, he could no longer claim the priority which was his due. Bessel had anticipated him with the parallax of 61 Cygni by just two months.

Thus from three different quarters, three successful and almost simultaneous assaults were delivered upon a longbeleagured citadel of celestial secrets. The same work has since been steadily pursued, with the general result of showing that, as regards their overwbelming majority, the stars are far too remote to show even the slightest trace of optical shifting from the revolution of the earth in its orbit. In more than fifty cases, however, small parallaxes have been determined, some certainly (that is, within moderate limits of error), others more or less precariously. The list is an instructive one, in its omissions no less than in its contents. It includes stars of many degrees of brightness, from Sirius down to a nameless telescopic star in the

1 Mem. Roy. Astr. Soc., vol. xi., p. 6 I. 
Great Bear ${ }^{1}$ yet the vicinity of this minute object is so much greater than that of the brilliant Vega, that the latter transported to its place would increase in lustre thirty times. Moreover, many of the brightest stars are found to have no sensible parallax, while the majority of those ascertained to be nearest to the earth are of fifth, sixth, even ninth magnitudes. The obvious conclusions follow that the range of variety in the sidereal system is enormously greater than had been supposed, and that estimates of distance based upon apparent magnitude must be wholly futile. Thus, the splendid Canopus, Arcturus, and Rigel, can be inferred, from their indefinite remoteness, to exceed our sun thousands of times in size and lustre; while many inconspicuous objects, which prove to be in our relative vicinity, must be notably his inferiors. The limits of real stellar magnitude are then set very widely apart. At the same time, both the so-called "optical" and "geometrical" methods of relatively estimating star-distances are seen to have a foundation of fact, although so disguised by complicated relations as to be of very doubtful individual application. On the whole, the chances are in favour of the superior vicinity of a bright star over a faint one; and, on the whole, the stars in swiftest apparent motion are amongst those whose actual remoteness is least. Indeed, there is no escape from either conclusion, unless on the supposition of special arrangements in themselves highly improbable, and, we may confidently say, non-existent.

The distances even of the few stars found to have measurable parallaxes are on a scale entirely beyond the powers of the human mind to conceive. In the attempt both to realise them distinctly, and to express them conveniently, a new unit of length, itself of bewildering magnitude, has originated. This is what we may call the light-journey of one year. The subtle vibrations of the ether, propagated on all sides from the surface of luminous bodies, travel at the rate of 186,300 miles a second, or (in round numbers) six billions of miles a year. Four and

1 That numbered $2 \mathrm{I}, \mathrm{I} 85$ in Lalande's Hist. Cel., found by Argelander to have a proper motion of $4.734^{\prime \prime}$, and by Winnecke a parallax of $0.5 \mathrm{II}$ ". Month. Not., vol. xviii., p. 289. 
a third such measures are needed to span the abyss that separates us from the nearest fixed star. In other words, light takes four years and four months to reach the earth from $a$ Centauri; yet $\boldsymbol{a}$ Centauri lies some ten billions of miles nearer to us (so far as is yet known) than any other member of the sidereal system!

The determination of parallax leads, in the case of binary systems, to the determination of mass; for the distance from the earth of the two bodies forming such a system being ascertained, the seconds of arc apparently separating them from each other can be translated into millions of miles; and we only need to add a knowledge of their period to enable us, by an easy sum in proportion, to find their combined mass in terms of that of the sun. Thus, since-according to Dr. Doberck's elements-the two stars forming $\boldsymbol{a}$ Centauri revolve round their common centre of gravity at a mean distance nearly 25 times the radius of the earth's orbit, in a period of 88 years, the attractive force of the two together must be just twice the solar. We may gather some idea of their relations by placing in imagination a second luminary like our sun in circulation between the orbits of Neptune and Uranus. But systems of still more majestic proportions are reduced by extreme remoteness to apparent insignificance. A double star of the fourth magnitude in Cassiopeia (Eta), to which a small parallax is ascribed on the authority of O. Struve, appears to be more than nine times as massive as the central orb of our world; while a much less conspicuous pair-85 Pegasi-exerts, if the available data can be depended upon, fully thirteen times the solar gravitating power.

Further, the actual rate of proper motions, so far as regards that part of them which is projected upon the sphere, can be ascertained for stars at known distances. The annual journey, for instance, of 6r Cygni across the line of sight amounts to I000, and that of $\boldsymbol{a}$ Centauri to 446 millions of miles. A small star, numbered I 830 in Groombridge's Circumpolar Catalogue, "devours the way" at the rate of 230 miles a second-a speed, in Newcomb's opinion, beyond the gravitating power of the 
entire sidereal system to control; and $\zeta$ Toucanæ possesses, according to Dr. Gill, nearly half that amazing velocity besides whatever movement each may have towards or from the earth, of which the spectroscope may eventually give an account.

Herschel's conclusion as to the movement of the sun among the stars was not admitted as valid by the most eminent of his successors. Bessel maintained that there was absolutely no preponderating evidence in favour of its supposed direction towards a point in the constellation Hercules. ${ }^{1}$ Biot, Burckhardt, even Herschel's own son, shared his incredulity. But the appearance of Argelander's prize-essay in $1837^{2}$ changed the aspect of the question. Herschel's first memorable solution in I 783 was based upon the motions of thirteen stars, imperfectly known; his second, in I805, upon those of no more than six. Argelander now obtained an entirely concordant result from the large number of 390, determined with the scrupulous accuracy characteristic of Bessel's work and his own. The reality of the fact thus persistently disclosed could no longer be doubted; it was confirmed five years later by the younger Struve, and still more strikingly in $1847^{3}$ by Galloway's investigation, founded exclusively on the apparent displacements of southern stars. In I859 and I863, the late Sir George Airy and Mr. Dunkin, ${ }^{4}$ employing all the resources of modern science, and commanding the wealth of material furnished by i 67 proper motions carefully determined by Mr. Main, reached conclusions closely similar to that indicated nearly eighty years previously by the first great sidereál astronomer; which Mr. Plummer's reinvestigation of the subject in $1883^{5}$ served but slightly to modify. Yet astronomers were not satisfied. Dr. Auwers of Berlin finished in 1886 a splendid piece of work, ${ }^{6}$ for which he received in 1888 the Gold Medal of the Royal Astronomical Society. It consisted in reducing afresh, with the aid of the most refined modern data, Bradley's original stars, and comparing

1 Fund. Astr., p. 309.

Trans., vol. cxxxvii., p. 79.

5 Ibid., vol. xlvii., p. 327.
2 Mem. Prés. à l'Ac. de St. Pétersb., t. iii. 3 Phil. * Mem. Roy. Astr. Soc., vols. xxviii. and xxxii. 6 Not yet completely published (1893). 
their places thus obtained for the year 1755 with those assigned to them from observations made at Greenwich after the lapse of ninety yearş. In the interval, as was to be anticipated, most of them were found to have travelled over some small span of the heavens, and there resulted a stock of nearly three thousand highly authentic proper motions. These ample materials were turned to account by M. Ludwig Struve ${ }^{1}$ for a discussion of the sun's motion, of which the upshot was to shift its point of aim to the bordering region of the constellations Hercules and Lyra. Still later, Professor Lewis Boss of Albany, N.Y., ${ }^{2}$ and M. Oscar Stumpe of Bonn, ${ }^{3}$ made similar experiments with variously assorted lists of stars, by which the more easterly position of the solar apex was fully confirmed. The brilliant Vega may indeed be said to mark a centre round which newly determined apexes tend loosely to group themselves. ${ }^{4}$ The general direction of the solar movement may nevertheless be regarded as fairly well known; but as to its rate, the grounds of inference long remained unsatisfactory. Otto Struve's estimate of I 54 million miles a year is based upon the assumption of an average annual parallax, for stars of the first magnitude, of about a quarter of a second ; an assumption negatived by actual experience. Fortunately, however, as will be seen further on, a method of determining the sun's velocity independently of any knowledge of star-distances is now rapidly becoming available.

As might have been expected, speculation has not been idle regarding the purpose and goal of the strange voyage of discovery through space upon which our system is embarked; but altogether fruitlessly. The variety of the conjectures hazarded in the matter is in itself a measure of their futility. Long ago, before the construction of the heavens had as yet been made the subject of methodical enquiry, Kant was disposed to regard Sirius as the "central sun" of the Milky Way; while Lambert surmised that the vast Orion nebula might serve as the regulating power of a subordinate group including our sun.

1 Mémoires de St. Pétersburg, t. xxxv., No. 3, 1887. 2 Astronomical Journal, No. 213. $\quad 3$ Astr. Nach., Nos. 2999, 3000. ${ }^{4}$ Cf. Month. Notices, vol. li., p. 243 ; Nalure, vol. xliv., p. 572. 
Herschel threw out the hint that the great cluster in Hercules (estimated to include I4,000 stars) might prove to be the supreme seat of attractive force $;^{1}$ Argelander placed his central body in the constellation Perseus $;^{2}$ Fomalhaut, the brilliant of the Southern Fish, was set in the post of honour by Boguslawski of Breslau. Mädler (who succeeded Struve at Dorpat in I839) concluded from a more formal inquiry that the ruling power in the sidereal system resided, not in any single preponderating mass, but in the centre of gravity of the self-controlled revolving multitude. ${ }^{3}$ In the former case (as we know from the example of the planetary scheme), the stellar motions would be most rapid near the centre; in the latter they would become accelerated with remoteness from it. ${ }^{4}$ Mädler showed that no part of the heavens could be indicated as a region of exceptionally swift movements, such as would result from the presence of a gigantic (though possibly obscure) ruling body; but that a community of extremely sluggish movements undoubtedly existed in and near the group of the Pleiades, where, accordingly, he placed the centre of gravity of the Milky Way. ${ }^{5}$ 'The bright star Alcyone thus became the "central sun," but in a purely passive sense, its headship being determined by its situation at the point of neutralisation of opposing tendencies, and of consequent rest. The solar period of revolution round this point was, by an avowedly conjectural method, fixed at $18,200,000$ years, implying, on the extremely hazardous supposition that the distance of Alcyone is thirty-four million times that of the earth from the sun, a velocity for our system of about thirty miles a second.

The scheme of sidereal government framed by the Dorpat astronomer was, it may be observed, of the most approved constitutional type; deprivation, rather than increase of influence

1 Phil. Trans., vol. xcvi., p. 230. t. iii., p. 603 (read Feb. 5, 1837).
2 Mém. Prés. à l'Ac. de St. Pétershourg,

3 Die Centralsonne, Astr. Nach., Nos. 566-567, 1846. + Sir J.' Herschel, note to Treatise on Astronomy, and /Phil. Trans., vol. cxxiji., part ii., p. 502. 5 The position is (as Sir J. Herschel pointed out, Outlines of Astronomy, p. 631, Ioth ed.) placed beyond the range of reasonable probability by its remoteness (fully $26^{\circ}$ ) from the galactic plane. 
accompanying the office of chief dignitary. But while we are still ignorant, and shall perhaps ever remain so, of the fundamental plan upon which the Galaxy is organised, recent investigations tend more and more to exhibit it, not as monarchical (so to speak), but as federative. The community of proper motions detected by Mädler in the vicinity of the Pleiades may accordingly possess a significance altogether different from what he imagined.

Bessel's so-called "foundation of an Astronomy of the Invisible" now claims attention. ${ }^{1}$ His prediction regarding the planet Neptune does not belong to the present division of our subject; a strictly analogous discovery in the sidereal system was, however, also very clearly foreshadowed by him. His earliest suspicions of non-uniformity in the proper motion of Sirius dated from I 834 ; they extended to Procyon in I840; and after a series of refined measurements with the new Repsold circle, he announced in 1844 his conclusion that these irregularities were due to the presence of obscure bodies round which the two bright Dog-stars revolved as they pursued their way across the sphere. ${ }^{2}$ He even assigned to each an approximate period of half a century. "I adhere to the conviction," he wrote later to Humboldt, "that Procyon and Sirius form real binary systems, consisting of a visible and an invisible star. There is no reason to suppose luminosity an essential quality of cosmical bodies. The visibility of countless stars is no argument against the invisibility of countless others." 3

An inference so contradictory to received ideas obtained little credit, until Peters found, in $185 \mathrm{I},{ }^{4}$ that the apparent anomalies in the movements of Sirius could be completely explained by an orbital revolution in a period of fifty years. Bessel's prevision was destined to be still more triumphantly vindicated. On the 3 Ist of January I862, while in the act of trying a new I8-inch refractor, Mr. Alvan G. Clark (one of the celebrated firm. of American opticians) actually discovered the hypothetical Sirian

1 Mädler in Westrrmann's Jahrbuch, 1867, p. 61 5. Sir J. Herschel, Month. Not., vol. vi., p. 139.

2 Letter from Bessel to p. 743, note. * Astr. Nach., Nos. 745-748.

3 Wolf, Gesch. d. Astr. 
companion in the precise position required by theory. It has now been watched through three-fifths of a revolution (period 49.4 years), and proves to be very slightly luminous in proportion to its mass. Its attractive power, in fact, is nearly half that of its primary, while it emits only $\frac{1}{10000}$ th of its light. Sirius itself, on the other hand, possesses a far higher radiative intensity than our sun. It gravitates-admitting Dr. Gill's parallax of $0.38^{\prime \prime}$ to be exact-like two suns, but shines like sixty-three. Possibly it is enormously distended by heat, and undoubtedly its atmosphere intercepts a very much smaller proportion of its light than in stars of the solar class. As regards Procyon, visual verification is still wanting, but to the mental eye the presence of a considerable disturbing mass was fully assured through the inquiry instituted by Auwers in I 862. ${ }^{1}$ The period of forty years then assigned to the system appears confirmed by recent observations.

But Bessel was not destined to witness the recognition of "the invisible" as a legitimate and profitable field for astronomical research. He died March I7, i 846, just six months before the discovery of Neptune, of an obscure disease, eventually found to be occasioned by an extensive fungusgrowth in the stomach. The place which he left vacant was not one easy to fill. His life's work might be truly described as "epoch-making." Rarely indeed shall we find one who reconciled with the same success the claims of theoretical and practical astronomy, or surveyed the science which he had made his own with a glance equally comprehensive, practical, and profound.

The career of Friedrich Georg Wilhelm Struve illustrates the maxim that science differentiates as it develops. He was, while much besides, a specialist in double stars. His earliest recorded use of the telescope was to verify Herschel's conclusion as to the revolving movement of Castor, and he never, varied from the predilection which this first observation at once indicated and determined. He was born at Altona, of a respectable yeoman family, April 15, I793, and in I8 I t took a degree in philology at the new Russian University of Dorpat. He then turned to 
science, was appointed in I8I3 to a professorship of astronomy and mathematics, and began regular work in the Dorpat Observatory just erected by Parrot for Alexander I. It was not, however, until I8I9 that the acquisition of a 5-foot refractor by Tronghton enabled him to take the position-angles of double stars with regularity and tolerable precision. The resulting catalogue of 795 stellar systems gave the signal for a general resumption of the Herschelian labours in this branch. Moreover, the extraordinary facilities for observation afforded by the Fraunhofer achromatic encouraged him to undertake, February I I, 1825, a review of the entire heavens down to $15^{\circ}$ south of the celestial equator, which occupied more than two years, and yielded, from an examination of above 120,000 stars, a harvest of about 2200 previonsly unnoticed composite objects. The ensuing ten years were devoted to delicate and patient measurements, the results of which were embodied in Mensure Micrometrica, published at St. Petersburg in I836. This monumental work gives the places, angles of position, distances, colours, and relative brightness of 3 II 2 double and multiple stars, all determined with the utmost skill and care. The record is one which gains in value with the process of time, and will for ages serve as a standard of reference by which to detect change or confirm discovery.

It appears from Struve's researches that about one in forty of all stars down to the ninth magnitude is composite, but that the proportion is doubled in the brighter orders. ${ }^{1}$ This he attributed to the difficulty of detecting the faint companions of very remote orbs. It was also noticed, both by him and Bessel, that double stars are in general remarkable for large proper motions. Struve's catalogue included no star of which the components were more than $32^{\prime \prime}$ apart, because beyond that distance the chances of merely optical juxtaposition become considerable; but the immense preponderance of extremely close over (as it were) loosely yoked bodies is such as to demonstrate their physical connection, even if no other proof were forthcoming. Many stars previously believed to be single divided under the

1 Ueber die Doppelsterne, Berieht, I827, p. 22. 
scrutiny of the Dorpat refractor; while in some cases, one nember of a (supposed) binary system revealed itself as double, thus placing the surprised observer in the unexpected presence of a triple group of suns. Five instances were noted of two pairs lying so close together as to induce a conviction of their mutual dependence ${ }^{1}$ besides which, I 24 examples occurred of triple, quadruple, and multiple combinations, the reality of which was open to no reasonable doubt. ${ }^{2}$

It was first pointed out by Bessel that the fact of stars exhibiting a common proper motion might serve as an unfailing test of their real association into systems. This was, accordingly, one of the chief criteria employed by Struve to distinguish true binaries from merely optical couples. On this ground alone, 6I Cygni was admitted to be a genuine double star; and it was shown that, although its components appeared to follow almost strictly rectilinear paths, yet the probability of their forming a connected pair is actually greater than that of the sun rising to-morrow morning. ${ }^{3}$ Moreover, this tie of an identical movement was discovered to unite bodies ${ }^{4}$ far beyond the range of distance ordinarily separating the members of binary systems, and to prevail so extensively as to lead to the conclusion that single do not outnumber conjoined stars more than twice or thrice. ${ }^{5}$

In I835 Struve was summoned by the Emperor Nicholas to superintend the erection of a new observatory at Pulkowa, near St. Petersburg, destined for the special cultivation of sidereal astronomy. Boundless resources were placed at his disposal, and the institution created by him was acknowledged to surpass all others of its kind in splendour, efficiency, and completeness. Its chief instrumental glory was a refractor of fifteen inches aperture by Merz and Mahler (Fraunhofer's successors), which left the famous Dorpat telescope far behind, and remained long without a rival. On the completion of this model establish-

1 Ueber die Doppelsterne, Bericht, 1827, p. 25. 2 Mensurce Micr., p. xcix. 3 Stellarum Fixarum imprimis Duplicium et Multiplicium Positiones Iledice, pp. cxc., cciii. $\quad{ }^{+}$For instance, the southern stars, 36A Ophiuchi (itself double) and 30 Scorpii, which are $\mathrm{I}^{\prime} \mathrm{IO}^{\prime \prime}$ apart. Ibid., p. cciii. ${ }^{5}$ Stellarum Fixa. rum, \&c., p. ccliii. 
ment, August I9,- I839, Struve was installed as its director, and continued to fulfil the important duties of the post with his accustomed vigour until I 858 , when illness compelled his virtual resignation in favour of his son Otto Struve, born at Dorpat in I 8 I9. He died November 23, 1864.

An inquiry into the laws of stellar distribution, undertaken during the early years of his residence at Pulkowa, led Struve to confirm in the main the inferences arrived at by Herschel as to the construction of the heavens. According to his view, the appearance known as the Milky Way is produced by a collection of (for the most part) irregularly condensed starclusters, within which the sun is somewhat eccentrically placed. The nebulous ring which thus integrates the light of countless worlds was supposed by him to be made up of stars scattered over a bent or "broken plane," or to lie in two planes slightly inclined to each other, our system occupying a position near their intersection. ${ }^{1}$ He further attempted to show that the limits of this vast assemblage must remain for ever shrouded from human discernment, owing to the gradual extinction of light in its passage through space, ${ }^{2}$ and sought to confer upon this celebrated hypothesis a definiteness and certainty far beyond the aspirations of its earlier advocates, Chéseaux and Olbers; but arbitrary assumptions vitiated his reasonings on this, as well as on some other points. ${ }^{3}$

In his special line as a celestial explorer of the most comprehensive type, Sir William Herschel had but one legitimate successor, and that successor was his son. John Frederick William Herschel was born at Slough, March I7, I792, graduated with the highest honours from St. John's College, Cambridge, in I8 13 , and entered upon legal studies with a view to being called to the Bar. But his share in an early compact with Peacock and Babbage, "to do their best to leave the world wiser than they found it," was not thus to be fulfilled. The acquaintance of Dr. Wollaston decided his scientific vocation. Already, in I816, we find him reviewing some of his father's

${ }^{1}$ Études d'Astronomie Stellaire, 1847, p. 82. $\quad$ 2 1bid., p. 86. ${ }^{3}$ See Encke's criticism in Astr. Nach., No. 622. 
double stars; and he completed in 1820 the I8-inch speculum which was to be the chief instrument of his investigations. Soon afterwards, he undertook, in conjunction with Mr. (afterwards Sir James) South, a series of observations, issuing in the presentation to the Royal Society of a paper ${ }^{1}$ containing micrometrical measurements of 380 binary stars, by which the elder Herschel's inferences of orbital motion were, in many cases, strikingly confirmed. A star in the Northern Crown, for instance ( $\boldsymbol{\eta}$ Coronæ), had completed more than one entire circuit since its first discovery; another, $\tau$ Serpentarii, had closed up into apparent singleness ; while the motion of a third, $\xi$ Ursæ Majoris, in an obviously eccentric orbit, was so rapid as to admit of being traced and measured from month to month.

It was from the first confidently believed that the force retaining double stars in curvilinear paths was identical with that governing the planetary revolutions. But that identity was not ascertained until Savary of Paris showed, in $1827,,^{2}$ that the movements of the above-named binary in the Great Bear, could be represented with all attainable accuracy by an ellipse calculated on orthodox gravitational principles with a period of $58 \frac{1}{4}$ years. Encke followed at Berlin with a still more elegant method; and Sir John Herschel, pointing out the uselessness of analytical refinements where the data were necessarily so imperfect, described in I83 I a graphical process by which "the aid of the eye and hand" was brought in "to guide the judgment in a case where judgment only, and not calculation, could be of any avail." ${ }_{3}$ The subject has since been cultivated with diligence, and not without success; but our acquaintance with stellar orbits can hardly yet be said to have emerged from the tentative stage.

In I 825 Herschel undertook, and executed with great assiduity during the ensuing eight years, a general survey of the northern heavens, directed chiefly towards the verification of his father's nebular discoveries. The outcome was a catalogue of 2306 nebulæ and clusters, of which 525 were observed for the first

1 Phil. Trans., vol. cxiv., part iii., I824.

2 Conn. d. Temps, 1830.

$$
\text { 3 R. A. S. Mem., vol. v., } 1833 \text {, p. } 178 .
$$


time, besides 3347 double stars discovered almost incidentally. ${ }^{1}$ "Strongly invited," as he tells us himself, "by the peculiar interest of the subject, and the wonderful nature of the objects which presented themselves," he resolved to attempt the completion of the survey in the southern hemisphere. With this noble object in view, he embarked his family and instruments on board the Mount Stewart Elphinstone, and, after a prosperous voyage, landed at Cape Town on the I6th of January I 834. Choosing as the scene of his observations a rural spot under the shelter of Table Mountain, he began regular "sweeping" on the 5th of March. The site of his great reflector is now marked with an obelisk, and the name of Feldhausen has become memorable in the history of science; for the four years' work done there may truly be said to open the chapter of our knowledge as regards the southern skies.

The full results of Herschel's journey to the Cape were not made public until 1847 , when a splendid volume ${ }^{2}$ embodying them was brought out at the expense of the Duke of Northumberland. They form a sequel to his father's labours such as the investigations of one man have rarely received from those of another. What the elder observer did for the northern heavens, the younger did for the southern, and with generally concordant results. Reviving the paternal method of "star-gauging," he showed, from a count of 2299 fields, that the Milky Way surrounds the solar system as a complete annulus of minute stars; not, however, quite symmetrically, since the sun appears to lie somewhat nearer to those portions visible in the southern hemisphere, which accordingly display a brighter lustre and a more complicated structure than the northern branches. The singular cosmical agglomerations known as the "Magellanic Clouds" were now, for the first time, submitted to a detailed, though admittedly incomplete, examination, the almost inconceivable richness and variety of their contents being such that a lifetime might with great profit be devoted to their study. In the Greater Nubecula, within a compass of forty-two square degrees,

1 Plill. 'Trans., vol. cxxiii., and Results, \&c., Introd. 2 Results of Astronomical Observations made during the years 1834-8 at the Cape of Good Hope. 
Herschel reckoned 278 distinct nebulæ and clusters, besides fifty or sixty outliers, and a large number of stars intermixed with diffused nebulosity -in all, 9 I9 catalogued objects, and, for the Lesser Cloud, 244. Yet this was only the most conspicuous part of what his twenty-foot revealed. Such an extraordinary concentration of bodies so various led him to the inevitable conclusion that "the Nubeculæ are to be regarded as systems sui generis, and which have no analogues in our hemisphere." 1 He noted also the blankness of surrounding space, especially in the case of Nubecula Minor, "the access to which on all sides," he remarked, "is through a desert;" as if the cosmical material in the neighbourhood had been swept up and garnered in these mighty groups. ${ }^{2}$

Of southern double stars, he discovered and gave careful measurements of 2102 , and described I708 nebulæ, of which at least 300 were new. The list was illustrated with a number of drawings, some of them extremely beautiful and elaborate.

Sir John Herschel's views as to the nature of nebulæ were considerably modified by Lord Rosse's success in "resolving" with his great reflectors a crowd of these objects into stars. His former somewhat hesitating belief in the existence of phosphorescent matter, "disseminated through extensive regions of space in the manner of a cloud or fog," 3 was changed into a conviction that no valid distinction could be established between the faintest wisp of cosmical vapour just discernible with a powerful telescope, and the most brilliant and obvious cluster. He admitted, however, an immense range of possible variety in the size and mode of aggregation of the stellar constituents of various nebulæ. Some might appear nebulous from the closeness of their parts; some from their smallness. Others, he suggested, might be formed of "discrete luminous bodies floating in a non-luminous medium;" 4 while the annular kind probably consisted of "hollow shells of stars." ${ }_{5}$ That a physical, and not merely an optical, connection unites nebulæ

1 Results, \&c., p. 147. 2 See Proctor's Universe of Stars, p. 92. ${ }^{3} A$ I'reatise on Astronomy, 1833, p. 406. + Results, dc., p. 139. 5 1bid., pp. 24, I42. 
with the embroidery (so to speak) of small stars with which they are in many instances profusely decorated, was evident to him, as it must be to all who look as closely and see as clearly as he did. His description of No. 2093 in his northern catalogue as " a network of tracery of nebula following the lines of a similar network of stars," 1 would alone suffice to dispel the idea of accidental scattering; and many other examples of a like import might be quoted. The remarkably frequent occurrence of one or more minute stars in the close vicinity of "planetary" nebulæ led him to infer their dependent condition; and he advised the maintenance of a strict watch for evidences of circulatory movements, not only over these supposed stellar satellites, but also over the numerous "double nebulæ," in which, as he pointed out, "all the varieties of double stars as to distance, position, and relative brightness, have their counterparts." He, moreover, investigated the subject of nebular distribution by the simple and effectual method of graphic delineation or "charting," and succeeded in showing that while a much greater uniformity of scattering prevails in the southern heavens than in the northern, a condensation is nevertheless perceptible about the constellations Pisces and Cetus, roughly corresponding to the "nebular region" in Virgo by its vicinity (within $20^{\circ}$ or $30^{\circ}$ ) to the opposite pole of the Milky Way. $\mathrm{He}$ concluded "that the nebulous system is distinct from the sidereal, though involving, and perhaps to a certain extent intermixed with, the latter." 2

Towards the close of his residence at Feldhausen, Herschel was fortunate enough to witness one of those singular changes in the aspect of the firmament which occasionally challenge the attention even of the incurious, and excite the deepest wonder of the philosophical observer. Immersed apparently in the Argo nebula is a large star denominated $\boldsymbol{\eta}$ Argûs. When Halley visited St. Helena in 1677 , it seemed of the fourth magnitude; but Lacaille in the middle of the following century, and others after him, classed it as of the second. In I 827 the traveller Burchell, being then at St. Paul, near Rio Janeiro, remarked

1 Plil. Trans., vol. cxxiii., p. 5С3. 2 Results, \&c., p. 136. 
that it had unexpectedly assumed the first rank-a circumstance the more surprising to him because he had frequently, when in Africa during the years I8I I to I8I I, noted it as of only fourth magnitude. This observation, however, did not become generally known until later. Herschel, on his arrival at Feldhausen, registered the star as a bright second, and had no suspicion of its unusual character until December 16, 1837, when he suddenly perceived it with its light almost tripled. It then far outshone Rigel in Orion, and on the 2nd of January following, it very nearly matched $\boldsymbol{a}$ Centauri. From that date it declined; but a second and even brighter maximum occurred in April I843, when Maclear, then director of the Cape Observatory, saw it blaze out with a splendour approaching that of Sirius. Its waxings and wanings were marked by curious "trepidations" of brightness extremely perplexing in theory. In 1863 it had sunk below the fifth magnitude, and in 1869 was barely visible to the naked eye; yet it was not until eighteen years later that it touched a minimum of 7.6 magnitude. Soon afterwards a recovery of brightness set in, but was not carried very far; and the star now shines steadily as of the seventh magnitude, its reddish light contrasting effectively with the silvery rays of the surrounding nebula. An attempt to include its fluctuations within a cycle of seventy years ${ }^{1}$ has signally failed; the extent and character of the vicissitudes to which it is subject stamping it rather as a species of connecting link between periodical and temporary stars. ${ }^{2}$

Among the numerous topics which engaged Herschel's attention at the Cape was that of relative stellar brightness. Having contrived an "astrometer" in which an "artificial star," formed by the total reflection of moonlight from the base of a prism, served as a standard of comparison, he was able to estimate the lustre of the natural stars examined by the distances at which the artificial object appeared equal respectively to each. He thus constructed a table of 19I of the principal stars, ${ }^{3}$ both in the northern and southern hemispheres, setting forth the numerical

${ }^{1}$ Loomis in Month. Not., vol. xxix., p. 298. 2 See the Author's System of the Stars, pp. I16-120. 3 Uutlines of Astr, App. I. 
values of their apparent brightness relatively to that of $\boldsymbol{a}$ Centauri, which he selected as a unit of measurement. Further, the light of the full moon being found by him to exceed that of his standard star 27,408 times, and Dr. Wollaston having shown that the light of the full moon is to that of the sun as I : 80I,072 ${ }^{1}$ (Zöllner made the ratio I : 6I8,000), it became possible to compare stellar with solar radiance. Hence was derived, in the case of the few stars at ascertained distances, a knowledge of real lustre. Alpha Centauri, for example, emits about four times, Capella 250 times as much light as our sun; while Arcturus, judging from its indefinite distance, must display the splendour of a couple of thousand such luminaries.

Herschel returned to England in the spring of 1838 , bringing with him a wealth of observation and discovery such as had perhaps never before been amassed in so short a time. Deserved honours awaited him. He was created a baronet on the occasion of the Queen's coronation (he had been knighted in I83I); universities and learned societies vied with each other in showering distinctions upon him; and the success of an enterprise in which scientific zeal was tinctured with an attractive flavour of adventurous romance, was justly regarded as a matter of national pride. His career as an observing astronomer was now virtually closed, and he devoted his leisure to the collection and arrangement of the abundant trophies of his father's and his own activity. The resulting great catalogue of 5079 nebulæ (including all then certainly known), published in the Philosophical Transactions for $\mathbf{1 8 6 4}$, is, and will probably long remain, the fundamental source of information on the subject; ${ }^{2}$ but he unfortunately did not live to finish the companion work on double stars, for which he had accumulated a vast store of materials. $^{3}$ He died at Collingwood in Kent, May I I, I87 I, in

1 Phil. Trans., vol. cxix.. p. 27. $\quad{ }^{2}$ Dr. Dreyer's New General Catalogue, published in 1888 as vol. xlix. of the Royal Astronomical Society's Memoirs, is an enlargement of Herschel's work. It includes 7,840 entries. ${ }^{3} \mathrm{~A}$ list of 10,320 composite stars was drawn out by him in order of right ascension, and has been published in vol. xl. of $\mathrm{Mem} . R$. A. S.; but the data requisite for their formation into a catalogue were not forthcoming. See Main's and Pritchard's Preface to above, and Dunkin's Obituary Notices, p. 73. 
the eightieth year of his age, and was buried in Westminster Abbey, close beside the grave of Sir Isaac Newton.

The consideration of Sir John Herschel's Cape observations brings us to the close of the period we are just now engaged in studying. They were given to the world, as already stated, three years before the middle of the century, and accurately represent the condition of sidereal science at that date. Looking back over the fifty years traversed, we can see at a glance how great was the stride made in the interval. Not alone was acquaintance with individual members of the cosmos vastly extended, but their mutual relations, the laws governing their movements, their distances from the earth, masses, and intrinsic lustre, had begun to be successfully investigated. Begun to be; for only regarding a scarcely perceptible minority had even approximate conclusions been arrived at. Nevertheless the whole progress of the future lay in that beginning; it was the thin end of the wedge of exact knowledge. The principle of measurement had been substituted for that of probability; a basis had been found large and strong enough to enable calculation to ascend from it to the sidereal heavens; and refinements had been introduced, fruitful in performance, but still more in promise. Thus, rather the kind than the amount of information collected was significant for the time to come-rather the methods employed than the results actually secured rendered the first half of the nineteenth century of epochal importance in the history of our knowledge of the stars. 
CHAPTER III.

PROGRESS OF KNOWLEDGE REGARDING THE SUN.

The discovery of sun-spots in 16 10 by Fabricius and Galileo first opened a way for inquiry into the solar constitution; but it was long before that way was followed with system or profit. The seeming irregularity of the phenomena discouraged continuous attention; casual observations were made the basis of arbitrary conjectures, and real knowledge received little or no increase. In 1620 we find Jean Tarde, canon of Sarlat, arguing that because the sun is "the eye of the world," and the eye of the world cannot suffer from ophthalmia, therefore the appearances in question must be due, not to actual specks or stains on the bright solar disc, but to the transits of a number of small planets across it! To this new group of heavenly bodies he gave the name of "Borbonia Sidera," and they were claimed in I633 for the House of Hapsburg, under the title of "Austriaca Sidera" by Father Malapertius, a Belgian Jesuit. ${ }^{1}$ A similar. view was temporarily maintained against Galileo, by the justly celebrated Father Scheiner of Ingolstadt, and later by William Gascoigne, the inventor of the micrometer; but most of those who were capable of thinking at all on such subjects (and they were but few) adhered either to the cloud theory or to the slag theory of sun-spots. The first was championed by Galileo, the second by Simon Marius, "astronomer and physician" to the brother Margraves of Brandenburg. The latter opinion received a further notable development from the fact that in 1618, a year remarkable for the appearance of three bright comets, the sun

1 Kosmos, Bd. iii., p. 409; Lalande, Bibliographie Astronomique, pp. 179, 202. 
was almost free from spots; whence it was inferred that the cindery refuse from the great solar conflagration, which usually appeared as dark blotches on its surface, was occasionally thrown off in the form of comets, leaving the sun, like a snuffed taper, to blaze with renewed brilliancy. ${ }^{1}$

In the following century, Derham gathered from observations carried on during the years I703-I I, "That the spots on the sun are caused by the eruption of some new volcano therein, which at first pouring out a prodigious quantity of smoke and other opacous matter, causeth the spots; and as that fuliginous matter decayeth and spendeth itself, and the volcano at last becomes more torrid and flaming, so the spots decay, and grow to umbræ, and at last to faculæ." 2

The view, confidently upheld by Lalande, ${ }^{3}$ that spots were rocky elevations uncovered by the casual ebbing of a luminous ocean, the surrounding penumbræ representing shoals or sandbanks, had even less to recommend it than Derham's volcanic theory. Both were, however, significant of a growing tendency to bring solar phenomena within the compass of terrestrial analogies.

For I64 years, then, after Galileo first levelled his telescope at the setting sun, next to nothing was learned as to its nature; and the facts immediately ascertained of its rotation on an axis nearly erect on the plane of the ecliptic, in a period of between twenty-five and twenty-six days, and of the virtual limitation of the spots to a so-called "royal" zone extending some thirty degrees north and south of the solar equator, gained little either in precision or development from five generations of astronomers.

1 R. Wolf, Die Sonne und ilte Flecken, p. y. Marius himself, however, seems to have held the Aristotelian terrestrial-exhalation theory of cometary origin. See his curious little tract, Astronomische und Astrologische Beschreibung des Cometen, Nürnberg, 16r9. 2 Phil. Trans., vol. xxvii., p. 274. Umbrce (now called penumbr(e) are spaces of half-shadow which usually encircle spots. Faculae ("little torches," so named by Scheiner) are bright streaks or patches closely associated with spots. ${ }^{3}$ Mém. Ac. Sc., I 776 (pub. 1779), p. 507. The merit, however (if merit it be), of having first put forward (about I67I) the hypothesis alluded to in the text belongs to D. Cassini. See Delambre, Hist. de l'Astr. Moả., t. ii., p. 694 ; and Kosmos, Bd. iii., p. 4 Io. 
But in November I769 a spot of extraordinary size engaged the attention of Alexander Wilson, professor of astronomy in the University of Glasgow. He watched it day by day, and to good purpose. As the great globe slowly revolved, carrying the spot towards its western edge, he was struck with the gradual contraction and final disappearance of the penumbra on the side next the centre of the disc; and when on the 6th of December the same spot re-emerged on the eastern limb, he perceived, as he had anticipated, that the shady zone was now deficient on the opposite side, and resumed its original completeness as it returned to a central position. Similar perspective effects were visible in numerous other spots subsequently examined by him, and he was thus in $1774^{1}$ able to prove by strict geometrical reasoning that such appearances were, as a matter of fact, produced by vast excavations in the sun's substance. It was not, indeed, the first time that such a view had been suggested. Father Scheiner's later observations plainly foreshadowed it ${ }^{2}$ a conjecture to the same effect was emitted by Leonard Rost of Nuremberg early in the eighteenth century $;^{3}$ both by Lahire in I 703 and by J. Cassini in I 7 I 9 spots had been seen to form actual notches on the solar limb; while Pastor Schülen of Essingen convinced himself in 1770 , by the careful study of appearances similar to those noted by Wilson, of the fact detected by him. ${ }^{4}$ Nevertheless, Wilson's demonstration came with all the surprise of novelty, as well as with all the force of truth.

The general theory by which it was accompanied rested on a very different footing. It was avowedly tentative, and was set forth in the modest shape of an interrogatory. "Is it not reasonable to think," he asked, "that the great and stupendous body of the sun is made up of two kinds of matter, very different in their qualities; that by far the greater part is solid and dark, and that this immense and dark globe is encompassed with a thin covering of that resplendent substance from which the sun would seem to derive the whole of his vivifying heat

1 Phil. Trans., vol. lxiv., part i., pp. 7-I I. ${ }^{2}$ Rosa Ursina, lib. iv., p. 507. 3 R. Wolf, Die Sonne und ihre Flecken, p. 12. + Schellen, Die Spectralanalyse, Bd. ii., p. 56 (3rd ed.) 
and energy?" 1 He further suggested that the excavations or spots might be occasioned "by the working of some sort of elastic vapour which is generated within the dark globe," and that the luminous matter being in some degree fluid, and being acted upon by gravity, tended to flow down and cover the nucleus. From these hints, supplemented by his own diligent observations and sagacious reasonings, Herschel elaborated a scheme of solar constitution which held its ground until the physics of the sun were revolutionised by the spectroscope.

A cool, dark, solid globe, its surface diversified with mountains and valleys, clothed in luxuriant vegetation, and " richly stored with inhabitants," protected by a heavy cloud-canopy from the intolerable glare of the upper luminous region, where the dazzling coruscations of a solar aurora some thousands of miles in depth evolved the stores of light and heat which vivify our world-such was the central luminary which Herschel constructed with his wonted ingenuity, and described with his wonted eloquence.

"This way of considering the sun and its atmosphere," he says, $^{2}$ "removes the great dissimilarity we have hitherto been used to find between its condition and that of the rest of the great bodies of the solar system. The sun, viewed in this light, appears to be nothing else than a very eminent, large, and lucid planet, evidently the first, or, in strictness of speaking, the only primary one of our system; all others being truly secondary to it. Its similarity to the other globes of the solar system with regard to its solidity, its atmosphere, and its diversified surface, the rotation upon its axis, and the fall of heavy bodies, leads us on to suppose that it is most probably also inhabited, like the rest of the planets, by beings whose organs are adapted to the peculiar circumstances of that vast globe."

We smile at conclusions which our present knowledge condemns as extravagant and impossible, but such incidental flights of fancy in no way derogate from the high value of Herschel's contributions to solar science. The cloud-like character which he attributed to the radiant shell of the sun (first named by

${ }_{1}$ Phil. Trans., vol. lxiv., p. 20.

2 1bid., vol. lxxxv., 1795, p. 63. 
Schröter the "photosphere") is borne out by all recent investigations; he observed its mottled or corrugated aspect, resembling, as he described it, the roughness on the rind of an orange; showed that "faculæ" are elevations or heaped-up ridges of the disturbed photospheric matter; and threw out the idea that spots may ensue from an excess of the ordinary luminous emissions. A certain "empyreal" gas was, he supposed (very much as Wilson had done), generated in the body of the sun, and rising everywhere by reason of its lightness, made for itself, when in moderate quantities, small openings or "pores," abundantly visible as dark points on the solar disc. But should an uncommon quantity be formed, "it will," he maintained, "burst through the planetary" regions of clouds, and thus will produce great openings; then, spreading itself above them, it will occasion large shallows (penumbræ), and mixing afterwards gradually with other superior gases, it will promote the increase, and assist in the maintenance of the general luminous phenomena." 3

This partial anticipation of the modern view that the solar radiations are maintained by some process of circulation within the solar mass, was reached by Herschel through prolonged study of the phenomena in question. The novel and important idea contained in it, however, it was at that time premature to attempt to develop. But though many of the subtler suggestions of Herschel's genius passed unnoticed by his contemporaries, the main result of his solar researches was an unmistakable one. It was nothing less than the definitive introduction into astronomy of the paradoxical conception of the central fire and hearth of our system as a cold, dark, terrestrial mass, wrapt in a mantle of innocuous radiance-an earth, so to speak, within-a sun without.

Let us pause for a moment to consider the value of this remarkable innovation. It certainly was not a step in the direction of truth. On the contrary, the crude notions of

1 Phil. Trans., vol. xci., I801, p. 303. 2 The supposed opaque or protective stratum beneath the photosphere was named by him "planetary," from the analogy of terrestrial clouds. $\quad 3$ Ibid., p. 305 . 
Anaxagoras and Xeno approached more nearly to what we now know of the sun, than the complicated structure devised for the happiness of a nobler race of beings than our own by the benevolence of eighteenth-century astronomers. And yet it undoubtedly constituted a very important advance in science. It was the first earnest attempt to bring solar phenomena within the compass of a rational system ; to put together into a consistent whole the facts ascertained; to fabricate, in short, a solar machine that would in some fashion work. It is true that the materials were inadequate and the design faulty. The resulting construction has not proved strong enough to stand the wear and tear of time and discovery, but has had to be taken to pieces and remodelled on a totally different plan. But the work was not therefore done in vain. None of Bacon's aphorisms show a clearer insight into the relations between the human mind and the external world than that which declares "Truth to emerge sooner from error than from confusion." I A definite theory (even if a false one) gives holding-ground to thought. Facts acquire a meaning with reference to it. It affords a motive for accumulating them and a means of co-ordinating them; it provides a framework for their arrangement, and a receptacle for their preservation, until they become too strong and numerous to be any longer included within arbitrary limits, and shatter the vessel originally framed to contain them.

Such was the purpose subserved by Herschel's theory of the sun. It helped to clarify ideas on the subject. The turbid sense of groping and viewless ignorance gave place to the lucidity of a plausible scheme. The persuasion of knowledge is a keen incentive to its increase. Few men care to investigate what they are obliged to admit themselves entirely ignorant of; but once started on the road of knowledge, real or supposed, they are eager to pursue it. By the promulgation of a confident and consistent view regarding the nature of the sun, accordingly, research was encouraged, because it was rendered hopeful, and inquirers were shown a path leading indefinitely onwards where an impassable thicket had before seemed to bar the way.

1 Novum Organum, lib. ii., aph. 20. 
We have called the "terrestrial" theory of the sun's nature an innovation, and so, as far as its general acceptance is concerned, it may justly be termed; but, like all successful innovations, it was a long time brewing. It is extremely curious to find that Herschel had a predecessor in its advocacy who never looked through a telescope (nor, indeed, imagined the possibility of such an instrument), who knew nothing of sunspots, was still (mistaken assertions to the contrary notwithstanding) in the bondage of the geocentric system, and regarded nature from the lofty standpoint of an idealist philosophy. This was the learned and enlightened Cardinal Cusa, a fisherman's son from the banks of the Moselle, whose distinguished career in the Church and in literature extended over a considerable part of the fifteenth century (140I-64). In his singular treatise De Doctî Ignorantia, one of the most notable literary monuments of the early Renaissance, the following passage occurs:- "To a spectator on the surface of the sun, the splendour which appears to us would be invisible, since it contains, as it were, an earth for its central mass, with a circumferential envelope of light and heat, and between the two an atmosphere of water and clouds and translucent air." The luminary of Herschel's fancy could scarcely be more clearly portrayed; some added words, however, betray the origin of the Cardinal's idea. "The earth also," he says, "would appear as a shining star to any one outside the fiery element." It was, in fact, an extension to the sun of the ancient elemental doctrine; but an extension remarkable at that period, as premonitory of the tendency, so powerfully developed by subsequent discoveries, to assimilate the orbs of heaven to the model of our insignificant planet, and to extend the brotherhood of our system and our species to the farthest limit of the visible or imaginable universe.

In later times we find Flamsteed communicating to Newton, March 7, I68I, his opinion "that the substance of the sun is terrestrial matter, his light but the liquid menstruum encompassing him." 1 Bode in I776 arrived independently at the conclusion that " the sun is neither burning nor glowing, but in its

1 Brewster's Life of Newton, vol. ii., p. I03. 
essence a dark planetary body, composed like our earth of land and water, varied by mountains and valleys, and enveloped in a vaporous atmosphere "; ${ }^{1}$ and the learned in general applauded and acquiesced. The view, however, was in 1787 still so far from popular, that the holding of it was alleged as a proof of insanity in Dr. Elliot when accused of a murderous assault on Miss Boydell. His friend Dr. Simmons stated on his behalf that he had received from him in the preceding January a letter giving evidence of a deranged mind, wherein he asserted "that the sun is not a body of fire, as hath been hitherto supposed, but that its light proceeds from a dense and universal aurora, which may afford ample light to the inhabitants of the surface beneath, and yet be at such a distance aloft as not to annoy them. No objection, he saith, ariseth to that great luminary's being inhabited; vegetation may obtain there as well as with us. There may be water and dry land, hills and dales, rain and fair weather; and as the light, so the season must be eternal, consequently it may easily be conceived to be by far the most blissful habitation of the whole system !" The Recorder, however, we are told, objected that if an extravagant hypothesis were to be adduced as proof of insanity, the same might hold good with regard to some other speculators, and desired Dr. Simmons to tell the court what he thought of the theories of Burnet and Buffon. ${ }^{2}$

Eight years later, this same " extravagant hypothesis," backed by the powerful recommendation of Sir William Herschel, obtained admittance to the venerable halls of science, there to abide undisturbed for nearly seven decades. It is true there were individual objectors, but their arguments made little impression on the general body of opinion. Ruder blows were required to shatter an hypothesis flattering to human pride of invention in its completeness, in the plausible detail of observations by which it seemed to be supported, and in its condescension to the natural pleasure in discovering resemblance under all but total dissimilarity.

1 Beschäftigungen d. Berl. Ges. Naturforschender Freunde, Bd. ii., p. 233. 2 Gentleman's Magazine, 1787, vol. ii., p. 636. 
Sir John Herschel included among the results of his multifarious labours at the Cape of Good Hope a careful study of the sun-spots conspicuously visible towards the end of the year 1836 and in the early part of 1837. They were remarkable, he tells us, for their forms and arrangement, as well as for their number and size; one group, measured on the 29th of March in the latter year, covering (apart from what may be called its outlying dependencies) the vast area of five square minutes or 3780 million square miles. ${ }^{1}$ We have at present to consider, however, not so much these observations in themselves, as the chain of theoretical suggestions by which they were connected. The distribution of spots, it was pointed out, on two zones parallel to the equator, showed plainly their intimate connection with the solar rotation, and indicated as their cause fluid circulations analogous to those producing the terrestrial trade and anti-trade winds.

"The spots, in this view of the subject," he went on to say, ${ }^{2}$ "would come to be assimilated to those regions on the earth's surface where, for the moment, hurricanes and tornadoes prevail ; the upper stratum being temporarily carried downwards, displacing by its impetus the two strata of luminous matter beneath, the upper of course to a greater extent than the lower, and thus wholly or partially denuding the opaque surface of the sun below. Such processes cannot be unaccompanied by vorticose motions, which, left to themselves, die away by degrees and dissipate, with the peculiarity that their lower portions come to rest more speedily than their upper, by reason of the greater resistance below, as well as the remoteness from the point of action, which lies in a higher region, so that their centres (as seen in our waterspouts, which are nothing but small tornadues) appear to retreat upwards. Now this agrees perfectly with what is observed during the obliteration of the solar spots, which appear as if filled in by the collapse of their sides, the penumbra closing in upon the spot and disappearing after it."

When, however, it comes to be asked whether a cause can be found by which a diversity of solar temperature might be pro-

1 Resuits, \&c., p. 432. 2 Ibid., \&c., 434. 
duced corresponding with that which sets the currents of the terrestrial atmosphere in motion, we are forced to reply that we know of no such cause. For Sir John Herschel's hypothesis of an increased retention of heat at the sun's equator, due to the slightly spheroidal or bulging form of its outer atmospheric envelope, assuredly gives no sufficient account of such circulatory movements as he supposed to exist. Nevertheless, the view that the sun's rotation is intimately connected with the formation of spots is so obviously correct, that we can only wonder it was not thought of sooner, while we are even now unable to explain with any certainty how it is so connected.

Mere scrutiny of the solar surface, however, is not the only means of solar observation. We have a satellite, and that satellite from time to time acts most opportunely as a screen, cutting off a part or the whole of those dazzling rays in which the master-orb of our system veils himself from over-curious regards. The importance of eclipses to the study of the solar surroundings is of comparatively recent recognition; nevertheless, much of what we know concerning them has been snatched, as it were, by surprise under favour of the moon. In former times, the sole astronomical use of such incidents was the correction of the received theories of the solar and lunar movements; the precise time of their occurrence was the main fact to be noted, and subsidiary phenomena received but casual attention. Now, their significance as a geometrical test of tabular accuracy is altogether overshadowed by the interest attaching to the physical observations for which they afford propitious occasions. This change may be said to date, in its pronounced form, from the great eclipse of 1842. Although a necessary consequence of the general direction taken by scientific progress, it remains associated in a special manner with the name of Francis Baily.

The "philosopher of Newbury" was by profession a London stockbroker, and a highly successful one. Nevertheless, his services to science were numerous and invaluable, though not of the brilliant kind which attract popular notice. Born at 
Newbery in Berkshire, April 28, I774, and placed in the City at the age of fourteen, he derived from the acquaintance of Dr. Priestley a love of science which never afterwards left him. It was, however, no passion such as flames up in the brain of the destined discoverer, but a regulated inclination, kept well within the bounds of an actively pursued commercial career. After travelling for a year or two in what were then the wilds of North America, he went on the Stock Exchange in I799, and earned during twenty-four years of assiduous application to affairs a high reputation for integrity and ability, to which corresponded an ample fortune. In the meantime the Astronomical Society (largely through his co-operation) had been founded; he had for three years acted as its secretary, and he now felt entitled to devote himself exclusively to a subject which had long occupied his leisure hours. He accordingly in I825 retired from business, purchased a house in Tavistock Place, and fitted up there a small observatory. He was, however, by preference a computator rather than an observer. What Sir John Herschel calls the "archæology of practical astronomy" found in him an especially zealous student. $\mathrm{He}$ re-edited the star-catalogues of Ptolemy, Ulugh Beigh, Tycho Brahe, Hevelius, Halley, Flamsteed, Lacaille, and Mayer; calculated the eclipse of Thales and the eclipse of Agathocles, and vindicated the memory of the first Astronomer Royal. But he was no less active in meeting present needs than in revising past performances. The subject of the reduction of observations, then, as we have already explained, ${ }^{1}$ in a state of deplorable confusion, attracted his most earnest attention, and he was close on the track of Bessel when made acquainted with the method of simplification devised at Königsberg. Anticipated as an inventor, he could still be of eminent use as a promoter of these valuable improvements; and, carrying them out on a large scale in the star-catalogue of the Astronomical Society (published in I827), "he put" (in the words of Herschel) "the astronomical world in possession of a power which may be said, 
without exaggeration, to have changed the face of sidereal astronomy." 1

His reputation was still further enhanced by his renewal, with vastly improved apparatus, of the method, first used by Henry Cavendish in I797-98, for determining the density of the earth. From a series of no less than 2I 53 delicate and difficult experiments, conducted at Tavistock Place during the years I838-42, he concluded our planet to weigh 5.66 as much as a globe of water of the same bulk; and this result (slightly corrected) is still accepted as a very close approximation to the truth.

What we have thus glanced at is but a fragment of the truly surprising mass of work accomplished by Baily in the course of a variously occupied life. A rare combination of qualities fitted him for his task. Unvarying health, undisturbed equanimity; methodical habits, the power of directed and sustained thought, combined to form in him an intellectual toiler of the surest, though not perhaps of the very highest quality. He was in harness almost to the end. He was destined scarcely to know the miseries of enforced idleness or of consciously failing powers. In 1842 he completed the laborious reduction of Lalande's great catalogue, undertaken at the request of the British Association, and was still engaged in seeing it through the press when he was attacked with what proved his last, as it was probably his first serious illness. He, however, recovered sufficiently to attend the Oxford Commemoration of July 2, I844, where an honorary degree of D.C.L. was conferred upon him in company with Airy and Struve; but sank rapidly after the effort, and died on the 3oth of August following, at the age of seventy, lamented and esteemed by all who knew him.

It is now time to consider his share in the promotion of solar research. Eclipses of the sun, both ancient and modern, were a speciality with him, and he was fortunate in those which came under his observation. Such phenomena are of three kindspartial, annular, and total. In a partial eclipse, the moon, instead of passing directly between us and the sun, slips by, as it

1 Memoir of Francis Baily, Mem. R. A. S., vol. xv., p. $5^{24}$. 
were, a little on one side, thus cutting off from our sight only a portion of his surface. An annular eclipse, on the other hand, takes place when the moon is indeed centrally interposed, but falls short of the apparent size required for the entire concealment of the solar disc, which consequently remains visible as a bright ring or annulus, even when the obscuration is at its height. In a total eclipse, on the contrary, the sun completely disappears behind the dark body of the moon. The difference of the two latter varieties is due to the fact that the apparent diameters of the sun and moon are so nearly equal as to gain alternate preponderance one over the other through the slight periodical changes in their respective distances from the earth.

Now on the I 5 th of May I836, an annular eclipse was visible in the northern parts of Great Britain, and was observed by Baily at Inch Bonney, near Jedburgh. It was here that he saw the phenomenon which obtained the name of "Baily's Beads," from the notoriety conferred upon it by his vivid description.

"When the cusps of the sun," he writes, "were about $40^{\circ}$ asunder, a row of lucid points, like a string of bright beads, irregular in size and distance from each other, suddenly formed round that part of the circumference of the moon that was about to enter, or which might be considered as having just entered on the sun's disc. Its formation, indeed, was so rapid that it presented the appearance of having been caused by the ignition of a fine train of gunpowder. Finally, as the moon pursued her course, the dark intervening spaces (which, at their origin, had the appearance of lunar mountains in high relief, and which still continued attached to the sun's border), were stretched out into long, black, thick, parallel lines, joining the limbs of the sun and moon; when all at once they suddenly gave way, and left the circumference of the sun and moon in those points, as in the rest, comparatively smooth and circular, and the moon perceptibly advanced on the face of the sun." 1

These curious appearances were not an absolute novelty. Weber in I79I, and Von Zach in I820, had seen the "beads"; Van Swinden had described the "belts" or "threads." 2 These

$$
1 \text { Mlem. R. A. S., vol. x., pp. 5-6. } 2 \text { Ibid., pp. 14-17. }
$$


last were, moreover (as Baily clearly perceived), completely analogous to the "black ligament" which formed so troublesome a feature in the transits of Venus in 1764 and 1769, and which, to the regret and confusion, though no longer to the surprise of observers, was renewed in that of 1874. The phenomenon is largely an effect of what is called irradiation, by which a bright object seems to encroach upon a dark one; but under good atmospheric and instrumental conditions it becomes inconspicuous. The "Beads" must always appear when the projected lunar edge is serrated with mountains. In Baily's observation, they were exaggerated and distorted by an irradiative clinging together of the limbs of sun and moon.

The immediate result, however, was powerfully to stimulate attention to solar eclipses in their physical aspect. Never before had an occurrence of the kind been expected so eagerly or prepared for so actively as that which was total over Central and Southern Europe on the 8th of July 1842. Astronomers hastened from all quarters to the favoured region. The Astronomer Royal (Airy) repaired to Turin; Baily to Pavia; Otto Struve threw aside his work amidst the stars at Pulkowa, and went south as far as Lipeszk; Schumacher travelled from Altona to Vienna; Arago from Paris to Perpignan. Nor did their trouble go unrewarded. The expectations of the most sanguine were outdone by the wonders disclosed.

Baily (to whose narrative we recur) had set up his Dollond's achromatic ( $3 \frac{1}{2}$ feet focal length) in an upper room of the University of Pavia, and was eagerly engaged in noting a partial repetition of the singular appearances seen by him in I836, when he was "astounded by a tremendous burst of applause from the streets below, and at the same moment was electrified at the sight of one of the most brilliant and splendid phenomena that can well be imagined. For at that instant the dark body of the moon was suddenly surrounded with a corona, or kind of bright glory similar in shape and relative magnitude to that which painters draw round the heads of saints, and which by the French is designated an auréole. Pavia contains many thousand inhabitants, the major part of whom were, at this early 
hour, walking about the streets and squares or looking out of windows, in order to witness this long-talked-of phenomenon; and when the total obscuration took place, which was instantaneous, there was an universal shout from every observer, which 'made the welkin ring,' and for the moment, withdrew my attention from the object with which I was immediately occupied. I had indeed anticipated the appearance of a luminous circle round the moon during the time of total obscurity; but I did not expect, from any of the accounts of preceding eclipses that I had read, to witness so magnificent an exhibition as that which took place. . . . The breadth of the corona, measured from the circumference of the moon, appeared to me to be nearly equal to half the moon's diameter. It had the appearance of brilliant rays. The light was most dense (indeed I may say quite dense) close to the border of the moon, and became gradually and uniformly more attenuate as its distance therefrom increased, assuming the form of diverging rays in a rectilinear line, which at the extremity were more divided, and of an unequal length; so that in no part of the corona could I discover the regular and well-defined shape of a ring at its outer margin. It appeared to me to have the sun for its centre, but I had no means of taking any accurate measures for determining this point. Its colour was quite white, not pearl-colour, nor yellow, nor red, and the rays had a vivid and flickering appearance, somewhat like that which a gaslight illumination might be supposed to assume if formed into a similar shape. . . Splendid and astonishing, however, as this remarkable phenomenon really was, and although it could not fail to call forth the admiration and applanse of every beholder, yet I must confess that there was at the same time something in its singular and wonderful appearance that was appalling; and I can readily imagine that uncivilised nations may occasionally have become alarmed and terrified at such an object, more especially at times when the true cause of the occurrence may have been but faintly understood, and the phenomenon itself wholly unexpected.

"But the most remarkable circumstance attending the phenomenon was the appearance of three large protuberances 
apparently emanating from the circumference of the moon, but evidently forming a portion of the corona. They had the appearance of mountains of a prodigious elevation; their colour was red tinged with lilac or purple; perhaps the colour of the peach-blossom would more nearly represent it. They somewhat resembled the snowy tops of the Alpine mountains when coloured by the rising or setting sun. They resembled the Alpine mountains also in another respect, inasmuch as their light was perfectly steady, and had none of that flickering or sparkling motion so visible in other parts of the corona. All the three projections were of the same roseate cast of colour, and very different from the brilliant vivid white light that formed the corona; but they differed from each other in magnitude. . . The whole of these three protuberances were visible even to the last moment of total obscuration; at least, I never lost sight of them when looking in that direction; and when the first ray of light was admitted from the sun, they vanished, with the corona, altogether, and daylight was instantaneously restored." I

Notwithstanding unfavourable weather, the "red flames" were perceived with little less clearness and no less amazement from the Superga than at Pavia, and were even discerned by Mr. Airy with the naked eye. "Their form" (the Astronomer Royal wrote) "was nearly that of saw-teeth in the position proper for a circular saw turned round in the same direction in which the hands of a watch turn; . . . their colour was a full lake-red, and their brilliancy greater than that of any other part of the ring." 2

The height of these extraordinary objects was estimated by Arago at two minutes of arc, representing, at the sun's distance, an actual elevation of 54,000 miles. When carefully watched, the rose-flush of their illumination was perceived to fade through violet to white as the light returned; the same changes in a reversed order having accompanied their first appearance. Their forms, however, during about three minutes of visibility, showed no change, although of so apparently unstable a

$$
{ }^{1} \text { Mem. R. A. S., vol. xv., pp. 4-6. }{ }^{2} \text { lbid., vol. xv., p. } 16 .
$$


character as to suggest to Arago "mountains on the point of crumbling into ruins" through topheaviness. ${ }^{1}$

The corona, both as to figure and extent, presented very different appearances at different stations. This was no doubt due to varieties in atmospheric conditions. At the Superga, for instance, all details of structure seem to have been effaced by the murky air, only a comparatively feeble ring of light being seen to encircle the moon. Elsewhere, a brilliant radiated formation was conspicuous, spreading at four opposite points into four vast luminous expansions, compared to feather-plumes or aigrettes. $^{2} \quad$ Arago at Perpignan noticed considerable irregularities in the divergent rays: some appeared curved and twisted; a few lay across the others, in a direction almost tangential to the moon's limb; the general effect being described as that of a "hank of thread in disorder." 3 At Lipeszk, where the sun stood much higher above the horizon than in Italy or France, the corona showed with surprising splendour. Its apparent extent was judged by Struve to be no less than twenty-five minutes (more than six times Airy's estimate), while the great plumes spread their radiance to three or four degrees from the dark lunar edge. So dazzling was the light, that many well-instructed persons denied the totality of the eclipse. Nor was the error without precedent, although the appearances attending respectively a total and an annular eclipse are in reality wholly dissimilar. In the latter case, the surviving ring of sunlight becomes so much enlarged by irradiation, that the interposed dark lunar body is reduced to comparative insignificance, or even invisibility. Maclaurin tells us, ${ }^{4}$ that during an eclipse of this character which he observed at Edinburgh in I 737, " gentlemen by no means shortsighted declared themselves unable to discern the moon upon the sun without the aid of a smoked glass;" and Baily (who, however, was shortsighted) could distinguish, in 1836 , with the naked eye, no trace of "the globe of purple velvet" which the telescope revealed as projected upon the face of the sun. ${ }^{5}$ Moreover, the diminution of light was

1 Annuaire, 1846, p. 409. $\quad 2$ Ibid., p. 317. ${ }^{3}$ Ibid., p. 322. ${ }^{4}$ Phil. Trans., vol. xl., p. 192. ${ }^{5}$ Mem. $R$. A. S., vol. x., p. I7. 
described by him as "little more than might be caused by a temporary cloud passing over the sun"; the birds continued in full song; and "one cock in particular was crowing with all his might while the annulus was forming."

Very different were the effects of the eclipse of 1842 , as to which some interesting particulars were collected by Arago. ${ }^{1}$ Beasts of burthen, he tells us, paused in their labour, and could by no amount of punishment be induced to move until the sun reappeared. Birds and beasts abandoned their food; linnets were found dead in their cages; even ants suspended their toil. Diligence-horses, on the other hand, seemed as insensible to the phenomenon as locomotives. The convolvulus and some other plants closed their leaves; but those of the mimosa remained open. The little light that remained was of a livid hue. One, observer described the general coloration as resembling the lees of wine, but human faces showed pale olive or greenish. We may, then, rest assured that none of the remarkable obscurations recorded in history were due to eclipses of the annular kind.

The existence of the corona is no modern discovery. Indeed, it is too conspicuous an apparition to escape notice from the least attentive or least practised observer of a total eclipse. Nevertheless, explicit references to it are rare in early times. Plutarch, however, speaks of a " certain splendour" compassing round the hidden edge of the sun as a regular feature of total eclipses $;^{2}$ and the corona is expressly mentioned in a description of an eclipse visible at Corfu in 968 A.D. ${ }^{3}$ The first to take the phenomenon into scientific consideration was Kepler. $\mathrm{He}$ showed, from the positions in their orbits at the time, of the sun and moon, that an eclipse observed by Clavius at Rome in 1567 , could not have been annular, ${ }^{4}$ as the dazzling coronal radiance visible during the obscuration had caused it to be believed.

1 Ann. du Bureau des Long. 1846, p. 309. 2 De Facie in Orbe Lunce, xix. ı. Cf. Grant, Astr. Nach., No. 1838. As to the phenomenon mentioned by Philostratus in his Life of Apollonius (viii. 23) see W. T. Lynn, Observatory, vol. ix., p. 128. ${ }^{3}$ Schmidt, Astr. Nach., No. 1832. ${ }^{4}$ Astronomia Pars Optica, Op. omnia, t. ii., p. 317. 
Although he himself never witnessed a total eclipse of the sun, he carefully collected and compared the remarks of those more fortunate, and concluded that the ring of "flame-like splendour" seen on such occasions was caused by the reflection of the solar rays from matter condensed in the neighbourhood either of the sun or moon. ${ }^{1}$ To the solar explanation he gave his own decided preference, but, with one of those curious flashes of half-prophetic insight characteristic of his genius, declared that "it should be laid by ready for use, not brought into immediate requisition." 2 So literally was his advice acted upon, that the theory, which we now know to be (broadly speaking) the correct one, only emerged from the repository of anticipated truths after 236 years of almost complete retirement, and even then timorously and with hesitation.

The first eclipse of which the attendant phenomena were observed with tolerable exactness was that which was central in the South of France, May I2, I706. Cassini then put forward the view that the "crown of pale light" seen round the lunar" disc was caused by the illumination of the zodiacal light; ${ }^{3}$ but it failed to receive the attention which, as a step in the right direction, it undoubtedly merited. Nine years later we meet with Halley's comments on a similar event, the first which had occurred in London since March 20, II4O. By nine in the morning of April 22 (o.s.), I7I5, the obscuration, he tells us, "was about ten digits, ${ }^{4}$ when the face and colour of the sky began to change from perfect serene azure blue to a more dusky livid colour, having an eye of purple intermixt. . . . A few seconds before the sun was all hid there discovered itself round the moon a luminous ring, abont a digit or perhaps a tenth part of the moon's diameter in breadth. It was of a pale whiteness or rather pearl colour, seeming to me a little tinged with the colours of the iris, and to be concentric with the moon, whence I concluded it the moon's atmosphere. But the great height thereof, far exceeding our earth's atmosphere, and the observa-

${ }_{1}$ De Stellâ Novâ, Op., t. ii., pp. 696-697. 3 Mém. de l'Ac. des Sciences, I7 I 5, p. I 19.

2 Astr. Pars Optica, p. 320. diameter.

A digit $\doteq \frac{1}{12}$ th of the solar 
tion of some, who found the breadth of the ring to increase on the west side of the moon as emersion approached, together with the contrary sentiments of those whose judgment I shall always revere" (Newton is most probably referred to), "makes me less confident, especially in a matter whereto I confess I gave not all the attention requisite." He concludes by declining to decide whether the "enlightened atmosphere," which the appearance " in all respects resembled," " belonged to sun or moon." 1

A French Academician, who happened to be in London at the time, was less guarded in expressing an opinion. The Chevalier de Louville declared emphatically for the lunar atmospheric theory of the corona, ${ }^{2}$ and his authority carried great weight. It was, however, much discredited by an observation made by Maraldi in 1724 , to the effect that the luminous ring, instead of travelling with the moon, was traversed by it. ${ }^{3}$ This was in reality decisive, though, as usual, belief lagged far behind demonstration. Moreover, the advantage accruing from this fresh testimony was adjudged to the wrong claimant. In I 7 I 5 a novel explanation had been offered by Delisle and Lahire, ${ }^{4}$ supported by experiments regarded at the time as perfectly satisfactory. The aureola round the eclipsed sun, they argued, is simply a result of the diffraction or apparent bending of the sunbeams that graze the surface of the lunar globe-an effect of the same kind as the coloured fringes of shadows. And this view prevailed amongst men of science until (and even after) Brewster showed, with clear and simple decisiveness, that such an effect could by no possibility be appreciable at our distance from the moon. ${ }^{5}$ Don José Joaquim de Ferrer, who observed a total eclipse of the sun at Kinderhook, in the State of New York, on June 16, r806, seems to have been ignorant that such a refined optical rationale of the phenomenon was current in the learned world. Two alternative explanations alone presented themselves to his mind as possible. The bright ring round the moon must be due to the illumination either of a lunar or of a

1 Phil. Trans., vol. xxix., pp. 247-249. « Mém. de l'Ac. des S'sciences, 1715 ; Histoire, p. 49 ; Mémoires, pp. 93-98. ${ }^{3}$ Ibid., I724, p. 178. $\quad$ * Mém. de l'Ac. des Sciences, I715, pp. I6I, 166-169.

5 Ed. Ency., art. Astronomy, p. 635. 
solar atmosphere. If the former, he calculated that it should have a height fifty times that of the earth's gaseous envelope. "Such an atmosphére," he rightly concluded, "cannot belong to the moon, but must without any doubt belong to the sun." 1 He, however, stood alone in this unhesitating assertion.

The importance of the problem was first brought fully home to astronomers by the eclipse of $\mathrm{I} 842$. The brilliant and complex appearance which, on that occasion, challenged the attention of so many observers, demanded and received, no longer the casual attention hitherto bestowed upon it, but the most earnest study of those interested in the progress of science. Nevertheless, it was only by degrees and through a process of "exclusions" (to use a Baconian phrase) that the corona was put in its right place as a solar appendage. As every other available explanation proved inadmissible and dropped out of sight, the broad presentation of fact remained, which, though of sufficiently obvious interpretation, was long and persistently misconstrued. Nor was it until I 869 that absolutely decisive evidence on the subject was forthcoming, as we shall see further on.

Sir John Herschel, writing to his venerable aunt, relates that when the brilliant red flames burst into view behind the dark moon on the morning of the 8th July i 842 , the populace of Milan, with the usual inconsequence of a crowd, raised the shout, "Es leben die Astronomen!" 2 In reality, none were less prepared for their apparition than the class to whom the applanse dne to the magnificent spectacle, was thus adjudged. And in some measure through their own fault; for many partial hints and some distinct statements from earlier observers had given unheeded notice that some such phenomenon might be expected to attend a solar eclipse.

What we now call the "chromosphere" is an envelope of glowing gases, principally hydrogen, by which the sun is completely covered, and from which the "prominences" are emanations, eruptive or otherwise. Now, continual indications of the presence of this fire-ocean had been detected during

1 Trans. Am. Phil. Soc., vol. vi., p. 274. " Memoir of Caroline Herschel, p. 327 . 
CH.A. IH.

eclipses in the eighteenth and nineteenth centuries. Captain Stannyan, describing in a letter to Flamsteed an occurrence of the kind witnessed by him at Berne on May r (o.s.), I706, says that the sun's "getting out of the eclipse was preceded by a blood-red streak of light from its left limb." 1 A precisely similar appearance was noted by both Halley and De Louville in I715; during annular eclipses by Lord Aberdour in $1737,{ }^{2}$ and by Short in $1748,{ }^{3}$ the tint of the ruby border being, however, subdued to "brown or "dusky red" by the surviving" sunlight; while observations identical in character were made at Amsterdam in $1820,{ }^{4}$ at Edinburgh (by Henderson) in 1836, and at New York in $1838 .^{5}$

"Flames" or "prominences," if more conspicuous, are less constant in their presence than the glowing stratum from which they spring. The first to describe them was a Swedish professor named Vassenius, who observed a total eclipse at Gothenburg. May 2 (o.s.), $1733 .{ }^{6}$ His astonishment equalled his admiration when he perceived, just outside the edge of the lunar disc, and suspended, as it seemed, in the coronal atmosphere, three or four reddish spots or clouds, one of which was so large as to be detected with the naked eye. As to their nature, he did not even offer a speculation, further than by tacitly referring them to the moon, in which position they appear to have remained so long as the observation was held in mind. It was repeated in I778 by a Spanish admiral, but with no better success in directing efficacious attention to the phenomenon. Don Antonio Ulloa was on board his ship the Espagne in passage from the Azores to Cape St. Vincent on the 24th of June in that year when a total eclipse of the sun occurred, of which he has left a valuable description. His notices of the corona are full of

1 Plil. Trans., vol. xxv., p. 2240. $\quad 2$ Ibid., vol. xl., p. 182. 3 Ibid., vol. xlv., p. 586. $\quad$ Hem. R. A. S., vol. i., pp. 145, 148. ${ }_{5}^{5}$ American Journal of Science, vol. xlii., p. 396. $\quad$ 'Plil. Trans., vol. xxxviii., p. 134. Father Secchi has, however, pointed out a tolerably distinct mention of a prominence so far back as I 239 A.D. In a description of a total eclipse of that cate it is added, "Et quoddam foramen erat ignitum in circulo solis ex parte inferiore" (Muratori, Rer. It. Scriptores, t. xiv., col. I097). The "circulus solis" of course signifies the corona." 
interest; but what just now concerns us is the appearance of "a red luminous point" "near the edge of the moon," which gradually increased in size as the moon moved away from it, and was visible during about a minute and a quarter. ${ }^{1} \mathrm{He}$ was satisfied that it belonged to the sun because of its fiery colour and growth in magnitude, and supposed that it was occasioned by some crevice or inequality in the moon's limb, through which the solar light penetrated.

Allusions less precise, both prior and subsequent, which it is now easy to refer to similar objects (such as the "slender columns of smoke" seen by Ferrer), ${ }^{2}$ might be detailed; but the evidence already adduced suffices to show that the prominences viewed with such amazement in 1842 were no unprecedented or even unusual phenomenon.

It was more important, however, to decide what was their nature than whether their appearance might have been anticipated. They were generally, and not very incorrectly, set down as solar clouds. Arago believed them to shine by reflected light, ${ }^{3}$ but the Abbe Peytal rightly considered them to be selfluminous. Writing in a Montpellier paper of July I6, I842, he declared that we had now become assured of the existence of a third or solar envelope, composed of a glowing substance of a bright rose tint, forming mountains of prodigious elevation, analogous in character to the clouds piled above our horizons. ${ }^{4}$ This first distinct recognition of a very important feature of our great luminary was probably founded on an observation made by Bérard at Toulon during the then recent eclipse, "of a very fine red band, irregularly dentelated, or, as it were, crevassed here and there," 5 encircling a large arc of the moon's circumference. It can hardly, however, be said to have attracted general notice until the 28th of July $185 \mathrm{I}$. On that day a total eclipse took place, which was observed with considerable success in various parts of Sweden and Norway by a number of English astronomers. Mr. Hind saw, on the south limb of

1 Phil. Trans., vol. lxix., p. 114. 2 Trans. Am. Phil. Soc., vol. vi., 1809, p. 267. 3 Annuaire, I846, p. 460.4 Ibid., p. 439, note. ${ }^{5}$ Ibid., I 846 p. 4 I6. 
the moon, "a long range of rose-coloured flames," 1 described by Dawes as "a low ridge of red prominences, resembling in outline the tops of a very irregular range of hills." 2 Airy termed the portion of this "rugged line of projections" visible to him the sierra, and was struck with its brilliant light and "nearly scarlet" colour. ${ }^{3}$ Its true character of a continuous solar envelope was inferred from these data by Grant, Swan, and Littrow ; and was by Father Secchi formally accepted as established after the great eclipse of $1860 .{ }^{4}$

Several prominences of remarkable forms, especially one variously compared to a Turkish scimitar, a sickle, and a boomerang, were seen in $185 \mathrm{I}$. In connection with them two highly significant circumstances were pointed out. First, that of the approximate coincidence between their positions and those of sun-spots previously observed. ${ }^{5}$ Next, that "the moon passed over them, leaving them behind, and revealing successive portions as she advanced." ${ }_{6}$ This latter fact (as to which there could be no doubt, since it was separately noted by at least four first-rate observers), was justly considered by the Astronomer Royal and others as affording absolute certainty of the solar dependence of these singular objects. Nevertheless sceptics were still found. M. Faye, of the French Academy, inclined to a lunar origin for them $;^{7}$ Professor von Feilitsch of Greifswald published in 1852 a treatise for the express purpose of proving. all the luminous phenomena attendant on solar eclipses-corona, prominences and "sierra"-to be purely optical appearances. Happily, however, the unanswerable arguments of the photographic camera were soon to be made available against such hardy incredulity.

Thus, the virtual discovery of the solar appendages, both coronal and chromospheric, may be said to have been begun in

1 Mem. R. A. S., vol. xxi., p. 82. $\quad 2$ Ibid., p. 90. $\quad{ }^{3}$ Ibid., pp. 7-8. $\quad{ }^{4} \mathrm{Le}$ Soleil, t. i., p. $3^{86 .}{ }^{5}$ By Williams and Stanistreet, Mem. $R$ A. S., vol. xxi., pp. 54,56 . Santini had made a similar observation at Padua in 1842. Grant, Hist. Astr., p. 401. ${ }^{6}$ Lassell in Month. Not., vol. xii., p. 53. ${ }^{7}$ Comptes Rendus, t. xxxiv., p. I55. 8 Optische Untersuchungen, and Zeitschrift für populäre Mittheilungen, Bd. i., 1860, p. 201. 
I 842, and completed in 185 $\mathrm{I}$. The current Herschelian theory of the solar constitution remained, however, for the time, intact. Difficulties, indeed, were thickening around it; but their discussion was perhaps felt to be premature, and they were permitted to accumulate withơut debate, until fortified by fresh testimony into unexpected and overwhelming preponderance. 


\section{CHAPTER IV.}

\section{PLANETARY DISCOVERIES.}

Is the course of his early gropings towards a law of the planetary distances, Kepler tried the experiment of setting a planet, invisible by reason of its smallness, to revolve in the vast region of seemingly desert space separating Mars from Jupiter. ${ }^{1}$ The disproportionate magnitude of the same interval was explained by Kant as due to the overweening size of Jupiter. The zone in which each planet moved was, according to the philosopher of Königsberg, to be regarded as the empty storehouse from which its materials had been derived. A definite relation should thus exist between the planetary masses and the planetary intervals. ${ }^{2}$ Lambert, on the other hand, sportively suggested that the body or bodies (for it is noticeable that he speaks of them in the plural) which once bridged this portentous gap in the solar system, might, in some remote age, have been swept away by a great comet, and forced to attend its wanderings through space. ${ }^{3}$

These speculations were destined before long to assume a more definite form. Johann Daniel Titius, a professor at Wittenberg (where he died in 1796), pointed out in 1772 , in a note to a translation of Bonnet's Contemplation de la Nature, ${ }^{4}$ the existence of a remarkable symmetry in the disposition of the bodies constituting the solar system. By a certain series of numbers, increasing in regular progression, ${ }^{5}$ he showed that the distances

1 Op., t. i., p. I07. He interposed, but tentatively only, another similar body between Mercury and Venus. 2 Allgemeine Naturgeschichte (ed. 1798), pp. I18-1 19. 3 Cosmologisclee Briefe, No. I (quoted by Von Zach, Mlowat. Corr., vol. iii., p. 592). "Second ed., p. 7. See Bode, Fon dem neven Hauptplaneten, p. 43, note. 5 The representative numbers are obtained by adding 4 to the following series (irregular, it will be observed, in its first 
of the six known planets from the sun might be represented with a close approach to accuracy. But with one striking interruption. The term of the series succeeding that which corresponded to the orbit of Mars was without a celestial representative. The orderly flow of the sequence was thus singularly broken. The space where a planet should-in fulfilment of the "Law"-have revolved, was, it appeared, untenanted. Johann Elert Bode, then just about to begin his long career as leader of astronomical thought and work at Berlin, marked at once the anomaly, and filled the vacant interval with an hypothetical planet. The discovery of Uranus at a distance falling but slightly short of perfect conformity with the law of Titius, lent weight to a seemingly hazardous prediction, and Von Zach was actually at the pains, in 1785 , to calculate what he termed "analogical" elements ${ }^{1}$ for this unseen and (by any effect or influence) unfelt body. The search for it, though confessedly scarcely less chimerical than that of alchemists for the philosopher's stone, he kept steadily in view for fifteen years, and at length (September 2 I, I800) succeeded in organising, in combination with five other German astronomers assembled at Lilienthal, a force of what he jocularly termed celestial police, for the express purpose of tracking and intercepting the fugitive subject of the sun. The zodiac was accordingly divided for purposes of scrutiny into twenty-four zones; their apportionment to separate observers was in part effected, and the association was rapidly getting into working order, when news arrived that the missing planet had been found, through no systematic plan of search, but by the diligent, though otherwise directed labours of a distant watcher of the skies.

Giuseppe Piazzi was born at Ponte in the Valtelline, July I6, 1746. He studied at various places and times under Tiraboschi, Beccaria, Jacquier, and Le Sueur; and having entered the Theatine order of monks at the age of eighteen, he taught philosophy, science, and theology in several of the Italian cities,

member, which should be $\frac{1}{2}$ instead of o) : o, 3, 6, 12, 24, 48, \&c. The formula is a purely empirical one, and is, moreover, completely at fault as regards the distance of Neptune. 1 Monat. Corr., vol. iii., p. 596. 
as well as in Malta, until 1780 , when the chair of mathematics in the University of Palermo was offered to and accepted by him. Prince Caramanico, then viceroy of Sicily, had scientific leanings, and was easily won over to the project of building an observatory, a commodious foundation for which was afforded by one of the towers of the viceregal palace. This architecturally incongruous addition to an ancient Saracenic edifice-once the abode of Kelbite and Zirite Emirs-was completed in February I79I. Piazzi, meanwhile, had devoted nearly three years to the assiduous study of his new profession, acquiring a practical knowledge of Lalande's methods at the École Militaire, and of Maskelyne's at the Royal Observatory; and returned to Palermo in I789, bringing with him, in the great five-foot circle which he had prevailed upon Ramsden to construct, the most perfect measuring instrument hitherto employed by an astronomer.

He had been above nine years at work on his star-catalogue, and was still profoundly unconscious that a place amongst the Lilienthal band ${ }^{1}$ of astronomical detectives was being held in reserve for him, when, on the first evening of the nineteenth century, January I, I80I, he noted the position of an eighthmagnitude star in a part of the constellation Taurus, to which an error of Wollaston's had directed his special attention. Reobserving, according to his custom, the same set of fifty stars on four consecntive nights, it seemed to him, on the 2 nd, that the one in question had slightly shifted its position to the west; on the 3 rd he assured himself of the fact, and believed that he had chanced upon a new kind of comet without tail or coma. 'The wandering body (whatever its nature) exchanged retrograde for direct motion on January $14^{2}$ and was carefully watched by Piazzi until February I I, when a dangerous illness interrupted his observations. He had, however, not omitted to give notice of his discovery; but so precarious were communications in those unpeaceful times, that his letter to Oriani of January 23

${ }^{1}$ Wolf, Gesclichte der Astronomie, p. 648. $\quad 2$ Such reversals of direction in the apparent movements of the planets are a consequence of the earth's revolution in its orbit. 
did not reach Milan until April 5, while a missive of one day later addressed to Bode came to hand at Berlin, March 20. The delay just afforded time for the publication, by a young philosopher of Jena named Hegel, of a "Dissertation " showing, by the clearest light of reason, that the number of the planets could not, exceed seven, and exposing the folly of certain devotees of induction who sought a new celestial body merely to fill a gap in a numerical series.

Unabashed by speculative scorn, Bode had scarcely read Piazzi's letter when he concluded that it referred to the precise body in question. The news spread rapidly, and created a profound sensation not unmixed with alarm lest this latest addition to the solar family should have been found only to be again lost. For by that time Piazzi's moving star was too near the sun to be any longer visible, and in order to rediscover it after conjunction a tolerably accurate knowledge of its path was indispensable., But a planetary orbit had never before been calculated from such scanty data as Piazzi's observations afforded; ${ }^{2}$ and the attempts made by nearly every astronomer of note in Germany to compass the problem were manifestly inadequate, failing even to account for the positions in which the, body had been actually seen, and ì fortiori serving only to mislead as to the places where, from September r8or, it ought, once more to have become discernible. It was in this extremity that the celebrated mathematician Gauss came to the rescue. He was then in his twenty-fifth year, and was earning his bread by tuition at Brunswick, with many possibilities, but no settled career before him. The news from Palermo may be said to have converted him from an arithmetician into an astronomer. He was already in possession of a new and more general method of computing elliptical orbits ; and the system of "least squares," which he had devised though not published, enabled him to extract the most probable result from a given set of observations. Armed with these novel powers, he set to work, and the

1 Dissertatio Philosophica de Orbitis Planetarum, I8or. See Wolf, Gesch. d. Astr., p. 685. "Observations on Uranus, as a supposed fixed star, reached back to 1690 . 
communication in November of his elements and ephemeris for the lost object revived the drooping hopes of the little band of eager searchers. 'Their patience, however, was to be still further' tried. Clouds, mist, and sleet seemed to have conspired to cover the retreat of the fugitive; but on the last night of the year the sky cleared mexpectedly with the setting in of a hard frost, and there, in the north-western part of Virgo, nearly in the position assigned by Gauss to the runaway planet, a strange star was discerned by Von Zach ${ }^{1}$ at Gotha, and on the subsequent evening-the anniversary of the original discovery-by Olbers at Bremen. The name of Ceres (as the tutelary goddess of Sicily) was, by Piazzi's request, bestowed upon this first known of the numerous and probably all but innumerable family of the minor planets.

The recognition of the second followed as the immediate consequence of the detection of the first. Olbers had made himself so familiar with the positions of the small stars along the track of the long-missing body, that he was at once struck (March 28, 1802) with the presence of an intruder near the spot where he had recently identified Ceres. He at first believed the newcomer to be a variable star usually inconspicuous, but just then at its maximum of brightness; but within two hours he had convinced himself that it was no fixed star, but a rapidly moving object. The aid of Gauss was again invoked, and his prompt calculations showed that this fresh celestial acquaintance (named "Pallas" by Olbers) revolved round the sun at nearly the same mean distance as Ceres, and was beyond question of a strictly analogous character.

This result was perplexing in the extreme. The symmetry and simplicity of the planetary scheme appeared fatally compromised by the admission of many, where room could, according to old-fashioned rules, only be found for one. A daring hypothesis of Olbers's invention provided an exit from the difficulty. He supposed that both Ceres and Pallas were

1 He had caught a glimpse of it on December 7, but was prevented by bad weather from verifying his suspicion. Monat. Corr., vol. v., p. I7I. 
fragments of a primitive trans-Martian planet, blown to pieces in the remote past, either by the action of internal forces or by the impact of a comet; and predicted that many more such fragments would be found to circulate in the same region. He, moreover, pointed out that these numerous orbits, however much they might differ in other respects, must all have a common line of intersection, ${ }^{1}$ and that the bodies moving in them must consequently pass, at each revolution, through two opposite points of the heavens, one situated in the Whale, the other in the constellation of the Virgin, where already Pallas had been found and Ceres recaptured. The intimation that fresh discoveries might be expected in those particular regions was singularly justified by the detection of two bodies now known respectively as Juno and Vesta. The first was found near the predicted spot in Cetus by Harding, Schröter's assistant at Lilienthal, September 2, I804; the second by Olbers himself in Virgc, after three years of patient scrutiny, March 29, I 807 .

The theory of an exploded planet now seemed to have everything in its favour. It required that the mean or average distances of the newly-discovered bodies should be nearly the same, but admitted a wide range of variety in the shapes and positions of their orbits, provided always that they preserved common points of intersection. These conditions were fulfilled with a striking approach to exactness. Three of the four "asteroids" (a designation introduced by Sir W. Herschel ${ }^{2}$ ) conformed with very approximate precision to "Bode's law" of distances; they all traversed, in their circuits round the sun, nearly the same parts of Cetus and Virgo; while the eccentricities and inclinations of their paths departed widely from the planetary type-that of Pallas, for example, making with the ecliptic an angle of nearly $35^{\circ}$. The minuteness of these bodies appeared further to strengthen the imputation of a

${ }^{1}$ Planetary fragments, hurled in any direction, and uith any velocity short of that which would for ever release them from the solar sway, would continue to describe elliptic orbits round the sun, all passing through the scene of the explosion, and thus possessing a common line of intersection. '2 Phil. Trans., vol. xcii., part ii., p. 228 . 
fragmentary character. Herschel estimated the diameter of Ceres at 162, that of Pallas at I47 miles. ${ }^{1}$ Juno is smaller than either; and even Vesta, which surpasses all the minor planets in size, and may, under favourable circumstances, be seen with the naked eye, has a diameter probably under 350 miles. A suspected variability of brightness in some of the asteroids, somewhat hazardously explained as due to the irregularities of figure to be expected in cosmical potsherds (so to speak), was added to the confirmatory evidence. ${ }^{2}$ The strong point of the theory, however, lay not in what it explained, but in what it had predicted. It had been twice confirmed by actual exploration of the skies, and had produced, in the recognition of Vesta, the first recorded instance of the premeditated discovery of a heavenly body.

The view not only commended itself to the facile imagination of the unlearned, but received the sanction of the highest scientific authority. The great Lagrange bestowed upon it his analytical imprimatur, showing that the explosive forces required to produce the supposed catastrophe came well within the bounds of possibility - a velocity of less than twenty times that of a cannon-ball leaving the gun's mouth sufficing, according to its calculation, to have launched the asteroidal fragments on their respective paths. Indeed, he was disposed to regard the hypothesis of disruption as more generally available than its author had designed it to be, and proposed to supplement with it, as explanatory of the eccentric orbits of comets, the nebular theory of Laplace, thereby obtaining, as he said, "a complete view of the origin of the planetary system more conformable to Nature and mechanical laws than any yet proposed." 3

Nevertheless, the hypothesis of Olbers has not held its ground. It seemed as if all the evidence available for its support had been produced at once and spontaneously, while the unfavourable items were elicited slowly, and, as it were, by cross-

1 Phil. Trans., vol. xcii., part ii., p. 2 18. In a letter to Von Zach of June 24, I802, he speaks of Pallas as "almost incredibly small," and makes it only seventy English miles in diameter. Monat. Corr., vol. vi., pp. 89-90. i 2 Olbers Monat. Corr., vol. vi., p. $88 . \quad 3$ Conn. d. Tems. for I8I4, p. 218. 
examination. A more extended acquaintance with the group of bodies whose peculiarities it was framed to explain has shown them, after all, as recalcitrant to any such explanation. Coincidences at the first view significant and striking have been swamped by contrary examples; and a hasty general conclusion has, by a not uncommon destiny, at last perished under the accumulation of particulars. Moreover, as has been remarked by Professor Newcomb, ${ }^{1}$ mutual perturbations would rapidly efface all traces of a common disruptive origin, and the catastrophe, to be perceptible in its effects, should have been comparatively recent.

A new generation of astronomers had arisen before any additions were made to the little family of the minor planets. Piazzi died in I826, Harding in I834, Olbers in I840; all those who had prepared or participated in the first discoveries passed away without witnessing their resumption. In 1830, however, a certain Hencke, ex-postmaster in the Prussian town of Driessen. set himself to watch for new planets, and after fifteen long years his patience was rewarded. The asteroid found by him, December 8, I 845, received the name of Astræa, and his further prosecution of the search resulted, July I, I 847, in the discovery of Hebe. A few weeks later (August I 3), Mr. Hind, after many months' exploration from Mr. Bishop's observatory in the Regent's Park, picked up Iris, and October i 8, Flora." The next on the list was Metis, found by Mr. Graham, April 25, I848, at Markee in Ireland. ${ }^{3}$ At the close of the period to which our attention is at present limited, the number of these small bodies known to astronomy was thirteen; and the course of discovery has since proceeded far more rapidly and with less interruption.

Both in itself and in its consequences the recognition of the minor planets was of the highest importance to science. The traditional ideas regarding: the constitution of the solar system were enlarged by the admission of a new class of bodies, strongly contrasted, yet strictly co-ordinate with the oldestablished planetary order; the profusion of resource, so

1 Popular Astronomy, p. 327. 2 Month. Not. vol. vii., p. 299; vol. viii., p. I. "Ibicl., vol. viii., p. I46. 
conspicuous in the living kingdoms of Nature, was seen to prevail no less in the celestial spaces; and some faint preliminary notion was afforded of the indefinite complexity of relations underlying the apparent simplicity of the majestic scheme to which our world belongs. Theoretical and practical astronomy both derived profit from the admission of these apparently insignificant strangers to the rights of citizenship of the solar system. The disturbance of their motions by their giant neighbour afforded a more accurate knowledge of the Jovian mass, which Laplace had taken about $\frac{1}{50}$ th too small; the anomalous character of their orbits presented geometers with highly stimulating problems in the theory of perturbations; while the exigencies of the first discovery had produced the Theoric Motus, and won Gauss over to the ranks of calculating astronomy. Moreover, the sure prospect of further detections powerfully incited to the exploration of the skies; observers became more numerous and more zealous in view of the prizes held out to them; star-maps were diligently constructed, and the sidereal multitude strewn along the great zodiacal belt acquired a fresh interest when it was perceived that its least, conspicuous member might be a planetary shred or projectile in the majestic disguise of a distant sun. Harding's "Celestial Atlas," designed for the special purpose of facilitating asteroidal research, was the first systematic attempt to represent to the eye the telescopic aspect of the heavens. It was while engaged on its construction that the Lilienthal observer successfully intercepted Juno on her passage through the Whale in I804; whereupon promoted to Göttingen, he there completed, in 1822 , the arduous task so opportunely entered upon a score of years previously. Still more important were the great starmaps of the Berlin Academy, undertaken at Bessel's suggestion, with the same object of distinguishing errant from fixed stars, and executed, under Encke's supervision, during the years 1830-59. They have played a noteworthy part in the history of planetary discovery, nor of the minor kind alone.

We have now to recount an event unique in scientific history. The discovery of Neptune has been characterised as the result 
of a "movement of the age," 1 and with some justice. It had become necessary to the integrity of planetary theory. Until it was accomplished, the phantom of an unexplained anomaly in the orderly movements of the solar system must have continued to haunt astronomical consciousness. Moreover, it was prepared by many, suggested as possible by not a few, and actually achieved, simultaneously, independently, and completely, by two investigators.

The position of the planet Uranus was recorded as that of a fixed star no less than twenty times between 1690 and the epoch of its final detection by Herschel. But these early observations, far from affording the expected facilities for the calculation of its orbit, proved a source of grievous perplexity. The utmost ingenuity of geometers failed to combine them satisfactorily with the later Uranian places, and it became evident, either that they were widely erroneous, or that the revolving body was wandering from its ancient track. The simplest course was to reject them altogether, and this was done in the new Tables published in I82 I by Alexis Bouvard, the indefatigable computating partner of Laplace. But the trouble was not thus to be got rid of. After a few years fresh irregularities began to appear, and continued to increase until absolutely "intolerable." It may be stated as illustrative of the perfection to which astronomy had been brought, that divergencies regarded as menacing the very foundation of its theories never entered the range of unaided vision. In other words, if the theoretical and the real Uranus had been placed side by side in the sky, they would have seemed, to the sharpest eye, to form a single body. ${ }^{2}$

The idea that these enigmatical disturbances were due to the, attraction of an unknown exterior body was a tolerably obvious one; and we accordingly find it suggested in many different

${ }^{1}$ Airy, Mem. R. A. S., vol. xvi., p. $386 . \quad$ " See Newcomb's Pop. Astr., p. 359. The error of Uranus amounted, in 1844 , to $2^{\prime}$; but even the tailor of Breslau, whose extraordinary powers of vision Humboldt commemorates (Kosmos, Bd. ii., p. 112), could only see Jupiter's first satellite at its greatest elongation, $2^{\prime} 15^{\prime \prime}$. He might, however, possibly have distinguished two objects of equal lustre at a lesser interval. 
quarters. Bouvard himself was perhaps the first to conceive it. He kept the possibility continually in view, and bequeathed to his nephew's diligence the inquiry into its reality when he felt that his own span was drawing to a close ; but before any progress had been made with it, he had already (June 7, I843) "ceased to breathe and to calculate." The Rev. T. J. Hussey actually entertained in 1834 the notion, but found his powers inadequate to the task, of assigning an approximate place to the disturbing body; and Bessel, in I840, laid his plans for an assault in form upon the Uranian difficulty, the triumphant exit from which fatal illness frustrated his hopes of effecting or even witnessing.

The problem was practically untouched when, in I84I, an undergraduate of St. John's College, Cambridge, formed the resolution of grappling with it. The projected task was an arduous one. There were no guiding precedents for its conduct. Analytical obstacles had to be encountered so formidable as to appear invincible even to such a mathematician as Airy. John Couch Adams, however, had no sooner taken his degree, which he did as senior wrangler in Jannary I 843, than he set resolutely to work, and on October 2I, I845, was able to communicate to the Astronomer Royal numerical estimates of the elements and mass of the unknown planet, together with an indication of its actual place in the heavens. These results, it has been well said, ${ }^{1}$ gave "the final and inexorable proof" of the validity of Newton's Law. The date October 2 I, I845; " may therefore be regarded as marking a distinct epoch in the history of gravitational astronomy."

Sir George Biddell Airy had begun in 1835 his long and energetic administration of Greenwich Observatory, ${ }^{2}$ and was already in possession of data vitally important to the momentous inquiry then on foot. At his suggestion, and under his superintendence, the reduction of all the planetary observations made at Greenwich from I750 downwards had been undertaken in I833. The results, published in I846, constituted a

1 J. W. L. Glaisher, Observatory, vol. xv., p. 177. 2 He resigned the post of Astronomer Royal, August 15, 1881, and died, in his ninety-first year, January 2, 1892. 
permanent and universal stock of materials for the correction of planetary theory. But in the meantime, investigators, both native and foreign, were freely supplied with the "places and errors," which, clearly exhibiting the discrepancies between observation and calculation-between what was and what was expected-formed the very groundwork of future improvements.

Mr. Adams had no reason to complain of official discourtesy. His labours received due and indispensable aid ; but their purpose was regarded as chimerical. "I have always," Sir George Airy wrote, " "considered the correctness of a distant mathematical result to be a subject rather of moral than of mathematical evidence." But that actually before him seemed, from its very novelty, to incur a suspicion of unlikelihood. No problem in planetary disturbance had heretofore been attacked, so to speak, from the rear. The inverse method was untried, and might well be deemed impracticable. For the difficulty of determining the perturbations produced by a given planet is small compared with the difficulty of finding a planet by its resulting perturbations. Laplace might have quailed before it; yet it was now grappled with as a first essay in celestial dynamics. Moreover, Mr. Adams unaccountably neglected to answer until too late a question regarded by Sir George Airy in the light of an experimentum crucis as to the soundness of the new theory. Nor did he himself take any steps to obtain a publicity which he was more anxious to merit than to secure. The investigation consequently remained buried in obscurity. It is now known that had a search been instituted in the autumn of 1845 for the remote body whose existence had been so marvellously foretold, it would have been found within three and a half lunar diameters $\left(\mathrm{I}^{\circ} 49^{\prime}\right)$ of the spot assigned to it by Mr. Adams. Official zeal, however, rarely oversteps the beaten track; and the problematical needle was left to lie in its bundle of hay, from which, indeed, but for an unlucky accident, it would certainly have been extricated by an unofficial explorer. Mr. Dawes saw Adams's papers at Greenwich ; ${ }^{2}$ was struck with their purport, and wrote to his

1 Mem. R. A. S., vol. xvi., p. 399. ' 2 Holden, Publications Astr. Society of the Pacific, vol. iv., p. 21 . 
friend "Mr. Lassell, giving him the calculated place of, and begging him to search for, the unknown body. With his powerful reflector he could at once have identified it by its disc, as Herschel did Uranus ; but a sprained ankle intervened. By the time he had recovered, Mr. Dawes's letter was found to have been, by mischance, destroyed; and the needful particulars contained in it were not easily recoverable. So the English geometer's theory remained debarred from its proper experimental verification.

A competitor, however, equally daring and more fortunateaudax fortuna adjutus, as Gauss said of him-was even then entering the field. Urbain Jean Joseph Leverrier, the son of a small Government employé in Normandy, was born at Saint-Lô March I I, I8I I. He studied with brilliant success at the Ecole Polytechnique, accepted the post of astronomical teacher there in I837, and, "docile to circumstance," immediately concentrated the whole of his vast, though as yet undeveloped powers upon the formidable problems of celestial mechanics. He lost no time in proving to the mathematical world that the race of giants was not extinct. Two papers on the stability of the solar system, presented to the Academy of Sciences, September I6, and October I4, I839, showed him to be the worthy successor of Lagrange and Laplace, and encouraged hopes destined to be abundantly realised. His attention was directed by Arago to the Uranian difficulty in I845, when he cheerfully put aside certain intricate cometary researches upon which he happened to be engaged, in order to obey with dutiful promptitude the summons of the astronomical chief of France. In his first memoir on the subject (communicated to the Academy, November 10, I 845), he proved the inadequacy of all known causes of disturbance to account for the vagaries of Uranus; in a second (June I, I846), he demonstrated that only an exterior body, occupying at a certain date a determinate position in the zodiac, could produce the observed effects; in a third (August 3I, I846), he assigned the orbit of the disturbing body, and announced its visibility as an object with a sensible disc about as bright as a star of the eighth magnitude. 
The question was now visibly approaching an issue. On September Io, Sir John Herschel declared to the British Association respecting the hypothetical new planet: "We see it as Columbus saw America from the coast of Spain. Its movements have been felt, trembling along the far-reaching line of our analysis with a certainty hardly inferior to that of occular demonstration." Less than a fortnight later, September 23, Professor Galle, of the Berlin Observatory, received a letter from Leverrier requesting his aid in the telescopic part of the inquiry already analytically completed. He directed his refractor to the heavens that same night, and perceived, within less than a degree of the spot indicated, an object with a measurable disc nearly three seconds in diameter. Its absence from Bremiker's recently-completed map of that region of the sky showed it to be no star, and its movement in the predicted direction confirmed without delay the strong persuasion of its planetary nature. ${ }^{1}$

In this remarkable manner the existence of the remote member of our system known as "Neptune" was ascertained. But the discovery, which faithfully reflected the duplicate character of the investigation which led to it, had been already secured at Cambridge before it was announced from Berlin. Sir George Airy's incredulity vanished in the face of the striking coincidence between the position assigned by Leverrier to the unknown planet in June, and that laid down by Mr. Adams in the previous October; and on the 9th of July he wrote to Professor Challis, director of the Cambridge Observatory, recommending a search with the Northumberland equatoreal. Had a good star-map been at hand, the process would have been a simple one; but of Bremiker's "Hora XXI." no news had yet reached England, and there was no other chart sufficiently comprehensive to be available for an inquiry which, in the absence of such aid, promised to be both long and laborious. As the event proved, it might have been neither. "After four days of observing," Professor Challis wrote, October I2, I846, to Sir

1 For an account of D'Arrest's share in the detection see Copernicus, vol. ii., pp: 63. 96. 
George Airy, "The planet was in my grasp if only I had examined or mapped the observations." 1 Had he done so, the first honours in the discovery, both theoretical and optical, would have fallen to the University of Cambridge. But Professor Challis had other astronomical avocations to attend to, and, moreover, his faith in the precision of the indications furnished to him was, by his own confession, a very feeble one. For both reasons he postponed to a later stage of the proceedings the discussion and comparison of the data nightly furnished to him by his telescope, and thus allowed to lie, as it were, latent in his observations the momentous result which his diligence had ensured, but which his delay suffered to be anticipated. ${ }^{2}$

Nevertheless it should not be forgotten that the Berlin astronomer had two circumstances in his favour apart from which his swift success could hardly have been achieved. The first was the possession of a good star-map; the second was the clear and confident nature of Leverrier's instructions. "Look where I tell you," he seemed authoritatively to say, "and you will see an object such as I describe." 3 And in fact, not only Galle on the 23rd of September, but also Challis on the 29th, immediately after reading the French geometer's lucid and impressive treatise, picked out from among the stellar points strewing the zodiac, a small planetary disc, which eventually proved to be that of the precise body he had been in search of during two months.

The controversy that ensued had its unworthy side; but it was entered into by neither of the parties principally concerned. Mr. Adams bore the disappointment, which the laggard proceedings at Greenwich and Cambridge had inflicted upon him, with quiet heroism. His silence on the subject of what another man would have called his wrongs remained unbroken to the end of his life; ${ }^{4}$ and he took every opportunity of testifying his admiration for the genius of Leverrier.

1 Mem. R. A. S., vol. xvi., p. 412. 2 He had recorded the places of $3 \mathbf{1} 50$ stars (three of which were different positions of the planet), and was preparing to map them, when, October I, news of the discovery arrived from Berlin. Prof. Challis's Report, quoted in Obituary Notice, Month. Not., Feb. 1883, p. 170. ${ }^{3}$ Se: Airy in Mem. R. A. S., vol. xvi., p. 4 II. ${ }^{4} \mathrm{He}$ died January 21,1892 , in his 7 ist year. 
Personal questions, however, vanish in the magnitude of the event they relate to. By it the last lingering doubts as to the absolute exactness of the Newtonian Law were dissipated. Recondite analytical methods received a confirmation brilliant and intelligible even to the minds of the vulgar, and emerged from the patient solitude of the study to enjoy an hour of clamorous triumph. For ever invisible to the unaided eye of man, a sister-globe to our earth was shown to circulate, in perpetual frozen exile, at thirty times its distance from the sun. Nay, the possibility was made apparent that the limits of our system were not even thus reached, but that yet profounder abysses of space might shelter obedient, though little favoured members of the solar family, by future astronomers to be recognised through the sympathetic thrillings of Neptune, even as Neptune himself was recognised through the tell-tale deviations of Uranus.

It is curious to find that the fruit of Adams's and Leverrier's laborious investigations had been accidentally all but snatched half a century before it was ripe to be gathered. On the 8th, and again on the Ioth of May 1795, Lalande noted the position of Neptune as that of a fixed star, but perceiving that the two observations did not agree, he suppressed the first as erroneous, and pursued the inquiry no further. An immortality which he would have been the last to despise hung in the balance; the feather-weight of his carelessness, however, kicked the beam, and the discovery was reserved to be more hardly won by later comers.

Bode's Law did good service in the quest for a trans-Uranian planet by affording ground for a probable assumption as to its distance. A starting-point for approximation was provided by it; but it was soon found to be considerably at fault. Even Uranus is about 36 millions of miles nearer to the sun than the order of progression requires; and Neptune's vast distance of 2800 million should be increased by no less than 800 million miles, and its period of 165 lengthened out to 225 years, $^{1}$ in order to bring it into conformity with the curious and un-

1 Ledger, The Sun, its Planets and their Satellites, p. 4I4. 
explained rule which planetary discoveries have alternately tended to confirm and to invalidate.

Within seventeen days of its identification with the Berlin achromatic, Neptune was found to be attended by a satellite. This discovery was the first notable performance of the celebrated two-foot reflector ${ }^{1}$ erected by $\mathrm{Mr}$. Lassell at his suggestively named residence of Starfield, near Liverpool. William Lassell was a brewer by profession, but by inclination an astronomer. Born at Bolton in Lancashire, June 18, I799, he closed a life of eminent usefulness to science, October 5, 1880, thus spanning with his well-spent years almost the entire of the momentous period which we have undertaken to traverse. At the age of twenty-one, being without the means to purchase, he undertook to construct telescopes, and naturally turned his attention to the reflecting sort, as favouring amateur efforts by the comparative simplicity of its structure. His native ingenuity was remarkable, and was developed by the hourly exigencies of his successive enterprises. Their uniform success encouraged him to enlarge his aims, and in 1844 he visited Birr Castle for the purpose of inspecting the machine used in polishing the giant speculum of Parsonstown. In the construction of his new instrument, however, he eventually discarded the model there obtained, and worked on a method of his own, assisted by the supreme mechanical skill of James Nasmyth. The result was a Newtonian of exquisite definition, with an aperture of two and a focal length of twenty feet, provided by a novel artifice with the equatoreal mounting, previously regarded as available only for refractors.

This beautiful instrument afforded to its maker, October ro, I846, a cursory view of a Neptunian attendant. But the planet was then approaching the sun, and it was not until the following July that the observation could be verified, which it was completely, first by Lassell himself, and somewhat later by Otto Struve and Bond of Cambridge (U.S.). When it is considered that this remote object shines by reflecting sunlight

1 Presented by the Misses Lassell, after their father's death, to the Royal Observatory. 
reduced by distance to $\frac{1}{900}$ th of the intensity with which it illuminates our moon, the fact of its visibility, even in the most perfect telescopes, is a somewhat surprising one. It can only, indeed, be accounted for by attributing to it dimensions very considerable for a body of the secondary order. It shares with the moons of Uranus the peculiarity of retrograde motion; that is to say, its revolutions, rumning counter to the grand current of movement in the solar system, are performed from east to west, in a plane inclined at an angle of $35^{\circ}$ to that of the ecliptic. Their swiftness serves to measure the mass of the globe round which they are performed. For while our moon takes twenty-seven days and nearly eight hours to complete its circuit of the earth, the satellite of Neptune, at a distance not greatly inferior, sweeps round its primary in five days and twenty-one hours, showing (according to a very simple principle of computation) that it is urged by a force seventeen times greater than the terrestrial pull upon the lunar orb. Combining this result with that of measurements of the small telescopic disc of this farthest known planet, it is found that while in mass Neptune equals seventeen earths, in bulk it is equivalent to eighty-five. This is as much as to say that it is composed of relatively very light materials, or more probably of materials distended by internal heat, as yet unwasted by radiation into space, to about five times the volume they would occupy in the interior of our globe. 'The fact, at any rate, is fairly well ascertained, that the average density of Neptune differs little from that of water.

We must now turn from this late-recognised member of our system to bestow some brief attention upon the still fruitful field of discovery offered by one of the immemorial five. The family of Saturn.has been more gradually introduced to the notice of astronomers than that of its brilliant neighbour. Titan, the sixth Saturnian moon in order of distance, led the way, being detected by Huygens, March 25, I655; Cassini made the acquaintance of four more between I67I and I684; while Mimas and Enceladus, the two innermost, were caught by Herschel in I789, as they threaded their lucid way along the 
edge of the almost vanished ring. In the distances of these seven revolving bodies from their primary, an order of progression analogous to that pointed out by Titius in the planetary intervals was found to prevail ; but with one conspicuous interruption, similar to that which had first suggested the search for new members of the solar system. Between Titan and Japetus-the sixth and seventh reckoning outwards-there was obviously room for another satellite. It was discovered on both sides of the Atlantic simultaneously, on the igth of September I848. Mr. W. C. Bond, employing the splendid I 5-inch refractor of the Harvard Observatory, noticed, September I6, a minute star situated in the plane of Saturn's rings. The same object was discerned by Mr. Lassell on the i 8th. On the following evening, both observers perceived that the problematical speck of light kept up with, instead of being left behind by, the planet as it moved, and hence inferred its true character. $^{1}$ Hyperion, the seventh by distance and eighth by recognition of Saturn's attendant train, is of so insignificant a size when compared with some of its fellow-moons ('Titan is but little inferior to the planet Mars), as to have suggested to Sir John Herschel ${ }^{2}$ the idea that it might be only one of several bodies revolving very close together-in fact, an asteroidal satellite; but the conjecture has, so far, not been verified.

The coincidence of its duplicate discovery was singularly paralleled two years later. Galileo's amazement when his "optic glass" revealed to him the "triple form of Saturn-planeta tergeminus-has proved to be, like the laughter of the gods, " inextinguishable." It must revive in every one who contemplates anew the unique arrangements of that world apart known to us as the Saturnian system. The resolution of the so-called ansa, or "handles," into one encircling ring by Huygens in I655; the discovery by Cassini in 1675 of the division of that ring into two concentric ones ; together with Laplace's investigation of the conditions of stability of such a formation, constituted, with some minor observations, the sum of the knowledge obtained, up to the middle of the present century, on the subject

1 Grant, Hist. of Astr., p. 27 I. 2 Month. Not., vol. ix., p. 9I. 
of this remarkable formation. The first place in the discovery now about to be related belongs to an American astronomer.

William Cranch Bond, born in 1789 at Falmouth (now Portland), in the State of Maine, was a watchmaker whom the solar eclipse of I 806 attracted to study the wonders of the heavens. When, in I8I 5, the erection of an observatory in connection with Harvard College, Cambridge, was first contemplated, he undertook a mission to England for the purpose of studying the working of similar institutions there, and on his return erected a private observatory at Dorchester, where he worked diligently for many years. Meanwhile, the time was approaching for the resumption of the long-postponed design of the Harvard authorities; and on the completion of the new establishment in I844, Bond, who had for some time been officially connected with the College and had carried on his scientific labours within its precincts, was offered, and accepted the post of its director. Placed in I847 in possession of one of the finest instruments in the world-a masterpiece of Merz and Mahler-he headed the now long list of distinguished Transatlantic observers. Like the elder Struve, he left an heir to his office and to his eminence; but George Bond unfortunately died in I865, at the early age of thirty-nine, having survived his father but six years.

On the night of November I5, I 850-the air, remarkably enough, being so hazy that only the brightest stars could be perceived with the naked eye-William Bond discovered a third dusky ring, extending about halfway between the inner brighter one and the globe of Saturn. A fortnight later, but before the observation had been announced in England, the same appearance was seen by the Rev. W. R. Dawes with the comparatively small refractor of his observatory at Wateringbury, and on December 3 was described by Mr. Lassell (then on a visit to him) as "something like a crape veil covering a part of the sky within the inner ring." 1 Next morning the Times containing the report of Bond's discovery reached Wateringbury. The most surprising circumstance in the matter was that the novel 
appendage had remained so long unrecognised. As the rings opened out to their full extent, it became obvious with very moderate optical assistance; yet some of the most acute observers who havé ever-lived, using instruments of vast power, had heretofore failed to detect its presence. It soon appeared, however, that Galle of Berlin ${ }^{1}$ had noticed, June IO, I838, a veil-like extension of the lucid ring across half the dark space separating it from the planet; but the observation, although communicated at the time to the Berlin Academy of Sciences, had remained barren. Traces of the dark ring, moreover, were found in a drawing executed by Campani in $1664 ;{ }^{2}$ and Picard (June I 5 , I673), ${ }^{3}$ Hadley (spring of 1720), ${ }^{4}$ and Herschel,,${ }^{5}$ had all undoubtedly seen it under the aspect of a dark bar or belt crossing the Saturnian globe. It was, then, of no recent origin; but there seemed reason to think that it had lately gained considerably in brightness. The full meaning of this remarkable fact it was reserved for later investigations to develop.

What we may, in a certain sense, call the closing result of the race for discovery, in which several observers seemed at that time to be engaged, was the establishment, on a satisfactory footing, of our acquaintance with the dependent system of Uranus. Sir William Herschel, whose researches formed, in so many distinct lines of astronomical inquiry, the starting-points of future knowledge, detected, January I I, I $787,{ }^{6}$ two Uranian moons, since called Oberon and Titania, and ascertained the curious circumstance of their motion in a plane almost at right angles to the ecliptic, in a direction contrary to that of all previously known denizens (other than cometary) of the solar kingdom. He believed that he caught occasional glimpses of four more, but never succeeded in assuring himself of their substantial existence. Even the two first remained unseen save by himself until I828, when his son re-observed them with a 20-foot reflector, similar to that with which they had been

1 Astr. Nach., No. 756 (May 2, I85I). p. 248 . 3 Hind, lbid., vol. xv., p. 32 . Hadley, Phil. Trans., vol. xxxii., p. 385 . p. 64. ${ }^{6}$ Phil. Trans., vol. Ixxvii., p. 125.
2 F. Secchi, Month. Not., vol. xiii.,

+ Lynn, Observatory, Oct. I, I883 ;

5 Proctor, Saturn and its System, 
originally discovered. Thenceforward they were kept fairly within view, but their four questionable companions, in spite of some false alarms of detection, remained in the dubious condition in which Herschel had left them. At last, on October 24, I $85 \mathrm{I}^{1}$ after some years of fruitless watching, Mr. Lassell espied "Ariel" and "Umbriel," two Uranian attendants, interior to Oberon and Titania, and of abont half their brightness; so that their disclosure is still reckoned amongst the very highest proofs of instrumental power and perfection. In all probability they were then for the first time seen; for although Professor Holden, ${ }^{2}$ director of the Lick Observatory, has made out a plausible case in favour of the fitful visibility to Herschel of each of them in turn, Mr. Lassell's argument, ${ }^{3}$ that the glare of the planet in Herschel's great specula must have rendered almost impossible the perception of objects so minute and so close to its disc, appears tolerably decisive to the contrary. Uranus is thus attended by four moons, and, so far as present knowledge extends, by no more. Among the most important of the "negative results" 4 secured by Mr. Lassell's observations at Malta during the years $1852-53$ and $1861-65$, were the convincing evidence afforded by them that, without great increase of optical power, no further Neptunian or Uranian satellites can be perceived, and the consequent relegation of Herschel's baffling quartette, notwithstanding the unquestioned place long assigned to them in astronomical text-books, to the repose of unreality.

1 Month. Not., vol. xi., p. 248.

p. 26. "Ibid., vol. xli., p. I90.

2 Ibid., vol. xxxv, pp. I6-22. 3 Ibid., 


\section{CHAPTER V.}

\section{COMETS.}

Newton showed that the bodies known as "comets," or hirsute stars, obey the law of gravitation; but it was by no means certain that the individual of the species observed by him in I680 formed a permanent member of the solar system. The velocity, in fact, of its rush round the sun was quite possibly sufficient to carry it off for ever into the depths of space, there to wander, a celestial casual, from star to star. With another comet, however, which appeared two years later, the case was different. Edmund Halley, who afterwards succeeded Flamsteed as Astronomer Royal, calculated the elements of its orbit on Newton's principles, and found them to resemble so closely those similarly arrived at for comets observed by Peter Apian in I 53 I, and by Kepler in 1607, as almost to compel the inference that all three apparitions were of a single body. This implied its revolution in a period of about seventy-six years, and Halley accordingly fixed its return for 1758-9. So conscious was he of the importance of the announcement that he appealed to a "candid posterity," in the event of its verification, to acknowledge that the discovery was due to an Englishman. The prediction was one of the test-questions put by Science to Nature, on the replies to which largely depend both the development of knowledge and the conviction of its reality. In the present instance, the answer afforded may be said to have laid the foundation of this branch of astronomy. Halley's comet punctually reappeared on Christmas Day, I758, and effected its perihelion passage on the I 2 th of March following, thus proving beyond dispute that some at least of these erratic bodies are 
domesticated within our system, and strictly conform, if not to its unwritten customs (so to speak), at any rate to its fundamental laws. Their movements, in short, were demonstrated by the most unanswerable of all arguments - that of verified calculation-to be calculable, and their investigation was erected into a legitimate department of astronomical science.

This notable advance was the chief result obtained in the field of inquiry just now under consideration durihg the eighteenth century. But before it closed, its cultivation had received a powerful stimulus through the invention of an improved method. The name of Olbers has already been brought prominently before our readers in connection with asteroidal discoveries; these, however, were but chance excursions from the path of cometary research which he steadily pursued through life. An early predilection for the stars was fixed in this particular direction by one of the happy inspirations of genius. As he was watching, one night in the year 1779, by the sick-bed of a fellow-student in medicine at Göttingen, an important simplification in the mode of computing the paths of comets occurred to him. Although not made public until I797, "Olbers's method" was then universally adopted, and is still regarded as the most expeditious and convenient in cases where absolute rigour is not required. By its introduction, not only many a toilsome and thankless hour was spared, but workers were multiplied, and encouraged in the prosecution of labours more useful than attractive.

The career of Heinrich Olbers is a brilliant example of what may be done by an amateur in astronomy. He at no time did regular work in an observatory; he was never the possessor of a transit or any other fixed instrument; moreover, all the best years of his life were absorbed in the assiduous exercise of a toilsome profession. In $178 \mathrm{I}$ he settled as a physician in his native town of Bremen (he was born in 1758 at Arbergen, a neighbouring village, of which his father was pastor), and continued in active practice for over forty years. It was thus only the hours which his robust constitution enabled him to spare from sleep that were available for his intellectual pleasures. 
Yet his recreation was, as Von Zach remarked, ${ }^{1}$ no less prolific of useful results than the severest work of other men. The upper part of his house in the Sandgasse was fitted up with such instruments and appliances as restrictions of space permitted, and there, night after night during half a century and upwards. he discovered, calculated, or observed the cometary visitants of northern skies. Almost as effective in promoting the interests of science as the valuable work actually done by him, was the influence of his genial personality. He engaged confidence by his ready and discerning sympathy; he inspired affection by his benevolent disinterestedness; he quickened thought and awakened zeal by the suggestions of a lively and inventive spirit, animated with the warmest enthusiasm for the advancement of knowledge. Nearly every astronomer in Germany enjoyed the benefits of a frequently active correspondence with him, and his communications to the scientific periodicals of the time were numerous and striking. The motive power of his mind was thus widely felt and continually in action. Nor did it wholly cease to be exerted even when the advance of age and the progress of infirmity rendered him incapable of active occupation. He was, in fact, alive even to the last day of his long life of eighty-one years; and his death, which occurred March 2, I840, left vacant a position which a rare combination of moral and intellectual qualities had conspired to render unique.

Amongst the many younger men who were attracted and stimulated by intercourse with him was Johann Franz Encke. But while Olbers became a mathematician because he was an astronomer, Encke became an astronomer because he was a mathematician. A born geometer, he was naturally sent to Göttingen and placed under the tuition of Gauss. But geometers are men; and the contagion of patriotic fervour which swept over Germany after the battle of Leipsic did not spare Gauss's promising pupil. He took up arms in the Hanseatic Legion, and marched and fought until the oppressor of his country was safely ensconced behind the ocean-walls of St. Helena. In the course of his campaigning he met Lindenau,

1 Allgemeine Geographische Ephemeriden, vol. iv., p. 287. 
the militant director of the Seeberg Observatory, and by his influence was appointed his assistant, and eventually, in I822, became his successor. Thence he was promoted in I825 to Berlin, where he superintended the building of the new observatory, so actively promoted-by Humboldt, and remained at its head until within some eighteen months of his death in August I 865.

On the 26th of November i 8 18, Pons of Marseilles discovered a comet, whose inconspicuous appearance gave little promise of its becoming one of the most interesting objects in our system. Encke at once took the calculation of its elements in hand, and brought out the unexpected result that it revolved round the sun in a period of about $3 \frac{1}{4}$ years. ${ }^{1}$ He, moreover, detected its identity with comets seen by Méchain in 1786, by Caroline Herschel in 1795, by Pons, Huth, and Bouvard in 1805, and after six laborious weeks of research into the disturbances experienced by it from the planets during the entire interval since its first ascertained appearance, he fixed May 24, I822, as the date of its next return to perihelion. Although on that occasion, owing to the position of the earth, invisible in the northern hemisphere, Sir Thomas Brisbane's observatory at Paramatta was fortunately ready equipped for its recapture, which Rümker effected quite close to the spot indicated by Hncke's ephemeris.

The importance of this event can be better understood when it is remembered that it was only the second instance of the recognised return of a comet (that of Halley's, sixty-three years previously, having, as already stated, been the first); and that it, moreover, established the existence of a new class of celestial objects, somewhat loosely distinguished as "comets of short period." These bodies (of which a couple of dozen have been found to circulate within the orbit of Saturn) are remarkable as showing certain planetary affinities in the manner of their motions not at all perceptible in the wider travelling members of their order. They revolve, without exception, in the same direction

1 Astr. Jahrbuch, 1823, p. 217. The period (1208 days) of this body is considerably shorter than that of any other known comet. 
as the planets-from west to east; they exhibit a marked tendency to conform to the zodiacal track which limits planetary excursions north and south; and their paths round the sun, although much more eccentric than the approximately circular planetary orbits, are far less so than the extravagantly long ellipses in which comets comparatively untrained (as it were) in the habits of the solar system ordinarily perform their revolutions.

No great comet is of the "planetary" kind. 'These are, indeed, only by exception visible to the naked eye ; they display extremely feeble tail-producing powers, and give small signs of central condensation. Thin wisps of cosmical cloud, they flit across the telescopic field of view without sensibly obscuring the smallest star. Their appearance, in short, suggests-what some notable facts in their history will presently be shown to confirm - that they are bodies already effete, and verging towards dissolution. If it be asked what possible connection can be shown to exist between the shortness of period by which they are essentially characterised, and what we may call their superannuated condition, we are not altogether at a loss for an answer. Kepler's remark, ${ }^{1}$ that comets are consumed by their own emissions, has undoubtedly a measure of truth in it. The substance ejected into the tail must, in overwhelmingly large proportion, be for ever lost to the central mass from which it issues. True, it is of a nature inconceivably tenuous; but unrepaired waste, however small in amount, cannot be persisted in with impunity. The incitement to such self-spoliation proceeds from the sun; it accordingly progresses more rapidly the more numerous are the returns to the solar vicinity. Comets of short period may thus reasonably be expected to wear out quickly.

They are, moreover, bodies subject to many adventures and vicissitudes. Their aphelia-or the farthest points of their orbits from the sun-are usually, if not invariably, situated so near to the path either of Jupiter or of Saturn, as to permit these giant planets to act as secondary rulers of their destinies.

1 "Sicut bombyces filo fundendo, sic cometas cauda exspiranda consumi .et denique mori."-De Cometis, Op., vol. vii., p. 110. 
By their influence they were, in all likelihood, originally fixed in their present tracks; and by their influence, exerted in an opposite sense, they may, in some cases, be eventually ejected from them. Careers so varied, as can easily be imagined, are apt to prove instructive, and astronomers have not been backward in extracting from them the lessons they are fitted to convey. Encke's comet, above all, has served as an index to much curious information, and it may be hoped that its function in that respect is by no means at an end. The great extent of the solar system traversed by its eccentric path makes it peculiarly useful for the determination of the planetary masses. At perihelion it penetrates within the orbit of Mercury; it considerably transcends at aphelion the farthest excursion of Pallas. Its vicinity to the first-named planet in August I835 offered the first convenient opportunity of placing that body in the astronomical balance. Its weight or mass had previously been assumed, not ascertained; and the comparatively slight deviation from its regular course impressed upon the comet by its attractive power showed that it had been assumed nearly twice too great. ${ }^{1}$ 'That fundamental datum of planetary astronomy-the mass of Jupiter-was corrected by similar neans; and it was reassuring to find the correction in satisfactory accord with that already introduced from observation of the asteroidal movements.

The fact that comets contract in approaching the sun had been noticed by Hevelius; Pingré admitted it with hesitating perplexity; ${ }^{2}$ the example of Encke's comet rendered it conspicuous and undeniable. On the 28th of October I828, the diameter of the nebulous matter composing this body was estimated at 3 12,000 miles'. It was then about one and a half times as remote from the sun as the earth is at the time of the

1 Considerable uncertainty, however, still prevails on the point. The inverse relation assumed by Lagrange to exist between distance from the sun and density brought out the Mercurian mass $\frac{1}{202 \frac{1}{5} 810}$ that of the sun (Laplace, Exposition du Syst. du Monde, t. ii., p. 50, ed. 1824). Von Asten deduced from the movements of Encke's comet, 1818-48, a value of $\frac{1}{763640}$; while Backlund derives $\frac{1}{2668700}$ from the close approach of the same body to the pianet in August 1878 (Bull. Astr., t. iii., p. 473). $\quad 2$ Arago, Annuairc (1832), p. 218. 
equinox. On the 24th of December following, its distance being reduced by nearly two-thirds, it was found to be only 14,000 miles across. That is to say, it had shrunk during those two months of approach to $\frac{1}{11000}$ th part of its original volume! Yet it had still seventeen days' journey to make before reaching perihelion. The same curious circumstance was even more markedly apparent at its return in I838. Its bulk, or the actual space occupied by it, was reduced, as it drew near the hearth of our system (so far at least as could be inferred from optical evidence), in the enormous proportion of 800,000 to I. A corresponding expansion on each occasion accompanied its retirement from the sphere of observation. Similar changes of volume, though rarely to the same astounding extent, have been perceived in other comets. They still remain unexplained; but it can scarcely be doubted that they are due to the action of the same energetic internal forces which reveal themselves in so many splendid and surprising cometary phenomena.

Another question of singular interest was raised by Encke's acute inquiries into the movements and disturbances of the first known "comet of short period." He found from the first that its revolutions were subject to some influence besides that of gravity. After every possible allowance had been made for the pulls, now backward, now forward, exerted upon it by the several planets, there was still a surplus of acceleration left unaccounted for. Each return to perihelion took place about two and a half hours sooner than received theories warranted. Here, then, was a "residual phenomenon" of the utmost promise for the disclosure of novel truths. Encke (in accordance with the opinion of Olbers) explained it as due to the presence in space of some such "subtle matter" as was long ago invoked by Euler" to be the agent of eventual destruction for the fair scheme of planetary creation. The apparent anomaly of accounting for an accelerative effect by a retarding cause disappears when it is considered that any check to the motion of bodies revolving round a centre of attraction causes them to draw closer to it, thus shortening

${ }^{1}$ Hind, The Comets, p. 20. ' 2 Phil. Trans., vnl. xlvi., p. 204. 
their periods and quickening their circulation. If space were filled with a resisting medium capable of impeding, even in the most infinitesimal degree, the swift course of the planets, their orbits should necessarily be, not ellipses, but very close elliptical spirals, along which they would slowly, but inevitably, descend into the burning lap of the sun. The circumstance that no such tendency can be traced in their revolutions by no means sets the question at rest. For it might well be that an effect totally imperceptible until after the lapse of countless ages, as regards the solid orbs of our system, might be obvious in the movements of bodies like comets of small mass and great bulk; just as a feather or a gauze veil at once yields its motion to the resistance of the air, while a cannon-ball cuts its way through with comparatively slight loss of velocity.

It will thus be seen that issues of the most momentous character hang on the time-keeping of comets; for plainly all must in some degree suffer the same kind of hindrance as Encke's, if the cause of that hindrance be the one suggested. None of its congeners, however, show any trace of similar symptoms. True, the late Professor Oppolzer announced, ${ }^{1}$ in I880, that a comet, first seen by Pons in 1819 , and rediscovered by Winnecke in 1858 , having a period of 2052 days ( 5.6 years), was accelerated at each revolution precisely in the manner required by Encke's theory. But M. von Haerdtl's subsequent investigation, the materials for which included numerous observations of the body in question at its return to the sun in I886, decisively negatived the presence of any such effect. ${ }^{2}$ Moreover, the researches of Von Asten and Backlund ${ }^{3}$ into the movements of Encke's comet revealed a perplexing circumstance. They confirmed Encke's results for the period covered by them, but exhibited the acceleration as having suddenly diminished by nearly one-half in I868. The reality and permanence of this change were fully established by observations of the return in March I885. Some physical alteration of the retarded body seems indicated; but visual evidence countenances no such

1 Astr. Nach., No. 2314. 2 Comptes Rendus, t. cvii., p. $588 .{ }^{3}$ Mém. de St. Petersburg, t. xxxii., No. 3, 1884; Astr. Nach., No. 2727. 
assumption. In aspect the comet is no less thin and diffuse than in $\mathbf{I} 795$ or in $\mathbf{I} 848$.

The character of the supposed resistance in inter-planetary space has, it may be remarked, been often misapprehended. What Encke stipulated for was not a medium equally diffused throughout the visible universe, such as the ethereal vehicle of the vibrations of light, but a rare fluid, rapidly increasing in density towards the sun. ${ }^{1}$ This cannot be a solar atmosphere, since it is mathematically certain, as Laplace has shown, ${ }^{2}$ that no envelope partaking of the sun's axial rotation can extend farther from his surface than nine-tenths of the mean distance of Mercury; while physical evidence assures ns that the actual depth of the solar atmosphere bears a very minute proportion to the possible depth theoretically assigned to it. That matter, however, not atmospheric in its nature-that is, neither forming one body with the sun nor altogether aëriform-exists in its neighbourhood, can admit of no reasonable doubt. The great lens-shaped mass of the zodiacal light, stretching out at times far beyond the earth's orbit, may indeed be regarded as an extension of the corona, the streamers of which themselves mark the wide diffusion, all round the solar globe, of granular or gaseous materials. Yet comets have been known to penetrate the sphere occupied by them without perceptible loss of velocity. The hypothesis, then, of a resisting medium receives at present no countenance from the movements of comets, whether of short or of long periods.

Although Encke's comet has made thirty-two complete rounds of its orbit since its first detection in 1786 , it shows no certain signs of decay. Variations in its brightness are, it is true, conspicuous, but they do not proceed continuonsly. ${ }^{3}$

The history of the next known planet-like comet has proved of even more curious interest than that of the first. It was discovered by an Austrian officer named Wilhelm von Biela at Josephstadt in Bohemia, February 27, I826, and ten days later by the French astronomer Gambart at Marseilles. Both observers

1 Month. Not.. vol. xix., p. 72. 2 Mécanique Céleste, t. ii., p. 197. ${ }^{3}$ See Berberich, Astr. Nach., Nos. 2836-7, 3125; Deichmiiller, Ibid., No. 3123. 
computed its orbit, showed its remarkable similarity to that traversed by comets visible in I772 and I805, and connected them together as previous appearances of the body just detected by assigning to its revolutions a period of between six and seven years. The two brief letters conveying these strikingly similar inferences were printed side by side in the same number of the Astronomische Nachrichten (No. 94); but Biela's priority in the discovery of the comet was justly recognised by the bestowal upon it of his name.

The object in question was at no time (subsequently to its appearance in I805) visible to the naked eye. Its aspect in Sir John Herschel's great reflector on the 23rd of September" I832, was described by him as that of a "conspicuous nebula," about $2 \frac{1}{2}$ to 3 minutes in diameter. No trace of a tail was discernible. While he was engaged in watching it, a small knot of minute stars (I6th or I th magnitude) was directly traversed by it, "and when on the cluster," he tells us, ${ }^{1}$ it "presented the appearance of a nebula resolvable and partly resolved into stars, the stars of the cluster being visible through the comet." Yet the depth of cometary matter through which such faint stellar rays penetrated undimmed, was, near the central parts of the globe, not less than 50,000 miles.

It is curious to find that this seemingly harmless, and we may perhaps add effete body, gave occasion to the first (and not the last) cometary "scare" of this enlightened century. Its orbit, at the descending node, may be said to have intersected that of the earth; since, according as it bulged in or out under the disturbing influence of the planets, the passage of the comet was effected inside or outside the terrestrial track. Now certain calculations published by Olbers in $1828^{2}$ showed that, on October 29, I832, a considerable portion of its nebulous surroundings would actually sweep over the spot which, a month later, would be occupied by our planet. It needed no more to sat the popular imagination in a ferment. Astronomers, after all, could not, by an alarmed public, be held to be infallible. Their computations, it was averred, which a trifling oversight

1 Month. Not., vol. ii., p. 117. 2 Astr. Nach., No. 128. 
would suffice to vitiate, exhibited clearly enough the danger, but afforded no guarantee of safety from a collision, with all the terrific consequences frigidly enumerated by Laplace. Nor did the panic subside until Arago formally demonstrated that the earth and comet could by no possibility approach within less than fifty millions of miles. ${ }^{1}$

The return of the same body in 1845-46 was marked by an extraordinary circumstance. When first seen, November 28, it wore its usual aspect of a faint round patch of cosmical fog; but on December I9, Mr. Hind noticed that it had become distorted somewhat into the form of a pear; and ten days later, it had divided into two separate objects. This singular duplication was first perceived at New Haven in America, December 29, ${ }^{2}$ by Messrs. Herrick and Bradley, and by Lieutenant Maury at Washington, January I3, I846. The earliest British observer of the phenomenon (noticed by Wichmann the same evening at Königsberg) was Professor Challis. "I see two comets!" he exclaimed, putting his eye to the great equatoreal of the Cambridge Observatory on the night of January I5; then, distrustful of what his senses had told him, he called in his judgment to correct their improbable report by resolving one of the dubious objects into a hazy star. ${ }^{3}$ On the $23 \mathrm{rd}$, however, both were again seen by him in unmistakable cometary shape, and until far on in March (Otto Struve caught a final glimpse of the pair on the I6th of April), ${ }^{4}$ continued to be watched with equal curiosity and amazement by astronomers in every part of the northern hemisphere. What Seneca reproved Ephorus for supposing to have taken place in 373 B.C.- -what Pingré blamed Kepler for conjecturing in I6I8, had then

1 Annuaire (1832), p. 186. 2 Am. Journ. of Science, vol. i. (2nd series), p. 293. Prof. Hubbard's calculations indicated a probability that the definitive separation of the two nuclei occurred as early as September 30, 1844, Astronomical Journal (Gould's), vol. iv., p. 5. See also, on the subject of this comet, W. T. Lynn, Intellectual Observer, vol. xi., p. 208 ; E. Ledger, Observatory, August, I883, p. 244 ; and H. A. Newton, Am. Journ. of Science, vol. xxxi., p. 81, February I886. ${ }^{3}$ Month. Not., vol. vii., p. 73. ${ }^{4}$ Builletin Ac. Imp. de St. Pétersbourg, t. vi., col. 77. The latest observation of the parent. nucleus was that of Argelander, April 27, at Bonn. 
actually occurred under the attentive eyes of science in the middle of the nineteenth century!

At a distance from each other of about two-thirds the distance of the moon from the earth, the twin comets meantime moved on tranquilly, so far, at least, as their course through the heavens was concerned. 'Their extreme lightness, or the small amount of matter contained in each, could not have received a more signal illustration than by the fact that their revolutions round the sun were performed independently; that is to say, they travelled side by side without experiencing any appreciable mutual disturbance, thus plainly showing that at an interval of only I 57,250 miles their attractive power was virtually inoperative. Signs of internal agitation, however, were not wanting. Each fragment threw out a short tail in a direction perpendicular to the line joining their centres, and each developed a bright nucleus, although the original comet had exhibited neither of these signs of cometary vitality. A singular interchange of brilliancy was, besides, observed to take place between these small objects, each of which alternately outshone and was outshone by the other, while an arc of light, apparently proceeding from the more lustrous, at times bridged the intervening space. Obviously, the gravitational tie, rendered powerless by exiguity of matter, was here replaced by some other form of mutual action, the nature of which can as yet be dealt with only by conjecture.

Once more, in August 1852, the double comet returned to the neighbourhood of the sun, but under circumstances not the most advantageous for observation. Indeed, the companion was not detected until September 16, by Father Secchi at Rome, and was then perceived to have increased its distance from the originating body to a million and a quarter of miles, or about eight times the average interval at the former appearance. Both vanished shortly afterwards, and have never since been seen, notwithstanding the eager watch kept for objects of such singular interest, and the accurate knowledge of their track supplied by Santini's investigations. We can scarcely doubt that the fate has overtaken them which Newton assigned as the 
end of all cometary existence. Diffundi tandem et spargi per coelos universos. ${ }^{1}$

Biela's is not the only vanished comet. Brorsen's, discovered at Kiel in 1846, and observed at several subsequent returns, failed unaccountably to become visible in $1890 .^{2}$ Yet numerous sentinels were on the alert to surprise its approach along a wellascertained track, traversed in five and a half years. The object presented from the first a somewhat time-worn aspect. It was devoid of tail, or any other kind of appendage; and the rapid loss of the light acquired during perihelion passage was accompanied by the inordinate expansion of an already tenuous globular mass. Another lost or mislaid comet is one found by De Vico at Rome, August 22, I844. It ought to have returned early in I850, but failed, then and subsequently, to keep its appointments ; for its supposed identity with Finlay's comet of I886 has not been ratified by closer inquiry. ${ }^{3}$

A telescopic comet with a period of $7 \frac{1}{2}$ years, discovered. November 22, I 843, by M. Faye of the Paris Observatory, formed the subject of a characteristically patient and profound inquiry on the part of Leverrier, designed to test its suggested identity with Lexell's comet of I770. The result was decisive against the hypothesis of Valz, the divergences between the orbits of the two bodies being found to increase instead of to diminish, as the history of the new-comer was traced backwards into the last century. ${ }^{4}$ Faye's comet pursues a more nearly circular path than any similar known object, except Holmes's comet of 1892 ; even at its nearest approach to the sun it remains farther off than Mars when he is most distant from it; and it was proved by the admirable researches of Professor Axel Möller, ${ }^{5}$ of Lund, to exhibit no trace of the action of a resisting medium.

Periodical comets are evidently bodies which have lived, each through a chapter of accidents; and a significant hint as to the nature of their adventures can be gathered from the fact that their aphelia are pretty closely grouped about the tracks of the

1 D'Arrest, Astr. Nach., Nu. 1624. 2 Der Brorsen'sche Comet. Von Dr. $\begin{array}{ll}\text { E. Lamp, Kiel, 1892. } & { }^{3} \text { Schulhof, Bull. Astr., t. vi., p. 515. } 4 \text { Comptes } \\ \text { Rendus, t. xxv., p. } 570 . & 5 \text { Month. Not., vol. xil., p. } 248 .\end{array}$ 
niajor planets. Halley's, and four other comets are thus related to Neptune; eight connect themselves with Uranus, nine with Saturn, twenty-five at least with Jupiter. Some form of dependence is plainly indicated, and the recent researches of MM. 'Tissandier ${ }^{1}$ and Callandreau, ${ }^{2}$ and of Professor Newton, ${ }^{3}$ of Yale College, leave scarcely a doubt that the "capture-theory" represents the essential truth in the matter. The original parabolic paths of these comets were then changed into ellipses by the backward pull of a planet, whose sphere of influence they chanced to enter when approaching the sun from outer space. Moreover, since a body thus affected should necessarily return at each revolution to the scene of encounter, the same process of retardation may, in some cases, have been repeated many times, until the more restricted cometary orbits were reduced to their present dimensions. The prevalence, too, among periodical comets, of direct motion, is shown to be inevitable by M. Callandreau's demonstration that those travelling in a retrograde direction would, by planetary action, be thrown outside the probable range of terrestrial observation. The scarcity of hyperbolic comets can be similarly explained. They would be created whenever the attractive influence of the disturbing planet was exerted in a forward or accelerative sense, but could come only by a rare exception to our notice. The inner planets, including the earth, have also unquestionably played their parts in modifying cometary orbits; and Mr. Plummer suggests, with some show of reason, that the capture of Encke's comet may be a feat due to Mercury. ${ }^{4}$

No great comet appeared between the "star" which presided at the birth of Napoleon and the "vintage" comet of I8I I. The latter was first descried by Flaugergues at Viviers, March 26, I8 I I Wisniewski, at Neu-Tscherkask in Southern Russia, carght the last glimpse of it, Angust I7, I8I2. Two disappearances in the solar rays as the earth moved round in its orbit, and two reappearances after conjunction, were included in

1 Bull. Astr., t. vi., pp. 24r, 289. ${ }^{2}$ Études sur la Theorie des Comètes périodiques, Paris, I891. ${ }^{3}$ Amer. Journ. of Science, vol. xlii.. pp. 183, 482, 1891. 4 Observatory, vol. xiv., p. 194. 
this unprecedentedly long period of visibility of 5 Io days. This relative permanence (so far as the inhabitants of Europe were concerned) was due to the high northern latitude attained near perihelion, combined with a certain leisureliness of movement, along a path everywhere external to that of the earth. The magnificent luminous train of this body, on October I 5 , the day of its nearest terrestrial approach, covered an arc of the heavens $23 \frac{1}{2}$ degrees in length, corresponding to a real extension of one hundred millions of miles. Its form was described by Sir William Herschel as that of "an inverted hollow cone," and its colour as yellowish, strongly contrasting with the bluish-green tint of the "head," round which it was flung like a transparent veil. The planetary disc of the head, I27,000 miles across, appeared to be composed of strongly condensed nebulous matter ; but somewhat eccentrically situated within it was a star-like nucleus of a reddish tinge, which Herschel presumed to be solid, and ascertained, with his usual care, to have a diameter of 428 miles. From the total absence of phases, as well as from the vivacity of its radiance, he confidently inferred that its light was not borrowed, but inherent. ${ }^{1}$

'This remarkable apparition formed the subject of a memoil' by Olbers, the striking yet steadily reasoned-out suggestions contained in which there was at that time no means of following up with profit. Only of late has the "electrical theory," of which Zöllner ${ }^{3}$ regarded Olbers as the founder, assumed a definite and measurable form, capable of being tested more and more surely by the touchstone of fact, as knowledge makes its slow inroads on the fundamental mystery of the physical universe.

The paraboloidal shape of the bright envelope separated by a dark interval from the head of the great comet of I8I I, and constituting, as it were, the root of its tail, seemed to the astronomer of Bremen to reveal the presence of a double repulsion; the expelled vapours accumulating where the two forces, solar and cometary, balanced each other, and being then swept

1 Phil. Trans., vol. cii., pp. I 18-124. 2 Ueber den Schweif des grossen Cometen von I8I I, Monat. Corr., vol. xxv., pp. 3-22. Reprinted by Zöllner, Ueher die Natur der Cometen, pp. 3-15. $\quad 3$ Natur der Cometen, p. 148. 
backward in a huge train. He accordingly distinguished three classes of these bodies:-First, comets which develop no matter subject to solar repulsion. These have no tails, and are probably mere nebulosities, without solid nuclei. Secondly, comets which are acted upon by solar repulsion only, and consequently throw out no emanations towards the sun. Of this kind was a bright comet visible in 1807. ${ }^{1}$ Thirdly, comets like that of I $8 \mathrm{I}$, giving evidence of action of both kinds. These are distinguished by a dark hoop encompassing the head and dividing it from the luminous envelope, as well as by an obscure caudal axis, resulting from the hollow, cone-like structure of the tail.

Again, the ingenious view recently put forward by M. Bredichin as to the connection between the form of these appendages and the kind of matter composing them, was very clearly anticipated by Olbers. The amount of tail-curvature, he pointed out, depends in each case upon the proportion borne by the velocity of the ascending particles to that of the comet in its orbit; the swifter the outrush, the straighter the resulting tail. But the velocity of the ascending particles varies with the energy of their repulsion by the sun, and this again, it may be presumed, with their quality. Thus multiple tails are developed when the same comet throws off, as it approaches perihelion, specifically distinct substances. The long, straight ray which proceeded from the comet of 1807 , for example, was doubtless made up of particles subject to a much more vigorous solar repulsion than those formed into the shorter curved emanation issuing from it nearly in the same direction. In the comet of $\mathrm{r} 8 \mathrm{II}$, he calculated that the particles expelled from the head travelled to the remote extremity of the tail in eleven minutes, indicating by this enormous rapidity of movement (comparable to that of the transmission of light) the action of a force greatly more powerful than the opposing one of gravity. The not uncommon phenomena of multiple envelopes, on the other hand, he ex-

1 The subject of a classical memoir by Bessel, published in 1810. 
plained as due to the varying amounts of repulsion exercised by the nucleus itself on the different kinds of matter developed from it.

The movements and perturbations of the comet of I8I I were no less profoundly studied by Argelander than its physical constitution by Olbers. The orbit which he assigned to it is of such vast dimensions as to require no less than 3065 years for the completion of its circuit; and to carry the body describing it at each revolution to fourteen times the distance from the sun of the frigid Neptune. Thus, when it last visited our neighbourhood, Achilles may have gazed on its imposing train as he lay on the sands all night bewailing the loss of Patroclus; and when it returns, it will perhaps be to shine upon the ruins of empires and civilisations still deep buried among the secrets of the coming time. ${ }^{1}$

On the 26th of June 1819, while the head of a comet passed across the face of the sun, the earth was in all probability involved in its tail. But of this remarkable double event nothing was known until more than a month later, when the fact of its past occurrence emerged from the calculations of Olbers. Nor had the comet itself been generally visible previous to the first days of July. Several observers, however, on the publication of these results, brought forward accounts of singular spots perceived by them upon the sun at the time of the transit, and the original drawing of one of them, by Pastorff of Buchholtz, has been preserved. This undoubtedly authentic delineation ${ }^{3}$ represents a round nebulous object with a bright spot in the centre, of decidedly cometary aspect, and not in the least like an ordinary solar "macula." Mr. Hind, ${ }^{4}$ nevertheless, has shown that its position on the sun is irreconcilable with that which the comet must have occupied; and Mr. Ranyard's discovery of a similar smaller drawing by the same author, dated May 26, I $828,{ }^{5}$ reduces to evanescence the probability of its connection

1 A fresh investigation of its orbit has been published by N. Herz of Vienna. See Bull. Astr., t. ix., p. 427. 2 Astr. Jahrbuch (Bode's), 1823, p. I34. 3 Reproduced in Webb's Celestial Objects, 4th. ed. 4 Month. Not., vol. xxxvi., p. 309. 5 Celestial Objects, p. 40, note. 
with that body. Indeed, recent experience renders very doubtful the possibility of such an observation.

The return of Halley's comet in I 835 was looked forward to as an opportunity for testing the truth of floating cometary theories, and did not altogether disappoint expectation. As early as 1817 , its movements and disturbances since I759 were proposed by the Turin Academy of Sciences as the subject of a prize awarded to Baron Damoiseau. Pontécoullant was adjudged a similar distinction by the Paris Academy in 1829 ; while Rosenberger's calculations were rewarded with the gold medal of the Royal Astronomical Society. ${ }^{1}$ The result entirely disproved the hypothesis (designed to explain the invariability of the planetary periods) of what may be described as a vortex of attenuated matter moving with the planets, and offering, consequently, no resistance to their motion. For since Halley's comet revolves in the opposite direction-in other words, has a "retrograde" movement-it is plain that if compelled to make head against an ethereal current, it would rapidly be deprived of the tangential velocity which enables it to keep at its proper distance from the sun, and would thus gradually but conspicuously approach, and eventually be precipitated upon it. No such effect, however, has in this crucial instance been detected.

On the 6th of August 1835, a nearly circular misty object was seen at Rome not far from the predicted place of the comet. It was not, however, until the middle of September that it began to throw out a tail, which by the I 5 th of October had attained a length of about 24 degrees (on the rgth, at Madras, it extended to fully 30), ${ }^{2}$ the head showing to the naked eye as a reddish star rather brighter than Aldebaran or Antares. ${ }^{3}$ Some curious phenomena accompanied the process of tail formation. An outrush of luminous matter, resembling in shape a partially opened fan, issued from the nucleus towards the sun, and at a certain point, like smoke driven before a high wind, was vehemently swept backward in a prolonged train.

1 See Airy's Address, Mem. R. A. S., vol. x., p. 376.2 Hind, The Comets, p. 47. 3 Arago, Annuaire, I836, p. 228. 
The appéarance of the comet at this time was compared by Bessel, ${ }^{1}$ who watched it with minute attention, to that of a blazing rocket. He made the singular observation that this fan of light, which seemed the source of supply for the tail, oscillated like a pendulum to and fro across a line joining the sun and nucleus, in a period of $4 \frac{3}{5}$ days; and he was unable to escape from the conclusion ${ }^{2}$ that a repulsive force, about twice as powerful as the attractive force of gravity, was concerned in the production of these remarkable effects. Nor did he hesitate to recur to the analogy of magnetic polarity, or to declare, still more emphatically than Olbers, "the emission of the tail to be a purely electrical phenomenon." 3

The transformations undergone by this body were almost as strange and complete as those which affected the brigands in Dante's Inferno. When first seen, it wore the aspect of a nebula; later it put on the distinctive garb of a comet; it next appeared as a star; finally, it dilated, first in a spherical, then in a paraboloidal form, until May 5, I836, when it vanished from Herschel's observation at Feldhausen as if by melting into adjacent space through the excessive diffusion of its light. A very uncommon circumstance in its development was that it lost (it would appear) all trace of tail previous to its arrival at perihelion on the I6th of November. Nor did it begin to recover its elongated shape for more than two months afterwards. On the 23rd of January, Boguslawski perceived it as a star of the sixth magnitude, without measurable disc. ${ }^{4}$ Only two nights later, Maclear, director of the Cape Observatory, found the head to be I 3 I seconds across. ${ }^{5}$ And so rapidly did the augmentation of size progress, that Sir John Herschel estimated the actual bulk of this singular object to have increased forty-fold in the ensuing week. "I can hardly doubt," he remarks, "that the comet was fairly evaporated in perihelio by the heat, and

1 Astr. Nuch., No. 300. 2 It deserves to be recorded that Robert Hooke drew a very similar inference from his observations of the comets of 1680 and r682. Month. Not., vol. xiv., pr. 77-83. " 3 Briefuechsel zuischen Olbers und Bessel, Bd. ii., p. 390. $\quad$ *Herschel, Results, p. 405. 5 Mlem. R. A. S., vol. x., p. 92. 
resolved into transparent vapour, and is now in process of rapid condensation and re-precipitation on the nucleus." 1 A plausible, but no longer admissible, interpretation of a still unexplained phenomenon. The next return of this body, which will be considerably accelerated by Jupiter's influence, is expected to take place in 19 IO. $^{2}$

By means of an instrument devised by himself for testing the quality of light, Arago obtained decisive evidence that some at least of the radiance proceeding from Halley's comet was derived by reflection from the sun. ${ }^{3}$. Indications of the same kind had been afforded ${ }^{4}$ by the comet which suddenly appeared above the north-western horizon of Paris, July 3, I8I9, after having enveloped (as already stated) our terrestrial abode in its filmy appendages; but the "polariscope" had not then reached the perfection subsequently given to it, and its testimony was accordingly far less reliable than in 1835 . Such experiments, however, are in reality more beautiful and ingenious than instructive, since ignited as well as obscure bodies possess the power of throwing back light incident upon them, and must consequently transmit to us from the neighbourhood of the sun rays partly direct, partly reflected, of which a certain proportion will exhibit the peculiarity known as polarisation.

The most brilliant comets of the century were suddenly rivalled if not surpassed by the extraordinary object which blazed out beside the sun, February 28, I843. It was simultaneously perceived in Mexico and the United States, in Southern Europe, and at sea off the Cape of Good Hope, where the passengers on board the Owen Glendower were amazed by the sight of a "short, dagger-like object," closely following the sun towards the western horizon. ${ }^{5}$ At Florence, Amici found its distance from the sun's centre at noon to be only $\mathrm{I}^{\circ} 23^{\prime}$; and spectators at Parma were able, when sheltered from the direct glare of midday, to trace the tail to a length of four or five degrees. The full dimensions of this astonishing

1 Results, p. 401. 2 Pontécoulant, Comptes Rendus, t. lviii., p. 825. 3 Annuaire, 1836, p. 233. +Cosmos, vol. i., p. 90, note (Otté's trans.) 5 Herschel, Outlines, p. 399, 9th ed. 
appurtenance began to be disclosed a few days later. On the 3 rd of March it measured $25^{\circ}$, and on the IIth, at Calcutta, Mr. Clerihew observed a second streamer, nearly twice as long as the first, and making an angle with it of $18^{\circ}$, to have been emitted in a single day. This rapidity of projection, Sir John Herschel remarks, "conveys an astounding impression of the intensity of the forces at work." "It is clear," he continues, "that if we have to deal here with matter, such as we conceive itviz., possessing inertia - at all, it must be under the dominion of forces incomparably more energetic than gravitation, and quite of a different nature." 1

On the I 7 th of March a silvery ray, some $40^{\circ}$ degrees long and slightly curved at its extremity, shone out above the sunset clouds in this country. No previous intimation had been received of the possibility of such an apparition, and even astronomers-no lightning messages across the seas being as yet possible-were perplexed. The nature of the phenomenon, indeed, soon became evident, but the wonder of it did not diminish with the study of its attendant circumstances. Never before, within astronomical memory, had our system been traversed by a body pursuing such an adventurous career. The closest analogy was offered by the great comet of I680 (Newton's), which rushed past the sun at a distance of only 144,000 miles; but even this-on the cosmical scale-scarcely perceptible interval was reduced nearly one-half in the case we are now concerned with. The centre of the comet of I843 approached the formidable luminary within 78,000 miles, leaving, it is estimated, a clear space of not more than 32,000 between the surfaces of the bodies thus brought into such perilous proximity. The escape of the wanderer was, however, secured by the extraordinary rapidity of its flight. It swept past perihelion at a rate-366 miles a second-which, if continued, would have carried it right round the sun in two hours; and in only eleven minutes more than that short period it actually described half the curvature of its orbit-an arc of $180^{\circ}$-although

${ }^{1}$ Herschel, Outlines, p. 398 (9th ed.). 
in travelling over the remaining half many hundreds of sluggish years will doubtless be consumed.

The behaviour of this comet may be regarded as an experimentum crucis as to the nature of tails. For clearly no fixed appendage many millions of miles in length could be whirled like a brandished sabre from one side of the sun to the other in I 3 I minutes. Cometary trains are then, as Olbers rightly conceived them to be, emanations, not appendages-inconceivably rapid outflows of highly rarefied matter, the greater part, if not all, of which becomes permanently detached from the nucleus.

That of the comet of 1843 reached, about the time that it became visible in this country, the extravagant length of 200 millions of miles. ${ }^{1}$ It was narrow, and bounded by nearly parallel and nearly rectilinear lines, resembling-to borrow a comparison of Aristotle's-a " road" through the constellations ; and after the 3 rd of March showed no trace of hollowness, the axis being, in fact, rather brighter than the edges. Distinctly perceptible in it were those singular aurora-like coruscations which gave to the "tresses" of Charles V.'s comet the appearance-as Cardan described it-of "a torch agitated by the wind," and have not unfrequently been observed to characterise other similar objects. A consideration first adverted to by Olbers proves these to originate in our own atmosphere. For owing to the great difference in the distances from the earth of the origin and extremity of such vast effluxes, the light proceeding from their various parts is transmitted to our eyes in notably different intervals of time. Consequently a luminous undulation, even though propagated instantaneously from end to end of a comet's tail, would appear to us to occupy many minutes in its progress. But the coruscations in question pass as swiftly as a falling star. They are, then, of terrestrial production.

Periods of the utmost variety were by different computators assigned to the body, which arrived at perihelion, February 27, I 843, at 9.47 P.M. Professor Hubbard of Washington found

1 Boguslawski calculated that it extended on the 21 st of March to $58 \mathrm{r}$ million miles.-Report Brit. Ass., I845, p. 89. 
that it required 533 years to complete a revolution; MM. Laugier and Mauvais of Paris considered the true term to be $35 ;^{1}$ Clausen looked for its return at the end of between six and seven years. All these estimates were indeed admittedly uncertain, the available data affording no sure means of determining the value of this element; yet there seems no doubt that they fitted in more naturally with a period counted by centuries than with one reckoned by decades. Nor could any previous appearance be satisfactorily made out, although the similarity of the course pursued by a brilliant comet in 1668, known as the "Spina" of Cassini, made an identification not impossible. This would imply a period of 175 years, and it was somewhat hastily assumed that a number of earlier celestial visitants might thus be connected as returns of the same body.

It may now be asked what were the conclusions regarding the nature of comets drawn by astronomers from the considerable mass of novel experience accumulated during the first half of this century? The first and best assured was that the matter composing them is in a state of extreme tenuity. Numerous and trustworthy observations showed that the feeblest rays of light might traverse some hundreds of thousands of miles of their substance, even where it was apparently most condensed, without being perceptibly weakened. Nay, instances were recorded in which stars were said to have gained in brightness from the process $!^{2}$ On the 24 th of June 1825 , Olbers ${ }^{3}$ saw the comet then visible all but obliterated by the central passage of a star too small to be distinguished with the naked eye, its own light remaining wholly unchanged. A similar effect was noted December I, I8I I, when the great comet of that year approached so close to Altair, the lucida of the Eagle, that the star seemed to be transformed into the nucleus of the comet. ${ }^{4}$ Even the central blaze of Halley's comet in I835 was powerless to impede the passage of stellar rays. Struve ${ }^{5}$ observed at Dorpat, on

1 Comptes Rendus, t. xvi., p. 919. 2 Piazzi noticed a considerable increase of lustre in a very faint star of the twelfth magnitude viewed through a comet. Mädler, Reden, \&c., p. 248, note. ${ }^{3}$ Astr. Jahrbuch, I828, p. I5I. 4 Mädler, Gesch. d. Astr., Bd. ii., p. 412. ${ }^{5}$ Recueil de l'Ac. Imp. de St. Pétersbourg, 1835, p. 143 . 
September I7, an all but central occultation; Glaisher ${ }^{1}$ one (so far as he could ascertain) absolutely so eight days later at Cambridge. In neither case was there any appreciable diminution of the star's light. Again, on the I Ith of October I847, Mr. Dawes, ${ }^{2}$ an exceptionally keen observer, distinctly saw a star of the tenth magnitude through the exact centre of a comet discovered on the first of that month by Maria Mitchell of Nantucket.

Examples, on the other hand, are not wanting of the diminution of stellar light under similar circumstances; but probably in general not more than would be accounted for by the illumination of the background with diffused nebulous radiance. ${ }^{3}$ In one solitary instance, however, on the 28th of November I 828, a star was alleged to have actually vanished behind a comet. ${ }^{4}$ The observer of this unique phenomenon was Wartmann of Geneva; but his instrument was so defective as to leave its reality open to grave doubt, especially when it is considered that the eclipsing body was Encke's comet, which better equipped astronomers have, on various occasions, found to be perfectly translucent.

From the failure to detect any effects of refraction in the light of stars occulted by comets, it was inferred (though, as we know now, erroneously) that their composition is rather that of dust than that of vapour; that they consist not of any continuous substance, but of discrete solid particles, very finely divided and widely scattered. In conformity with this view was the known smallness of their masses. Laplace had shown that if the amount of matter forming Lexell's comet had been as much as $\frac{1}{500} \overline{0}$ of that contained in our globe, the effect of its attraction, on the occasion of its approach with I,438,000 miles of the earth, July I, I770, must have been apparent in the lengthening of the year. And that some comets, at any

1 Guillemin's World of Comets, trans. by J. Glaisher, p. 294, note. ${ }^{2}$ Month. Not., vol. viii., p. 9. $\quad{ }^{3}$ A real, though only partial, stoppage of light seems indicated by Herschel's observations on the comet of 1807. Stars seen through the tail, October .I8, lost much of their lustre. One near the head was only faintly visible by glimpses. Phil. Trans., vol. xcvii., p. 153. ${ }^{4}$ Arago, Annuaire, J832, p. 205. 
rate, possess masses immeasurably below this maximum value, was clearly proved by the undisturbed parallel march of the two fragments of Biela in 1846.

But the discovery in this branch most distinctive of the period under review is that of "short period" comets, of which four" were known in I850. These, by the character of their movements, serve as a link between the planetary and cometary worlds, and by the nature of their construction, seem to mark a stage in cometary decay. For that comets are rather transitory agglomerations, than permanent products of cosmical manufacture, appeared to be demonstrated by the division and disappearance of one amongst their number, as well as by the singular and rapid changes in appearance undergone by many, and the seemingly irrevocable diffusion of their substance visible in nearly all. They might then be defined, according to the ideas respecting them prevalent forty-five years ago, as bodies unconnected by origin with the solar system, but encountered, and to some extent appropriated by it in its progress through space, owing their visibility in great part, if not altogether, to light reflected from the sun, and their singular and striking forms to the action of repulsive forces emanating from him, the penalty of their evanescent splendour being paid in gradual waste and final dissipation and extinction.

1 Viz., Encke's, Biela's, Faye's, and Brorsen's. 


\section{CHAPTER VI. A.}

\section{INSTRUMENTAL ADVANCES.}

Ir is impossible to follow with intelligent interest the course of astronomical discovery without feeling some curiosity as to the means by which such surpassing results have been secured. Indeed, the bare acquaintance with what has been achieved, without any corresponding knowledge of how it has been achieved, supplies food for barren wonder rather than for fruitful and profitable thought. Ideas advance most readily along the solid ground of practical reality, and often find true sublimity while laying aside empty marvels. Progress is the result, not so much of sudden flights of genius, as of sustained, patient, often commonplace endeavour; and the true lesson of scientific history lies in the close connection which it discloses between the most brilliant developments of knowledge and the faithful accomplishment of his daily task by each individual thinker and worker.

It would be easy to fill a volume with the detailed account of the long succession of optical and mechanical improvements by means of which the observation of the heavens has been brought to its present degree of perfection; but we must here content ourselves with a summary sketch of the chief amongst them. The first place in our consideration is naturally claimed by the telescope.

This potent instrument, we need hardly remind our readers, is of two distinct kinds-that in which light is gathered together into a focus by refraction, and that in which the same end is attained by reflection. The image formed is in each case viewed through a magnifying lens, or combination of lenses, 
called the eye-piece. Not for above a century after the "optic glasses" invented or stumbled upon by the spectacle-maker of Middleburg ( 1608 ) had become diffused over Europe, did the reflecting telescope come, even in England, the place of its birth, into general use. Its principle (a sufficiently obvious one) had indeed been suggested by Mersenné as early as $1639 ;^{1}$ James Gregory in $1663^{2}$ described in detail a mode of embodying that principle in a practical shape; and Newton, adopting an original system of construction, actually produced in I668 a tiny speculum, one inch across, by means of which the effective distance of objects was reduced thirty-nine times. Nevertheless, the exorbitantly long tubeless refractors, introduced by Huygens, maintained their reputation until Hadley exhibited to the Royal Society in $1723^{3}$ a reflector sixty-two inches in focal length, which rivalled in performance, and of course indefinitely surpassed in manageability, one of the "aerial" kind of I 23 feet.

The concave-mirror system now gained a decided ascendant, and was brought to unexampled perfection by James Short of Edinburgh during the years I732-68. Its capabilities were, however, first fully developed by William Herschel. The energy and inventiveness of this extraordinary man marked an epoch wherever they were applied. His ardent desire to measure and gauge the stupendous array of worlds which his specula revealed to him, made him continually intent upon adding to their "space-penetrating power" by increasing their light-gathering surface. These, as he was the first to explain, ${ }^{4}$ are in a constant proportion one to the other. For a telescope with twice the linear aperture of another will collect four times as much light, and will consequently disclose an object four times as faint as could be seen with the first, or, what comes to the same, an object equally bright at twice the distance. In other words, it will possess double the space-penetrating power of the smaller instrument. Herschel's great mirrors-the first examples of the giant telescopes of modern times-were then primarily engines

1 Grant, Hist. Astr., p. 527. 2 Optica Promota, p. 93. $\quad 3$ Phil. Trans., vol. xxxii., p. 383 . \&lbid., vol. xc., p. 65. 
for extending the bounds of the visible universe; and from the sublimity of this final cause was derived the vivid enthusiasm which animated his efforts towards success.

It seems probable that the seyen-foot telescope constructed by him in 1775-that is, within little more than a year after his experiments in shaping and polishing metal had begun-already exceeded in genuine power all the productions of earlier opticians ; and both his skill and his ambition rapidly developed. His endeavours culminated, after mirrors of ten, twenty, and thirty feet focal length had successively left his hands, in the gigantic forty-foot, completed August 28, I789. It was the first reflector in which only a single mirror was employed. In the "Gregorian" form, the focussed rays are, by a second reflection from a small concave ${ }^{1}$ mirror, thrown straight back through a. central aperture in the larger one, behind which the eye-piece is fixed. The object under examination is thus seen in the natural direction. The "Newtonian," on the other hand, shows the object in a line of sight at right angles to the true one, the light collected by the speculum being diverted to one side of the tube by the interposition of a small plane mirror, situated at an angle of $45^{\circ}$ to the axis of the instrument. Upon these two systems Herschel worked until I 787, when, becoming convinced of the supreme importance of economising light (necessarily wasted by the second reflection), he laid aside the small mirror of his forty-foot then in course of construction, and turned it into a "front-view" reflector. This was done-according to a plan proposed by Lemaire in 1732 -by slightly inclining the speculum so as to enable the image formed by it to be viewed with an eye-glass fixed at the upper margin of the tube. The observer thus stood with his back turned to the object he was engaged in scrutinising.

The advantages of the increased brilliancy afforded by this modification were strikingly illustrated by the discovery, August 28

1 Cassegrain, a Frenchman, substituted in 1672 a convex for a concave secondary speculum. The tube was thereby enabled to be shortened by twice the focal length of the mirror in question. The great Melbourne reflector (four feet aperture, by Grubb) is constructed upon this plan. 
and September I7, I789, of the two Saturnian satellites nearest the ring. Nevertheless, the monster telescope of Slough cannot be said to have realised the sanguine expectations of its constructor. The occasions on which it could be usefully employed were found to be extremely rare. It was injuriously affected by every change of temperature. The great weight (25 cwt.) of a speculum four feet in diameter rendered it peculiarly liable to distortion. With all imaginable care, the delicate lustre of its surface could not be preserved longer than two years, ${ }^{1}$ when the difficult process of repolishing had to be undertaken. It was accordingly never used after I8II, when having gone blind from damp, it lapsed by degrees into the condition of a museum inmate.

The exceedingly high magnifying power s employed by Herschel constituted a novelty in optical astronomy, to which he attached great importance. Yet the work of ordinary observation would be hindered rather than helped by them. The attempt to increase in this manner the efficacy of the telescope is speedily checked by atmospheric, to say nothing of other difficulties. Precisely in the same proportion as an object is magnified, the disturbances of the medium through which it is seen are magnified also. Even on the clearest and most tranquil nights, the air is never for a moment really still. The rays of light traversing it are continually broken by minute fluctuations of refractive power caused by changes of temperature and pressure, and the currents which these engender. With such luminous quiverings and waverings the astronomer has always more or less to reckon; their absence is simply a question of degree ; if sufficiently magnified, they are at all times capable of rendering observation impossible.

Thus, such vast powers as 3000, 4000, 5000, even 6652, ${ }^{2}$ which Herschel now and again applied to his great telescopes, would, save on the rarest occasions, prove an impediment rather

1 Phil. Trans., vol. civ., p. 275, note. 2 Plil. Trans., vol. xc., p. 7o. With the forty-foot, however, only very moderate powers seemed to have been employed, whence Dr. Robinson argued a deficiency of defining power. Proc. Roy. Irish Ac., vol. ii., p. II. 
than an aid to vision. They were, however, used by him only for special purposes-experimentally, not systematically, and with the clearest discrimination of their advantages and drawbacks. It is obvious that perfectly different ends are subserved by increasing the aperture and by increasing the power of a telescope. In the one case, a larger quantity of light is captured and concentrated; in the other, the same amount is distributed over a wider area. A diminution of brilliancy accordingly attends, cateris paribus, upon each augmentation of apparent size. For this reason, such faint objects as nebulæe are most successfully observed with moderate powers applied to instruments of a great capacity for light, the details of their structure actually disappearing when highly magnified. With stellar groups the reverse is the case. Stars cannot be magnified, simply because they are too remote to have any sensible dimensions; but the space between them can. It was thus for the purpose of dividing very close double stars that Herschel increased to such an unprecedented extent the magnifying capabilities of his instruments ; and to this improvement incidentally the discovery of Uranus, March I3, I78 I, ${ }^{1}$ was due. For by the examination with strong lenses of an object which, even with a power of 227 , presented a suspicious appearance, he was able at once to pronounce its disc to be real, and not merely "spurious," and so to distinguish it unerringly from the crowd of stars amidst which it was moving.

While the reflecting telescope was astonishing the world by its rapid development in the hands of Herschel, its unpretending rival was slowly making its way towards the position which the future had in store for it. The great obstacle which long stood in the way of the improvement of refractors was the defect known as "chromatic aberration." This is due to no other cause than that which produces the rainbow and the spectrumthe separation, or "dispersion" in their passage through a refracting medium, of the variously coloured rays composing a beam of white light. In an ordinary lens there is no common

1 Phil. Trans., vol. Ixxi., p. 492. 
point of concentration; each colour has its own separate focus ; and the resulting image, formed by the super-position of as many images as there are hues in the spectrum, is indistinctly terminated with a tinted border, eminently baffling to exactness of observation.

The extravagantly long telescopes of the seventeenth century were designed to avoid this evil (as well as another source of indistinct vision in the spherical shape of lenses); but no attempt to remedy it was made until an Essex gentleman succeeded, in 1733 , in so combining lenses of flint and crown glass as to produce refraction without colour. ${ }^{1}$ Mr. Chester More Hall was, however, equally indifferent to fame and profit, and took no pains to make his invention public. The effective discovery of the achromatic telescope was, accordingly, reserved for John Dollond, whose method of correcting at the same time chromatic and spherical aberration was laid before the Royal Society in I758. Modern astronomy may be said to have been thereby rendered possible. Refractors have always been found better suited than reflectors to the ordinary work of observatories. They are, so to speak, of a more robust, as well as of a more plastic nature. They suffer less from vicissitudes of temperature and climate. They retain their efficiency with fewer precautions and under more trying circumstances. Above all, they co-operate more readily with mechanical appliances, and lend themselves with far greater facility to purposes of exact measurement.

A practical difficulty, however, impeded the realisation of the brilliant prospects held out by Dollond's invention. It was found impossible to procure flint-glass, such as was needed for optical use-that is, of perfectly homogeneous quality-except in fragments of insignificant size. Discs of more than two or three inches in diameter were of extreme rarity; and the crushing excise duty imposed upon the article by the financial

${ }^{1}$ It is remarkable that, as early as 1695 , the possibility of an achromatic combination was inferred by David Gregory from the structure of the human eye. See his Catoptrica et Dioptricke Spherica Elementa, p. 98. 
unwisdom of the Government, both limited its production, and, by rendering experiments too costly for repetition, barred its improvement.

Up to this time, Great Britain had left foreign competitors far behind in the instrumental department of astronomy. The quadrants and circles of Bird, Cary and Ramsden were unapproached abroad. The reflecting telescope came into existence and reached maturity on British soil. The refracting telescope was cured of its inherent vices by British ingenuity. But with the opening of the nineteenth century, the almost unbroken monopoly of skill and contrivance which our countrymen had succeeded in establishing was invaded, and British workmen had to be content to exchange a position of supremacy for one of at least partial and temporary inferiority.

Somewhere about the time that Herschel set about polishing his first speculum, Pierre Louis Guinand, a Swiss artisan, living near Chaux-de-Fonds, in the canton of Neuchâtel, began to grind spectacles for his own use, and was thence led on to the rude construction of telescopes by fixing lenses in pasteboard tubes. The sight of an English achromatic, however, stirred a higher ambition, and he took the first opportunity of procuring some flint-glass from England (then the only source of supply), with the design of imitating an instrument the full capabilities of which he was destined to be the humble means of developing. The English glass proving of inferior quality, he conceived the possibility, unaided and ignorant of the art as he was, of himself making better, and spent seven years (1784-90) in fruitless experiments directed to that end. Failure only stimulated him to enlarge their scale. He bought some land near Les Brenets, constructed upon it a furnace capable of melting two quintals of glass, and reducing himself and his family to the barest necessaries of life, he poured his earnings (he at this time made bells for repeaters) unstintingly into his crucibles. $^{1}$ His undaunted resolution triumphed. In 1799 he carried to Paris and there showed to Lalande several discs of flawless crystal four to six inches in diameter. Lalande advised him to keep his secret,

1 Wolf, Biographien, Bd. ii., p. 301. 
but in 1805 he was induced to remove to Munich, where he became the instructor of the immortal Fraunhofer. His return to Les Brenets in 1814 was signalised by the discovery of an ingenious mode of removing striated portions of glass by breaking and re-soldering the product of each melting, and he eventually attained to the manufacture of perfect discs up to I8 inches in diameter. An object-glass for which he had furnished the material to Cauchoix, procured him, in I823, a royal invitation to settle in Paris; but he was no longer equal to the change, and died at the scene of his labours, February 13 following.

This same lens (12 inches across) was afterwards purchased by Sir James South, and the first observation made with it, February I3, I830, disclosed to Sir John Herschel the sixth minute star in the central group of the Orion nebula, known as the "trapezium."1 Bequeathed by South to Trinity College, Dublin, it has been employed at the Dunsink Observatory by Brünnow and Ball in their investigations of stellar parallax. A still larger objective (of I 3.2 inches) made of Guinand's glass was secured about the same time in Paris, by Mr. Edward Cooper of Markree Castle, Ireland. The peculiarity of the method discovered at Les Brenets resided in the manipulation, not in the quality of the ingredients; the secret, that is to say, was not chemical, but mechanical. ${ }^{2}$ It was communicated by Henry Guinand (a son of the inventor) to Bontemps, one of the directors of the glassworks at Choisy-le-Roi, and by him transmitted to Messrs. Chance of Birmingham, with whom he entered into partnership when the revolutionary troubles of I 848 obliged him to quit his native country. 'The celebrated American opticians, Alvan Clark \& Sons, derived from the Birmingham firm the materials for some of their earlier telescopes, notably the 19-inch Chicago and 26-inch Washington equatoreals; but the discs for the great Lick refractor, and others shaped by them in recent years, have been supplied by Feil of Paris.

Two distinguished amateurs, meanwhile, were preparing to

1 Month. Not., vol. i., p. I53, note. ${ }^{2}$ Henrivaux, Encyclopédie Chimique, t. v., fasc. 5 , p. 363 . 
reassert on behalf of reflecting instruments their claim to the place of honour in the van of astronomical discovery. Of Mr. Lassell's specula something has already been said. ${ }^{1}$ They were composed of an alloy of copper and tin, with a minute proportion of arsenic (after the example of Newton ${ }^{2}$ ), and were remarkable for perfection of figure and brilliancy of surface.

The resources of the Newtonian system were developed still more fully - it might almost be said to the uttermost-by the enterprise of an Irish nobleman. William Parsons, known as Lord Oxmantown until I84I, when, on his father's death, he succeeded to the title of Earl of Rosse, was born at York, June 17, I800. His public duties began before his education was completed. He was returned to Parliament as member for King's County while still an undergraduate at Oxford, and continued to represent the same constituency for thirteen years (I82I-34). From I845 until his death, which took place at Birr Castle, Parsonstown, October 31, I867, he sat, silent but assiduous, in the House of Lords as an Irish representative peer; he held the not unlaborious post of President of the Royal Society from I849 to I854; presided over the meeting of the British Association at Cork in 1843, and was elected ViceChancellor of Dublin University in I862. In addition to these extensive demands upon his time and thoughts, were those derived from his position as (practically) the feudal chief of a large body of tenantry in times of great and anxious responsibility, to say nothing of the more genial claims of an unstinted hospitality. Yet, while neglecting no public or private duty, this model nobleman found leisure to render to science services. so conspicuous as to entitle his name to a lasting place in its annals.

$\mathrm{He}$ early formed the design of reaching the limits of the attainable in enlarging the powers of the telescope, and the qualities of his mind conspired with the circumstances of his fortune to render the design a feasible one. From refractors it was obvious that no such vast and rapid advance could be 
expected.' English glass-manufacture was still in a backward state. So late as 1839, Simms (successor to the distinguished instrumentalist Edward Troughton) reported a specimen of crystal scarcely $7 \frac{1}{2}$ inches in diameter, and perfect only over six, to be unique in the history of English glass-making. ${ }^{1}$ Yet at that time the fifteen-inch achromatic of Pulkowa had already left the workshop of Fraunhofer's successors at Munich. It was not indeed until I845, when the impost which had so long hampered their efforts was removed, that the optical artists of these islands were able to compete on equal terms with their rivals on the Continent. In the case of reflectors, however, there seemed no insurmountable obstacle to an almost unlimited increase of lightgathering capacity; and it was here, after some unproductive experiments with fluid lenses, that Lord Oxmantown concentrated his energies.

He had to rely entirely on his own invention, and to earn his own experience. James Short had solved the problem of giving to metallic surfaces a perfect parabolic figure (the only one by which parallel incident rays can be brought to an exact focus ); but so jealous was he of his secret, that he caused all his tools to be burnt before his death ${ }^{2}$ nor was anything known of the processes by which Herschel had achieved his astonishing results. Moreover, Lord Oxmantown had no skilled workmen to assist him. His implements, both animate and inanimate, had to be formed by himself. Peasants taken from the plough were educated by him into efficient mechanics and engineers. The delicate and complex machinery needed in operations of such hairbreadth nicety as his enterprise involved, the steam-engine which was to set it in motion, at times the very crucibles in which his specula were cast, issued from his own workshops.

In I827 experiments on the composition of speculum-metal were set on foot, and the first polishing-machine ever driven by steam-power was contrived. But twelve arduous years of struggle with recurring difficulties passed before success began to dawn. A material less tractable than the alloy selected of
1 J. Herschel, The Telescope, p. 39.
2 Month. Not., vol. xxix., p. 125. 
four chemical equivalents of copper to one of $\operatorname{tin}^{1}$ can scarcely be conceived. It is harder than steel, yet brittle as glass, crumbling into fragments with the slightest inadvertence of handling or treatment ${ }^{2}$ and the precision of figure requisite to secure good definition is almost beyond the power of language to convey. The quantities involved are so small as not alone to elude sight, but to confound imagination. Sir John Herschel tells us that "the total thickness to be abraded from the edge of a spherical speculum 48 inches in diameter and 40 feet focus, to convert it into a paraboloid, is only $\frac{1}{21333}$ of an inch ;" 3 yet upon this minute difference of form depends the clearness of the image, and, as a consequence, the entire efficiency of the instrument. "Almost infinite," indeed (in the phrase of the late Dr. Robinson), must be the exactitude of the operation adapted to bring about so delicate a result.

At length, in I840, two specula, each three feet in diameter, were turned out in such perfection as to prompt a still bolder experiment. The various processes needed to ensure success were now ascertained and under control; all that was necessary was to repeat them on a larger scale. A gigantic mirror, six feet across and fifty-four in focal length, was accordingly cast on the 13th of April 1842; in two months it was ground down to figure by abrasion with emery and water, and daintily polished with rouge; and by the month of February 1845 the "leviathan of Parsonstown" was available for the examination of the heavens.

The suitable mounting of this vast machine was a problem scarcely less difficult than its construction. The shape of a speculum needs to be maintained with an elaborate care equal to that used in imparting it. In fact, one of the most formidable obstacles to increasing the size of such reflecting surfaces consists in their liability to bend under their own

1 A slight excess of copper renders the metal easier to work, but liable to tarnish. Robinson, Proc. Roy. Irish. Ac., vol. ii., p. 4. ${ }^{2}$ Brit. Ass., 1843, Dr. Robinson's closing Address. dthenceum, Sept. 23, p. $866 .{ }^{3}$ The Telescope, p. 82. 
weight. That of the great Rosse speculum was no less than four tons. Yet, although six inches in thickness, and composed of a material only a degree inferior in rigidity to wrought iron, the strong pressure of a man's hand at its back produced sufficient flexure to distort perceptibly the image of a star reflected in it. ${ }^{1}$ Thus the delicacy of its form was perishable equally by the stress of its own gravity, and by the slightest irregularity in the means taken to counteract that stress. The problem of affording a perfectly equable support in all possible positions was solved by resting the speculum upon twenty-seven platforms of cast iron, felt-covered, and carefully fitted to the shape of the areas they were to carry, which platforms were themselves borne by a complex system of triangles and levers, ingeniously adapted to distribute the weight with complete uniformity. ${ }^{2}$

A tube which resembled, when erect, one of the ancient round towers of Ireland, ${ }^{3}$ served as the habitation of the great mirror. It was constructed of deal staves bound together with iron hoops, was fifty-eight feet long (including the speculum-box), and seven in diameter. A reasonably tall man could walk through it (as Dean Peacock once did) with umbrella uplifted. Two piers of solid masonry, about fifty feet high, seventy long, and twentythree apart, flanked the huge engine on either side. Its lower extremity rested on an universal joint of cast iron ; above, it was slung in chains, and even in a gale of wind remained perfectly steady. The weight of the entire, although amounting to fifteen tons, was so skilfully counterpoised, that the tube could with ease be raised or depressed by two men working a windlass. Its horizontal range was limited by the lofty walls erected for its support to about ten degrees on each side of the meridian; but it moved vertically from near the horizon through the zenith as far as the pole. Its construction was of the Newtonian kind, the observer looking into the side of the tube near its upper end, which a series of galleries and sliding stages enabled him to reach

1 Lord Rosse in Phil Trans., vol. cxl., p. 302. " This method is the same in principle with that applied by Grubb in 1834 to a 15 -inch speculum for the observatory of Armagh. Phil. Trans., vol. clix., p. 145. ${ }^{3}$ Robinson, Proc. Roy. Ir. Ac., vol. iii., p. I 20. 
in any position. It has also, though rarely, been used without a second mirror, as a "Herschelian" reflector.

The splendour of the celestial objects as viewed with this vast "light-grasper" surpassed all expectation. "Never in my life," exclaimed Sir James Sonth, "did I see such glorious sidereal pictures!" 1 The orb of Jupiter produced an effect compared to that of the introduction of a coach-lamp into the telescope $;^{2}$ and certain star-clusters exhibited an appearance (we again quote Sir James South) "such as man before had never seen, and which for its magnificence baffles all description." But it was in the examination of the nebulæ that the superiority of the new instrument was most strikingly displayed. A large number of these misty objects, which the utmost powers of Herschel's specula had failed to resolve into stars, yielded at once to the Parsonstown reflector; while many others were, so to speak, metamorphosed through the disclosure of previonsly unseen details of structure.

One extremely curious result of the increase of light was the abolition of the distinction between the two classes of "annular" and "planetary" nebulæ. Up to that time, only four ringshaped systems-two in the northern and two in the southern hemisphere-were known to astronomers; they were now reinforced by five of the planetary kind, the discs of which were observed to be centrally perforated; while the sharp marginal definition visible in weaker instruments was replaced by ragged edges or filamentous fringes.

Still more striking was the discovery of an entirely new and highly remarkable species of nebulæ. These were termed "spiral," from the more or less regular convolutions, resembling the whorls of a shell, in which the matter composing them appeared to be distributed. The first and most conspicuous specimen of this class was met with in April I 845 ; it is situated in Canes Venatici, close to the tail of the Great Bear, and wore, in Sir J. Herschel's instruments, the aspect of a split ring encompassing a bright nucleus, thus presenting, as he supposed, a complete analogue to the system of the Milky Way. In the

$$
1 \text { Astr. Nach., No. 536. }{ }^{2} \text { Airy, Month. Not, vol. ix., p. I20. }
$$


Rosse mirror it shone out as a vast whirlpool of light-a stupendous witness to the presence of cosmical activities on the grandest scale, $\cdot$ yet regulated by laws as to the nature of which we are profoundly ignorant. Professor Stephen Alexander of New Jersey, however, concluded, from an investigation (necessarily founded on highly precarious data) of the mechanical condition of these extraordinary agglomerations, that we see in them "the partially scattered fragments of enormous masses once rotating in a state of dynamical equilibrium." He further suggested "that the separation of these fragments may still be in progress," 1 and traced back their origin to the disruption, through its own continually accelerated rotation, of a "primitive spheroid" of inconceivably vast dimensions. Such also, it was added (the curvilinear form of certain outliers of the Milky Way, giving evidence of a spiral structure), is probably the history of our own cluster; the stars composing which, no longer held together in a delicately adjusted system like that of the sun and planets, are advancing through a period of seeming confusion towards an appointed goal of higher order and more perfect and harmonious adaptation. ${ }^{2}$

The class of spiral nebulæ included, in I850, fourteen members, besides several in which the characteristic arrangement seemed partial or dubious. ${ }^{3}$ A tendency in the exterior stars of many clusters to gather (as in our Galaxy) into curved branches was likewise noted; and the existence of unsuspected analogies was proclaimed by the significant combination in the "Owl" nebulæ (a large planetary in Ursa Major) 4 of the twisted forms of a spiral with the perforation distinctive of an annular nebula.

Once more, by the achievements of the Parsonstown reflector, the supposition of a "shining fluid" filling vast regions of space was brought into (as it has since proved) undeserved discredit. Although Lord Rosse himself rejected the inference, that because many nebulæ had been resolved, all were resolvable, very few

1 Astronomical Journal (Gould's', vol. ii., p. 97. 2 2 Ibid., vol. ii., p. 160. 3 Lord Rosse in Phil. Trans., vol. cxl., p. 505. ${ }^{4}$ No. 2343 of Herschel's (1864) Catalogue. Before I850 a star marked each of the two larger openings by which it is pierced; since then one only has been seen. Webb, Celestial Objects (4th ed.), p. 409 . 
imitated his truly scientific caution; and the results of Bond's investigations ${ }^{1}$ with the Harvard College refractor quickened and strengthened the current of prevalent opinion. It is now certain that the evidence furnished on both sides of the Atlantic as to the stellar composition of some conspicuous objects of this class, notably the Orion and "Dumb-bell" nebulæ, was delusive ; but the spectroscope alone was capable of meeting it with a categorical denial. Meanwhile there seemed good ground for the persuasion, which now, for the last time, gained the upper hand, that nebulæ are, without exception, true "island-universes," or assemblages of distant suns.

Lord Rosse's telescope possesses a nominal power of $6000-$ that is, it shows the moon as if viewed with the naked eye at a distance of forty miles. But this seeming advantage is neutralised by the weakening of the available light through excessive diffusion, as well as by the troubles of the surging sea of air through which the observation must necessarily be made. Professor Newcomb, in fact, doubts whether with any telescope our satellite has ever been seen to such advantage as it would be if brought within 500 miles of the unarmed eye. ${ }^{2}$

The French opticians' rule of doubling the number of millimetres contained in the aperture of an instrument to find the highest magnifying power usefully applicable to it, would give 3600 as the maximum for the leviathan of Birr Castle; but in a climate like that of Ireland the occasions must be rare when even that limit can be reached. Indeed, the experience acquired by its use plainly shows that atmospheric rather than mechanical difficulties impede a still further increase of telescopic power. Its construction may accordingly be said to mark the ne plus ultra of effort in one direction, and the beginning of its conversion towards another. It became thenceforward more and more obvious that the conditions of observation must be ameliorated before any added efficacy could be given to it. The full effect of an uncertain climate in nullifying optical improvements was recognised, and the attention of astronomers began to be turned

1 Mem. Am. Ac., vol, iii., p. 87 ; and Astr. Nacl., No.611. 2 Pop. Astr., p. 145. 
towards' the advantages offered by more tranquil and more translucent skies.

Scarcely less important for the practical uses of astronomy than the optical qualities of the telescope is the manner of its mounting. The most admirable performance of the optician can render but unsatisfactory service if its mechanical accessories are ill-arranged or inconvenient. Thus the astronomer is ultimately dependent upon the mechanician; and so excellently have his needs been served, that the history of the ingenious contrivances by which discoveries have been prepared would supply a subject (here barely glanced at) not far inferior in extent and instruction to the history of those discoveries themselves.

There are two chief modes of using the telescope, to which all others may be considered subordinate. ${ }^{1}$ Either it may be invariably directed towards the south, with no motion save in the plane of the meridian, so as to intercept the heavenly bodies at the moment of transit across that plane; or it may be arranged so as to follow the daily revolution of the sky, thus keeping the object viewed permanently in sight, instead of simply noting the instant of its flitting across the telescopic field. The first plan is that of the "transit instrument," the second that of the "equatoreal." Both were, by a remarkable coincidence, introduced about $1690^{2}$ by Olaus Römer, the brilliant Danish astronomer who first measured the velocity of light.

The uses of each are entirely different. With the transit, the really fundamental task of astronomy-the determination of the movements of the heavenly bodies-is mainly accomplished; while the investigation of their nature and peculiarities is best conducted with the equatoreal. One is the

1 This statement must be taken in the most general sense. Supplementary observations of great value are now made at Greenwich with the altitude and azimuth instrument, which likewise served Piazzi to determine the places of his stars; while a "prime vertical instrument" is prominent at Pulkowa. 2 As early as 1620 , according to R. Wolf (Gesch. der Astr., p. 587), Father Scheiner made the experiment of connecting a telescope with an axis directed to the pole, while chinese "equatoreal armillæ," dating from the thirteenth century, still exist at Pekin. J. L. E. Dreyer, Copernicus, vol. i., p. I34. 
instrument of mathematical, the other of descriptive astronomy. One furnishes the materials with which theories are constructed, and the tests by which they are corrected; the other registers new facts, takes note of new appearances, sounds the depths and pries into every nook of the hervens.

The great improvement of giving to a telescope equatoreally mounted an automatic movement by connecting it with clockwork, was proposed in 1674 by Robert Hooke!- Bradley in I72 I actually observed Mars with a telescope "moved by a machine that made it keep pace with the stars ;"1 and Von Zach relates ${ }^{2}$ that he had once followed Sirius for twelve hours with a "heliostat" of Ramsden's construction. But these eighteenthcentury attempts were of no practical effect. Movement by clockwork was virtually a complete novelty when it was adapted by Fraunhofer in $\mathrm{I} 824$ to the Dorpat refractor. By simply giving to an axis unvaryingly directed towards the celestial pole an equable rctation with a period of twenty-four hours, a telescope attached to it, and pointed in any direction, will trace out on the sky a parallel of declination, thus necessarily accompanying the movement of any star upon which it may be fixed. It thus forms part of the large sum of Fraunhofer's merits to have secured this inestimable advantage to observers.

It was considered by Sir John Herschel that Lassell's application of equatoreal mounting to a nine-inch Newtonian in I840 made an epoch in the history of "that eminently British instrument, the reflecting telescope." ${ }^{3}$. Nearly a century earlier, ${ }^{4}$ it is true, Short had fitted one of his Gregorians to a complicated system of circles in such a manner that, by moving a handle, it could be made to follow the revolution of the sky; but the arrangement did not obtain, nor did it deserve, general adoption. Lassell's plan was a totally different one; he employed the crossed axes of the true equatoreal, and his success removed, to a great extent, the fatal objection of inconvenience in use, until then unanswerably urged against reflectors. The very largest of these can now be mounted equatoreally; even the Rosse

1 Miscellaneous Worlis, p. 350. 2 Astr. Jahrluch, 1799 (published 1796), p. I I5. 3 Month. Not., vol. xli., p. I89. ${ }^{4}$ Thit. Trans., vol. xlvi., p. 242. 
was eventually provided with a movement by clockwork within its limited range along declination-parallels.

The art of accurately dividing circular arcs into the minute equal parts which serve as the units of astronomical measurement, remained, during the whole of the eighteenth century, almost exclusively in English hands. It was brought to a high degree of perfection by Graham, Bird and Ramsden, all of whom, however, gave the preference to the old-fashioned mural quadrant and zenith sector over the entire circle, which Römer had already found the advantage of employing. The five-foot vertical circle, which Piazzi with some difficulty induced Ramsden to complete for him in I789, was the first divided instrument constructed in what may be called the modern style. It was provided with magnifiers for reading off the divisions (one of the neglected improvements of Römer), and was set up above a smaller horizontal circle, forming an "altitude and azimuth" combination (again Römer's invention), by which both the elevation of a celestial object above the horizon, and its position as referred to the horizon could be measured. In the same year Borda invented the " repeating circle" (the principle of which had been suggested by Tobias Mayer in $1756^{1}$ ), a device for exterminating, so far as possible, errors of graduation by repeating an observation with different parts of the limb. This was perhaps the earliest systematic effort to correct the imperfections of instruments by the manner of their use.

The manufacture of astronomical circles was brought to a very refined state of excellence early in the present century by Reichenbach at Munich, and after 1818 by Repsold at Hamburg. Bessel states ${ }^{2}$ that the "reading-off" on an instrument of the kind by the latter artist was accurate to about $\frac{1}{80}$ th of a human hair. Meanwhile the traditional reputation of the English school was fully sustained; and Sir George Airy did not hesitate to express his opinion that the new method of graduating circles, published by Troughton in $1809,{ }^{3}$ was the "greatest improvement ever made in the art of instrument-making." 4

1 Grant, Hist. of Astr., p. 487. $\quad 2$ Pop. Vorl., p. 546. 3 Phil. Trans., vol. xcix., p. 105. 4 Report Brit. Ass., 1832, p. 132. 
But a more secure road to improvement than that of mere mechanical exactness was pointed out by Bessel. His introduction of a regular theory of instrumental errors might almost be said to have created a new art of observation. Every instrument, he declared in memorable words, ${ }^{1}$ must be twice madeonce by the artist, and again by the observer. Knowledge is power. Defects that are ascertained and can be allowed for are as good as non-existent. Thus the truism that the best instrument is worthless in the hands of a careless or clumsy observer, became supplemented by the converse maxim, that defective appliances may, by skilful use, be made to yield valuable results. The Königsberg observations-of which the first instalment was published in 1815-set the example of regular "reduction" for instrumental errors. Since then, it has become an elementary part of an astronomer's duty to study the idiosyncrasy of each one of the mechanical contrivances at his disposal, in order that its inevitable, but now certified deviations from ideal accuracy may be included amongst the numerous corrections by which the pure essence of even approximate truth is distilled from the rude impressions of sense.

Nor is this enough; for the casual circumstances attending each observation have to be taken into account with no less care than the inherent or constitutional peculiarities of the instrument with which it is made. There is no "once for all" in astronomy. Vigilance can never sleep; patience can never tire. Variable as well as constant sources of error must be anxiously heeded; one infinitesimal inaccuracy must be weighed against another; all the forces and vicissitudes of nature-frosts, dews, winds, the interchanges of heat, the disturbing effects of gravity, the shiverings of the air, the tremors of the earth, the weight and vital warmth of the observer's own body, nay, the rate at which his brain receives and transmits its impressions, must all enter into his calculations, and be sifted out from his results.

It was in 1823 that Bessel drew attention to discrepancies 1 Pop. Vorl., p. 432. 
in the times of transits given by different astronomers. ${ }^{1}$ The quantities involved were far from insignificant. He was himself nearly a second in advance of all his contemporaries, Argelander lagging behind him as much as a second and a quarter. Each individual, in fact, was found to have a certain definite rate of perception, which, under the name of "personal equation," now forms so important an element in the correction of observations that a special instrument for accurately determining its amount in each case is in actual use at Greenwich.

Such are the refinements upon which modern astronomy depends for its progress. It. is a science of hairbreadths and fractions of a second. It exists only by the rigid enforcement of arduous accuracy and unwearying diligence. Whatever secrets the universe still has in store for man will only be communicated on these terms. They are, it must be acknowledged, difficult to comply with. They involve an unceasing struggle against the infirmities of his nature and the instabilities of his position. But the end is not unworthy the sacrifices demanded. One additional ray of light thrown on the marvels of creation-a single, minutest encroachment upon the strongholds of ignorance-is recompense enough for a lifetime of toil. Or rather, the toil is its own reward, if pursued in the lofty spirit which alone becomes it. For it leads through the abysses of space and the unending vistas of time to the very threshold of that infinity and eternity of which the disclosure is reserved for a life to come.

${ }^{1}$ C. T. Anger, Grundzüge der neueren astronomischen Beobachtungs-Kunst, p. 3 . 



\section{PART II.}

RECENT PROGRESS OF ASTRONOMY.

\section{CHAPTER I.}

FOUNDATION OF ASTRONOMICAL PHYSICS.

In the year 1826, Heinrich Schwabe of Dessan, elated with the hope of speedily delivering himself from the hereditary incubus of an apothecary's shop, ${ }^{1}$ obtained from Munich a small telescope and began to observe the sun. His choice of an object for his researches was instigated by his friend Harding of Göttingen. It was a peculiarly happy one. The changes visible in the solar surface were then generally regarded as no less capricious than the changes in the skies of our temperate regions. Consequently, the reckoning and registering of sun-spots was a task hardly more inviting to an astronomer than the reckoning and registering of summer clouds. Cassini, Keill, Lemonnier, Lalande, were unanimous in declaring that no trace of regularity could be detected in their appearances or effacements. ${ }^{2}$ Delambre pronounced them "more curious than really useful." 3 Even Herschel, profoundly as he studied them, and intimately as he, was convinced of their importance as symptoms of solar activity, saw no reason to suspect that their abundance and scarcity. were subject to orderly alternation. One man alone in the eighteenth century, Christian Horrebow of Copenhagen, divined their periodical character, and foresaw the time when the effects of the sun's vicissitudes upon the globes revolving round bim

1. Wolf, Gesch. der Astr., p. 655. $\quad 2$ Manuel Johnson, Mem. R. A. S., vol. xxvi., p. 197. $\quad 3$ Astronomie Théorique et Pratique, t. iii., p. 20. 
might be investigated with success ; but this prophetic utterance was of the nature of a soliloquy rather than of a communication, and remained hidden away in an unpublished journal until I 859, when it was brought to light in a general ransacking of archives. $^{1}$

Indeed, Schwabe himself was far from anticipating the discovery which fell to his share. He compared his fortune to that of Saul, who, seeking his father's asses, found a kingdom. ${ }^{2}$ For the hope which inspired his early resolution lay in quite another direction. His patient ambush was laid for a possible intramercurial planet, which, he thought, must sooner or later betray its existence in crossing the face of the sun. He took, however, the most effectual measures to secure whatever new knowledge might be accessible. During forty-three years his " imperturbable telescope" 3 never failed (weather and health permitting) to bring in its daily report as to how many, or if any, spots were visible- on the sun's disc, the information obtained being day by day recorded on a simple and unvarying system. In I 843 he made his first announcement of a probable decennial period, ${ }^{4}$ but it met with no general attention; although Julius Schmidt of Bonn (afterwards director of the Athens Observatory), and Gautier of Geneva were impressed with his figures, and Littrow had himself, in $1836,{ }^{5}$ hinted at the likelihood of some kind of regular recurrence. Schwabe, however, worked on, gathering each year fresh evidence of a law such as he had indicated; and when Humboldt published in $185 \mathrm{I}$, in the third volume of his Kosmos, ${ }^{6}$ a table of the sun-spot statistics collected by him from 1826 downwards, the strength of his case was perceived with, so to speak, a start of surprise; the reality and importance of the discovery were simultaneously recognised, and the persevering Hofrath of Dessau found himself famous among astronomers. His merit-recognised by the bestowal of the Astronomical Society's Gold Medal in 1857-consisted in his choice of an original and appropriate line of work, and in the

1 Wolf, Gesch. der Astr., p. 654. 2 Month. Not, vol. xvii., p. 241. 3 Mem. R. A. S., vol. xxvi., p. 200. 'Astr. Nach., No. 495. ${ }^{5}$ Gebler's Physikalisches Wörterbuch, art. Sonnenflecken, p. 85 I. $\quad$ 'Zucite Abth., p. 40I. 
admirable tenacity of purpose with which he pursued it. His resonrces and acquirements were those of an ordinary amateur ; he was distinguished solely by the unfortunately rare power of turning both to the best account. He died where he was born and had lived, April I I, I875, at the ripe age of eighty-six.

Meanwhile, an investigation of a totally different character, and conducted by totally different means, had been prosecuted to a very similar conclusion. Two years after Schwabe began his solitary observations, Humboldt gave the first impulse, at the Scientific Congress of Berlin in I828, to a great international movement for attacking simultaneously, in various parts of the globe, the complex problem of terrestrial magnetism. Through the genius and energy of Gauss, Göttingen became its centre. Thence new apparatus, and a new system for its employment, issued; there, in I833, the first regular magnetic observatory was founded, whilst at Göttingen was fixed the universal time-standard for magnetic observations. The letter addressed by Humboldt in April I 836 to the Duke of Sussex as President of the Royal, Society, enlisted the co-operation of England. A network of magnetic stations was spread all over the British dominions, from Canada to Van Diemen's Land; measures were concerted with foreign authorities, and an expedition was fitted out, under the able command of Captain (afterwards Sir James) Clark Ross, for the special purpose of bringing intelligence on the subject from the dismal neighbourhood of the South Pole. In I84I, the elaborate organisation created by the disinterested efforts of scientific "agitators" was complete; Gauss's "magnetometers" were vibrating under the view of attentive observers in five continents, and simultaneous results began to be recorded.

Ten years later, in September I851, Dr. John Lamont, the Scotch director of the Munich Observatory, in reviewing the magnetic observations made at Göttingen and Munich from I835 to I850, perceived with some surprise that they gave unmistakable indications of a period which he estimated at $10 \frac{1}{3}$ years. ${ }^{1}$ 'The manner in which this periodicity manifested itself

\footnotetext{
1 Annalen der Physik (Poggendorff's), Bd. lxxxiv., p. 580.
} 
requires a word of explanation. The observations in question referred to what is called the "declination" of the magnetic needle-that is, to the position assumed by it with reference to the points of the compass when moving freely in a horizontal plane. Now this position-as was discovered by Graham in I722-is subject to a small daily fluctuation, attaining its maximum towards the east about $\delta$ A.M., and its maximum towards the west shortly before 2 P.M. In other words, the direction of the needle approaches (in these countries at the present time) nearest to the true north some four hours before noon, and departs furthest from it between one and two hours after noon. It was the range of this daily variation that Lamont found to increase and diminish once in every $10 \frac{1}{3}$ years.

In the following winter, Sir Edward Sabine, ignorant as yet of Lamont's conclusion, undertook to examine a totally different set of observations. The materials in his hands had been collected at the British colonial stations of Toronto and Hobarton from 1843 to 1848 , and had reference, not to the regular diurnal swing of the needle, but to those curious spasmodic vibrations, the inquiry into the laws of which was the primary object of the vast organisation set on foot by Humboldt and Gauss. Yet the upshot was practically the same. Once in about ten years magnetic disturbances (termed by Humboldt "storms") were perceived to reach a maximum of violence and frequency. Sabine was the first to note the coincidence between this unlooked-for result and Schwabe's sun-spot period. He showed that, so far as observation had yet gone, the two cycles of change agreed perfectly both in duration and phase, maximum corresponding to maximum, minimum to minimum. What the nature of the connection could be that bound together by a common law effects so dissimilar as the rents in the luminous garment of the sun, and the swayings to and fro of the magnetic needle, was, and still remains, beyond the reach of wellfounded conjecture; but the fact was from the first undeniable.

The memoir containing this remarkable disclosure was pres snted to the Royal Society, March I8, and read May 6, I852.

I Phil. Trans., vol. cxlii., p. Io3. 
On the 3 Ist of July following, Rudolf Wolf at Berre, ${ }^{1}$ and on the I 8th of August, Alfred Gautier at Sion, ${ }^{2}$ announced, separately and independently, perfectly similar conclusions. This triple event is perhaps the most striking instance of the successful employment of the Baconian method of co-operation in discovery, by which "particulars" are amassed by one set of investigators-corresponding to the "Depredators" and "Inoculators" of Solomon's House-while inductions are drawn from them by another and a higher class-the "Interpreters of Nature." Yet even here the convergence of two distinct lines of research was wholly fortuitous, and skilful combination owed the most brilliant part of its success to the unsought bounty of what we call Fortune.

The exactness of the coincidence thus brought to light was fully confirmed by further inquiries. A diligent search through the scattered records of sun-spot observations, from the time of Galileo and Scheiner onwards, put Wolf ${ }^{3}$ in possession of materials by which he was enabled to correct Schwabe's looselyindicated decennial period to one of slightly over eleven (I I.I I) years; and he further showed that this fell in with the ebb and flow of magnetic change even better than Lamont's IO $\frac{1}{3}$-year cycle. The analogy was also pointed out between the "lightcurve," or zig-zagged line representing on paper the varying intensity in the lustre of certain stars, and the similar delineation of spot-frequency; the ascent from minimum to maximum being, in both cases, usually steeper than the descent from maximum to minimum; while an additional point of resemblance was furnished by the irregularities in height of the various maxima. In other words, both the number of spots on the sun and the brightness of variable stars increase, as a rule, more rapidly than they decrease; nor does the amount of that increase, in either instance, show any approach to uniformity.

The endeavour, suggested by the very nature of the phenomenon, to connect sun-spots with weather was less successful.

1 Mittheilungen der Naturforschenden Gesellschaft, 1852, p. 183. 2 Archives des Sciences, t. xxi., p. 194. ${ }^{3}$ Neue Untersuchungen, Mitth. Naturf. Ges. 1852, p. 249. 
The earliest attempt of the kind was made by Sir William Herschel in the first year of the present century, and a very notable one it was. Meteorological statistics, save of the scantiest and most casual kind, did not then exist; but the price of corn from year to year was on record, and this, with full recognition of its inadequacy, he adopted as his criterion. Nor was he much better off for information respecting the solar condition. What little he could obtain, however, served, as he believed, to confirm his surmise that a copious emission of light and heat accompanies an abundant formation of "openings" in the dazzling substance whence our supply of those indispensable commodities is derived. ${ }^{1}$ He gathered, in short, from his inquiries very much what he had expected to gather, namely, that the price of wheat was high when the sun showed an unsullied surface, and that food and spots became plentiful together. ${ }^{2}$

This plausible inference, however, was scarcely borne out by a more exact collocation of facts. Schwabe failed to detect any reflection of the sun-spot period in his meteorological register. Gautier ${ }^{3}$ reached a provisional conclusion the reverse-though not markedly the reverse-of Herschel's. Wolf, in I 852, derived from an examination of Vogel's collection of Zürich Chronicles (IO00-I 800 A.D.) evidence showing (as he thought) that minimum years were usually wet and stormy, maximum years dry and genial ${ }^{4}$ but a subsequent review of the subject in I 859 convinced him that no relation of any kind between the two classes of phenomena was traceable. ${ }^{5}$ With the singular affection of our atmosphere known as the Aurora Borealis (more properly Aurora Polaris) the case was different. Here the Zürich Chronicles set Wolf on the right track in leading him to associate such luminous manifestations with a disturbed condition of the sun; since

1 Phil. Trans., vol. xci., p. 316. 2 Evidence of an eleven-yearly fluctuation in the price of food-grains in India was in 1886 alleged by Mr. Frederick Chambers in Nature, vol. xxxiv., p. 100. ${ }^{3}$ Bibl. Un. de Genève, t. li., p. 336. 4 Neue Untersuchungen, p. 269. 5 Die Sonne und ihre Flecken, p. 30. Arago was the first who attempted to decide the question by keeping, through a series of years, a parallel register of sun-spots and weather; but the data regarding the solar condition collected at the Paris Observatory from 1822 to 1830 were not sufficiently precise to found any inference upon. 
subsequent detailed observation has exhibited the curve of auroral frequency as following with such fidelity the jagged lines figuring to the eye the fluctuations of solar and magnetic activity, as to leave no reasonable doubt that all three rise and sink together under the influence of a common cause. As long ago as I 7 16, ${ }^{1}$ Halley had conjectured that the Northern Lights were due to magnetic "effluvia," but there was no evidence on the subject forthcoming until Hiorter observed at Upsala in I 74I their agitating influence upon the magnetic needle. That the effect was no casual one was made superabundantly clear by Arago's researches in I819 and subsequent years. Now both were perceived to be swayed by the same obscure power of cosmical disturbance.

The sun is not the only one of the heavenly bodies by which the magnetism of the earth is affected. Proofs of a similar kind of lunar action were laid by Kreil in I84 I before the Bohemian Society of Sciences, and were fully substantiated, though with minor corrections, by Sabine's more extended researches. It has thus been ascertained that each lunar day, or the interval of twenty-four hours and about fifty-four minutes between two successive meridian passages of our satellite, is marked by a perceptible, though very small double oscillation of the needle -two progressive movements from east to west, and two returns from west to east. ${ }^{2}$ Moreover, the lunar, like the solar influence (as was proved in each case by Sabine's analysis of the Hobarton and Toronto observations), extends to all three "magnetic elements," affecting not only the position of the horizontal or declination needle, but also the dip and intensity. It seems not unreasonable to attribute some portion of the same subtle power to the planets, and even to the stars, though with effects rendered imperceptible by distance.

We have now to speak of the discovery and application to the heavenly bodies of a totally new method of investigation. Spectrum analysis may be shortly described as a mode of distinguishing the various species of matter by the kind of light

1 Phil. Trans., vol. xxix., p. 421. 2 Phil. Trans., vol. cxliii., p. 558, and vol. cxlvi., p. 505 . 
proceeding from each. This definition at once explains how it is that, unlike every other system of chemical analysis, it has proved available in astronomy. Light, so far as quality is concerned, ignores distance. No intrinsic change, that we yet know of, is produced in it by a journey from the farthest bounds of the visible universe; so that, provided only that in quantity it remain sufficient for the purpose, its peculiarities can be equally well studied whether the source of its vibrations be one foot or a hundred billion miles distant. Now the most obvious distinction between one kind of light and another resides in colour. But of this distinction the eye takes cognisance in an æasthetic, not in a scientific sense. It finds gladness in the "thousand tints" of nature, but can neither analyse nor define them. Here the refracting prism-or the combination of prisms known as the "spectroscope" - comes to its aid, teaching it to measure as well as to perceive. It furnishes, in a word, an accurate scale of colour The various rays which, entering the eye together in a confused crowd, produce a compound impression made up of undistinguishable elements, are, by the mere passage through a triangular piece of glass, separated one from the other, and ranged side by side in orderly succession, so that it becomes possible to tell at a glance what kinds of light are present, and what absent. Thus, if we could only be assured that the various chemical substances when made to glow by heat, emit characteristic rays-rays, that is, occupying a place in the spectrum reserved for them, and for them only-we should at once be in possession of a mode of identifying such substances with the utmost readiness and certainty. This assurance, which forms the solid basis of spectrum analysis, was obtained slowly and with difficulty.

The first to employ the prism in the examination of various flames (for it is only in a state of vapour that matter emits distinctive light) was a young Scotchman named Thomas Melvill, who died in I753, at the age of twenty-seven. He studied the spectrum of burning spirits, into which were introduced successively sal ammoniac, potash, alum, nitre, and sea-salt, and observed the singular predominance, under almost all circumstances, of a particular shade of yellow light, perfectly definite in its degree of 
refrangibility ${ }^{1}$-in other words, taking up a perfectly definite position in the spectrum. His experiments were repeated by Morgan, ${ }^{2}$ Wollaston, and-with far superior precision and diligence-by Fraunhofer. ${ }^{3}$ The great Munich optician, whose work was completely original, rediscovered Melvill's deep yellow ray and measured its place in the colour-scale. It has since become well known as the "sodium line." and has played a very important part in the history of spectrum analysis. Nevertheless, its ubiquity and conspicuousness long impeded progress. It was elicited by the combustion of a surprising variety of substancessulphur, alcohol, ivory, wood, paper; its persistent visibility suggesting the accomplishment of some universal process of nature rather than the presence of one individual kind of matter. But if spectrum analysis were to exist as a science at all, it could only be by attaining certainty as to the unvarying association of one special substance with each special quality of light.

Thus perplexed, Fox Talbot ${ }^{4}$ hesitated in 1826 to enounce this fundamental principle. He was inclined to believe that the presence in the spectrum of any individual ray told unerringly of the volatilisation in the flame under scrutiny of some body as whose badge or distinctive symbol that ray might be regarded; but the continual prominence of the yellow beam staggered him. It appeared, indeed, without fail where sodium was; but it also appeared where it might be thought only reasonable to conclude that sodium was not. Nor was it until thirty years later that William Swan, ${ }^{5}$ by pointing out the extreme delicacy of the spectral test, and the singularly wide dispersion of sodium, made it appear probable (but even then only probable) that the questionable yellow line was really due invariably to that substance. Common salt (chloride of sodium) is, in fact, the most diffusive of solids. It floats in the air ; it flows with water ; every grain of dust has its attendant particle; its absolute

1 Observations on Light and Colours, p. 35: 2 Phil. Trans., vol. 1xxv., p. 190. 3 Denkschriften (Munich Ac. of Sc.) 1814-15, Bd. v., p. 197. ${ }^{4}$ Edinburgh Journal of Science, vol. v., p. 77. See also Phil. Mlag., Feb. I834, vol. iv., p. I12. 5 Ed. Phil. Trans., vol. xxi., p. $4 \mathrm{II}$. 
exclusion approaches the impossible. And withal, the light that it gives in burning is so intense and concentrated, that if a single grain be divided into 180 million parts, and one alone of such inconceivably minute fragments be present in a source of light, the spectroscope will show unmistakably its characteristic beam.

Among the pioneers of knowledge in this direction were Sir John Herschel ${ }^{1}$-who, however, applied himself to the subject in the interests of optics, not of chemistry-W. A. Miller, ${ }^{2}$ and Wheatstone. The last especially made a notable advance when, in the course of his studies on the "prismatic decomposition" of the electric light, he reached the significant conclusion that the rays visible in its spectrum were different for each kind of metal employed as "electrodes." 3 Thus indications of a wider principle were to be found in several quarters, but no positive certainty on any single point was obtained, until, in 1859, Gustav Kirchhoff, professor of physics in the University of Heidelberg, and his colleague, the eminent chemist Robert Bunsen, took the matter in hand. By them the general question as to the necessary and invariable connection of certain rays in the spectrum with certain kinds of matter, was first resolutely confronted, and first definitely answered. It was answered affirmatively-else there could have been no science of spectrum analysis-as the result of experiments more numerous, more stringent, and more precise than had previously been undertaken. ${ }^{4}$ And the assurance of their conclusion was rendered doubly sure by the discovery, through the peculiarities of their light alone, of two new metals, named from the blue and red rays by which they were respectively distinguished, "Cæsium," and "Rubidium." 5 Both were immediately afterwards actually obtained in small quantities by evaporation of the Durckheim mineral waters.

1 On the Absorption of Light by Coloured Media, Ed. Phil. Trans., vol. ix., p. 445 (1823). = Phil. Mag., vol. xxvii. (ser. iii.), p. 81. 3 Report Brit. Ass. 1835, p. I I (pt. ii.). Electrodes are the terminals from one to the other of which the electric spark passes, volatilising and rendering incandescent in its transit some particles of their substance, the characteristic light of which accordingly flashes out in the spectrum. + Phil. Mag., vol. xx., p. 93. s Annalen der Physik, Bd. cxiii., p. 357. 
The link connecting this important result with astronomy may now be indicated. In the year I802 William Hyde Wollaston hit upon the idea of substituting for the round hole used by Newton and his successors to admit light about to be examined with the prism, an elongated "crevice" $\frac{1}{20}$ th of an inch in width. He thereupon perceived that the spectrum, thus formed of light purified by the abolition of overlapping images, was traversed by seven dark lines. These he took to be natural boundaries of the various colours, ${ }^{1}$ and satisfied with this quasi-explanation, allowed the subject to drop. It was independently taken up after twelve years by a man of higher genius. In the course of experiments on light, directed towards the perfecting of his achromatic lenses, Fraunhofer, by means of a slit and a telescope, made the surprising discovery that the solar spectrum is crossed, not by seven, but by thousands of obscure transverse streaks. ${ }^{2}$ Of these he counted some 600, and carefully mapped 324, while a few of the most conspicuous he set up (if we may be permitted the expression) as landmarks, measuring their distances apart with a theodolite, and affixing to them the letters of the alphabet by which they are still universally known. Nor did he stop here. The same system of examination applied to the rest of the heavenly bodies showed the mild effulgence of the moon and planets to be deficient in precisely the same rays as sunlight; while in the stars it disclosed the differences in likeness which are always an earnest of increased knowledge. The spectra of Sirius and Castor, instead of being delicately ruled crosswise throughout, like that of the sun, were seen to be interrupted by three massive bars of darkness-two in the blue and one in the green $;^{3}$ the light of Pollux, on the other hand, seemed precisely similar to sunlight attenuated by distance or reflection, and that of Capella, Betelgeux, and Procyon to share some of its peculiarities. One solar line especially-that marked in his map with the letter D-proved common to all the four

1 Phil. 'Trans., vol. xcii., p. 378. $\quad 2$ Denkschriften, Bd. v., p. 202. $\quad 3$ Ibid., p. 220 ; Edin. Jour. of Science, vol. viii., p. . 
last-mentioned stars; and it was remarkable that it exactly coincided in position with the conspicuous yellow beam (afterwards, as we have said, identified with the light of glowing sodium) which he had already found to accompany most kinds of combustion. Moreover, both the dark solar and the bright terrestrial "D-lines" were displayed by the refined Munich appliances as double.

In this striking correspondence, discovered by Fraunhofer in I8I5, was contained the very essence of solar chemistry; but its true significance did not become apparent until long afterwards. Fraunhofer was by profession, not a physicist, but a practical optician. Time pressed; he could not and would not deviate from his appointed track; all that was possible to him was to indicate the road to discovery, and exhort others to follow it. ${ }^{1}$

Partially and inconclusively at first this was done. The "fixed lines" (as they were called) of the solar spectrum took up the position of a standing problem, to the solution of which no approach seemed possible. Conjectures as to their origin were indeed rife. An explanation put forward by Zantedeschi ${ }^{2}$ and others, and dubiously favoured by Sir David Brewster and Dr. J. H. Gladstone, ${ }^{3}$ was that they resulted from "interference" - that is, a destruction of the motion producing" in our eyes the sensation of light, by the superposition of two light-waves in such a manner that the crests of one exactly fill up the hollows of the other. This effect was supposed to be brought about by imperfections in the optical apparatus employed.

A more plausible view was that the atmosphere of the earth was the agent by which sunlight was deprived of its missing beams. For some of them this is actually the case. Brewster found in I832 that certain dark lines, which were invisible when the sun stood high in the heavens, became increasingly conspicuous as he approached the horizon. ${ }^{4}$ These are the well-known " atmospheric lines ;" but the immense majority of

1 Denlischriften, Bd. v., p. 222. ' 2 Arch. des Sciences, 1849, p. 43. " Plil. Trans., vol. cl., p. 159, note. ${ }^{4}$ Ed. Phil. Trans., vol. xii., p. 528. 
their companions in the spectrum remain quite unaffected by the thickness of the stratum of air traversed by the sunlight containing them. They are then obviously due to another cause.

There remained the true interpretation-absorption in the sun's atmosphere; and this, too, was extensively canvassed. But a remarkable observation made by Professor Forbes of Edinburgh ${ }^{1}$ on the occasion of the annular eclipse of May I5, I 836, appeared to throw discredit upon it. If the problematical dark lines were really occasioned by the stoppage of certain rays through the action of a vaporous envelope surrounding: the sun, they ought, it seemed, to be strongest in light proceeding from his edges, which, cutting that envelope obliquely, passed through a much greater depth of it. But the circle of light left by the interposing moon, and of course derived entirely from the rim of the solar disc, yielded to Forbes's examination precisely the same spectrum as light coming from its central parts. This circumstance helped to baffle inquirers, already sufficiently perplexed. It still remains an anomaly, of which no completely satisfactory explanation has been offered.

Convincing evidence as to the true nature of the solar lines was however at length, in the antumn of 1859 , brought forward at Heidelberg. Kirchhoff's experimentum crucis in the matter was a very simple one. He threw bright sunshine across a space occupied by vapour of sodium, and perceived with astonishment that the dark Fraunhofer line D, instead of being effaced by flame giving a luminous ray of the same refrangibility, was deepened and thickened by the superposition.

He tried the same experiment, substituting for sunbeams light from a Drummond lamp, and with similar result. A dark furrow, corresponding in every respect to the solar Dline, was instantly seen to interrupt the otherwise unbroken radiance of its spectrum. The inference was irresistible, that

1 Phil. Trans., vol. cxxvi., p. 453. "I conceive," he says, "that this result proves decisively that the sun's atmosphere has nothing to do with the production of this singular phenomenon" (p. 455). And Brewster's well-founded opinion that it had much to do with it was thereby, in fact, overthrown. 
the effect thus produced artificially was brought about naturally in the same way, and that sodium formed an ingredient in the glowing atmosphere of the sun. ${ }^{1}$ This first discovery was quickly followed up. by the identification of numerous bright rays in the spectra of other metallic bodies with others of the hitherto mysterious Fraunhofer lines. Kirchhoff was thus led to the conclusion that (besides sodium), iron, magnesium, calcium, and chromium, are certainly solar constituents, and that copper, zinc, barium, and nickel are also present, though in smaller quantities. ${ }^{2}$ As to cobalt, he hesitated to pronounce, but its existence in the sun has since been established.

These memorable results were founded upon a general principle first enunciated by Kirchhoff in a communication to the Berlin Academy, December I5, I859, and afterwards more fully developed by him. ${ }^{3}$ It may be expressed as follows: Substances of every kind are opaque to the precise rays which they emit at the same temperature; that is to say, they stop the kinds of light or heat which they are then actually in a condition to radiate. But it does not follow that cool bodies absorb the rays which they would give out if sufficiently heated. Hydrogen at ordinary temperatures, for instance, is almost perfectly transparent, but if raised to the glowing pointas by the passage of electricity-it then becomes capable of arresting, and at the same time of displaying in its own spectrum, light of four distinct colours.

This principle is fundamental to solar chemistry. It gives the key to the hieroglyphics of the Fraunhofer lines. The identical characters which are written bright in terrestrial spectra are written dark in the unrolled sheaf of sun-rays; the meaning remains unchanged. It must, however, be remembered that they are only relatively dark. The substances stopping

1 Monatsberichte, Berlin, I859, p. 664. 2 Abhandlungen, Berlin, I86I, pp. 80, 81. $\quad{ }^{3}$ Ibid., 186I, p. 77 ; Annalen der Physik, Bd. cxix., p. 275. A similar conclusion, reached by Balfour Stewart in $185^{8}$, for heat-rays ( $E d$. Phil. Trans., vol. xxii., p. 13), was, in 1860, without previous knowledge of Kirchhoff's work, extended to light (Phil. Mag., rol. xx., p. 534); but his experiments wanted the precision of those executed at Heidelberg. 
those particular tints in the neighbourhood of the sun are at the same time vividly glowing with the very same. Remove the dazzling solar background, by contrast with which they show as obscure, and they will be seen, and have, under certain circumstances, actually been seen, in all their native splendour. It is because the atmosphere of the sun is cooler than the globe it envelops that the different kinds of vapour constituting that atmosphere take more than they give, absorb more light than they are capable of emitting; raise them to the same temperature as the sun itself, and their powers of emission and absorption being brought exactly to the same level, the thousands of dusky rays in the solar spectrum will be at once obliterated.

The establishment of the terrestrial science of spectrum analysis was due, as we have seen, equally to Kirchhoff and Bunsen, but its celestial application to Kirchhoff alone. He effected this object of the aspirations, more or less dim, of many other thinkers and workers, by the union of two separate though closely related lines of research-the study of the different kinds of light emitted by various bodies, and the study of the different kinds of light absorbed by them. The latter branch appears to have been first entered upon by Dr. Thomas Young in $1803 ;^{1}$ it was pursued by the younger Herschel, ${ }^{2}$ by William Allen Miller, Brewster, and Gladstone. Brewster indeed made, in I 833, ${ }^{3}$ a formal attempt to found what might be called an inverse system of analysis with the prism based upon absorption; and his efforts were repeated, just a quarter of a century later, by Gladstone. ${ }^{4}$ But no general point of view was attained; nor, it may be added, was it by this path attainable.

Kirchhoff's map of the solar spectrum, drawn to scale with exquisite accuracy, and printed in three shades of ink to convey the graduated obscurity of the lines, was published in the Transactions of the Berlin Academy for $186 \mathrm{r}$ and $1862 .{ }^{5}$ Representations of the principal lines belonging to various

1 Miscrllaneous Works, vol. i., p. I89. 2 Ed. Plit. Trans., vol. ix., p. $45^{8}$. 3 Ibid., vol. xii., p. 519. " Quart. Jour. Chem. Soc., vol. x., p. 79. 5 A facsimile accompanied Sir H. Roscoe's translation of Kirchhoff's " Researches on the Solar Spectrum" (London, 1862-63). 
elementary bodies formed, as it were, a series of marginal notes accompanying the great solar scroll, and enabling the veriest tyro in the new science to decipher its meaning at a glance. Where the dark solar and bright metallic rays agreed in position, it might safely be inferred that the metal emitting them was a solar constituent; and such coincidences were numerous. In the case of iron alone, no less than sixty occurred in one-half of the spectral area, rendering the chances ${ }^{1}$ absolutely overwhelming against mere casual conjunction. The preparation of this elaborate picture proved so trying to the eyes that Kirchhoff was compelled by failing vision to resign the latter half of the task to his pupil Hofmann. The complete map measured nearly eight feet in length.

The conclnsions reached by Kirchhoff were no sooner announced than they took their place, with scarcely a dissenting voice, among the established truths of science. The broad result, that the dark-lines in the spectrum of the sun afford an index to its chemical composition no less reliable than any of the tests used in the laboratory, was equally captivating to the imagination of the vulgar, and authentic in the judgment of the learned; and, like all genuine advances in the knowledge of Nature, it stimulated curiosity far more than it gratified it. Now the history of how discoveries were missed is often quite as instructive as the history of how they were made; it may then be worth while to expend a few words on the thoughts and trials by which, in the present case, the actual event was heralded.

Three times it seemed on the verge of being anticipated. The experiment, which in Kirchhoff's hands proved decisive, of passing sunlight through glowing vapours and examining the superposed spectra, was performed by Professor W. A. Miller of King's College in $1845 .^{2}$ Nay, more, it was performed with express reference to the question, then already (as has been noted) in debate, of the possible production of Fraunhofer's lines by absorption in a solar atmosphere. Yet it led to nothing.

Again, at Paris in I849, with a view to testing the asserted

1 Estimated by Kirchhoff at a trillion to one. Abhandl., I86ı, p. 79. 2 Phil. Mag., vol. xxvii. (3rd series), p. 90. 
coincidence between the solar D-line and the bright yellow beam in the spectrum of the electric arc (really due to the unsuspected presence of sodium), Léon Foucault threw a ray of sunshine across the arc and observed its spectrum. ${ }^{1}$ He was surprised to see that the $D$-line was rendered more intensely dark by the combination of lights. To assure himself still further, he substituted a reflected image of one of the white-hot carbon-points for the sunbeam, with an identical result. The same ray was missing. It needed but another step to have generalised this result, and thus laid hold of a natural truth of the highest importance; but that step was not taken. Foucault, keen and brilliant though he was, rested satisfied with the information that the voltaic are had the power of stopping the kind of light emitted by it; he asked no further question, and was consequently the bearer of no further intelligence on the subject.

The truth conveyed by this remarkable experiment was, however, divined by one eminent man. Professor (now Sir Gabriel) Stokes of Cambridge stated to Sir William Thomson, shortly after it had been made, his conviction that an absorbing atmosphere of sodium surrounded the sun. And so forcibly was his hearer impressed with the weight of the arguments based upon the absolute agreement of the D-line in the solar spectrum with the yellow ray of burning sodium (then freshly certified by W. A. Miller), combined with Foncault's "reversal" of that ray, that he regularly inculcated, in his public lectures on natural philosophy at Glasgow, five or six years before Kirchhoff's discovery, not only the fact of the presence of sodium in the solar neighbourhood, but also the principle of the study of solar and stellar chemistry in the spectra of flames. ${ }^{2}$ Yet it does not appear to have occurred to either of these two distinguished professorsthemselves among the foremost of their time in the successful search for new truths-to verify practically a sagacious conjecture in which was contained the possibility of a scientific revolution. It is just to add, that Kirchhoff was unacquainted,

1 L'Institut, Feb. 7, 1849. p. 45; Phil. Mag., vol. xix. (4th series), p. 193. 2 Ann. d. Phys., vol. cxviii., p. I 10. 
when he undertook his investigation, either with the experiment of Foncault or the speculation of Stokes.

For C. J. Angström, on the other hand, perhaps somewhat too much has been claimed in the way of anticipation. His Optical Researches appeared at Upsala in 1853, and in their English garb two years later. ${ }^{1}$ They were undoubtedly pregnant with suggestion, yet made no epoch in discovery. The old perplexities continued to prevail after, as before their publication. To Angström, indeed, belongs the great merit of having revived Euler's principle of the equivalence of emission and absorption; but he revived it in its original crude form, and without the qualifying proviso which alone gave it value as a clue to new truths. According to his statement, a body absorbs all the series of vibrations it is, under any circumstances, capable of emitting, as well as those connected with them by simple harmonic relations. This is far too wide. To render it either true or useful, it had to be reduced to the cautious terms employed by Kirchhoff. Radiation strictly and necessarily corresponds with absorption only when the temperature is the same. In point of fact, Angström, though convinced that their explanation embraced that of the luminous lines in the spectrum of the electric arc, was still, in 1853 , divided between absorption and interference as the mode of origin of the Fraunhofer dark rays. Very important, however, was his demonstration of the compound nature of the spark-spectrum, which he showed to be made up of the spectrum of the metallic electrodes superposed upon that of the gas or gases across which the discharge passed.

It may here be useful-since without some clear ideas on the subject no proper understanding of recent astronomical progress is possible-to take a cursory view of the elementary principles of spectrum analysis. To many of our readers they are doubtless already familiar; but it is better to be trite in repetition than obscure from lack of explanation.

The spectrum, then, of a body is simply the light proceeding 1 Plit. Mag., vol. ix. (4th series), p. 327. 
from it spread out by refraction ${ }^{1}$ into a brilliant variegated band, passing from brownish-red through crimson, orange, yellow, green, and azure into dusky violet. The reason of this spreading-out or "dispersion" is that the various colours have different wave-lengths, and consequently meet with different degrees of retardation in traversing the denser medium of the prism. The shortest and quickest vibrations (producing the sensation we call "violet") are thrown farthest away from their original path-in other words, suffer the widest deviation; the longest and slowest (the red) travel much nearer to it. Thus the sheaf of rays which would otherwise combine into a patch of white light are separated through the divergence of their tracks after refraction by a prism, so as to form a tinted riband. This visible spectrum is prolonged invisibly at both ends by a long range of vibrations, either too rapid or too tardy to affect the eye as light, but recognisable through their chemical and heating effects.

Now all incandescent solid or liquid substances, and even gases ignited under great pressure, give what is called a "continuous spectrum ; " that is to say, the light derived from them is of every conceivable hue. Sorted out with the prism, its tints merge imperceptibly one into the other, uninterrupted by any dark spaces. No colours, in short, are missing. But gases and vapours rendered luminous by heat emit rays of only a few tints-sometimes of one only - which accordingly form an interrupted spectrum, usually designated as one of lines or bands. And since these rays are perfectly definite and characteristicnot being the same for any two substances-it is easy to tell what kind of matter is concerned in producing them. We may suppose that the inconceivably minute particles which by their rapid thrilling agitate the ethereal medinm so as to produce light, are free to give out their peculiar tone of vibration only when floating apart from each other in gaseous form ; but when crowded together into a condensed mass, the clear ring of the distinctive note is drowned, so to speak, in an universal mole-

1 Spectra may be produced by diffraction as well as by refraction; but we are here only concerned with the matter in its simplest aspect. 
cular clang. Thus prismatic analysis has no power to identify individual kinds of matter, except when they present themselves as glowing vapours.

A spectrum is said to be "reversed" when lines previously seen bright on a dark background appear dark on a bright background. In this form it is equally representative of chemical composition with the "direct" spectrum, being due to absorption, as the latter is to emission. And absorption and emission are, by Kirchhoff's law, strictly correlative. This is easily understood by the analogy of sound. For just as a tuning-fork responds to sound-waves of its own pitch, but remains indifferent to those of any other, so those particles of matter whose nature it is, when set swinging by heat, to vibrate a certain number of times in a second, thus giving rise to light of a particular shade of colour, appropriate those same vibrations, and those only, when transmitted past them,-or, phrasing it otherwise, are opaque to them, and transparent to all others.

It should further be explained that the shape of the bright or dark spaces in the spectrum has nothing whatever to do with the nature of the phenomena. The "lines" and "bands" so frequently spoken of are seen as such for no other reason than because the light forming them is admitted through a narrow, straight opening. Change that opening into a fine crescent or a sinuous curve, and the "lines" will at once appear as crescents or curves.

Resuming in a sentence what has been already explained, we find that the prismatic analysis of the heavenly bodies was founded upon three classes of facts: First, the unmistakable character of the light given by each different kind of glowing vapour; secondly, the identity of the light absorbed with the light emitted by each; thirdly, the coincidences observed between rays missing from the solar spectrum and rays absorbed by various terrestrial substances. Thus, a realm of knowledge, pronounced by Morinus ${ }^{1}$ in the seventeenth century, and no less dogmatically by Auguste Comte ${ }^{2}$ in the nineteenth, hope-

1 Astrologia Gallica (1661), p. 189. $\quad$ Pos. Phil., vol. i., pp. 114-1 I5 (Martineau's trans.). 
lessly out of reach of the human intellect, was thrown freely open, and the chemistry of the sun and stars took its place among the foremost of the experimental sciences.

The immediate increase of knowledge was not the chief result of Kirchhoff's labours; still more important was the change in the scope and methods of astronomy, which, set on foot in 1852 by the detection of a common period affecting at once the spots on the sun and the magnetism of the earth, was extended and accelerated by the discovery of spectrum analysis. The nature of that change is concisely indicated by the heading 'of the present chapter; we would now ask our readers to endeavour to realise somewhat distinctly what is implied by the "foundation of astronomical physics."

Nearly three centuries ago, Kepler drew a forecast of what he called a "physical astronomy" - a science treating of the efficient causes of planetary motion, and holding the "key to the inner astronomy." 1 What Kepler dreamed of and groped after, Newton realised. He showed the beautiful and symmetrical revolutions of the solar system to be governed by a uniformly acting cause, and that cause no other than the familiar force of gravity, which gives stability to all our terrestrial surroundings. The world under our feet was thus for the first time brought into physical connection with the worlds peopling space, and a very tangible relationship was demonstrated as existing between what used to be called the "corruptible" matter of the earth and the "incorruptible" matter of the heavens.

This process of unification of the cosmos-this levelling of the celestial with the sublunary-was carried no farther until the fact unexpectedly emerged from a vast and complicated mass of observations, that the magnetism of the earth is subject to subtle influences, emanating, certainly from some, and presumably (were their amount sufficient to be perceptible) from all of the heavenly bodies; the inference being thus rendered at least plausible, that a force not less universal than gravity itself, but with whose modes of action we are as yet un-

1 Proem. Astronomice Pars Optica (1604), Op., t. ii. 
acquainted, pervades the universe, and forms, it might be said, an intangible bond of sympathy between its parts. Now for the investigation of this influence two roads are open. It may be pursued by observation either of the bodies from which it emanates, or of the effects whith it produces-that is to say, either by the astronomer or by the physicist, or, better still, by both concurrently. Their acquisitions are mutually profitable; nor can either be considered as independent of the other. Any important accession to knowledge respecting the sun, for example, may be expected to cast a reflected light on the still obscure subject of terrestrial magnetism; while discoveries in magnetism or its alter ego electricity must profoundly affect solar inquiries.

The establishment of the new method of spectrum analysis drew far closer this alliance between celestial and terrestrial science. Indeed, they have come to merge so intimately one into the other, that it is no easier to trace their respective boundaries than it is to draw a clear dividing-line between the animal and vegetable kingdoms. Yet up to the middle of the present century, astronomy, while maintaining her strict union with mathematics, looked with indifference on the rest of the sciences; it was enough that she possessed the telescope and the calculus. Now the materials for her inductions are supplied by the chemist, the electrician, the inquirer into the most recondite mysteries of light and the molecular constitution of matter. She is concerned with what the geologist, the meteorologist, even the biologist, has to say; she can afford to close her ears to no new truth of the physical order. Her position of lofty isolation has been exchanged for one of community and mutual aid. The astronomer has become, in the highest sense of the term, a physicist; while the physicist is bound to be something of an astronomer.

This, then, is what is designed to be conveyed by the "foundation of astronomical or cosmical physics." It means the establishment of a science of Nature whose conclusions are not only presumed by analogy, but are ascertained by observation, to be valid wherever light can travel and gravity is obeyed-a science 
by which the nature of the stars can be studied upon the earth, and the nature of the earth can be made better known by study of the stars-a science, in a word, which is, or aims at being, one and universal, even as Nature-the visible reflection of the invisible highest Unity-is one and universal.

It is not too much to say that a new birth of knowledge has ensued. The astronomy so signally promoted by Bessel ${ }^{1}$ - the astronomy placed by Comte ${ }^{2}$ at the head of the hierarchy of the physical sciences-was the science of the movements of the heavenly bodies. And there were those who began to regard it as a science which, from its very perfection, had ceased to be interesting-whose tale of discoveries was told, and whose further advance must be in the line of minute technical improvements, not of novel and stirring disclosures. But the science of the nature of the heavenly bodies is one only in the beginning of its career. It is full of the audacities, the inconsistencies, the imperfections, the possibilities of youth. It promises everything; it has already performed much ; it will doubtless perform much more. The means at its disposal are vast and are being daily augmented. What has so far been secured by them it must now be our task to extricate from more doubtful surroundings and place in due order before our readers.

1 Pop. Vorl., pp. 14, 19, 408. 2 Pos. Phil, p. I1 5. 


\section{CHAPTER II.}

\section{SOLAR OBSERVATIONS AND THEORIES.}

THE zeal with which solar studies have been pursued during the last quarter of a century has already gone far to redeem the neglect of the two preceding ones. Since Schwabe's discovery was published in I85 I, observers have multiplied, new facts have been rapidly accumulated, and the previous comparative quiescence of thought on the great subject of the constitution of the sun, has been replaced by a bewildering variety of speculations, conjectures, and more or less justifiable inferences. It is satisfactory to find this novel impulse not only shared, but to a large extent guided, by our countrymen.

William Rutter Dawes, one of many clergymen eminent in astronomy, observed, in 1852, with the help of a solar eyepiece of his own devising, some curious details of spotstructure. $^{1}$ The umbra-heretofore taken for the darkest part of the spot-was seen to be suffused with a mottled, nebulous illumination, in marked contrast with the striated appearance of the penumbra; while through this "cloudy stratum" a "black opening" permitted the eye to divine farther unfathomable depths beyond. The hole thus disclosed-evidently the true nucleus-was found to be present in all considerable, as well as in many small maculæ.

Again, the whirling motions of some of these objects were noticed by him. The remarkable form of one sketched at Wateringbury, in Kent, January I7, I852, gave him the means 
of detecting and measuring a rotatory movement of the whole spot round the black nucleus at the rate of Ioo degrees in six days. "It appeared," he said, "as if some prodigious ascending force of a whirlwind character, in bursting through the cloudy stratum and the two higher and luminous strata, had given to the whole a movement resembling its own." 1 An interpretation founded, as is easily seen, on the Herschelian theory, then still in full credit.

An instance of the same kind was observed by the late Mr. W. R. Birt in $1860,{ }^{2}$ and cyclonic movements are now a recognised feature of sun-spots. They are, however, as Father Secchi ${ }^{3}$ concluded from his long experience, but temporary and casual. Scarcely three per cent. of all spots visible exhibit the spiral structure which should invariably result if a conflict of opposing, or the friction of unequal, currents were essential, and not merely incidental to their origin. A whirlpool phase not unfrequently accompanies their formation, and may be renewed at periods of recrudescence or dissolution; but it is both partial and inconstant, sometimes affecting only one side of a spot, sometimes slackening gradually its movement in one direction, to resume it, after a brief pause, in the opposite. Persistent and uniform motions, such as the analogy of terrestrial storms would absolutely require, are not to be found. So that the "cyclonic theory" of sun-spots, suggested by Herschel in $1847,{ }^{4}$ and urged, from a different point of view, by Faye in 1872 , may be said to have completely broken down.

The drift of spots over the sun's surface was first systematically investigated by Carrington, a self-constituted astronomer, gifted with the courage and the instinct of thoughtful labour. Born at Chelsea in May I826, Richard Christopher Carrington entered Trinity College, Cambridge, in $1844 . \mathrm{He}_{8}$ was intended for the Church, but Professor Challis's lectures diverted him to astronomy, and he resolved, as soon as he had taken his degree, to prepare, with all possible diligence, to follow his new vocation.
1 Mem. R. A. S., vol. xxi., p. I6o.
2 Month. Not., vol. xxi., p. I44.
3 Le Soleil, t. i., pp. 87-90 (2d ed. 1875).
4 See ante, p. 70. 
His father, who was a brewer on a large scale at Brentford, offered no opposition ; ample means were at his disposal ; nevertheless, he chose to serve an apprenticeship of three years as observer in the University of Durham, as though his sole object had been to earn a livelihood. He quitted the post only when he found that its restricted opportunities offered no further prospect of self-improvement.

He now built an observatory of his own at Redhill in Surrey, with the design of completing Bessel's and Argelander's survey of the northern heavens by adding to it the circumpolar stars omitted from their view. This project, successfully carried out between I 854 and I857, had another and still larger one superposed upon it before it had even begun to be executed. In I 852, while the Redhill Observatory was in course of erection, the discovery of the coincidence between the sun-spot and magnetic periods was announced. Carrington was profoundly interested, and devoted his enforced leisure to the examination of records, both written and depicted, of past solar observations. Struck with their fragmentary and inconsistent character, he resolved to "appropriate," as he said, by "close and methodical research," the eleven-year period next ensuing. ${ }^{1} \mathrm{He}$ calculated rightly that he should have the field pretty nearly to himself ; for many reasons conspire to make public observatories slow in taking up new subjects, and amateurs with freedom to choose, and means to treat them effectually, were even scarcer then than they are now.

The execution of this laborious task was commenced November 9, I853. It was intended to be merely a parergon-a " second subject," upon which daylight energies might be spent, while the hours of night were reserved for cataloguing those stars that "are bereft of the baths of ocean." Its results, however, proved of the highest interest, although the vicissitudes of life barred the completion, in its full integrity, of the original design. By the death, in 1858, of the elder Carrington, the charge of the brewery devolved upon his son; and eventually absorbed so much of his care that it was found advisable to

1 Observations at Redhill (1863), Introduction. 
bring the solar observations to a premature close, March 24, I 86I.

His scientific life may be said to have closed with them. Attacked four years later with severe, and, in its results permanent illness, he disposed of the Brentford business, and withdrew to Churt, near Farnham, in Surrey. There, in a lonely spot, on the top of a detached conical hill known as the "Devil's Jump," he built a second observatory, and erected an instrument which he was no longer able to use with pristine effectiveness; and there, November 27, 1875, he died of the rupture of a blood-vessel on the brain, before he had completed his fiftieth year. ${ }^{1}$

His observations of sun-spots were of a geometrical character. They concerned positions and movements, leaving out of sight physical peculiarities. Indeed, the prudence with which he limited his task to what came strictly within the range of his powers to accomplish, was one of Carrington's most valuable qualities. The method of his observations, moreover, was chosen with the same practical sagacity as their objects. As early as I 847, Sir John Herschel had recommended the daily self-registration of sun-spots, ${ }^{2}$ and he enforced the suggestion, with more immediate prospect of success, in I $854^{3}$ The art of celestial photography, however, was even then in a purely tentative stage, and Carrington wisely resolved to waste no time on dubious experiments, but employ the means of record and measurement actually at his command. These were very simple, yet very effective. To the "helioscope" employed by Father Scheiner 4 two centuries and a quarter earlier a species of micrometer was added. The image of the sun was projected upon a screen by means of a firmly clamped telescope, in the focus of which were placed two cross wires forming angles of $45^{\circ}$ with the meridian. The six instants were then carefully noted at which these were met by the edges of the disc as it traversed the screen and by the nucleus of the spot to be measured. ${ }^{5} \quad$ A short process of cal-

${ }^{1}$ Month. Not., vol. xxxvi., p. I42. ${ }^{2}$ Cape Observations, p. 435, note. ${ }^{3}$ Month. Not., vol. x., p. I58. " Rosa Ursina, lib. iii., p. $348 .{ }_{5}^{5}$ Observations at Redlill, p. 8. 
culation then gave the exact position of the spot as referred to the sun's centre.

From a series of $\mathbf{5 2 9 0}$ observations made in this way, together with a great number of accurate drawings, Carrington derived conclusions of great importance on each of the three points which he had proposed to himself to investigate. These were: the law of the sun's rotation, the existence and direction of systematic currents, and the distribution of spots on the solar surface.

Grave discrepancies were early perceived to exist between the determination of the sun's rotation by different observers. Galileo, with "comfortable generality," estimated the period at "about a lunar month" ; ${ }^{1}$ Scheiner, at twenty-seven days. ${ }^{2}$ Cassini, in I678, made it 25.58; Delambre, in I775, reduced it to twenty-five days. Later inquiries brought these divergences within no more tolerable limits. Laugier's result of 25.34 days-obtained in I84 I-enjoyed the highest credit, yet it differed widely in one direction from that of Böhm (I852), giving 25.52 days, and in the other from that of Kysæus (I846), giving 25.09 days. Now the cause of these variations was really obvious from the first, although for a long time strangely overlooked. Father Scheiner pointed out in 1630 that different spots gave different periods, adding the significant remark that one at a distance from the solar equator revolved more slowly than those nearer to it. ${ }^{3}$ But the hint was wasted. For upwards of two centuries ideas on the subject were either retrograde or stationary. What were called the "proper motions" of spots were, however, recognised by Schröter, ${ }^{4}$ and utterly baffled Langier, ${ }^{5}$ who despaired of obtaining any concordant result as to the sun's rotation except by taking the mean of a number of discordant ones. At last, in 1855 , a valuable course of observations made at Capo di Monte, Naples, in 1845-6,

1 Op. t. iii., p. 402. ${ }^{2}$ Rosa Ursina, lib. iv., p. 6or. Both Galileo and Scheiner spoke of the apparent or "synodical" period, which is about one and a third days longer than the true or "sidereal" one. The difference is caused by the revolution of the earth in its orbit in the same direction with the sun's rotation on its axis. ${ }^{3}$ Rosa Ursina, lib. iii., p. 260. ${ }^{4}$ Faye, Comptes Rendus, t. 1x., p. 818. ${ }^{5}$ Comptes Rendus, t. xii., p. 648. 
enabled C. H. F. Peters ${ }^{1}$ (later of Hamilton College, Clinton, N.Y.) to set in the clearest light the insecurity of determinations based on the assumption of fixity in objects plainly affected by movements uncertain both in amount and direction.

Such was the state of affairs when Carrington entered upon his task. Everything was in confusion; the most that could be said was that the confusion had come to be distinctly admitted and referred to its true source. What he discovered was this: that the sun, or at least the outer shell of the sun visible to us, has no single period of rotation, but drifts round, carrying the spots with it, at a rate continually accelerated from the poles to the equator. In other words, the time of axial revolution is shortest at the equator and lengthens with increase of latitude. Carrington devised a mathematical formula by which the rate or "law" of this lengthening was conveniently expressed; but it was a purely empirical one. It was a concise statement, but implied no physical interpretation. It summarised, but did not explain the facts. An assumed "mean period" for the solar rotation of 25.38 days (twenty-five days nine hours, very nearly), was thus found to be actually conformed to only in two parallels of solar latitude ( $14^{\circ}$ north and south), while the equatoreal period was slightly less than twenty-five, and that of latitudes $50^{\circ}$ rose to twenty-seven days and a half. ${ }^{2}$ These curious results gave quite a new direction to ideas on solar physics.

The other two "elements" of the sun's rotation were also ascertained by Carrington with hitherto unattained precision. He fixed the inclination of its axis to the ecliptic at $82^{\circ} 45^{\prime}$; the longitude of the ascending node at $73^{\circ} 40^{\prime}$ (both for the epoch I850 A.D.) These data-which have scarcely yet been improved upon-suffice to determine the position in space of the sun's equator. Its north pole is directed towards a star in the coils of the Dragon, midway between Vega and the Pole-star; its plane intersects that of the earth's orbit in such a way that our planet finds itself in the same level on or about the 3 rd of June and the $5^{\text {th }}$ of December, when any spots visible on the

1 Proc. Am. Ass. Adv. of Science, 1855, p. 85. ${ }^{2}$ Observations at Redhill, p. $22 \mathrm{I}$. 
disc cross it in apparently straight lines. At other times, the paths pursued by them seem curved-downward (to an observer in the northern hemisphere) between June and December, upward between December and June.

A singular peculiarity in the distribution of sun-spots emerged from Carrington's studies at the time of the minimum of 1856 . Two broad belts of the solar surface, as we have seen, are frequented by them, of which the limits may be put at $6^{\circ}$ and $35^{\circ}$ of north and south latitude. Individual equatoreal spots are not uncommon, but nearer to the poles than $35^{\circ}$ they are a rare exception. Carrington observed-as an extreme instance-in July I 858 , one in south latitude $44^{\circ}$; and Peters, in June 1846, watched, during several days, a spot in $50^{\circ} 24^{\prime}$ north latitude. But beyond this no true macula has ever been seen; for Lahire's reported observation of one in latitude $70^{\circ}$ is now believed to have had its place on the solar globe erroneously assigned; and the "veiled spots" described by Trouvelot in $1875^{1}$ as occurring within $10^{\circ}$ of the pole can only be regarded as, at the most, the same kind of disturbance in an undeveloped form.

But the novelty of Carrington's observations consisted in the detection of certain changes in distribution concurrent with the progress of the eleven-year period. As the minimum approached, the spot-zones contracted towards the equator, and there finally vanished; then, as if by a fresh impulse, spots suddenly reappeared in high latitudes, and spread downwards with the development of the new phase of activity. Scarcely had this remark been made public, ${ }^{2}$ when Wolf $^{3}$ found a confirmation of its general truth in Böhm's observations during the years I83336 ; and a perfectly similar behaviour was noted both by Spörer and Secchi at the minimum epoch of 1867 . The ensuing period gave corresponding indications; and it may now be looked upon as established that the spot-zones close in towards the equator with the advance of each cycle, their activity culminating, as a rule, in a mean latitude of about $16^{\circ}$, and expiring when it is reduced to $6^{\circ}$. Before this happens, however, a completely new

1 Am. Jour. of Science, vol. xi., p. 169. $\quad 2$ Month. Not., vol. xix., p. I.

3 Vierteljahrsschrift der Naturfors. Gesellschaft (Ziirich), 1859, p. 252. 
disturbance will have manifested itself some $35^{\circ}$ north and south of the equator, and will have begun to travel over the same course as its predecessor. Each series of sun-spots is thus, to some extent, overlapped by the ensuing one; so that while the average interval from one maximum to the next is eleven years, the period of each distinct wave of agitation is twelve or fourteen. ${ }^{1}$ Curious evidence of the retarded character of the maximum of $1883-4$ was to be found in the unusually low latitude of the spot-zones when it occurred. Their movement inwards having gone on regularly while the crisis was postponed, its final symptoms were displaced locally as well as in time. The "law of zones" (as it is called) was duly obeyed at the recent minimum of $1890,{ }^{2}$ and Spörer has found evidence of conformity to it so far back as 1619. ${ }^{3}$ His researches, however, also show that it was in abeyance for some seventy years previously to I 7 I6, during which period sun-spots remained persistently scarce, and auroral displays were feeble and infrequent even in high northern latitudes. An unaccountable suspension at that time of solar activity is thus unmistakably indicated.

Gustav Spörer, born at Berlin in 1822 , began to observe sunspots with the view of assigning the law of solar rotation in December i 860. His means were at first very limited, but his assiduity and success attracted attention, and a Government endowment was procured for the little solar observatory organised by him at Anclam, in Pomerania. Unaware of Carrington's discovery (first made known in January 1859), he arrived at and published, in June I86I, ${ }^{4}$ a similar conclusion as to the equatoreal quickening of the sun's movement on its axis. His sun-spot observations were continued at Anclam until the end of I873, and have since been pursued at the astro-physical observatory of Potsdam.

The time had now evidently come for a fundamental revision of current notions respecting the nature of the sun. Herschel's theory of a cool, dark, habitable globe, surrounded by, and protected against the radiations of a luminous and heat-giving

1 Lockyer, Chemistry of the Sun, p. 428. $\quad 2$ Maunder, Knowledge, vol. xv., p. I30. ${ }^{3}$ Month. Not., vol. 1., p. 251. ${ }^{4}$ Astr. Nach., No. I315. 
envelope, was shattered by the first dicta of spectrum analysis. Traces of it may be found for a few years subsequent to I859, ${ }^{1}$ but they are obviously survivals from an earlier order of ideas, doomed to speedy extinction. It needs only a moment's consideration of what was implied in the discovery of the origin of the Fraunhofer lines to see the incompatibility of the new facts with the old conceptions. It implied, not only the presence near the sun, as glowing vapours, of bodies highly refractory to heat, but that these glowing vapours formed the relatively cool envelope of a still hotter internal mass. Kirchhoff, accordingly, included in his great memoir "On the Solar Spectrum," read before the Berlin Academy of Sciences, July I I, I86I, an exposition of the views on the subject to which his memorable investigations had led him. They may be briefly summarised as follows.

Since the body of the sun gives a continuous spectrum, it must be either solid or liquid, ${ }^{2}$ while the interruptions in its light prove it to be surrounded by a complex atmosphere of metallic vapours, somewhat cooler than itself. Spots are simply clouds due to local depressions of temperature, differing in no respect from terrestrial clouds except as regards the kinds of matter composing them. These sun-clouds take their origin in the zones of encounter between polar and equatoreal currents in the solar atmosphere.

This explanation was liable to all the objections urged against the "cumulus theory" on the one hand, and the "trade-wind theory" on the other. Setting aside its propounder, it was consistently upheld perhaps by no man eminent in science except Spörer ; and his advocacy of it tended rather to delay the recognition of his own merits than to promote its general adoption.

M. Faye, of the Paris Academy of Sciences, was the first to propose a coherent scheme of the solar constitution covering

1 As late as I866 an elaborate treatise in its support was written by M. F. Coyteux, entitled Qu'est ce que le Soleil? Peut-il être habité? and answering the question in the affirmative.

2 The subsequent researches of Plïcker, Frankland, Wüllner, and others showed that gases strongly compressed give an absolutely unbroken spectrum. 
the whole range of new discovery. The fundamental ideas on the subject now in vogue here made their first connected appearance. Much, indeed, remained to be modified and corrected; but the transition was finally made from the old to the new order of conceptions, The essence of the change of view thus effected may be conveyed in a single sentence. The sun was thenceforth regarded, not as a mere heated body, or-still more remotely from the truth-as a cool body unaccountably spun round with a cocoon of fire, but as a vast heat-radiating machine. The terrestrial analogy was abandoned in one more particular besides that of temperature. The solar system of circulation, instead of being adapted, like that of the earth, to the distribution of heat received from without, was seen to be directed towards the transportation towards the surface of the heat contained within. Polar and equatoreal currents, tending to a purely superficial equalisation of temperature, were replaced by vertical currents bringing up successive portions of the intensely heated interior mass, to contribute their share in turn to the radiation into space which might be called the proper function of a sun.

Faye's views, which were communicated to the Academy of Sciences, January I6, 1865, ${ }^{1}$ were avowedly based on the anomalous mode of solar rotation discovered by Carrington. This may be regarded either as an acceleration increasing from the poles to the equator, or as a retardation increasing from the equator to the poles, according to the rate of revolution we choose to assume for the unseen nucleus. Faye preferred to consider it as a retardation produced by ascending currents continually left behind as the sphere widened in which the matter composing them was forced to travel. He further supposed that the depth from which these vertical currents rose, and consequently the amount of retardation effected by their ascent to the surface, became progressively greater as the poles were approached, owing to the considerable flattening of the spheroidal surface from which they started ${ }^{2}$ but the adoption

1 Comptes Reridus, t. 1x., pp. 89, I38. $\quad 2$ 1bid., t. c., p. 595. 
of this expedient has been shown to involve inadmissible consequences.

The extreme internal mobility betrayed by Carrington's and Spörer's observations led to the inference that the matter composing the sun was mainly or wholly gaseous. This had already been suggested by Father Secchi ${ }^{1}$ in January, and by Sir John Herschel in April $1864 ;^{2}$ but it first obtained general currency through Faye's more elaborate presentation. A physical basis was afforded for the view by Cagniard de la Tour's experiments in $1822,{ }^{3}$ proving that, under conditions of great heat and pressure, the vaporous state was compatible with a very considerable density. The position was strengthened when Andrews showed, in $1869,{ }^{4}$ that above a fixed limit of temperature, varying for different bodies, true liquefaction is impossible, even though the pressure be so tremendous as to retain the gas within the same space that enclosed the liquid. The opinion that the mass of the sun is gaseous now commands a very general assent; although the gaseity admitted is of such a nature as to afford the consistence rather of honey or pitch than of the aeriform fluids with which we are familiar.

On another important point the course of subsequent thought was powerfully influenced by Faye's conclusions in I865. Arago somewhat hastily inferred from experiments with the polariscope the wholly gaseous nature of the visible disc of the sun. Kirchhoff, on the contrary, believed (erroneously, as we now know) that the brilliant continuous spectrum derived from it proved it to be a white-hot solid or liquid. Herschel and Secchi ${ }^{5}$ indicated a cloud-like structure as that which would best harmonise the whole of the evidence at command. The novelty introduced by Faye consisted in regarding the photosphere no longer "as a defined surface, in the mathematical sense, but as a limit to which, in the general fluid mass, ascending currents carry the physical or chemical phenomena of

1 Bull. Meteor. dell Osservatorio dell Coll. Rom., Jan. I, I864, p. 4. 2 Quart. Jour. of Science, vol. i., p. 222. $\quad 3$ Ann. de Chim. et de Phys., t. xxii., p. I27. 4 Phil. Trans., vol. clix., p. 575. $\quad{ }^{5}$ Les Mondes, Dec. 22, 1864, p. 707. 
incandescence." 1 Uprushing floods of mixed vapours with strong mutual affinities - say of calcium or sodium and oxygen-at last attain a region cool enough to permit their combination; a fine dust of solid or liquid compound particles (of lime or soda, for example) there collects into the photospheric clonds, and descending by its own weight in torrents of incandescent rain, is ciissociated by the fierce heat below, and replaced by ascending and combining currents of similar constitution.

This first attempt to assign the part played in cosmical physics by chemical affinities, was marked by the importation into the theory of the sun of the now familiar phrase dissociation. It is indeed tolerably certain that no such combinations as those contemplated by Faye occur at the photospheric level, since the temperature there must be enormously higher than would be needed to reduce all metallic earths and oxides; but molecular changes of some kind, dependent perhaps in part upon electrical conditions, in part upon the effects of radiation into space, most likely replace them. The conjecture (originally thrown out, it would seem, by Faye himself) was countenanced by Ångström, ${ }^{2}$ and subsequently advocated by Professor Hastings of Baltimore, ${ }^{3}$ that the photospheric clouds are composed of particles of some member of the carbon-triad ${ }^{4}$ precipitated from its mounting vapour just where the temperature is lowered by expansion and radiation to the boiling-point of that substance. This view is, however, open to grave objections.

In Faye's theory, sun-spots were regarded as simply breaks in the photospheric clouds, where the rising currents had strength to tear them asunder. It followed that they were regions of increased heat-regions, in fact, where the temperature was too high to permit the occurrence of the precipitations to which the photosphere is due. Their obscurity was attributed, as in Dr. Brester's recently published Théorie du Soleil, ${ }^{5}$ to deficiency of emissive power. Yet here the verdict of the spectroscope is adverse and irreversible.

1 Comptes Rendus, t. 1x., p. I47.

2 Recherches sur le Spectre Solaire, p. 38.

$3 \mathrm{Am}$. Jour. of Science, I88I, vcl. xxi., p. 4I. ${ }^{4}$ Carbon, silicon, and boron.

5 Amsterdam, 1892. 
After every deduction, however, has been made, we still find that several ideas of permanent value were embodied in this comprehensive sketch of the solar constitution. The principal of these were: first, that the sun is a mainly gaseous body; secondly, that its stores of heart are rendered available at the surface by means of vertical convection-currents-by the bodily transport, that is to say, of intensely hot matter upwards, and of comparatively cool matter downwards ; thirdly, that the photosphere is a surface of condensation, forming the limit set by the cold of space to this circulating process, and that a similar formation may be supposed to attend, at a certain stage, the cooling of every cosmical body.

To Mr. Warren De la Rue belongs the honour of having obtained the earliest results of substantial value in celestial photography. What had been done previously was interesting in the way of promise, but much could not be claimed for it as actual performance. Some pioneering experiments were made by Dr. J. W. Draper of New York in 1840, resulting in the production of a few "moon-pictures" one-inch in diameter ; 1 but slight encouragement was derived from them, either to himself or others. Bond of Cambridge (U.S.), however, secured in I 850 with the Harvard I 5-inch refractor that daguerreotype of the moon with which the career of extra-terrestrial photography may be said to have formally opened. It was shown in London at the Great Exhibition of $185 \mathrm{I}$, and determined the direction of De la Rue's efforts. Yet it did little more than prove the art to be a possible one.

Warren De la Rue was born in Guernsey in I8I5, was educated at the École Sainte-Barbe in Paris, and made a large fortune as a paper manufacturer in England. ${ }^{2}$ The material supplies for his scientific campaign were thus amply and early provided. Towards the end of 1853 he took some successful lunar photographs. 'They were remarkable as the first examples of the application to astronomical light-painting of the collodion process, invented by Archer in I85I ; and also of the use of

1 H. Draper, Quart. Journ. of Sc., vol. i., p. 38ז ; also Phil. Mag., vol. xvii., 1840, p. 222. 2 He died in London, April 19, 1889, aged 74. 
reflectors (Mr. De la Rue's was one of thirteen inches, constructed by himself) for that kind of work. The absence of a driving apparatus was, however, very sensibly felt; the difficulty of moving the instrument by hand so as accurately to follow the moon's apparent motion being such as to cause the discontinuance of the experiments until $\mathbf{1} 857$, when the want was supplied. Mr. De la Rue's new observatory, built in that year at Cranford, twelve miles west of Hyde Park, was expressly dedicated to celestial photography; and there he immediately applied to the heavenly bodies the stereoscopic method of obtaining relief, and turned his attention to the delicate business of photographing the sun.

A solar daguerreotype ${ }^{1}$ was taken at Paris, April 2, 1845, by MM. Foucault and Fizeau, acting on a suggestion from Arago. But the attempt, though far from being unsuccessful, does not, at that time, seem to have been repeated. Its great difficulty consisted in the enormous light-power of the object to be represented, rendering an inconceivably short period of exposure indispensable, under pain of getting completely "burntup" plates. In I857 Mr. De la Rue was commissioned by the Royal Society to construct an instrument specially adapted to the purpose for the Kew Observatory. The resulting "photoheliograph" may be described as a small telescope (of $3 \frac{1}{2}$ inches aperture and 50 focus), with a plate-holder at the eye-end, guarded in front by a spring-slide, the rapid movement of which across the field of view secured for the sensitive plate a virtually instantaneous exposure. By its means the first solar light-pictures of real value were taken, and the autographic record of the solar condition recommended by Sir John Herschel was commenced and continued at Kew during fourteen years- I 858-72. The work of photographing the sun is now carried on in every quarter of the globe, from the Mauritius to Massachusetts, and the days are few indeed on which the self-betrayal of the camera can be evaded by our chief luminary. In the year I 883 the incorporation of Indian with Greenwich pictures afforded a record of the state of the solar surface on 340 days; and 360 were similarly provided for in 1885 .

1 Reproduced in Arago's Popular Astronomy, plate xii., vol. I. 
The conclusions reached by photographic means at Kew were communicated to the Royal Society in a series of papers drawn up jointly by Messrs. De la Rue, Balfour Stewart, and Benjamin Loewy, in 1865 and subsequent years. They influenced materially the progress of thought on the subject they were concerned with.

By its rotation the sun itself offers opportunities for bringing the stereoscope to bear upon it. Two pictures, taken at an interval of twenty-six minutes, show just the amount of difference needed to give, by their combination, the maximum effect of solidity. ${ }^{1}$ Mr. De la Rue thus obtained, in I86I, a stereoscopic view of a sun-spot and surrounding faculæ, representing the various parts in their true mutual relations. "I have ascertained in this way," he wrote, ${ }^{2}$ "that the faculæ occupy the highest portions of the sun's photosphere, the spots appearing like holes in the penumbræ, which appeared lower than the regions surrounding them; in one case, parts of the faculæ were discovered to be sailing over a spot apparently at some considerable height above it." Thus Wilson's inference as to the depressed nature of spots received, after the lapse of not far from a century, proof of the most simple, direct, and convincing kind. A careful application of Wilson's own geometrical test gave results only a trifle less decisive. Of 694 spots observed, 78 per cent. showed, as they traversed the disc, the expected effects of perspective $;^{3}$ and their absence in the remaining 22 per cent. might be easily explained by internal commotions producing irregularities of structure. The absolute depth of spot-cavities-at least of their sloping sides-was determined by Father Secchi through measures of the "parallax of profundity" 4-that is, of apparent displacements attendant on the sun's rotation, due to depression below the sun's surface. He found that in every case it fell short of 4000 miles, and averaged not more than I32I, corre-

' Report Brit. Ass., 1859, p. 148. 2 Phil. Trans., vol. clii., p. 407. 3 Researehes in Solar Physics, part i., p. $20 .{ }^{4}$ Both the phrase and the method were suggested by Faye, who estimates the average depth of the luminous sheath of spots at 2160 miles. Comptes Rendus, t. lxi., p. I082; t. xcvi., p. 356 . 
sponding, on the terrestrial scale, to an excavation in the earth's crust of $\mathrm{I}_{\frac{1}{5}}$ miles. There may be, however, and probably are, depths below this depth, of which the eye takes not even indirect cognisance; so that it would be hasty to pronounce spots to be a merely superficial phenomenon.

The opinion of the Kew observers as to the nature of such disturbances was strongly swayed by another curious result of the statistical method of inquiry. They found that of I I 37 instances of spots accompanied by faculæ, 584 had those faculæ chiefly or entirely on the left, 508 showed a nearly equal distribution, while 45 only had faculous appendages mainly on the right side. ${ }^{1}$ Now, the rotation of the sun, as we see it, is performed from left to right; so that the marked tendency of the faculæ was a lagging one. This was easily accounted for by supposing the matter composing them to have been flung upwards from a considerable depth, whence it would reach the surface with the lesser absolute velocity belonging to a smaller circle of revolution, and would consequently fall behind the cavities or "spots" formed by its abstraction. A result inconsistent with this deduction was, it is true, reached by M. Wilsing at Potsdam in $1888,{ }^{2}$ through an attempt to determine the sun's rotation from faculæ photographically recorded during six months of the year I 884. They unexpectedly gave a uniform period. No trace of the retardation shown by the spots, poleward from the equator, could be detected in their movements. All seemed to rotate together in a period of nearly $25 \frac{1}{4}$ days, which is just that of spots in $10^{\circ}$ of heliographic latitude. Beyond these limits, accordingly, faculæ ought, if the case really stood thus, to gain steadily upon spots. Observation, however, tells nothing of any such effect. Faculæ have never been seen to press onward in front of the spots to which they originally appertained. M. Wilsing's experiment must then be set aside as inconclusive. ${ }^{3}$ And, indeed, the materials available for it were not only insufficient in amount, but dubious in quality, the identity and

1 Proc. Roy. Soc., vol. xiv., p. 39. 2 Potsdam Publicationen, No. 18 ; Astr. Nach., Nos. 3000, 3153. ${ }^{3}$ Faye, Comptes Rendus, t. cxi., p. 77 ; Belopolsky, Astr. Nach., No. 299 I. 
permanence of faculæ from one week to another being exceedingly ill-assured.

The ideas of M. Faye were, on two fundamental points, contradicted by the Kew investigators. He held spots to be regions of uprush and of heightened temperature; they believed their obscurity to be due to a downrush of comparatively cool vapours. Now M. Chacornac, observing at Ville-Urbanne, March, 6, i 865, saw floods of photospheric matter visibly precipitating themselves into the abyss opened by a great spot, and carrying with them small neighbouring maculæ. ${ }^{1}$ Similar instances were repeatedly noted by Father Secchi, who considered the existence of a kind of suction in spots to be quite beyond question. ${ }^{2}$ The tendency in their vicinity, to put it otherwise, is centripetal, not centrifugal; and this alone seems to negative the supposition of a central uprush.

A fresh witness was by this time at hand. The application of the spectroscope to the direct examination of the sun's surface dates from March 4, 1866, when Mr. Norman Lockyer began his inquiry into the cause of the darkening in spots. ${ }^{3}$ It was made possible by the simple device of throwing upon the slit of the spectroscope an image of the sun, any part of which could be subjected to special scrutiny, instead of (as had hitherto been done) admitting rays from every portion of his surface indiscriminately. The answer to the inquiry was prompt and unmistakable, and was again, in this case, adverse to the French theorist's view. The obscurations in question were found to be produced by no deficiency of emissive power, but by an increase of absorptive action. The background of variegated light remains unchanged, but more of it is stopped by the interposition of a dense mass of relatively cool vapours. The spectrum of a sun-spot is crossed by the same set of multitudinous dark lines, with some minor differences, visible in the ordinary solar spectrum. We must then conclude that the same vapours (speaking generally) which are dispersed over the unbroken solar surface, are accumulated in the umbral cavity, the compression

1 Lockyer, Contributions to Solar Physics, p. 70.

2 Le Soleil, p. 87.

3 Proc. Roy. Soc., vol. xv., p. 256. 
incidental to such accumulation being betrayed by the thickening of certain lines of absorption. But there is also a general absorption, extending almost continuously from one end of the spot-spectrum to the other. Using, however, a spectroscope of exceptionally high dispersive power, Professor Young of Princeton, New Jersey, succeeded in I883 in resolving, for the most part, the supposed continuous obscurity of spot-spectra into a countless multitude of fine dark lines set very close together. ${ }^{1}$ This was done, still more perfectly, about five years later, by M. Dunér, ${ }^{2}$ Director of the Upsala observatory, who was besides able to trace some bare shadows, as it were, of the crowded doublets and triplets forming the array, from the spots into the general solar spectrum. He hence drew the inference that, between the photospheric and the spot-spectra, there is no fundamental difference, but that the latter is merely an intensification of the former.

As to the movements of the constipated vapours forming spots, the spectroscope is also competent to supply information. The principle of the method by which it is procured will be explained farther on. Suffice it here to say that the transport, at any considerable velocity, to or from the eye of the gaseous material giving bright or dark lines, can be measured by the displacement of such lines from their previously known normal positions. In this way movements have been detected in or above spots of enormous rapidity, ranging up to 320 miles per second. But the result, so far, has been to negative the ascription to them of any systematic direction. Uprushes and downrushes are doubtless, as Father Cortie remarks, 3 " correlated phenomena in the production of a sun-spot"; but neither seem to predominate as part of its regular internal economy.

The same kind of spectroscopic evidence tells heavily against a theory of sun-spots, started by Faye in I872, and still advocated by him. He had been foremost in pointing ont that the observations of Carrington and Spörer absolutely forbade the supposition that any phenomenon at all resembling our trade-

1 Phil. Mag., vol. xvi., p. 460. 2 Recherches sur la Rotation du Soleil, p. 12, Upsala, I891. 3 Jour. Brit. Astr. Ass., vol. i., p. 177. 
winds exists in the sun. They showed, indeed, that beyond the parallels of $20^{\circ}$ there is a general tendency in spots to a slow poleward displacement, while within that zone they incline to approach the equator; but thẹir "proper movements" gave no evidence of uniformly flowing currents in latitude. The systematic drift of the photosphere is strictly a drift in longitude; its direction is everywhere parallel to the equator. This fact being once clearly recognised, the "solar tornado" hypothesis at once fell to pieces; but M. Faye ${ }^{1}$ perceived another source of vorticose motion in the unequal rotating velocities of contiguous portions of the photosphere. The "pores" with which the whole surface of the sun is studded he took to be the smaller eddies resulting from these inequalities; the spots to be such eddies developed into whirlpools. It only needs to thrust a stick into a stream to produce the kind of effect designated. And it happens that the differences of angular movement adverted to attain a maximum just about the latitudes where spots are most frequent and conspicuous.

There are, however, grave difficulties in identifying the two kinds of phenomena. One (already mentioned) is the total absence of the regular swirling motion-in a direction contrary to that of the hands of a watch north of the solar equator, in the opposite sense south of it-which should impress itself upon every lineament of a sun-spot if the cause assigned were a primary producing, and not merely, as it possibly may be, a secondary determining one. The other, pointed out by Professor Young, ${ }^{2}$ is that the cause is inadequate to the effect. The difference of movement, or relative drift, supposed to occasion such prodigious disturbances, amounts, at the utmost, for two portions of the photosphere 123 miles apart, to about five yards a minute. Thus the friction of contiguous sections must be quite insignificant.

A view better justified by observation was urged by Father

1 Comptes Rendus, t. Ixxv., p. 1664; Revue Scientifique, t. v., p. 359 (1883). Mr. Herbert Spencer had already (in The Reader, Feb. 25, 1865) put forward an opinion that spots were of the nature of "cyclonic clouds." 2 The Sun, p. I74. For Faye's answer to the objection, see Comptes Rendus, t. xcv., p. I3IO. 
Secchi in and after the year I872, and was presented in an improved form by Professor Young in his excellent little book on The Sun, published in I882. Spots are manifestly associated with violent eruptive action, giving rise to the faculæ and prominences which usually garnish their borders. It is accordingly contended that upon the withdrawal of matter from below by the flinging up of a prominence must ensue a sinking-in of the surface, into which the partially cooled erupted vapours rush and settle, producing just the kind of darkening by increased absorption told of by the spectroscope. Round the edges of the cavity the rupture of the photospheric shell will form lines of weakness provocative of further eruptions, which will, in their turn, deepen and enlarge the cavity. The phenomenon will thus tend to perpetuate itself, until equilibrium is at last restored by internal processes. A sun-spot might then be described as an inverted terrestrial volcano, in which the outbursts of heated matter take place on the borders instead of at the centre of the crater, while the cooled products gather in the centre instead of at the borders.

But on the earth, the solid crust forcibly represses the steam gathering beneath until it has accumulated strength for an explosion, while there is no such restraining power that we know of in the sun. Zöllner, indeed, adapted his theory of the solar constitution to the special purpose of procuring it; yet with very partial success, since almost every new fact ascertained has proved adverse to his assumptions. Volcanic action is essentially spasmodic. It implies habitual constraint varied by temporary outbreaks, inconceivable in a gaseous globe, such as we believe the sun to be.

If the "volcanic hypothesis" represented the truth, no spot could possibly appear without a precedent eruption. The real order of the phenomena is exceedingly difficult to ascertain; nor is it perhaps invariable. Yet, some instances to the contrary notwithstanding, spots seem as a rule to begin the visible disturbance, while faculæ show subsequently to the opening of a rent in the photosphere.

This sequence forms an integral part of Professor Lockyer's 
theory of sun-spots, communicated to the Royal Society, May 6, I 886, ${ }^{1}$ and further developed some months later in his work on The Chemistry of the Sun. Spots are represented in it as incidental to a vast system of solar atmospheric circulation, starting with the polar out- and up-flows indicated by observations during some total eclipses, and eventuating in the plunge downward from great heights upon the photosphere of prodigious masses of condensed materials. From these falls result, primarily. spots; secondarily, through the answering uprushes in which chemical and mechanical forces co-operate, their girdles of flameprominences. The limitation of spots to middle latitudes is accounted for as follows. Above the equator, the height of fall is so great that the products of condensation are volatilised before reaching the photosphere. Near the poles, on the contrary, the cooled substances have attained too small an elevation to give. the velocity needed to bring them to the surface in a solid form. Hence their fall can produce nothing more conspicuous than pores and "veiled spots." This augmented height of descent with diminishing latitude offers besides an explanation of Carrington's law of solar rotation. For the nearer a spot lies to the equator, the faster it must travel, because its materials, falling from a greater elevation, bring down with them the increased velocity belonging to a wider circumference. Local changes of temperature and extent in the sun's atmosphere, due to the violent disturbances affecting it, are supposed, on this hypothesis, to occasion periodical fluctuations in spot-frequency, as well as the observed oscillations of the spot-zones. Nevertheless, the evidence is far from clear that a circulatory system such as it postulates is really in operation in the sun's atmosphere. A similar objection applies to M. E. von Oppolzer's recently published rationale of solar disturbances. ${ }^{2}$

A singular circumstance has now to be recounted. On the Ist of September 1859, while Carrington was engaged in his daily work of measuring the positions of sun-spots, he was startled by the sudden appearance of two patches of peculiarly intense light within the area of the largest group visible. His 
first idea was that a ray of unmitigated sunshine had penetrated the screen employed to reduce the brilliancy of the image; but, having quickly convinced himself to the contrary, he ran to summon an additional witness of an obviously remarkable occurrence. On his return he was disappointed to find the strange luminous outburst already on the wane; shortly afterwards the last trace of it vanished. Its entire duration was five minutes-from I I.I 8 to I I.23 A.M., Greenwich time; and during those five minutes it had traversed a space estimated at 35,000 miles! No perceptible change took place in the details of the group of spots visited by this transitory conflagration, which, it was accordingly inferred, took place at a considerable height above it. ${ }^{1}$

Carrington's account was precisely confirmed by an observation made at Highgate. Mr. R. Hodgson described the appearance seen by him as that "of a very brilliant star of light, much brighter than the sun's surface, most dazzling to the protected eye, illuminating the upper edges of the adjacent spots and streaks, not unlike in effect the edging of the clouds at sunset." 2

This unique phenomenon seemed as if specially designed to accentuate the inference of a sympathetic relation between the earth and the sun. From the 28th of August to the 4th of September I 859, a magnetic storm of unparalleled intensity, extent, and duration, was in progress over the entire globe. Telegraphic communication was everywhere interrupted-except, indeed, that it was, in some cases, found practicable to work the lines without batteries, by the agency of the earth-currents alone ${ }^{3}$ sparks issued from the wires; gorgeous auroræ draped the skies in solemn crimson over both hemispheres, and even within the tropics; the magnetic needle lost all trace of continuity in its movements, and darted to and fro as if stricken with inexplicable panic. The coincidence was drawn even closer. At the very instant $^{4}$ of the solar outburst witnessed by Carrington and Hodgson, the photographic apparatus at Kew registered a marked disturbance of all the three magnetic elements; while,

1 Month. Not., vol. xx., p. 13. $\quad 2$ 1bid., p. 15. $\quad 3$ Am. Jour., voi. xxix. (2nd series), pp. 94-95. $\quad 4$ The magnetic disturbance took place at I I. I 5 A.M. three minutes before the solar blaze compelled the attention of Carrington. 
shortly after the ensuing midnight, the electric agitation culminated, thrilling the earth with subtle vibrations, and lighting up the atmosphere from pole to pole with the coruscating splendours which, perhaps, dimly recall the times when our ancient planet itself shone as a star.

Here then, at least, the sun was-in Professor Balfour Stewart's phrase- "taken in the act" ${ }^{1}$ of stirring up terrestrial commotions. Nor have instances since been wanting of an indubitable connection between outbreaks of individual spots and magnetic disturbances. Four such were registered in I882; and symptoms of the same kind markedly attended the progress across the sun of the enormous spot-group of February I892the largest ever recorded at Greenwich. This extraordinary formation, which covered about $\frac{1}{300}$ of the sun's disc, preserved its individuality, though not its gigantic proportions, through five complete rotations. ${ }^{2}$ It was remarkable for a persistent drift in latitude, its place altering progressively from $17^{\circ}$ to $30^{\circ}$ south of the solar equator.

The nearest approach to the event of September I, I859, was photographically observed by Professor George E. Hale at Chicago, July I5, I892. ${ }^{3}$ An active spot in the southern hemisphere was the scene of this curiously sudden manifestation. During an interval of 12 minutes between two successive exposures, a bridge of dazzling light was found to have spanned the boundary-line dividing the twin-nuclei of the spot; and these, after another 27 minutes, were themselves almost obliterated by an overflow of far-spreading brilliancy. Yet two hours later, no trace of the outburst remained, the spot and its attendant faculæ remaining just as they had been previously to its occurrence. Unlike that seen by Carrington, it was accompanied by no exceptional magnetic phenomena, although a "storm" set in next day. ${ }^{4}$ Possibly a terrestrial analogue to the former might be discovered in the "auroral beam" which traversed the heavens

1 Phil. 'Trans., vol. cli., p. 428. $\quad 2$ Maunder, Journal Brit. Astr. Ass., vol. ii., p. 386; Miss E. Brown, Ibid., p. 210; Month. Not., vol. lii., p. 354. 3 Astr. and A stro-Physics, Ang. I892, p. 6i I.

4 lbid., Nov. I892, p. 819 (Sidgreaves). 
during a vivid display of polar lights, November I7, I882, and shared, there is every reason to believe, their electrical origin and character. ${ }^{1}$

Meantime M. Rudolf Wolf, transferred to the direction of the Zürich Observatory, had relaxed none of his zeal in the investigation of sun-spot periodicity. A laborious revision of the entire subject with the aid of fresh materials led him, in I $859,{ }^{2}$ to the conclusion that while the mean period differed little from that arrived at in I 852 of I I. I I years, very considerable fluctuations on either side of that mean were rather the rule than the exception. Indeed, the phrase "sun-spot period" must be understood as fitting very loosely the great fact it is taken to represent; so loosely, that the interval between two maxima may rise to sixteen and a half, or sink below seven and a half years. $^{3}$ In I $86 \mathrm{I}^{4}$ Wolf showed, and the remark was fully confirmed by the Kew observations, that the shortest periods brought the most acute crises, and vice versa; as if for each wave of disturbance a strictly equal amount of energy were available, which might spend itself lavishly and rapidly, or slowly and parsimoniously, but could in no case be exceeded. The further inclusion of recurring solar commotions within a cycle of fifty-five and a half years was simultaneously pointed out; and Hermann Fritz showed soon after that the aurora borealis is subject to an identical double periodicity. ${ }^{5}$ The same inquirer detected besides both for auroræ and sunspots a "secular period" of 222 years, ${ }^{6}$ and the Kew observations indicate for the latter, oscillations accomplished within twenty-six and twenty-four days, ${ }^{7}$ depending most likely upon the rotation of the sun. This is certainly reflected in

1 See J. Rand Capron, Phil. Mag., vol. xv., p. 318. ${ }^{2}$ Mittheilungen über die sonnenflecken, No ix., Vierteljahrsschrift der Naturforschenden Gesellschaft in Zürich, Jahrgang 4. ${ }^{3}$ Mitth., No. lii., p. 58 (1881). 4 Ibid., No. xii., p. 192. Mr. Joseph Baxendell, of Manchester, reached independently a similar conclusion. See Month. Not., vol. xxi., p. 141. ${ }^{5}$ Wolf, Mitth., No. xv., p. 107, \&c. Olmsted, following Hansteen, had already, in 1856, sought to establish an auroral period of sixty-five years. Smithsonian Contributions, vol. viii., p. 37. ${ }^{6} \mathrm{Hahn}$, Ueber die Beziehungen der Sonnenfleclienperiode zu meteorologischen Erscheinungen, p. 99 (1877).

7 Report Brit. Ass., I88I, p. $518 ; 1883$, p. 418 . 
magnetic, and, according to the statistics collected by Mr. M. A. Veeder, ${ }^{1}$ of Lyons, N.Y., also in auroral periodicity. The more closely spot-fluctuations are looked into, indeed, the more complex they prove. Maxima of one order are superposed upon, or in part neutralised by, maxima of another order; originating causes are masked by modifying causes; the larger waves of the commotion are indented with minor undulations, and these again crisped with tiny ripples, while the whole rises and falls with the swell of the great secular wave, scarcely perceptible in its progress because so vast in scale.

The idea that solar maculation depends in some way upon the position of the planets occurred to Galileo in I612. ${ }^{2}$ It has been industriously sifted by a whole bevy of modern solar physicists. Wolf in $1859^{3}$ found reason to believe that the eleven-year curve is determined by the action of Jupiter, modified by that of Saturn, and diversified by influences proceeding from the earth and Venus. Its tempting approach to agreement with Jupiter's period of revolution round the sun, indeed, irresistibly suggested a causal connection; yet it does not seem that the most skilful "coaxing" of figures can bring about a fundamental harmony. Carrington pointed out in 1863, that while, during eight successive periods, from I770 downwards, there were approximate coincidences between Jupiter's aphelion passages and sun-spot maxima, the relation had been almost exactly reversed in the two periods preceding that date ${ }^{4}$ and the latest conclusion of M. Wolf himself is that the Jovian origin must be abandoned. ${ }^{5}$ M. Duponchel ${ }^{6}$ of Paris was nevertheless not wholly unsuccessful in accommodating discrepancies with the help of perturbations by the large exterior planets; since his prediction of an abnormal lengthening of the maximum of $1883-4$, through certain peculiarities in the positions of Uranus and Neptune about the time it fell due, was partially verified by the event. The previous maximum having occurred in June I870, the next phase of agitation should, if punctual,

1 Astr. and Astro-Physics, March 1893, p. 264. 2 Opere, t. iii., p. 412. 3 Mitth., Nos. vii. and xviii. 4 Observations at Redlill, p. $248 .{ }^{5}$ Comptes Rendus, t. xcv., p. 1249. ${ }^{6}$ Ibid., t. xciii., p. 827 ; t. xcvi., p. 1418. 
have culminated about August 188I ; whereas, after an abortive effort at completion in April 1882, the final outburst was postponed to November I883. The interval was thus I 3.3 instead of I I. I years; and it is noticeable that the delay affected chiefly the southern hemisphere. Alternations of activity in the solar hemispheres were indeed a marked feature of the maximum of I883-4, which, in M. Faye's view, ${ }^{1}$ derived thence its indecisive character, while sharp, strong crises arise with the simultaneous advance of agitation north and south of the solar equator. The curve of magnetic disturbance, it should be added, followed with its usual strict fidelity the anomalous fluctuations of the sun-spot curve. The ensuing minimum occurred in February 1890.

It cannot be said that much progress has yet been made towards the disclosure of the cause, or causes, of the sunspot cycle. No external influence adequate to the effect has, at any rate, been pointed out. The Kew observers adduced evidence to show that solar outbreaks are modified by planetary configurations; ${ }^{2}$ but even this secondary kind of relationship has of late evaded notice. Other thinkers on this difficult subject have provided a quasi-explanation of the periodicity in question through certain assumed vicissitudes affecting internal processes; ${ }^{3}$ while Professor Lockyer reaches the same end by establishing self-compensatory fluctuations in the solar atmospheric circulation. In all these theories, however, the flow of change is arbitrarily arranged to suit a period, which imposes itself as a fact necessarily admitted, although not easily accounted for.

The question so much discussed, as to the influence of sunspots on weather, does not admit of a satisfactory answer. The facts of meteorology are too complex for easy or certain classification. Effects owning dependence on one cause often wear the livery of another; the meaning of observed particulars may be inverted by situation; and yet it is only by the collection and

1 Comptes Rendus, t. c., p. 593. ${ }^{2}$ Ed. Plil. Trans., vol. xxiii., p. 499 ; Prac. Roy. Soc., vols. xiv., p. 59 ; xx., p. 2 10. ${ }^{3}$ Schulz, Astr. Nach., Nos. 2817-18, 2847-8; Wilsing, Ibid., Nos. 3000, 3039; Belopolsky, Ibid., Nos. 2722, 2954. 
collocation of particulars that we can hope to reach any general law. There is, however, a good deal of evidence to support the opinion-the grounds for which were primarily derived from the labours of Mr. Meldrum at the Mauritius-that increased rainfall and atmospheric agitation attend spot-maxima; while Herschel's conjecture of a more copious emission of light and heat about the same epochs has received little support from direct investigations. The inequality seems indeed to be the other way. Radiation, according to the best recent authorities, gains strength at times of minimum. ${ }^{1}$

The examination of what we may call the texture of the sun's surface derived new interest from a remarkable announcement made by Mr. James Nasmyth in I862. ${ }^{2}$ He had (as he supposed) discovered the entire luminous stratum of the sun to be composed of a multitude of elongated shining objects on a darker background, shaped much like willow-leaves, of vast size, crossing each other in all possible directions, and possessed of unceasing relative motions. A lively controversy ensued. In England and abroad, the most powerful telescopes were directed to a scrutiny encompassed with varied difficulties. The results, on the whole, were such as to invalidate the precision of the disclosures made by the Hammerfield reflector. Mr. Dawes was especially emphatic in declaring that Nasmyth's "willowleaves" were nothing more than the "nodules" of Sir William Herschel seen under a misleading aspect of uniformity; and there is little doubt that he was right. It is, however, admitted that something of the kind may be seen in the penumbræ and "bridges" of spots, presenting an appearance compared by Dawes himself in I 852 to that of a piece of coarse straw-thatching left untrimmed at the edges. ${ }^{3}$

The term "granulated," suggested by Dawes in $1864,{ }^{4}$ best describes the mottled aspect of the solar disc as shown by modern telescopes and cameras. The grains, or rather the

1 Blanford, Nature, vol. xliii., p. 583. ${ }^{2}$ Report Brit. Ass., 1862, p. 16 (pt. ii.). $\quad{ }^{3}$ Mem. R. A. Soc., vol. xxi., p. г6r. ${ }^{4}$ Month. Not., vol. xxiv., p. 162. 
"floccules," with which it is thickly strewn, have been resolved by Langley, under exceptionally favourable conditions, into "granules" not above roo miles in diameter; and from these relatively minute elements, composing, jointly, about one-fifth of the visible photosphere, ${ }^{1}$ he estimates that three quarters of the entire light of the sun are derived, ${ }^{2}$ Janssen goes so far as to say that if the whole surface were as bright as its brightest parts, its luminous emission would be ten to twenty times greater than it actually is. ${ }^{3}$

The rapid changes in the forms of these solar cloud-summits are beautifully shown in the marvellous photographs taken by Janssen at Meudon, with exposures reduced at times to $\frac{1}{100000}$ of a second! By their means, also, the curious phenomenon known as the réseau photosphérique has been made evident. ${ }^{4}$ This consists in the diffusion over the entire disc of fleeting blurred patches, separated by a reticulation of sharply outlined, and regularly arranged granules. The appearance of imperfect definition in the smudged areas is doubtless due to agitations in the intervening solar atmosphere. M. Janssen considers that the photospheric cloudlets change their shape and character with the progress of the sun-spot period $;^{5}$ but nothing is as yet quite certain upon this point.

The "grains," or more brilliant parts of the photosphere, are now generally held to represent the upper termination of ascending and condensing currents, while the darker interstices (Herschel's "pores") mark the positions of descending cooler ones. In the penumbræ of spots, the glowing streams rushing up from the tremendous sub-solar furnace are bent sideways by the powerful indraught, so as to change their vertical for a. nearly horizontal motion, and are thus taken, as it were, in flank by the eye, instead of being seen end-on in mamelon form. Thus a plausible explanation is afforded of the channelled penumbral

1 Am. Jour. of Science, vol. vii., 1874, p. 92. p. IO3. 3 Ann. Bur. Long., 1879, p. 679. ${ }_{5}$ Ranyard, Knouledge, vol. xiv., p. I4, where compare the accompanying photographs.
2 Young, The Sun, 4 Ibid., I 878 , p. 689.
are the accompanying. (1) 
structure which suggested the comparison to a rude thatch. Accepting this theory as in the main correct, we perceive that the very same circulatory process which, in its spasms of activity, gives rise to spots, produces in its regular course the singular "marbled" appearance, for the recording of which we are no longer at the mercy of the fugitive or delusive impressions of the human retina. And precisely this circulatory process it is which gives to our great luminary its permanence as a sun, or warming and illuminating body. 


\section{CHAPTER III.}

\section{RECENT SOLAR ECLIPSES.}

By observations made during a series of five remarkable eclipses, comprised within a period of eleven years, knowledge of the solar surroundings was advanced nearly to its present stage. Each of these events brought with it a fresh disclosure of a definite and unmistakable character. We will now briefly review this orderly sequence of discovery.

Photography was first systematically applied to solve the problems presented by the eclipsed sun, July I8, I860. It is true that a very creditable daguerreotype, ${ }^{1}$ taken by Barkowski with the Königsberg heliometer during the eclipse of $185 \mathrm{I}$, is still valuable as a record of the corona of that year; and some subsequent attempts were made to register partial phases of solar occultation, notably by Professor Bartlett at West Point in I $854 ;^{2}$ but the ground remained practically unbroken until I860.

In that year the track of totality crossed Spain, and thither, accordingly, Mr. Warren De la Rue transported his photoheliograph, and Father Secchi his six-inch Cauchoix refractor. The question then primarily at issue was that relating to the nature of the red protuberances. Although, as already stated, the evidence collected in $185 \mathrm{I}$ gave a reasonable certainty of their connection with the sun, objectors were not silenced; and when the side of incredulity was supported by so considerable an authority as M. Faye, it was impossible to' treat it with contempt. Two crucial tests were available. If it could be shown that the

1 Vierteljahrsschrift As r. Ges., Jahrg. xxvi., p. 274. ${ }^{2}$ Astr. Jour., vol. iv., p. 33 . 
fantastic shapes suspended above the edge of the dark moon were seen under an identical aspect from two distant stations, that fact alone would annihilate the theory of optical illusion or "mirage"; while the certainty that they were progressively concealed by the advancing moon on one side, and uncovered on the other, would effectually detach them from dependence on our satellite, and establish them as solar appendages.

Now both these tests were eminently capable of being applied by photography. But the difficulty arose that nothing was known as to the chemical power of the rosy prominence-light, while everything depended on its right estimation. A shot had to be fired, as it were, in the dark. It was a matter of some surprise, and of no small congratulation, that, in both cases, the shot took effect.

Mr. De la Rue occupied a station at Rivabellosa, in the Upper Ebro valley; Father Secchi set up his instrument at Desierto de las Palmas, about 250 miles to the south-east, overlooking the Mediterranean. From the totally eclipsed sun, with its strange garland of flames, each observer derived several perfectly successful impressions, which were found, on comparison, to agree in the most minute details. This at once settled the fundamental question as to the substantial reality of these objects; while their solar character was demonstrated by the passage of the moon in front of them, indisputably attested by pictures taken at successive stages of the eclipse. That forms seeming to defy all laws of equilibrium were, nevertheless, not wholly evanescent, appeared from their identity at an interval of seven minutes, during which the lunar shadow was in transit from one station to the other; and the singular energy of their actinic rays was shown by the record on the sensitive plates of some prominences invisible in the telescope. Moreover, photographic evidence strongly confirmed the inference-previously drawn by Grant and others, and now repeated with fuller assurance by F. Secchi - that an uninterrupted stratum of prominence-matter encompasses the sun on all sides, forming a reservoir from which gigantic jets issue, and into which they subside.

Thus a first-fruits of accurate knowledge regarding the solar 
surroundings was gathered, and the value of the brief moments of eclipse indefinitely increased, by supplementing transient visual impressions with the faithful and lasting records of the camera.

In the year I 868 the history of eclipse spectroscopy virtually began, as that of eclipse photography in I860; that is to say, the respective methods then first gave definite results. On the I 8th of August I868, the Indian and Malayan peninsulas were traversed by a lunar shadow producing total obscuration during five minutes and thirty-eight seconds. Two English and two French expeditions were despatched to the distant regions favoured by an event so propitious to the advance of knowledge, chiefly to obtain the verdict of the prism as to the composition of prominences. Nor were they despatched in vain. An identical discovery was made by nearly all the observers. At Jamkandi, in the Western Ghauts, where Lieutenant (now Colonel) Herschel was posted, unremitting bad weather threatened to baffle his eager expectations; but during the lapse of the critical five and a half minutes the clouds broke, and across the driving wrack a "long, finger-like projection" jutted out over the margin of the dark lunar globe. In another moment the spectroscope was pointed towards it; three bright lines-red, orange, and blue-flashed out, and the problem was solved. ${ }^{1}$ The problem was solved in this general sense, that the composition out of glowing vapours of the objects infelicitously termed "protuberances" or "prominences" was no longer doubtful; although further inquiry was needed for the determination of the particular species to which those vapours belonged.

Similar, but more complete observations were made, with less atmospheric hindrance, by Tennant and Janssen at Guntoor, by Pogson at Masulipatam, and by Rayet at Wha-Tonne, on the coast of the Malay peninsula, the last observer counting as many as nine bright lines. ${ }^{2}$ Among them it was not difficult to recognise the characteristic light of hydrogen; and it was generally, though over-hastily, assumed that the orange ray

1 Proc. Roy. Soc., vol. xvii., p. I 16.

2 Comptes Rendus, t. lxvii., p. 757. 
matched the luminous emissions of sodium. But fuller opportunities were at hand.

The eclipse of 1868 is chiefly memorable for having taught astronomers to do without ecljpses, so far, at least, as one particular branch of solar inquiry is concerned. Inspired by the beauty and brilliancy of the variously tinted prominence-lines revealed to him by the spectroscope, Janssen exclaimed to those about him, "Je verrai ces lignes-là en dehors des éclipses!" On the following morning he carried into execution the plan which formed itself in his brain while the phenomenon which suggested it was still before his eyes. It rests upon an easily intelligible principle.

The glare of our own atmosphere alone hides the appendages of the sun from our daily view. To a spectator on an airless planet, the central globe would appear attended by all its splendid retinue of crimson prominences, silvery corona, and farspreading zodiacal light, projected on the star-spangled black background of an absolutely unilluminated sky. Now the spectroscope offers the means of indefinitely weakening atmospheric glare by diffusing a constant amount of it over an indefinitely widened area. But monochromatic or "bright-line" light is, by its nature, incapable of being so diffused. It can, of course, be deviated by refraction to any extent desired; but it always remains equally concentrated, in whatever direction it may be thrown. Hence, when it is mixed up with continuous light-as in the case of the solar flames shining through our atmosphere-it derives a relative gain in intensity from every addition to the dispersive power of the spectroscope with which the heterogeneous mass of beams is analysed. Employ prisms enough, and eventually the undiminished rays of persistent colour will stand out from the continually fading rainbow-tinted band, by which they were at first effectually veiled.

This Janssen saw by a flash of intuition while the eclipse was in progress; and this he realised at IO A.M. next morning, August 19, I868-the date of the beginning of spectroscopic work at the margin of the unobscured sun. During the whole of that day and many subsequent ones, he enjoyed, as he said, 
the advantage of a prolonged eclipse. The intense interest with which he surveyed the region suddenly laid bare to his scrutiny was heightened by evidences of rapid and violent change. On the I8th of August, during the eclipse, a huge spiral structure, at least 89,000 miles high, was perceived, planted in surprising splendour on the rim of the interposed moon. It was formed, as Major Tennant judged from its appearance in his photographs, by the encounter of two mounting torrents of flame, and was distinguished as the "Great Horn." Next day it was in ruins; hardly a trace remained to show where it had been. ${ }^{1}$ Janssen's spectroscope furnished him besides with the strongest confirmation of what had already been reported by the telescope and the camera as to the continuous nature of the scarlet "sierra" lying at the base of the prominences. Everywhere at the sun's edge the same bright lines appeared.

It was not until the Igth of September that Janssen thought fit to send news of his discovery to Europe. He little dreamed of being anticipated; nor did he indeed grudge that science should advance at the expense of his own undivided fame. A few minutes before his despatch was handed to the Secretary of the Paris Academy of Sciences, a communication similar in purport had been received from Mr. Norman Lockyer. There is no need to discuss the narrow and wearisome question of priority; each of the competitors deserves, and has obtained, full credit for his invention. With noteworthy and confident prescience, Mr, Lockyer, in I866, before anything was yet known regarding the constitution of the "red flames," ordered a strongly dispersive spectroscope for the express purpose of viewing, apart from eclipses, the bright-line spectrum which he expected them to give. Various delays, however, supervened, and the instrumeut was not in his hands until October 16, 1868. On the 2oth he picked up the vivid rays, of which the presence and (approximately) the positions had in the interim become known. But there is little doubt that, even without that previous knowledge, they would have been found; and that the

1 Comptes Rendus, t. 1xvii., p. 8.39 . 
eclipse of August I8 only accelerated a discovery already assured.

Dr. Huggins, meanwhile, had been tending towards the same goal during two and a half years in his observatory at Tulse Hill. The principle of the spectroscopic visibility of prominence-lines at the edge of an uneclipsed sun was quite explicitly stated by him in February I868, ${ }^{1}$ and he devised various apparatus for bringing them into actual view; but not until he knew where to look did he succeed in seeing them.

Astronomers, thus liberated, by the acquisition of power to view them at any time, from the necessity of studying prominences during eclipses, were able to concentrate the whole of their attention on the corona. The first thing to be done was to ascertain the character of its spectrum. This was seen in I 868 only as a faintly continuous one; for Rayet, who seems to have perceived its distinctive bright line far above the summits of the flames, connected it, nevertheless, with those objects. On the other hand, Lieutenant Campbell ascertained on the same occasion the polarisation of the coronal light in planes passing through the sun's centre, ${ }^{2}$ thereby showing that light to be, in whole or in part, reflected sunshine. But if reflected sunshine, it was objected, the chief at least of the dark Fraunhofer lines should be visible in it, as they are visible in moonbeams, sky illumination, and all other sun-derived light. The objection was well founded, but was prematurely urged, as we shall see.

On the 7th of August 1869, a track of total eclipse crossed the continent of North America diagonally, entering at Behring's Straits, and issuing on the coast of North Carolina. It was beset with observers ; but the most effective work was done in Iowa. At Des Moines, Professor Harkness of the Naval Observatory, Washington, obtained from the corona an "absolutely continuous spectrum," slightly less bright than that of the full moon, but traversed by a single green ray. ${ }^{3}$ The same green ray was seen at Burlington, and its position measured by

1 Month. Not., vol. xxvii., p. 88.

2 Proc. Rioy. Soc., vol. xvii., p. 123.

3 Washington Observations, i867, App. ii., Harkness's Report, p. 60. 
Professor Young. ${ }^{1}$ It was found to coincide with that of a dark line of iron in the solar spectrum, numbered 1474 on Kirchhoff's scale. This was perplexing, since it seemed, at first sight, to compel the inference that the corona was actually composed of vapour of iron, ${ }^{2}$ so attenuated as to give only one line of secondary importance out of the many hundreds belonging to it. But in I876 Young was able, by the use of greatly increased dispersion, to resolve the Fraunhofer line "I 474" into a pair, of which one component is due to iron, the other (the more refrangible) to the coronal gas. ${ }^{3}$ This substance, now distinguished as "coronium," of which nothing is known to terrestrial chemistry, appears luminous at least half a million of miles above the sun's surface, and is hence presumably much lighter even than hydrogen.

A further trophy was carried off by American skill ${ }^{4}$ sixteen months after the determination due to it of the distinctive spectrum of the corona. The eclipse of December 22, I870, though lasting only two minutes and ten seconds, drew observers from the New, as well as from the Old World to the shores of the Mediterranean. Janssen issued from beleagured Paris in a balloon, carrying with him the vital parts of a reflector specially constructed to collect evidence about the corona. But he reached Oran only to find himself shut behind a cloud-curtain more impervious than the Prussian lines. Everywhere the sky was more or less overcast. Mr. Lockyer's journey from England to Sicily, and shipwreck in the Psyche, were recompensed with a glimpse of the solar aureola during one second and a half! Three parties stationed at various heights on Mount Etna, saw absolutely nothing. Nevertheless important information was snatched in despite of the elements.

The prominent event was Young's discovery of the "reversing layer." As the surviving solar crescent narrowed before the encroaching moon, "the dark lines of the spectrum," he tells us, "and the spectrum itself, graduaily faded away, until all at

1 Am. Jour., vol. xlviii. (2nd series), p. 377. 2 This view was never assented to by either Young or Lockyer. ${ }_{3}^{3} A m$. Jour., vol. xi. (3rd series), p. 429. Everything in such observations depends upon the proper manipulation of the slit of the spectroscope. 
PART II.

once, as suddenly as a bursting rocket shoots out its stars, the whole field of view was filled with bright lines more numerous than one could count. The phenomenon was so sudden, so unexpected, and so wonderfully beantiful, as to force an involuntary exclamation." 1 Its duration was about two seconds, and the impression produced was that of a complete reversal of the Fraunhofer spectrum - that is, the substitution of a bright for every dark line.

Now something of the kind was theoretically necessary to account for the dusky rays in sunlight which have taught us so much, and have yet much more to teach us; so that, although surprising from its transitory splendour, the appearance could not strictly be called " unexpected." Moreover, its premonitory symptom in the fading out of those rays had been actually described by Father Secchi in 1868, ${ }^{2}$ and looked for by Young as the moon covered the sun in August I869. But with the slit of his spectroscope placed normally to the sun's limb, the bright lines gave a flash too thin to catch the eye. In I870 the position of the slit was tangential -it ran along the shallow bed of incandescent vapours, instead of cutting across it: hence his success.

The same observation was made at Xerez de la Frontera by Mr. Pye, a member of Young's party; and, although an exceedingly delicate one, has since frequently been repeated. The whole Fraunhofer series appeared bright (omitting other instances) to Maclear, Herschel, and Fyers in I87I, at the beginning or end of totality; to Pogson during a period (perhaps erroneously estimated) of from five to seven seconds, at the break up of an annular eclipse, June 6, I872; to Stone at Klipfontein, April 16, 1874, when he saw "the field full of bright lines." 3 But between the picture presented by the "veritable pluie de lignes brillantes," 4 which descended into M. Trépied's spectroscope for three seconds after the disappearance of the sun, May I7, I882, and the familiar one of the dark-line solar spectrum, certain differences were perceived, showing their

1 Mem. B. A. Soc., vol. xli., p. 435.

3 Mem. R. A. Soc., vol. xli., p. 43 .

2 Comptes Rendus, t. Ixvii., p. IоI9. + Comptes Rendus, t. xciv., p. I640. 
relation to be not simply that of a positive to a negative impression.

A "reversing layer," or stratum of mixed vapours, glowing, but at a lower temperature than that of the actual solar surface, was an integral part of Kirchhoff's theory of the production of the Fraunhofer lines. Here it was assumed that the missing rays were stopped, and here also it was assumed that the missing rays would be seen bright, could they be isolated from the overpowering splendour of their background. This isolation is effected by eclipses, with the result-beautifully confirmatory of theory-of reversing, or turning from dark to bright, the Fraunhofer spectrum. But there is a difficulty. If absorption be in truth thus localised, it should appear greatly strengthened near the edges of the solar disc. This, however, is not the case. Kirchhoff met the objection by giving a great depth to the reversing stratum, whereby the difference in length of the paths across that stratum traversed by rays from the sun's limb and centre became relatively insignificant. In other words, he supposed that the chief part of the light absent from the spectrum was arrested in the region of the corona.

Faye, on the other hand, abolished the reversing layer altogether (there was at that time no ocular demonstration of its existence); or rather, sunk it out of sight below the visible level of the photosphere, and got the necessary absorption done in the interstices of the photospheric clouds by the vapours in which they float, and from which they condense. It was, however, at once seen that the lines thus produced would be bright, not dark, since the brilliant cumuli would be cooled, by their greater power of radiation, below the temperature of the surrounding medium. Less obviously out of accord with facts was an explanation offered by Professor Hastings of Baltimore in I88I. ${ }^{1}$ Young's stratum, with its estimated thickness of 600 miles, represented in his view only the upper margin of a reversing ocean, in which the granules of the photosphere float at various depths. The necessary difference of temperature is derived from

1 Am. Jour. of Science, vol. xxi., p. 33 ; cf. Scheiner, Die Spectralanalyse der Gestirne, p. 196. 
the coolness of the descending vapours, which bathe the radiating particles and rob them of certain characteristic beams. Some observations, however, made by Professor Lockyer during the total eclipse of 1882, and by the late Father Perry of Stonyhurst ${ }^{1}$ and Mr. Turner of the Greenwich Observatory during that of I886, threw a new light upon the matter. They seem to prove the brief prismatic display seen at the beginning and end of totality to be only a part of a varied and extensive phenomenon. By careful watching, it was found to be preceded (in the advancing phase) by the stealing out, first of short, vivid lines close to the limb, corresponding to the highest known temperature, then of long, faint lines telling of absorption high up in the coronal regions. Just such effects had been predicted by Lockyer, ${ }^{2}$ and are required by his theory of the origin of the Fraunhofer spectrum through the combined and varying absorption of all the successive layers of the sun's atmosphere, each at a lower temperature, and with a higher molecular complexity than those beneath. Thus a strict correspondence between the bright rays of the so-called "reversing layer" and the solar dusky rays is not to be expected, and would, in fact, prove somewhat embarrassing. The question may eventually be decided by an instantaneous photograph of the complete "rainbowflash" accompanying totality.

The last of the five eclipses which we have grouped together for separate consideration was visible in Southern India and Australia, December I2, I87I. Some splendid photographs were secured by the English parties on the Malabar coast, showing, for the first time, the remarkable branching forms of the coronal emanations; but the most conspicuous result was Janssen's detection of some of the dark Fraunhofer lines, long vainly sought in the continuous spectrum of the corona. Chief amongst these was the D-line of sodium, the original index, it might be said, to solar chemistry. No proof could be afforded more decisive than this faint echoing back of the distinctive notes of the Fraunhofer spectrum, that the polariscope had spoken the truth in asserting a large part of the coronal radiance

1 Phil. Trans., vol. clxxx., pp. 387, 359.

2 Chemist. of the Sun, p. 359. 
to be reflected sunlight. But it is (especially at certain epochs) so drenched in original luminous emissions, that its characteristic features are almost obliterated. Janssen's success in seizing them was due in part to the extreme purity of the air at Sholoor, in the Neilgherries, where he was stationed; in part to the use of an instrument adapted by its large aperture and short focus to give an image of the utmost possible luminosity.

His observations further "peremptorily demonstrated" the presence of hydrogen far outside the region of prominences, and forming an integral constituent of the corona. This important fact was simultaneously attested by Lockyer at Baikul, and by Respighi at Poodacottah, each making separate trial of a "slitless spectroscope" devised for the occasion. This consists simply of a prism placed outside the object-glass of a telescope or the lens of a camera, whereby the radiance encompassing the eclipsed sun is separated into as many differently tinted rings as it contains different kinds of light. These tinted rings were viewed by Respighi through a telescope, and were photographed by Lockyer, with the same result of showing hydrogen to ascend uniformly from the sun's surface to a height of fully 200,000 miles. Another notable observation made by Herschel and Tennant at Dodabetta showed the green ray of coronium to be just as bright in a rift as in the adjacent streamer. The visible structure of the corona was thus seen to be independent of the distribution of the gases which enter into its composition.

By means, then, of the five great eclipses of $1860-7$ I it was ascertained: first, that the prominences, and at least the lower part of the corona, are genuine solar appurtenances; secondly, that the prominences are composed of hydrogen and other gases in a state of incandescence, and rise, as irregular outliers, from a continuous envelope of the same materials, some thousands of miles in thickness; thirdly, that the corona is of a highly complex constitution, being made up in part of glowing vapours, in part of matter capable of reflecting sunlight. We may now proceed to consider the results of subsequent eclipses. 
These have raised, and have helped to solve, some very curious questions. Indeed, every carefully watched total eclipse of the sun stimulates as well as appeases curiosity, and leaves a legacy of outstanding doubt, continually, as time and inquiry go on, removed, but continually replacéd. It cannot be denied that the corona is a perplexing phenomenon, and that it does not become less perplexing as we know more about it. It presented itself under quite a new and strange aspect on the occasion of the eclipse which visited the Western States of North America, July 29, 1878. The conditions of observation were peculiarly favourable. The weather was superb; above the Rocky Mountains the sky was of such purity as to permit the detection, with the naked eye, of Jupiter's satellites on several successive nights. The opportunity of advancing knowledge was made the most of. Nearly a hundred astronomers (including several Englishmen) occupied twelve separate posts, and prepared for an attack in force.

The question had often suggested itself, and was a natural one to ask, whether the corona sympathises with the general condition of the sun? whether, either in shape or brilliancy, it varies with the progress of the sun-spot period? A more propitious moment for getting this question answered could hardly have been chosen than that at which the eclipse occurred. Solar disturbance was just then at its lowest ebb. The development of spots for the month of July I878 was represented on Wolf's system of "relative numbers" by the fraction O.I, as against I 35.4 for December 1870, an epoch of maximum activity. The "chromosphere" 1 was, for the most part, shallow and quiescent ; its depth, above the spot-zones, had sunk from about 6000 to 2000 miles; prominences were few and faint. Obviously, if a type of corona corresponding to a minimum of sun-spots existed, it should be seen then or never. It was seen; but while, in some respects, it agreed with anticipation, in others it completely set it at naught.

The corona of 1878, as compared with those of 1869, I870,

1 The rosy envelope of prominence-matter was so named by Lockyer in I 868 (Phil. 'Trans., vol. clix., p. 430). 
and I87I, was generally admitted to be shrunken in its main outlines, and much reduced in brilliancy. Mr. Lockyer pronounced it ten times fainter than in I871; Professor Harkness estimated, its light at less than one-seventh that derived from the mist-blotted aureola of $1870 .^{1}$ In shape, too, it was markedly different. When sun-spots are numerous, the corona appears to be most fully developed above the spot-zones, thus offering to our eyes a rudely quadrilateral contour. The four great luminous sheaves forming the corners of the square are made up of rays curving together from each side into "synclinal" or ogival groups, each of which may be compared to the petal of a flower. To Janssen, in I87 I, the eclipsing moon seemed like the dark heart of a gigantic dahlia, painted in light on the sky; and the similitude to the ornament on a compass-card, used by Sir George Airy in I85 I, well conveys the decorative effect of the beamy, radiated kind of aureola, never, it would appear, absent when solar activity is at a tolerably high pitch. In his splendid volume on eclipses, ${ }^{2}$ with which the systematic study of coronal structure may be said to have begun, Mr. Ranyard first generalised the synclinal peculiarity by a comparison of records ; but the symmetry of the arrangement, though frequently striking, is liable to be confused by secondary formations. $\mathrm{He}$ further pointed out, with the help of careful drawings from the photographs of I87 I made by Mr. Wesley, the curved and branching shapes assumed by the component filaments of massive bundles of rays. Nothing of all this, however, was visible in I878. Instead, there was seen, as the groundwork of the corona, a ring of pearly light, nebulous to the eye, but shown by telescopes and in photographs to have a fibrous texture, as if made up of tufts of fine hairs. North and south, a series of short, vivid, electrical-looking flame-brushes diverged with conspicuous regularity from each of tire solar poles. Their direction was not towards the centre of the sun, but towards each summit of his axis, so that the farther rays on either side started almost tangentially to the surface. It is difficult not to connect this

${ }^{1}$ Bull. Phil. Soc. Washington, vol. iii., p. $118 . \quad 2$ Mem. R. A. Soc., vol. xli., 1879 . 
unusual display of polar activity ${ }^{1}$ with the great relative depth of the chromosphere in those regions, noticed by Trouvelot previous to the eclipse. ${ }^{2}$

But the leading, and a truly. amazing, characteristic of the phenomenon was formed by two vast, faintly luminous wings of light, expanded on either side of the sun in the direction of the ecliptic. These were missed by very few careful onlookers; but the extent assigned to them varied with skill in, and facilities for seeing. By far the most striking observations were made by Newcomb at Separation (Wyoming), by Cleveland Abbe from the shoulder of Pike's Peak, and by Langley at its summit, an elevation of 14,100 feet above the sea. Never before had an eclipse been viewed from anything approaching that altitude, or under so translucent a sky. A proof of the great reduction in atmospheric glare was afforded by the perceptibility of the corona for above four minutes after totality was over. During the 165 seconds of its duration, moreover, the remarkable streamers above alluded to continued "persistently visible," stretching away right and left of the sun to a distance of at least ten million miles! One branch was traced over an apparent extent of fully twelve lunar diameters, without sign of a definite termination having been reached; and there were no grounds for supposing the other more restricted. The axis of the longest ray was found to coincide exactly, so far as could be judged, with the ecliptic. ${ }^{3}$ Pale cross-beams were seen by Young and Abbe.

The resemblance to the zodiacal light was striking; and a community of origin between that enigmatical member of our system and the corona was irresistibly suggested. We should, indeed, expect to see, under such exceptionally favourable atmospheric conditions as Professor Langley enjoyed on Pike's Peak, the roots of the zodiacal light presenting near the sun

1 Professor W. A. Norton observed a similar phenomenon in 1869 , accompanied by some symptoms of equatorial emission. This is the more remarkable as 1869 was a year of many sun-spots. His evidence, though unsupported, and adverse to the theory of varying types, should not be overlooked. See $A m$. Jour. of Sc., vol. i. (3rd ser.), p. I. 2 Wash. Obs., I876, App. iii., p. $80 . \quad 3$ Ibid., p. 209. 
just such an appearance as he witnessed; but we can imagine no reason why their visibility should be associated with a low state of solar activity. Nevertheless this seems to be the case with the streamers which astonished astronomers in 1878 . For in August I867, when similar equatoreal emanations, accompanied by similar symptoms of polar excitement, were described and depicted by Grosch ${ }^{1}$ of the Santiago Observatory, sun-spots were at a minimum; while the corona of I715, which appears from the record of it by Roger Cotes ${ }^{2}$ to have been of the same type, preceded by three years the ensuing maximum. 'The eclipsed sun was seen by him at Cambridge, May 2, I7 I5, encompassed with a ring of light about one-sixth of the moon's diameter in breadth, upon which was superposed a luminous cross formed of long bright branches lying very nearly in the plane of the ecliptic, combined with shorter polar arms so faint as to be only intermittently visible. The resemblance between his sketch and Cleveland Abbe's drawing of the corona of I 878 is extremely striking. It should, nevertheless, be noted that some conspicuous spots were visible on the sun's disc at the time of Cotes's eclipse, and that the preceding minimum (according to Wolf) occurred in I7 I2. Thus, the coincidence of epochs is imperfect.

Professor Cleveland Abbe was fully persuaded that the long rays carefully observed by him from Pike's Peak were nothing else than streams of meteorites rushing towards or from perihelion; and it is quite certain that the solar neighbourhood must be crowded with such bcdies. But there are no grounds for supposing that they affect the ecliptic more than any other of the infinite number of planes passing through the sun's centre. On the contrary, everything we know leads us to believe that meteorites, like their cometary allies, yield no obedience to the rules of the road which bind the planets, but travel in either direction indifferently, and in paths inclined at any angle to the fundamental plane of our system. Besides, the peculiar structure at the base of the streamers

1 Astr. Nach., No. 1737. ${ }^{2}$ Correspondence with Newton, pp. I8I-I84; Ranyard, Mem. R. Astr. Soc., vol. xli., p. 50 I. 
displayed in the photographs, the curved rays meeting in pointed arches like Gothic windows, the visible upspringing tendency, the filamentous texture, speak unmistakably of the action of forces proceeding from, the sup, not of extraneous matter circling round him.

Again, it may be asked what possible relation can exist between the zodiacal plane and the sun's internal activity? For it is a remarkable fact that to this approximately, and not to the level of the solar equator, the streamers conformed. We are acquainted with no such relation; but it may be remarked that the coronal axis of symmetry has frequently been observed during eclipses to be inclined at an appreciable angle to the solar axis of rotation, and the corresponding "magnetic equator" might quite conceivably be the scene of emanations induced by some form of electrical repulsion.

The surest, though not the most striking, proof of sympathetic change in the corona is afforded by the analysis of its light. In 1878 the bright lines so conspicuous in the coronal spectrum in I 870 and I87 I were discovered to have faded to the very limits of visibility, Several skilled observers failed to see them at all ; but Young and Eastman succeeded in tracing both the hydrogen and the green "I474" rays all round the sun, to a height estimated at 340,000 miles. The substances emitting them were thus present, though in a low state of incandescence. The continuous spectrum was relatively strong; a faint reflection of the Fraunhofer lines was traced in it; and polarisation was undoubted, increasing towards the limb, whereas in 1870 it reached a maximum at a considerable distance from it. Experiments with Edison's tasimeter showed that the corona radiates a sensible amount of heat.

The next promising eclipse occurred May I7, I882. The concourse of astronomers which has become usual on such occasions assembled this time at Sohag, in Upper Egypt. Rarely have seventy-four seconds been turned to such account. To each observer a special task was assigned, and the advantages of a strict division of labour were visible in the variety and amount of the information gained. 
The year I 882 was one of numerous sun-spots. On the eve of the eclipse twenty-three separate maculæ were counted. If there were any truth in the theory which connected coronal forms with fluctuations in solar activity, it might be anticipated that the vast ecliptical expansions and polar "brushes" of I 878 would be found replaced by the star-like structure of I87I. This expectation was literally fulfilled. No zodiacal streamers were to be seen. The universal failure to perceive them, after express search in a sky of the most transparent purity, justifies the emphatic assertion that they were not there. Instead, the type of corona observed in India eleven years earlier, was reproduced, with its shining aigrettes, complex texture, and brilliant radiated aspect.

Concordant testimony was given by the spectroscope. The reflected light derived from the corona was weaker than in I878, while its original emissions were proportionately intensified. A complex spectrum testified to their heterogeneous nature. Many new bright lines were discovered. Tacchini determined four in the red end of the spectrum; Thollon perceived several in the violet; and Dr. Schuster measured and photographed about thirty. ${ }^{1}$ The Fraunhofer lines autographically recorded in the continuous spectrum were not less numerous. This was the first successful attempt to photograph the spectrum of the corona as seen with an ordinary slit-spectroscope. The slitless spectroscope, or "prismatic camera," although its statements are necessarily of a far looser character, was, however, also employed. And with profit, since it served to bring out at least one important fact-that of the uncommon strength in the chromospheric regions of the violet light concentrated in the two lines $\mathrm{H}$ and $\mathrm{K}$, attributed to calcium. Professor Lockyer observed the continuous part of the coronal spectrum to be curiously ribbed and fluted; and in the spectrum of one prominence twenty-nine rays were photographed, including the hydrogen ultra-violet series, discovered by Dr. Huggins in the emissions of white stars. ${ }^{2}$

1 Proc. Roy. Soc., vol. xxxv., p. I54. 2 Abney, Phil. Trans., vol. clxxv., p. 267. 
Dr. Schuster's photographs of the corona itself were the most extensive, as well as the most detailed, of any yet secured. One rift imprinted itself on the plates to a distance of nearly a diameter and a half from the limb; and the transparency of the streamers was shown by the delineation through them of the delicate tracery beyond. The singular and picturesque feature was added of a bright comet, self-depicted in. all the exquisite grace of swift movement betrayed by the fine curve of its tail, hurrying away from, possibly, its only visit to our sun, and rendered momentarily visible by the withdrawal of the splendour in which it had been, and was again quickly veiled.

From a careful study of these valuable records Dr. Huggins derived the idea of a possible mode of photographing the corona without an eclipse. ${ }^{1}$ As already stated, its ordinary invisibility is entirely due to the "glare" or reflected light diffused through our atmosphere. But Dr. Huggins found, on examining Schuster's negatives, that a large proportion of the light in the coronal spectrum, both continuous and interrupted, is collected in the violet region between the Fraunhofer lines $\mathrm{G}$ and $\mathrm{H}$. There, then, he hoped that, all other rays being excluded, it might prove strong enough to vanquish inimical glare, and stamp on prepared plates, through local superiority in illuminative power, the forms of the appendage by which it is emitted.

His experiments were begun towards the end of May I882, and by September 28 he had obtained a fair earnest of success. The exclusion of all other qualities of light save that with which he desired to operate, was accomplished (screens of tinted glass having been tried and discarded) by using chloride of silver as his sensitive material, that substance being chemically inert to all other but those precise rays in which the corona has the advantage. ${ }^{2}$ The genuineness of the impressions left upon his plates was strongly attested. "Not only the general

1 Proc. Roy. Soc., vol. xxxiv., p. 409 ; Report Brit. Ass., i883, p. 346. Experiments directed to the same end had been made by Dr. O. Lohse at Potsdam, 1878-80; not without some faint promise of ultimate success. Astr. Nach., No. 2486. 2 The sensitiveness of chloride of silver extends from $h$ to $\mathrm{H}$; that is, over the upper or more refrangible half of the space in which the main part of the coronal light is concentrated. 
features," Captain Abney affirmed,1 "are the same, but details, such as rifts and streamers, have the same position and form." It was found, moreover, that the corona photographed during the total eclipse of May 6, 1883, was intermediate in shape between the coronas photographed by Dr. Huggins before and after that event, each picture taking its proper place in a series of progressive modifications highly interesting in themselves, and full of promise for the value of the method employed to record them. ${ }^{2}$ But experiments on the subject were singularly interrupted. The volcanic explosion in the Straits of Sunda in August I883 brought to astronomers a peculiarly unwelcome addition to their difficulties. The magnificent sunglows due to the diffractive effects on light of the vapours and fine dust flung in vast volumes into the air, and rapidly diffused all round the globe, betokened an atmospheric condition of all others the most prejudicial to delicate researches in the solar vicinity. The filmy coronal forms, accordingly, which had been hopefully traced on Dr. Huggins's plates ceased to appear there; nor were any substantially better results obtained by Mr. C. Ray Woods, in the purer air either of the Riffel or the Cape of Good Hope, during the three ensuing years. Nay, doubts were expressed as to the genuineness of what had at first seemed to be accomplished; and the eclipse of the sun on August 29, I886, was anticipated as an opportunity for resolving them in one sense or the other. For, evidently, in a true coronal photograph taken during the partial phases, the contour of the moon off the sun must stand out against the faint radiance beyond; while deceptive appearances caused by airglare would take no notice of the moon, for the simple reason that they would originate in front of her. No trace of the lunar globe, however, was visible on any of the plates exposed on August 29, at Grenada ; and what vestiges of "structure" there were, came out almost better upon the moon than beside her, thus stamping themselves at once as spurious. It is hence quite certain that they had not been appreciably affected by coronal light.

This was discouraging; but when all the circumstances are

1 Proc. Roy. Soc., vol. xxxiv., p. 4I4. ${ }^{2}$ Report Brit. Assoc., I883, p. 35 I. 
taken into account, scarcely surprising. ${ }^{1}$ The corona was, on that occasion, shorn of much of its splendour through the action of moisture-laden air; the sun, when the observations were made, had less than nineteen degrees of altitude, so that a large proportion of the highly refrangible rays selected by silver chloride must have been cut off by atmospheric absorption; finally, the eruptive products from Krakatao were still far from having wholly subsided. That the effect sought is a possible one is proved by the distinct appearance of the moon projected on the corona, in photographs of the partially eclipsed sun in I 858 , i 889 , and I $890 .^{2}$

For the unequivocal success of Dr. Huggins's method rarely favourable conditions are undoubtedly requisite. Results of substantial value from it can hardly be hoped for in this climate, and at the sea-level. Every yard of ascent, however, tells in its favour; and its effectiveness may not improbably be enhanced, through changes in the coronal spectrum, at epochs of sun-spot maximum. Thus, we may hopefully look forward to the results of experiments shortly to be made in Colorado or Arizona with an apparatus devised by Professor Hale for the purpose of carrying out its essential principle of chromatic isolation $;^{3}$ and M. Deslandres has already at Paris, by different means, obtained some apparently genuine coronal impressions. ${ }^{4}$

The prosperous result of the Sohag observations stimulated the desire to repeat them on the first favourable opportunity. This offered itself one year later, May 6, I883, yet not without the drawbacks incident to terrestrial conditions. The eclipse promised was of rare length, giving no less than five minutes and twenty-three seconds of total obscurity, but its path was almost exclusively a "water-track." It touched land only on the outskirts of the Marquesas group in the Southern Pacific,

1 Captain L. Darwin, Phil. Trans., vol. clxxx., p. 31 I.

2 Liais, Comptes Rendus, t. xlvii., p. 789 ; Reports on Observations of the Total Eclipse of Jan. I, 1889, published by the Lick Observatory, p. 164; Trépied, C. Rendus, t. cx., p. 1321. For instances of the same visual appearance, see Trouvelot, Observatory, vol. ix p. 395 ; G. Dollond's observation of Nov. 29, 1826, Month. Notires, vol. i., p. 26; Hill, Jan. I, 1889, Lick Reports, p. 75, Stanoiéwitch, 19 Aug1887, C. Rendus, t. cvi., p. 43. $\quad 3$ Astr. and Astro-Physics, March 1893, p. 260. 4 Comptes Rendus, Jan. 23, 1893. 
and presented, as the one available foothold for observers, a coral reef named Caroline Island, seven and a half miles long by one and a half wide, unknown previously to I 874, and visited only for the sake of its stores of guano. Seldom has a more striking proof been given of the vividness of human curiosity as to the condition of the worlds outside our own, than in the assemblage of a group of distinguished men from the chief centres of civilisation, on a barren ridge, isolated in a vast and tempestuous ocean, at a distance, in many cases, of I I,000 miles and upwards from the ordinary scene of their labours. And all these sacrifices-the cost and care of preparation, the transport and readjustment of delicate instruments, the contrivance of new and more subtle means of investigating phenomena-on the precarious chance of a clear sky during one particular five minutes! The event, though fortunate, emphasised the hazard of the venture. The observation of the eclipse was made possible only by the happy accident of a serene interval between two storms.

The American expedition was led by Professor Edward S. Holden, and to it were courteously permitted to be attached Messrs. Lawrance and Woods, photographers, sent out by the Royal Society of London. M. Janssen was chief of the French Academy mission; he was accompanied from Meudon by Trouvelot, and joined from Vienna by Palisa, and from Rome by Tacchini. A large share of the work done was directed to assuring or negativing previous results. The circumstances of an eclipse favour illusion. $\dot{A}$ single observation by a single observer, made under unfamiliar conditions, and at a moment of peculiar excitement, can scarcely be regarded as offering more than a suggestion for future inquiry. But incredulity may be carried too far. Janssen, for instance, felt compelled by the survival of unwise doubts, to devote some of the precious minutes of obscurity at Caroline Island to confirming what, in his own persuasion, needed no confirmation-that is, the presence of reflected Fraunhofer lines in the spectrum of the corona. Trouvelot and Palisa, on the other hand, instituted an exhaustive, but fruitless search for the spurious "intramercurian" planet announced by Swift and Watson in I878. 
New information, however, was not deficient. The corona proved identical in type with that of $1882,{ }^{1}$ agreeably to what was expected at an epoch of protracted solar activity. Its light was, however, less violet in tijnge, owing to the absence of diffused " $\mathrm{H}$ and $\mathrm{K}$ " illumination from the prominences. The characteristic aigrettes (of which five appeared in Mr. Dixon's sketch) were of even greater brilliancy than in the preceding year, and the chemical effects of the coronal light proved unusually intense. Janssen's photographs, owing to the considerable apertures (six and eight inches) of his object-glasses, and the long exposures permitted by the duration of totality, were singularly perfect; they gave a greater extension to the corona than could be traced with the telescope, ${ }^{2}$ and showed its forms as absolutely fixed and of remarkable complexity.

The English pictures, taken with exposures up to sixty seconds, were likewise of great value. They exhibited details of structure from the limb to the tips of the streamers, which terminated definitely, and as it seemed actually, where the impressions on the plates ceased. The coronal spectrum was also successfully photographed, with a number of bright and dark lines; and a print was caught of some of the more prominent rays of the reversing layer just before and after totality. The use of the prismatic camera was baffled by the anomalous scarcity of prominences.

Another of the observations made at Caroline Island, although probably through some unexplained cause delusive, merits some brief notice. Using an ingenious apparatus for viewing simultaneously the spectrum from both sides of the sun, Professor Hastings noticed alternations, with the advance of the moon, in the respective heights above the right and left solar limbs of the coronal line "I 474," which were thought to imply that the old exploded idea was after all a true one, and that the corona, with its rifts and sheaves and "tangled hanks" of rays, is an illusive appearance produced by the diffraction of sunlight at the moon's edge. ${ }^{3}$ But the whole course of recent research is against such a supposition, even were the validity of Professor Hastings's

${ }^{1}$ Abney, Phil. Trans., vol. clxxx., p. II 19.

2 Comptes Rendus, t. xcvii. p. 592. 3 Memoirs National Ac. of Sciences, vol. ii., p. I02. 
arguments in favour of its optical possibility admitted. Atmospheric diffusion may indeed, under favouring circumstances, be effective in deceptively enlarging solar appendages; but always to a very limited extent.

The controversy is an old one as to the part played by our air in producing the radiance visible round the eclipsed sun. In its original form, it is true, it came to an end when Professor Harkness, in $1869,{ }^{1}$ pointed out that the shadow of the moon falls equally over the air and on the earth, and that if the sun had no luminous appendages, a circular space of almost absolute darkness would consequently surround the apparent places of the superposed sun and moon. Mr. Proctor, ${ }^{2}$ with his usual ability, impressed this mathematically certain truth (the precise opposite of the popular notion) upon public attention; and Sir John Herschel calculated that the diameter of the "negative halo" thus produced would be, in general, no less than $23^{\circ}$.

But about the same time a noteworthy circumstance relating to the state of things in the solar vicinity was brought into view. On February I I , I 869, Messrs. Frankland and Lockyer communicated to the Royal Society a series of experiments on gaseous spectra under varying conditions of heat and density, leading them to the conclusion that the higher solar prominences exist in a medium of excessive tenuity, and that even at the base of the chromosphere the pressure is far below that at the earth's surface. ${ }^{3}$ This inference was fully borne out by the researches of Wüllner; and Janssen expressed the opinion that the chromospheric gases are rarefied almost to the degree of an air-pump vacuum. ${ }^{4}$ Hence was derived a general and fully justified conviction that there could be outside, and incumbent upon the chromosphere, no such vast atmosphere as the corona appeared to represent. Upon the strength of which conviction the "glare" theory entered, chiefly under the auspices of Mr. Lockyer, upon the second stage of its existence.

The genuineness of the "inner corona" to the height of $5^{\text {' or }}$ 6 ' from the limb was admitted; but it was supposed that by the detailed reflection of its light in our air the far more extensive

1 Wash. Obs., 1867, App. ii., p. 64. 2 The Sun, p. 357. $\quad{ }^{3}$ Proc. Roy. Soc., vol. xvii., p. 289. $\quad 4$ Comptes Rendus, t. Ixxiii., p. 434 . 
"outer corona" was optically created, the irregularities of the moon's edge being called in to account for the rays and rifts by which its structure was varied. This view received some countenance from Captain (now Admiral) Maclear's observation, during the eclipse of I870, of bright lines "everywhere"-even at the centre of the lunar disc. Here, indeed, was an undoubted case of atmospheric diffusion; but here, also, was a safe index to the extent of its occurrence. Light scatters equally in all directions; so that when the moon's face at the time of an eclipse shows (as is the common case) a blank in the spectroscope, it is quite certain that the corona is not noticeably enlarged by atmospheric causes. A sky drifted over with thin cirrous clouds, and air charged with aqueous vapour amply accounted for the abnormal amount of scattering in 1870 .

But even in 1870 positive evidence was obtained of the substantial reality of the radiated outer corona, in the appearance on the photographic plates exposed by Willard in Spain and by Brothers in Sicily, of identical dark rifts. The truth is, that far from being developed by misty air, it is peculiarly liable to be effaced by it. The purer the sky, the more extensive, brilliant, and intricate in the details of its structure the corona appears. Take as an example General Myer's description of the eclipse of I869, as seen from the summit of White Top Mountain, Virginia, at an elevation above the sea of 5530 feet, in an atmosphere of peculiar clearness.

"To the unaided eye," he wrote," "the eclipse presented, during the total obscuration, a vision magnificent beyond description. As a centre stood the full and intensely black disc of the moon, surrounded by the aureola of a soft bright light, through which shot out, as if from the circumference of the moon, straight, massive, silvery rays, seeming distinct and separate from each other, to a distance of two or three diameters of the solar disc; the whole spectacle showing as on a background of diffused rose-coloured light."

On the same day, at Des Moines, Newcomb could perceive, through somewhat hazy air, no long rays, and the four-pointed

1 Wash. Obs., r867, App. ii., p. 195. 
outline of the corona reached at its farthest only a single semidiameter of the moon from the limb. The plain fact, that our atmosphere acts rather as a veil to hide the coronal radiance than as the medium through which it is visually formed, emerges from the records of innumerable other observations.

None of importance were made during the eclipse of September 9, 1885. The path of total obscuration touched land only on the shores of New Zealand, and two minutes was the outside limit of available time. Hence local observers had the phenomenon to themselves; nor were they even favoured by the weather in their efforts to make the most of it. One striking appearance was, however, disclosed. It was that of two "white" prominences of unusual brilliancy, shining like a pair of electric lamps hung one at each end of a solar diameter, right above the places of two large spots. ${ }^{1}$ This coincidence of diametrically opposite disturbances is of too frequent occurrence to be accidental. M. Trouvelot observed at Meudon, June 26, I885, two active and evanescent prominences thus situated, each rising to the enormous height of 300,000 miles, and on August 16, one scarcely less remarkable, balanced by an antipodal spot-group. ${ }^{2}$ It towered upward, as if by a process of unrolling, to a quarter of a million of miles; after which, in two minutes, the light died out of it; it had become completely extinct.

The eclipse of August 29, r886, was total during about four minutes over tropical Atlantic regions; and an English expedition, led by Professor Lockyer, was accordingly despatched to Grenada in the West Indies, for the purpose of using the opportunity it offered. But the rainy season was just then at its height; clouds and squalls were the order of the day; and the elaborately planned programme of observation could only in part be carried through. Some good work, none the less, was done. Observations of great theoretical importance were made, tending (as already stated) to widen the interpretation given to the fugitive shower of bright lines marking the beginning and end of totality. Professor Tacchini, who had been invited to accom-

1 Stokes, Anniversary Address, Nature, vol. xxxv., p. II4.

2 Comptes Rendus, t. ci., p. 50. 
pany the party, ascertained besides some significant facts about prominences. From a comparison of their forms and sizes during and after the eclipse, it appeared that only the glowing vaporous cores of these objects are shown by the spectroscope under ordinary circumstances; their upper sections, giving a faint continuous spectrum, and composed of presumably cooler materials, can only be seen when the veil of scattered light usually drawn over them is removed by an eclipse. Thus all moderately tall prominences have silvery summits; but all do not appear to possess the "red heart of flame," by which alone they can be rendered perceptible to daylight observation. Some are now found to be ordinarily invisible, because silvery throughout- "sheeted ghosts," as it were, met only in the dark.

Specimens of the class had been noted as far back as I842, but Tacchini first drew particular attention to them. The one observed by him in 1886 rose in a branching form to a height of I 50,000 miles, and gave a brilliantly continuous spectrum, with bright lines at $H$ and $K$, but no hydrogen-lines. ${ }^{1}$ Hence the total invisibility of the object before and after the eclipse. During the eclipse, it was seen framed, as it were, in a pointed arch of coronal light, the symmetrical arrangement of which with regard to it could scarcely have been accidental. Both its upspringing shape, and the violet rays of calcium strongly emitted by it, contradicted the supposition that "white prominences" represent a downrush of refrigerated materials.

The corona of 1886, as photographed by Dr. Schuster and Mr. Maunder, showed neither the petals and plumes of I87I, nor the streamers of 1878 . It might be called of an intermediate type. ${ }^{2}$ Wide polar rifts were filled in with tufted radiations, and bounded on either side by irregularly disposed, compound luminous masses. In the south-western quadrant, a triangular ray was conspicuous, and seemed to $\mathrm{Mr}$. W. $\mathrm{H}$. Pickering the visual presentation of a huge, hollow cone. ${ }^{3}$ Branched, and recurving jets were curiously associated with it.

1 Harvard Annals, vol. xviii., p. 99. $\quad 2$ Wesley, Phil. Trans., vol. clxxx., p. 350. 3 Harvard Annals, vol. xviii., p. 108. 
The intrinsic photographic brightness of the corona proved, from Pickering's measures, to be about $\frac{1}{54}$ that of the average surface of the full moon. ${ }^{1}$

The Russian eclipse of August 19, I887, can only be remembered as a disastrous failure. Much was expected of it. The shadow-path ran overland from Leipsic to the Japanese sea, so that the solar appurtenances would, it was hoped, be disclosed to observers echeloned along a line of 6000 miles. But the incalculable element of weather rendered all forecasts nugatory. The clouds never parted, during the critical three minutes, over Central Russia, where Mr. Turner's, Professor Young's, and many other parties were stationed; and a supplementary American expedition, led by Professor D. P. Todd, was equally unfortunate in Japan. Some good photographs were, nevertheless, secured by Professor Arai, Director of the Tokio Observatory, as well as by MM. Belopolsky and Glasenapp at Petrovsk and Jurjevitch respectively. They showed a corona of simpler form than that of the year before, but not yet of the pronounced type first associated by Mr. Ranyard with the lowest stage of solar activity.

The genuineness of the association was ratified by the duplicate spectacle of the next-ensuing minimum year. Two total eclipses of the sun distinguished i 889. The first took place on New Year's Day, when a narrow shadow-path crossed California, allowing less than two minutes for the numerous experiments prompted by the varied nature of modern methods of research. American astronomers availed themselves of the occasion to the full. The heavens were propitious. Photographic records were obtained in unprecedented abundance, and of unusual excellence. Their comparison and study placed it beyond reasonable doubt that the radiated corona belonging to periods of maximum sun-spots gives place, at periods of minimum, to the "winged" type of I878. Professor Holden perceived further that the equatoreal extensions characterising the latter are, to a certain extent, "trumpet-shaped." 2 Their extremities diverge, as if mutually repellent, instead of flowing together along a medial plane. The
1 Harvard Annals, vol. xviii., p. 108.
2 Lick Report, p. 20. 
maximum actinic brilliancy of the corona of January I, I889, was determined at Lick to be twenty-one times less than that of the full moon. ${ }^{1}$ Its colour was described as "of an intense luminous silver, with a bluish tinge, similar to the light of an electric arc." 2 Its spectrum was comparatively simple. Very few bright lines besides those of hydrogen and coronium, and apparently no dark ones, stood out from the prismatic background.

"The marked structural features of the corona, as presented by the negatives" taken by Professors Nipher and Charroppin, were, according to the statement of Professor Pritchett of St. Louis, ${ }^{3}$ "the so-called filaments, and the streamers extending approximately in the direction of the ecliptic. The filaments extend," he continues, "over a region of twenty degrees or more on each side of the poles. Comparing our negatives with a copy of a negative taken by the Lick Observatory party, I find the number and arrangement of these filaments to coincide accurately. There are slight differences in the lengths of some of the filaments, but no greater than might be accounted for by differences of exposure and atmospheric conditions.

"The broad and strongly marked equatorial belt stretches directly across this mass of filaments, apparently cutting off the filaments, at the somewhat irregular line of separation. The impression conveyed to the eye is that the equatorial stream of denser coronal matter extends across and through the filaments, simply obscuring them by its greater brightness. The effect is just as if the equatorial belt were superposed upon, or passed through, the filamentary structure. There is nothing in the photographs to prove that the filaments do not exist all round the sun. ${ }^{4}$ The testimony from negatives of different lengths of exposure goes to show that the equatorial streamers are made up of numerous interlacing parts inclined at varying angles to the sun's equator, but all trending, in a general way, along it, or roughly speaking, along the ecliptic. The direction and character of these component streamers can be best studied at the edges

${ }_{1}$ Lick Report, p. 14. $\quad{ }_{2}^{2}$ Ibid., p. 155. $\quad{ }^{3}$ Publ. Astr. Soc. of the Pacific, vol. iii., p. I58. ${ }^{4}$ Professor Holden concluded, with less qualification, "that so-called 'polar' rays exist at all latitudes on the sun's surface." Lick Report, p. 19. 
of the photographs, where, on account of the smaller number shown, their direction and force can be made out. It seems probable that, could we have a faithful reproduction of the extreme outer corona, where individual streamers could be traced out for a considerable distance, our knowledge of the coronal structure would be materially increased."

So far, the coronal extensions have not been photographed. Señor Valle, who came, for the purposes of the eclipse, from the Tacubaya Observatory, in Mexico, to Norman, a Californian hamlet, was able to trace the "fish-tail" structures, with the naked eye, to a distance of more than three degrees from the sun; while on Father Charroppin's best negative, exposed at the same place during twenty-eight seconds, they appeared barely one-third of that length. Nor could much more of them be seen either in Mr. Barnard's exquisite miniature pictures, or in the photographs obtained by Mr. W. H. Pickering with a thirteen-inch refractor-the largest instrument ever used in eclipse-photography.

The self-portraiture of the corona thus remains incomplete, and opinions are divided as to how its deficiencies can be supplied. Professor Holden points out ${ }^{1}$ that the problem under attack is totally different from that of photographing very faint nebulæ; for these are relieved against almost absolute darkness, while coronal streamers fade out into a partially illuminated sky. What has to be caught is hence a differential effect, which long exposures, or excessive light-power in the instrument employed would tend to obliterate. Father Charroppin, ${ }^{2}$ and $\mathrm{Mr}$. A. Taylor, ${ }^{3}$ on the other hand, advocate long exposures for the wingtips, but short exposures for the polar filaments, and the mass of inner equatoreal details. No single photograph, indeed, can properly depict the different sections of this enigmatical appendage to the sun.

The total eclipse of December 22, I889, held out the hope, which unfortunately proved delusive, of a practical decision of these questions. Messrs. Burnham and Schaeberle secured at

1 Report on Eclipse of Dec. 1889, p. I8. ${ }^{2}$ Publ. Astr. Pacific Society, vol. iii., p. $26 . \quad 3$ Observatory, vol. xvi., p. 95. 
Cayenne some excellent photographs showing enough of the corona to prove its identical character with that exhibited in the beginning of the year, but not enough to convey additional information about its termingl forms or innermost structure. Any better result was indeed impossible, the moisture-laden air having cut down the actinic power of the coronal light to onefourth its previous value.

Two English expeditions organised by the Royal Astronomical Society fared still worse. Mr. Taylor was stationed on the West Coast of Africa, one hundred miles south of Loanda; Father Perry chose as the scene of his operations the Salut Islands, off French Guiana. Each was supplied with a reflector constructed by Dr. Common, endowed, by its extremely short focal length of forty-five, combined with an aperture of twenty inches, with a light-concentrating force capable, it was hoped, of compelling the very filmiest coronal branches to self-registration. Had things gone well, two sets of coronal pictures, absolutely comparable in every respect, and taken at an interval of two hours and a half, would have been at the disposal of astronomers. But things went very far from well. Clonds altogether obscured the sun in Africa; they only separated to allow of his shining through a saturated atmosphere in South America. Father Perry's observations were the last heroic effort of a dying man. Stricken with malaria, he crawled to the hospital as soon as the eclipse was over, and expired five days later, at sea, on board the Comus. He was buried at Barbados. And the sacrifice of his life had, after all, purchased no decisive success. Most of the plates exposed by him suffered deterioration from the climate, or from an inevitably delayed development. A drawing from the best of them by Miss Violet Common ${ }^{1}$ represented a corona differing from its predecessor of January I, chiefly through the oppositely unsymmetrical relations of its parts. Then, the western wing had been broader at its base than the eastern; now, the inequality was conspicuously the other way. ${ }^{2}$

1 Published as the Frontispiece to the Observatory, No. 160. ibid., p. 107.

${ }^{2}$ Wesley, 
An opportunity for retrieving the mischances of the past was offered April 16, I893. The line of totality charted for that day ran from Chili to Cape Verde. English expeditions were sent both to Brazil and Senegambia; MM. Bigourdan and Deslandres of Paris stationed themselves near the Senegal ; and at least three American parties occupied posts in various provinces of South America. But the upshot cannot become known in time for inclusion in the present record.

The problem of deducing the real shape of the corona, as it exists in space, from its projection upon a flat surface hung up in the sky for our inspection during total eclipses, was first grappled with in its entirety by Professor J. M. Schaeberle of the Lick Observatory." His resulting "mechanical theory" makes the corona to consist, in its physical reality, of streams of matter shot out with great velocity from the spot-zones by forces acting perpendicularly to the sun's surface. The rays thus formed are not however straight. The particles composing them, since they bring the rotational speed of a smaller into a larger sphere, lag behind as they ascend, and eventually return to the sun, after describing sections of extremely elongated ellipses. That is, unless their initial velocity equals or exceeds the critical rate of 383 miles a second, by which they would be finally driven off into space. This state of things is perennial; but the visual effect changes with the point of view. "According as the observer is above, below, or in the plane of the sun's equator," our author remarks, "the perspective overlapping and interlacing of the two sets of streamers cause the observed apparent variations in the type of the corona." The corona, then, is always essentially the same, and only certain limited portions of the solar surface are concerned in its production. What seem like polar emanations are really, on this hypothesis, the tips of zonal streamers issuing from behind the moon. These speculative conclusions were strikingly illustrated by Professor Schaeberle's device of photographing, in various positions, a model globe bristling with properly arranged needles. But the objection

1 Lick Report on Eclipse of Dec. 22, 1889, p. 47; Month. Notices, vol. 1., p. 372 . 
immediately occurs that, if coronal shapes depended only upou the situation of the earth with regard to the sun's equator, ${ }^{1}$ they should be subject to an annual periodicity. The same type should recur at the. same time of year. This, however, is far from being the case. "Winged" coronas have been recorded in May (at Cotes's eclipse of I7 I5), August, July, December, and January; radiated coronas in July, December, May, and August. Nothing could well be more unlike the corona of December 2I, I870, than the corona of December 22, I889. Yet according to the "mechanical theory," they ought to have been perfectly similar. The agreement with the spot-cycle, on the contrary, of the physical changes in this beautiful, if commonly hidden, solar appendage, appear so far unfailing; although optical changes, such as those pointed out by Professor Schaeberle, are doubtless added. Coronal types, then, however fundamental their relations to the state of the sun's activity, are necessarily modified in accordance with geometrical laws, through variations in the standpoint from which they are regarded. The effects of perspective should also be constantly kept in view in studying internal coronal structure. Their intricate nature has been sufficiently shown by Professor Schaeberle's painstaking research.

Professor Bigelow's theory of the corona ${ }^{2}$ goes deep into the nature of things. He indeed claims for it no more than an abstract character; but it is a case in which correct mathematical construction is scarcely separable from physical truth. By an able discussion of the beautiful American photographs of January I, I889, he showed a marked coincidence between the distinctive coronal forms and the calculated effects of a repulsive force acting according to the laws of electric potential. Finely subdivided matter is, on this view, expelled from the sun along: lines of force emanating from points near his poles, and tends to accumulate at " equipotential surfaces." "The straight polar

1 Prof. Schaeberle evidently admits some genuine change in coronal forms through the shifting of the spot-zones, but he does not include the effect in his formal investigation. 2 The Solar Corona discussed by Spherical Harmonics, Smithsonian Institution, Washington, 1889. 
rays of high tension carry the lightest substances, as hydrogen, meteoric matter, débris of comets, and other coronal material, away from the sun, and they become soon invisible by dispersion." The strong quadrilateral rays, conspicuous at periods of great solar activity, come next in strength of potential, which, however, falls off rapidly outward. "The explanation of the long equatorial wings, with absence of well-marked quadrilaterals, is that they are due to the closing of the lines of force about the equator. The re-entrance of these lines forms along the equator, the place of zero potential, a sort of pocket or receptacle wherein the coronal matter is gradually carried by the forces, accumulated and retained as a solar accompaniment." The appurtenance thus formed and fed may, Professor Bigelow thinks, be no other than the mysterious Zodiacal light. The entire theory is, however, expressly left floating in the analytical empyrean; it is too soon to attempt its establishment upon a secure physical basis. "In deference," its deviser says, "to the doubt that free electricity can exist at such temperatures as prevail on the sun's surface," he has avoided "speaking. of the apparent coronal structure as a phenomenon of electricity." Its details, if it were, he limits himself to pointing out, would be just what they are. Hence the great interest and value of their precise photographic registration.

Summing up what we have learned about the corona during some fifty minutes of scrutiny in as many years, we may state, to begin with, that it is not a solar atmosphere. It does not gravitate upon the sun's surface and share his rotation, as our air gravitates upon and shares the rotation of the earth; and this for the simple reason that there is no visible growth of pressure downwards (such as the spectroscope would infallibly give notice of) in its gaseous constituents; whereas under the sole influence of the sun's attractive power, their density should be multiplied many million times in the descent through a mere fraction of their actual depth. ${ }^{1}$

The corona is properly described as a solar appendage; and

1 See Huggins, Proc. Roy. Soc., vol. xxxix., p. I08; and Young, North Am. Review, Feb. 1885 , p. 179 . 
may be conjecturally defined as matter in a perpetual state of efflux from, and influx to our great luminary, under the stress of electrical repulsion in one direction and of gravity in the other. $^{1}$ Its constitution is of a composite character. It is partly made up of self-luminous gases, chiefly hydrogen, and the unknown substance named coronium giving the green ray " I474"; partly of white-hot solid or liquid particles, shining with continuous light, both reflected and original. There is a probability amounting almost to certainty that it is affected both in shape and constitution by the periodic ebb and flow of solar activity, its low-tide form being winged, its high-tide form stellate; while the rays emitted by the gases contained in it fade, and the continuous spectrum brightens, at times of minimum sunspots, as if by a fall of temperature producing, on the one hand, a decline in luminosity of the incandescent materials existing near the sun, and, on the other, a condensation of vapours previously invisible into compact particles of some reflective capacity. The coronal materials must be of inconceivable tenuity, since comets cut their way through them without experiencing sensible retardation. Not even Mr. Crookes's vacua can give an idea of the rarefaction which this fact implies. Yet the observed luminous effects may not in reality bear witness contradictory of it. One solitary molecule in each cubic inch of space, might, in Professor Young's opinion, produce them; while in the same volume of ordinary air at the sea-level, the molecules number (according to Mr. Johnstone Stoney) 20,000 trillions !

The most important lesson, however, derived from eclipses is that of independence of them. Some of its fruits in the daily study of prominences the next chapter will collect; and the harvest has been rendered more abundant, as well as more valuable, since it has been found possible to enlist, in this department too, the versatile usefulness of the camera.

1 Professor W. A. Norton, of Yale College, appears to have been the earliest formal advocate of the Expulsion Theory of the solar surroundings, in the second (1845) and later editions of his Treatise on Astronomy. 


\section{CHAPTER IV.}

\section{SOLAR SPECTROSCOPY.}

'THE new way struck out by Janssen and Lockyer was at once and eagerly followed. In every part of Europe, as well as in North America, observers devoted themselves to the daily study of the chromosphere and prominences. Foremost among these were Lockyer in England, Zöllner at Leipzig, Spörer at Anclam, Young at Hanover, New Hampshire, Secchi and Respighi at Rome. There were many others, but these names are conspicuous from the outset.

The first point to be cleared up was that of chemical composition. Leisurely measurements verified the presence above the sun's surface of hydrogen in prodigious masses, but showed that sodium had nothing to do with the orange-yellow ray identified with it in the haste of the eclipse. From its vicinity to the D pair (than which it is slightly more refrangible), the prominenceline was, however, designated $\mathrm{D}_{3}$, and the unknown substance emitting it was named by Frankland "helium." Young is inclined to associate with it two other faint but persistent lines in the spectrum of the chromosphere $;^{1}$ and Messrs. Liveing and Dewar pointed out, in $1879,{ }^{2}$ that the wave-lengths of all three are bound together with that of the coronal ray " 1474 " 3 by numerical ratios virtually the same with those underlying the vibrations of hydrogen, and also conformed to by certain lines of lithium and magnesium. Professor Lockyer, however, considers both helium and coronium to be "modifications" of hydrogen;

1 Phil. Mag., vol. xlii., 1871, p. 380. 2 Proc. Roy. Soc., vol. xxviii., p. 475.

3 Wave-length on Ångström's scale = 5315.9 ten millionths oĩ a millimetre. 
and Professor Grünwald ${ }^{1}$ of Prague classes them more definitely, on the grounds of a plausible, though perhaps misleading theory, as its constituents. But the actual relation would seem to be one of analogy rather than of identity.

The importance of the part played in the prominence-spectrum by the violet lines of calcium, did not escape Professor Young's notice; but since $\mathrm{H}$ and $\mathrm{K}$ lie near the limit of the visible spectrum, photography was needed for a thorough investigation of their appearances. Aided by its resources, Professor George E. Hale, a young American spectroscopist already of high distinction, made in I89I the curious discovery of their unfailing and conspicuous presence. ${ }^{2}$ The substance emitting them, accordingly, not only constitutes a fundamental ingredient of the chromosphere, but rises in the fantastic jets thence issuing, to greater heights than bydrogen itself. Whether this substance be calcium, such as we know it, or some unknown element separated from calcium, is a question not yet decided; what is certain is that the $\mathrm{H}$ and $\mathrm{K}$ derived from solar prominences have no permanent companionship with any other of the lines terrestrially characteristic of the metal.

Hydrogen and helium form the chief and unvarying materials of the solar sierra and its peaks; but a number of metallic elements make their appearance spasmodically under the influence of disturbances in the layers beneath. In September I87 I, Young ${ }^{3}$ drew up at Dartmouth College a list of 103 lines significant of injections into the chromosphere of iron, titanium, calcium, magnesium, and many other substances. During two months' observation in the pure air of Mount Sherman (8335 feet high) in the summer of 1872 , these tell-tale lines mounted up to 273; and he believes their number might still be doubled by steady watching. Indeed, both Young and Lockyer have more than once seen the whole field of the spectroscope momentarily inundated with bright rays, as if the "reversing layer" seen at the beginning and end of eclipses had been suddenly

1 Astr. Nach., No. 2797. 2 Ibid., No. 3053; Amer. Jour., vol. xlii., p. 160 ; see also Deslandres, Comptes Rendus, t. cxiii., p. 307. ${ }^{3}$ Phil. Mag., vol. xlii., p. 377 . 
thrust upwards in the chromosphere, and as quickly allowed to drop back again. It would thus appear that the two form one continuous region, of which the lower parts are habitually occupied by the heaviest vapours, but where orderly arrangement is continually overturned by violent eruptive disturbances.

The study of the forms of prominences practically began with Dr. Huggins's observation of one through an "open slit," February 13, I 869. ${ }^{1}$ At first it had been thought possible to study them only in sections-that is, by admitting mere narrow strips or "lines" of their various kinds of light; while the actual shape of the objects emitting those lines had been arrived at by such imperfect devices as that of giving to the slit of the spectroscope a vibratory movement rapid enough to enable the eye to retain the impression of one part while others were successively presented to it. It was an immense gain to find their rays strong enough to bear so much of dilution with ordinary light as was involved in opening the spectroscopic shutter wide enough to exhibit the tree-like, or hornlike, or flame-shaped bodies rising over the sun's rim in their undivided proportions. Several diversely-coloured images of them are formed in the spectroscope; each prominence may be seen under a crimson, a yellow, a green, and a deep blue aspect. The crimson, however (built up out of the C-line of hydrogen), is the most intense, and is commonly used for purposes of observation and illustration.

Friedrich Zöllner was, by a few days, beforehand with Huggins in describing the open-slit method, but was somewhat less prompt in applying it. His first survey of a complete prominence, pictured in, and not simply intersected by, the slit of his spectroscope, was obtained July I, I 869. ${ }^{2}$ Shortly afterwards the plan was successfully adopted by the whole band of investigators.

A difference in kind was very soon perceived to separate these objects into two well-marked classes. Its natural and obvious character was shown by its having struck several observers independently. The distinction of "cloud-promi-

${ }^{1}$ Proc. Roy. Soc., vol. xvii., p. $302 . \quad 2$ Astr. Nach., No. 1769. 
nences" from "flame-prominences" was announced by Lockyer, April 27; by Zöllner, June 2; and by Respighi, Dec. 4, I870.

The first description is tranquil and relatively permanent. sometimes enduring without striking change for many days. The species it includes mimic terrestrial cloud-scenery-now appearing like fleecy cirrus transpenetrated with the red glow of sunset-now like prodigious masses of cumulo-stratus hanging heavily above the horizon. The solar clonds, however, have the peculiarity of possessing stems. Slender columns can ordinarily be seen to connect the surface of the chromosphere with its outlying portions. Hence the fantastic likeness to forest scenery presented by the long ranges of fiery trunks and foliage at times seeming to fringe the sun's limb. But while this formation suggests an actual outpouring of incandescent material, certain facts require a different interpretation. At a distance, and quite apart from the chromosphere, prominences have been perceived, both by Secchi and Young, to form, just as clonds form in a clear sky, condensation being replaced by ignition. Filaments were then thrown out downward towards the chromosphere, and finally the usual appearance of a "stemmed prominence" was assumed. Still more remarkable was an observation made by Trouvelot at Harvard College Observatory, June 26, I874. ${ }^{1}$ A gigantic comma-shaped prominence, 82,000 miles high, vanished from before his eyes by a withdrawal of light as sudden as the passage of a flash of lightning. The same observer has frequently witnessed a gradual illumination or gradual extinction of such objects, testifying to changes in the thermal or electrical condition of matter already in situ.

The first photograph of a prominence, as shown by the spectroscope in daylight, was taken by Professor Young in I870. ${ }^{2}$ But neither his method, nor that described by Dr. Braun in $1872,{ }^{3}$ had any practical success. This was reserved to crown the efforts towards the same end of Professor Hale. They were begun at Harvard College in I889, and continued

1 Am. Jour. of Science, vol. xv., p. 85.

2 Jour. Franklin Institute, vol. lx., p. $232 a .{ }^{3}$ Pogg. Annalen, Bd. cxlviii., p. 475; Astr. Nach., No. 3014. For a complete history of the subject, see Hale, Astr. and Astro-Physics, March I893, p. 24 r. 
at Chicago in I $890 .^{1}$ The great difficulty was to extricate the coloured image of the gaseous structure spectroscopically visible at the sun's limb, from the encompassing glare, a very little of which goes a long way in fogging sensitive plates. To counteract its mischievous effects, a second slit, besides the usual narrow one in front of the collimator, was placed on guard, as it were, behind the dispersing apparatus, so as to shut out from the sensitised surface all light save that of the required quality. The sun's image being then allowed to drift across the outer slit, while the plate-holder was kept moving at the same rate, the successive sectional impressions thus rapidly obtained finally "built up" a complete picture of the prominence. A still better expedient was, however, soon afterwards contrived. ${ }^{2}$ The $\mathrm{H}$ and $\mathrm{K}$ rays of calcium are always, as we have seen, bright in the spectrum of prominences. They are besides fine and sharp, while the corresponding absorptionlines in the ordinary solar spectrum are wide and diffuse. Hence, prominences formed by the spectroscope out of these particular qualities of violet light, can be photographed entire and at once, for the simple reason that they are projected upon a naturally darkened background. Atmospheric glare is abolished by local absorption. This beautiful method was first realised by Professor Hale in June I89I at the Kenwood Physical Observatory, Chicago; and he designs its extension to those evasive white prominences, of which, but for the calcium-element in their light, no tidings could possibly be procured outside of total eclipses.

A "spectroheliograph," consisting of a spectroscopic and a photographic apparatus of special type, attached to the eye-end of an equatoreal twelve inches in aperture, was erected at Kenwood in March I89I; and with its aid, Professor Hale has entered upon original researches of high promise for the advancement of solar physics. Noteworthy above all is his achievement of photographing both prominences and faculæ on the very face

1 Astr. Nach., Nos. 3006, 3037 ; Amer. Jour. of Science, vol. xlii., p. 160. Janssen (Report Brit. Ass., 1869, ii. p. 23) invented, but did not apply the double slit method of isolating light of a definite refrangibility, independently arrived at by Hale twenty years later. ${ }^{2}$ Astr. ${ }^{-}$Nach., No. 3053. 3 Astronomy and Astro-Physics, May I892, p. 407. 
of the sun. The latter had, until then, been very imperfectly observed. They were only visible, in fact, when relieved by their brilliancy against the dusky edge of the solar disc. Their convenient emission of calcium light, however, makes it possible to photograph them in all positions, and emphasises their close relationship to prominences, whether white or red. The simultaneous picturing, moreover, of the entire chromospheric ring, with whatever trees or fountains of fire chance to be at the moment issuing from it, has been accomplished by a very simple device. The disc of the sun itself having been screened with a circular metallic diaphragm, it is only necessary to cause the slit to traverse the virtually eclipsed luminary, in order to get an impression of the whole round of its fringing appendages, such as is exhibited in the lower part of Plate $I$. (the upper part reproduces six photographs of a prominence, taken in Ih. 40m., November 1 5, I 892). And the record can be still further completed by removing the screen, and carrying the slit back at a quicker rate, when "an image of the sun's surface, with the faculæ and spots, is formed on the plate exactly within the image of the chromosphere formed during the first exposure. The whole operation," Professor Hale continues, "is completed in less than a minute, and the resulting photographs give the first true pictures of the sun, showing all of the various phenomena at its surface." 1

The ultra-violet prominence spectrum was, for the first time, photographed from an uneclipsed sun, in June I89I, at Chicago. Besides $\mathrm{H}$ and $\mathrm{K}$, three of a remarkable series of hydrogenlines, discovered by Dr. Huggins in the spectra of stars like Sirius, imprinted themselves on the plate. ${ }^{2}$ Meanwhile M. Deslandres, ${ }^{3}$ who had been carrying on at the Paris Observatory the novel work initiated by Professor Hale, was enabled, by fitting quartz lenses to his spectroscope, and substituting a reflecting for a refracting telescope, to get rid of the obstructive action of glass upon the shorter light-waves, and thus to extend greatly the scope of his inquiry into the peculiarities of those

1 Astr. and Astro-Plysics, Aug. I892, p. 604.

2 Amer. Jour. of Science, vol. xlii., p. 163. $\quad 3$ Comptes Rendus, t. cxiii., p. 307. 

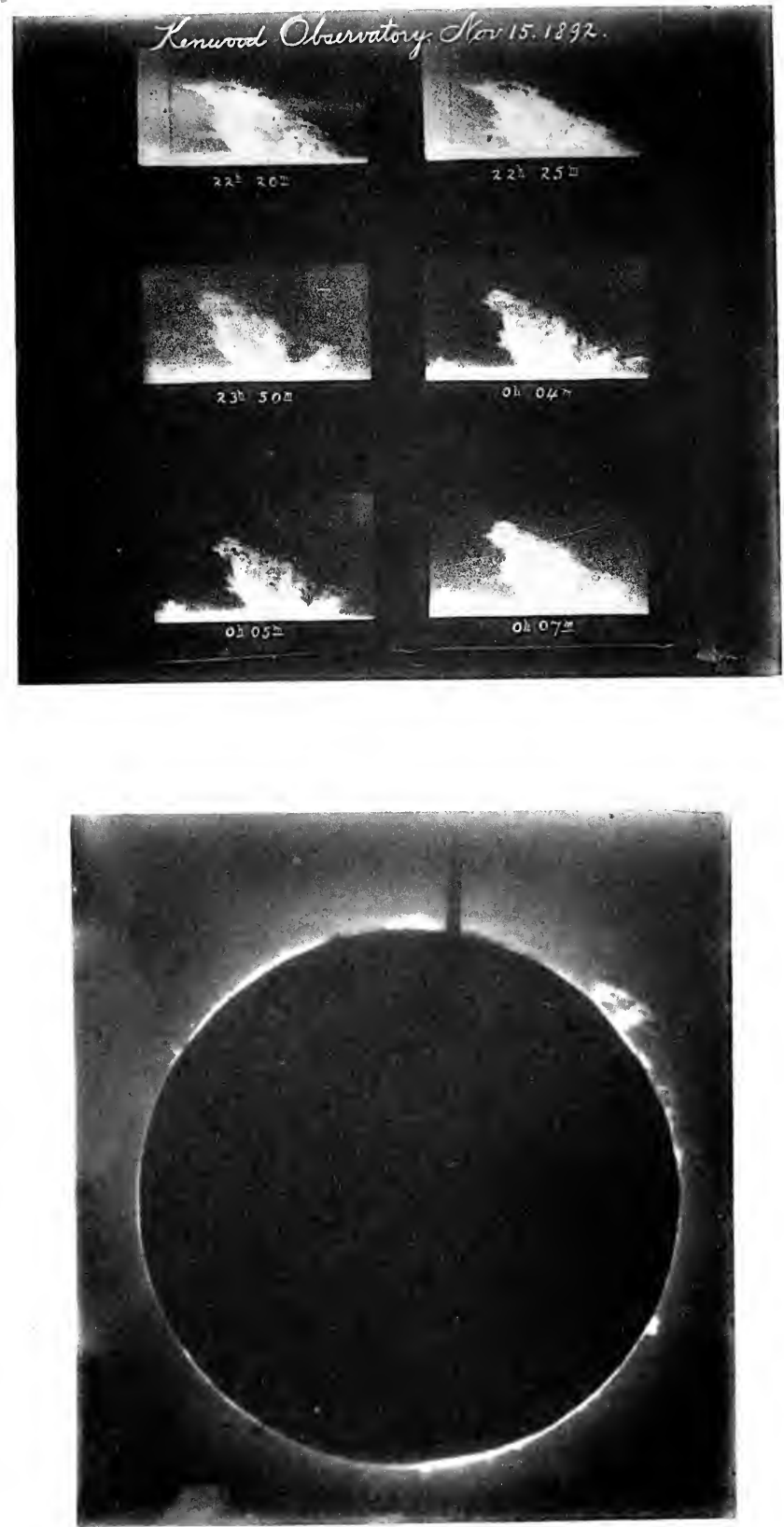

PHOTOGRAPHS OF THE SOLAR CHROMOSPHERE AND PROMINENCES.

Taken with the Spectroheliograph of the Kenwood Obsevvatory, Chicago. 

derived from prominences. ${ }^{1}$ As the result, not only all the nine white-star lines were photographed from a brilliant sun-flame, but five additional ones were found to continue the series upward. The wave-lengths of these last had, moreover, been calculated beforehand with singular exactness, from a simple formula known as "Balmer's Law,"2 depending upon a principle analogous to that determining the harmonics of a vibrating string. 'The new quintette of lines, accordingly, filled places in a manner already prepared for them, and were thus unmistakably associated with the hydrogen-spectrum. This is now found to be represented in prominences by nineteen lines, forming a kind of harmonic progression, only four of which are visibly darkened in the Fraunhofer spectrum of the sun.

The chemistry of "cloud-prominences" is simple. Hydrogen, helium, and calcium are their only recognised constituents. "Flame-prominences," on the other hand, show, in addition, the characteristic rays of a number of metals, among which iron, titanium, barium, sodium, and magnesium are conspicuous. They are intensely brilliant; sharply defined in their varying forms of jets, spikes, fountains, waterspouts ; of rapid formation and speedy dissolution, seldom attaining to the vast dimensions of the more tranquil kind. They are of eruptive or explosive origin, and are closely connected with spots; whether causally, the materials ejected as "flames" cooling and settling down as dark, depressed patches of increased absorption $;^{3}$ or consequentially, as a reactive effect of falls of solidified substances from great heights in the solar atmosphere. ${ }^{4}$ The two classes of phenomena, at any rate, stand in a most intimate relation ; they obey the same law of periodicity, and are confined to the same portions of the sun's surface, while quiescent prominences may be found right up to the poles and close to the equator.

The general distribution of prominences, including both species, follows that of faculæ much more closely than that of spots. From Father Secchi's and Professor Respighi's observations, I869-7I, were derived the first clear ideas on the

1 Astr. and Astro-Physics, April 1892, p. 314. '2 Wiedemann's Annalen der Physik, Bd. xxv., p. 8o. 3 Secchi, Le Soleil, t. ii., p. 294. "4 Lockyer, Chemistry of the Sun, p. 418 . 
subject, which have been supplemented and modified by the later researches of Professors Tacchini and Riccò at Rome and Palermo. The results are somewhat complicated, but may be stated broadly as follows. . The district of greatest prominencefrequency covers and overlaps by several degrees that of greatest spot-frequency. That is to say, it extends to about $40^{\circ}$ north and south of the equator. ${ }^{1}$ There is a visible tendency to a second pair of maxima nearer the poles, which are themselves, like the equator, regions of minimum occurrence. Distribution in time is governed by the spot-cycle, but the maximum lasts longer for prominences than for spots.

The structure of the chromosphere was investigated in I869 and subsequent years by the late Professor Respighi, director of the Capitoline Observatory, as well as by Spörer, and Bredichin, then of Moscow, now director of the Pulkowa Observatory. They found this supposed solar envelope to be of the same eruptive nature as the vast protrusions from it, and to be made up of a congeries of minute flames ${ }^{2}$ set close together like blades of grass. "The appearance," Professor Young writes. " "which probably indicates a fact, is as if countless jets of heated gas were issuing through vents and spiracles over the $\dot{w}$ hole surface, thus clothing it with flame which heaves and tosses like the blaze of a conflagration."

The summits of these filaments of fire are commonly inclined, as if by a wind sweeping over them, when the sun's activity is near its height, but erect during his phase of tranquillity. Spörer, in I87I, inferred the influence of permanent polar currents, ${ }^{4}$ but Tacchini showed in 1876 that the deflections upon which this inference was based ceased to be visible as the spotminimum drew near. ${ }^{5}$

Another peculiarity of the chromosphere, denoting the remoteness of its character from that of a true atmosphere ${ }^{6}$ is the irregularity of its distribution over the sun's surface. There

1 L'Astronomie, August I884, p. 292 (Riccô); see also Evershed, Jour. British Astr. Ass., vol. ii., p. I74. ${ }^{2}$ Averaging about 100 miles across and 300 high. Le Soleil, t. ii., p. 35 . 3 The Sun, p. I8o. 4 Astr. Nach., No. 1854. ${ }^{5} \mathrm{Mem}$. degli Spettroscopisti Italiani, t. v., p. 4. Restated by Secchi, ibid., t. vi., p. $56 .{ }^{6}$ Its non-atmospheric character was early defined by Proctor, Month. Not., vol. xxxi., p. 196. 
are no signs of its bulging out at the equator, as the laws of fluid equilibrium in a rotating mass would require; but there are some that the fluctuations in its depth are connected with the phases of solar agitation. At times of minimum it seems to accumulate and concentrate its activity at the poles; while maxima probably bring a more equable general distribution, with local depressions at the base of great prominences and above spots.

The reality of the appearance of violent disturbance presented by the "flaming" kind of prominence can be tested in a very remarkable manner. Christian Doppler, ${ }^{1}$ professor of mathematics at Prague, enounced in 1842 the theorem that the colour of a luminous body, like the pitch of a sonorous body, must be changed by movements of approach or recession. The reason is this. Both colour and pitch are physiological effects, depending, not upon absolute wave-length, but upon the number of waves entering the eye or ear in a given interval of time. And this number, it is easy to see, must be increased if the source of light or sound is diminishing its distance, and diminished if it is decreasing it. In the one case, the vibrating body pursues and crowds together the waves emanating from it; in the other, it retreats from them, and so lengthens out the space covered by an identical number. The principle may be thus illustrated. Suppose shots to be fired at a target at fixed intervals of time. If the marksman advances, say twenty paces between each discharge of his rifle, it is evident that the shots will fall faster on the target than if he stood still; if, on the contrary, he retires by the same amount, they will strike at correspondingly longer intervals. The result will of course be the same whether the target or the marksman be in movement.

So far Doppler was altogether right. As regards sound, any one can convince himself that the effect he predicted is a real one, by listening to the alternate shrilling and sinking of the steam-whistle when an express train rushes through a station. But in applying this principle to the colours of stars he went widely astray; for he omitted from consideration the double range of invisible vibrations which partake of, and to the eye

${ }^{1}$ Abh. d. Kön. Böhm. Ges. d. Wiss., Bd. ii., 1841-42, p. 467. 
exactly compensate, changes of refrangibility in the visible rays. There is, then, no possibility of finding a criterion of velocity in the hue of bodies shining, like the sun and stars, with continuous light. There is a slight shift of the entire spectrum up or down in the scale of refrangibility; certain rays normally visible become exalted or degraded (as the case may be) into invisibility, and certain other rays at the opposite end undergo the converse process ; but the sum-total of impressions on the retina continues the same.

We are not, however, without the means of measuring this sub-sensible transportation of the light-gamut. Once more the wonderful Fraunhofer lines came to the rescue. They were called by the earlier physicists "fixed lines;" but it is just because they are not fixed that, in this instance, we find them useful. They share, and in sharing betray, the general shift of the spectrum. This aspect of Doppler's principle was adverted to by Fizeau in $1848,{ }^{1}$ and the first tangible results in the estimation of movements of approach and recession between the earth and the stars, were communicated by Dr. Huggins to the Royal Society, April 23, I868. Eighteen months later, Zöllner devised his "reversion-spectroscope " 2 for doubling the measureable effects of line-displacements; aided by which ingenious instrument, and following a suggestion of its inventor, Professor H. C. Vogel succeeded at Bothkamp, June 9, I $87 \mathrm{I},{ }^{3}$ in detecting effects of that nature due to the solar rotation. This application constitutes at once the test and the triumph of the method. ${ }^{4}$

The eastern edge of the sun is continually moving towards us with an equatoreal speed of about a mile and a quarter per second, the western edge retreating at the same rate. The displacements-towards the violet on the east, towards the red on the west-corresponding to this velocity are very small; so small that it seems hardly credible that they should have been laid bare to perception. They amount to but $\frac{1}{150}$ th part of the interval between the two constituents of the D-line of sodium;

1 In a paper read before the Société Philomathique de Paris, December 23, 1848, and first published in extenso in Ann. de Chim. et de Phys., t. xix., p. 211 (1870). ${ }^{2}$ Astr. Nach., No. 1772. ${ }^{3}$ Ibid., No. 1864. ${ }^{4}$ See Cornu, Sur la Mèthode Doppler-Fizeau, p. D. 23. 
and the D-line of sodium itself can be separated into a pair only by a powerful spectroscope. Nevertheless, Professor Young ${ }^{1}$ was able to show quite satisfactorily, in I876, not only deviations in the solar lines from their proper places indicating a velocity of rotation (I.42 miles per second) slightly in excess of that given by observations of spots, but the exemption of terrestrial lines (those produced by absorption in the earth's atmosphere) from the general push upwards or downwards. Shortly afterwards, Professor Langley, director of the Allegheny Observatory, having devised a means of comparing with great accuracy light from different portions of the sun's disc, found that while the obscure rays in two juxtaposed spectra derived from the solar poles were absolutely continuous, no sooner was the instrument rotated through ninety degrees, so as to bring its luminous supplies from opposite extremities of the equator, than the same rays became perceptibly "notched." The telluric lines, meanwhile, remained unaffected, so as to be "virtually mapped" by the process. ${ }^{2}$ This rapid and unfailing mode of distinction was used by Cornu with perfect ease during his investigation of atmospheric absorption near Loiret in Aug. and Sept. I883. ${ }^{3}$

A beautiful experiment of the same kind was performed by M. Thollon, of M. Bischoffsheim's observatory at Nice, in the summer of I $880 .^{4} \mathrm{He}$ confined his attention to one delicately defined group of four lines in the orange, of which the inner pair are solar (iron) and the outer terrestrial. At the centre of the sun the intervals separating them were sensibly equal; but when the light was taken alternately from the right and left limbs, a relative shift in alternate directions of the solar, towards and from the stationary telluric rays became apparent. A parallel observation was made at Dunecht, December I4, I883, when it was noticed that a strong iron-line in the yellow part of the solar spectrum is permanently double on the sun's eastern, but single on his western limb $;^{5}$ opposite motion-displacements bringing about this curious effect of coincidence with, and separation from, an adjacent stationary line of our own atmo-

1 Am. Jour. of Sc., vol. xii., p. 321. 2 Ibid., vol. xiv., p. 140. ${ }^{3}$ Bull. Astronom., Feb. 1884, p. 77. ${ }_{4}$ Comptes Rendus, t. xci., p. $368 . \quad 5$ Month. Not., vol. xliv., p. 170. 
sphere's production, according as the spectrum is derived from the retreating or advancing margin of the solar globe. Statements of fact so precise and anthoritative amount to a demonstration that results of this kind are worthy of confidence; and they already occupy an important place among astronomical data.

The subtle method of which they served to assure the validity was employed in 1887-9 by M. Dunér to test and extend Carrington's and Spörer's conclusions as to the anomalous nature of the sun's axial movement. ${ }^{1}$ His observations on the shiftings of Fraunhofer lines at various heliographic latitudes, made with a fine diffraction-spectroscope just then mounted at the observatory of Upsala, were published in I89I. ${ }^{2}$ Their upshot was to confirm and widen the law of retardation with increasing latitude derived from the progressive motions of spots. Determinations made within fifteen degrees of the pole, consequently far beyond the region of spots, gave a rotationperiod of $38 \frac{1}{2}$, that of the equatoreal belt being of $25 \frac{1}{2}$ days. Spots near the equator indeed complete their rounds in a period shorter than this last by at least half a day; and proportionate differences were found to exist in each corresponding latitude; but Dunér's observations, it must be remembered, apply to a distinct part of the complex solar machine from the disturbed photospheric surface. It is amply possible that the absorptive strata producing the Fraunhofer lines, significant by their varying displacements at either limb, of the inferred varying rates of rotation, may gyrate more slowly than the spot-generating level. "This peculiar law of the sun's rotation," Professor Holden remarks, " shows conclusively that it is not a solid body, in which case, every one of its layers in every latitude must necessarily rotate in the same time. It is more like a vast whirlpool where the velocities of rotation depend not only on the situation of the rotating masses as to latitude, but also as to depth beneath the exterior surface."

Professor Lockyer ${ }^{4}$ was the first to perceive the applicability of

1 See ante, p. 183. $\quad 2$ Recherches sur la Rotation du Soleil, Upsal, 1891. 3 Publ. Astr. Soc. of the Pacific, vol. ii., p. I93. \& Proc. Roy. Soc., vols. xvii., p. 415 ; xviii., p. 120. 
the surprising discovery of line-shiftings through motion in line of sight to the study of prominences, the discontinuous light of which affords precisely the same means of detecting movement without seeming change of place, as do lines of absorption in a continuous spectrum. Indeed, his observations at the sun's edge almost compelled him to have recourse to an explanation made available just when the need of it began to be felt. $\mathrm{He}$ saw bright lines, not merely pushed aside from their normal places by a barely perceptible amount, but bent, torn, broken, as if by the stress of some tremendous violence. These remarkable appearances were quite simply interpreted as the effects of movements varying in amount and direction in the different parts of the extensive mass of incandescent vapours falling. within a single field of view. Very commonly they are of a cyclonic character. The opposite distortions of the same coloured rays betray the fury of "counter-gales" rushing along at the rate of 120 miles a second; while their undisturbed sections: prove the persistence of a "heart of peace" in the midst of that unimaginable fiery whirlwind. Velocities up to 250 miles $\alpha$ second, or I 5,000 times that of an express train at the top of its. speed, were thus observed by Young during his trip to Mount Sherman, August 2, I872; and these were actually doubled in an extraordinary outburst observed by Father Jules Fényi, on June I7, I891, at the Haynald Observatory in Hungary, as well as by M. Trouvelot at Meudon. ${ }^{1}$

Motions ascertainable in this way near the limb are, of course, horizontal as regards the sun's surface; the analogies they present might, accordingly, be styled meteorological rather than volcanic. But vertical displacements on a scale no less stupendous can also be shown to exist. Observations of the spectra of spots centrally situated (where motions in the line of sight are vertical) disclose the progress of violent uprushes and downrushes of ignited gases, for the most part in the penumbral or outlying districts. They appear to be occasioned by fitful and irregular disturbances, and have none of the systematic quality which would be required for the elucidation of sun-spot theories.

1 Comptes Rendus, t. cxii, p. I42I ; t. cxiii., p. 3 Iо. 
Indeed, they almost certainly take place at a great height above the actual opening in the photosphere.

As to vertical motions above the limb, on the other hand, we have direct visual evidence of a truly amazing kind. The projected glowing matter has, by the aid of the spectroscope, been watched in its ascent. On September 7, I87 I, Young examined at noon a vast hydrogen cloud, I00,000 miles long, as it showed to the eye, and 54,000 high. It floated tranquilly above the chromosphere at an elevation of some i 5,000 miles, and was connected with it by three or four upright columns, presenting the not uncommon aspect compared by Lockyer to that of a grove of banyans. Called away for a few minutes at I2.3O, on returning at 12.55 the observer found-

"That in the meantime the whole thing had been literally blown to shreds by some inconceivable uprush from beneath. In place of the quiet cloud I had left, the air, if I may use the expression, was filled with flying débris-a mass of detached, vertical, fusiform filaments, each from $\mathrm{IO}^{\prime \prime}$ to $3 \mathrm{O}^{\prime \prime}$ long by $2^{\prime \prime}$ or $3^{\prime \prime}$ wide, ${ }^{1}$ brighter and closer together where the pillars had formerly stood, and rapidly ascending. They rose, with a velocity estimated at I66 miles a second, to fully 200,000 miles above the sun's surface, then gradually faded away like a dissolving cloud, and at I.I 5 only a few filmy wisps, with some brighter streamers low down near the photosphere, remained to mark the place." 2

A velocity of projection of at least 500 miles per second was, according to Proctor's calculation, ${ }^{3}$ betrayed by this extraordinary display. It was marked by the simultaneous record at Greenwich of a magnetic disturbance, and was succeeded, the same evening, by a fine aurora. It has proved by no means an isolated occurrence. Young saw its main features repeated, October $7,188 \mathrm{I},{ }^{4}$ on a still vaster scale; for the exploded prominence attained, this time, an altitude of 350,000 miles-the highest yet chronicled. Professor Lockyer, more-

1 At the sun's distance, one second of arc represents about 450 miles. 2 Am. Jour. of Sc., vol. ii., I87 I, p. 468. ${ }^{3}$ Month. Not., vol. xxxii., p. 51.

4 Nature, vol. xxiii., p. 28 I. 
over, saw a prominence 40,000 miles high blown to pieces in ten minutes; while uprushes have been witnessed by Respighi, of which the initial velocities were judged by him to be 400 or 500 miles a second. When it is remembered that a body starting from the sun's surface at the rate of 379 miles a second would, if it encountered no resistance, escape for ever from his control, it is obvious that we have, in the enormous forces of eruption or repulsion manifested in the outbursts just described, the means of accounting for the vast diffusion of matter in the solar neighbourhood. Nor is it possible to explain them away, as Cornu, ${ }^{1}$ Faye, ${ }^{2}$ and others have sought to do, by substituting for the rush of matter in motion, progressive illumination through electric discharges, chemical processes, ${ }^{3}$ or even through the mere reheating of gases cooled by expansion. ${ }^{4}$ All the appearances are against such evasions of the difficulty presented by velocities stigmatised as "fabulous" and "improbable," but which, there is the strongest reason to believe, really exist.

On the I 2th of December, I 878, Professor Lockyer formally expounded before the Royal Society his famous hypothesis of the compound nature of the "chemical elements." 5 An hypothesis, it is true, over and over again propounded from the simply terrestrial point of view. What was novel was the supra-terrestrial evidence now adduced in its support; and even this had been, in a general and speculative way, anticipated by Professor F. W. Clarke of Washington. ${ }^{6}$ Professor Lockyer had been led to his conclusion along several converging lines of research. In a letter to M. Dumas, dated December 3, I873, he had sketched out the successive stages of " celestial dissociation "which he conceived to be represented in the sun and stars. The absence from the solar spectrum of metalloidal absorption he explained by the separation, in the fierce solar furnace, of such substances as oxygen, nitrogen, sulphur, chlorine, \&c.,

1 Comptes Rendus, t. Ixxxvi., p. 532. $\quad 2$ Ibid., t. xcvi., p. $359 . \quad{ }^{3}$ A. Brester, Théorie $d u$ Soleil, p. 66 . ' Such prominences as have been seen to grow by the spread of incandescence are of the quiescent kind, and present no deceptive appearance of violent motion. ${ }^{5}$ Proc. Roy. Soc., vol. xxviii., p. 157. 6 "Evolution and the Spectroscope," Pop. Science Monthly, Jan. 1873. 
into simpler constituents possessing unknown spectra; while metals were at that time still admitted to be capable of existing there in a state of integrity. Three years later he shifted his position onward. He announced, as the result of a comparative study of the Fraunhofer and electric-arc spectra of calcium, that the "molecular grouping" of that metal, which at low temperatures gives a spectrum with its chief line in the blue, is nearly broken up in the sun into another or others "with lines in the violet. ${ }^{1}$ The further progress of his work showed him this discrepancy between solar and terrestrial spectra as no exception, but "a truly typical case." 2

During four years (I 875-78 inclusive) this diligent observer was engaged in mapping a section of the more refrangible part of the solar spectrum (wave-lengths 3800-4000) on a scale of magnitude such that, if completed down to the infra-red, its length would have been about half a furlong. The attendant laborious investigation, by the aid of photography, of metallic spectra, seemed to indicate the existence of what he called "basic lines." These held their ground persistently in the spectra of two or more metals after all possible "impurities" had been eliminated, and were therefore held to attest the presence of a common substratum of matter in a simpler state of aggregation than any with which we are ordinarily acquainted.

Later inquiries have shown, however, that between the spectral lines of different substances there are probably no absolute coincidences. "Basic" lines are really formed of doublets or triplets merged together by insufficient dispersion. Of Thalèn's original list of seventy rays common to several spectra, ${ }^{3}$ very few have so far resisted Thollon's and Young's powerful spectroscopes; the process of resolution may in fact be regarded as practically complete. Thus the argument from

1 Proc, Roy. Soc., vol. xxiv., p. 353. These are the $\mathrm{H}$ and $\mathrm{K}$ of prominences. Their chemical meaning is still obscure. H. W. Vogel discovered in 1879 a hydrogen line nearly coincident with $\mathrm{H}$ (Monatsb. Preuss. Ak., Feb. I879, p. I 18). $\quad 2$ Proc. Roy. Soc., vol. xxviii., p. 444. $\quad{ }^{3}$ Many of these were shown by Lockyer, who was the first to sift the matter, to be due to very slight admixtures of the several metals concerned. 
community of lines to community of substance has virtually collapsed. Moreover, the singularity noted by Professor Lockyer as a strong argument for solar dissociation of these twin-lines - these spots of rendezvous, it might be said, for different sets of vibrations - being specially selected for display in solar disturbances, has not been re-attested by the Stonyhurst observations. ${ }^{1}$

They have nevertheless proved confirmatory of results obtained at South Kensington under Professor Lockyer's direction since November 1879. Down to February I888, the spectra of 850 spots had been studied on a fixed plan, ${ }^{2}$ and the procured data tabulated with rigid impartiality. The principle of the method employed is this. The whole range of Fraunhofer lines is visible when the light from a spot is examined with the spectroscope; but relatively few are widened. Now these widened lines presumably constitute the true spotspectrum; they, and they alone, tell what kinds of vapour are thrust down into the strange dusky pit of the nucleus, the unaffected lines taking their accustomed origin from the overlying strata of the normal solar atmosphere. Here then we have the criterion that was wanted-the means of distinguishing, spectroscopically and chemically, between the cavity and the absorbing layers piled up above it. By its persistent employment some marked peculiarities have been brought outqualified, however, where negative conclusions are in question, by the necessary limitations of the method of research. Positive results, meanwhile, of an indubitable kind, are not wanting. Such are the unfamiliar character of numerous lines in spotspectra, especially at epochs of disturbance; above all, the strange individuality in the behaviour of every one of these darkened and distended rays. ${ }^{3}$ Each seems to act on its own account; it comports itself as if it were the sole representative of the substance emitting it; its appearance is unconditional upon that of any of its terrestrial companions in the same spectrum.

For some metals, as cobalt, chromium, and calcium, the lines

1 Rev. A. L. Cortie, Month. Not., vol. li., p. 77.

2 Chemistry of the Sun,

p. 312. 3 Ibid., p. 314 . 
widened in spots are the same with those brightened in the uprushing flames at the sun's edge ; for a good many others, they are, as a rule, totally dissimilar, the spot-spectrum of iron, for example, having only a remote relationship to its "storm" spectrum. It is, moreover, prétty clear, from the character of the lines severally affected, that the change is connected with a difference of temperature, and that the prominences are much hotter than the spots. Hence two well-defined heat-levels are placed, as it were, at the disposal of the solar chemist, while a third, assumed to be lower than either, characterised by the ordinary Fraunhofer spectrum, is found at the photospheric surface.

By far the most curious fact, however, elicited by these inquiries, was that of the attendance of chemical vicissitudes upon the advance of the sun-spot period. As the maximum approached, unknown replaced known components of the spot-spectra in a most pronounced and unmistakable way. ${ }^{1}$ It would really seem as if the vapours emitting lines of iron, titanium, nickel, \&c., had ceased to exist as such, and their room been taken by others, total strangers in terrestrial laboratories. These, in Professor Lockyer's view, are simply the finer constituents of their predecessors, dissociation having been effected by the higher temperature ensuing upon increased solar activity. And for the present there is at hand no other explanation of the striking facts brought forward by him, and supported by others collected on his method by Father Cortie. ${ }^{2}$

But the strongest point of the "dissociation theory" has yet to be mentioned. It is that the contortions or displacements due to motion are frequently seen to affect a single line belonging to a particular substance, while the other lines of that same substance remain imperturbable. Now, how is this most singular fact, which seems at first sight to imply that a body may be at rest and in motion at one and the same instant, to be accounted for? It is accounted for, on the present hypothesis, easily enough, by supposing that the rays thus discrepant in their testimony, do not belong to one kind of matter, but to several, combined at ordi-

1 Chemistry of the Sun, p. 324. 2 2 Month. Not., vol. li., p. 76. 
nary temperatures, to form a body in appearance elementary. Of these different vapours, one or more may of course be rushing rapidly towards or from the observer, while the others remain still; and since the line of sight across the average prominence region penetrates, at the sun's edge, a depth of about 300,000 miles, ${ }^{1}$ all the incandescent materials separately occurring along which line are projected into a single "flame" or "cloud," it will be perceived that there is ample room for diversities of behaviour.

The alternative mode of escape from the perplexity consists in assuming that the vapour in motion is rendered luminous under conditions which reduce its spectrum to a few rays, the unaffected lines being derived from a totally distinct mass of the same substance shining with its ordinary emissions. ${ }^{2}$ But these conditions are assuredly not those prevailing in solar cyclones; while the seemingly capricious choice of lines associated to indicate rest or motion, negative a supposition implying orderly and invariable sequence. It is thus difficult to resist the conclusion that distinct kinds of matter are really aligned before the eye, embarrassing us with the contradictory testimony of their integrated light.

Professor Lockyer's view has the argument from continuity in its favour. It only asks us to believe that processes which we know to take place on the earth under certain conditions, are carried further in the sun, where the same conditions are, it may be presumed, vastly exalted. We find that the bodies we call "compound" split asunder at fixed degrees of heat within the range of our resources. Why should we hesitate to admit that the bodies we call " simple" do likewise at degrees of heat without the range of our resources?" The term "element" simply expresses terrestrial incapability of reduction. That, in celestial laboratories, the means and their effect here absent should be

1 Thollon's estimate (Comptes Rendus, t. xcvii., p. 902) of 300,000 kilometres seems considerably too low. Limiting the "average prominence region" to a shell 54,000 miles deep ( $2^{\prime}$ of arc as seen from the earth), the visual line will, at mid-height (27,000 miles from the sun's surface), travel through (in round numbers) 320,000 miles of that region. ${ }^{2}$ Liveing and Dewar, Phil. Mag., vol. xvi. (5th ser.), p. 407 . 
present, would be an inference challenging, in itself, no expression of incredulity.

Yet it is, in point of fact, a revolutionary one, and its acceptance will involve the reconstruction of more than one fair edifice of scientific thought. It appears, none the less, likely to become inevitable. There are indeed theoretical objections, which, though probably not insuperable, are unquestionably grave. Our seventy chemical "elements," for instance, are placed by the law of specific heats on a separate footing from their known compounds. We are not, it is true, compelled by it to believe their atoms to be really and absolutely such-to contain, that is, the "irreducible minimum" of material substance; but we do certainly gather from it that they are composed on a different principle from the salts and oxides made and unmade at pleasure by chemists. Then the multiplication of the species of matter with which Professor Lockyer's results menace us, is at first sight startling. They may lead, we are told, to eventual unification, but the prospect seems remote. For the present each terrestrial "element" is asserted by them to be broken up in the sun into several, and the existence of even a single common constituent is uncertain. The components of iron alone, for instance, should be counted by the dozen. And there are other metals, such as cerium, which, giving a still more complex spectrum, would doubtless be still more numerously resolved. It is true Professor Lockyer interprets the observed phenomena as indicating the successive combinations, in varying proportions, of a very few original ingredients $;^{1}$ but if the emission, at exalted temperatures, of a single quality of light be admitted as the criterion of a truly elementary body, then the independent behaviour of a considerable number of lines in the spectrum of each metal seems to assert that its formative units are numerous.

Thus, added complexity is substituted for that fundamental unity of matter which has long formed the dream of speculators. And it is extremely remarkable that Mr. Crookes, working along 
totally different lines, has been led to analogous conclusions. To take only one example. As the outcome of processes of sifting and testing of extreme delicacy carried on for years, he finds that the metal yttrium splits up into five, if not eight constituents. $^{1}$ Evidently, old notions are doomed, nor are any preconceived ones likely to take their place. But, whatever comes of it, we have no choice but to admit facts.

There can be no doubt that the spectra of bodies are an index to changes in their molecular constitution of every kind and degree, from a complete disruption of the molecule into atoms, homogeneous or heterogeneous, to some unspeakably minute, yet orderly and harmonious rearrangement of parts in the complex little system of which the movements are the source of light. Professor Lockyer's "working hypothesis" thus raises questions which science is not yet prepared to answer. It brings us face to face with the mysteries of the ultimate constitution of matter, and of its relations to the vibrating medium filling space. It makes our ignorance on these subjects seem at once more dense and more definite. Nevertheless, this in itself (though the saying appears paradoxical) constitutes an advance. Unfelt ignorance persists. Ignorance that is stricken with measy self-consciousness is already on the way to be turned into knowledge.

Professor A. J. Ångström of Upsala takes rank after Kirchhoff as a subordinate founder, so to speak, of solar spectroscopy. His great map of the "normal" solar spectrum ${ }^{2}$ was published in 1868, two years before he died. Robert Thalèn was his coadjutor in its execution, and the immense labour which it cost was amply repaid by its eminent and lasting usefulness. For more than a score of years it held its ground as the universal standard of reference in all spectroscopic inquiries within the range of the visible emanations. Those that are invisible by reason of the quickness of their vibrations, were mapped by the late Dr. Henry

1 Nature, Oct. 14, 1886. 2 The normal spectrum is that depending exclu. sively upon wave-length-the fundamental constant given by nature as regards light. It is obtained by the interference of rays, in the manner first exemplified by Fraunhofer, and affords the only unvarying standard for measurement. In the refraction-spectrum (upon which Kirchhoff's map was founded), the relative positions of the lines vary with the material of the prisms. 
Draper of New York in I873, and with superior accuracy by M. Coruu in I88I. The infra-red part of the spectrum, investigated by Langley, Abney, and Knut Ångström, reaches perhaps no definite end. The radiations oscillating too slowly to affect the eye as light, may pass by insensible gradations into the long Hertzian waves of electricity. ${ }^{1}$

Professor Rowland's photographic map of the solar spectrum, published in I886, and in a second enlarged edition in I889, opened fresh possibilities for its study, from far down in the red to high up in the ultra-violet. The accompanying scale of absolute wave-lengths, ${ }^{2}$ destined perhaps to supersede that of Ångström, varies so little from the new Potsdam scale, based on determinations by MM. Müller and Kempf, that the two systems may be said to guarantee each the other's accuracy. Knowledge of the solar spectrum has in fact of late so far outstripped knowledge of terrestrial spectra, that the recognition of their common lines is hampered by intolerable uncertainties. Thousands of the solar lines charted with minute precision thus remain unidentified for want of a corresponding precision in the registration of metallic lines. Their much-needed revision has, however, been undertaken by Professor Hasselberg at Stockholm $;^{3}$ and a special study of the complex and fundamentally important iron-spectrum was published by Thalèn in $188 .{ }^{4}$ Rowland, too, has for some years been engaged, with great success, on photographic comparisons of the solar with elemental spectra; and Mr. Frank McClean has done excellent work of the same kind. So the prospect is improving.

Another condition sine qua non of progress in this department is the separation of true solar lines from those produced by absorption in our own atmosphere. And here little remains to be done. Thollon's great Atlas ${ }^{5}$ was designed for this purpose of discrimination. Each of its thirty-three maps (covering the region $\mathrm{A}$ to $b$ ) exhibits in quadruplicate a subdivision of

1 Scheiner, Die Spectralanalyse der Gestirne, p. I68. 2 Phil. Mag., vol. xxvii., p. 479. ${ }^{3}$ Astr. and Astro-Physics, Nov. 1892, p. 793. 4 Scheiner, Spectralanalyse, p. 401, reprints a list of 1172 of his wave-lengths. ${ }^{5}$ Annales de l' Observatoire de Nice, t. iii., 1890. 
the solar spectrum under varied conditions of weather and zenith-distance. Telluric effects are thus made easily legible, and they account wholly for 866 , partly for 246 , out of a total of 3200 lines. The lamented death of the artist, April 8 , I 887, interrupted, however, the balf-finished task of the last seven years of his life, the completion of which has been undertaken by the Abbé Spée, of Brussels. A most satisfactory record, meanwhile, of selective atmospheric action has been supplied by Dr. Becker's valuable drawings, ${ }^{1}$ and by $\mathrm{Mr}$. McClean's photographs of the analysed light of the sun at high, low, and medium altitudes; and the autographic pictures obtained by Mr. George Higgs of Liverpool, of certain rhythmical groups in the red, emerging with surprising strength near sunset, excite general and well-deserved admiration. ${ }^{2}$ The main interest, however, of all these documents resides in the information afforded by them regarding the chemistry of the sun.

The discovery that hydrogen exists in the atmosphere of the sun was made by Ångström in I862. His list of solar elements published in that year, ${ }^{3}$ the result of an investigation separate from though conducted on the same principle as Kirchhoff's, included the substance which we now know to be predominant among them. Dr. Plücker of Bonn had identified in 1859 the Fraunhofer line $\mathrm{F}$ with the green ray of hydrogen, but drew no inference from his observation. The agreement was verified by Ångström; two further coincidences were established; and in I866 a fourth hydrogen line in the extreme violet (named $h$ ) was detected in the solar spectrum. With Thalèn, he besides added manganese, titanium, and cobalt to the constituents of the sun enumerated by Kirchhoff, and raised the number of identical rays in the solar and terrestrial spectra of iron to no less than $460 .^{4}$

Thus, when Professor Lockyer entered on that branch of inquiry in 1872 , fourteen substances were recognised as common to the earth and sun. Early in 1878 he was able to increase the list provisionally to thirty-three. ${ }^{5}$ All these are metals;

${ }^{1}$ Trans. Royal Society of Edinburgh, vol. xxxvi., p. 99. ${ }^{2}$ Rev. A. L. Cortie, Astr. and Astro-Physics, May I892, p. 401. ${ }^{3}$ Ann. d. Phys., Bd.cxvii., p. 296. ${ }^{4}$ Comptes Rendus, t. lxiii., p. $647 . \quad{ }^{5}$ Ibid., t. lxxxvi., p. 317. Some half dozen of these identifications have proved fallacious. 
for there is strong reason to believe that hydrogen presents a solitary instance of an ordinarily gaseous metal, just as mercury does of an ordinarily liquid one. This rapid success was due to his adoption of the test of length in lien of that of strength in the comparison of lines. He measured their relative significance, in other words, rather by their persistence through a wide range of temperature than by their brilliancy at any one temperature. The distinction was easily drawn. Photographs of the electric arc, in which any given metal had been volatilised, showed some of the rays emitted by it stretching across the axis of the light to a considerable distance on either side, while many others clung more or less closely to its central hottest core. The former "long lines," regarded as certainly representative, were those primarily sought in the solar spectrum; while the attendant "short lines," often, in point of fact, due to foreign admixtures, were set aside as likely to be misleading. ${ }^{1}$ The criterion is a valuable one, and its employment has greatly helped to quicken the progress of solar chemistry.

Carbon was the first non-metallic element discovered in the sun. Messrs. Trowbridge and Hutchins of Harvard College concluded in $\mathrm{I} 887,,^{2}$ on the ground of certain spectral coincidences, that this protean substance is vaporised in the solar atmosphere at a temperature approximately that of the voltaic arc. Partial evidence to the same effect had earlier been alleged by Lockyer, as well as by Liveing and Dewar; and the case was rendered tolerably complete by the photographs taken by MM. Kayser and Runge in I889. ${ }^{3}$ The work of photographically comparing the spectrum of the sun with the spectra of the various chemical elements, lately carried on by Professor Rowland at the Johns Hopkins University, Baltimore, has shown it to be irresistible. Two hundred carbon-lines have actually been thus sifted out from sunlight, and it contains others significant of the presence of silicon-a related substance, and one as important to rock-building on the earth as carbon is to the maintenance of life. The general result, so far, of Professor

1 Chemistry of the Sun, p. 143. $\quad 2$ Amer. Jour. of Science, vol. xxxiv., p. 348. 3 Berlin Abhandlungen, 1889. 
Rowland's labours has been the establishment among solar materials, not only of these two out of the fourteen metalloids, or non-metallic substances, but of thirty-three metals, including silver and tin. Gold, mercury, bismuth, antimony, and arsenic are discarded from the catalogue; platinum and uranium, with six other metals, are recorded as doubtful; while iron crowds the spectrum with over two thousand obscure rays. ${ }^{1}$

The question whether the sun contains oxygen must still be answered negatively. Dr. Henry Draper ${ }^{2}$ announced, in 1877, his imagined discovery, in the solar spectrum, of eighteen especially brilliant spaces corresponding to its direct emissions. But the discrimination of bright lines from a very slightly less lucid background must, it is plain, be always a matter of much delicacy and some uncertainty, especially when the lines to be discriminated are not sharp, but more or less blurred and widened. And in fact, the correspondences which had appeared so striking in Dr. Draper's photographs, proved, when put to the test of very high dispersion, to be wholly illusory. ${ }^{3}$

The solar spectrum, it is now admitted, includes no significant bright rays. ${ }^{4}$ The book of solar chemistry must be read in characters exclusively of absorption. Nevertheless, the whole truth is unlikely to be written there. That a substance displays none of its distinctive beams in the spectrum of the sun or of a star, affords scarcely a presumption against its presence. For it may be situated below the level where absorption occurs, or under a pressure such as to efface lines by continuous lustre; it may be at a temperature so high that it gives out more light than it takes up, and yet its incandescence may be masked by the absorption of other bodies; finally, it may just balance absorption by emission, with the result of complete spectral neutrality. An instructive example is that of helium, the enigmatical chromospheric element. Father Secchi remarked in $1868^{5}$ that there is no dark line in the solar spectrum

1 Amer. Jour. of Science, vol. xli., p. 243. See Appendix, Table II. 2 lbid., vol. xiv., p. 89 ; Nature, vol. xvi., p. 364 ; Month. Not., vol. xxxix., p. 440. ${ }^{3}$ Month. Not., vol. xxxviii., p. 473 ; Trowbridge and Hutchins, Amer. Jour. of Science, vol. xxxiv., p. 263. ${ }^{4}$ Scheiner, Die Spectralanalyse, p. 180.5 Comptes Rendus, t. lxvii., p. II23. 
matching its light; and his observation has been fully confirmed. ${ }^{1}$ The substance, for some unknown reason, seems incapable of exercising the least absorption.

Our terrestrial vital element might then easily wear an impenetrable disguise in the sun; more especially since the inner organisation of the oxygen molecule is a considerably plastic one. It is readily modified by heat,, and these modifications are reflected in its varying modes of radiating: light. Dr. Schuster enumerated in $1879^{2}$ four distinct oxygen spectra, corresponding to various stages of temperature, or phases of electrical excitement; and a fifth has been added by M. Egoroff's discovery in $1883^{3}$ that certain well-known groups of dark lines in the red end of the solar spectrum (Fraunhofer's A and B) are due to absorption by the cool oxygen of our air. These persist down to the lowest temperatures, and even survive a change of state. They are produced essentially the same by liquid as by aërial oxygen. ${ }^{4}$

It seemed, however, possible to M. Janssen that these bands owned a joint solar and terrestrial origin. Oxygen in a fit condition to produce them might, he considered, exist in the outer atmosphere of the sun; and he resolved to decide the point. No one could bring more skill and experience to bear upon it than he. ${ }^{5}$ By observations on the summit of the Faulhorn, as well as by direct experiment, he demonstrated, nearly thirty years ago, the leading part played by water-vapour in generating the atmospheric spectrum; and he had recourse to similar means for appraising the share in it assignable to oxygen. An electric beam, transmitted from the Eiffel Tower to Meudon in the summer of 1888 , having passed through a weight of oxygen about equal to that piled above the surface of the earth, showed the groups A and B just as they appear in the high-sun spectrum. ${ }^{6}$ Atmospheric action is then adequate to produce them. But M. Janssen desired to prove, in addition, that they

1 Rev. A. L. Cortie, Month. Not., vol. li., p. 18.

2 Phil. 'I'rans., vol. clxx., p. $46 . \quad 3$ Comptes Rendus, t. xcvii., p. 555 ; t. ci., p. $1145 .{ }^{4}$ Liveing and Dewar, Astr. and Astro-Physics, Oct. 1892, p. 705. t. Ix., p. 213 ; t. lxiii., p. 289.6 Ibid., t. criii., p. 1035.

5 Comptes Rendus, 
diminish proportionately to its amount. His ascent of Mont Blanc ${ }^{1}$ in 1890 was undertaken with this object. It was perfectly successful. In the solar spectrum, examined from that eminence, oxygen-absorption was so much enfeebled as to leave no possible doubt of its purely telluric origin. Our pabulum vitce is not then at present recognisable as a solar element.

The rays of the sun, besides being stopped selectively in our atmosphere, suffer also a marked general absorption. This tells chiefly upon the shortest wave-lengths; the ultra-violet spectrum is in fact closed, as if by the interposition of an opaque screen. Nor does the screen appear very sensibly less opaque from an elevation of IO,000 feet. Dr. Simony's spectral photographs, taken on the Peak of Teneriffe, ${ }^{2}$ extended but slightly further up than M. Cornu's, taken in the valley of the Loire. Could the veil be withdrawn, some indications as to the originating temperature of the solar spectrum might be gathered from its range, since the proportion of quick vibrations given out by a glowing body grows with the intensity of its incandescence. And this brings us to the subject of our next Chapter.

1 Comptes Rendus, t. cxi., p. 43I. 2 Ibid., p. 94I ; Huggins, Proc. Roy. Soc., vol. xlvi., p. I68. 


\section{CHAPTER V. \\ TEMPERATURE OF THE SUN.}

NewTon was the first who attempted to measure the quantity of heat received by the earth from the sun. His object in making the experiment was to ascertain the temperature encountered by the comet of i68o at its passage through perihelion. He found it, by multiplying the observed heating effects of direct sunshine according to the familiar rule of the "inverse squares of the distances," to be about 2000 times that of red-hot iron."1

Determinations of the sun's thermal power made with some scientific exactness, date, however, from i837. A few days previous to the beginning of that year, Herschel began observing at the Cape of Good Hope with an "actinometer," and obtained results agreeing quite satisfactorily with those derived by Pouillet from experiments made in France some months later with a "pyrheliometer." 2 Pouillet found that the vertical rays of the sun falling on each square centimetre of the earth's surface are competent (apart from atmospheric absorption) to raise the temperature of I.7633 grammes of water one degree Centigrade per minute. This number (I.7633) he called the "solar" constant"; and the unit of heat chosen is known as the "calorie." Hence it was computed that the total amount of solar heat received during a year would suffice to melt a layer of ice covering the entire earth to a depth of 30.89 metres, or IOO feet; while the heat emitted would melt, at the sun's surface, a stratum II.80 metres thick each minute. A careful series of observations showed that nearly half the heat incident upon our atmosphere is stopped in its passage through it.

1 Principia, p. 498 (Ist ed.). $\quad 2$ Comptes Rendus, t. vii., p. 24. 
Herschel got somewhat larger figures, though he assigned only a third as the spoil of the air. Taking a mean between his. own and Pouillet's, he calculated that the ordinary expenditure of the sun per minute would have power to melt a cylinder of ice I84 feet in diameter, reaching from his surface to that of $\boldsymbol{a}$ Centauri ; or, putting it otherwise, that an ice-rod 45.3 miles across, continually darted into the sun with the velocity of light, would scarcely consume, in dissolving, the thermal supplies now poured abroad into space. ${ }^{1}$ It is nearly certain that this estimate should be increased by about two-thirds in order to bring: it up to the truth.

Nothing would, at first sight, appear simpler than to passfrom a knowledge of solar emission-a strictly measurable quantity - to a knowledge of the solar temperature; this being defined as the temperature to which a surface thickly coated with lamp-black (that is, of standard radiating power) should be raised to enable it to send us, from the sun's distance, the amount of heat actually received from the sun. Sir John Herschel showed that heat-rays at the sun's surface must be 92,000 times as dense as when they reach the earth; but it by no means follows that either the surface emitting or a body absorbing those heat-rays must be 92,000 times hotter than a body exposed here to the full power of the sun. The reason is, that the rate of emission-consequently the rate of absorption, which is its correlative-increases very much faster than the temperature. In other words, a body radiates or cools at a continually accelerated pace as it becomes more and more intensely heated above its surroundings.

Newton, however, took it for granted that radiation and temperature advance pari passu-that you have only to ascertain the quantity of heat received from and the distance of a remote body in order to know how hot it is. ${ }^{2}$ And the validity of this principle, known as "Newton's Law" of cooling, was never questioned until De la Roche pointed out, in 18 I $2,{ }^{3}$ that it was

1 Results of Astr. Observations, p. 446. 2 " Est enim calor solis ut radiorum densitas, hoc est, reciproce ut quadratum distantiæ locorum a sole." Principia, p. 508 (3d ed. 1726). $\quad 3$ Jour. de Physique, t. lxxv., p. 215. 
approximately true only over a low range of temperature; while five years later, Dulong and Petit generalised experimental results into the rule, that while temperature grows by arithmetical, radiation increases 'by geopietrical progression. ${ }^{1}$ Adopting this formula,-Pouillet derived from his observations on solar heat a solar temperature of somewhere between $\mathrm{I} 46 \mathrm{I}^{\circ}$ and $\mathbf{I} 76 \mathbf{I}^{\circ}$ Cent. Now, the higher of these points-which is nearly that of melting platinum-is undoubtedly surpassed at the focus of certain burning-glasses which have been constructed of such power as virtually to bring objects placed there within a quarter of a million of miles of the photosphere. In the rays thus concentrated, platinum and diamond become rapidly vaporised, notwithstanding the great loss of heat by absorption, first in passing through the air, and again in traversing the lens. Pouillet's maximum is then manifestly too low, since it involves the absurdity of supposing a radiating mass capable of heating a distant body more than it is itself heated.

Less demónstrably, but scarcely less surely, Mr. J. J. Waterston, who attacked the problem in 1860 , erred in the opposite direction. Working up, on Newton's principle, data collected by himself in India and at Edinburgh, he got for the "potential temperature" of the sun $12,880,000^{\circ}$ Fahr., ${ }^{2}$ equivalent to 7, I 56,000 Cent. The phrase potential temperature (for which Violle substituted, in 1876 , effective temperature) was designed to express the accumulation in a single surface, postulated for the sake of simplicity, of the radiations not improbably received from a multitude of separate solar layers reinforcing each other ; and might thus (it was explained) be considerably higher than the cactual temperature of any one stratum.

At Rome, in I86I, Father Secchi repeated Waterston's experiments, and reaffirmed his conclusion ${ }^{3}$ while Soret's observations, made on the summit of Mont Blanc in $1867,{ }^{4}$ furnished him with materials for a fresh and even higher estimate of ten million degrees Centigrade. ${ }^{5}$ Yet from the very same data,

1 Ann. de Chimie, t. vii., 1817, p. 365. 2 Phil. Mag., vol. xxiii. (4th ser.), p. 505. ${ }^{3}$ Nuovo Cimento, t. xvi., p. $294 . \quad{ }^{4}$ Comptes Rendus, t. lxv., p. 526. 5 The direct result of $5 \frac{1}{3}$ million degrees was doubled in allowance for absorption in the sun's own atmosphere. Comptes Rendus, t. lxxiv., p. 26. 
substituting Dulong and Petit's for Newton's law, Vicaire deduced in 1872 a provisional solar temperature of $1398^{\circ} .^{1}$ This is below that at which iron melts, and we know that ironvapour exists high up in the sun's atmosphere. The matter was taken into consideration on the other side of the Atlantic by Ericsson in I871. He attempted to re-establish the shaken credit of Newton's principle, and arrived, by its means, at a temperature of four million degrees of Fahrenheit." More recently, what he considered an " underrated computation," based upon observations of the quantity of heat received by his "sun motor," gave him three million degrees. This, he rightly asserted, must be accepted, if only the temperature produced by radiant heat be proportional to its density, or inversely as its diffusion. $^{3}$ Could this be granted, the question would be much simplified; but there is no doubt that the case is far otherwise when heat becomes intensified.

In 1876 the sun's temperature was proposed as the subject of a prize by the Paris Academy of Sciences; but although the essay of M. Jules Violle was crowned, the problem was declared to remain unsolved. Violle (who adhered to Dulong and Petit's formula) arrived at an effective temperature of $\mathrm{I} 500^{\circ} \mathrm{C}$., but considered that it might actually reach $2500^{\circ} \mathrm{C}$., if the emissive power of the photospheric clouds fell far short (as seemed probable) of the lamp-black standard. ${ }^{4}$ Experiments made in April and May I88 I giving a somewhat higher result, he raised this figure to $3000^{\circ} \mathrm{C} .^{5}$

Appraisements so outrageously discordant as those of Waterston, Secchi, and Ericsson on the one hand, and those of the French savans on the other, served only to show that all were based upon a vicious principle. The late Professor F. Rosetti, ${ }^{6}$ accordingly, of the Paduan University, at last perceived the necessity for getting out of the groove of "laws" plainly in contradiction with facts. The temperature, for instance, of the oxy-hydrogen flame was fixed by Bunsen at $2800^{\circ}$ C.-an

1 Comptes Rendus, t. lxxiv, p. 3I. 2 Nature, vols. iv., p. 204 ; v., p. 505. 3 Ibid., vol. xxx., p. 467 . ${ }^{4}$ Ann. de Chim., t. x. (5th ser.), p. 36r. ${ }^{5}$ Comptes Rendus, t. xcvi., p. 254. 6 Phil. Mag., vol. viii., p. 324, I879. 
estimate certainly not very far from the truth. But if the two systems of measurement applied to the sun be used to determine the heat of a solid body rendered incandescent in this flame, it comes out, by Newton's mode of calculation, $45,000^{\circ} \mathrm{C}$.; by Dulong and Petit's, $870^{\circ}$ C. Both, then, are justly discarded, the first as convicted of exaggeration, the second of undervaluation. The formula substituted by Rosetti was tested successfully up to $2000^{\circ} \mathrm{C}$. ; but since it is, like its predecessors, a purely empirical rule, is guaranteed by no principle, and can, in consequence, not be trusted out of sight, it may, like them, break down at still higher elevations. All that can be said is that it gives the most plausible results. Radiation, so far as it obeys this new prescription, increases as the square of the absolute temperature-that is. of the number of degrees counted from the "absolute zero" of $-273^{\circ} \mathrm{C}$. Its employment gives for the sun's radiating surface an effective temperature of $20,380^{\circ} \mathrm{C}$. (including a supposed loss of one-half in the solar atmosphere); and setting a probable deficiency in emission (as compared with lamp-black) against a probable mutual reinforcement of superposed strata, Professor Rosetti considered "effective" as nearly equivalent to "actual" temperature. Yet another "law of cooling" was proposed by M. Stefan at Vienna in $1879 .{ }^{2}$ It is that emission grows as the fourth power of absolute temperature. Hence the temperature of the photosphere would be proportional to the square root of the square root of its heating effects at a distance, and appeared, by Stefan's calculations from Violle's measures of solar radiative intensity, to be just $6000^{\circ} \mathrm{C}$. M. H. Le Chatelier ${ }^{3}$ makes it $7600^{\circ}$, and he is the latest investigator on the subject. His formula, based on a series of laborious experiments, conveys an intricate and unaccountable relation between the temperature of an incandescent body and the intensity of its red radiations. It proved, however, trustworthy up to $\mathrm{I} 800^{\circ} \mathrm{C}$. ; and he hence believes that his result for the sun cannot well be more than one thousand degrees in error, one way or the other.

1 Phil. Mag., vol. viii., p. 325, 1879. 2 Sitzungsberichte, Wien, Bd. Ixxix., ii., p. 391. 3 Comptes Rendus, March 28, 1892 ; Astr. and Astro-Physics, June I892, p. 5 I 7 . 
A new line of inquiry was struck out by Zïllner in 1870. Instead of tracking the solar radiations backward with the dubious guide of empirical formulæ, he investigated their intensity at their source. He showed ${ }^{1}$ that, taking prominences to be simple effects of the escape of powerfully compressed gases, it was possible, from the known mechanical laws of heat and gaseous constitution, to deduce minimum values for the temperatures prevailing in the area of their development. These came out $27,700^{\circ} \mathrm{C}$. for the strata lying immediately above, and $68,400^{\circ} \mathrm{C}$. for the strata lying immediately below the photosphere, the former being regarded as the region into which, and the latter as the region from which, the eruptions took place. In this calculation, no prominences exceeding 40,000 miles (I.5') in height were included. But in I884, G. A. Hirn of Colmar, taking into account the enormous velocities of projection observed in the interim, fixed two million degrees Centigrade as the lowest internal temperature by which they could be accounted for; although of opinion that the condensations, presumed to give origin to the photospheric clouds, were incompatible with a higher external temperature than $50,000^{\circ}$ to $100,000^{\circ} \mathrm{C.}^{2}$

This method of going straight to the sun itself, observing what goes on there, and inferring conditions, has much to recommend it; but its profitable use demands knowledge we are still very far from possessing. We are quite ignorant, for instance, of the actual circumstances attending the birth of the solar flames. The assumption that they are nothing but phenomena of elasticity is a purely gratuitous one. Spectroscopic indications, again, give hope of eventually affording a fixed point of comparison with terrestrial heat-sources; but their interpretation is still beset with uncertainties; nor can, indeed, the expression of transcendental temperatures in degrees of impossible thermometers be, at the best, other than a futile attempt to convey notions respecting a state of things altogether outside the range of our experience.

A more tangible, as well as a less disputable proof of solar radiative intensity than any mere estimates of temperature, was provided in some experiments made by Professor Langley in

${ }^{1}$ Astr. Nach., Nos. 1815-16. . ${ }^{2}$ L'Astronomie, Sept. 1884, p. 334. 
I878. ${ }^{1}$ Using means of unquestioned validity, he found the sun's disc to radiate 87 times as much heat, and 5300 times as much light, as an equal area of metal in a Bessemer converter after the air-blast had continued about twenty minutes. The brilliancy of the incandescent steel, nevertheless, was so blinding, that melted iron, flowing in a dazzling white-hot stream into the crucible, showed "deep brown by comparison, presenting a contrast like that of dark coffee poured into a white cup." Its temperature was estimated (not quite securely, as Young has pointed out) ${ }^{2}$ at $1800^{\circ}$ to $2000^{\circ} \mathrm{C}$.; and no allowances were made, in computing relative intensities, for atmospheric ravages on sunlight, for the extra impediments to its passage presented by the smoke-laden air of Pittsburg, or for the obliquity of its incidence. Thus a very large balance of advantage lay on the side of the metal.

A further element of uncertainty in estimating the intrinsic strength of the sun's rays has still to be considered. From the time that his disc first began to be studied with the telescope, it was perceived to be less brilliant near the edges. Lucas Valerius of the Lyncean Academy seems to have been the first to note this fact, which, strangely enough, was denied by Galileo in a letter to Prince Cesi of January 25, 16r $3 \cdot{ }^{3}$ Father Scheiner, however, fully admitted it, and devoted some columns of his bulky tome to the attempt to find an appropriate explanation. ${ }^{4}$ In I729, Bouguer measured, with much accuracy, the amount of this darkening; and from his data, Laplace, adopting a principle of emission now known to be erroneous, concluded that the sun loses eleven-twelfths of his light through absorption in his own atmosphere. ${ }^{5}$ The real existence of this atmosphere, which is totally distinct from the beds of ignited vapours producing the Fraunhofer lines, is not open to doubt, although its nature is still a matter of conjecture. The separate effects of its action on luminous, thermal, and chemical rays were carefully studied by Father Secchi, who in $1870^{6}$ inferred the total absorption to be

1 Jour. of Science, vol. i. (3d ser.), p. 653. t. vi., p. 198. 4 Rosa Ursina, lib. iv., p. 618. 6 Le Soleil (Ist ed.), p. 136.
2 The Sun, p. $269 . \quad 3 O_{p}$., 5 Méc. Cél., liv. x., p. 323. 
$\frac{88}{100}$ of all radiations taken together, and added the important observation that the light from the limb is no longer white, but reddish-brown. Absorptive effects were thus seen to be unequally distributed; and they could evidently be studied to advantage only by taking the various rays of the spectrum separately, and finding out how much each had suffered in transmission.

This was done by H. C. Vogel in $1877 .{ }^{1}$ Using a polarising photometer, he found that only i 3 per cent. of the violet rays escape at the edge of the solar disc, 16 of the blue and green, 25 of the yellow, and 30 per cent. of the red. Midway between centre and limb, 88.7 of violet light and 96.7 of red penetrate the absorbing envelope, the removal of which would leave the sun's visible spectrum of above two and a half times its present intensity in the most, and one and a half times in the least refrangible parts. The nucleus of a small spot was ascertained to be of the same luminous intensity as a portion of the unbroken surface about two and a half minutes from the limb. These experiments having been made during a spot-minimum when there is reason to think that absorption is below its average strength, Vogel suggested their repetition at a time of greater activity. They were extended to the heat-rays by Edwin B. Frost at Potsdam in I89I. ${ }^{2}$ His careful experiments went to show that, were the sun's atmosphere removed, his thermal power, as regards ourselves, would be increased $\mathbf{I . 7}$ times. They established, too, the intrinsic uniformity in radiation of all parts of his disc.

Professor Langley, now of Washington, gave to measures of the kind a refinement previously undreamt of. Reliable determinations of the energy of the individual spectral rays were, for the first time, rendered possible by his invention of the "bolometer" in I880. ${ }^{3}$ This exquisitely sensitive instrument affords the means of measuring heat, not directly, like the thermopile, but in its effects upon the conduction of electricity. It represents, in the phrase of the inventor, the finger laid upon the throttle-valve of a steam-engine. A minute force becomes

1 Monatsber., Berlin, I877, p. 104.

2 Astr. Nach., Nos. 3105-3106; Astr. and Astro-Physics, Oct. 1892, p. 720 . Cf. Wilson and Rambaut, Proc. R. Irish Acad., vol. ii., p. 299, 1892.

3 Am. Jour. of Sc., vol. xxi., p. 187. 
the modulator of a much greater force, and thus from imperceptible becomes conspicuous. By locally raising the temperature of an inconceivably fine strip of platinum serving as the conducting-wire in a circuit, the flow of electricity is impeded at that point, and the included galvanometer records a disturbance of the electrical flow. Amounts of heat have, in this way, been detected in less than ten seconds, which, expended during a thousand years on the melting of a kilogramme of ice, would leave a part of the work still undone.

The heat contained in the diffraction spectrum is, with equal dispersions, barely one-tenth of that in the prismatic spectrum. It had, accordingly, never previously been found possible to measure it in detail-that is, ray by ray. But it is only from the diffraction, or normal spectrum that any true idea can be gained as to the real distribution of energy among the various constituents, visible and invisible, of a sunbeam. The effect of passage through a prism is to crowd together the red rays very much more than the blue. To this prismatic distortion was owing the establishment of a psendomaximum of heat in the infra-red, which disappeared when the natural arrangement by wave-length was allowed free play. Professor Langley's bolometer has shown that the hottest part of the normal spectrum virtually coincides with its most luminous part, both lying in the orange, close to the D line. ${ }^{1}$ Thus the last shred of evidence in favour of the threefold division of solar radiations vanished, and it became obvious that the varying effects-thermal, luminous, or chemical-produced by them are due, not to any distinction of quality in themselves, but to the different properties of the substances they impinge upon. They are simply bearers of energy, conveyed in shorter or longer vibrations; the result in each separate case depending upon the capacity of the material particles meeting them for taking up those shorter or longer vibrations, and turning them variously to account in their inner economy.

A long series of experiments at Allegheny was completed

1 For J. W. Draper's partial anticipation of this result, see Am. Jour. of $S_{c}$., vol. iv., 1872 , p. 174 . 
in the summer of I88 I on the crest of Mount Whitney in the Sierra Nevada. Here, at an elevation of 14,887 feet, in the driest and purest air, perhaps, in the world, atmospheric absorptive inroads become less sensible, and the indications of the bolometer, consequently, surer and stronger. An enormous expansion was at once given to the invisible region in the solar spectrum below the red. Captain Abney had got chemical effects from undulations twelve ten-thousandths of a millimetre in length. These were the longest recognised as, or indeed believed, on theoretical grounds, to be capable of existing. Professor Langley now got heating effects from rays of above twice that wave-length, his delicate thread of platinum groping its way down nearly to thirty ten-thousandths of a millimetre, or three "microns." The known extent of the solar spectrum was thus at once more than doubled. Its visible portion covers a range of about one octave; bolometric indications already in I 884 comprised between three and four. The great importance of the newly explored region appears from the fact that three-fourths of the entire energy of sunlight reside in the infra-red, while scarcely more than one-hundredth part of that amount is found in the better known ultra-violet space. ${ }^{1}$ These curious facts were reinforced, in $1886,{ }^{2}$ by further particulars learned with the help of rock-salt lenses and prisms, glass being impervious to very slow as to very rapid vibrations. Traces were thus detected of solar heat distributed into bands of transmission alternating with bands of atmospheric absorption, down to a wave-length of eighteen microns. The meteorological importance of this circumstance, as Professor Langley has not failed to note, is very great. It means that radiations corre-sponding to the temperature of freezing water, can reach space from the earth's surface, as well as the earth's surface from space.

Atmospheric absorption had never before been studied with such precision as it was by Professor Langley on Mount Whitney.

1 Phil. Mag., vol. xiv., p. 179 (March 1883). 22 "The Solar and the Lunar Spectrum," Memoirs National Acad. of Sciences, vol. iv.; "On hitherto Unrecognised Wave-lengths," Amer. Jour. of Science, vol. xxxii., Aug. I886. 
Aided by simultaneous observations from Lone Pine, at the foot of the Sierra, he was able to calculate the intensity belonging to each ray before entering the earth's gaseous envelope-in other words, to construct an extra-atmospheric curve of energy in the spectrum. The result showed that the blue end suffered far more than the red, absorption varying inversely as wave-length. This property of stopping predominantly the quicker vibrations is shared, as both Vogel and Langley ${ }^{1}$ have conclusively shown, by the solar atmosphere. The effect of this double absorption is as if two plates of reddish glass were interposed between us and the sun, the withdrawal of which would leave his orb, not only three or four times more brilliant, but in colour of a distinct greenish-blue, not very different from the tint of the second (F) line of hydrogen. ${ }^{2}$

The fact of the unveiled sun being blue has an important bearing upon the question of his temperature, to afford a somewhat more secure answer to which was the ultimate object of Professor Langley's persevering researches ; for it is well known that, as bodies grow hotter, the proportionate representation in their spectra of the more refrangible rays becomes greater. The lowest stage of incandescence is the familiar one of red heat. As it gains intensity, the quicker vibrations come in, and an optical balance of sensation is established at white heat. The final term of blue heat, as we now know, is attained by the photosphere. On this ground alone, then, of the large original preponderance of blue light, we must raise our estimate of solar heat; and actual measurements show the same upward tendency. Until quite lately, Pouillet's figure of I.7 calories per minute per square centimetre of terrestrial surface, was the received value for the "solar constant." Forbes had, it is true, got 2.85 from observations on the Faulhorn in $1842 ;^{3}$ but they failed to obtain the confidence they merited. Pouillet's result was not definitely superseded until Violle, from actinometrical measures at the summit and base of Mont Blanc in I875, computed the intensity of solar radiation at $2.54,{ }^{4}$ and Crova, about the same

1 Comptes Rendus, t. xcii., p. 701. ${ }^{2}$ Nature, vol. xxvi., p. 589. ${ }^{3}$ Phil. Trans., vol. cxxxii., p. 273. ${ }^{4}$ Ann. de Chim., t. x., p. 321. 
time, at Montpellier, showed it to be above two calories. ${ }^{1}$ Langley went higher still. Working out the results of the Mount Whitney expedition, he was led to conclude atmospheric absorption to be fully twice as effective as had hitherto been supposed. Scarcely sixty per cent., in fact, of those solar radiations which strike perpendicularly through a seemingly translucent sky, attain the sea-level. 'The rest are reflected, dispersed, or absorbed. This discovery involved a large addition to the original supply so mercilessly cut down in transmission, and the solar constant rose at once to three calories-its actual standard value. ${ }^{2}$ Phrased otherwise, this means that the sun's heat reaching the outskirts of our atmosphere is capable of doing without cessation the work of an engine of three-horse power for each square yard of the earth's surface. Thus, modern inquiries, though they give no signs of agreement, within any tolerable limits of error, as to the probable temperature of the sun, tend, with growing certainty, to render more and more evident the vastness of the thermal stores contained in the great central reservoir of our system.

1 Ann. de Chim., t. xi., p. 505. 2 From actinometrical observations made at Kieff in I890, M. Savélieff deduces a solar constant of 3.47 (Comptes Rendus, t. cxii., p. I200), but there seems no sufficient reason at present for aỏvancing beyond Langley's value of 3.0. 
THE question of the sun's distance arises naturally from the consideration of his temperature, since the intensity of the radiations emitted as compared with those received and measured, depends upon it. But the knowledge of that distance has a value quite apart from its connection with solar physics. The semi-diameter of the earth's orbit is our standard measure for the universe. It is the great fundamental datum of astronomy - the unit of space, any error in the estimation of which is multiplied and repeated in a thousand different ways, both in the planetary and sidereal systems. Hence its determination has been called by Airy "the noblest problem in astronomy." It is also one of the most difficult. The quantities dealt with are so minute that their sure grasp tasks all the resources of modern science. An observational inaccuracy which would set the moon nearer to or farther from us than she really is by one hundred miles, would vitiate an estimate of the sun's distance to the extent of sixteen million! ${ }^{1}$ What is needed in order to attain knowledge of the desired exactness is no less than this: to measure an angle about equal to that subtended by a halfpenny 2000 feet from the eye, within a little more than a thousandth part of its value.

The angle thus represented is what is called the "horizontal parallax" of the sun. By this amount-the breadth of a halfpenny at 2000 feet-he is, to a spectator on the rotating earth, removed at rising and setting from his meridian place in the heavens. Such, in other terms, would be the magnitude of the

\footnotetext{
${ }^{1}$ Airy, Month. Not., vol. xvii., p. 210.
} 
terrestrial radius as viewed from the sun. If we knew this magnitude with certainty and precision, we should also know with certainty and precision-the dimensions of the earth being, as they are, well ascertained-the distance of the sun. In fact, the one quantity commonly stands for the other in works treating professedly of astronomy. But this angle of parallax or apparent displacement cannot be directly measured - cannot even be perceived with the finest instruments. Not from its smallness. The parallactic shift of the nearest of the stars as seen from opposite sides of the earth's orbit, is many times smaller. But at the sun's limb, and close to the horizon, where the visual angle in question opens out to its full extent, atmospheric troubles become overwhelming, and altogether swamp the far more minute effects of parallax.

There remain indirect methods. Astronomers are well acquainted with the proportions which the various planetary orbits bear to each other. They are so connected, in the manner expressed by Kepler's Third Law, that the periods being known, it only needs to find the interval between any two of them in order to infer at once the distances separating them all from one another and from the sun. The plan is given; what we want to discover is the scale upon which it is drawn; so that, if we can get a reliable measure of the distance of a single planet from the earth, our problem is solved.

Now some of our fellow-travellers in our unending journey round the sun, come at times well within the scope of celestial trigonometry. The orbit of Mars lies at one point not more than thirty-five million miles outside that of the earth, and when the two bodies happen to arrive together in or near the favourable spot-a conjuncture which recurs every fifteen years - the desired opportunity is granted. Mars is then "in opposition," or on the opposite side of us from the sun, crossing the meridian consequently at midnight. ${ }^{1}$ It was from an opposition of Mars, observed in 1672 by Richer at Cayenne in concert with

1 Mars comes into opposition once in about 780 days; but owing to the eccentricity of both orbits, his distance from the earth at those epochs varies from thirty-five to sixty-two million miles. 
Cassini in Paris, that the first scientific estimate of the sun's distance was derived. It appeared to be nearly eighty-seven millions of miles (parallax 9.5"); while Flamsteed deduced $81,700,000$ (parallax $10^{\prime \prime}$ ) from his independent observations of the same occurrence-a difference quite insignificant at that stage of the inquiry. But Picard's result was just half Flamsteed's (parallax 20"; distance forty-one million miles); and Lahire considered that we must be separated from the hearth of our system by an interval of at least $\mathrm{I} 36$ million miles. ${ }^{1}$ So that uncertainty continued to be on a gigantic scale.

Venus, on the other hand, comes closest to the earth when she passes between it and the sun. At such times of "inferior conjunction" she is, however, still twenty-six million miles, or (in round numbers) rog times more distant than the moon. Moreover, she is so immersed in the sun's rays that it is only when her path lies across his disc that the requisite facilities for measurement are afforded. These "partial eclipses of the sun by Venus" (as Encke termed them) are coupled together in pairs, ${ }^{2}$ of which the components are separated by eight years, recurring at intervals alternately of $105 \frac{1}{2}$ and $121 \frac{1}{2}$ years. 'Thus, the first calculated transit took place in December I63 I, and its companion (observed by Horrocks) in the same month (N.S.) I639. Then, after the lapse of $121 \frac{1}{2}$ years, came the June couple of I76I and 1769; and again, after I05 $\frac{1}{2}$, the two recently observed, December 8, I874, and December 6, I882. Throughout the twentieth century there will be no transit of Venus; but the astronomers of the twenty-first will only have to wait four years for the first of a June pair. The rarity of

1 J. D. Cassini, Hist. Abrégée de la Parallaxe du Soleil, p. 122, 1772. 2 The present period of coupled eccentric transits will, in the course of ages, be succeeded by a period of single, nearly central transits. The alignments by which transits are produced, of the earth, Venus, and the sun, close to the place of intersection of the two planetary orbits, now occur, the first a little in front of, the second, after eight years less two and a half days, a little behind the node. But when the first of these two meetings takes place very near the node, giving a nearly central transit, the second falls too far from it, and the planet escapes projection on the sun. The reason of the liability to an eight-yearly recurrence is that eight revolutions of the earth are accomplished in only a very little more time than thirteen revolutions of Venus. 
these events is due to the fact that the orbits of the earth and Venus do not lie in the same plane. If they did, there would be a transit each time that our twin-planet overtakes us in her more rapid circling-that is, on an average, every 584 days. As things are actually arranged, she passes above or below the sun, except when she happens to be very near the line of intersection of the two tracks.

Such an occurrence as a transit of Venus seems, at first sight, full of promise for solving the problem of the sun's distance. For nothing would appear easier than to determine exactly either the duration of the passage of a small, dark orb across a large brilliant disc, or the instant of its entry upon or exit from it. And the differences in these times (which, owing to the comparative nearness of Venus, are quite considerable), as observed from remote parts of the earth, can be translated into differences of space-that is, into apparent or parallactic displacements, whereby the distance of Venus becomes known, and thence, by a simple sum in proportion, the distance of the sun. But in that word "exactly" what snares and pitfalls lie hid! It is so easy to think and to say; so indefinitely hard to realize. The astronomers of the eighteenth century were full of hope and zeal. They confidently expected to attain, through the double opportunity offered them, to something like a permanent settlement of the statistics of our system. They were grievously disappointed. The uncertainty as to the sun's distance, which they had counted upon reducing to a few hundred thousand miles, remained at many millions.

In 1822, however, Encke, then director of the Seeberg Observatory near Gotha, undertook to bring order out of the confusion of discordant and discordantly interpreted observations. His combined result for both transits (I76I and 1769) was published in $1824,{ }^{1}$ and met universal acquiescence. The parallax of the sun thereby established was $8.5776^{\prime \prime}$, corresponding to a mean distance $^{2}$ of $95 \frac{1}{4}$ million miles. Yet this abolition of doubt was

1 Die Entfernung der Sonne: Fortsetzung, p. 108. Encke slightly corrected his result of 1824 in Berlin Abh., 1835, p. 295. 2 Owing to the ellipticity of its orbit, the earth is nearer to the sun in January than in June by $3,100,000$ 
far from being so satisfactory as it seemed. Serenity on the point lasted exactly thirty years. It was disturbed in 1854 by Hansen's announcement ${ }^{1}$ that the observed motions of the moon could be drawn into accord with theory only on the terms of bringing the sun considerably nearer to us than he was supposed to be.

Dr. Matthew Stewart, professor of mathematics in the University of Edinburgh, bad made a futile attempt in 1763 to deduce the sun's distance from his disturbing power over our satellite. ${ }^{2}$ Tobias Mayer of Göttingen, however, whose short career was so fruitful of suggestions, struck out the right way to the same end; and Laplace, in the seventh book of the Mécanique Céleste, ${ }^{3}$ gave a solar parallax derived from the lunar " parallactic inequality" substantially identical with that issuing from Encke's subsequent discussion of the eighteenth century transits. Thus two wholly independent methods-the trigonometrical, or method by survey, and the gravitational, or method by perturbationseemed to corroborate each the upshot of the use of the other until the nineteenth century was well past its meridian. It is singular how often errors conspire to lead conviction astray.

Hansen's note of alarm in I854 was echoed by Leverrier in I 858.4 He found that an apparent monthly oscillation of the sun which reflects a real monthly movement of the earth round its common centre of gravity with the moon, and which depends for its amount solely on the mass of the moon and the distance of the sun, required a diminution in the admitted value of that distance by fully four million miles. Three years later he pointed out that certain perplexing discrepancies between the observed and computed places both of Venus and Mars, would vanish on the adoption of a similar measure. ${ }^{5}$ Moreover, a favourable

miles. The quantity to be determined, or "mean distance," is that lying midway between these extremes-is, in other words, half the major axis of the ellipse in which the earth travels. I Month. Not., vol. xv., p. 9. 2 The Distance of the Sun from the Earth determined by the Theory of Gravity, Edinburgh, I763. $\quad 3$ Opera, t. iii., p. 326. ${ }^{4}$ Comptes Rendus, t. xlvi., p. 882. The parallax $8.95^{\prime \prime}$ derived by Leverrier from the above-described inequality in the earth's motion, was corrected by Stone to 8.91. Month. Not., vol. xxviii., p. 25. 5 Month. Not., vol. xxxv., p. I56. 
opposition of Mars gave the opportunity in I862 for fresh observations, which, separately worked out by Stone and Winnecke, agreed with all the newer investigations in fixing the great unit at slightly over 9I million miles. In Newcomb's hands they gave $92 \frac{1}{2}$ million. ${ }^{1}$ The accumulating evidence in favour of a large reduction in the sun's distance was just then reinforced by an auxiliary result of a totally different and unexpected kind.

The discovery that light does not travel instantaneously from point to point, but takes some short time in transmission, was made by Olaus Römer in I675, through observing that the eclipses of Jupiter's satellites invariably occurred later, by a considerable interval, when the earth was on the far side, than when it was on the near side of its orbit. Half this interval, or the time spent by a luminous vibration in crossing the "mean radius" of the earth's orbit, is called the "light-equation"; and the determination of its precise value has claimed the minute care distinctive of modern astronomy. Delambre in I 792 made it 493 seconds. Glasenapp, a Russian astronomer, vaised the estimate in $\mathrm{I} 874$ to $50 \mathrm{I}$, Professor Harkness adopting a safe medium value of 498 seconds. Hence, if we had any independent means of ascertaining how fast light travels, we could tell at once how far off the sun is.

There is yet another way by which knowledge of the swiftness of light would lead us straight to the goal. The heavenly bodies are perceived, when carefully watched and measured, to be pushed forward out of their true places, in the direction of the earth's motion, by a very minute quantity. This effect (already adverted to) has been known since Bradley's time as "aberration." It arises from a combination of the two movements of the earth round the sun and of the light-waves through the ether. If the earth stood still, or if light spent no time on the road from the stars, such an effect would not exist. Its amount represents the proportion between the velocities with which the earth and the light-rays pursue their respective journeys. This proportion is, roughly, one to ten thousand.

1 Wash. Obs., 1865, App. ii., p. 28. 
So that here again, if we knew the rate per second of luminous transmission, we should also know the rate per second of the earth's movement, consequently the size of its orbit and the distance of the sun.

But, until lately, instead of finding the distance of the sun from the velocity of light, there has been no means of ascertaining the velocity of light except thropgh the imperfect knowledge possessed as to the distance of the sun. The first successful terrestrial experiments on the point date from I 849 ; and it is certainly no slight triumph of human ingenuity to have taken rigorous account of the delay of a sunbeam in flashing from one mirror to another. Fizeau led the way, ${ }^{1}$ and he was succeeded, after a few months, by Léon Foucault, 2 who, in I862, had so far perfected Wheatstone's method of revolving mirrors, as to be able to announce with authority that light travelled slower, and that the sun was in consequence nearer, than had been supposed. ${ }^{3}$ Thus a third line of separate research was found to converge to the same point with the two others.

Such a conspiracy of proof was not to be resisted, and at the anniversary meeting of the Royal Astronomical Society in February I864, the correction of the solar distance took the foremost place in the annals of the year. Lest, however, a sudden bound of four million miles nearer to the centre of our system should shake public faith in astronomical accuracy, it was explained that the change in the solar parallax corresponding to that huge leap, amounted to no more than the breadth of a human hair I 25 feet from the eye ! 4 The Nautical Almanac gave from I 870 the altered value of $8.95^{\prime \prime}$, for which Newcomb's result of $8.85^{\prime \prime}$, admitted since I 869 into the Berlin Ephemeris, was substituted some ten years later. In astronomical literature the change was initiated by Sir Edmund Beckett in the first edition (1865) of his Astronomy without Mathematics.

1 Comptes Kendus, t. xxix., p. 90. $\quad 2$ Ibid., t. xxx., p. 551. $\quad 3$ Ibid., t. lv., p. 501. The previously admitted velocity was 308 million metres per second; Foucault reduced it to 298 million. Combined with Struve's "constant of aberration" this gave 8.86 " for the solar parallax, which exactly agreed with Cornu's result from a repetition of Fizeau's experiments in 1872 . Comptes Rendus, t. lxxvi., p. 338. 4 Month. Not., vol. xxiv., p. 103 . 
If any doubt remained as to the misleading character of Encke's deduction, so long implicitly trusted in, it was removed by Powalky's and Stone's re-discussions, in I864 and I868 respectively, of the transit observations of i769. Using improved determinations of the longitude of the various stations (very imperfectly known to their able predecessor), and a selective judgment in dealing with their materials, which, however indispensable, did not escape adverse criticism, they brought out results confirmatory of the no longer disputed necessity for largely increasing the solar parallax, and proportionately diminishing the solar distance. Once more in 1890 , and this time with better success, the eighteenth century transits were investigated by Professor Newcomb. ${ }^{1}$ Turning to account the experience gained in the interim regarding the optical phenomena accompanying such erents, he elicited from the mass of somewhat discordant observations at his command, a parallax (8.79") remarkably close to agreement with the value towards which several lines of recent research converge.

Conclusions on the subject, however, were still regarded as purely provisional. A transit of Venus was fast approaching, and to its arbitrament, as to that of a court of final appeal, the pending question was to be referred. It is true that the verdict in the same case by the same tribunal a century earlier had proved of so indistinct a character as to form only a startingpoint for fresh litigation; but that century had not passed in vain, and it was confidently anticipated that observational difficulties, then equally unexpected and insuperable, would yield to the elaborate care and skill of forewarned modern preparation.

The conditions of the transit of December 8, I874, were sketched out by the then Astronomer-Royal (Sir George Airy) in $1857,,^{2}$ and formed the subject of eager discussion in this and other countries down to the very eve of the occurrence. In these Mr. Proctor took a leading part, supplying official omissions, and working out, with geometrical accuracy, the details of the relations between the different parts of the earth and

1 Astr. Papers of the American Ephemeris, vol. ii., p. 263. ${ }^{2}$ Month. Not., vol. xvii., p.. 208. 
Venus's shadow-cone; and it was due to his urgent representations that provision was made for the employment of the method identified with the name of Halley, ${ }^{1}$ which had been too hastily assumed inapplicable-to the first of each transit-pair. It depends upon the difference in the length of time taken by the planet to cross the sun's disc, as seen from various points of the terrestrial surface, and requires, accordingly, the visibility of both entrance and exit at the same station. Since these were, in 1874, separated by about three and a half hours, and the interval is often much longer, the choice of posts for the successful use of the "method of durations" is a matter of some difficulty.

The system described by Delisle in I760, on the other hand, involves merely noting the instant of ingress or egress (according to situation) from opposite extremities of a terrestrial diameter; the disparity in time giving a measure of the planet's apparent displacement, hence of its actual rate of travel in miles per minute, from which its distances severally from earth and sun are immediately deducible. Its chief attendant difficulty is the necessity for accurately fixing the longitudes of the points of observation. This. however, was much more sensibly felt a century ago than it is now, and the improved facility and certainty of modern determinations have tended to five the Delislean plan a decided superiority over its rival.

These two traditional methods were supplemented in 1874 by the camera and the heliometer. From photography, above all, much was expected. Observations made by its means would have the advantages of impartiality, multitude, and permanence. Peculiarities of vision and bias of judgment would be eliminated; the slow progress of the phenomenon would permit an indefinite number of pictures to be taken, their epochs fixed to a fraction of a second ; while subsequent leisurely comparison and measurement could hardly fail, it was thought, to educe approximate truth from the mass of accumulated evidence. The use of the heliometer (much relied on by German observers) was so far similar to that of the camera that the object aimed at by both was the determination of the relative positions of the centres of

${ }_{1}$ Because closely similar to that proposed by him in Phil. Trans. for 1716. 
the sun and Venus viewed, at the same absolute instant, from opposite sides of the globe. So that the two older methods seek to ascertain the exact times of meeting between the solar and planetary limbs; while the two modern methods work by measurement of the position of the dark body already thrown into complete relief by its shining background. The former are "methods by contact," the latter "methods by projection."

Every country which had a reputation to keep or to gain for scientific zeal was forward to co-operate in the great cosmopolitan enterprise of the transit. France and Germany each sent out six expeditions; twenty-six stations were in Russian, twelve in English, eight in American, three in Italian, one (equipped with especial care) in Dutch occupation. In all, at a cost of nearly a quarter of a million, some fourscore distinct posts of observation were provided; among them such inhospitable and all but inaccessible rocks in the bleak Southern Ocean, as St. Paul's and Campbell Islands, swept by hurricanes, and fitted only for the habitation of seabirds, where the daring votaries of science, in the wise prevision of a long leaguer by the elements, were supplied with stores for many months, or even a whole year. Siberia and the Sandwich Islands were thickly beset with obser $\in \mathrm{rs}$; parties of three nationalities encamped within the mists of Kerguelen Island, expressively termed the "Land of Desolation," in the sanguine, though not wholly frustrated hope of a glimpse of the sun at the right moment. M. Janssen narrowly escaped destruction from a typhoon in the China seas on his way to Nagasaki ; Lord Lindsay (now Earl of Crawford and Balcarres) equipped, at his private expense, an expedition to the Mauritius, which was in itself an epitome of modern resource and ingenuity.

During several years the practical methods best suited to ensure success for the impending enterprise, formed a subject of European debate. Official commissions were appointed to receive and decide upon evidence; and experiments were in progress for the purpose of defining the actual circumstances of the contacts, the accurate determination of which constituted the only tried, though by no means an assuredly safe road to the 
end in view. In England, America, France, and Germany, artificial transits were mounted, and the members of the various expeditions were carefully trained to unanimity in estimating the phases of junction, and separation between a moving dark circular body and a broad illuminated disc. In the last century, a formidable and prevalent phenomenon had swamped all pretensions to rigid accuracy. This was an effect analogous to "Baily's Beads," which acquired notoriety as the "Black Drop" or "Black Ligament." It may be described as substituting adhesion for contact, the limbs of the sun and planet, instead of meeting and parting with the desirable clean definiteness, clinging together as if made of some glutinous material, and prolonging their connection by means of a dark band or dark threads stretched between them. Some astronomers ascribe this baffling appearance entirely to instrumental imperfections; others to atmospheric agitation; others again to the optical encroachment of light upon darkness known as "irradiation." It is probable that all these causes conspire, in various measure, to produce it; but it is certain that by suitable precautions, combined with skill in the observer, and a reasonably tranquil air, its conspicuous appearance may, in most cases, be obviated.

The organisation of the British forces reflected the utmost credit on the energy and ability of Lieutenant-Colonel Tupman, of the Royal Marine Artillery, who was responsible for the whole. No useful measure was neglected. Each observer went out ticketed with his " personal equation," his senses drilled into a species of martial discipline, his powers absorbed, so far as possible, in the action of a cosmopolitan observing machine. Instrumental uniformity and uniformity of method were attainable, and were attained; but diversity of judgment unhappily survived the best-directed efforts for its extirpation.

The eventful day had no sooner passed than telegrams began to pour in, announcing an outcome of considerable, though not unqualified success. The weather had proved generally favourable; all the manifold arrangements had (save for some casual mishaps) worked well; contacts had been plentifully observed; photographs in lavish abundance had been secured; a store of 
materials, in short, had been laid up, of which it would take years to work out the full results by calculation. Gradually, however, it came to be known that the hope of a definitive issue must be abandoned. Unanimity was found to be as remote as ever. The dreaded "black ligament" gave, indeed, less trouble than was expected; but another appearance supervened which took most observers by surprise. This was the illumination due to the atmosphere of Venus. Astronomers, it is true, were not ignorant that the planet had, on previous occasions, been seen girdled with a lucid ring; but its power to mar observations by the distorting effect of refraction had scarcely been reckoned with. It proved, however, to be very great. Such was the difficulty of determining the critical instant of internal contact, that (in Colonel Tupman's words) "observers side by side, with adequate optical means, differed as much as twenty or thirty seconds in the times they recorded for phenomena which they have described in almost identical language." 1

Such uncertainties in the data admitted of a corresponding variety in the results. From the British observations of ingress and egress Sir George Airy ${ }^{2}$ derived, in I877, a solar parallax of $8.76^{\prime \prime}$ (corrected to $8.754^{\prime \prime}$ ), indicating a mean distance of 93,375,000 miles. Mr. Stone obtained a value of ninety-two millions (parallax 8.88"), and held any parallax less than $8.84^{\prime \prime}$ or more than 8.93 " to be "absolntely negatived" by the documents available. ${ }^{3}$ Yet, from the same, Colonel Tupman deduced 8.8 I", ${ }^{4}$ implying a distance 700,000 miles greater than Stone had obtained. The French observations of contacts gave (the best being selected) a parallax of about $8.88^{\prime \prime}$; French micrometric measures the obviously exaggerated one of $9.05^{\prime \prime} .^{5}$

Photography, as practised by most of the European parties, was a total failure. Utterly discrepant values of the microscopic displacements designed to give the scale of the solar system, issued from attempts to measure even the most promising pictures. "You might as well try to measure the zodiacal light," it was remarked to Sir George Airy. Those taken on

1 Month. Not., vol. xxxviii., p. 447. $\quad 2$ Ibid., p. II. $\quad 3$ Ibid., p. 294. 4 Ibid., p. 334. 5 Comptes Rendus, t. xcii., p. 81 2. 
the American plan (adopted by Lord Lindsay), of using telescopes of so great focal length as to afford, without further enlargement, an image of the requisite size, gave notably better results. From an elaborate comparison of these (some dating from Vladivostock, Nagasaki, and Pekin, others from Kerguelen and Chatham Islands), Professor D. P. Todd, director of the Amherst College Observatory, deduced a solar distance of about ninety-two million miles (parallax $\left.8.883^{\prime \prime} \pm 0.034^{\prime \prime}\right),{ }^{1}$ a value, as $\mathrm{Mr}$. Stone has pointed out, favoured by a considerable accumulation of independent evidence.

On the whole, estimates of the great spatial unit cannot be said to have gained any security from the combined effort of 1874. A few months before the transit, Mr. Proctor considered that the uncertainty then amounted to I, 448,000 miles; ${ }^{2}$ five years after the transit, Professor Harkness judged it to be still I, 575,950 miles ; ${ }^{3}$ yet it had been hoped that it would have been brought down to 100,000 . As regards the end for which it had been undertaken, the grand campaign had come to nothing. Nevertheless, no sign of discouragement was apparent. There was a change of view, but no relaxation of purpose. The problem, it was seen, could be solved by no single heroic effort. but by the patient approximation of gradual improvements. Astronomers, accordingly, looked round for fresh means, or more refined expedients for applying those already known. A new phase of exertion was entered upon.

On September 5, i 877, Mars came into opposition close to the part of his orbit which lies nearest to that of the earth, and Dr. Gill (since I 879 Her Majesty's astronomer at the Cape of Good Hope) took advantage of the circumstance to appeal once more to him for a decision on the qucestio vexata of the sun's distance. $\mathrm{He}$ chose, as the scene of his labours, the Island of Ascension, and for their plan a method recommended by Airy in $1857,{ }^{4}$ but never before fairly tried. This is known as the "diurnal method of parallaxes." Its principle consists in substituting successive morning and evening observations from the same spot, for simultaneous observations from remote spots, the rotation of

1 Observatory, No. 51, p. 205. 2 Transits of Venus, p. 89 (Ist ed.): ${ }^{3} \mathrm{Am}$. Jour. of Sc., vol. xx., p. 393. 4 Month. Not., vol. xvii., p. 219. 
the earth supplying the necessary difference in the points of view. Its great advantage is that of unity in performance. A single mind, looking through the same pair of eyes, reinforced with the same optical appliances, is employed throughout, and the errors inseparable from the combination of data collected under different conditions are avoided. 'There are many cases in which one man can do the work of two better than two men can do the work of one. The result of Dr. Gill's skilful determinations (made with Lord Lindsay's heliometer) was a solar parallax of $8.78^{\prime \prime}$, corresponding to a distance of 93,080,000 miles. ${ }^{1}$ The bestowal of the Royal Astronomical Society's gold medal stamped the merit of this distinguished service.

But there are other subjects for this kind of inquiry besides Mars and Venus. Professor Galle of Breslau suggested in $1872^{2}$ that some of the minor planets might be got to repay astronomers for much disinterested toil spent in unravelling their motions, by lending aid to their efforts towards a correct celestial survey. Ten or twelve come near enough, and are bright enough for the purpose; and, in fact, the absence of sensible magnitude is one of their chief recommendations, since a point of light offers far greater facilities for exact measurement than a disc. The first attempt to work this new vein was made at the opposition of Phocæa in I872; and from observations of Flora in the following year at twelve observatories in the northern and southern hemispheres, Galle deduced a solar parallax of $8.87^{\prime \prime} .^{3}$ At the Mauritius in 1874, Lord Lindsay and Dr. Gill applied the "diurnal method" to Juno, then conveniently situated for the purpose; and the continued use of similar occasions affords an nnexceptionable means for improving knowledge of the sun's distance. They frequently recur; they need no elaborate preparation; a single astronomer armed with a heliometer can do all the requisite work. Dr. Gill, however, organised a more complex plan of operations upon Iris in I888, and upon Victoria and Sappho in r889. A novel method was adopted. Its object was to secure simultaneous observations made from opposite sides

1 Mem. Roy. Astr. Soc., vol. xlvi., p. 163. 2 Astr. Nach., No. I897.

3 Hilfiker, Bern Mittheilungen, 1878, p. 109. 
of the globe just when the planet lay in the plane passing through the centre of the earth and the two observers, the same pair of reference-stars being used on each occasion. The displacements caused by parallax were, thus in a sense doubled, since the star to which the planet seemed approximated in the northern hemisphere, showed as if slightly removed from it in the southern, and vice versat. And as the planet pursued its course, during the weeks that the favourable period lasted, fresh star-couples came into play. In these determinations, only heliometers were employed. Dr. Elkin, of Yale College, co-operated throughout, and the heliometers of Dresden, Göttingen, Bamberg, and Leipzig, shared in the work, while Dr. Auwers of Berlin was Dr. Gill's personal coadjutor at the Cape for the opposition of Victoria. The photographic registration of planet and star-places was not neglected; and thus the question of the sun's distance is at last likely to be definitively settled. Already a result has been deduced by the Cape Astronomer from the opposition of Victoria which amply repays the time and pains expended in procuring it. They were of formidable amount. Meridian observations of the comparison-stars occupied twenty-one observatories during four months; the direct work of triangulation kept four heliometers in almost exclusive use for the best part of a year; and the data thus collected were rendered communicative only by the computative toil of three years, on the part of Dr. Gill himself and a too scanty staff of assistants. The upshot has been to assign a parallax to the sun of $8.809^{\prime}$, corresponding (in round numbers) to a distance of 92,700,000 miles; and the extremely small appended probable error of $0.007^{\prime \prime}$ shows that this dictum can be trusted within narrow limits. Moreover, a nearly identical result has been derived from the opposition of Iris.

The second of the nineteenth-century pair of Venus-transits was looked forward to with much-abated enthusiasm. Russia refused her active co-operation in observing it, on the ground that oppositions of the minor planets were trigonometrically more useful, and financially far less costly; and her example was followed by Austria, while Italian astronomers limited their 
sphere of action to their own peninsula. Nevertheless, it was generally held that a phenomenon which the world could not again witness until it was four generations older should, at the price of any effort, not be allowed to pass in neglect.

An International Conference, accordingly, met at Paris in I 88 I with a view to concerting a plan of operations. America, however, preferring independent action, sent no representative; and the European breakdown of photography in recording transit-phases was admitted by its official abandonment. It was decided to give Delisle's method another trial; and the ambiguities attending and marring its use were sought to be obviated by careful regulations for ensuring agreement in the estimation of the critical moments of ingress and egress. ${ }^{1}$ But, in fact (as M. Puiseux had shown ${ }^{2}$ ), contacts between the limbs of the sun and planet, so far from possessing the geometrical simplicity long attributed to them, are really made up of a prolonged succession of various and varying phases, impossible either to predict or identify with anything like rigid exactitude. Sir Robert Ball compared the task of determining the precise instant of their meeting or parting, to that of telling the hour with accuracy on a watch without a minute-hand; and the comparison is admittedly inadequate. For not only is the apparent movement of Venus across the sun extremely slow, being but the excess of her real motion over that of the earth; but three distinct atmospheresthe solar, terrestrial, and cytherean-combine to deform outlines, and mask the geometrical relations which it is desired to connect with a strict count of time.

The result was very much what had been expected. The arrangements were excellent, and were only in a few cases disconcerted by bad weather. The British parties, under the experienced guidance of Mr. Stone, the Radcliffe observer, took up positions scattered (not at random) over the globe from Queensland to Bermuda, and accumulated an ample supply of skilful observations; the Americans gathered in a whole library of photographs, among them a fine series taken at the new Lick Observatory on Mount Hamilton; the Germans 
and Belgians trusted to the heliometer; the French used the camera as an adjunct to the method of contacts. Yet little or no approach was made to solving the problem. The range of doubt as to the sun's distance remained as wide as before. 'The value published in $\mathbf{I} 884,{ }^{i}$ by $M$. Houzeau, late director of the Brussels Obsèrvatory, forcibly illustrates this unwelcome conclusion. From 606 measures of Venus on the sun, taken with a new kind of heliometer at Santiago in Chili, he derived a solar parallax of $8.907^{\prime \prime}$, and a distance of 91,727,000 miles. But the "probable error" of this determination amounted to 0.084 " either way; that is, it was subject to a "more or less" of 900,000 miles, or to a total uncertainty of 1,800,000. The probable error of the English result, published in I887, was less formidable, ${ }^{2}$ yet the details of the discussion showed that no great confidence could be placed in it. The sun's distance came out 92,560,000 miles; while 92,360,000 was given by Professor Harkness's investigation of I475 American photographs. ${ }^{3}$ Finally, Dr. Auwers derived from the German heliometric measures the unsatisfactorily small value of $92,000,000$ miles. ${ }^{4}$ The transit of 1882 had not then brought about the desired unanimity.

The state and progress of knowledge on this important subject were summed up by Faye and Harkness in I88I. The methods employed in its investigation fall (as we have seen) into three separate classes-the trigonometrical, the gravitational, and the "phototachymetrical"-an ungainly adjective used to describe the method by the velocity of light. Each has its special difficulties and sources of error; each has counter-balancing advantages. The only distinct and trustworthy results, so far, from celestial surveys, have been furnished by Dr. Gill's observations of Mars in 1877, and of Iris and Victoria in I888-9. But the method by lunar and planetary disturbances is unlike all the others in having time on its side. It is this which Leverrier declared with emphasis must in-

1 Bull. de l'Acad., t. vi., p. $842 . \quad 2$ Month. Not., vol. xlviii., p. $20 \mathrm{I}$. 3 Astr. Jour., No. I82. ${ }_{4}$ Astr. Nach., No. 3066. t. xcii., p. 375 ; Am. Jour. of $S c .$, vol. xxii., p. 375 . 
evitably prevail, because its accuracy is continually growing. ${ }^{1}$ The scarcely perceptible errors which still impede its application are of such a nature as to accumulate year by year; eventually, then, they will challenge, and must receive, a more and more perfect correction.

The light-velocity method has, however, some immediate advantages. By a beautiful series of experiments on Foucault's principle, Master A. A. Michelson, of the United States Navy, fixed in 1879 the rate of luminous transmission at 299,930 (corrected later to 299,9IO) kilometres a second. ${ }^{2}$ This determination was held by Professor Todd to be entitled to four times as much confidence as any previous one; and if the solar parallax of $8.758^{\prime \prime}$ deduced from it by Professor Harkness errs somewhat by defect, it is doubtless because Glasenapp's "light-equation," with which it was combined, errs slightly by excess. But all earlier efforts of the kind were thrown into the shade by Professor Newcomb's arduous operations at Washington in I880-I882. ${ }^{3}$ The scale upon which they were conducted was in itself impressive. Foucault's entire apparatus in I862 had been enclosed in a single room; Newcomb's revolving and fixed mirrors, between which the rays of light were to run their timed course, were set up on opposite shores of the Potomac, at a distance of nearly four kilometres. This advantage was turned to the utmost account by ingenuity and skill in contrivance and execution ; and the deduced velocity of 299,860 kilometres $=186,328$ miles a second, had an estimated error (30 kilometres) only one-tenth that ascribed by Cornu to his own result in 1874 .

Just as these experiments were concluded in I882, M. Magnus Nyrén, of St. Petersburg, published an elaborate investigation of the small annular displacements of the stars due to the successive transmission of light, involving an increase of Struve's "constant of aberration" from 20.445" to 20.492". And from the new value combined with Newcomb's light-velocity, was

1 Month. Not., vol. xxxv., p. 401. 2 Am. Jour. of Sc., vol. xviii., p. 393. 3 Nature, vol. xxxiv., p. I70; Astron. Papers of the American Ephemeris, vol. ii., p. II3. 
derived a valuable approximation to the sun's distance, concluded at 92,905,02 I miles (parallax $=8.794^{\prime \prime}$ ). Yet it is not quite certain that Nyrén's correction was an improvement. A differential method of determining the amount of aberration, struck out by M. Loewy of Paris, ${ }^{1}$ avoids most of the snares and pitfalls of the absolute method previously in vogue. There are, indeed, drawbacks to its prerogatives; nevertheless, the upshot of its application in I89I deserves notice. It went to show that Struve's constant might better be retained than altered, Loewy's of 20.447" varying from it only to an insignificant extent. Professor Hall had, moreover, deduced nearly the same value (20.454") from the Washington observations since 1862, of $\boldsymbol{a}$ Lyræ (Vega); whence, in conjunction with Newcomb's rate of light transmission, he arrived at a solar parallax of $8.8 \mathrm{I}^{\prime \prime} .^{2}$

Now it is noteworthy that this precise value was derived by Professor Harkness in I89 I ${ }^{3}$ through the combination, according to the method of least squares - that is, by the mathematical rules of probability - of all the various quantities upon which the sun's parallax depends. His result thus sums up and harmonises the whole of the multifarious evidence bearing upon the point; and confidence in it is strengthened by its perfect agreement no less with the most authentic verdict yet pronounced by the swift traveller, light, than with the issue of Dr. Gill's recent trigonometrical operations. We may then, at least provisionally, accept 92,700,000 miles as the length of the earth's mean orbital radius. Nor do we hazard much in fixing I 50,000 miles as the outside limit of its future correction.

1 Comptes Rendus, t. cxii., p. 549. ¿Astr. Jour., Nos. 169, 170.

3 The Solar Parallax and its Related Constants, Washington, I89I. 


\section{CHAPTER VII.}

\section{PLANETS AND SATELLITES.}

Johann Hieronymus Schröter was the Herschel of Germany. He did not, it is true, possess the more brilliant gifts of his rival. Herschel's piercing discernment, comprehensive intelligence, and inventive splendour were wanting to him. He was, nevertheless, the founder of descriptive astronomy. in Germany, as Herschel was in England.

Born at Erfurt in I 745, he prosecuted legal studies at Göttingen, and there imbibed from Kästner a life-long devotion to science. From the law, however, he got the means of living, and, what was to the full as precious to him, the means of observing. Entering the sphere of Hanoverian officialism in I 788, he settled a few years later at Lilienthal, near Bremen, as "Oberamtmann," or chief magistrate. Here he built a small observatory, enriched in 1785 with a seven-foot reflector by Herschel, then one of the most powerful instruments to be found anywhere out of England. It was soon surpassed, through his exertions, by the first-fruits of native industry in that branch. Schrader of Kiel transferred his workshops to Lilienthal in 1792, and constructed there, under the superintendence and at the cost of the astronomical Oberamtmann, a thirteen-foot reflector, declared by Lalande to be the finest telescope in existence, and one twenty-seven feet in focal length, probably as inferior to its predecessor in real efficiency as it was superior in size.

Thus, with instruments of gradually increasing power, Schröter studied during thirty-four years the topography of the 
moon and planets. 'The field was then almost untrodden; he had but few and casual predecessors, and has since had no equal in the sustained and concentrated patience of his hourly watchings. Both their prolixityand their enthusiasm are faithfully reflected in his various treatises. Yet the one may be pardoned for the sake of the other, especially when it is remembered that he struck out a substantially new line, and that one of the main lines of future advance. Moreover, his infectious zeal communicated itself; he set the example of observing when there was scarcely an observer in Germany; and under his roof Harding and Bessel received their training as practical astronomers.

But he was reserved to see evil days. Early in I8I3 the French under Vandamme occupied Bremen. On the night of April 20, the Vale of Lilies was, by their wanton destructiveness, laid waste with fire; the Government offices were destroyed, and with them the chief part of Schröter's property, including the whole stock of his books and writings. There was worse behind. A few days later, his observatory, which had escaped the conflagration, was broken into, pillaged, and ruined. His life was wrecked with it. He survived the catastrophe three years without the means to repair, or the power to forget it, and gradually sank from disappointment into decay, terminated by death, August 29, I8I6. He had, indeed, done all the work he was capable of ; and though not of the first quality, it was far from contemptible. He laid the foundation of the comparative study of the moon's surface, and the descriptive particulars of the planets laboriously collected by him constituted a store of more or less reliable information hardly added to during the ensuing half century. They rested, it is true, under some shadow of doubt ; but the most recent observations have tended on several points to rehabilitate the discredited authority of the Lilienthal astronomer. We may now briefly resume, and pursue in its further progress the course of his studies, taking the planets in the order of their distances from the sun.

In April 1792 Schröter first saw reason to conclude, from the gradual degradation of light on its partially illuminated disc, 
that Mercury possesses a tolerably dense atmosphere. ${ }^{1}$ During the transit of May 7, I799, he was, moreover, struck with the appearance of a ring of softened luminosity encircling the planet to an apparent height of three seconds, or about a quarter of its own diameter." Although a "mere thought" in texture, yet it remained persistently visible both with the seven-foot and the thirteen-foot reflectors, armed with powers up to 288 . It had a well-marked greyish boundary, and reminded him, though indefinitely fainter, of the penumbra of a sun-spot. A similar appendage, but more distinctly bright, had been noticed by De Plantade at Montpellier, November I I, I736, and again in 1786. and 1789 by Prosperin and Flangergues. Mercury projected on the sun, November 9, I802, appeared to Ljunberg at Copenhagen surrounded with a dark zone ; but Herschel, on the same. day, saw its "preceding limb cut the luminous solar clouds with the most perfect sharpness." ${ }^{3}$ The presence, however, of a " halo," appearing to some observers a little darker, to others a little brighter than the solar surface, was unmistakable in I 832 . Professor Moll of Utrecht described it as " a nebulous ring of a darker tinge, approaching to the violet colour." 4 To Huggins and Stone, November 5, I868, it showed as lucid and most distinct. No change in the colour of the glasses used, or the powers applied, conld get rid of it, and it lasted throughout the transit. ${ }^{5}$ It was again well seen by Christie and Dunkin at Greenwich, May 6, I878, ${ }^{6}$ and with much precision of detail by Trouvelot at Cambridge (U.S.). ${ }^{7}$ Professor Holden, on the other hand, noted at Hastings-on-Hudson the total absence of all anomalous appearances. ${ }^{8}$ No observations of much interest were made during the transit of November 8, I88I. Dr. Little, at Shanghai, perceived an unvarying "darkish halo," of which, however, neither Mr. Ellery at Melbourne, nor Mr. Tebbutt at Windsor, New South Wales, saw any trace. ${ }^{9}$ They, however,

1 Neueste Beyträge zur Erweiterung der Sternliunde, Bd. iii., p. 14 (1800). 2 Ibid., p. 24. 3 Phil. Trans., vol. xciii., p. $215 . \quad{ }^{4}$ Mem. Roy. Astr. Soc., vol. vi., p. I I6. 5 Month. Not., vol. xxix., pp. I1, 25. ${ }^{6}$ Ibid., vol. xxxviii., p. 398. 7 Am. Jour. of Sc., vol. xvi., p. 124. ${ }^{8}$ Wash. Obss. for 1876, Pt. ii., p. 34. 9 Month. Not., vol. xlii., pp. roI-104. 
took note of a certain whitish spot on the planet's disc, which. ever since 1697, when it was detected by Wurzelbauer at Erfurt, has been one of the most frequent attendant phenomena of a transit of Mercury. It is not always centrally situated, and is sometimes seen in duplicate, so that Powell's explanation by diffraction is obviously insufficient. Nevertheless there can scarcely be a doubt that it is an optical effect of some kind.

As to the "halo," it is less easy to decide. That Mercury possesses a considerable refractive atmosphere is certified by the observation of De Plantade in $1736,{ }^{1}$ and the still more definite observation of Simms in $1832,{ }^{2}$ of a luminous edge to the part of the disc outside the sun at ingress or egress. The natural complement to this appearance would be a dusky annulus round the planet on the sun-precisely such as was seen by Moll and Little-due to the imperfect transparency of its gaseous envelope. But the brilliant ring vouched for by others is not so readily explicable. Airy has shown that it cannot possibly be caused by refraction, and must accordingly be set down as "strictly an ocular nervous phenomenon." 3 It is the less easy to escape from this conclusion that we find the virtually airless moon capable of exhibiting a like appendage. Professor Stephen Alexander of the United States Survey, with two other observers, perceived, during the eclipse of the sun of July I8, I 860, the advancing lunar limb to be bordered with a bright band ${ }^{4}$ and photographic effects of the same kind appear in pictures of transits of Venus and partial solar eclipses. Little fresh information on the point was gleaned during the transit of May 9, 189I. No uncommon effects of any kind were perceived at the Lick Observatory, either with the great telescope, or any of the other instruments employed. ${ }^{5}$ The daylight definition there is, however, always exceptionally bad. The late Professor Naegamvala of Poona, on the other hand, saw steadily the well-known aureola as "brighter than the sun." 6 There cannot be much doubt of its mainly illusory nature.

1 Mém. de l'Ac., I736, p. 440. 2 Month. Not., vol. ii., p. 103. 3 1bid., vol. xxiv., p. 18. ${ }^{4}$ Ibid., vol. xxiii., p. 234 (Challis). ${ }^{5}$ Publ. Astr. Pacific Society, vol. iii., p. 225. ${ }^{6}$ Mnnth. Not., vol. li., p. 501 . 
As to the constitution of this planet, the spectroscope has little to tell. Its light is of course that of the sun reflected, and its spectrum is consequently a faint echo of the Fraunhofer spectrum. Dr. H. C. Vogel, who first examined it in April r87 I, suspected traces of the action of an atmosphere like ours, ${ }^{1}$ but, it would seem, on slight grounds. It is, however, certainly very poor in blue rays. More definite conclusions were, in I 874, ${ }^{2}$ derived by Zöllner from photometric observations of Mercurian phases. A similar study of the waxing and waning moon had afforded him the curious discovery that light-changes dependent upon phase vary with the nature of the reflecting surface, following a totally different law on a smooth homogeneous globe and on a rugged and mountainous one. Now the phases of Mercury-so far as could be determined from only two sets of observations-correspond with the latter kind of structure. Strictly analogous to those of the moon, they seem to indicate an analogous superficial conformation. It is at any rate certain that the reflective capacity of Mercury does not differ much from the lunar standard. The measurements of Zöllner and Winnecke ${ }^{3}$ concur in assigning to it an "albedo" represented by the fraction 0.13 (that of the moon being $=0.17$ ), signifying that it absorbs all but thirteen per cent. of the light with which the fierce near sun inundates it. The inferred absence of an atmosphere is indeed scarcely reconcilable with some of the transit-phenomena just adverted to; but heights and hollows in abundance seem to exist.

On March 26, I800, Schröter, observing with his I3-foot reflector in a peculiarly clear sky, perceived the southern horn of Mercury's crescent to be quite distinctly blunted. ${ }^{4}$ Interception of sunlight by a Mercurian mountain rather more than eleven English miles high, explained the effect to his satisfaction. By carefully timing its recurrence, he concluded rotation on an axis in a period of 24 hours 4 minutes. This was the first determination of the kind, and was the reward of twenty years' unceasing vigilance. It was confirmed by watching the successive appear-

1 Untersuchungen über die Spectra der Planeten, p. 9. 2 Sirius, vol. vii., p. 131. 3 Astr. Nach., No. 2245. ${ }^{4}$ Neueste Beyträge, Bd. iii., p. 50. 
ances of a dusky streak and blotch in May and June I80r. ${ }^{1}$ These, however, were inferred to be no permanent markings on the body of the planet, but atmospheric formations, the streak at times drifting forwards (it was thought) under the fluctuating influence of Mercurian breezes. From a rediscussion of these somewhat doubtful observations Bessel inferred that Mercury rotates on an axis inclined $70^{\circ}$ to the plane of its orbit in 24 hours 53 seconds.

The rounded appearance of the southern horn seen by Schröter was more or less doubtfully canght by Noble (I864). Burton, and Franks (I877); ${ }^{2}$ but was obvious to Mr. W. F. Denning at Bristol on the morning of November 5, I882.3 That the southern polar regions are usually less bright than the northern, is well ascertained; but the canse of the deficiency. remains dubious. If inequalities of surface are in question, they must be on a considerable scale; and a similar explanation might be given "of the deformations of the "terminator"-or dividing-line between darkness and light in the planet's phases - first remarked by Schröter, and again clearly seen by 'Trouvelot in I878 and r881. ${ }^{4}$ The displacement, during four days, of certain brilliant and dusky spaces on the disk indicated to Mr. Denning in 1882 rotation in about twenty-five hours; while the general aspect of the planet reminded him of that of Mars. ${ }^{5}$ But the difficulties in the way of its observation are enormously enhanced by its constant close attendance on the sun.

In his sustained study of the aspect of Mercury, Schröter had no imitator until Schiaparelli took up the task at Milan in I882. His observations were made in daylight. It was found that much more could be seen, and higher magnifying powers used, high up in the sky near the sun, than at low altitudes, through the agitated air of morning or evening twilight. A notable discovery ensued. ${ }^{6}$ Following the planet hour by hour, instead of making necessarily brief inspections at intervals of about a

1 Astr. Jahrbuch, 1804, pp. 97-102. (4th ed.), ${ }^{3}$ L'Astronomie, t. ii., p. I4I.

2 Webb, Celestial Objects, p. 46 et Mercure, p. 87. ${ }^{5}$ Observatory No. 82, p. 40. ${ }^{6}$ Atti dell' Accad. dei Lincei, t. v. ii., p. 283 , 1889 ; Astr. Nach., No. 2944. 
day, as previous observers had done, it was found that the markings faintly visible remained sensibly fixed, hence, that there was no rotation in a period at all comparable with that of the earth. And after long and patient watching, the conclusion was at last reached that Mercury turns on his axis in the same time needed to complete a revolution in his orbit. One of his hemispheres, then, is always averted from the sun, as one of the moon's hemispheres from the earth, while the other never shifts from beneath his torrid rays. The "librations," however, of Mercury are on a larger scale than those of the moon, because he travels in a more eccentric path. The temporary inequalities arising between his "even pacing" on an axis and his alternately accelerated and retarded elliptical movement occasion, in fact, an oscillation to and fro of the boundaries of light and darkness on his globe over an arc of $47^{\circ} 22^{\prime}$, in the course of his year of 88 days. Thus the regions of perpetual day and perpetual night are separated by two segments, amounting to one-fourth of the entire surface, where the sun rises and sets once in 88 days. No variation from the fierce glare on one side of the globe, and the nocturnal blackness on the other, can, indeed, take place. Yet these apparently intolerable climatic conditions may be somewhat mitigated by the vigorous atmospheric circulation to which they would naturally give rise.

To Schiaparelli's attentive scrutiny, Mercury appeared as a "spotty globe," enveloped in a tolerably dense atmosphere. The brownish stripes and streaks, discerned on his rose-tinged disc, were judged to be permanent, and formed the basis of a chart constructed by him. But they were not always equally well seen. They disappeared regularly near the limb, owing doubtless to the increased depth of the air-strata in that direction, and they were at times veiled even when centrally situated. Some of them had been clearly perceived by De Ball at Bothkamp in I882. ${ }^{1}$

The theory of Mercury's movements has always given trouble. In Lalande's, ${ }^{2}$ as in Mästlin's time, the planet seemed to exist for no other purpose than to throw discredit on astronomers; and even to Leverrier's powerful analysis it long proved recalcitrant.

$$
{ }^{1} \text { Astr. Nach., No. } 2479 . \quad{ }^{2} \text { Hist. de l'Astr., p. } 682 .
$$


On the I2th of September I859, however, he was able to announce before the Academy of Sciences ${ }^{1}$ the terms of a compromise between observation and calculation. They involved the addition of a new member to the solar system. The hitherto unrecognised presence of a body about the size of Mercury itself, revolving at somewhat less than half its mean distance from the sun (or, if farther, then of less mass, and vice vers $\hat{a}$ ), would, it was pointed out, produce exactly the effect required, of displacing the perihelion of the former planet 38 seconds a century more than could otherwise be accounted for. The planes of the two orbits, however, should not lie far apart, as otherwise a nodal disturbance would arise not perceived to exist. It was added that a ring of asteroids similarly placed would answer the purpose equally well, and was more likely to have escaped notice.

Upon the heels of this forecast followed promptly a seeming verification. Dr. Lescarbault, a physician residing at Orgères, whose slender opportunities had not blunted his hopes of achievement, had, ever since I845, when he witnessed a transit of Mercury, cherished the idea that an unknown planet might be caught thus projected on the solar background. Unable to observe continuously until I858, he, on March 26, I859, saw what he had expected-a small, perfectly round object slowly traversing the sun's disc. The fruitless expectation of reobserving the phenomenon, however, kept him silent, and it was not until December 22, after the news of Leverrier's prediction had reached him, that he wrote to acquaint him with his supposed discovery. ${ }^{2}$ The Imperial Astronomer thereupon hurried down to Orgères, and by personal inspection of the simple apparatus used, by searching cross-examination and local inquiry, convinced himself of the genuine character and substantial accuracy of the reported observation. He named the new planet "Vulcan," and computed elements giving it a period of revolution slightly under twenty days. ${ }^{3}$ But it has never since been seen. M. Liais, director of the Brazilian Coast Survey, thought himself justified in asserting that it
1 Comptes Rendus, t. xlix., p. 379.
I Ibid., t. 1., p. 40.
3 lbid., p. 46. 
never had been seen. Observing the sun for twelve minutes after the supposed ingress recorded at Orgères, he noted those particular regions of its surface as "très uniformes d'intensité." 1 He subsequently, however, admitted Lescarbault's good faith, at first rashly questioned. The planet-seeking doctor was, in truth, only one among many victims of similar illusions.

Waning interest in the subject was revived by a fresh announcement of a transit witnessed, it was asserted, by Weber at Peckeloh, April 4, I876. ${ }^{2}$ The pseudo-planet, indeed, was detected shortly afterwards on the Greenwich photographs, and was found to have been seen by M. Ventosa at Madrid in its true character of a sun-spot without penumbra; but Leverrier had meantime undertaken the investigation of a list of twenty similar dubious appearances, collected by Haase, and republished by Wolf in $1872 .^{3}$ From these five were picked out as referring in all likelihood to the same body, the reality of whose existence was now confidently asserted, and of which more or less probable transits were fixed for March 22, I877, and October I 5, I882. ${ }^{4}$ But, widespread watchfulness notwithstanding, no suspicious object came into view at either epoch.

The next announcement of the discovery of "Vulcan" was on the occasion of the total solar eclipse of July 29, I878." "This time it was stated to have been seen at some distance south-west of the obscured sun, as a ruddy star with a minute planetary disc; and its simultaneous detection by two observers -the late Professor James C. Watson, stationed at Rawlins (Wyoming Territory), and Professor Lewis Swift at Denver (Colorado) - was at first readily admitted. But their separate observations could, on a closer examination, by no possibility be brought into harmony, and, if valid, certainly referred to two distinct objects, if not to four ; each astronomer eventually claiming a pair of planets. Nor could any one of the four be

${ }^{1}$ Astr. Nach., Nos. 1248 and 1281. ${ }^{2}$ Comptes Rendus, t. Ixxxiii., pp. 510, 561. ${ }^{3}$ Handbuch der Mathematik, Bd. ii., p. 327. ${ }^{4}$ Comptes Rendus, t. lxxxiii. p. 721. 5 Nature, vol. xviii., pp. 461, 495, 539. 
identified with Lescarbault's and Leverrier's Vulcan, which, if a substantial body revolving round the sun, must then (as Oppolzer showed) ${ }^{1}$ have been found on the east side of that luminary. The most feasible explanation of the puzzle seems to be that Watson and Swift merely saw each the same two stars in Cancer: haste and excitement doing the rest. ${ }^{2}$ Nevertheless they strenuously maintained their opposite conviction. ${ }^{3}$

Intra-Mercurian planets have since been diligently searched for when the opportunity of a total eclipse offered, especially during the long obscuration at Caroline Island. Not only did Professor Holden "sweep" in the solar vicinity, but Palisa and Trouvelot agreed to divide the field of exploration, and thus make sure of whatever planetary prey there might be within reach ; yet with only negative results. Belief in the presence of any considerable body or bodies within the orbit of Mercury is, accordingly, now at a low ebb. Yet the existence of the anomaly in the Mercurian movements indicated by Leverrier has been made only surer by further research. ${ }^{4}$ Its elucidation constitutes one of the "pending problems" of astronomy.

From the observation at Bologna in $1666-67$ of some very faint spots, Domenico Cassini concluded a rotation or libration of Venus-he was not sure which-in about twenty-three hours. ${ }^{5}$ By Bianchini in 1726 the period was augmented to twenty-four days eight hours. J. J. Cassini, however, in I740, showed that the data collected by both observers were consistent with rotation in twenty-three hours twenty minutes. ${ }^{6}$ So the matter rested until Schröter's time. He, after watching nine years in vain, perceived at last, February 28, I 788, the ordinarily uniform brightness of the planet's disc to be marbled with a filmy streak,

1 Astr. Nach., No. 2239. 2 1bid., Nos. 2253-2254 (C. H. F. Peters). 3 Ibid., Nos. 2263 and 2277. See also Tisserand in Ann. Bur. des Long., 1882, p. 729. 4 See J. Bauschinger's Untersuchungen (1884), summarised in Bull. Astr., t. i., p. 506, and Astr. Nach., No. 2594. Newcomb finds the anomalous motion of the perihelion to be even larger ( $43^{\prime \prime}$ instead of $\left.38^{\prime \prime}\right)$ than Leverrier made it. Month. Not., Feb. 1884, p. 187. Harzer's attempt to account for it in Astr. Nach., No. 3030, is more ingenious than successful. 5 Jour. des Scavans, Dec. 1667, p. $122 . \quad 6$ Élémens d'Astr., p. 525. 
which returned periodically to the same position in about twentythree hours twenty-eight minutes. This approximate estimate was corrected by the application of a more definite criterion. On December 28, I789, the southern horn of the crescent Venus was seen truncated, an outlying lucid point interrupting the darkness beyond. Precisely the same appearance recurred two years later, giving for the planet's rotation a period of twentythree hours twenty-one minutes. ${ }^{1}$ To this only twenty-two seconds were added by De Vico, as the result of over 10,000 observations made with the Cauchoix refractor of the Collegio Romano, I839-4I. ${ }^{2}$ The axis of rotation was found to be much more bowed towards the orbital plane than that of the earth, the equator making with it an angle of $53^{\circ} \mathrm{II}^{\prime}$.

These conclusions inspired, it is true, much distrust, consequently there were no received ideas on the subject to be subverted. Nevertheless, vivid surprise was excited by Schiaparelli's announcement, early in $1890,{ }^{3}$ that Venus rotates after the fashion just previously ascribed to Mercury. His assertion, however, that the day and year of Venus agree in length was not positive. He claimed only to have demonstrated that her period of rotation must lie between six and nine months, a strong probability of exact coincidence with the 225 days of her orbital revolution being urged by reasons of the physical order. A continuous series of observations, from November 1877 to February 1878, with their records in above a hundred drawings, supplied the chief part of the data upon which he rested his conclusions. They certainly appeared exceptionally wellgrounded. Most observers have depended, in their attempts to ascertain the rotation-period of Venus, upon evanescent shadings, most likely of atmospheric origin, and scarcely recognisable from day to day. Schiaparelli fixed his attention upon round, defined, lustrously white spots, the presence of which near the cusps of the illuminated crescent has been

1 Beobachtungen über die sehr beträchtlichen Gebirge und Rotation der Venus, 1792, p. 35. Schröter's final result in $18 \mathrm{II}$ was $23 \mathrm{~h} .2 \mathrm{Im} .7 \cdot 977 \mathrm{~s}$. Monat. Corr., Bd. xxv., p. $367 .{ }^{2}$ Astr., Nach., No. 404. ${ }^{3}$ Rendiconti del R. Istituto Lombardo, t. xxiii., serie ii. 
attested for close upon two centuries. His steady watch over them showed the invariability of their position with regard to the terminator; and this is as much as to say that the regions of day and night do not shift on the surface of the planet. In other words, she keeps the same face always turned towards the sun. Moreover, since her orbit is nearly circular, libratory effects are very small. They amount in fact to only just onethirtieth of those serving to modify the severe contrasts of climate in Mercury.

Confirmatory evidence of Schiaparelli's result for Venus is not wanting. Thus, observations irreconcilable with a swift rate of rotation were made at Bothkamp in $\mathrm{i} 87 \mathrm{I}$ by Vogel and Lohse ${ }^{1}$ and a drawing executed by Professor Holden with the great Washington refractor, December I 5, I877, showed the same markings in the positions recorded at Milan to have been occupied by them eight hours previously. Above all, a series of observations, carried out by M. Perrotin at Nice, May I 5 to October 4, I890, with the special aim of testing the inference of synchronous rotation and revolution, proved strongly corroborative of it. ${ }^{2}$ Yet it has been vigorously controverted. M. Niesten of the Brussels Observatory, finds the numerous drawings of Venus made by him and M. Stuyvaert during the years I88I to I890, to fit in with De Vico's elements of rotation; ${ }^{3}$ and M. Trouvelot ${ }^{4}$ so far agrees with him as to adopt a period of about twenty-four hours, while preferring Schiaparelli's nearly upright axis to one deviating from the vertical by an angle of no less than $53^{\circ}$. The testimony of these two able observers is thus so very far from being concordant that it can scarcely be said to invalidate the daring hypothesis of the Milanese astronomer.

Effects attributed to great differences of level in the surface of Venus have struck many observers. Francesco Fontana at Naples in I643 noticed irregularities along the inner edge of the crescent. $^{5}$ Lahire in I700 considered them-regard being had

1 Bothliamp Beobachtungen, Heft ii., p. 120. ${ }^{2}$ Comptes Rendus, t. cxi., p. 587. 3 Bull. de l'Acad. roy. de Belgique, t. xxi., p. 452, 1891. "Observations sur les Planètes Vénus et Mercure, 1892. ${ }^{5}$ Novce Observationes, p. 92. 
to difference of distance-to be much more strongly marked than those visible in the moon. ${ }^{1}$ Schröter's assertions to the same effect, though scouted with some unnecessary vehemence by Herschel, ${ }^{2}$ have since been repeatedly confirmed; amongst others by Mädler, De Vico, Langdon, who in I873 saw the broken line of the terminator with peculiar distinctness through a veil of auroral cloud ; ${ }^{3}$ by Denning, ${ }^{4}$ March 30, I88 I, despite preliminary impressions to the contrary, as well as by $\mathrm{C}$. V. Zenger at Prague, January 8, I883. The great mountain mass, presumed to occasion the periodical blunting of the southern horn, was precariously estimated by the Lilienthal observer to rise to the prodigious height of nearly twenty-seven miles, or just five times the elevation of Mount Everest! Yet the phenomenon persists, whatever may be thought of the explanation. Moreover, the speck of light beyond, interpreted as the visible sign of a detached peak rising high enough above the encircling shadow to catch the first and last rays of the sun, was frequently discerned by Baron Van Ertborn in $1876 ;^{5}$ while an object near the northern horn of the crescent, strongly resembling a lunar ring-mountain, was delineated both by De Vico in I84I and by Denning forty years later.

We are almost equally sure that Venus as that the earth is encompassed with an atmosphere. Yet, notwithstanding luminous appearances plainly due to refraction during the transits both of I76I and 1769, Schröter, in I792, took the initiative in coming to a definite conclusion on the subject. ${ }^{6}$ It was founded, first, on the rapid diminution of brilliancy towards the terminator, attributed to atmospheric absorption; next, on the extension beyond a semicircle of the horns of the crescent; lastly, on the presence of a bluish gleam illuminating the early hours of the Cytherean night with what was taken to be genuine twilight. Even Herschel admitted that sunlight, by the same effect through which the heavenly bodies show visibly

1 Mém de l'Ac., I700, p. 296. 2 Phil. Trans., vol. Ixxxiii., p. 201. ${ }^{3}$ Webb, Cel. Objects, p. 58. ${ }^{4}$ Month. Not., vol. xlii., p. I I I. ${ }_{5}$ Bull. Ac. de Bruxelles, t. xliii., p. 22. ${ }^{6}$ Phil. Trans., vol. lxxxii., p. 309; Aphroditographische Fragmente, p. 85 (1796). 
above our horizons while still geometrically below them, appeared to be bent round the shoulder of the globe of Venus. Ample confirmation of the fact has since been afforded. At Dorpat in May 1849 , the planet being within $3^{\circ} 26^{\prime}$ of inferior conjunction, Mädler found the arms of waning light upon the disc to embrace no less than $240^{\circ}$ of its extent; ${ }^{1}$ and in December I842, Mr. Guthrie, of Bervie, N.B., actually- observed, under similar conditions, the whole circumference to be lit up with a faint nebulous glow. ${ }^{2}$ Here the solar rays evidently pierced the planet's atmosphere from behind, pursuing a curved path, as if through a lens. The same curious phenomenon was intermittently seen by Mr. Leeson Prince at Uckfield in September, I $863 ;^{3}$ but with more satisfactory distinctness by Mr. C. S. Lyman of Yale College, ${ }^{4}$ before and after the conjunction of December II, I866, and during nearly five hours previous to the transit of 1874 , when the yellowish ring of refracted light showed at one point an approach to interruption, possibly through the intervention of a bank of clouds. These effects can be accounted for, as Mr. Neison pointed out, ${ }^{5}$ only by supposing the atmosphere of Venus to be nearly twice as dense at the surface of its globe, and to possess nearly twice as much refractive power as that of the earth. Mr. Proctor gives, however, a considerably lower estimate. ${ }^{6}$

Similar appearances are conspicuous during transits. But while the Mercurian halo is characteristically seen on the sun, the "silver thread" round the limb of Venus commonly shows on the part off the sun. There are, however, instances of each description in both cases. Mr. Grant, in collecting the records of physical phenomena accompanying the transits of $176 \mathrm{I}$ and I769, remarks that no one person saw both kinds of annulus, and argues thus a dissimilarity in their respective modes of production. $^{7}$ Such a dissimilarity probably exists, in the sense that the inner section of the ring is due to absorption, the outer

1 Astr. Nach., No. 679. 2 Month. Not., vol. xiv., p. 169. ${ }^{3}$ lbid., vol. xxiv., p. 25. $4 A m$. Jour. of Sc., vol. xliii., p. 129 (2d ser.); vol. ix., p. 47 (3d ser.). ${ }^{5}$ Month. Not., vol. xxxvi., p. 347. ${ }^{6}$ Old and New Astronomy, p. $448 .{ }^{7}$ Hist. Phys. Astr., p. 431 . 
to refraction by the same planetary atmosphere; but the distinction of separate visibility has not been borne out by recent experience. Several of the Australian observers during the transit of I874 witnessed the complete phenomenon. Mr. J. Macdonnell, at Eden, saw a "shadowy nebulous ring" surround the whole disc when ingress was two-thirds accomplished; $\mathrm{Mr}$. Tornaghi, at Goulburn, perceived a halo, entire and unmistakable, at half egress. ${ }^{1}$ Similar observations were made at Sydney, ${ }^{2}$ and were renewed in 1882 by Lescarbault at Orgères, by Metzger in Java, and by Barnard atVanderbilt University. ${ }^{3}$

Spectroscopic indications of aqueous vapour as present in the atmosphere of Venus, were obtained in I874 and I882, by Tacchini and Riccò in Italy, and by Young in New Jersey. ${ }^{4}$ Janssen, however, who made a special study of the point subsequently to the transit of I882, found them much less certain than he had anticipated $;^{5}$ and Vogel, by repeated examinations, I87I-73, could detect only the very slightest variations from the pattern of the solar spectrum. Some additions there indeed seem to be in the thickening of certain water-lines, and also of a group (B) since shown by Egoroff to be developed through the absorptive action of cool oxygen; but so nearly evanescent as to induce the persuasion that the light we receive from Venus is reflected from a heavy cloud-stratum, and has traversed, consequently, only the rarer upper portion of its atmosphere. ${ }^{6}$ This would also account for the extreme brilliancy of the planet. On the 26th and 27th of September I878, a close conjunction gave Mr. James Nasmyth the rare opportunity of watching Venus and Mercury for several hours side by side in the field of his reflector; when the former appeared to him like clean silver, the latter as dull as lead or zinc. ${ }^{7}$ Yet the light incident upon Mercury is, on an average, three and a half times stronger than the light reaching Venus. Thus the reflective power of Venus must be singularly strong.

1 Mem. Roy. Astr. Soc., vol. xlvii., pp. 77, 84. ${ }^{2}$ Astr. Reg., vol. xiii., p. 132. ${ }^{3}$ L'Astronomie, t. ii., p. 27; Astr. Nach., No. 2021 ; Am. Jour. of Sc., vol. xxv., p. $430 . \quad{ }^{4} \mathrm{Mem}$. Spectr. Ital., Dicembre I882; Am. Jour. of Sc., vol. xxv., p. $328 .{ }^{5}$ Comptes Rendus, t. cxvi., p. $288 .{ }^{6}$ Vogel, Spectra der Planeten, p. 15. 7 Nature, vol, xix., p. 23. 
And we find accordingly, from a combination of Zöllner's with Pickering's results, that its albedo is but little inferior to that of new-fallen snow ; in other words, it gives back 72 per cent. of the luminous rays impinging upon it.

This view, that we see only a Cytherean cloud-canopy, has been confirmed by M. Landerer's observation of the non-polarised character of the light reflected by the crescent Venus ; ${ }^{1}$ yet it is not easily reconcilable with the supposed permanence of many of its spots, or with the perception of shadow effects on a rugged crust. It is, however, with some reservation, shared by M. Trouvelot, who in 1875 and some subsequent years pursued at Cambridge (U.S.) a diligent telescopic study of the planet, continued later at Meudon. Not the least surprising fact about this sister-globe is that the axis on which it rotates is hooded at each end with some shining substance. These polar appendages were discovered in I 8 I 3 by Gruithuisen, ${ }^{2}$ who set them down as polar snow-caps like those of Mars. Nor is it altogether certain that he was wrong. Trouvelot, indeed, in January I 878, perceived (or thought that he perceived) the southern one to be composed of isolated peaks thrown into relief against the sky, and hence concluded each to represent a lofty group of mountains penetrating the vapourstratum supposed to form the greater part of the visible disc. He pointed out, moreover, that the place of the southern spot might be called identical with that of a projection above the limb detected by MM. Bouquet de la Grye and Arago in measuring photographs of Venus in transit taken at Puebla and Port-auPrince in $1882 .{ }^{3}$ This projection corresponded to a real elevation of about sixty-five miles. But it was more probably due to "photographic irradiation" from a local excess of brilliancy, the result-according to the French investigator's conjecture-of accumulations of ice and snow, or the continuous formation of vast cloud-masses.

The same photographs seem to show that in figure Venus very closely resembles our earth, the estimated equatorial bulging produced by rotation being $\frac{1}{303}$ of the radius.

1 Comptes Rendus, t. cxiv., p. 1524. ${ }^{2}$ Nova Acta Acad. Naturce Curiosorum, Bd.x., 239. ${ }^{3}$ Observatory, vols.iii., p. 416, vii., p. 239 ; L'Astronomie, t. x., p. 26 I. 
The "secondary," or "ashen light," of Venus was first noticed by Riccioli in I643; it was seen by Derham about 17 I 5 , by Kirch in I721, by Schröter and Harding in $1806 ;{ }^{1}$ and the reality of the appearance has since been authenticated by numerous and trustworthy observations. It is precisely similar to that of the "old moon in the new moon's arms ;" and Zenger, who witnessed it with unusual distinctness, January $8,1883,{ }^{2}$ supposes it due to the same cause-namely, to the faint glean of reflected earthlight from the night-side of the planet. When we remember, however, that "full earth-light" on Venus, at its nearest, has little more than $\frac{1}{12000}$ its intensity on the moon, we see at once that the explanation is inadequate. Nor can Professor Safarik's, ${ }^{3}$ by phosphorescence of the warm and teeming oceans with which Zöllner ${ }^{4}$ regarded the globe of Venus as mainly coverea, be seriously entertained. Vogel's suggestion is more plausible. He and O. Lohse, at Bothkamp, November 3-I I, I87I, saw the dark hemisphere partially illuminated by secondary light, extending $30^{\circ}$ from the terminator, and thought the effect might be produced by a very extensive twilight. ${ }^{5}$ Others have had recourse to the analogy of our auroræ, and J. Lamp suggested that the greyish gleam, visible to him at Bothkamp, October $2 \mathrm{I}$ and $26, \mathrm{I}_{887,}{ }^{6}$ might be an accompaniment of electrical processes connected with the planet's meteorology. Whatever the origin of the phenomenon, it may serve, on a night-enwrapt hemisphere, to dissipate some of the thick darkness otherwise encroached upon only by "the pale light of stars."

Venus was once supposed to possess a satellite. But belief in its existence has died out. No one, indeed, has caught even a deceptive glimpse of such an object during the last I 25 years. Yet it was repeatedly, and one might have thought, well observed in the seventeenth and eighteenth centuries. Fontana "discovered" it in I645; Cassini-an adept in the art of

1 Astr.Jahrbuch, r809, p. 164. ${ }^{2}$ Month. Not., vol. xliii., p. 331. ${ }^{3}$ Report Brit. Ass., 1873, p. 407. The paper contains a valuable record of observations of the phenomenon. 4 Photom. Untersuchungen, p. $30 \mathrm{I}$. Beobachtungen, Heft ii., p. г26. ${ }^{6}$ Astr. Nach., No. 2818.

5 Bothkamp 
seeing-recognised it in I672, and again in I686; Short watched it for a full hour in 1740 with varied instrumental means; Tobias Mayer in I759, Montaigne in I761, several astronomers at Copenhagen in March 1764, noted what they considered its unmistakable presence; as did Horrebow in I 768. But M. Paul Stroobant, ${ }^{1}$ who in I 887 submitted all the available data on the subject to a searching examination, identified Horrebow's satellite with $\theta$ Libræ, a fifth-magnitude star; and a few other apparitions were, by his industry, similarly explained away. Nevertheless, several withstood all efforts to account for them, and together form a most curious case of illusion. For it is quite certain that Venus has no such conspicuous attendant.

The third planet encountered in travelling outward from the sun is the abode of man. He has in consequence opportunities for studying its physical habitudes altogether different from the baffling glimpses afforded to him of the other members of the solar family. Regarding the earth, then, a mass of knowledge so varied and comprehensive has been accumulated as to form a science-or rather several sciences-apart. But underneath all lie astronomical relations, the recognition and investigation of which constitute one of the most significant intellectual events of the present century.

It is indeed far from easy to draw a line of logical distinction between items of knowledge which have their proper place here, and those which should be left to the historian of geology. There are some, however, of which the cosmical connections are so close that it is impossible to overlook them. Amongst these is the ascertainment of the solidity of the globe. At first sight it seems difficult to conceive what the apparent positions of the stars can have to do with subterranean conditions; yet it was from star measurements alone that Hopkins, in 1839, concluded the earth to be solid to a depth of at least 800 or Ioo0 miles. ${ }^{2}$ His argument was, that if it were a mere shell filled with liquid, precession and nutation would be much

1 Mémoires del'Acad. de Bruxelles, t. xlix., No. 5, 4to ; Astr. Nach., No. 2809; Cf. Schorr, Der Venusmond, I875. $\quad 2$ Phil. Trans., I839, I841, I842. 
larger than they are observed to be. For the shell alone would follow the pull of the sun and moon on its equatorial girdle, leaving the liquid behind; and being thus so much the lighter, would move the more readily. There is, it is true, grave reason to doubt whether this reasoning corresponds with the actual facts of the case ${ }^{1}$ but the conclusion to which it led has been otherwise substantiated.

Indications to an identical effect have been derived from another kind of external disturbance, affecting our globe through the same agencies. Lord Kelvin (then Sir William Thomson) pointed out in $1862^{2}$ that tidal influences are brought to bear on land as well as on water, although obedience to them is perceptible only in the mobile element. Some bodily distortion of the earth's figure must however take place, unless we suppose it of absolute or "preternatural" rigidity, and the amount of such distortion can be determined from its effect in diminishing oceanic tides below their calculated value. For if the earth were perfectly plastic to the stresses of solar and lunar gravity, tides-in the ordinary sense-would not exist. Continents and oceans would swell and subside together. It is to the difference in the behaviour of solid and liquid terrestrial constituents that the ebb and flow of the waters are due.

Six years later, the distinguished Glasgow professor suggested that this criterion might, by the aid of a prolonged series of exact tidal observations, be practically applied to test the interior condition of our planet. ${ }^{3}$ In 1882 , accordingly, suitable data extending over thirty-three years having at length become available, Professor G. H. Darwin performed the laborious task of their analysis, with the general result that the " effective rigidity" of the earth's mass must be at least as great as that of steel. ${ }^{4}$

1 Delaunay objected (Comptes Rendus, t. lxvii., p. 65) that the viscosity of the contained liquid (of which Hopkins took no account) would, where the movements were so excessively slow as those of the earth's axis, almost certainly cause it to behave like a solid. Sir W. Thomson, however (Report Brit. Ass., 1876, ii., p. I), considers Hopkins's argument valid as regards the comparatively quick solar semi-annual and lunar fortnightly nutations. ${ }^{2}$ Phil. Trans., vol. cliii., p. 573. $\quad{ }^{3}$ Report Brit. Ass., 1868, p. 494. $\quad{ }^{4}$ Ibid., I882, p. 474 . 
Ratification of this conclusion has lately been derived from an unexpected quarter. The question of a possible mobility in the earth's axis of rotation has often been mooted. Now at last it has received an affirmative; reply. Dr. Küstner detected, in his observations of I884-5, effects apparently springing from a minute variation in the latitude of Berlin. The matter having been brought before the International Geodetic Association in I 888, special observations were set on foot at Berlin, Potsdam, Prague, and Strasbourg, the upshot of which was to bring plainly to view synchronous, and seemingly periodic fluctuations of latitude to the extent of half a second of arc. The reality of these was verified by an expedition to Honolulu in I89I-2, the variations there corresponding inversely to those simultaneously determined in Europe. ${ }^{1}$ Their character was completely defined by Dr. S. C. Chandler's discussion in October ${\text { I } 89 .^{2}}^{2} \mathrm{He}$ showed that they could be explained by supposing the pole of the earth to describe a circle with a radius of thirty feet in a period of about fourteen months, or 427 days. Confirmation of this hypothesis was found by Dr. B. A. Gould in the Cordoba observations, ${ }^{3}$ and it was provided with a physical basis through the able co-operation of Professor Newcomb. ${ }^{4}$ The earth, owing to its ellipsoidal shape, should, apart from disturbance, rotate upon its " axis of figure," or shortest diameter ; since thus alone can the centrifugal forces generated by its spinning balance each other. Temporary causes, however, such as heavy falls of snow or rain limited to one continental area, the shifting of ice-masses, even the movements of winds, may render the globe slightly lop-sided, and thus oblige it to forsake its normal axis, and rotate on one somewhat divergent from it. This "instantaneous axis" (for it is incessantly changing) should, by mathematical theory, revolve round the axis of figure in a period of 306 days. Provided, that is to say, the earth were a perfectly rigid body. But it is far from being so; it yields sensibly to every strain put upon it; and this yielding tends to protract the time of circulation of the displaced pole. The length of its period, then, serves as a kind of measure of the plasticity of the

1 Albrecht, Astr. Nach., No. 3131 ; Marcuse, ibid., No. 3139. ' Astr. Jour., Nos. 248, 249, 277 . $\quad 3$ Ibid., No. $258 . \quad 4$ Month. Not., vol. lii., p. 336. 
globe; which, according to Newcomb's calculation, ${ }^{1}$ seems to be a little less than that of steel. In an earth compacted of steel, the instantaneous axis would revolve in 44I days; in the actual earth, hence concluded to have an advantage, in point of stiffness, over the fictitious metallic one, the process is accomplished in, at the most, 430 days. By this new path, accordingly, astronomers have been led to a virtually identical estimate of the consistence of our globe with that derived from tidal investigations.

Variations of latitude are by their nature ephemeral and irregular. They alternately subside, and are renewed. For the shifting axis strives of itself to get back to its natural place, although it can never rest long absolutely fixed there. That its deviations to the extent of no more than thirty feet should have been betrayed and determined by means of stellar observations, bears emphatic witness to the extraordinary accuracy of modern celestial measurements.

In a paper read before the Geological Society, December I 5 , I 830, ${ }^{2}$ Sir John Herschel threw out the idea that the perplexing changes of climate revealed by the geological record might be explained through certain slow fluctuations in the eccentricity of the earth's orbit, produced by the disturbing action of the other planets. Shortly afterwards, however, he abandoned the position as untenable ${ }^{3}$ and it was left to the late Dr. James Croll, in $1864^{4}$ and subsequent years, to reoccupy and fortify it. Within restricted limits (as Lagrange and, more certainly and definitely, Leverrier proved), the path pursued by our planet round the sun alternately contracts, in the course of ages, into a moderate ellipse, and expands almost to a circle, the major axis, and consequently the mean distance, remaining invariable. Even at present, when the eccentricity approaches a minimum, the sun is nearer to us in January than in July by above three million miles, and some 850,000 years ago this difference was more than four times as great. Dr. Croll brought together ${ }^{5}$ a

1 Astr. Nach., No. 3097.

3 See his Treatise on Astronomy, p. I99 (1833).

(4th ser.), p. I2I.

Cosmology, 1885 .
2 Trans. Geol. Soc., vol. iii. (2nd ser.), p. 293.

5 Climate and Time, 1875 ; Discussions on Climate and 
mass of evidence to support the view that, at epochs of considerable eccentricity, the hemisphere of which the winter, occurring at aphelion, was both intensified and prolonged, must have undergone extensive glaciation; while the opposite hemisphere, with a short, mild winter, and long, cool summer, enjoyed an approach to perennial spring. These conditions, through the shifting of the earth's perihelion combined with the precession of the equinoxes, were exactly reversed at the end of IO, 500 years, the frozen hemisphere blooming into a luxuriant garden as its seasons came round to occur at the opposite sides of the terrestrial orbit, and the vernal hemisphere subsiding simultaneously into ice-bound rigour. ${ }^{1}$ Thus a plausible explanation was offered of the anomalous alternations of glacial and semi-tropical periods, attested, on incontrovertible geological evidence, as having succeeded each other in times past over what are now temperate regions. They succeeded each other, it is true; with much less frequency and regularity than the theory demanded; but the discrepancy was overlooked or smoothed away. The most recent glacial epoch was placed by Dr. Croll about 200,000 years ago, when the eccentricity of the earth's orbit was 3.4 times as great as it now is. At present, a faint representation of such a state of things is afforded by the southern hemisphere. One condition of glaciation in the coincidence of winter with the maximum of remoteness from the sun, is present; the other-a high eccentricity-is deficient. Yet the ring of ice-bound territory hemming in the southern pole is well known to be far more extensive than the corresponding region in the north.

The verification of this ingenious hypothesis depends upon a variety of intricate meteorological conditions, some of which have been adversely interpreted by competent authorities. ${ }^{2}$ What is still more serious, its acceptance seems precluded by timerelations of a simple kind. Dr. Wright ${ }^{3}$ has established with some approach to certainty that glacial conditions ceased in

1 See for a popular account of the theory, Sir R. Ball's The Cause of an Ice Age, I892. $\quad{ }_{2}^{2}$ See A. Woeikof, Phil. Mag., vol. xxi., p. 223. $\quad 3$ The Ice Age in North America, London, I89o. 
Canada and the United States about ten or twelve thousand years ago. The erosive action of the Falls of Niagara qualifies them to serve as a clepsydra, or water-clock on a grand scale; and their chronological indications have been amply corroborated elsewhere and otherwise on the same continent. The astronomical Ice Age, however, should have been enormously more antique. No reconciliation of the facts with the theory appears possible.

The first attempt at an experimental estimate of the "mean density" of the earth was Maskelyne's observation in I774 of the deflection of a plumb-line through the attraction of Schehallien. The conclusion thence derived, that our globe weighs $4 \frac{1}{2}$ times as much as an equal bulk of water, ${ }^{1}$ was not very exact. It was considerably improved upon by Cavendish, who, in I798, brought into use the "torsion-balance" constructed for the same purpose by John Michell. The resulting estimate of 5.48 was raised to 5.66 by Francis Baily's elaborate repetition of the process in 1838-42. From experiments on the subject made in I 872-73 by Cornu and Baille the slightly inferior value of 5.56 was obtained; and it was further shown that the data collected by Baily, when corrected for a systematic error, gave practically the same result (5.55). ${ }^{2}$ The research, which was begun in 1867 , is being continued at Paris with extraordinary precautions against recondite sources of error, ${ }^{3}$ and will presumably yield before long a definitive result. Meantime, M. Wilsing obtained, in I 889, by means of a pendulum-apparatus, a mean density for our planet of $5.58 ;^{4}$ Professor Poynting's result with a common balance, in 1890 , coming out $5.49 .^{5}$ Newton's guess at the average weight of the earth as five or six times that of water has thus been curiously verified.

Operations for determining the figure of the earth have been carried out during the present century on an unprecedented scale. The Russo-Scandinavian arc, of which the measurement was completed under the direction of the elder Struve in I855,

1 Phil. Trans., vol. lxviii., p. 783.

2 Comptes Rendus, t. Ixxvi., p. 954

3 Observatory, vol. xiv., p. 249.

4 Potsdam Publ., Nos. 22, 23.

5 Phil

Trans., vol. clxxxii., p. 565 . 
reached from Hammerfest to Ismailia on the Danube, a length of $25^{\circ} 20^{\prime}$. But little inferior to it. was the Indian arc, begun by Lambton in the first years of the century, continued by Everest, revised and extended by Walker. The general upshot is to show that the polar compression of the earth is somewhat greater than had been supposed. The admitted fraction until lately was $\frac{1}{300}$; that is to say, the thickness of the protuberant equatorial ring was taken to be $\frac{1}{300}$ of the equatorial radius. But Sabine's pendulum experiments, discussed by Airy in I826, gave $\frac{1}{2} \frac{1}{89} ;^{1}$ and arc measurements tend more and more towards agreement with this figure. A fresh investigation led the late J. B. Listing in $1878^{2}$ to state the dimensions of the terrestrial spheroid as follows: equatorial radius $=6,377,377$ metres; polar radius $=6,355,270$ metres; ellipticity $=\overline{2} \frac{1}{8} \cdot \overline{4} . \overline{8}$. The fraction, however, at present adopted is $\frac{1}{2} \frac{1}{2}$.

But it is far from certain that the figure of the earth is one of strict geometrical regularity. Nay, it is by no means clear that even its main outlines are best represented by what is called an "ellipsoid of revolution"-in other words, by a globe flattened at top and bottom, but symmetrical on every side. From a survey of geodetical results all over the world, Colonel Clarke concluded that different meridians possess different amounts of curvature ${ }^{3}$ so that the equator, instead of being a circle, as it should be-apart from perturbing causesin a rotating body, must, on this view, be itself an ellipse, and our planet be correctly described as in shape "an ellipsoid of three unequal axes." But the point is still sub judice. Operations towards its decision are in active progress both in Europe and India.

The moon possesses for us an unique interest. She in all probability shared the origin of the earth; she perhaps prefigures its decay. She is at present its minister and companion. Her existence, so far as we can see, serves no other purpose than to illuminate the darkness of terrestrial nights, and to

1 Phil. Trans., vol. cxvi., p. 548. $\quad 2$ Astr. Nach., No. 2228. $\quad 3$ Phrl. Mag., vol. vi. (5th ser.), p. 92. 
measure, by swiftly-recurring and conspicuous changes of aspect, the long span of terrestrial time. Inquiries stimulated by visible dependence, and aided by relatively close vicinity, have resulted in a wonderfully minute acquaintance with the features of the single lunar hemisphere open to our inspection.

Selenography, in the modern sense, is not yet a hundred years old. It originated with the publication in I79I of Schröter's Selenotopographische Fragmente. ${ }^{1}$ Not but that the lunar surface had already been diligently studied, chiefly by Hevelius, Cassini, and Tobias Mayer; the idea, however, of investigating the moon's physical condition, and detecting symptoms of the activity there of natural forces through minute topographical inquiry, first obtained effect at Lilienthal. Schröter's delineations, accordingly, imperfect though they were, afforded a starting-point for a comparative study of the superficial features of our satellite.

The first of the curious objects which he named " rills" was noted by him in I787. Before I80I he had found eleven; Lohrmann added 75; Mädler 55; Schmidt published in I866 a catalogue of 425 , of which 278 had been detected by himself $;^{2}$ and he eventually brought the number up to nearly rooo. They are, then, a very persistent lunar feature, though wholly without terrestrial analogue. There is no difference of opinion as to their nature. They are quite obviously clefts in a rocky surface, IOO to 500 yards deep (the depression of the great rill near Aristarchus was estimated by Schmidt at 554 yards), usually a couple of miles across, and pursuing straight, curved, or branching tracks up to 50 miles in length. As regards their origin, the most probable view is that they are fissures produced in cooling; but Neison inclines to consider them rather as dried watercourses. ${ }^{3}$

On February 24, I792, Schröter perceived what he took to be distinct traces of a lunar twilight, and continued to observe them during nine ensuing years. ${ }^{4}$ They indicated, he thought, the presence of a shallow atmosphere (not reaching a height of more

1 The second volume was published at Göttingen in 1802 .

2 Ueber Rillen auf dem Monde, p. 13. $\quad 3$ The Moon, p. 73. $\quad 4$ Selen. Fragm., Th. ii , p. 399. 
than 8400 feet), about $\frac{1}{29}$ th as dense as our own. Bessel, on the other hand, considered that the only way of "saving" a lunar atmosphere was to deny it any refractive power, the sharpness and suddenness of star-occultations negativing the possibility of gaseous surroundings of greater density (admitting an extreme supposition) than $\frac{\mathbf{1}}{500}$ that of terrestrial air. ${ }^{1}$ Newcomb places the maximum at $\frac{1}{400}$. Sir John Herschel cóncluded "the nonexistence of any atmosphere at the moon's edge having oneI980th part of the density of the earth's atmosphere." 2

This decision was fully borne out by Dr. Huggins's spectroscopic observation of the disappearance behind the moon's limb of the small star $\varepsilon$ Piscium, January 4, I $865 .^{3}$ Not the slightest sign of selective absorption or unequal refraction was discernible. The entire spectrum went out at once, as if a slide had suddenly dropped over it. The spectroscope has uniformly told the same tale; for M. Thollon's observation during the total solar eclipse at Sohag of a supposed thickening at the moon's rim, of certain dark lines in the solar spectrum, is now acknowledged to have been illusory. Moonlight, analysed with the prism, is found to be pure reflected sunlight, diminished in quantity, owing to the low reflective capability of the lunar surface, to less than onefifth its incident intensity, but wholly unmodified in quality.

Yet there is little or no doubt that the diameter of the moon, as determined from occultations, is 4 " smaller than it appears by direct measurement. This fact, which emerged from Sir George Airy's discussion, in $1865,{ }^{4}$ of an extensive series of Greenwich and Cambridge observations, would naturally result from lunar atmospheric refraction. He showed, however, that even if the entire effect were thus produced (a certain share is claimed by irradiation) the atmosphere involved would be 2000 times thinner than our own air at the sea-level. A gaseous stratum of such extreme tenuity could scarcely produce any spectroscopic effect. It is certain (as Mr. Neison has pointed out ${ }^{5}$ ) that a lunar atmosphere of very great extent and of no inconsiderable mass,

${ }^{3}$ Astr. Nach., No. 263 (1834) ; Pop. Vorl., pp. 615-620 (1838). 2 Outlines of Astr., par. 431. $\quad 3$ Month. Not., vol. xxv., p.61. $\quad$ 4 Ibid., p. 264. $\quad$ 5The Moon, p. 25. 
would possess, owing to the low power of lunar gravity, a very small surface density, and might thus escape direct observation while playing a very important part in the economy of our satellite. Some renewed evidence of actual crepuscular gleams on the moon has been gathered by MM. Paul and Prosper Henry of the Paris Observatory, ${ }^{1}$ as well as by $\mathrm{Mr}$. W. H. Pickering, in the pure air of Arequipa, at an altitude of 8000 feet above the sea. An occultation of Jupiter, too, observed by him August I2, I $892,{ }^{2}$ was attended with a slight flattening of the planet's disc through effects of refraction, it was supposed, in a lunar atmosphere-but in a lunar atmosphere possessing, at the most, $\frac{1}{4000}$ the density at the sea-level, or terrestrial air, and capable of holding, in equilibrium, no more than $\frac{1}{2} \frac{1}{50}$ of an inch of mercury. Yet this small barometric value corresponds, Mr. Pickering remarks, "to a pressure of hundreds of tons per square mile of the lunar surface."

The first to emulate Schröter's selenographical zeal was Wilhelm Gotthelf Lohrmann, a land-surveyor of Dresden, who, in I824, published four out of twenty-five sections of the first scientifically executed lunar chart, on a scale of $37 \frac{1}{2}$ inches to a lunar diameter. His sight, however, began to fail three years later, and he died in I840, leaving materials from which the work was completed and published in I 878 by Dr. Julius Schmidt, late director of the Athens Observatory. Much had been done in the interim. Beer and Mädler began at Berlin in I 830 their great trigonometrical survey of the lunar surface, as yet neither revised nor superseded. A map, issued in four parts, I834-36, on nearly the same scale as Lohrmann's, but more detailed and authoritative, embodied the results. It was succeeded, in 1837 , by a descriptive volume bearing the imposing title, Der Mond; oder allgemeine vergleichende Selenographie. This summation of knowledge in that branch, though in truth leaving many questions open, had an air of finality which tended to discourage further inquiry. ${ }^{3}$ It gave form to a reaction against the sanguine views entertained by Hevelius, Schröter, Herschel and Gruithuisen as to the possi-

1 Webb, Cel. Objects, p. 79.

${ }^{3}$ Neison, The Moon, p. I04.

2 Astr. and Astro-Physics, Nov. 1892, p. 778. 
bilities of agreeable residence on the moon, and relegated the "Selenites," one of whose cities Schröter thought he had discovered, and of whose festal processions Gruithuisen had not despaired of becoming a spectator, to the shadowy land entered through the Ivory Gate. All examples of change in lunar formations were, moreover, dismissed as illusory. The light contained in the work was, in short, a "dry light," not sțimulating to the imagination. "A mixture of a lie," Bacon shrewdly remarks. "doth ever add pleasure." For many years, accordingly, Schmidt had the field of selenography almost to himself.

Reviving interest in the subject was at once excited and displayed by the appointment, in I864, of a Lunar Committee of the British Association. The indirect were of greater value than the direct fruits of its labours. An English school of selenography rose into importance. Popularity was gained for the subject by the diffusion of works conspicuous for ingenuity and research. 'Messrs. Nasmyth's and Carpenter's beantifully illustrated volume (I874) was succeeded, after two years, by a still more weighty contribution to lunar science in Mr. Neison's well-known book, accompanied by a map, based on the survey of Beer and Mädler, but adding some 500 measures of positions, . besides the representation of several thousand new objects. With Schmidt's Charte der Gebirge des Mondes, Germany once more took the lead. This splendid delineation-the result of thirty-four years' labour-was built upon Lohrmann's foundation, but embraced the detail contained in upwards of 3000 original drawings. No less than 32,856 craters are represented in it, on a scale of seventy-five inches to a diameter. An additional help to lunar inquiries was provided at the same time in this country by the establishment, through the initiative of the late Mr. W. R. Birt, of the Selenographical Society.

But the strongest incentive to diligence in studying the rugged features of our celestial helpmate has been the idea of probable or actual variation in them. A change always seems to the inquisitive intellect of man like a breach in the defences of Nature's secrets, through which it may hope to make its way to the citadel. What is desirable easily becomes credible; 
and thus statements and rumours of lunar convulsions have successively, during the last hundred years, obtained credence, and successively, on closer investigation, been rejected. The subject is one as to which illusion is peculiarly easy. Our view of the moon's surface is a bird's-eye view. Its conformation reveals itself indirectly through irregularities in the distribution of light and darkness. The forms of its elevations and depressions can be inferred only from the shapes of the black, unmitigated shadows cast by them. But these shapes are in a state of perpetual and bewildering fluctuation, partly through changes in the angle of illumination, partly through changes in our point of view, caused by what are called the moon's "librations." 1 The result is, that no single observation can be exactly repeated by the same observer, since identical conditions recur only after the lapse of a great number of years.

Local peculiarities of surface, besides, are liable to produce perplexing effects. The reflection of earth-light at a particular angle from certain bright summits completely, though temporarily, deceived Herschel into the belief that he had witnessed, in I783 and I787, volcanic outbursts on the dark side of the moon. The persistent recurrence, indeed, of similar appearances under circumstances less amenable to explanation inclined Webb to the view that effusions of native light actually occur. $^{2}$ More cogent proofs must, however, be adduced before a fact so intrinsically improbable can be admitted as true.

But from the publication of Beer and Mädler's work until I866, the received opinion was that no genuine sign of activity had ever been seen, or was likely to be seen, on our satellite; that her face was a stereotyped page, a fixed and irrevisable

1 The combination of a uniform rotational, with an unequal orbital movement causes a slight swaying of the moon's globe, now east, now west, by which we are enabled to see round the edges of the averted hemisphere. There is also a "parallactic" libration, depending on the earth's rotation ; and a species of nodding movement-the "libration in latitude"-is produced by the inclination of the moon's axis to her orbit, and by her changes of position with regard to the terrestrial equator. Altogether, about $\frac{2}{11}$ of the invisible side come into view. ${ }^{2}$ Cel. Objects, p. $5^{8}$ (4th ed.). 
record of the past. A profound sensation, accordingly, was produced by Schmidt's announcement, in October I866, that the crater "Linné," in the Mare Serenitatis, had disappeared," effaced, as it was supposed, by an igneous outflow. The case seemed undeniable, and is still dubious. Linné had been known to Lohrmann and Mädler, I 822-32, as a deep crater, five or six miles in diameter, the third largest in the dusky plain known as the "Mare Serenitatis"; and Schmidt had observed and drawn it, I840-43, under a practically identical aspect. Now it appears under high light as a whitish spot, in the centre of which, as the rays begin to fall obliquely, a pit, probably under two miles across, emerges into view. The crateral character of this comparatively minute depression was detected by Father Secchi, February I I, 1867.

This, however, is not all. Schröter's description of Linné, as seen by him November 5, I788, tallies quite closely with modern observation ; ${ }^{2}$ while its inconspicuousness in 1797 is shown by its omission from Russell's lumar globe and maps. ${ }^{3}$ We are thus driven to adopt one of two suppositions: either Lohrmann, Mädler, and Schmidt were entirely mistaken in the size and importance of Linné, or a real change in its outward semblance supervened during the first half of the century, and has since passed away, perhaps again to recur. The latter hypothesis seems the more probable; and its probability is strengthened by much evidence of actual obscuration or variation of tint in other parts of the lunar surface, more especially on the floor of the great "walled plain" named "Plato." 4 From a re-examination of this region, and of the Mare Serenitatis, with a thirteen-inch Clark refractor at Arequipa in I89I-2, Mr. W. H. Pickering inclines to the belief that lunar volcanic action, once apparently so potent, is not yet wholly extinct. ${ }^{5}$

An instance of an opposite kind of change was alleged by Dr. Hermann J. Klein of Cologne in March $1878 .^{6}$ In Linné,

1 Astr. Nach., No. 1631. 2 Respighi, Les Mondes, t. xiv., p. 294 ; Huggins, Month. Not, vol. xxvii., p. 298. $\quad 3$ Birt, Ibid., p. 95. $\quad 4$ Report Brit. Ass., I872, p. 245. 5 Observatory, vol. xv., p. 250. $\quad{ }^{6}$ Astr. Reg., vol. xvi., p. 265 ; Astr. Nach., No. 2275. 
the obliteration of an old crater had been assumed; in "Hyginus N.," the formation of a new crater was asserted. Yet, quite possibly, the same cause may have produced the effects thought to be apparent in both. It is, however, far from certain that any real change has affected the neighbourhood of Hyginus. The novelty of Klein's observation of May I9, I877, may have consisted simply in the detection of a hitherto unrecognised feature. The region is one of complex formation, consequently of more than ordinary liability to deceptive variations in aspect under rapid and entangled fluctuations of light and shade. ${ }^{1}$ Moreover, it seems to be certain, from Messrs. Pratt and Capron's attentive study, that "Hyginus N." is no true crater, but a shallow, saucer-like depression, difficult of clear discernment. ${ }^{2}$ Under suitable illumination, nevertheless, it contains, and is marked by, an ample shadow. ${ }^{3}$

In both these controverted instances of change, lunar photography was invoked as a witness; but, notwithstanding the great advances made in the art by Mr. De la Rue in this country, by Dr. Henry Draper, and above all by Mr. Lewis M. Rutherfurd, in America, without decisive results. The autographic moon-pictures, however, lately obtained at Paris and on Mount Hamilton, are on a larger scale, and show a vastly greater amount of detail than those available when Linné became obliterated; and Dr. Weinek's discovery of a previously unknown crater on one of the Lick plates ${ }^{4}$ forecasts perhaps the eventual importance to selenography of the method. But no lunar photograph yet taken can compete with a really fine telescopic view.

Melloni was the first to get undeniable heating effects from moonlight. His experiments were made on Mount Vesuvius early in $1846,{ }^{5}$ and were repeated with like result by Zantedeschi at Venice four years later. A rough measure of the intensity of those effects was arrived at by Piazzi Smyth at Guajara, on the

1 See Lord Lindsay and Dr. Copeland in Month. Not., vol. xxxix., p. 195. 2 Observatory, vols. ii., p. 296 ; iv., p. 373. Mr. N. E. Green (Astr. Reg., vol. xvii., p. 144) concludes the object a mere "spot of colour," dark under oblique light. $\quad 3$ Webb, Cel. Objects, p. Ior. $\quad{ }^{4}$ Astr. Nach., No. 3 I 30.

5 Comptes Rendus, t. xxii., p. 541. 
Peak of Teneriffe, in I856. At a distance of fifteen feet from the thermomultiplier, a Price's candle was found to radiate just twice as much heat as the full moon. ${ }^{1}$ But by far the most exact and extensive series of observations on the subject were those made by the present Earl of Rosse, I869-72. The lunar radiations, from the first to the last quarter, displayed, when concentrated with the Parsonstown three-foot mirror, appreciable thermal energy, increasing with the phase, and largely due to "dark heat," distinguished from the quicker-vibrating sort by inability to traverse a plate of glass. This was supposed to indicate an actual heating of the surface, during the long lunar day of 300 hours, to about $500^{\circ} \mathrm{F}^{2}$ (corrected later to $197^{\circ}$ ), ${ }^{3}$ the moon thus acting as a direct radiator no less than as a reflector of heat. But the conclusion was very imperfectly borne out by Dr. Boeddicker's observations with the same instrument and apparatus during the total lunar eclipse of October $4, \mathbf{1 8 8 4 .}{ }^{4}$ This first opportunity of measuring the heat-phases of an eclipsed moon was used with the remarkable result of showing that the heat disappeared almost completely, though not quite simultaneously, with the light. Confirmatory evidence of the extraordinary promptitude with which our satellite parts with heat already to some extent appropriated, was afforded by Professor Langley's bolometric observations at Allegheny of the partial eclipse of September 23, I885. ${ }^{5}$ Yet it is certain that the moon sends us a perceptible quantity of heat on its own account, besides simply throwing back solar radiations. For in February 1885, Professor Langley succeeded, after many fruitless attempts, in getting measures of a "lunar heatspectrum." The incredible delicacy of the operation may be judged of from the statement that the sum-total of the thermal energy dispersed by his rock-salt prisms was insufficient to raise a thermometer fully exposed to it one-thousandth of a degree Centigrade! The singular fact was, however, elicited that this almost evanescent spectrum is made up of two superposed

1 Phil. Trans., vol. cxlviii., p. 502. '2 Proc. Roy. Soc., vol. xvii., p. 443.

${ }_{5}^{3}$ Phil. Trans., vol. clxiii., p. 623. $\quad 4$ Trans. R. Dublin Soc., vol. iii., p. 321. Science, vol. vii., p. 9. 
spectra, one due to reflection, the other, with a maximum far down in the infra-red, to radiation. ${ }^{1}$ The corresponding temperature of the moon's sunlit surface Professor Langley considers to be about that of freezing water. ${ }^{2}$ Repeated experiments having failed to get any thermal effects from the dark part of the moon, it was inferred that our satellite "has no internal heat sensible at the surface"; so that the radiations from the lunar soil giving the low maximum in the heat-spectrum, "must be due purely to solar heat which has been absorbed and almost immediately re-radiated." Professor Langley's explorations of the terra incognita of immensely long wave-lengths where lie the unseen heat-emissions from the earth into space, led him to the discovery that these, contrary to the received opinion, are in good part transmissible by our atmosphere, although they are completely intercepted by glass. Another important result of the Allegheny work was the abolition of the anomalous notion of the "temperature of space," fixed by Pouillet at-I $42^{\circ} \mathrm{C}$. For space in itself can have no temperature, and stellar radiation is a negligible quantity. Thus, it is safe to assume "that a perfect thermometer suspended in space at the distance of the earth or moon from the sun, but shielded from its rays, would sensibly indicate the absolute zero; ${ }^{3}$ which absolute zero is ordinarily placed at $-273^{\circ} \mathrm{C}$.

A "Prize Essay on the Distribution of the Moon's Heat" (The Hague, I89I), by Mr. Frank W. Very, who had shared actively in Professor Langley's long-sustained inquiry, embodies the fruits of its continuation. They show the lunar disc to be tolerably uniform in thermal power. The brighter parts are also indeed hotter, but not much. The traces perceived of a slight retention of heat by the substances forming the lunar surface, agreed well with Dr. Boeddicker's observations of the total eclipse of the moon, January 28, I 888. ${ }^{4}$ For they showed as before an unmistakable divergence between the heat and light-phases. A

1 Amer. Jour. of Science, vol. xxxviii., p. 428. 2 "The Temperature of the Moon," Memoirs National Acad. of Ściences, vol. iv., p. 193, 1889. 3 Ibid., p. II I ; see also App. ii., p. 206. p. $48 \mathrm{I}, \mathrm{I} 89 \mathrm{I}$. 
curious decrease of heat previous to the first touch of the earth's shadow upon the lunar globe remains unexplained, unless it be admissible to suppose the terrestrial atmosphere capable of absorbing heat at an elevation of 190 miles.

Although that fundamental part of astronomy known as "celestial mechanics" lies outside the scope of this work, and we must therefore pass over in silence the immense labours of Plana, Damoiseau, Hansen, Delaunay, G. W. Hill, and Airy in reconciling the observed and calculated motions of the moon, there is one slight but significant discrepancy which is of such importance to the physical history of the solar system, that some brief mention must be made of it.

Halley discovered in $\mathbf{1 6 9 3}$, by examining the records of ancient eclipses, that the moon was going faster then than 2000 years previously - so much faster, as to have got ahead of the place in the sky she would otherwise have occupied, by abont two of her own diameters. It was one of Laplace's highest triumphs to have found an explanation of this puzzling fact. He showed, in 1787 , that it was due to a very slow change in the ovalness of the earth's orbit, tending, during the present age of the world, to render it more nearly circular. The pull of the sun upon the moon is thereby lessened; the counter-pull of the earth gets the upper hand; and our satellite, drawn nearer to us by something less than an inch each year, ${ }^{1}$ proportionately quickens her pace. Many thousands of years hence the process will be reversed; the terrestrial orbit will close in at the sides, the lunar orbit will open out under the growing stress of solar gravity, and our celestial chronometer will lose instead of gaining time.

This is all quite true as Laplace put it; but it is not enough. Adams, the virtual discoverer of Neptune, found with surprise in I 853 that the received account of the matter was " essentially incomplete," and explained, when the requisite correction was introduced, only half the observed acceleration. ${ }^{2}$ What was to be done with the remaining half? Here Delaunay, the eminent

1 Airy, Observatory, voì. iii., p. 420.

Proc. Roy. Soc., vol. vi., p. 321.

2 Phil. Trans., vol. cxliii., p. 397 ; 
French mathematical astronomer, unhappily drowned at Cherbourg in 1872 by the capsizing of a pleasure-boat, came to the rescue. ${ }^{1}$

It is obvious to any one who considers the subject a little attentively, that the tides must act to some extent as a frictionbrake upon the rotating earth. In other words, they must bring about an almost infinitely slow lengthening of the day. For the two masses of water piled up by lunar influence on the hither and farther sides of our globe, strive, as it were, to detach themselves from the unity of the terrestrial spheroid, and to follow the movements of the moon. The moon, accordingly, holds them against the whirling earth, which revolves like a shaft in a fixed collar, slowly losing motion and gaining heat, eventually dissipated through space. ${ }^{2}$ This must go on (so far as we can see) until the periods of the earth's rotation and of the moon's revolution coincide. Nay, the process will be continued-should our oceans survive so long-by the feebler tideraising power of the sun, ceasing only when day and night cease to alternate, when one side of our planet is plunged in perpetual darkness and the other seared by unchanging light.

Here, then, we have the secret of the moon's turning always the same face towards the earth. It is that in primeval times, when the moon was liquid or plastic, an earth-raised tidal wave rapidly and forcibly reduced her rotation to its present exact agreement with her period of revolution. This was divined by Kant $^{3}$ nearly a century before the necessity for such a mode of action presented itself to any other thinker. In a weekly paper published at Königsberg in 1754 , the modern doctrine of "tidal friction" was clearly outlined by him, both as regards its effects actually in progress on the rotation of the earth, and as regards its effects already consummated on the rotation of the moon-the whole forming a preliminary attempt at what he called a " natural

1 Comptes Rendus, t. lxi., p. I023.

2 Professor Darwin calculates that the heat generated by tidal friction in the course of lengthening the earth's period of rotation from 23 to 24 hours, equalled 23 million times the amount of its present annual loss by cooling. Nature, vol. xxxiv., p. 422.

3 Sämmtl. Werke (ed. 1839), Th. vi., pp. 5-12. See also Mr. C. J. Monro's useful indications in Nature, vol. vii., p. 24 I. 
history" of the heavens. His sagacious suggestion, however, remained entirely unnoticed until revived-it would seem independently_by Julins Robert Mayer in $\mathrm{I} 848 ;^{1}$ while similar, and probably original, conclusions were reached by William Ferrel of Allensville, Kentucky, in I $858 .^{2}$

Delaunay was not then the inventor or discoverer of tidal friction; he merely displayed it as an effective cause of change. He showed reason for believing that its action in checking the earth's rotation, far from being, as Ferrel had supposed, completely nentralised by the contraction of the globe through cooling, was a fact to be reckoned with in computing the movements, as well as in speculating on the history of the heavenly bodies. The outstanding acceleration of the moon was thus at once explained. It was explained as apparent only-the reflection of a real lengthening, by one second in I00,000 years, of the day. But on this point the last word has not yet been spoken.

Professor Newcomb undertook in I870 the onerous task of investigating the errors of Hansen's Lunar Tables as compared with observations prior to 1750 . The results, published in $1878,{ }^{3}$ have proved somewhat perplexing. They tend, in general, to reduce the amount of acceleration left unaccounted for by Laplace's gravitational theory, and proportionately to diminish the importance of the part played by tidal friction. But, in order to bring about this diminution, and at the same time conciliate Alexandrian and Arabian observations, it is necessary to reject as total the ancient solar eclipses known as those of Thales and Larissa. This may be a necessary, but it must be admitted to be a hazardous expedient. Its upshot was to indicate a possibility that the observed and calculated values of the moon's acceleration might after all prove to be identical ; and the small outstanding discrepancy was still further diminished by Tisserand's investigation, differently conducted, of the same Arab eclipses discussed by Newcomb. ${ }^{4}$ The necessity of having recourse to a lengthening day is then less pressing than it seemed

1 Dynamik des Himmels, p. 40.

3 Wash. Obs. for 1875, vol. xxii., App. ii. Annuaire, Paris, 1892.
2 Gould's Astr. Jour., vol. iii., p. 138. 4 Comptes Rendus, t. cxiii., p. 669 ; 
some time ago; and the effect, if perceptible in the moon's motion, should, as M. Tisserand remarks, be proportionately so in the motions of all the other heavenly bodies. The presence of the apparent general acceleration that should ensue can be tested with most promise of success, according to the same authority, by delicate comparisons of past and future transits of Mercury.

Newcomb further showed that small residual irregularities are still found in the movements of our satellite, inexplicable either by any known gravitational influence, or by any uniform value that could be assigned to secular acceleration. ${ }^{1}$ If set down to the account of imperfections in the "time-keeping" of the earth, it could only be on the arbitrary supposition of fluctuations in its rate of going themselves needing explanation. This, it is true, might be found, as Sir W. Thomson pointed out in 1876,2 in very slight changes of figure, not altogether unlikely to occur. But into this cloudy and speculative region astronomers for the present decline to penetrate. They prefer, if possible, to deal only with calculable causes, and thus to preserve for their "most perfect of sciences" its special prerogative of assured prediction.

1 Newcomb, Pop. Astr. (4th ed.). p. Ior. $\quad 2$ Report Brit. Ass. I876, p. 12. 


\section{CHAPTER VIII. \&}

\section{PLANETS AND SATELLITES-(continued).}

"THE analogy between Mars and the earth is perhaps by far the greatest in the whole solar system." So Herschel wrote in $1783,{ }^{1}$ and so it may safely be repeated to-day, after an additional hundred years of scrutiny. The circumstance lends a particular interest to inquiries into the physical habitudes of our exterior planetary neighbour.

Fontana was the first to catch glimpses, at Naples in I636 and $1638,,^{2}$ of dusky stains on the ruddy disc of Mars. They were next seen by Hooke and Cassini in I666, and this time with sufficient distinctness to serve as indexes to the planet's rotation, determined by the latter as taking place in a period of twentyfour hours forty minutes. ${ }^{3}$ Increased confidence was given to this result through Maraldi's precise verification of it in I7 I9. Among the spots observed by him, he distinguished two as stable in position, though variable in size. They were of a peculiar character, showing as bright patches round the poles, and had already been noticed during sixty years back. A current conjecture of their snowy nature obtained validity when Herschel connected their fluctuations in extent with the progress of the Martian seasons. It was hard to resist the inference of frozen precipitations when once it was clearly perceived that the shining polar zones did actually diminish alternately and grow with the alternations of summer and winter in the corresponding hemisphere.

This, it may be said, was the opening of our acquaintance

1 Phil. Trans., vol. Ixxiv., p. 260. ${ }^{2}$ Nova Observationes, p. 105. ${ }^{3}$ Phil. Trans., vol. i., p. 243. ${ }^{4}$ Mém. de l'Ac., 1720, p. 146. 
with the state of things prevailing on the surface of Mars. It was accompanied by a steady assertion, on Herschel's part, of permanence in the dark markings, notwithstanding partial obscurations by clouds and vapours floating in a "considerable but moderate atmosphere." Hence the presumed inhabitants of the planet were inferred to "probably enjoy a situation in many respects similar to ours." 1

Schröter, on the other hand, went altogether wide of the truth as regards Mars. He held that the surface visible to us is a mere shell of drifting cloud, deriving a certain amount of apparent stability from the influence on evaporation and condensation of subjacent but unseen areographical features $;^{2}$ and his opinion prevailed with his contemporaries. It was, however, rejected by Kunowsky in 1822, and finally overthrown by Beer and Mädler's careful studies during five consecutive oppositions, I830-39. They identified at each the same dark spots, frequently blurred with mists, especially when the local winter prevailed, but fundamentally unchanged. ${ }^{3}$ In 1862 Lockyer established a " marvellous agreement" with Beer and Mädler's results of I830, leaving no doubt as to the complete fixity of the main features, amid "daily, nay, hourly," variations of detail through transits of clouds. ${ }^{4}$ On seventeen nights of the same opposition, F. Kaiser of Leyden obtained drawings in which nearly all the markings noted at Berlin in I830 reappeared, besides spots frequently seen respectively by Arago in I813, by Herschel in 1783, and one sketched by Huygens in 1672 with a writing-pen in his diary. ${ }^{5}$ From these data the Leyden observer arrived at a period of rotation of 24h. $37 \mathrm{~m}$. 22.62s., being just one second shorter than that deduced, exclusively from their own observations, by Beer and Mädler. The exactness of this result has been practically confirmed by the inquiries of Professor Bakhuyzen of Leyden. ${ }^{6}$ Using for a middle term of comparison the disinterred

1 Phil. Trans., vol.lxxiv., p. 273. $\quad 2$ A large work, entitled Areographische Fragmente, in which Schröter embodied the results of his labours on Mars, 1785-1803, narrowly escaped the conflagration of 1813 , and was published at Leyden in I88r. ${ }^{3}$ Beiträge, p. I24. ${ }^{4}$ Mem. R. A. Soc., vol. xxxii., p. 183. Astr. Nach., No. 1468. ' Observatory, vol. viii., p. 437. 
observations of Schröter, with those of Huygens at one, and of Schiaparelli at the other end of an interval of 220 years, he was enabled to show, with something like certainty, that the time of rotation (24h. $37 \mathrm{~m} .22 .735 \mathrm{~s}$.) ascribed to Mars by Mr. Proctor ${ }^{1}$ in reliance on a drawing executed by Hooke in 1666, was too long by nearly one-tenth of a second. The minuteness of the correction indicates the nicety of care employed. Nor employed vainly; for, owing to the comparative antiquity of the records available in this case, an almost infinitesimal error becomes so multiplied by frequent repetition as to produce palpable discrepancies in the positions of the markings at distant dates. Hence Bakhuyzen's period of $24 \mathrm{~h}$. $37 \mathrm{~m}$. 22.66s. is undoubtedly of a precision unapproached as regards any other heavenly body save the earth itself.

Two facts bearing on the state of things at the surface of Mars were, then, fully acquired to science in or before the year 1862. The first was that of the seasonal fluctuations of the polar spots; the second, that of the permanence of certain dark grey or greenish patches, perceived with the telescope as standing out from the deep yellow ground of the disc. The opinion has steadily gained consistency during the last halfcentury that these varieties of tint correspond to the real diversities of a terraqueous globe, the " ripe cornfield" ${ }^{2}$ sections representing land, the dusky spots and streaks, oceans and straits. Sir J. Herschel in 1830 led the way in ascribing the redness of the planet's light to an inherent peculiarity of soil. ${ }^{3}$ Previously it had been assimilated to our sunset glows rather than to our red sandstone formations-set down, that is, to an atmospheric stoppage of blue rays. But the extensive Martian atmosphere, implicitly believed in on the strength of some erroneous observations by Cassini and Römer in the seventeenth century, vanished before the sharp occultation of a small star in Leo, witnessed by Sir James South in $1822 ;^{4}$

I Month. Not., vols. xxviii., p. 37 ; xxix., p. 232 ; xxxiii., p. $55^{2} .{ }^{2}$ Flammarion, L'A stronomie, t. i., p. $266 . \quad{ }^{3}$ Smyth, Cel. Cycle, vol. i., p. I48 (Ist ed.).

4 Phil. Trans., vol. cxxi., p. 417. 
and Dawes's observation in $1865,{ }^{1}$ that the ruddy tinge is deepest near the central parts of the disc, certified its nonatmospheric origin. The absolute whiteness of the polar snowcaps was alleged in support of the same inference by Dr. Huggins in $1867 .^{2}$

All recent observations tend to show that the atmosphere of Mars is much thinner than our own. This was to have been expected $\grave{a}$ priori, since the same proportionate mass of air would, owing to the small size and inferior specific gravity of Mars, as compared with the earth, form a very much sparser covering over each square mile of his surface. ${ }^{3}$ Besides, gravity there possesses less than four-tenths its force here, so that this sparser covering would weigh less, and be less condensed, than if it enveloped the earth. Atmospheric pressure would accordingly be of about two and a quarter, instead of fifteen terrestrial pounds per square inch. This corresponds with what the telescope shows us. It is extremely doubtful whether any features of the earth's actual surface could be distinguished by a planetary spectator, however well provided with optical assistance. Professor Langley's inquiries ${ }^{4}$ have led him to conclude that fully twice as much light is absorbed by our air as had previously been supposed-say forty per cent. of vertical rays in a clear sky. Of the sixty reaching the earth, less than a quarter would be reflected even from white sandstone; and this quarter would again pay heavy toll in escaping back to space. Thus not more than perhaps ten or twelve out of the original hundred sent by the sun would, under the most favourable circumstances, and from the very centre of the earth's disc, reach the eye of a Martian or lunar observer. The light by which he views our world is, there is little doubt, light reflected from the various strata of our atmosphere, cloud- or mist-laden or serene, as the case may be, with an occasional snow-mountain figuring as a permanent white spot.

This consideration at once shows us how much more tenuous

1 Month. Not., vol. xxv., p. 227. 2 Phil. Mag., vol. xxxiv., p. 75. ${ }^{3}$ Proctor, Quart. Jour. of Science, vol. x., p. 185 ; Maunder, Sunday Mag., Jan., Feb. March, 1882. 4 Am. Jour. of Sc., vol, xxviii., p. I63. 
the Martian air must be, since it admits of topographical delineations of the Martian globe. The clouds, too, that form in it seem in general to be rather of the nature of ground-mists than of heavy cumulus. ${ }^{1}$ Aqueous vapour is indeed present. A characteristic group of dark rays, due to its absorptive action, was detected by Dr. Huggins in the analysed light of the planet in 1867,2 and serves to raise the conjecture of "snowy poles" to a verisimilitude scarcely to be distinguished from certainty.

The climate of Mars seems to be unexpectedly mild. Its theoretical mean temperature, taking into account both distance from the sun and albedo, is thirty-four Centigrade degrees below freezing. ${ }^{3} \quad$ Yet its polar snows are both less extensive and less permanent than those on the earth. The southern white hood, always eccentrically situated, was noticed by Schiaparelli in I 877 to have survived the summer only as a small lateral patch, the pole itself being quite free from snow. Moreover, Mr. W. H. Pickering observed with astonishment the disappearance, in the course of thirty-three days of June and July i 892, of 1,600,000 square miles of southern snow. Curiously enough, the initial stage of shrinkage in the white calotte was marked by its division into two unequal parts, as if in obedience to the mysterious principle of duplication governing so many Martian phenomena. ${ }^{4}$ Changes of the hues associated respectively with land and water, simultaneously noted in lower latitudes, were thought to be occasioned by floods ensuing upon this rapid antarctic thaw. ${ }^{5}$ It. is true that scarcity of moisture would account for the scantiness and transitoriness of snowy deposits easily liquefied because thinly spread. But we might expect to see the whole wintry hemisphere, at any rate, frostbound, since the sun radiates less than half as much heat on Mars as on the earth. Water seems, nevertheless, to remain, as a rule, uncongealed everywhere outside the polar regions. We are at a loss to imagine by what beneficent arrangement the rigorous conditions naturally to be

1 Burton, Trans. Roy. Dublin Soc., vol. i., I880, p. 169. 2 Month. Not., vol. xxvii., p. 179. $\quad{ }^{3}$ C. Christiansen, Beiblätter, 1886, p. $532 . \quad{ }^{4}$ Flammarion, $L a$ Planète Mars, p. 574. ${ }^{5}$ Astr. and Astro-Physics, Oct. 1892, p. 67 I. 
looked for, can be modified into a climate which might be found tolerable by creatures constituted like ourselves.

Martian topography may be said to form nowadays a separate sub-department of descriptive astronomy. The amount of detail become legible by close scrutiny of a little disc which, once in fifteen years, attains a maximum of about $\frac{1}{5000}$ the area of the full moon, must excite surprise and might provoke incredulity. Spurious discoveries, however, have little chance of holding their own where there are so many competitors quite as ready to dispute as to confirm.

The first really good map of Mars was constructed in 1869 by Proctor from drawings by Dawes. Kaiser of Leyden followed in 1872 with a representation founded upon data of his own providing in 1862-64; and M. Terby, in his valuable Aréographie, presented to the Brussels Academy in $1874^{1}$ a careful discussion of all important observations from the time of Fontana downwards, thus virtually adding to knowledge by summarising and digesting it. The memorable opposition of September 5, I877, marked a fresh epoch in the study of Mars. While executing a trigonometrical survey (the first attempted) of the disc, then of the unusual size of $25^{\prime \prime}$ across, Signor G. V. Schiaparelli, director of the Milan Observatory, detected a novel and curious feature. What had been taken for Martian continents were found to be, in point of fact, agglomerations of islands, separated from each other by a network of so-called "canals" (more properly channels). ${ }^{2}$ These are obviously extensions of the "seas," originating and terminating in them, and sharing their grey-green hue, but running sometimes to a length of three or four thousand miles in a straight line, and preserving throughout a nearly uniform breadth of about sixty miles. Further inquiries have fully substantiated the discovery made at the Brera Observatory. The "canals" of Mars are an actually existent and permanent phenomenon. An examination of the drawings in his possession showed M. Terby that they had been seen, though not distinctively recognised, by Dawes,

1 Mémoires Couronnés, t. xxxix. ${ }^{2}$ Lockyer, Nature vol. xlvi., p. 447. 
Secchi, and Holden ; several were independently traced out by Burton at the opposition of 1879 ; and all were recovered by Schiaparelli himself in 1879 and $188 \mathrm{I}-82$.

When the planet culminated at midnight, and was therefore in opposition, December 26, $188 \mathrm{I}$, its distance was greater, and its apparent diameter less than in 1877 , in the proportion of sixteen to twenty-five. Its atmosphere was, however, more transparent, and ours of less impediment to northern observers, the object of scrutiny standing considerably higher in northern skies. Never before, at any rate, had the true aspect of Mars come out so clearly as at Milan, with the $8 \frac{3}{4}$-inch Merz refractor of the observatory, between December I88I and February i882. The canals were all again there, but this time they were-in as many as twenty cases-seen in duplicate. That is to say, a twin-canal ran parallel to the original one at an interval of 200 to 400 miles. $^{1}$

We are here brought face to face with an apparently insoluble enigma. Schiaparelli regards the "gemination" of his canals as a periodical phenomenon depending on the Martian seasons. It is, at any rate, not an illusory one, since it was plainly apparent, during the opposition of 1886 , to MM. Perrotin and Thollon at Nice, ${ }^{2}$ and to the former, using the new thirty-inch refractor of that observatory, in I 888 ; Mr. A. Stanley Williams, with the help of only a $6 \frac{1}{2}$-inch reflector, distinctly perceived in I 890 seven of the duplicate objects noted at Milan, ${ }^{3}$ and the Lick observations, both of 1890 and of I 892, brought unequivocal confirmation to the accuracy of Schiaparelli's impressions. ${ }^{4}$ Various conjectures have been hazarded in explanation of this bizarre appearance. The difficulty of conceiving a physical reality corresponding to it has suggested recourse to an optical rationale. Proctor regarded it as an effect of diffraction, ${ }^{5}$ Stanislas Meunier, of oblique reflection from overlying mist-banks ; ${ }^{6}$ Flammarion considers it possible that companion-canals might, under special circumstances, be evoked as a kind of mirage, ${ }^{7}$ by refraction. But none of these speculations

1 Mem. Spettr. Italiani, t. xi., p. $28 .{ }^{2}$ Bull. Astr., t. iii., p. 324. ${ }^{3}$ Jour. Brit. Astr. Ass., vol. i., p. $88 .{ }_{4}^{4}$ Publ. Pac. Astr. Soc., vol. ii., p. 299. ${ }^{5}$ Old and New Astr., p. 545. ${ }^{6}$ L'Astronomie, t. xi., p. 445. 7 La Planete Mars, p. 588 . 
are really admissible, when all the facts are taken into account. The view that the canals of Mars are vast rifts due to the cooling of the globe, is recommended by the circumstance that they always follow great circles; nevertheless, it would break down if, as Schiaparelli holds, the fluctuations in their visibility depend upon actual obliterations and re-emergences.

The closeness of the terrestrial analogy has thus of late been much impaired. The distribution of land and water on Mars, at any rate, appears to be of a completely original type. The interlacing everywhere of continents with arms of the sea (if that be the correct interpretation of the visual effects) implies that their levels scarcely differ $;^{1}$ and Schiaparelli carries most observers with him in holding that their outlines are not absolutely constant, encroachments of dusky upon bright tints suggesting extensive inundations. Mr. N. E. Green's observations at Madeira in 1877 seem to indicate, on the other hand, a rugged south polar region. The contour of the snow-cap not only appeared to him indented, as if by valleys and promontories, but brilliant points were discerned outside the white area, attributed to isolated snow-peaks. ${ }^{2}$ Still more elevated, if similarly explained, must be the "ice island " first seen in a comparatively low latitude by Dawes in January 1865.

On August 4, I892, Mars stood opposite to the sun at a distance of only $34,865,000$ miles from the earth. In point of vicinity, then, its situation was scarcely less favourable than in 1877. Yet the low altitude of the planet practically neutralised this advantage for northern observers, and public expectation, which had been raised to the highest pitch by the announcements of sensation-mongers, was somewhat disappointed at the "meagreness" of the news authentically received from Mars. Valuable series of observations were, nevertheless, made at Lick and Arequipa; and they unite in testifying to the genuine prevalence of surface-variability, especially in certain regions of intermediate tint, and perhaps of the "crude consistence" of "boggy . Syrtis, neither sea, nor good dry land." Professor Holden insists on the "enormous difficulties in the way

${ }^{1}$ L'A stronomie, t. viii. ${ }^{2}$ Month. Not., vol. xxxviii., p. 4r; Memoirs R. Astr. Soc., vol. xliv., p. 123. 
of completely explaining the recorded phenomena by terrestrial analogies" ; ${ }^{1}$ Mr. W. H. Pickering speaks of "conspicuous and startling changes." They however merely overlay, and partially disguise a general stability. Among the novelties detected by Mr. Pickering, were a number of "lakes," under the aspect of black dots at the junctions of two or more canals; ${ }^{2}$ and he, no less than the Lick astronomers and M. Perrotin at Nice, ${ }^{3}$ observed brilliant clouds projecting beyond the limb, while carried round by the planet's rotation. They seemed to float at an altitude of at least twenty miles, or about four times the height of terrestrial cirrus; but this was not wonderful, considering the low power of gravity acting upon them. Great capital was made in the journalistic interest out of these imaginary signals from intelligent Martians, desirous of opening communications with (to them) problematical terrestrial beings. Their exemplary perseverance was certified by the previous occurrence of similar effects, witnessed by M. Terby at Louvain in I888, and at the Lick Observatory in 1890.

The first photograph of Mars was taken by Gould at Cordoba in I879. Little real service in planetary delineation has, it is true, been so far rendered by the art, yet one achievement must be recorded to its credit. A set of photographs obtained by Mr. W. H. Pickering on Wilson's Peak, California, April 9, I890, showed the southern polar cap of Mars as of moderate dimensions, but with a large dim adjacent area. Twenty-four hours later, on a corresponding set, the dim area was brilliantly white. The polar cap had become enlarged in the interim, apparently through a wide-spreading snow-fall, by the annexation of a territory equal to that of the United States. The season was towards the close of winter in Mars. This was the first time that the process of glacial extension had been actually (it might be said) superintended in that distant globe.

Mars was gratuitously supplied with a pair of satellites long before he was found actually to possess them. Kepler interpreted Galileo's anagram of the "triple" Saturn in this sense; they

\footnotetext{
1 Astr. and Astro-Physics, Oct. 1892, p. 668.

3 Comptes Rendus, t. cxv., p. 379.

2 Ibid., Dec. 1892, p. 850.
} 
were perceived by Micromégas on his long voyage through space; and the Laputan astronomers had even arrived at a knowledge, curiously accurate under the circumstances, of their distances and periods. But terrestrial observers could see nothing of them until the night of August I I, I877. The planet was then within one month of its second nearest approach to the earth during this century; and in I845 the Washington 26-inch refractor was not in existence. ${ }^{1}$ Professor Asaph Hall, accordingly, determined to turn the conjuncture to account for an exhaustive inquiry into the surroundings of Mars. Keeping his glaring disc just outside the field of view, a minute attendant speck of light was "glimpsed "August I I. Bad weather, however, intervened, and it was not until the I6th that it was ascertained to be what it appeared-a satellite. On the following evening a second, still nearer to the primary, was discovered, which, by the bewildering rapidity of its passages hither and thither, produced at first the effect of quite a crowd of little moons. ${ }^{2}$

Both these delicate objects have since been repeatedly observed, both in Europe and America, even with comparatively small instruments. At the opposition of I884, indeed, the distance of the planet was too great to permit of the detection of both elsewhere than at Washington. But the Lick equatoreal showed them, July I 8, I888, when their brightness was only 0. I2 its amount at the time of their discovery; so that they can now be followed for a considerable time before and after the least favourable oppositions.

The names chosen for them were taken from the Iliad, where "Deimos" and "Phobos" (Fear and Panic) are represented as the companions in battle of Ares. In several respects, they are interesting and remarkable bodies. As to size, they may be said to stand midway between meteorites and satellites. From careful photometric measures executed at Harvard in I877 and I879, Professor Pickering concluded their diameters to be respectively six and seven miles. ${ }^{3}$ This is on the assump-

1 See Mr. Wentworth Erck's remarks in Trans. Roy. Dublin Soc., vol. i., p. 29. 2 Mcnth. Not., vol. xxxviii., p. 206. 3 Annals Harvard Coll. Obs., vol. xi., pt. ii., p. 217. 
tion that they reflect the same proportion of the light incident upon them that their primary does. But it may very well be that they are less reflective, in which case they would be more extensive. The albedo of Mars, according to Zöllner, is 0.28 ; his surface, in other words, returns 28 per cent. of the rays striking it. If we put the albedo of his satellites equal to that of our moon, O.I7, their diameters will be increased from 6 and 7 to 8 and 9 miles, Phobos, the inner one, being the larger. Their actual dimensions are unlikely to exceed this estimate. It is interesting to note that Deimos, according to Professor Pickering's very distinct perception, does not share the reddish tint of Mars.

Both satellites move quickly in small orbits. Deimos completes a revolution in thirty hours eighteen minutes, at a distance from the surface of its ruling body of 12,500 miles; Phobos in seven hours thirty-nine minutes twenty-two seconds, at a distance of only 3760 miles. This is the only known instance of a satellite circulating faster than its primary rotates, and is a circumstance of some importance as regards theories of planetary development. To a Martian spectator the curious effect would ensue of a celestial object, seemingly exempt from the general motion of the sphere, rising in the west, setting in the east, and culminating twice, or even thrice a day; which, moreover, in latitudes above $69^{\circ}$ north or south, would be permanently and altogether hidden by the intervening curvature of the globe.

The detection of new members of the solar system has come to be one of the most ordinary of astronomical events. Since I 846 no single year has passed without bringing its tribute of asteroidal discovery. In the last of the seventies alone, a full score of miniature planets were distinguished from the thronging stars amid which they seem to move; 1875 brought seventeen such recognitions; their number touched a minimum of one in I88I ; it rose in I882, and again in I886, to eleven; dropped to six in I 889, remounted to fifteen in I890, to twenty-one in I89I, and attained a maximum of twenty-nine in 1892 . On January. I, I893, 352 asteroids were recognised as revolving between the orbits of Mars and Jupiter. Of these, no less than 83 are 
claimed by a single observer-Professor J. Palisa of Vienna; Dr. C. H. F. Peters of Clinton (N.Y.), whose varied and useful career terminated July I9, I890, comes second with 48; Charlois claims 40; Watson, Borrelly, Luther, Hind, Goldschmidt, Paul and Prosper Henry, and many others have each contributed numerously to swell the sum-total. The construction by Chacornac and his successors at Paris, and more recently by Peters at Clinton, of ecliptical charts showing all stars down to the thirteenth and fourteenth magnitudes respectively, rendered the picking ont of moving objects above that brightness a mere question of time and diligence. Both, however, are vastly economised by the photographic method. Tedious comparisons of the sky with charts are no longer needed for the identification of unrecorded, because simulated stars. Planetary bodies declare themselves by appearing upon properly exposed sensitive plates, not in circular, but in linear form. Their motion converts their images into trails, long or short according to the time of exposure. The first asteroid (No. 323) thus detected was by M. Max Wolf, at Heidelberg, December 22, I89I. Fifteen others were similarly discovered in I892, by the same skilful operator; and ten more through Charlois's adoption at Nice of the novel plan for picking up errant light specks. Its continued use-which promises soon to become exclusive-led, during the first three months of 1893 , to the reinforcement, at the same two observatories, of the asteroidal band by no less than twenty-three new members. Far more onerous than the task of their discovery is that of keeping them in view once discovered-of tracking out their paths, fixing their places, and calculating the disturbing effects upon them of the mighty Jovian mass. These complex operations have come to be centralised at Berlin under the superintendence of Professol Tietjen, and their results are given to the public through the medium of the Berliner Astronomisches Jahrbuch.

The crowd of orbits thus disclosed invites attentive study. D'Arrest remarked in $\mathbf{1} 85 \mathbf{I}^{1}{ }^{1}$ when only thirteen minor planets were known, that supposing their paths to be represented by solid hoops, not one of the thirteen could be lifted from its 
place without bringing the others with it. The complexity of interwoven tracks thus illustrated has grown almost in the numerical proportion of discovery. Yet no two actually intersect, because no two lie exactly in the same plane, so that the chances of collision are at present nil. There is only one case, indeed, in which it seems to be eventually possible. M. Lespiault has pointed out that the curves traversed by "Fịdés" and "Maïa" approach so closely that a time may arrive when the bodies in question will either coalesce or unite to form a binary system. ${ }^{1}$

The maze threaded by the 375 asteroids contrasts singularly with the harmonionsly ordered and rhythmically separated orbits of the larger planets. Yet the seeming confusion is not without a plan. The established rules of our system are far from being totally disregarded by its minor members. The orbit of Pallas, with its inclination of $34^{\circ} 42^{\prime}$, touches the limit of departure from the ecliptic level; the average plane of the asteroidal paths differs by little more than one degree from that of the sun's equator ${ }^{2}$ their mean eccentricity is below that of the curve traced out by Mercury, and.all without exception are pursued in the planetary direction-from west to east.

The zone in which these small bodies travel is about three times as wide as the interval separating the earth from the sun. It extends perilously near to Jupiter, and actually encroaches upon the sphere of Mars. In one of his lectures at Gresham College in $1879,{ }^{3} \mathrm{Mr}$. Ledger remarked that the minor planet Aethra, when in perihelion, gets inside Mars in aphelion by as much as five millions of miles, though at so different a level in space that there is no close approach.

The distribution of the asteroids over the zone frequented by them is very unequal. They are most densely congregated about the place where a single planet ought, by Bode's Law, to revolve; it may indeed be said that only stragglers from the main body are found more than fifty million miles within or without a mean distance from the sun 2.8 times that of the

1 L. Niesten, Annuaire, Bruxelles, I88I, p. 269. $\quad 2$ According to Svedstrup (Astr. Nach., Nos. 2240-4I), the inclination to the ecliptic of the "mean asteroid's" orbit is $=6^{\circ} . \quad 3$ Sun and Planets, p. 267. 
earth. Significant gaps, too, occur where some force prohibitive of their presence would seem to be at work. What the nature of that force may be, Professor Daniel Kirkwood, then of the Indiana University, indicated, first in I 866 when the number of known asteroids was only eighty-eight, and again with more confidence in 1876 from the study of a list then run up to $172 .^{1}$ It appears that these bare spaces are found just where a revolving body would have a period connected by a simple. relation with that of Jupiter. It would perform two or three circuits to his one, five to his two, nine to his five, and so on. Kirkwood's inference is that the gaps in question were cleared of asteroids by the attractive influence of Jupiter. For disturbances recurring time after time-owing to commensurability of periods-nearly at the same part of the orbit, would have accumulated until the shape of that orbit was notably changed. The body thus displaced would have come in contact with other cosmical particles. of the same family with itself-in former ages, it may be assumed, more evenly distributed than now-would have coalesced with them, and permanently left its original track. In this way the regions of maximum perturbation would gradually have become denuded of their occupants.

We can scarcely doubt that this law of commensurability has largely influenced the present distribution of the asteroids. But its effects must have been produced while they were still in an unformed, perhaps a nebular condition. In a system giving room for a considerable modification through disturbance, the recurrence of conjunctions with a dominating mass at the same orbital point, need not involve instability. ${ }^{2}$ Thus, if Menippe really performs five while Jupiter performs two revolutions, she may, serious perturbations notwithstanding, continue to do so. The elements, however, computed for this small body are as yet. unverified by a recapture since its discovery in 1878. And in general, the correspondence of facts with Professor Kirkwood's hypothesis has become closer the more numerously they have been ascertained. ${ }^{3}$

1 Smiths. Report, 1876, p. 358; The Asteroids (Kirkwood), p. 42, 1888. 2 Tisserand, Annuaire, Paris, 1891, p. B. 15. ${ }^{3}$ Berberich, Astr. Nach., No. 3088. 
The existence, too, of numerous pairs and groups of asteroids travelling in strikingly similar tracks, must date from a remote antiquity. They result, in Professor Kirkwood's ${ }^{1}$ opinion, from the divellent action of Jupiter ipon embryo pygmy planets, just as comets moving in pursuit of one another are a consequence of the sundering influence of the sun.

Leverrier fixed, in I $853,{ }^{2}$ one-fourth of the earth's mass as the outside limit for the combined masses of all the bodies circulating between Mars and Jupiter; but it is far from probable that this maximum is at all nearly approached. $M$. Berberich ${ }^{3}$ thinks that the moon would more than outweigh the whole of them, a million of the lesser bodies shining like stars of the twelfth magnitude being needed, according to his judgment, to constitute her mass. And M. Niesten estimated that the whole of the 216 asteroids discovered up to August I880 amounted in volume to only $\frac{1}{4000}$ of our globe, ${ }^{4}$ and we may safely add-since they are tolerably certain to be lighter, bulk for bulk, than the earth-that their proportionate mass is smaller still. Professor Pickering, from determinations of light-intensity, assigns to Vesta a diameter of 319 miles, to Pallas 167 , to Juno 94, down to twelve and fourteen for the smaller members of the group. ${ }^{5}$ An albedo equal to that of Mars is assumed as the basis of the calculation. Still more recently, Professor G. Müller ${ }^{6}$ of Potsdam has examined photometrically the phases of seven minor planets, of which four-namely, Vesta, Iris, Massalia, and Amphitrite-were found to conform precisely to the behaviour of Mars as regards light-change from position, while Ceres, Pallas, and Irene varied after the manner of the moon and Mercury. The first group were hence inferred to resemble Mars in physical constitution, nature of atmosphere, and reflective capacity; the second to be moon-like bodies. The low albedo of these last rendering them less conspicuous proportionately to their extent of surface than the others, the value of their

1 The Asteroids, p. 48 ; Publ. Astr. Pac. Soc., vols. ii., p. 48, iii., p. 95 ; Astr. and Astro-Physics, Nov. 1892, p. 785. ${ }^{2}$ Comptes Rendus, t. xxxvii., p. 797. 3 Bull. Astr., t. v., p. 180. 4 Annuaire, Bruxelles, 1881, p. 243. ${ }^{5}$ Harvard Annals, vol. xi., part ii., p. 294. ${ }^{6}$ Astr. Nach., Nos. 2724-5. 
diameters arrived at by Pickering probably require some increase. Vesta, however (of which the Harvard estimate of size has been still further assured at Potsdam), still holds its place as the largest minor planet. The rapid and regular changes of its brightness, observed by Professor M. W. Harrington ${ }^{1}$ at Anm Arbor, and supposed by him to be those of a swiftly rotating and unequally reflective globe, are unconfirmed and disbelieved in by Müller.

There is no direct evidence that any of the minor planets possess atmospheres. The aureolæ seen by Schröter to surround Ceres and Pallas have been dissipated by optical improvements. Vogel in 1872 thought he had detected an air-line in the spectrum of Vesta $;^{2}$ but admitted that its presence required confirmation, which has not been forthcoming.

Crossing the zone of asteroids on our journey outward from the sun, we meet with a group of bodies widely different from the "inferior" or terrestrial planets. Their gigantic size, low specific gravity, and rapid rotation, obviously from the first threw the "superior" planets into a class apart; and modern research has added qualities still more significant of a dissimilar physical constitution. Jupiter, a huge globe 86,000 miles in diameter, stands pre-eminent among them. $\mathrm{He}$ is, however, only primus inter pares; all the wider inferences regarding his condition may be extended, with little risk of error, to his fellows; and inferences in his case rest on surer grounds than in the case of the others, from the advantages offered for telescopic scrutiny by his comparative nearness.

Now the characteristic modern discovery concerning Jupiter is that he is a body midway between the solar and terrestrial stages of cosmical existence-a decaying sun or a developing earth, as we choose to put it-whose vast unexpended stores of internal heat are mainly, if not solely, efficient in producing the interior agitations betrayed by the changing features of his visible disc. This view was anticipated in the last century.

${ }^{1}$ Am. Jour. of Sc., vol. xxvi. (3rd ser.), p. 464. ${ }^{2}$ Spectra der Planeten, p. 24. 
Buffon wrote in his Époques de la Nature (I778) : 1_" La surface de Jupiter est, comme l'on sait, sujette à des changemens sensibles, qui semblent indiquer que cette grosse planète est encore dans un état d'inconstance et de bouillonnement."

Primitive incandescence, attendant, in his fantastic view, on planetary origin by cometary impacts with the sum, combined, he concluded, with vast bulk to bring about this result. Jupiter has not yet had time to cool. Kant thought similarly in $1785 ;^{2}$ but the idea did not commend itself to the astronomers of the time, and dropped out of sight until $\mathrm{Mr}$. Nasmyth arrived at it, afresh in $1853 .^{3}$ Even still, however, terrestrial analogies held their ground. The dark belts ruming parallel to the equator, first seen at Naples in 1630, continued to be associated-as Herschel had associated them in $178 \mathrm{I}$-with Jovian trade-winds, in raising which the deficient power of the sun was supposed to be compensated by added swiftness of rotation. But opinion was not permitted to halt here.

In I860 G. P. Bond of Cambridge (U.S.) derived some remarkable indications from experiments on the light of Jupiter. ${ }^{4}$ They showed that fourteen times more of the photographic rays striking it are reflected by the planet than by our moon, and that, unlike the moon, which sends its densest rays from the margin, Jupiter is brightest near the centre. But the most perplexing part of his results was that Jupiter actually seemed to give out more light than he received. Bond, however, considered his data too uncertain for the support of so bold an assumption as that of original luminosity, and, even if the presence of native light were proved, thought that it might emanate from auroral clouds of the terrestrial kind. The conception of a sun-like planet was still a remote, and seemed an extravagant one.

Only since it was adopted and enforced by Zöllner in $1865,{ }^{5}$ can it be regarded as permanently acquired to science. The rapid changes in the cloud-belts both of Jupiter and Saturn, he remarked, attest a high internal temperature. For we know

1 Tome i., p. 93. $\quad 2$ Berlinische Monatsschrift, 1785, p. 211. 3 Month. Not., vol. xiii., p. 40. ${ }^{4}$ Mem. Am. Ac., vol. viii., p. 22 I. ${ }^{5}$ Photom. Unters., p. 303. 
that all atmospheric movements on the earth are sun-heat transformed into motion. But sun-heat at the distance of Jupiter possesses but $\frac{1}{27}$, at that of Saturn $\frac{1}{100}$ of its force here. The large amount of energy, then, obviously exerted in those remote firmaments must have some other source, to be found nowhere else than in their own active and all-pervading fires, not yet banked in with a thick solid crust.

The same acute investigator dwelt, in $187 \mathrm{I}^{1}$ on the similarity between the modes of rotation of the great planets and of the sun, applying the same principles of explanation to each case. The fact of this similarity is undoubted. Cassini ${ }^{2}$ and Schröter both noticed that markings on Jupiter travelled quicker the nearer they were to his equator; and Cassini even hinted at their possible assimilation to sun-spots. ${ }^{3}$ It is now well ascertained that, as a rule (not without exceptions), equatorial spots give a period some $5 \frac{1}{2}$ minutes shorter than those in latitudes of about $30^{\circ}$. But, as Mr. Denning has pointed out, ${ }^{4}$ no single period will satisfy the observations either of different markings at the same epoch, or of the same markings at different epochs. Accelerations and retardations, depending upon processes of growth or change, take place in very much the same kind of way as in solar maculæ, inevitably suggesting similarity of origin.

Among popular writers, Mr. Proctor was foremost in realising the highly primitive condition of these giant orbs, and in impressing the facts and their logical consequences upon the public mind. The inertia of ideas on the subject was overcome largely through the arguments reiterated in the various and well-known works published by him subsequently to i870. It should be added that Mr. Mattieu Williams in his Fuel of the Sun adopted, equally early, similar views.

The interesting query as to Jupiter's surface incandescence has been studied since Bond's time with the aid of all the appliances furnished to physical inquirers by modern inventiveness, yet without bringing to it a categorical reply. Zöllner

1 Astr. Nach., No. I851.

2 Mém. de l'Ac., t. x., p. 514.

${ }^{3}$ Ibid., 1692,

p. 7. Month. Not., vol. xliv., p. 63 . 
in I 865 estimated his albedo at 0.62 , that of fresh-fallen snow being 0.78 , and of white paper 0.70. ${ }^{1}$ But the disc of Jupiter is by no means purely white. The general ground is tinged with ochre, the polar zones are leaden or fawn-coloured, large spaces are at times stained or diffused with chocolate-browns and rosy hues. It is occasionally seen ruled from pole to pole with dusky bars, and is never wholly free from obscure markings. The reflection then by it, as a whole, of 62 per cent. of the rays impinging upon it, might well suggest some original reinforcement.

Nevertheless, the spectroscope gives little countenance to the supposition of any considerable permanent light-emission. The spectrum of Jupiter, as examined by Huggins, I 862-64, and by Vogel, I 87 I-73, shows the familiar Fraunhofer rays belonging to reflected sunlight. But it also shows lines of native absorption. Some of these are identical with those produced by the action of our own atmosphere, especially one or more groups due to aqueous vapour ; others are of unknown origin, and it is remarkable that one amongst the latter-a strong band in the redagrees in position with a dark line in the spectra of some ruddy stars. $^{2}$ There is, besides, a general absorption of blue rays, intensified-as Le Sueur observed at Melbourne in $1869^{3}$-in the dusky markings, evidently through an increase of depth in the atmospheric strata traversed by the light proceeding from them.

All these observations, however (setting aside the stellar line as of doubtful significance), point to a cool planetary atmosphere. There is, we believe, only one on record evincing unmistakably the presence of intrinsic light. On September 27, I879, Dr. Henry Draper obtained a photograph of Jupiter's spectrum, in which a strengthening of the impression was visible in the parts corresponding to the planet's equatoreal regions. ${ }^{4}$ This is just the right sort of evidence, but it is altogether exceptional. We are driven then to conclude that native emissions from Jupiter's visible surface are local and fitful, not

1 Photom. Unters., pp. 165, 273. Zöllner's photometric methods are, however, seriously called in question by seeliger, $V$. J. S. Astr. Ges., Jahrg. xxi., p. 225. 2 Vogel, Sp. d. Planeten, p. 33, note. $\quad 3$ Proc. Roy. Soc., vol. xviii., p. 250.

4 Month. Not., vol. xl., p. 433. 
permanent and general. Indeed, the blackness of the shadows cast by his satellites on his disc sufficiently proves that he sends out virtually none but reflected light. ${ }^{1}$ This conclusion, however, by no means invalidates that of his high internal temperature.

The curious phenomena attending Jovian satellite-transits may be explained partly as effects of contrast, partly as due to temporary obscurations of the small discs projected on the large disc of Jupiter. At their first entry upon its marginal parts, which are several times less luminous than those near the centre, they invariably show as bright spots, then usually vanish as the background gains lustre, to reappear, after crossing the disc, thrown into relief, as before, against the dusky limb. But instances are not rare, more especially of the third and fourth satellites standing out, during the entire middle part of their course, in such inky darkness as to be mistaken for their own shadows. The earliest witness of a "black transit" was Cassini, September 2, 1665; Römer in 1677, and Maraldi in I707 and I7I3, made similar observations, which have been multiplied during the present century. In some cases the process of darkening has been visibly attended by the formation, or emergence into view, of spots on the transiting body, as noted by the two Bonds at Harvard, March I8, I848.2 The third satellite was seen by Dawes, half dark, half bright, when crossing Jupiter's disc, August 21, I867 $;^{3}$ one-third dark by Davidson of California, January I 5, I884, under the same circumstances $;^{4}$ and unmistakably spotted, both on and off the planet, by Schröter, Secchi, Dawes, and Lassell.

The first satellite sometimes looks dusky, but never absolutely black, in travelling over the disc of Jupiter. The second appears uniformly white-a circumstance attributed by Dr. Spitta ${ }^{5}$ to its high albedo. The singularly different aspects, even during successive transits of the third and fourth satellites, are connected by Professor Holden ${ }^{6}$ with the varied

1 The anomalous shadow-effects recorded by Webb (Cel. Objects, p. I7o, 4th ed.) are obviously of atmospheric and optical origin. 2 Engelmann, Ueber die Helligkeitsverhältnisse der Jupiterstrabanten, p. 59. ${ }^{3}$ Month. Not., vol. xxviii., p. I1. 4 Observatory, vol. vii., p. I75. ${ }^{5}$ Month. Not., vol. xlviii., p. 43. $\quad{ }^{6}$ Publ. Astr. Pac. Soc., vol. ii., p. 296. 
luminosity of the segments of the planetary surface they are projected upon; but fluctuations in their own brightness ${ }^{1}$ must be at least a concurrent cause; and these seem to depend, in some degree, upon their orbital positions. This amounts to saying that, as Herschel concluded in I797, they always, like our moon, turn the same face towards their primary, thus always presenting to us, when in the same relative obscure or brilliant sections of their globes. As regards the outer satellite, Engelmann's researches in I87 I, and the late C. E. Burton's in I873, make this almost certain; and there is a strong probability that it also applies to the other three. The phenomena, however, are quite too irregular to be completely rationalised on so simple and obvious a principle. We must also admit changes in the power of reflecting light of the satellites themselves, which Vogel's detection of lines in their spectra-or traces of such-indicative of gaseous envelopes similar to that of Jupiter, entitle us to regard as possibly of atmospheric production.

This is rendered almost certain, in the case of the third satellite, by a duplicate series of observations made upon it by Messrs. Schaerberle and Campbell at Lick, in the autumn of 1891. ${ }^{2}$ They perceived, with the great telescope, its small disc (less than $2^{\prime \prime}$ in diameter) to be usually crossed by three dusky and broken bands, fading off towards each limb, as if through atmospheric effacement, a constitution analogous to that of Jupiter himself being thus unexpectedly suggested. Rotation on an axis perpendicular to the shadings was evident, and is most likely performed in seven days four hours, the period of the satellite's revolution.

The rule of isochronous rotation and circulation is also undoubtedly obeyed by the first satellite. On September 8, I890, Professor Barnard saw it elongated, and as if double, during one of its dark transits; ${ }^{3}$ and his observation, repeated August 3,

1 There is a consensus among observers as to the variability of all Jupiter's satellites, though Pickering strangely finds no trace of it in his exact measures of their light. See Harvard Annals, vol. xi., pt. ii., p. $245 .{ }^{2}$ Publ. Astr. Pac. Soc., vol. iii., p. 359. $\quad 3$ Astr. Nach., No. 2995; Month. Not., vol. li., p. 556 . 
I89I, was completely verified by Messrs. Schaeberle and Campbell, who ascertained, moreover, that the longer axis of the eggshaped moon was directed towards Jupiter's centre. ${ }^{1}$ The elongation represents, in fact, a fixed tidal wave, by the arresting action of which the satellite's rotation relative to its primary was, long ages ago, brought to a standstill.

The system of Jupiter, as it was discovered by Galileo and investigated by Laplace, appeared in its outward aspect so symmetrical, and displayed in its inner mechanism such harmonious dynamical relations, that it might well have been deemed complete. Nevertheless, a new member has been added to it. Near midnight on September 9, 1892, Professor Barnard discerned with the Lick 36-inch, "a tiny speck of light" closely following the planet. ${ }^{2} \mathrm{He}$ instantly divined its nature, watched its hurried disappearance in the adjacent glare, and made sure of the reality of his discovery on the ensuing night. It was a delicate business throughout, the liliputian luminary subsiding into invisibility before the slightest glint of Jovian light, and tarrying, only for brief intervals, far enough from the disc to admit of its exclusion by means of an occulting plate. The new satellite is estimated to be of the thirteenth stellar magnitude, and, if equally reflective of light with its next neighbour, Io (satellite No. I), its diameter must be of about one hundred miles. It revolves at a distance of I I 2,000 miles from Jupiter's centre, and of 67,000 from his bulging equatorial surface. $^{3}$ Its period of $\mathrm{I} \mathrm{Ih} .57 \mathrm{~m}$. 23s. is just two hours longer than Jupiter's period of rotation, so that Phobos still remains a unique example of a secondary body revolving faster than its primary rotates. Jupiter's innermost moon conforms in its motions strictly, and indeed inevitably, to the plane of his equatorial protuberance, following, however, a sensibly elliptical path. Its very insignificance raises the suspicion that it may not prove solitary. Possibly it belongs to a zone peopled by asteroidal satellites. More than fifteen thousand such small bodies could be furnished out of the materials of a single full-sized satellite

1 Publ. Astr. Pec. Soc., vol. iii., p. 355. 2 Astr. Jour., No. 275 ; Observatory, vol. xv. p. 425. ${ }^{3}$ Astr. Jour., Nos. 285-6. 
spoiled in the making. But we must be content for the present to register the fact without seeking to penetrate the meaning of its existence. Very high and very fine telescopic power is needed for its perception. In America it has been observed by Professor Stone with the 26-inch of the University of Virginia; by Professor Young's assistant, Mr. Reed, with the Halstead 23-inch; and by Professor Hough with the 18 $\frac{1}{2}$-inch of the Dearborn Observatory, Chicago; all three refractors by Alvan Clark. Outside of the United States, it has been seen, so far, only with Dr. Common's five-foot reflector. But several of the great Continental refractors are doubtless fully capable of showing it.

In the course of his observations on Jupiter at Brussels in I878, M. Niesten was struck with a rosy cloud attached to a whitish zone beneath the dark southern equatorial band. ${ }^{1}$ Its size was enormous. At the distance of Jupiter, its measured dimensions of $13^{\prime \prime}$ by $3^{\prime \prime}$ implied a real extension in longitude of 30,000 , in latitude of something short of 7000 miles. The earliest record of its appearance seems to be by Professor Pritchett, director of the Morrison Observatory (U.S.), who figured and described it July 9, $1878 .^{2}$ It was again delineated August 9, by Tempel at Florence. ${ }^{3}$ In the following year it attracted the wonder and attention of almost every possessor of a telescope. Its colour had by that time deepened into a full brick-red, and was set off by contrast with a white equatorial spot of unusual brilliancy. During three ensuing years these remarkable objects continued to offer a visible and striking illustration of the compound nature of the planet's rotation. The red spot completed a circuit in nine hours fifty-five minutes thirty-six seconds; the white spot in about five and a half minutes less. Their relative motion was thus no less than 260 miles an hour, bringing them together in the same meridian at intervals of forty-four days ten hours forty-two minutes. Neither, however, preserved continuously the same uniform rate of travel. The period of each had lengthened by some seconds

1 Bull. Ac. R. Bruxelles, t. xlviii., p. 607. ${ }^{2}$ Astr. Nach., No. 2294. 
in I883, while sudden displacements, associated with the recovery of lustre after recurrent fadings, were observed in the position of the white spot, ${ }^{1}$ recalling the leap forward of a reviving sun-spot. Just the opposite effect attended the rekindling of the companion object. While semi-extinct in I882-4, it lost little motion; but a fresh access of retardation was observed by Professor Young ${ }^{2}$ in connection with its brightening in I 886 . This suggests very strongly that the red spot is fed from below. A shining aureola of "faculæ," described by Bredichin at Moscow, and by Lohse at Potsdam, as encircling it in September $1879,{ }^{3}$ was held to strengthen the solar analogy.

The conspicuous visibility of this astonishing object lasted three years. When the planet returned to opposition in I882-83, it had faded so considerably that Riccò's uncertain glimpse of it at Palermo, May 3 I, I883, was expected to be the last. It had, nevertheless, begun to recover in December, and in the beginning of I 886 presented to $\mathrm{Mr}$. Denning much the same aspect as in October 1882. ${ }^{4}$ Observed by him in an intermediate stage, February 25, I885, when "a mere skeleton of its former self," it bore a striking likeness to an "elliptical ring" observed in the same latitude by Mr. Gledhill at Halifax in 1869-70. This, indeed, might be called the preliminary sketch for the famous object brought to perfection ten years later, but which Mr. H. C. Russell of Sydney saw and drew in June $1876,{ }^{5}$ in what might be called an unfinished condition, before it had separated from its matrix, the dusky south tropical belt. In earlier times, too, a marking "at once fixed and transient" had been repeatedly perceived attached to the southernmost of the central belts. It gave Cassini in 1665 a rotation-period of nine hours fifty-six minutes, ${ }^{6}$ reappeared and vanished eight times during the next forty-three years, and was last seen by Maraldi in I713. It was, however, very

1 Denning, Month. Not., vol. xliv., pp. 64, 66; Nature, vol. xxv., p. 226. 2 Sidereal Mess., Dec. 1886, p. 289. ${ }^{3}$ Astr. Nach., Nos. 2280, 2282. 4 Month. Not., vol. xlvi., p. I17. ${ }^{5}$ Proc. Roy. Soc. N. S. Wales, vol. xiv., p. 68.

6 Phil. Trans., vol. i., p. I43. 
much smaller than the recent object, and showed no unusual colour. ${ }^{1}$

The assiduous observations made on the "Great Red Spot" by Mr. Denning at Bristol and by Professor Hough at Chicago afforded grounds only for negative conclusions as to its nature. It certainly did not represent the outpourings of a Jovian volcano; it was in no sense attached to the Jovian soil-if the phrase have any application to that planet; it was not a mere disclosure of a glowing mass elsewhere seethed over by rolling vapours. It was, indeed, almost certainly not self-luminons, a satellite projected npon it in transit having been seen to show as bright as upon the dusky equatorial bands. A fundamental objection to all three hypotheses is that the rotation of the spot was variable. It did not then ride at anchor, but floated free. Some held that its surface was depressed below the average cloud-level, and that the cavity was filled with vapours. Professor H. C. Wilson, on the other hand, observing with the sixteen-inch equatoreal of the Goodsell Observatory, in Minnesota, received the uniform impression of the object "being at a higher level than the other markings." 2 A crucial experiment on this point was proposed by Mr. Stanley Williams in I890. ${ }^{3}$ A dark spot moving faster along the same parallel was timed to overtake the red spot towards the end of July. A unique opportunity hence appeared to be at hand of determining the relative vertical depths of the two formations, one of which must inevitably, it was thonght, pass above the other. No forecast included a third alternative, which was nevertheless adopted by the dark spot. It evaded the obstacle in its path by skirting round its southern edge. ${ }^{4}$ Nothing, then, was gained by the conjunction, beyond an additional proof of the singular repellent influence exerted by the red spot over the markings in its vicinity. It has, for example, gradually carved out a deep bay for its accom-

1 For indications relative to the early history of the red spot, see Holden, Publ. Astr. Pac. Soc., vol. ii., p. 77 ; Noble, Month. Not., vol. xlvii., p. 515 ; A. S. Williams, Observatory, vol. xiii., p. 338 . March 1892, p. 192. $\quad 3$ Month. Not., vol. 1., p. 520.

2 Astr. and Astro-Physics, pp. $297,326$.

4 Observatory, vol. xiii., 
modation in the grey belt just north of it. The effect was not at first steadily present. Trouvelot, Barnard, and Elvins of Toronto, delineated the excavation in I879; yet there was no sign of it in the following year. Its development can be traced in Dr. Boeddicker's beautiful drawings of Jupiter, made with the Parsonstown three-foot reflector from I88I to I886. ${ }^{1}$ They record the belt as straight in I88I, but as strongly indented from January 1883 ; and the cavity now promises to outlast the spot. So long as it survives, however, the forces at work in the spot can have lost little of their activity. For it must be remembered that the belt has a rotation-period five and a half minutes shorter than the red spot, which, accordingly (as Mr. Elvins has remarked), breasts and diverts, by its interior energy, a current of flowing matter, ever ready to fill up its natural bed, and override the barrier of obstruction.

The famous spot was described by Keeler in I889 as " of a pale pink colour, slightly lighter in the middle. Its outline was a fairly true ellipse, framed in by bright white clouds." 2 The fading continuously in progress from 1887 was temporarily interrupted in I891. The revival, however, was brief. Professor Barnard wrote in August 1892: "The great red spot is still visible, but it has just passed through a crisis that seemingly threatened its very existence. For the past month it has been all but impossible to catch the feeblest trace of the spot, though the ever-persistent bay in the equatorial belt close north of it, and which has been so intimately connected with the history of the red spot, has been as conspicuous as ever. For a while there was only the feeblest glow of warmth where the spot ought to be. This has been the case under the very best seeing. It is now, however, possible to detect a feeble outline of the following end, and the feeblest traces of the entire spot. An obscuring medium seems to have been passing over it, and has now drifted somewhat preceding the spot." 3

Jupiter was systematically photographed with the Lick thirty-six inch telescope during the oppositions of I890, I89I,

1 Trans. R. Dublin Soc., vol. iv., p. 271, 1889. 2 Publ. Astr. Pac. Sóoc., vol. ii., p. 289. $\quad{ }^{3}$ Astr. and Astro-Physics, Oct. I892, p. 686. 
and I892, the image thrown on the plates (after eightfold direct enlargement) being one inch in diameter. Mr. Stanley Williams's measurements and discussion of the set for I89I showed the high value of the materials thus collected, although much more minute details can be seen than can at present be photographed. The red spot shows as "very distinctly annular" in several of these pictures. ${ }^{1}$

In I870, Mr. Ranyard, ${ }^{2}$ acting upon an earlier suggestion of Dr. Huggins, collected records of unusual appearances on the disc of Jupiter, with a view to investigate the question of their recurrence at regular intervals. He concluded that the development of the deeper tinges of colour, and of the equatorial " porthole" markings girdling the globe in regular alternations of bright and dusky, agreed, so far as could be ascertained, with epochs of sun-spot maximum. The further inquiries of Dr. Lohse at Bothkamp in $1873^{3}$ went to strengthen the coincidence, which had been anticipated $\grave{a}$ priori by Zöllner in $1871 .^{4}$ Yet subsequent experience has rather added to than removed doubts as to the validity of that first conclusion. It may, indeed, be taken for granted that what Hahn terms the universal pulse of the solar system ${ }^{5}$ affects the vicissitudes of Jupiter; but the law of those vicissitudes is far from being so obviously subordinate to the rhythmical flow of central disturbance as are certain terrestrial phenomena. The great planet being in fact himself a "semi-sun," may be regarded as an originator, no less than a recipient of agitating influences, the combined effects of which may well appear insubordinate to any obvious law.

It is likely that Saturn is in a still earlier stage of planetary development than Jupiter. He is the lightest for his size of all the planets. In fact, he would float in water. And since his density is shown, by the amount of his equatorial bulging to increase centrally, ${ }^{6}$ it follows that his superficial materials must be

1 Publ. Astr. Pac. Soc., vol. iv., p. 176.

2 Month. Not., vol. xxxi., p. 34. 3 Beobachtungen, Heft ii., p. 99. ${ }^{4}$ Ber. Säch*. Ges. der. Wiss., I871, p. 553. $\quad{ }_{5}$ Beziehungen der Sonnenflecken periode, p. $175 .{ }^{6}$ A. Hall, Astr. Nach., No. 2269. 
of a specific gravity so low as to be inconsistent, on any probable supposition, with the solid or liquid states. Moreover, the chief arguments in favour of the high temperature of Jupiter apply, with increased force, to Saturn; so that it may be concluded, without much risk of error, that a large proportion of his bulky globe, 7 I,000 miles in diameter, is composed of heated vapours, kept in active and agitated circulation by the process of cooling.

His unique set of appendages has, since the middle of the century, formed the subject of searching and fruitful inquiries, both theoretical and telescopic. The mechanical problem of the stability of Saturn's rings was left by Laplace in a very unsatisfactory condition. Considering them as rotating solid bodies, he pointed out that they could not maintain their position unless their weight were in some way unsymmetrically distributed; but made no attempt to determine the kind or amount of irregularity needed to secure this end. Some observations by Herschel gave astronomers an excuse for taking for granted the fulfilment of the condition thus vaguely postulated; and the question remained in abeyance until once more brought prominently forward by the discovery of the dusky ring in I 850 .

The younger Bond led the way, among modern observers, in denying the solidity of the structure. The fluctuations in its aspect were, he asserted in $185 \mathrm{I}^{1}$ inconsistent with such an hypothesis. The fine dark lines of division, frequently detected in both bright rings, and as frequently relapsing into imperceptibility, were due, in his opinion, to the real mobility of their particles, and indicated a fluid formation. Professor Benjamin Peirce of Harvard University immediately followed with a demonstration, on abstract grounds, of their non-solidity. ${ }^{2}$ Streams of some fluid denser than water were, he maintained, the physical reality giving rise to the anomalous appearance first disclosed by Galileo's telescope.

The mechanism of Saturn's rings, proposed as the subject of the Adams Prize, was dealt with by the late James Clerk ${ }^{1}$ Astr. Jour. (Gould's), vol. ii., p. 17. $\quad 2$ 1bid., p. 5. 
Maxwell in I857. His investigation forms the groundwork of all that is at present known in the matter. Its upshot was to show that neither solid nor fluid rings could continue to exist, and that the only possible composition of the system was by an aggregated multitude of unconnected particles, each revolving independently in a period corresponding to its distance from the planet. ${ }^{1}$ This idea of a satellite-formation had been, remarkably enough, several times entertained and lost sight of. It was first put forward by Roberval in the seventeenth century, again by Jaques Cassini in 17 15, and with perfect definiteness by Wright of Durham in $1750 .^{2}$ Little heed, however, was taken of these casual anticipations of a truth which reappeared, a virtual novelty, as the legitimate outcome of the most refined modern methods.

The details of telescopic observation accord, on the whole, admirably with this hypothesis. The displacements or disappearance of secondary dividing-lines-the singular striated appearance, first remarked by Short in the eighteenth century, last by Perrotin and Lockyer at Nice, March 18, I884 ${ }^{3}$-show the effects of waves of disturbance traversing a moving mass of gravitating particles $;{ }^{4}$ the broken and changing line of the planet's shadow on the ring gives evidence of variety in the planes of the orbits described by those particles. The whole ring-system, too, appears to be somewhat elliptical. ${ }^{5}$

The satellite-theory has derived unlooked-for support from photometric inquiries. Professor Seeliger pointed out in $1888^{6}$ that the unvarying brilliancy of the outer rings under all angles of illumination, from $0^{\circ}$ to $30^{\circ}$, can be explained from no other point of view. Nor does the constitution of the obscure inner ring offer any difficulty. For it is doubtless formed of similar small bodies to those aggregated in the lucid members of the system, only much more thinly strewn, and reflecting,

1 On the Stability of the Motion of Saturn's Rings, p. 67.

2 Mém. de l'Ac., I 7 I 5, p. 47 ; Montucla, Hist. des. Math., t. iv., p. I9; An Original Theory of the Universe, p. II5. 3 Comptes Rendus, t. xcviii., p. 718. 4 Proctor, Saturn and its System (1865), p. 125. $\quad{ }_{5}^{5}$ Perrotin, Comptes Rendus, t. cvi., p. I7 16. ${ }^{6}$ Abhandl. Akad. der Wiss., Munich Bd. xvi., p. 407. 
consequently, much less light. It is not, indeed, at first easy to see why these sparser flights should show as a dense dark shading on the body of Saturn. Yet this is invariably the case. The objection has been urged by Professor Hastings of Baltimore. The brightest parts of these appendages, he remarks, ${ }^{1}$ are more lustrous than the globe they encircle; but if the inner ring consists of identical materials, possessing presumably an equal reflective capacity, the mere fact of their scanty distribution would not cause them to show as dark against the same globe. Professor Seeliger, however, replies ${ }^{2}$ that the darkening is due to the never-ending swarms of their separate shadows transiting the planet's disc. Sunlight is not, indeed, wholly excluded. Many rays come and go between the open ranks of the meteorites. For the dusky ring is transparent. The planet it encloses shows through it, as if veiled with a strip of crape. A beautiful illustration of its quality in this respect was derived by Professor Barnard from an eclipse of Japetus, November I, I889. ${ }^{3}$ The eighth moon remained steadily visible during its passage through the shadow of the inner ring, but with a progressive loss of lustre in approaching its bright neighbour. There was no breach of continuity. The satellite met no gap, corresponding to that between the dusky ring and the body of Saturn, through which it could shine with undiminished light, but was slowly lost sight of as it plunged into deeper and deeper gloom. The important facts were thus established, that the brilliant and obscure rings merge into each other, and that the latter thins out towards the Saturnian globe.

A question of singular interest, and one which we cannot refrain from putting to ourselves, is-whether we see in the rings of Saturn a finished structure, destined to play a permanent part in the economy of the system; or whether they represent merely a stage in the process of development out of the chaotic state in which it is impossible to doubt that the materials of all planets were originally merged. M. Otto Struve

1 Smiths. Report, 1880 (Holden). $\quad{ }^{2}$ Quoted by Dr. E. Anding, Astr. Nach., No. 2881. ${ }^{3}$ Astr. and Astro-Physics, Feb. 1892, p. 119; Month. Not., vul. l., p. 108. 
has attempted to give a definite answer to this important query.

A study of early and later records of observations disclosed to him, in $185 \mathrm{I}$, an apparent progressive approach of the inner edge of the bright ring to the planet. The rate of approach he estimated at about sixty English miles a year, or I I,000 miles during the 194 years elapsed since the time of Huygens. ${ }^{1}$ Were it to continue, a collapse of the system must be far advanced within three centuries. But was the change real or illusory - a plausible, but deceptive inference from insecure data? M. Struve resolved to put it to the test. A set of elaborately careful micrometrical measures of the dimensions of Saturn's rings, executed by himself at Pulkowa in the autumn of 1851 , was provided as a standard of future comparison; and he was enabled to renew them, under closely similar circumstances, in $1882 .^{2}$ But the expected diminution of the space between Saturn's globe and his rings had not taken place. There was, indeed, a slight extension in the width of the system, both outward and inward; but so slight that it could hardly be considered to lie outside the limits of probable error. Still it is worth notice that just such a separation of the rings was indicated by Clerk Maxwell's theory, so that there is an $\dot{a}$ priori likelihood of its being in progress. Moreover, since 1657, when Huygens described the interval between the ring and the planet as rather exceeding the width of the ring, it is all but certain that a growth inward has actually occurred. For the two bright rings together, instead of being narrower than the interval, are now more than once and a half times as broad. Hence the expressions used by Huygens, no less than most of the old drawings, are glaringly inconsistent with the planet's present appearance.

The rings of Saturn replace, in Professor G. H. Darwin's view, ${ }^{3}$ an abortive satellite, scattered by tidal action into annular form. For they lie closer to the planet than is consistent with

1 Mém. de l'Ac. Imp. (St. Petersb.), t. vii., 1853, p. $464 . \quad 2$ Astr. Nach., No. 2498. Professor A. Hall's measures in 1886 , with the great Washington refractor, were absolutely negative as regards evidence of change : Washingtrn Observations, App. ii., p. 22.

3 Harper's Magazine, June I889. 
the integrity of a revolving body of reasonable bulk. The limit of possible existence for such a mass was fixed by Roche of Montpellier, in $1848,{ }^{1}$ at 2.44 mean radii of its primary; while the outer edge of the ring-system is distant 2.38 radii of Saturn from his centre. The virtual discovery of its pulverulent condition dates, then, according to Professor Darwin, from 1848. $\mathrm{He}$ conjectures that the appendage will eventually disappear, partly through the dispersal of its constituent particles inwards, and their gradual collapse upon the planet's surface, partly by their dispersal outwards, to a region beyond "Roche's limit," where coalescence might proceed unhindered by the strain of unequal attractions. One modest satellite, revolving inside Mimas, would then be all that was left of the singular appurtenances we now contemplate with admiration.

There seems reason to admit that Kirkwood's law of commensurability has had some effect in bringing about the present distribution of the matter composing these appendages. Here the disturbing bodies are Saturn's moons, while the divisions and boundaries of the rings represent the spaces where their disturbing action conspires to eliminate revolving particles. Kirkwood, in fact, showed, in $1867,{ }^{2}$ that a body circulating in the chasm between the bright rings known as "Cassini's division," would have a period nearly commensurable with those of four out of the eight moons; and Dr. Meyer of Geneva has since calculated all such combinations with the result of bringing out coincidences between regions of maximum perturbation and the limiting and dividing lines of the system. ${ }^{3}$ This is in itself a strong confirmation of the view that the rings are made up of independently revolving small bodies.

On December 7, 1876, Professor Asaph Hall discovered at Washington a bright equatorial spot on Saturn, which he followed and measured through above sixty rotations, each performed in ten hours fourteen minutes twenty-four seconds. ${ }^{4}$

1 See also, Méms. de l'Acad. de Montpellier, t. viii., p. 296, 1873. 2 Meteuric Astrunomy, chap. xii. He carried the subject somewhat farther in 1871. See Observatory, vol. vi., p. 335. " Astr. Nach., No. 2527. $\quad{ }^{4}$ Am. Jour. of Sc., vol. xiv., p. 325 . 
He was careful to add that this represents the period, not necessarily of the planet, but only of the individual spot. The only previous determination of Saturn's axial movement (setting aside some insecure estimates by Schröter) was Herschel's in I794, giving a period of ten hours sixteen minutes. The substantial accuracy of Hall's result was verified by Mr. Denning in I891. ${ }^{1}$ From ten white equatorial spots observed in May and June of that year by Mr. Stanley Williams, he derived a rotation-period only two seconds longer than that determined at Washington, to which a dark spot conformed exactly. Individual discrepancies, however, to the extent of twenty seconds, showed that the spots were not devoid of motions of their own.

Saturn's outermost satellite, Japetus, is markedly variableso variable that it sends us, when brightest, just $4 \frac{1}{2}$ times as much light as when faintest. Moreover, its fluctuations depend upon its orbital position in such a way as to make it a conspicuous telescopic object when west, a scarcely discernible one when east of the planet. Herschel's inference ${ }^{2}$ of a partially obscured globe turning always the same face towards its primary, seems the only admissible one, and is confirmed by Pickering's measurements of the varying intensity of its light. He remarks further that the dusky and brilliant hemispheres must be so disposed as to divide the disc, viewed from Saturn, into nearly equal parts; so that this Saturnian moon, even when " full," appears very imperfectly illuminated over one-half of its surface. ${ }^{3}$

The spectrum of Saturn is closely similar to that of Jupiter. It shows the distinctive dark line in the red (wave-length 6I8), which we may call the "red-star line"; and Janssen, examining it from the summit of Etna in 1867,4 found unmistakable traces of aqueous absorption. The light from the ring appears to be entirely unmodified by original atmospheric action. ${ }^{5}$

1 Observatory, vol. xiv., p. 369. 2 Phil. Trans., vol. lxxxii., p. 14. 3 Smiths. Report, 1880. ${ }^{4}$ Comptes Rendus, t. lxiv. p. 1304. ${ }^{5}$ Huggins, Proc. R. Soc., vol. xlvi., p. 23 r ; Keeler, Astr. Nach., No. 2927. 
Uranus, when favourably situated, can easily be seen with the naked eye as a star between the fifth and sixth magnitudes. There is, indeed, some reason to suppose that he had been detected as a wandering orb by savage "watchers of the skies" in the Pacific long before he swam into Herschel's ken. Nevertheless, inquiries into his physical habitudes are still in an early stage. They are exceedingly difficult of execution, even with the best and largest modern telescopes; and their results remain so far more or less clouded with uncertainty.

It will be remembered that Uranus presents the unusual spectacle of a system of satellites travelling nearly at right angles to the plane of the ecliptic. The existence of this anomaly gives a special interest to investigations of his axial movement, which might be presumed, from the analogy of the other planets, to be executed in the same tilted plane. Yet this is far from being certainly the case.

Mr. Buffham in 1870-72 caught traces of bright markings on the Uranian disc, doubtfully suggesting a rotation in about twelve hours in a plane not coincident with that in which his satellites circulate. ${ }^{1}$ Dusky bands resembling those of Jupiter, but very faint, were barely perceptible to Professor Young at Princeton in 1883. Yet, though almost necessarily inferred to be equatorial, they made a considerable angle with the trend of the satellites' orbits. ${ }^{2}$ More distinctly by the brothers Henry, with the aid of their fine refractor, two grey parallel rulings, separated by a brilliant zone, were discerned every clear night at Paris from January to June $1884 .^{3}$ What were taken to be the polar regions appeared comparatively dusky. The direction of the equatorial rulings (for so we may safely call them) made an angle of $40^{\circ}$ with he satellites' line of travel. Similar observations were made at Nice by MM. Perrotin and Thollon, March to June I884, a lucid spot near the equator, in addition, indicating rotation in a period of about ten hours. ${ }^{4}$ The discrepancy was, however, considerably reduced by Perrotin's study of the planet in I889 with the new thirty-inch

1 Month. Not., vol. xxxiii., p. 164.

2 Astr. Nach., No. 2545.

3 Comptes Rendus, t. xcviii., p. I4I9.

4 1bid., pp. 718, 967. 
equatoreal. ${ }^{1}$ The dark bands, thus viewed to better advantage than in 1884 , appeared to deviate no more than $10^{\circ}$ from the satellites' orbit-plane. No definitive results, on the other hand, were derived by Professors Holden, Schaeberle, and Keeler, from their observations of Uranus in 1889-90 with the potent instrument on Mount Hamilton. Shadings, it is true, were almost always, though faintly, seen; but. they showed an anomalous character. They consisted, not of parallel, but of forked bands. ${ }^{2}$ The possibility thus suggests itself that Uranus may display two systems of markings, one indicating a vertical circulation on the model of that of Jupiter, the other resulting from horizontal convection-currents, such as prevail in the terrestrial atmosphere, necessarily rendered oblique by the effects of rotation. Inconsistent observations could, if this were the case, be explained by differences in the relative conspicuousness of the straight or oblique shadings.

Measurements of the little sea-green disc which represents to us the massive bulk of Uranus, by Young, Schiaparelli, ${ }^{3}$ Safarik, H. C. Wilson of Cincinnati, ${ }^{4}$ and Perrotin, prove it to be quite distinctly bulged; and all agree that the bulging lies just in the plane of the satellites' orbits. If this be so, there can be no question but that the same plane is that of the planet's rotation, the spheroidal shape of a rotating globe being the necessary consequence of the greater equatorial velocity of its particles. The tendency to conformity, too, of late visible in the dusky streaks, renders the peculiarities of the Uranian aspect less puzzling.

The spectrum of this planet was first examined by Father Secchi in 1869, and later, though with more advantages for accuracy, by Huggins and Vogel. It is a very remarkable one. In lieu of the reflected Fraunhofer lines, imperceptible perhaps through feebleness of light, six broad bands of original absorption appear, ${ }^{5}$ one corresponding to the blue-green ray

1 V. J. S. Astr. Ges., Jahrg. xxiv., p. 267.

2 Publ. Astr. Pac. Soc, vol. iii., p. 287. ${ }^{3}$ Astr. Nach., No. 2526. + Ibrd., No. 2730. Seeliger found no perceptible compression in I884; Sitzungsb., Munich, p. 278.55 Vogel, Annalen der Phys., vol. clriii., p. 470. 
of hydrogen (F), another to the "red-star line" of Jupiter and Saturn, the rest as yet unidentified. The hydrogen band seems much too strong and diffuse to be the mere echo of a solar line, and implies accordingly the presence of free hydrogen in the Uranian atmosphere, where a temperature must thus prevail sufficiently high to reduce water to its constituent elements. Notwithstanding its high albedo-0.62, according to Zöllnerthere is at present no evidence that any of the light of Uranus is inherent. Mr. Albert Taylor announced indeed, in I889, his detection, with Dr. Common's giant reflector, of bright flutings in its spectrum $;^{1}$ but Professor Keeler's examination proved them to be merely contrast effects. ${ }^{2}$ Dr. and Mrs. Huggins, moreover, obtained about the same time a photograph purely solar in character. The spectrum it represented was crossed by numerous Fraunhofer lines, and by no others. It was then composed, presumably, entirely of reflected light.

Judging from the indications of an almost evanescent spectrum, Neptune, as regards physical condition, is the twin of Uranus, as Saturn of Jupiter. Of the circumstances of his rotation we are as good as completely ignorant. Mr. Maxwell Hall, indeed, noticed at Jamaica, in November and December I883, certain rhythmical fluctuations of brightness, suggesting revolution on an axis in slightly less than eight hours; ${ }^{3}$ but Professor Pickering reduces the supposed variability to an amount altogether too small for certain perception, and Dr. G. Müller denies its existence in toto. It is true their observations were not precisely contemporaneous with those of $\mathrm{Mr}$. Hall, ${ }^{4}$ who believes the partial obscurations recorded by himself to have been of a passing kind, and to have suddenly ceased after a fortnight of prevalence. Their less conspicuous renewal was visible to him in November I884, confirming a rotation-period of 7.92 hours.

It has been ascertained by indirect means that the orbit of Neptune's satellite is inclined at least $20^{\circ}$ to his equator. $\mathrm{Mr}$.

1 Month. Not., vol. xlix., p. 405. 2 Astr. Nach., No. 2927; Scheiner's Spectralanalyse, p. 221. ${ }^{3}$ Month. Not., vol. xliv., p. 257. ${ }^{4}$ Observatory, vol. vii., pp. 134, 221, 264. 
Marth ${ }^{1}$ having drawn attention to the rapid shifting of its plane of motion, M. Tisserand and Professor Newcomb ${ }^{2}$ independently published the conclusion that such shifting is a necessary result of Neptune's ellipsoidal shape. The movement is of the kind exemplified-although with inverted relations-in the precession of the equinoxes. The pole of the satellite's orbit, owing to the pull of Neptune's equatorial protuberance, describes a circle round the pole of his equator, in a retrograde direction, and in a period of over five hundred years. The amount of compression indicated for the primary body is, at the outside, $\frac{1}{85}$; whence it can be inferred that Neptune possesses a lower rotatory velocity than the other giant planets.

The possibility that Neptune may not be the most remote body circling round the sun has been contemplated ever since he has been known to exist. Within the last few years the position at a given epoch of a planet far beyond him has been approximately fixed by two separate investigators.

Professor George Forbes of Edinburgh adopted in 1880 a novel plan of search for unknown members of the solar system, the first idea of which was thrown out by M. Flammarion in November I 879. ${ }^{3}$ It depends upon the movements of comets. It is well known that those of moderately short periods are, for a reason already explained, connected with the larger planets in such a way that the cometary aphelia fall near some planetary orbit. Jupiter claims above a score of such partial dependants, Neptune owns five, and there are two considerable groups, the farthest distances of which from the sun lie respectively near 100 and 300 times that of the earth. At each of these vast intervals, one involving a period of 1000 , the other of .5000 years, Professor Forbes maintains that an unseen planet circulates. He has even computed elements for the nearer of the two, and fixed its place on the celestial sphere. ${ }^{4}$

1 Month. Not., vol. xlvi., p. 507. 2 Comptes Rendus, t. cvii., p. 804; Astr. Jour., No. I86. ${ }^{3}$ Astr. Pop., p. 66I ; La Nature, Jan. 3, I880. 4 Pror. Roy. Soc. Edinb., vols. x., p. 429; xi., p. 89. M. Deichmüller (Vierteljahırsschrift Astr. Ges., Jahrg. xxi., p. 206) pointed out in 1886 that cometary orbits extending beyond the distance of Neptune are too imperfectly known to serve as the basis of any trustworthy conclusion. 
In the meantime, Professor Todd had been groping for the same object by the help of a totally different set of indications. The old approved method of perturbations was that adopted by him; but those of Neptune have scarcely yet had time to develop, so that he was thrown back upon the "residual errors" of Uranus. They gave him a virtually identical situation for the new planet with that arrived at by Professsor Forbes. ${ }^{1}$ Yet its assigned distance was little more than half that of the nearer of Professor Forbes's remote pair, and it completed a revolution in 375, instead of 1000 years. The agreement in position, then, of the two hypothetical bodies was merely an odd coincidence; and the telescopic search for the one has proved as fruitless as the photographic search for the other. ${ }^{2}$

1 Amer. Jour. of Science, vol. xx., p. 225. 2 Roberts, Month. Not., vol. lii., p. 501 . 


\section{CHAPTER IX.}

\section{THEORIES OF PLANETARY EVOLUTION.}

WE cannot doubt that the solar system, as we see it, is the result of some process of growth-that, during innumerable ages, the forces of Nature were at work upon its materials, blindly modelling them into the shape appointed for them from the beginning by Omnipotent Wisdom. To set ourselves to inquire what that process was, may be an audacity, but it is a legitimate, nay, an inevitable one. For man's implanted instinct to "look before and after" does not apply to his own little life alone, but regards the whole history of creation, from the highest to the lowest-from the microscopic germ of an alga or a fungus to the visible frame and furniture of the heavens.

Kant considered that the inquiry into the mode of origin of the world was one of the easiest problems set by Nature; but it cannot be said that his own solution of it was a satisfactory one. $\mathrm{He}$, however, struck out in I755 a track which thought still pursues. In his Allgemeine Naturgeschichte the growth of sun and planets was traced from the cradle of a vast and formless mass of evenly diffused particles, and the uniformity of their movements was sought to be accounted for by the uniform action of attractive and repulsive forces, under the dominion of which their development was carried forward.

In its modern form, the "Nebular Hypothesis" made its appearance in I796. $^{1}$ It was presented by Laplace with diffidence, as a speculation unfortified by numerical buttresses

1 Exposition du Système du Monde, t. ii., p. 295. 
of any kind, yet with visible exultation in having, as he thought, penetrated the birth-secret of our system. He demanded, indeed, more in the way of postulates than Kant had done. $\mathrm{He}$ started with a sun ready made, ${ }^{1}$ and surrounded with a vast glowing atmosphere, extending into space out beyond the orbit of the farthest planet, and endowed with a slow rotatory motion. As this atmosphere or nebula cooled, it contracted; and as it contracted, its rotation, by a well-known mechanical law, became accelerated. At last, a point arrived when tangential velocity at the equator increased beyond the power of gravity to control, and equilibrium was restored by the separation of a nebulous ring revolving in the same period as the generating mass. After a time, the ring broke up into fragments, all eventually reunited in a single revolving and rotating body. This was the first and farthest planet.

Meanwhile the parent nebula continued to shrink and whirl quicker and quicker, passing, as it did so, through successive crises of instability, each resulting in, and terminated by, the formation of a planet, at a smaller distance from the centre, and with a shorter period of revolution than its predecessor. In these secondary bodies the same process was repeated on a reduced scale, the birth of satellites ensuing upon their contraction, or not, according to circumstances. Saturn's ring, it was added, afforded a striking confirmation of the theory of annular separation, ${ }^{2}$ and appeared to have survived in its original form in order to throw light on the genesis of the whole solar system; while the four first discovered asteroids offered an example in which the débris of a shattered ring had failed to coalesce into a single globe.

This scheme of cosmical evolution was a characteristic bequest from the eighteenth century to the nineteenth. It possessed the self-sufficing symmetry and entireness appropriate to the ideas of a time of renovation, when the complexity of .nature was little accounted of in comparison with the imperious orderliness of the thoughts of man. Since it was propounded,

1 In later editions a retrospective clause was added admitting a prior condition of all but evanescent nebulosity. $\quad 2$ Méc. Cél., lib. xiv., ch. iii. 
however, knowledge has transgressed many boundaries, and set at naught much ingenious theorising. How has it fared with Laplace's sketch of the origin of the world? It has at least not been discarded as efféte. The groundwork of speculation on the subject is still furnished by it. It is, nevertheless, admittedly inadequate. Of much that exists it gives no account, or an erroneous one. The march of events certainly did not everywhere-even if it did anywhere-follow the exact path prescribed for it. Yet modern science attempts to supplement, but scarcely ventures to supersede it.

Thought has, in many directions, been profoundly modified by Mayer's and Joule's discovery, in 1842, of the equivalence between heat and motion. Its corollary was the grand idea of the "conservation of energy," now one of the cardinal principles of science. This means that, under the ordinary circumstances of observation, the old maxim ex nihilo nihil fit applies to force as well as to matter. The supplies of heat, light, electricity, must be kept up, or the stream will cease to flow. The question of the maintenance of the sun's heat was thus inevitably raised; and with the question of maintenance that of origin is indissolubly connected.

Dr. Julius Robert Mayer, a physician residing at Heilbronn, was the first to apply the new light to the investigation of what Sir John Herschel had termed the "great secret." He showed that if the sun were a body either simply cooling or in a state of combustion, it must long since have "gone out." Had an equal mass of coal been set alight, four or five centuries after the building of the Pyramid of Cheops, and kept burning at such a rate as to supply solar light and heat during the interim, only a few cinders would now remain in lieu of our undiminished glorious orb. Mayer looked round for an alternative. He found it in the "meteoric hypothesis" of solar conservation." The importance in the economy of our system of the bodies known as falling stars was then (in I848) beginning to be recognised. It was known that they revolved in countless swarms round the sun; that the earth daily encountered millions of them; and it

1 Beiträge zur Dynamik des Himmels, p. I2. 
was surmised that the cone of the zodiacal light represented their visible condensation towards the attractive centre. From the zodiacal light, then, Mayer derived the store needed for maintaining the sun's radiations. He proved that, by the stoppage of their motion through falling into the sun, bodies would evolve from 4600 to 9200 times as much heat (according to their ultimate velocity) as would result from the burning of equal masses of coal, their precipitation upon the sun's surface being brought about by the resisting medium observed to affect the revolutions of Encke's comet. . There was, however, a difficulty. The quantity of matter needed to keep, by the sacrifice of its movement, the hearth of our system warm and bright, would be very considerable. Mayer's lowest estimate put it at 94,000 billion kilogrammes per second, or a mass equal to that of our moon bi-annually. But so large an addition to the gravitating power of the sun would quickly become sensible in the movements of the bodies dependent upon him. Their revolutions would be notably accelerated. Mayer admitted that each year would be shorter than the previous one by a not insignificant fraction of a second, and postulated an unceasing waste of substance, such as Newton had supposed must accompany emission of the material corpuscles of light, to neutralise continual reinforcement.

Mayer's views obtained a very small share of publicity, and owned Mr. Waterston as their independent author in this country. The meteoric, or "dynamical" theory of solar sustentation was expounded by him before the British Association in I853. It was developed with his usual ability by Sir William Thomson in the following year. The inflow of meteorites, he remarked, "is the only one of all conceivable causes of solar heat which we know to exist from independent evidence." 1 We know it to exist, but we now also know it to be entirely insufficient. The supplies presumed to be contained in the zodiacal light would be quickly exhausted; a constant inflow from space would be needed to meet the demand. But if moving bodies were drawn into the sun at anything like the required

1 Trans. Roy. Soc. of Edinburgh, vol. xxi., p. 66. 
rate, the air, even out here at ninety-three millions of miles distance, would be thick with them; the earth would be red-hot from their impacts; ${ }^{1}$ geological deposits would be largely meteoric $;^{2}$ to say nothing of the effects on the mechanism of the heavens. Sir William Thomson himself urged the inadmissibility of the "extra-planetary" theory of meteoric supply on the very tangible ground that, if it were true, the year would be shorter now, actually by six weeks, than at the opening of the Christian era. The "intra-planetary" supply, however, is too scanty to be anything more than a temporary makeshift.

The meteoric hypothesis was naturally extended from the maintenance of the sun's heat to the formation of the bodies circling round him. The earth-no less doubtless than the other planets-is still growing. Cosmical matter in the shape of falling stars and aërolites, to the amount, adopting Professor Newton's estimate, of IoO tons daily, is swept up by it as it pursues its orbital round. Inevitably the idea suggested itself that this process of appropriation gives the key to the life-history of our globe, and that the momentary streak of fire in the summer sky represents a feeble survival of the glowing hailstorm by which, in old times, it was fashioned and warmed. Mr. E. W. Brayley supported this view of planetary production in $\mathrm{I} 864,{ }^{3}$ and it has recommended itself to Haidinger, Helmholtz, Proctor, and Faye. But the negative evidence of geological deposits appears fatal to it.

The theory of solar energy now generally regarded as the true one, was enounced by Helmholtz in a popular lecture in 1854 . It depends upon the same principle of the equivalence of heat and motion which had suggested the meteoric hypothesis. But here the movement surrendered and transformed belongs to the particles, not of any foreign bodies, but of the sun itself. Drawn together from a wide ambit by the force of their own gravity, their fall towards the sun's centre must have engendered a vast thermal store, of which $\frac{453}{45} \frac{3}{4}$ are computed to be already spent.

${ }^{1}$ Newcomb, Pop. Astr., p. 52 I (2nd ed.). $\quad 2$ M. Williams, Nature, vol. iii., p. 26. ${ }^{3}$ Comp. Brit. Almanac, p. 94. 
Presumably, however, this stream of reinforcement is still flowing. In the very act of parting with heat, the sun develops a fresh stock. His radiations, in short, are the direct result of shrinkage through cooling. A diminution of the solar diameter by 380 feet yearly would just suffice to cover the present rate of emission, and would for ages remain imperceptible with our means of observation, since, after the lapse of 6000 years, the lessening of angular size would scarcely amount to one second. ${ }^{1}$ But the process, though not terminated, is strictly a terminable one. In less than five million years the sun will have contracted to half its present bulk. In seven million more, it will be as dense as the earth. It is difficult to believe that it will then be a luminous body. ${ }^{2}$ Nor can an unlimited past duration be admitted. Helmholtz considered that radiation might have gone on with its actual intensity for twenty-two, Langley allows only eighteen million years. The period can scarcely be stretched, by the most generous allowances, to double the latter figure. But this is far from meeting the demands of geologists and biologists.

An attempt was made in $\mathrm{I} 88 \mathrm{I}$ to supply the sun with machinery analogous to that of a regenerative furnace, enabling it to consume the same fuel over and over again, and so to prolong indefinitely its beneficent existence. The inordinate "waste" of energy, which shocks our thrifty ideas, was simultaneously abolished. The earth stops and turns variously to account one 2250-millionth part of the solar radiations; each of the other planets and satellites takes a proportionate share; the rest, being all but an infinitesimal fraction of the whole, is dissipated through endless space, to serve what purpose we know not. Now, on the late Sir William Siemens's plan, this reckless expenditure would cease; the solar incomings and outgoings would be regulated on approved economic principles, and the inevitable final bankruptcy would be staved off to remote ages. Let us see how it is to be done.

We must first imagine space to be filled with combustible substances-hydrogen, hydro-carbons, and oxygen-in an ex-

${ }^{1}$ Radau, Bull. Astr., t. ii., p. $316 . \quad{ }^{2}$ Newcomb, Pop. Astr., pp. 521-525. 
cessively rarefied state. Next, that the sun keeps up, by its rotation, a fan-like action on this floating matter, drawing it inward at the polar surfaces, and projecting it outward at the equator "in a continuous disc-like stream." 1 But it will not travel from the sun unchanged. Combustion will have intervened. In other words, the particles sucked in will have surrendered their stored up energy in the shape of heat and light, and they will depart, no longer combustible, but the mere inert products of combustion. By the very power of the radiations they had contributed to supply, however, they may be restored to activity. Sir W. Siemens obtained, as he thought, some experimental evidence that carbonic acid and water may possibly be dissociated in space, as they undoubtedly are in the leaves of plants by the power of direct sunshine. Their particles, thus compulsorily separated, and by the act restocked with energy, are ready to rush together again with fresh evolution of heat and light. A mechanical circulation is, in this way, combined with a pendulum-swing of chemical change, and the round might go on for ever, if only one condition were granted. That one condition is an unlimited supply of motive power. It is, however, an inexorable law of nature that there is no work without waste. Ex nihilo nihil fit.

In this case, the heart-throb of the circulating system resides in the rotation of the sun. Therein is contained a certain definite amount of mechanical power-enough, according to Sir W. Thomson, if directly converted into heat, to keep up the sun's emission during I I6 years and six days-a mere moment in cosmical time. More economically applied, it would no doubt go farther. Its exhaustion would nevertheless, under the most favourable circumstances, ensue in a comparatively short period. ${ }^{2}$ Many other objections equally unanswerable have been urged to the "regenerative" hypothesis, but this one suffices.

1 Proc. Roy. Soc., vol. xxxiii., p. 393. $\quad{ }^{2}$ To this hostile argument, as urged by Mr. E. Douglas Archibald, Sir W. Siemens opposed the increase of rotative velocity through contraction (Nature, vol. xxv. p. 505). But contraction cannot restore lost momentum. 
Dr. Croll's collision-hypothesis is ${ }^{1}$ less demonstrably unsound, but scarcely less unsatisfactory. By the mutual impact of two dark masses rushing together with tremendous speed, he sought to provide the solar nebula with an immense original stock of heat for the reinforcement of that subsequently evolved in the course of its progressive contraction. The sun, while still living on its capital, would thus have a larger capital to live on, and the time-demands of the less exacting geologists and biologists might be successfully met. But the primitive event, assumed for the purpose of dispensing them from the inconvenience of "hurrying up their phenomena," is not one that a sane judgment can readily admit to have ever, in point of actual fact, happened.

There remains, then, as the only intelligible rationale of solar sustentation, Helmholtz's shrinkage theory. And this has a very important bearing upon the nebular view of planetary formation; it may, in fact, be termed its complement. For it involves the postulate that the sun's materials, once enormously diffused, gradually condensed to their present volume with development of heat and light, and, it may plausibly be added, with the separation of dependent globes. - The data furnished by spectrum analysis, too, favour the supposition of a common origin for sun and planets by showing their community of substance; while gaseous nebulæ present examples of vast masses of tenuous vapour, such as our system may plausibly be conjectured to have primitively sprung from.

But recent science raises many objections to the details, if it supplies some degree of confirmation to the fundamental idea of Laplace's cosmogony. The detection of the retrograde movement of Neptune's satellite made it plain that the anomalous conditions of the Uranian world were due to no extraordinary disturbance, but to a systematic variety of arrangement at the outskirts of the solar domain. So that, were a transNeptunian planet discovered, we should be fully prepared to find it rotating, and surrounded by satellites circulating from east to west. The uniformity of movement, upon the probabilities

1 Stellar Evolution, and its Relations to Geological Time, I889. 
connected with which the French geometer mainly based his scheme, thus at once vanishes.

The excessively rapid revolution of the inner Martian moon is a further stumbling-block. On Laplace's view, no satellite can revolve in a shorter time than its primary rotates; for in its period of circulation survives the period of rotation of the parent mass which filled the sphere of its opbit at the time of giving it birth. And rotation quickens as contraction goes on; therefore, the older time of axial rotation should invariably be the longer. This obstacle can, however, it seems, be turned.

More serious is one connected with the planetary periods, pointed out by Babinet in $1861 .^{1}$ In order to make them fit in with the hypothesis of successive separation from a rotating and contracting body, certain arbitrary assumptions have to be made of fluctuations in the distribution of the matter forming that body at the various epochs of separation. ${ }^{2}$ Such expedients usually merit the distrust which they inspire.

Again, it was objected by Professor Kirkwood in $1869^{3}$ that there could be no sufficient cohesion in such an enormously diffused mass as the planets are supposed to have sprung from, to account for the wide intervals between them. The matter separated through the growing excess of centrifugal speed, would have been cast off, not by rarely recurring efforts, but continually, fragmentarily, pari passu with condensation and acceleration. Each wisp of nebula, as it found itself unduly hurried, would have declared its independence, and set about revolving and condensing on its own account. The result would have been a meteoric, not a planetary system.

Moreover, it is a question whether the relative ages of the planets do not follow an order just the reverse of that concluded by Laplace. Professor Newcomb holds the opinion that the rings which eventually constituted the planets divided from the main body of the nebula almost simultaneously, priority, if there were any, being on the side of the inner and smaller ones $;^{4}$

1 Comptes Rendus, t. lii., p. 481. See also Kirkwood, Observatory, vcl. iii., p. 409. $\quad 2$ Fouché, Comptes Rendus, t. xcix., p. 903. 3 Month. Not., vol. xxix., p 96. « Pop. Astr., p. 257. 
while in M. Faye's cosmogony, ${ }^{1}$ the retrograde motion of the systems formed by the two outer planets is ascribed-on grounds, it is true, of dubious validity - to their comparatively late origin.

This ingenious scheme is designed, not merely to complete, but to supersede that of Laplace, which, undoubtedly, through the inclusion by our system of oppositely directed rotations, forfeits its claim simply and singly to account for the fundamental peculiarities of its structure.

M. Faye's leading contention is that, under the circumstances assumed by Laplace, not the two outer planets alone, but the whole company, must have been possessed of retrograde rotation. For they were formed-ex hypothesi-after the sun ; central condensation had reached an advanced stage when the rings they were derived from separated; the principle of inverse squares consequently held good, and Kepler's Laws were in full operation. Now particles circulating in obedience to these laws can only - since their velocity decreases outward from the centre of attraction-coalesce into a globe with a backward axial movement. Nor was Laplace blind to this flaw in his theory; but his effort to remove it, though it passed muster for the best part of a century, ${ }^{2}$ was scarcely successful. His planet-forming rings were made to rotate all in one piece, their outer parts thus necessarily travelling at a swifter linear rate than their inner parts, and eventually uniting, equally of necessity, into a forward-spinning body. The strength of cohesion involved may, however, safely be called imposslble, especially when it is considered that nebulous materials were in question.

The reform proposed by M. Faye consists in admitting that all the planets inside Uranus are of pre-solar origin-that they took globular form in the bosom of a nearly homogeneous nebula, revolving in a single period, with motion accelerated from centre to circumference, and hence agglomerating into masses with a direct rotation. Uranus and Neptune owe their exceptional characteristics to their later birth. When they came into exist-

1 Sur l'Origine, du Monde, 1884. 2 Kirkwood adverted to it in 1864, Am. Jour., vol. xxxviii., p. I. 
ence, the development of the sun was already far advanced, central force had acquired virtually its present strength, unity of period had been abolished by its predominance, and motion was retarded outward.

Thus, what we may call the relative chronology of the solar system is thrown once more into confusion. The order of seniority of the planets is now no easier to determine than the "Who first, who last?" among the victims of Hector's spear. For M. Faye's arrangements, notwithstanding the skill with which he has presented them, cannot be unreservedly accepted. The objections to them, thoughtfully urged by M. C. Wolf ${ }^{1}$ and Professor Darwin, ${ }^{2}$ are grave. Not the least so is his omission to take account of an agency of change presently to be noticed.

We now come to a most remarkable investigation-one, indeed, unique in its profession to lead us back with mathematical certainty towards the origin of a heavenly body. We refer to Professor Darwin's inquiries into the former relations of the earth and moon. ${ }^{3}$

They deal exclusively with the effects of tidal friction, and primarily with those resulting, not from oceanic, but from " bodily" tides, such as the sun and moon must have raised in past ages on a liquid or viscous earth. The immediate effect of either is, as already explained, to destroy the rotation of the body on which the tide is raised, as regards the tide-raising body, bringing it to turn always the same face towards its disturber. This, we can see, has been completely brought about in the case of the moon. There is, however, a secondary or reactive effect. Action is always mutual. Precisely as much as the moon pulls the terrestrial tidal wave backward, the tidal wave pulls the moon forward. But pulling a body forward in its orbit implies the enlargement of that orbit; in other words, the moon is, as a consequence of tidal friction, very slowly receding from the earth. This will go on (other circumstances remaining unchanged) until the lengthening day overtakes the more tardily

I Bull. Astr., t. ii.

2 Nature, vol. xxxi., p. 506.

3 Phil. Trans., vol. clxxi., p. 713 . 
lengthening month, when each will be of about 1400 hours. ${ }^{1}$ A position of what we may call tidal equilibrium between earth and moon will (apart from disturbance by other bodies) then be attained.

If, however, it be true that, in the time to come, the moon will be much farther from us, it follows that in the time past she was much nearer to us than she now is. Tracing back her history by the aid of Professor Darwin's clue, we at length find her revolving in a period of somewhere between two and four hours, almost in contact with an earth rotating just at the same rate. This was before tidal friction had begun its work of grinding down axial velocity and expanding orbital range. But the position was not one of stable equilibrium. The slightest inequality must have set on foot a series of uncompensated changes. If the moon had whirled the least iota faster than the earth spun, she must have been precipitated upon it. Her actual existence shows that the trembling balance inclined the other way. By a second or two to begin with, the month exceeded the day; the tidal wave crept ahead of the moon; tidal friction came into play, and our satellite started on its long spiral journey outward from the parent globe. This must have occurred, it is computed, at least fifty-four million years ago.

That this kind of tidal reactive effect played its part in bringing the moon into its present position, and is still, to some slight extent, at work in changing it, there can be no doubt whatever. An irresistible conjecture carried the explorer of its rigidly deducible consequences one step beyond them. The moon's time of revolution, when so near the earth as barely to escape contact with it, must have been, by Kepler's Law, more than two and less than two and a half hours. Now, it happens that the most rapid rate of rotation of a fluid mass of the earth's average density, consistent with spheroidal equilibrium, is two hours and twenty minutes. Quicken the movement but by one second and the globe must fly asunder. Hence the inference

1 Mr. J. Nolan has pointed out (Nature, vol. xxxiv., p. 287) that the length of the equal day and month will be reduced to about I240 hours by the effects of solar tidal friction. 
seems justified that the earth actually did fly asunder through over-fast spinning, the ensuing disruption representing the birththroes of the moon. It is likely that the event was hastened or helped by solar tidal disturbanee.

To recapitulate. Analysis tracks backward the two bodies until it leaves them in very close contiguity, one rotating and the other revolving in approximately the same time, and that time certainly not far different from, and quite possibly identical with, the critical period of instability for the terrestrial spheroid. "Is this," Professor Darwin asks, "a mere coincidence, or does it not rather point to the break-up of the primeval planet into two masses in consequence of a too rapid rotation?" 1

We are tempted, but are not allowed to give an unqualified assent. Mr. James Nolan of Victoria has made it clear that the moon could not have subsisted as a continuous mass under the powerful disruptive strain which would have acted upon it when revolving almost in contact with the present surface of the earth ; and Professor Darwin, admitting the objection, concedes to our satellite, in its initial stage, the alternative form of a flock of meteorites. ${ }^{2}$ But such a congregation must have been quickly dispersed, by tidal action, into a meteoric ring. The same investigator subsequently fixed 6500 miles from centre to centre as the minimum distance at which the moon could have revolved in its entirety ; and he concluded it "necessary to suppose that, after the birth of a satellite, if it takes place at all in this way, a series of changes occur which are quite unknown." 3 The evidence, however, for the efficiency of tidal friction in bringing about the actual configuration of the lunar-terrestrial system, is not invalidated by this failure to penetrate its natal mystery. Under its influence the principal elements of that system fall into interdependent mutual relations. It connects, causally and quantitatively, the periods of the moon's revolution and of the earth's rotation, the obliquity of the ecliptic, the inclination and eccentricity of the lunar orbit. All this can scarcely be accidental.

1 Phil. Trans, vol. clxxi., p. 835 . 2 Nature, vol. xxxiii., p. 368 ; see also Nolan, Ibid., vol. xxxiv., p. 286.

3 Phil. Trans., vol. clxxviii., p. 422. 
Professor Darwin's first researches on this subject were communicated to the Royal Society, December 18, 1879. They were followed January $20, \mathrm{I} 88 \mathrm{I},{ }^{1}$ by an inquiry on the same principles into the earlier condition of the entire solar system. The results were a warning against hasty generalisation. They showed that the lunar-terrestrial system, far from being a pattern for their development, was a singular exception among the bodies swayed by the sun. Its peculiarity resides in the fact that the moon is proportionately by far the most massive attendant upon any known planet. Its disturbing power over its primary is thus abnormally great, and tidal friction has, in consequence, played a predominant part in bringing their mutual relations into their present state.

The comparatively late birth of the moon tends to ratify this inference. The dimensions of the earth did not differ (according to our present authority) very greatly from what they now are when her solitary offspring came, somehow, into existence. This is found not to have been the case with any other of the planets. It is unlikely that the satellites of Jupiter, Saturn, or Mars (we may safely add, of Uranus or Neptune) ever revolved in much narrower orbits than those they now traverse; it is practically certain that they did not, like our moon, originate very near the present surfaces of their primaries. ${ }^{2}$ What follows? The tide-raising power of a body grows with vicinity in a rapidly accelerated ratio. Lunar tides must then have been on an enormous scale when the moon swung round at a fraction of its actual distance from the earth. But no other satellite with which we are acquainted occupied at any time a corresponding position. Hence no other satellite ever possessed tideraising capabilities in the least comparable to those of the moon. We conclude once more that tidal friction had an influence here quite different from its influence elsewhere.

There is, however, another branch of the same subject. We know that the sun as well as the moon causes tides in our oceans. There must then be solar, no less than lunar, tidal friction. The question at once arises: What part has it played

$$
1 \text { Phil. Trans., vol. clxxii., p. 491. } \quad 2 \text { Ibid., p. } 530 .
$$


in the development of the solar system? Has it ever been one of leading importance, or has its influence always been, as it now is, subordinate, almost negligeable? To this, too, Professor Darwin supplies an answer.

It can be stated without hesitation that the sun did not give birth to the planets, as the earth has been supposed to have given birth to the moon, by the disruption "of its already condensed, though plastic and glowing mass, pushing them then gradually backward from its surface into their present places. For the utmost possible increase in the length of the year through tidal friction is one hour; and five minutes is a more probable estimate. ${ }^{1}$ So far as the pull of tide-waves raised on the sun by the planets is concerned, then, the distances of the latter have never been notably different from what they now are; though that cause may have converted the paths traversed by them from circles into ellipses.

Over their physical history, however, it was probably in a large measure influential. The first vital issue for each of them was -satellites or no satellites? Were they to be governors as well as governed, or should they revolve in sterile isolation throughout. the æons of their future existence? Here there is strong reason to believe that solar tidal friction was the overruling power. It is remarkable that planetary fecundity increases-at. least so far outward as Saturn-with distance from the sun. Can these two facts be in any way related? In other words, is there any conceivable way by which tidal influence could prevent or impede the throwing-off of secondary bodies? We have only to think for a moment in order to see that this is precisely one of its direct results. ${ }^{2}$

Tidal friction, whether solar or lunar, tends to reduce the axial movement of the body it acts upon. But the separation of satellites depends-according to the received view-upon the attainment of a disruptive rate of rotation. Hence, if solar tidal friction were strong enough to keep down the pace below this critical point, the contracting mass would remain intactthere would be no satellite-production. This, in all probability,

1 Phil. Trans., vol. clxxii., p. 533. 2 This was perceived by M. Ed. Roche in 1872. Mém. de l'Acad. cles Sciences de Montpellier, t. viii., p. 247. 
actually occurred in the case both of Mercury and Venus. They cooled without dividing, because the solar friction-brake applied to them was too strong to permit acceleration to pass the limit of equilibrium. The complete destruction of their relative axial movement has been rendered probable by Schiaparelli's observations; and that the process went on rapidly, is a reasonable further inference. The earth barely escaped the fate of loneliness incurred by her neighbours. Her first and only epoch of instability was retarded until she had nearly reached maturity. The late appearance of the moon accounts for its large relative size-through the increased cohesion of an already strongly condensed parent mass - and for the distinctive peculiarities of its history and influence on the producing globe.

Solar tidal friction, although it did not hinder the formation of two minute dependants of Mars, has been invoked to explain the anomalously rapid revolution of one of them. Phobos, we have seen, completes more than three revolutions while Mars rotates once. But this was probably not always so. The two periods were originally nearly equal. The difference, it is alleged, was brought about by tidal waves raised by the sun on the viscous spheroid of Mars. Rotatory velocity was thereby destroyed. the Martian day slowly lengthened, and, as a secondary consequence, the period of the inner satellite, become shorter than the augmented day, began progressively to diminish. So that Phobos, unlike our moon, was in the beginning farther from its primary than now.

But here again Mr. Nolan enters a caveat. Applying the simple test of numerical evaluation, he shows that before solar tidal friction can lengthen the rotation-period of Mars by so much as one minute, Phobos must already have been precipitated upon its surface. ${ }^{1}$ For the enormous disparity of mass between it and the sun is so far neutralised by the enormous disparity in their respective distances from Mars, that solar tidal force there is only fifty times that of the little satellite. But the tidal effects of a satellite circulating quicker than its primary rotates, exactly reverse those of one moving, like our moon, comparatively slowly, so that the tides raised by Phobos tend

' Nature, vol. xxxiv., p. 287. 
to shorten both periods. Its orbital momentum, however, is so extremely small in proportion to the rotational momentum of Mars, that any perceptible inroad upon the latter is attended by a lavish and ruinous expenditure of the former. It is as if a man owning a single five-pound note were to play for equal stakes with a man possessing a million. The bankruptcy sure to ensue is typified by the coming fate of the Martian inner satellite. The catastrophe of its fall needs to bring it about only a very feeble reactive pull compared with the friction which should be applied in order to protract the Martian day by one minute. And from the proportionate strength of the forces at work, it is quite certain that one result cannot take place without the other. Nor can things have been materially different in the past; hence the idea must be abandoned that the primitive time of rotation of Mars survives in the period of its inner satellite.

The anomalous shortness of the latter may, however, in M. Wolf's opinion, ${ }^{1}$ be explained by the "traînées elliptiques" with which Roche supplemented nebular annulation. ${ }^{2}$ These are traced back to the descent of separating strata from the shoulders of the great nebulous spheroid towards its equatorial plane. Their rotational velocity being thus relatively small, they formed "inner rings," very much nearer to the centre of condensation than would have been possible on the unmodified theory of Laplace. Phobos might, in this view, be called a polar offset of Mars; and the rings of Saturn are thought to own a similar origin.

Outside the orbit of Mars, solar tidal friction can scarcely be said at present to possess any sensible power. But it is far from certain that this was always so. It seems not unlikely that its influence was the overruling one in determining the direction of planetary rotation. M. Faye, as we have seen, objected to Laplace's scheme that only retrograde secondary systems could be produced by it. In this he was anticipated by Kirkwood, who, however, supplied an answer to his own objection. $^{3}$

1 Bull. Astr., t. ii., p. 223. Jour., vol. xxxviii. (1864), p. I.

2 Montpellier Méms., t. viii., p. 242. 3 Amer. 
Sun-raised tides must have acted with great power on the diffused masses of the embryo planets. By their means they doubtless very soon came to turn (in lunar fashion) the same hemisphere always towards their centre of motion. This amounts to saying that even if they started with retrograde rotation, it was, by solar tidal friction, quickly rendered direct. For it is scarcely necessary to point out that a planet turning an invariable face to the sun, rotates in the same direction in which it revolves, and in the same period. As, with the progress of condensation, tides became feebler, and rotation more rapid, the accelerated spinning necessarily proceeded in the sense thus prescribed for it. Hence the backward axial movements of Uranus and Neptune may very well be a survival, due to the inefficiency of solar tides at their great distance, of a state of things originally prevailing universally throughout the system.

The general outcome of Professor Darwin's researches has been to leave Laplace's cosmogony untouched. He concludes nothing against it, and, what perhaps tells with more weight in the long run, has nothing to substitute for it. In one form or another, if we speculate at all on the development of the planetary system, our speculations are driven into conformity with the broad lines of the Nebular Hypothesis-so far, at least, as admitting an original material unity and motive uniformity. But we can see now, better than formerly, that these supply a bare and imperfect sketch of the truth. We should err gravely were we to suppose it possible to reconstruct, with the help of any knowledge our race is ever likely to possess, the real and complete history of our admirable system. "The subtlety of nature," Bacon says, "transcends in many ways the subtlety of the intellect and senses of man." By no mere barren formula of evolution, indiscriminately applied all round, the results we marvel at, and by a fragment of which our life is conditioned, were brought forth; but by the manifold play of interacting forces, variously modified and variously prevailing, according to the local requirements of the design they were appointed to execute. 
ON the 2nd of June 1858, Giambattista Donati discovered at Florence, in the constellation Leo, a feeble round nebulosity about one-tenth the diameter of the full moon. It proved to be a comet approaching the sun. But it changed little in apparent place or brightness for some weeks. The gradual development of a central condensation of light was the first symptom of coming splendour. At Harvard, in the middle of July, a strong stellar nucleus was seen; on August I4 a tail began to be thrown out. As the comet wanted still over six weeks of the time of its perihelion-passage, it was obvious that great things might be expected of it. They did not fail of realisation.

Not before the early days of September was it generally recognised with the naked eye, though it had been detected without a glass at Pulkowa, August 19. But its growth was thenceforward surprisingly rapid, as it swept with accelerated motion under the hindmost foot of the Great Bear, and past the starry locks of Berenice. A sudden leap upward in lustre was noticed on September I2, when the nucleus shone with about the brightness of the pole-star, and the tail, notwithstanding large foreshortening, could be traced with the lowest telescopic power over six degrees of the sphere. The appendage, however, attained its full development only after perihelion, September 30, by which time, too, it lay nearly square to the line of sight from the earth. On October Io it stretched in a magnificent scimitar-like curve over a third and upwards of the visible hemisphere, representing a real extension in space of fifty-four million miles. But the most striking view was 
presented on October 5, when the brilliant star Arcturus became involved in the brightest part of the tail, and during many hours contributed, its lustre undiminished by the interposed nebulous screen, to heighten the grandeur of the most majestic celestial object of which living memories retain the impress. Donati's comet was, according to Admiral Smyth's testimony, ${ }^{1}$ outdone "as a mere sight-object" by the great comet of I8 I I ; but what it lacked in splendour, it surely made up in grace, and variety of what we may call "scenic" effects.

Some of these were no less interesting to the student than they were impressive to the spectator. At Pulkowa, on the I6th September, Winnecke ${ }^{2}$ observed a faint outer envelope resembling a veil of almost evanescent texture flung somewhat widely over the head. Next evening, the first of the "secondary" tails appeared, possibly as parts of the same phenomenon. This was a narrow straight ray, forming a tangent to the strong curve of the primary tail, and reaching to a still greater distance from the nucleus. It continued faintly visible for about three weeks, during part of which time it was seen in duplicate. For from the chief train itself, at a point where its curvature abruptly changed, issued, as if through the rejection of part of its materials, a second beam nearly parallel to the first, the rigid line of which contrasted singularly with the softly diffused and waving aspect of the plume of light from which it sprang. Olbers's theory of unequal repulsive forces was never more beautifully illustrated. The triple tail seemed a visible solar analysis of cometary matter.

The processes of luminous emanation going on in this body forcibly recalled the observations made on the comets of 1744 and 1835. From the middle of September, the nucleus, estimated by Bond to be under five hundred miles in diameter, was the centre of action of the most energetic kind. Seven distinct "envelopes" were detached in succession from the nebulosity surrounding the head, and after rising towards the sun during periods of from four to seven days, finally cast their material backward to form the right and left branches of the great train.

1 Month. Not., vol. xix., p. 27. 2 Mém. de l'Ac. Imp., t. ii., 1859, p. 46. 
The separation of these by an obscure axis-apparently as black, quite close up to the nucleus, as the sky-indicated for the tail a hollow, cone-like structure ${ }^{1}$ while the repetition of certain spots and rays in the same corresponding situation on one envelope after another, served to show that the nucleus-to some local peculiarity of which they were doubtless due-had no proper rotation, but merely shifted sufficiently on an axis to preserve the same aspect towards the sun as it moved round it. $^{2}$ This observation of Bond's was strongly confirmatory of Bessel's hypothesis of opposite polarities in such bodies' opposite sides.

The protrusion towards the sun, on September 25, of a brilliant luminous fan-shaped sector completed the resemblance to Halley's comet. The appearance of the head was now somewhat that of a "bat's-wing" gaslight. There were, however, no oscillations to and fro, such as Bessel had seen and speculated upon in 1835. As the size of the nucleus contracted with approach to perihelion, its intensity augmented. On October 2, it outshone Arcturus, and for a week or ten days was a conspicuous object half an hour after sunset. Its lustre-setting aside the light emitted from the tail-was, at that date, 6300 times what it had been on June I 5, though theoretically-taking into account, that is, only the differences of distance from sun and earth-it should have been only $\frac{1}{33}$ of that amount. Here, it might be thought, was convincing evidence of the comet itself becoming ignited under the growing intensity of the solar radiations. Yet experiments with the polariscope were interpreted in an adverse sense, and Bond's conclusion that the comet sent us virtually unmixed reflected sunshine was generally acquiesced in. It did not, however, survive the first application of the spectroscope to these bodies.

Very féw comets have been so well or so long observed as Donati's. It was visible to the naked eye during I I 2 days; it was telescopically discernible for 275 , the last observation having been made by Mr. William Mann at the Cape of Good Hope, March 4, I859. Its course through the heavens combined

1 Harvard Annals, vol. iii., p. 368.2 Ihid., p. 371 . 
singularly with the orbital place of the earth to favour curious inspection. The tail, when near its greatest development, lost next to nothing by the effects of perspective, and at the same time lay in a plane sufficiently inclined to the line of sight to enable it to display its exquisite curves to the greatest advantage. Even the weather was, on both sides of the Atlantic, propitious during the period of greatest interest, and the moon as little troublesome as possible. The splendid volume compiled by the younger Bond is a monument to the care and skill with which these advantages were turned to account. Yet this stately apparition marked no turning-point in the history of cometary science. By its study knowledge was indeed materially advanced, but along the old lines. No quick and vivid illumination broke upon its path. Quite insignificant objects-as we have already partly seen-have often proved more vitally instructive.

Donati's comet has been identified with no other. Its path is an immensely elongated ellipse, lying in a plane far apart from that of the planetary movements, carrying it at perihelion considerably within the orbit of Venus, and at aphelion out into space to $5 \frac{1}{2}$ times the distance from the sun of Neptune. The entire circuit occupies over 2000 years, and is performed in a retrograde direction, or against the order of the Signs. Before its next return, about the year 4000 A.D., the enigma of its presence and its purpose may have been to some extent-though we may be sure not completely-penetrated.

On June 30, I86I, the earth passed, for the second time in this century, through the tail of a great comet. Many of our readers must remember the unexpected disclosure, on the withdrawal of the sun below the horizon on that evening, of an object so remarkable as to challenge universal attention. A goldenyellow planetary disc, wrapt in dense nebulosity, shone out while the June twilight of these latitudes was still in its first strength. The number and complexity of the envelopes surrounding the head produced, according to the late Mr. Webb, ${ }^{1}$ a magnificent effect. Portions of six distinct emanations were traceable. "It was as though a number of light, hazy clouds

1 Month. Nut., vol. xxii., p. 306. 
were floating round a miniature full moon." As the sky darkened the tail emerged to view. ${ }^{1}$ Although in brightness and sharpness of definition it could not compete with the display of $\mathrm{i} 858$, its dimensions proved to be extraordinary. It reached upwards beyond the zenith when the head had already set. By some authorities its extreme length was stated at II $8^{\circ}$, and it showed no trace of curvature. Most remarkable, however, was the appearance of two widely divergent rays, each pointing towards the head, though cut off from it by sky-illumination, of which one was seen by Mr. Webb, and both by Mr. Williams at Liverpool, a quarter of an hour before midnight. There seems no doubt that Mr. Webb's interpretation was the true one, and that these beams were, in fact, "the perspective representation of a conical or cylindrical tail, hanging closely above our heads, and probably just being lifted up out of our atmosphere." 2 The cometary train was then rapidly receding from the earth, so that the sides of the "outspread fan" of light, as which it showed when we were right in the line of its axis, must have appeared (as they did) to close up in departure. The swiftness with which the visually opened fan shut, proved its vicinity; and indeed Mr. Hind's calculations showed that we were not so much near, as actually within its folds at that very time.

Already M. Liais, from his observations at Rio de Janeiro, June I I to I4, and Mr. Tebbutt in New South Wales on June I 5, had anticipated such an encounter, while the former subsequently proved that it must have occurred in such a way as to cause an immersion of the earth in cometary matter to a depth of 300,000 miles. $^{3}$ The comet then lay between the earth and the sun at a distance of about fourteen million miles from the former ; its tail stretched outward just along the line of intersection of its own with the terrestrial orbit to an extent of fifteen million miles; so that our globe, happening to pass at the time, found itself during some hours involved in the flimsy appendage.

No perceptible effects were produced by the meeting; it was

1 Stothard, Month. Not., vol. xxi., p. 243. $\quad 2$ Intell. Cbserver, vol. i., p. 65.

3 Comptes Rendus, t. lxi., p. 953. 
known to have occurred by theory alone. A peculiar glare in the sky, thought by some to have distinguished the evening of June 30, was, at best, inconspicuous. Nor were there any symptoms of unusual electrical excitement. The Greenwich instruments were, indeed, disturbed on the following night; but it would be rash to infer that the comet had art or part in their agitation.

The perihelion-passage of this body occurred June I I, I86I ; and its orbit has been shown by M. Kreutz of Bonn, from a very complete investigation founded on observations extending over nearly a year, to be an ellipse traversed in a period of 409 years. ${ }^{1}$

Towards the end of August I862, a comet became visible to the naked eye high up in the northern hemisphere, with a nucleus equalling in brightness the lesser stars of the Plough and a feeble tail $20^{\circ}$ in length. It thus occupied quite a secondary position among the members of its class. It was, nevertheless, a splendid object in comparison with a telescopic nebulosity discovered by Tempel at Marseilles, December 19, I 865. This, the sole comet of I 866, slipped past perihelion, January II, without pomp of train or other appendages, and might have seemed hardly worth the trouble of pursuing. Fortunately, however, this was not the view entertained by observers and computers ; since upon the knowledge acquired of the movements of these two bodies has been founded one of the most significant discoveries of modern times. The first of them is now styled the comet (I862 iii.) of the August meteors, the second (I866 i.) that of the November meteors. The steps by which this curious connection came to be ascertained were many, and were taken in succession by a number of individuals. But the final result was reached by Schiaparelli of Milan, and remains deservedly associated with his name.

The idea prevalent in the last century as to the nature of shooting stars was that they were mere aerial ignes fatuiinflammable vapours accidentally kindled in our atmosphere. But Halley had already entertained the opinion of their cosmical

1 Smiths. Report, I88I (Holden). 
origin; and Chladni in 1794 formally broached the theory that space is filled with minute circulating atoms, which, drawn by the earth's attraction, and ignited by friction in its gaseous envelope, produce the luminous effects so frequently witnessed. ${ }^{1}$ Acting on his suggestion, Brandes and Benzenberg, two students at the University of Göttingen, began in 1798 to determine the heights of falling stars by simultaneous observations at a distance. They soon found that they move with planetary velocities in the most elevated regions of our atmosphere, and by the ascertainment of this fact laid a foundation of distinct knowledge regarding them. Some of the data collected, however, served only to perplex opinion, and even caused Chladni temporarily to renounce his. Many high authorities, headed by Laplace in 1802, declared for the lunar-volcanic origin of meteorites; but thought on the subject was turbid, and inquiry seemed only to stir up the mud of ignorance. It needed one of those amazing spectacles, at which man assists, not now as formerly in abject terror for his own frail fortunes, but with keen curiosity, and the vivid expectation of new knowledge, to bring about a clarification.

On the night of November 12-13, 1833, a tempest of falling stars broke over the earth. North America bore the brunt of its pelting. From the Gulf of Mexico to Halifax, until daylight with some difficulty put an end to the display, the sky was scored in every direction with shining tracks and illuminated with majestic fireballs. At Boston, the frequency of meteors was estimated to be about half that of flakes of snow in an average snowstorm. Their numbers, while the first fury of their coming lasted, were quite beyond counting; but as it waned, a reckoning was attempted, from which it was computed, on the basis of that much diminished rate, that 240,000 must have been visible during the nine hours they continued to fall. ${ }^{2}$

Now there was one very remarkable feature common to the innumerable small bodies which traversed, or were consumed

1 Ueber den Ursprung der von Pallas gefundenen Eisenmassen, p. 24. 2 Arago, Annuaire, 1836, p. 294. 
in our atmosphere that night. They all seemed to come from the same part of the sky. Traced backward, their paths were invariably found to converge to a point in the constellation Leo. Moreover, that point travelled with the stars in their nightly round. In other words, it was entirely independent of the earth and its rotation. It was a point in inter-planetary space.

The effective perception of this fact ${ }^{1}$ amounted to a discovery, as Olmsted and Twining, who had "simultaneous ideas" on the subject, were the first to realize. Denison Olmsted was then professor of mathematics in Yale College. He showed early in I $834^{2}$ that the emanation of the showering meteors from a fixed "radiant" proved their approach to the earth along nearly parallel lines, appearing to diverge by an effect of perspective; and that those parallel lines must be sections of orbits described by them round the sun and intersecting that of the earth. For the November phenomenon was now seen to be a periodical one. On the same night of the year 1832, although with less dazzling and universal splendour than in America in 1833, it had been witnessed over great part of Europe and in Arabia. Olmsted accordingly assigned to the cloud of cosmical particles (or "comet," as he chose to call it), by terrestrial encounters with which he supposed the appearances in question to be produced, a period of about 182 days; its path a narrow ellipse, meeting, near its farthest end from the sun, the place occupied by the earth on November I2.

Once for all, then, as the result of the star-fall of 1833 , the study of luminous meteors became an integral part of astronomy. Their membership of the solar system was no longer a theory or a conjecture-it was an established fact. The discovery might be compared to, if it did not transcend in importance, that of the asteroidal group. "C'est un nouveau monde planétaire," Arago wrote, ${ }^{3}$ " qui commence à se révéler à nous."

Evidences of periodicity continued to accumulate. It was

1 Humboldt had noticed the emanation of the shooting stars of 1799 from a single point, or "radiant," as Greg long afterwards termed it; but no reasoning was founded on the observation. ${ }^{2} A m$. Jour. of $S c$., vol. xxvi., p. I32. 3 Annuaire, 1836, p. 297. 
remembered that Humboldt and Bonpland had been the spectators at Cumana, after midnight on November I2, I799, of a fiery shower little inferior to that of 1833 , and reported to have been visible from the equator to Greenland. Moreover, in I834 and some subsequent years, there were waning repetitions of the display, as if through the gradual thinning-out of the meteoric supply. The extreme irregularity of its distribution was noted by Olbers in 1837, who conjectured that we might have to wait until 1867 to see the phenomenon renewed on its former scale of magnificence. ${ }^{1}$ This was the first hint of a thirty-three or thirtyfour year period.

The falling stars of November did not alone attract the attention of the learned. Similar appearances were traditionally associated with August Io by the popular phrase in which they figured as "the tears of St. Lawrence." But the association could not be taken on trust from mediæval authority. It had to be proved scientifically, and this Quetelet of Brussels succeeded in doing in December $1836 .^{2}$

A second meteoric revolving system was thus shown to exist. But its establishment was at once perceived to be fatal to the " cosmical cloud" hypothesis of Olmsted. For if it be a violation of probability to attribute to one such agglomeration a period of an exact year, or sub-multiple of a year, it would be plainly absurd to suppose the movements of two or more regulated by such highly artificial conditions. An alternative was proposed by Adolf Erman of Berlin in 1839. ${ }^{3}$ No longer in clouds, but in closed rings, he supposed meteoric matter to revolve round the sun. Thus the mere circumstance of intersection by a meteoric, of the terrestrial orbit, without any coincidence of period, would account for the earth meeting some members of the system at each annual passage through the "node" or point of intersection. This was an important step in advance, yet it decided nothing as to the forms of the orbits of such annular assemblages; nor was it followed up in any direction for a quarter of a century.

${ }^{1}$ Ann. de l'Observ., Bruxelles, I839, p. 248. $\quad 2$ Ibid., 1837, p. 272. ${ }^{3}$ Astr. Nach., Nos. 385,390 . 
Professor Hubert A. Newton, of Yale College, took up in $1864^{1}$ the dropped thread of inquiry. A search through old records carried the November phenomenon back to the year 902 A.D., long distinguished as "the year of the stars." For in the same night in which Taormina was captured by the Saracens, and the cruel Aghlabite tyrant Ibrahim ibn Ahmed died "by the judgment of God" before Cosenza, stars fell from heaven in such abundance as to amaze and terrify beholders far and near. This was on October I3, and recurrences were traced down through the subsequent centuries, always with a day's delay in about seventy years. It was easy, too, to derive from the dates a cycle of $33 \frac{1}{4}$ years, so that Professor Newton did not hesitate to predict the exhibition of an unusually striking meteoric spectacle on November 13-14, 1866. ${ }^{2}$

For the astronomical explanation of the phenomena, recourse was had to a method introduced by Erman of computing meteoric orbits. It was found, however, that conspicuous recurrences every thirty-three or thirty-four years could be explained on the supposition of five widely different periods, combined with varying degrees of extension in the revolving group. Professor Newton himself gave the preference to the shortest of the five-of $354 \frac{1}{2}$ days, but indicated the means of deciding with certainty upon the true one. It was furnished by the advancing motion of the node, or that day's delay of the November shower every seventy years, which the old chronicles had supplied data for detecting. For this is a strictly measurable effect of gravitational disturbance by the various planets, the amount of which naturally depends upon the course pursued by the disturbed bodies. Here the great mathematical resources of Professor Adams were brought to bear. By laborious processes of calculation, he ascertained that four out of Newton's five possible periods were entirely incompatible with the observed nodal displacement, while for the fifth-that of $33 \frac{1}{4}$ years-.a perfectly harmonious result was obtained. ${ }^{3}$ This was the last link in the chain of evidence proving that the November

${ }^{1}$ Am. Jour. of Sc., vol. xxxvii. (2nd. ser.), p. 377. ${ }^{2}$ Ibid., vol. xxxviii., p. 6r. 3 Month. Not., vol. xxvii., p. 247. 
meteors-or "Leonids," as they had by that time come to be called-revolve round the sun in a period of 33.27 years, in an ellipse spanning the vast gulf between the orbits of the earth and Uranus, the group being iso extended as to occupy six or eight years in defiling past the scene of terrestrial encounters. But before it was completed in March I867, the subject had assumed a new aspect and importance.

Professor Newton's prediction of a remarkable star-shower in November I866 was punctually fulfilled. This time, Europe served as the main target of the celestial projectiles, and observers were numerous and forewarned. The display, although, according to Mr. Baxendell's memory, ${ }^{1}$ inferior to that of 1833 , was of extraordinary impressiveness. Dense crowds of meteors, equal in lustre to the brightest stars, and some rivalling Venus. at her best, ${ }^{2}$ darted from east to west across the sky with enormous apparent velocities, and with a certain determinateness of aim, as if let fly with a purpose, and at some definite object. $^{3}$ Nearly all left behind them trains of emerald green or clear blue light, which occasionally lasted many minutes, before they shrivelled and curled up out of sight. The maximum rush occurred a little after one o'clock on the morning of November 14, when attempts to count were overpowered by frequency. But during a previous interval of seven minutes five seconds, four observers at Mr. Bishop's observatory at Twickenham reckoned 514, and during an hour I I20. ${ }^{4}$ Before daylight the earth had fairly cut her way through the star-bearing stratum; the "ethereal rockets" had ceased to fly.

This event brought the subject of shooting stars once more vividly to the notice of astronomers. Schiaparelli had, indeed, been already attracted by it. The results of his studies were made known in four remarkable letters, addressed, before the close of the year 1866, to Father Secchi, and published in the. Bulletino of the Roman Observatory. ${ }^{5}$ Their upshot was to show, in the first place, that meteors possess a real velocity

1 Am. Jour. of Sc., vol. xliii. (2nd ser.), p. 87. ${ }^{2}$ Grant, Month. Not., vol. xxvii., p. 29. ${ }^{3}$ P. Smyth, Month. Not., vol. xxvii., p. $256 .{ }^{4}$ Hind, Ibid., p. 49. 'Seproduced in Les Mondes, t. xiii. 
considerably greater than that of the earth, and travel, accordingly, to enormously greater distances from the sun along tracks resembling those of comets in being very eccentric, in lying at all levels indifferently, and in being pursued in either direction. It was next inferred that comets and meteors equally. have an origin foreign to the solar system, but are drawn into it temporarily by the sun's attraction, and occasionally fixed in it by the backward pull of some planet. But the crowning fact was reserved for the last. It was the astonishing one that the August meteors move in the same orbit with the bright comet of r 862-that the comet, in fact, is but a larger member of the family of Perseids (so named because their radiant point is situated in the constellation Perseus).

This discovery was quickly capped by others of the same kind. Leverrier published, January 2 I, I867, ${ }^{1}$ elements for the November swarm, at once identified by Dr. C. F. W. Peters of Altona, with Oppolzer's elements for Tempel's comet of $1866 .^{2}$ A few days later, Schiaparelli, having re-calculated the orbit of the meteors from improved data, arrived at the same conclusion; while Professor Weiss of Vienna pointed to the agreement between the orbits of a comet which had appeared in. I86I and of a star shower found to recur on April 20 (Lyraïds), as well as between those of Biela's comet and certain conspicuous meteors of November $28 .^{3}$

These instances do not seem to be exceptional. The number of known or suspected accordances of cometary tracks with meteor streams contained in a list drawn up in $1878^{4}$ by Professor Alexander S. Herschel (who has made the subject peculiarly his own), amounts to seventy-six; although the four first detected still remain the most conspicuous, and perhaps the only absolutely sure examples of a relation as significant as it was, to most astronomers, unexpected.

There had, indeed, been anticipatory ideas. Not that Kepler's comparison of shooting stars to "minute comets," or Maskelyne's "forse risulterà che essi sono comete," in a letter to the Abate

1 Comptes Rendus, t. Ixiv., p. 96. 2 Astr. Nach., No. 1626. 3 Ibid., No. 1632. 4 Month. Not., vol. xxxviii., p. 369. 
Cesaris, December 12, I $783,{ }^{1}$ need count for much. But Chladni, in $1819,{ }^{2}$ considered both to be fragments or particles of the same primitive matter, irregularly dispersed through space as nebulæ; and Morstadt of Prague suggested about $1837^{3}$ that the November meteors might be dispersed atoms from the tail of Biela's comet, the path of which is cut across by the earth near that epoch. Professor Kirkwood, however, by a luminous intuition, penetrated the whole secret, so far as it has yet been made known. In an article published, or rather buried, in the Danville Quarterly Review for December r86r, he argued, from the observed division of Biela, and other less noted instances of the same kind, that the sun exercises a "divellent influence" on the nuclei of comets, which may be presumed to continue its action until their corporate existence (so to speak) ends in complete pulverisation. "May not," he continued, "our periodic meteors be the débris of ancient, but now disintegrated comets, whose matter has become distributed round their orbits?" 4

The gist of Schiaparelli's discovery could not be more clearly conveyed. For it must be borne in mind that with the ultimate destiny of comets' tails this had nothing to do. The tenuous matter composing them is, no doubt, permanently lost to the body from which it emanated; but science does not pretend to track its further wanderings through space. It can, however, state categorically that these will no longer be conducted along the path forsaken under solar compulsion. From the central, and probably solid parts of comets, on the other hand, are derived the granules by the swift passage of which our skies are seamed with periodic fires. It is certain that a loosely agglomerated mass (such as there is every reason to believe cometary nuclei to be) must gradually separate through the unequal action of gravity on its various parts-through, in short, solar tidal influence. Thenceforward its fragments will revolve independently in parallel orbits, at first as a swarm, finally-

1 Schiaparelli, Le Stelle Cadenti, p. 54.

2 Ueber Feuer-Meteore, p. 406. 3 Astr. Nach., No. 347 (Mädler) ; see also Boguslawski, Die Kometen, p. 98, 1857. 4 Nature, vol. vi., p. 148. 
when time has been given for the full effects of the lagging of the slower moving particles to develop-as a closed ring. The first condition is still, more or less, that of the November meteors; those of August have already arrived at the second. For this reason, Leverrier pronounced, in 1867 , the Perseid to be of older formation than the Leonid system. He even assigned a date at which the introduction of the last-named bodies into their present orbit was probably effected through the influence of Uranus. In I 26 A.D. a close approach must have taken place between the planet and the parent comet of the November stars, after which its regular returns to peribelion, and the consequent process of its disintegration, set in. Though not complete, it is already far advanced.

The view that meteorites are the dust of decaying comets was now to be put to a definite test of prediction. Biela's comet had not been seen since its duplicate return in I852. Yet it had been carefully watched for with the best telescopes; its path was accurately known; every perturbation it could suffer was scrupulously taken into account. Under these circumstances, its repeated failure to come up to time might fairly be thought to imply a cessation from visible existence. Might it not, however, be possible that it would appear under another form-that a star-shower might have sprung from and would commemorate its dissolution?

An unusually large number of falling stars were seen by Brandes, December 6, I798. Nearly anniversary displays attracted notice in the years I830, I838, and 1847 , and the point from which they emanated was shown by Heis at Aix-la-Chapelle to be situated near the bright star $\gamma$ Andromedae. ${ }^{1}$ Now this is precisely the direction in which the orbit of Biela's comet would seem to lie, as it runs down to cut the terrestrial track very close to the earth's place at the above dates. The inference was then an easy one, that the meteors were pursuing the same path with the comet; and it was separately arrived at, early in 1867 , by Weiss, D'Arrest, and Galle. ${ }^{2}$ But Biela travels in the opposite

1 A. S. Herschel, Month. Not., vol. xxxii., p. 355. Astr. Nach., Nos. $1632,1633,1635$. 
direction to Tempel's comet, and its attendant "Leonids"; its motion is direct, or from west to east, while theirs is retrograde. Consequently, the motion of its node is in the opposite direction too. In other words, the meeting-place of its orbit with that of the earth retreats (and very rapidly) along the ecliptic instead of advancing. So that if the "Andromedes" stood in the supposed intimate relation to Biela's comet, they might be expected to anticipate the times of their recurrence by us much as a week (or thereabouts) in half a century. All doubt as to the fact may be said to have been removed by Signor Zezioli's observation of the annual shower in more than usual abundance at Bergamo, November 30, I867.

The missing comet was next due at perihelion in the year 1872, and the probability was contemplated by both Weiss and Galle of its being replaced by a copious discharge of falling stars. The precise date of the occurrence was not easily determinable, but Galle thought the chances in favour of November 28. The event anticipated the prediction by twenty-four hours. Scarcely had the sun set in Western Europe on November 27 when it became evident that Biela's comet was shedding over us the pulverised products of its disintegration. The meteors came in volleys from the foot of the Chained Lady, their numbers at times baffling the attempt to keep a reckoning. At Moncalieri, about 8 P.M., they constituted (as Father Denza said ${ }^{1}$ ) a "real rain of fire." Four observers counted, on an average, four hundred each minute and a half; and not a few fireballs, equalling the moon in diameter, traversed the sky. On the whole, however, the stars of i 872, though about equally numerous, were less brilliant than those of I866; the phosphorescent tracks marking their passage were comparatively evanescent and their movements sluggish. This is easily understood when we remember that the Andromedes overtake the earth, while the Leonids rush to meet it; the velocity of encounter for the first class of bodies being under twelve, for the second above forty-four miles a second. The spectacle was, nevertheless, magnificent. It presented itself successively to various parts of

1 Nature, vol. vii., p. 122. 
the earth, from Bombay and the Mauritius to New Brunswick and Venezuela, and was most diligently and extensively observed. Here it had well-nigh terminated by midnight. ${ }^{1}$

It was attended by a slight aurora, and although Tacchini had telegraphed that the state of the sun rendered some show of polar lights probable, it has too often figured as an accompaniment of star-showers to permit the coincidence to rank as fortuitous. Admiral Wrangel was accustomed to describe how, during the prevalence of an aurora on the Siberian coast, the passage of a meteor never failed to extend the luminosity to parts of the sky previously dark ${ }^{2}$ and the power of exciting electrical disturbance seems to belong to all such flitting cosmical atoms.

A singular incident connected with the meteors of 1872 has now to be recounted. The late Professor Klinkerfues, who had observed them very completely at Göttingen, was led to believe that not merely the débris strewn along its path, but the comet itself must have been in the closest proximity to the earth during their appearance. ${ }^{3}$ If so, it might be possible, he thought, to descry it as it retreated in the diametrically opposite direction from that in which it had approached. On November 30, accordingly, he telegraphed to Mr. Pogson, the Madras astronomer, "Biela touched earth November 27; search near Theta Centauri" - the "anti-radiant," as it is called, being situated close to that star. Bad weather prohibited observation during thirty-six hours, but when the rain-clouds broke on the morning of December 2, there a comet was, just in the indicated position. In appearance it might bave passed well enough for one of the Biela twins. It had no tail, but a decided nucleus, and was about 45 seconds across, being thus altogether below the range of naked-eye discernment. It was again observed December 3, when a short tail was perceptible; but overcast skies supervened, and it has never since been seen. Its identity accordingly remains in doubt. It seems tolerably certain, however, that it was not the lost comet, which ought to have passed

1 A. S. Herschel, Report Brit. Ass., 1873, p. 390. ${ }^{2}$ Humboldt, Cosmos, vol. i., p. II4 (Otté's trans.). ${ }^{3}$ Month. Not., vol. xxxiii., p. 128. 
that spot twelve weeks earlier, and was subject to no conceivable disturbance capable of delaying to that extent its revolution. On the other hand, there is the strongest likelihood that it belonged to the same system ${ }^{1}$ - that it was a third fragment, torn from the parent-body of the Andromedes at a period anterior to our first observations of it.

In thirteen years, Biela's comet (or its relics) travels nearly twice round its orbit, so that a renewal of the meteoric shower of I 872 was looked for on the same day of the year I885, the probability being emphasised by an admonitory circular from Dunecht. Astronomers were accordingly on the alert, and were not disappointed. In England, observation was partially impeded by clouds; but at Malta, Palermo, Beyrout, and other southern stations, the scene was most striking. The meteors were both larger and more numerous than in 1872. Their numbers in the densest part of the drift were estimated by Professor Newton at 75,000 per hour, visible from one spot to so large a group of spectators that practically none could be missed. Yet each of these multitudinous little bodies was found by him to travel in a clear cubical space of which the edge measured twenty miles! ${ }^{2}$ Thus the dazzling effect of a luminous throng was produced without jostling or overcrowding, by particles, it might almost be said, isolated in the void.

Their aspect was strongly characteristic of the Andromede family of meteors. "They invariably," Mr. Denning wrote, ${ }^{3}$ " traversed short paths with very slow motions, and became extinct in evolved streams of yellowish sparks." The conclusion seemed obvious "that these meteors are formed of very soft materials, which expand while incalescent, and are immediately crumbled and dissipated into exiguous dust."

The Biela meteors of I 885 did not merely gratify astronomers with a fulfilled prediction, but were the means of communicating to them some valuable information. Although their main body was cut through by the moving earth in six hours, and was not more than 100,000 miles across, skirmishers were thrown out to

1 Even this was denied by Bruhns, Astr. Nach., No. 2054. 2 Am. Jour., vol. xxxi., p. 425. $\quad 3$ Month. Not., vol. xlvi., p. 69 . 
nearly a million miles on either side of the compact central battalions. Members of the system were, on the 26th of November, recorded by Mr. Denning at the hourly rate of about I30; and they did not wholly cease to be visible until December I. They afforded besides a particularly well-marked example of that diffuseness of radiation, previously observed in some less conspicuous displays. Their paths seemed to diverge from an area, rather than from a point in the sky. They came so ill to focus, that divergences of several degrees were found between the most authentically determined radiants. These incongruities are attributed by Professor Newton to the irregular shape of the meteoroids, evoking unsymmetrical resistance from the air, and hence cansing them to glance from their original direction on entering it. Thus their luminous tracks did not always represent (even apart from the effects of the earth's attraction) the true prolongation of their course through space.

The Andromedes of 1872 were laggards behind the comet from which they sprang: those of 1885 were its avant-couriers. That wasted and disrupted body was not due at the node until January 26, I 886 , sixty days, that is, after the earth's encounter with its meteoric fragments. These are now probably scattered over more than five hundred million miles of its orbit; ${ }^{1}$ yet Professor Newton considers that all must have formed one compact group with Biela at the time of its close approach to Jupiter about the middle of I84I. For otherwise, both comet and meteorites could not have experienced, as they seem to have done, the same kind and amount of disturbance. The rapidity of cometary disintegration is thus curiously illustrated.

A short-lived persuasion that the missing heavenly bodyitself had been recovered, was created by Mr. Edwin Holmes's discovery, at London, November 6, I892, of a tolerably bright, tailless comet, just in a spot which Biela's comet must have traversed in approaching the intersection of its orbit with that of the earth. A hasty calculation by Berberich assigned elements to the new-

1 In Schiaparelli's opinion, centuries must have elapsed while the observed amount of scattering was being produced. Le stelle Cadenti, 1886, p. I12. 
comer seeming, not only to ratify the identity, but to promise a quasi-encounter with the earth on November 2I. The only effect of the prediction, however, was to raise a panic among the negroes of the Southern States of America. The comet quietly ignored it, and moved away from, instead of towards the appointed meeting-place. Its projection then, on the night of its discovery, upon a point of the Biela-orbit, was by a mere caprice of chance. North America, nevertheless, was visited on November 23 by a genuine Andromede shower. Although the meteors were less numerous than in 1885, Professor Young estimated that 30,000, at the least, of their orange fire-streaks came, during five hours, within the range of view at Princeton. ${ }^{1}$ The anticipation of their due time by four days implied-if they were a prolongation of the main Biela group, the nucleus of which passed the spot of encounter five months previously-a recession of the node since $\mathrm{I} 885$ by nearly four degrees. Unless, indeed, Mr. Denning were right in supposing the display to have proceeded from "an associated branch of the main swarm through which we passed in I872 and I885." 2 The existence of separated detachments of Biela meteors, attributed to disturbing planetary action, was contemplated as highly probable by Schiaparelli. ${ }^{3}$ Such may have been the belated flights met with in I830, I838, I841, and I847, and such the advance-flight plunged through in 1892 .

Biela does not offer the only example of cometary disruption. Setting aside the unauthentic reports of early chroniclers, we meet the "double comet" discovered by Liais at Olinda (Brazil), February 27, I860, of which the division appeared recent, and about to be carried farther. ${ }^{4}$ But a division once established, separation must continually progress. The periodic times of the fragments can never be identical; one must drop a little behind the other at each revolution, until at length they come to travel in remote parts of nearly the same orbit. Thus the comet predicted by Klinkerfues and discovered by Pogson had

1 Astr. and Astro-Physics, Dec. 1892, p. 943. 2 Observatory, vol. xvi., p. 55. 3 Le Stelle Cadenti, p. I33; Rendiconti dell Istituto Lombardo, t. iii., ser. ii., p. 23. Cf. Bredichin, Astr. Nach., Nos. 3154, 3156. 4 Month. Not., vol. xx., p. 336. 
already lagged to the extent of twelve weeks, and we shall meet instances farther on where the retardation is counted, not by weeks, but by years. Here, original identity emerges only from calculation and comparison of orbits.

Comets then die, as Kepler wrote long ago, sicut bombyces filo fundendo. This certainty, anticipated by Kirkwood in I861, we have at least acquired from the discovery of their generative connection with meteors. Nay, their actual materials become, in smaller or larger proportions, incorporated with our globe. It is not indeed universally admitted that the ponderous masses of which, according to Daubrée's estimate, ${ }^{1}$ at least 600 fall annually from space upon the earth, ever formed part of the bodies known to us as comets. Some follow Tschermak in attributing to aerolites a totally different origin from that of periodical shooting-stars. That no clear line of demarcation can be drawn is no valid reason for asserting that no real distinction exists; and it is certainly remarkable that a meteoric fusilade may be kept up for hours without a single solid projectile reaching its destination. It would seem as if the celestial army had been supplied with blank cartridges. Yet, since a few detonating meteors have been found to proceed from ascertained radiants of shooting-stars, it is difficult to suppose that any generic difference separates them.

Their assimilation is further urged-though not with any demonstrative force-by two instances, the only two on record, of the tangible descent of an aerolite during the progress of a star-shower. On April 4, 1095, the Saxon Chronicle informs us that stars fell "so thickly that no man could count them," and adds that one of them having struck the ground in France, a bystander "cast water upon it, which was raised in steam with a great noise of boiling:" 2 And again, on November 27, 1885, while the skirts of the Andromede-tempest were trailing over Mexico, a "ball of fire" was precipitated from the sky at Mazapil, within view of a ranchman. ${ }^{3}$ Scientific examination proved it to be a " siderite," or mass of " nickel-iron ; " its weight

1 Revue d. d. Mondes, Dec. I5, I885, p. 889.

2 Palgrave, Phil. Trans., vol, cxxv., p. I75.

${ }^{3}$ W. E. Hidden, Century May., vol. xxxiv., p. 534. 
exceeded eight pounds, and it contained many nodules of graphite. We are not, however, authorised by the circumstances of its arrival in regarding the Mazapil fragment of cosmic metal as a specimen torn from Biela's comet. In this, as in the preceding case, the coincidence of the fall with the shower may have been purely casual. No hint is given of any sort of agreement between the sample provided for curious study, and the swarming meteors consumed in the upper air.

Professor Newton's inquiries into the tracks pursued by meteorites previous to their collisions with the earth, tend to distinguish them, at least specifically, from shooting-stars. $\mathrm{He}$ found that nearly all had been travelling with a direct movement in orbits the perihelia of which lay in the outer half of the space separating the earth from the sun. ${ }^{1}$ Shooting-stars, on the other hand, are entirely exempt from such limitations. The Yale College Professor concludes "that the larger meteorites moving in our solar system are allied much more closely with the group of comets of short period than with the comets whose orbits are nearly parabolic." They would thus seem to be more at home than might have been expected amid the planetary family. Father Carbonelle has moreover shown ${ }^{2}$ that meteorites, if explosion-products of the earth or moon, should, with rare exceptions, follow just the kind of paths assigned to them, from data of observation, by Professor Newton. Yet it is altogether improbable that projectiles from terrestrial volcanoes should, at any geological epoch, have received impulses powerful enough to enable them, not only to surmount the earth's gravity, but to penetrate its atmosphere.

A striking-indeed, an almost startling-peculiarity, on the other hand, divides from their congeners a class of meteors identified by Mr. Denning during ten years' patient watching of such phenomena at Bristol. ${ }^{3}$ These are described as " meteors with stationary radiants," since for months together they seem to come from the same fixed points in the sky. Now this

${ }^{1}$ Amer. Jour. of Science, vol. xxxvi., p. i., I888. ${ }^{2}$ Revue des Questions Scientifiques, Jan. 1889, p. 194; Tisserand, Bull. Astr., t. viii., p. 460. 3 Month. Not., vol. xlv., p. 93. 
implies quite a portentous velocity. The direction of meteorradiants is affected by a kind of aberration, analogous to the aberration of light. It results from a composition of terrestrial with meteoric motion. Hence, unless that of the earth in its orbit be by comparison insignificant, the visual line of encounter must shift, if not perceptibly from day to day, at any rate conspicuously from month to month. The fixity, then, of halfa-dozen or more systems observed by $\mathrm{Mr}$. Denning seems to demand the admission that their members travel so fast as to throw the earth's movement completely out of the account. The required velocity would be, by Mr. Ranyard's calculation, at least 880 miles a second. ${ }^{1}$ But the aspect of the meteors justifies no such extravagant assumption. Their seeming swiftness is very various, and-what is highly significant-it is notably less when they pursue than when they meet the earth. Yet the "incredible and unaccountable" ${ }^{2}$ fact of the existence of these "long radiants," although doubted by Tisserand ${ }^{3}$ on the ground of its theoretical refractoriness, must apparently be admitted.

The Perseids afford, on the contrary, a remarkable instance of a "shifting radiant." Mr. Denning's observations of these' yellowish, leisurely meteors extended over nearly six weeks, from July 8 to August I6; " the point of radiation meantime progressing no less than $57^{\circ}$ in right ascension. Doubts as to their common origin were hence freely expressed, especially by Mr. Monck of Dublin. ${ }^{4}$ But the late Dr. Kleiber ${ }^{5}$ proved by strict geometrical reasoning, that the forty-nine radiants successively determined for the shower were all in reality comprised within one narrowly limited region of space. In other words, the application of the proper corrections for the terrestrial movement, and for the effects of attraction by which each individual shooting-star is compelled to describe a hyperbola round the earth's centre, reduces the extended line of radiants to a compact group with the cometary radiant for its central point; the cometary radiant being the spot in the sky met by a tangent to

1 Observatory, vol. viii., p. 4.

3 Comptes Rendus, t. cix., p. 344 .

5 Month. Not., vol. lii., p. 34 I.
2 Denning, Month. Not., vol. xxxviii., p. I I4. 4 Publ. Astr. Pac. Noc., vol. iii., p. II4. 
the orbit of the Perseid comet of 1862 at its intersection with the orbit of the earth. The reality of the connection between the comet and the meteors could scarcely be more cogently demonstrated; while the vast diniensions of the stream into which the latter are found to be diffused, cannot but excite astonishment not unmixed with perplexity.

The first successful application of the spectroscope to comets was by Donati in I $864 .{ }^{1}$ A comet discovered by Tempel, July 4, brightened until it appeared like a star somewhat below the second magnitude, with a feeble tail $30^{\circ}$ in length. It was remarkable as having, on August 7, almost totally eclipsed a small star-a very rare occurrence. ${ }^{2}$ On August 5 Donati admitted its light through his train of prisms, and found it, thus analysed, to consist of three bright bands-yellow, green, and blue-separated by wider dark intervals. This implied a good deal. Comets had previously been considered, as we have seen, to shine mainly, if not wholly, by reflected sunlight. They were now perceived to be self-luminous, and to be formed, to a large extent, of glowing gas. The next step was to determine what kind of gas it was that was thus glowing in them; and this was taken by Dr. Huggins in $1868 .^{3}$

A comet of subordinate brilliancy, known as comet I 868 ii., or sometimes as Winnecke's, was the subject of his experiment. On comparing its spectrum with that of an olefiant-gas 'vacuum tube' rendered luminous by electricity, he found the agreement exact. It has since been abundantly confirmed. All the eighteen comets tested by light-analysis, between I868 and 1880, showed the typical hydro-carbon spectrum ${ }^{4}$ common to the whole group of those compounds, but probably due immediately to the presence of acetylene. Some minor deviations from the laboratory pattern, in the shifting of the maxima of light from the edge towards the middle of the yellow and blue bands, have been experimentally reproduced by Vogel and Hasselberg in tubes containing a mixture of carbonic oxide with olefiant

${ }^{1}$ Astr. Nach., No. 1488. $\quad 2$ Annuaire, Paris, 1883, p. 185. $\quad 3$ Phil. Tirans., vol. clviii., p. 556 . ${ }^{4}$ Hasselberg, Mém. de l'Ac. Imp. de St. Pétersbourg, t. xxviii. (7th ser.), No. 2 p. 66. 
gas. ${ }^{1}$ Their illumination by disruptive electric discharges was, however, a condition sine qua non for the exhibition of the cometary type of spectrum. When a continuous current was employed, the carbonic oxide bands asserted themselves to the exclusion of the hydro-carbons. The distinction has great significance as regards the nature of comets. For it indicates, in the first place, that combinations of carbon with oxygen, as well as with hydrogen, are present in them ; while it affords, in the second, a criterion as to the quality of the electrical processes by which their constituent vapours are rendered luminous. Of particular interest in this connection is the circumstance that carbonic oxide is one of the gases evolved by meteoric stones and irons under stress of heat. ${ }^{2}$ It must then apparently have formed part of an aeriform mass in which they were immersed at an earlier stage of their history. These facts afford the only trustworthy evidence of the extra-terrestrial existence of oxygen.

In a few exceptional comets with large perihelion-distances, the usual carbon-bands have been missed. Two such were observed by Dr. Huggins in I866 and I 867 respectively. ${ }^{3}$ In each, a green ray, approximating in position to the fundamental nebular line, crossed an otherwise unbroken spectrum. And Holmes's comet of $1892^{4}$ displayed only a faint prismatic band devoid of any characteristic feature. ${ }^{5}$ Now the path of this body is inscribed, as it were, between the orbits of Jupiter and Mars ; and of Dr. Huggins's pair, the first (comet I866 i. of the November meteors) approaches very little nearer than the earth does to the sun; while the second (comet I867 ii.) maintains a still greater distance from it. Hence possibly the unusual nature of the spectra of all three.

The earliest comet of first-class lustre to present itself for spectroscopic examination was that discovered by Coggia at Marseilles, April I7, I874. Invisible to the naked eye till June, it blazed out in July a splendid ornament of our northern

1 Scheiner, Die Spectralanalyse der Gestirne, p. 234. ${ }^{2}$ Dewar, Proc. Roy. Inst., vol. xi., p. 541. $\quad 3$ Proc. R. Soc., vol. xv., p. 5 ; Month. Not., vol. xxvii., p. 288. ${ }^{4}$ Keeler, Astr. and Astro-Physics, Dec. 1892, p. $929 . \quad{ }^{5}$ Vogel, Astr. Nach., No. 3142. 
skies, with a just perceptibly curved tail, reaching more than half-way from the horizon to the zenith, and a nucleus surpassing in brilliancy the brightest stars in the Swan. Bredichin, Vogel, and Huggins ${ }^{1}$ were unanimous in pronouncing its spectrum to be that of marsh or olefiant gas. Father Secchi, in the clear sky of Rome, was able to push the identification even closer than had heretofore been done. The completehydro-carbon spectrum consists of five zones of variously coloured light. Three of these only-the three central ones-had till then been obtained from comets; owing, it was supposed, to their temperature not being high enough to develop the others. The light of Coggia's comet, however, was found to contain all five, traces of the violet band emerging June 4, of the red, July 2.2 Presumably, all five would show universally in cometary spectra, were the dispersed rays strong enough to enable them to be seen.

The gaseous surroundings of comets are then largely made up of a compound of hydrogen with carbon. Other materials are also present; but the hydro-carbon element is probably unfailing and predominant. Its luminosity is, there is little doubt, an effect of electrical excitement. Zöllner showed in $1872^{3}$ that owing to evaporation and other changes produced by rapid approach to the sun, electrical processes of considerable intensity must take place in comets; and that their original light is immediately connected with these, and depends upon solar radiation, rather through its direct or indirect electrifying effects, than through its more obvious thermal power, may be considered a truth permanently acquired to science. ${ }^{4}$ They are not, it thus seems, bodies incandescent through heat, but glowing by electricity; and this is compatible, under certain circumstances, with a relatively low temperature.

The gaseous spectrum of comets is accompanied, in varying degrees, by a continuous spectrum. This is usually derived most strongly from the nucleus, but extends, more or less, to the nebulous appendages. In part, it is certainly due to reflected sunlight; in part, most likely, to the ignition of minute solid particles.

${ }_{1}^{1}$ Proc. Roy. Soc., vol. xxiii., p. 154. ${ }^{2}$ Hasselberg, loc. cit., p. $58 . \quad{ }^{3}$ Ueber die Natur der Cometen, p. $112 .{ }^{4}$ Hasselberg, loc. cit., p. 38. 


\section{CHAPTER XI.}

\section{RECENT COMETS (continued).}

'THE mystery of comets' tails has been to some extent penetrated; so far, at least, that, by making certain assumptions strongly recommended by the facts of the case, their forms can be, with very approximate precision, calculated beforehand. We have, then, the assurance that these extraordinary appendages are composed of no ethereal or super-sensual stuff, but of matter such as we know it, and subject to the ordinary laws of motion, though in a state of extreme tenuity. This is unquestionably: one of the most remarkable discoveries of our time.

Olbers, as already stated, originated in 1812 the view that the tails of comets are made up of particles subject to a force of electrical repulsion proceeding from the sun. It was developed and enforced by Bessel's discussion of the appearances presented by Halley's comet in 1835 . He, moreover, provided a formula for computing the movement of a particle under the influence of a repulsive force of any given intensity, and thus laid firmly the foundation of a mathematical theory of cometary emanations. Professor W. A. Norton, of Yale College, considerably improved this by inquiries begun in 1844 , and resumed on the apparition of Donati's comet; and Dr. C. F. Pape at Altona ${ }^{1}$ gave numerical values for the impulses outward from the sun, which must have actuated the materials respectively of the curved and straight tails adorning the same beautiful and surprising. object.

The physical theory of repulsion, however, was, it might be said, still in the air. Nor did it assume an aspect of even

1 Astr. Nach., Nos. Ir72-74. 
moderate plausibility until Zöllner took it in hand in $1871 .^{1}$ It is perfectly well ascertained that the energy of the push or pull produced by electricity depends (other things being the same) upon the surface of the body acted on; that of gravity, upon its mass. The efficacy of solar electrical repulsion relatively to solar gravitational attraction grows, consequently, as the size of the particle diminishes. Make this small enough, and it will virtually cease to gravitate, and will unconditionally obey the impulse to recession.

This principle Zöllner was the first to realise in its application to comets. It gives the key to their constitution. Admitting (as we seem bound to do) that the sun and they are similarly electrified, their more substantially aggregated parts will still follow the solicitations of his gravity, while the finely-divided particles escaping from them will, simply by reason of their minuteness, fall under the sway of his repellent electric power. They will, in other words, form "tails." Nor is any extravagant assumption called for as to the intensity of the electrical charge concerned in producing these effects. Zöllner, in fact, showed ${ }^{2}$ that it need not be higher than that attributed by the best authorities to the terrestrial surface.

It is now more than thirty years since Professor Bredichin directed his attention to these curious phenomena. His persistent inquiries on the subject, however, date from the appearance of Coggia's comet in 1874. On computing the value of the repulsive force exerted in the formation of its tail, and comparing it with values of the same force arrived at by him in 1862 for some other conspicuous comets, it struck him that the numbers representing them fell into three welldefined classes. "I suspect," he wrote in 1877 , "that comets are divisible into groups, for each of which the repulsive force is perhaps the same." 3 This idea was confirmed on fuller investigation. In 1882 the appendages of thirty-six well-observed comets had been reconstructed theoretically, without a single exception being met with to the rule of the three types.

1 Berichte Sächs. Ges., 1871, p. 174. ${ }_{2}^{2}$ Natur der Cometen, p. 124; Astr. Nach., No. 2086. $\quad 3$ Annales de l'Obs. de Moscou, t. iii., pt. i., p. 37. 
A further study of forty comets led, however, in 1885 , to a modification of the numerical results previously arrived at.

In the first of these, the repellent energy of the sun is fourteen times as strong as his attractive energy $;^{1}$ the particles forming the enormously long straight rays projected outward from this kind of comet, leave the nucleus with a mean velocity of just seven kilometres per second, which, becoming constantly accelerated, carries them in a few days to the limit of visibility. The great comets of I8I I, I843, and I86I, that of 1744 (so far as its principal tail was concerned), and Halley's comet at its various apparitions, belonged to this class. In the second type, the value of the repulsive force is less narrowly limited. For the axis of the tail, it exceeds by one-tenth $(=I \cdot I)$ the power of solar gravity; for the anterior edge, it is more than twice $(2 \cdot 2)$, for the posterior only half as strong. The corresponding initial velocity (for the axis) is 1500 metres a second, and the resulting appendage a scimitar-like or plumy tail, such as Donati's and Coggia's comet furnished splendid examples of. Tails of the third type are constructed with forces of repulsion from the sun ranging from one-tenth to three-tenths that of his gravity, producing an accelerated movement of attenuated matter from the nucleus, beginning at the leisurely rate of 300 to 600 metres a second. They are short, strongly bent, brush-like emanations, and in bright comets seem to be only found in combination with tails of the higher classes. Multiple tails, indeed-that is, tails of different types emitted simultaneously by one comet-are perceived, as experience advances and observation becomes closer, to be rather the rule than the exception. ${ }^{2}$

Now, what is the meaning of these three types? Is any translation of them into physical fact possible? To this question Bredichin supplied in 1879 a plausible answer. ${ }^{3}$ It was already a current surmise that multiple tails are composed

1 Bull. Astr., t. iii., p. 598. The value of the repellent force for the comet of $18 \mathrm{r}$ (which offered peculiar facilities for its determination) was found = 17.5. ${ }^{2}$ Faye, Comptes Rendus, t. xciii., p. 13. ${ }^{3}$ Annales, t. v., pt. ii., p. 137 . 
of different kinds of matter, differently acted on by the sun. Both Olbers and Bessel had suggested this explanation of the straight and curved emanations from the comet of I807; Norton had applied it to the faint light-tracks proceeding from that of Donati ; ${ }^{1}$ Winnecke, to the varying deviations of its more brilliant plumage. Bredichin defined and ratified the conjecture. $\mathrm{He}$ undertook to determine (provisionally as yet) the several kinds of matter appropriated severally to the three classes of tails. These he found to be hydrogen for the first, hydro-carbons for the second, and iron for the third. The ground of this apportionment is that the atomic weights of these substances bear to each other the same inverse proportion as the repulsive forces employed in producing the appendages they are supposed to form ; and Zöllner had pointed out in 1875 that the "heliofugal" power by which comets' tails are developed, would, in fact, be effective just in that ratio. ${ }^{2}$ Hydrogen, as the lightest known element-that is, the least under the influence of gravity-was naturally selected as that which yielded most readily to the counter-persuasions of electricity. Hydro-carbons had been shown by the spectroscope to be present in comets, and were fitted by their specific weight, as compared with that of hydrogen, to form tails of the second type; while the atoms of iron were just heavy enough to compose those of the third, and, from the plentifulness of their presence in meteorites, might be presumed to enter, in no inconsiderable proportion, into the mass of comets. These three substances, however, were by no means supposed to be the sole constituents of the appendages in question. On the contrary, the great breadth of what, for the present, were taken to be characteristically "iron" tails, was attributed to the presence of many kinds of matter of high and slightly different specific weights; ${ }^{3}$ while the expanded plume of Donati was shown to be, in reality, a whole system of tails, made up of many substances, each spreading into a separate hollow cone, more or less deviating from, and partially superposed upon the others.

These felicities of explanation must not, however, make us

1 Am. Jour. of Sc., vol. xxxii. (2nd ser.), p. 57. ${ }^{2}$ Astr. Nach., No. 2082. 3 Annales, t. vi., pt. i., p. 60. 
forget that the chemical composition attributed to the first type of cometary train has, so far, received no countenance from the spectroscope. The emission lines of free, incandescent hydrogen have never been derived from any part of these bodies. Opinions are, accordingly, far from being unanimous as to the cause of their structural peculiarities. Ranyard, ${ }^{1}$ Zenker, and Faye advocate the agency of heat-repulsion in producing them; Kiaer somewhat obscurely explains them through the evolution of gases by colliding particles ${ }^{2}$ Herz of Vienna concludes tails to be mere illusory appendages produced by electrical discharges through the rare medium assumed to fill space. ${ }^{3}$ But Hirn ${ }^{4}$ has conclusively shown that no such medium could possibly exist without promptly bringing ruin upon our "daedal earth" and its revolving companions.

Never was a theory more promptly or profusely illustrated than this of Bredichin. Within three years of its promulgation, five bright comets made their appearance, each presenting some distinctive peculiarity by which knowledge of these curious objects was materially helped forward. The first of these is remembered as the "Great Southern Comet." It was never visible in these latitudes, but made a short though stately progress through southern skies. Its earliest detection was at Cordoba on the last evening of January, I880; and it was seen on February I, as a luminous streak, reaching just after sunset from the south-west horizon towards the pole, in New South Wales, at Monte Video, and the Cape of Good Hope. The head was lost in the solar rays until February 4, when Dr. Gould, director of the National Observatory of the Argentine Republic at Cordoba, caught a glimpse of it very low in the west; and on the following evening, Mr. Eddie, at Graham's Town, discovered a faint nucleus, of a straw-coloured tinge, about the size of the annular nebula in Lyra. Its condensation, however, was very imperfect, and the whole apparition was of an exceedingly filmy texture. The tail was enormously long. On February 5 it extended-large perspective retrenchment notwithstanding-

${ }^{1}$ Astr. Register, March, I883. $\quad{ }^{2}$ Astr. Nach., No. 3018. $\quad{ }^{3}$ Ibid., No. 3093.

4 Constitution de l'Espace Céleste, p. 224. 
over an arc of $50^{\circ}$; but its brightness nowhere exceeded that of the Milky Way in Taurus. There was little curvature perceptible ; the edges of the appendage ran parallel, forming a nebulous causeway from star to star; and the comparison to an auroral beam was appropriately used. The aspect of the famous comet of 1843 was forcibly recalled to the memory of Mr. Janisch, governor of St. Helena; and the resemblance proved not merely superficial. But the comet of I880 was less brilliant, and even more evanescent. After only eight days of visibility, it had faded so much as no longer to strike, though still discoverable by the unaided eye; and on February 20 it was invisible with the great Cordoba equatoreal pointed to its known place.

But the most astonishing circumstance connected with this body is the identity of its path with that of its predecessor in 1843. This is undeniable. Dr. Gould, ${ }^{1} \mathrm{Mr}$. Hind, and Dr. Copeland, ${ }^{2}$ each computed a separate set of elements from the first rough observations, and each was struck with an agreement between the two orbits so close as to render them virtually indistinguishable. "Can it be possible," Mr. Hind wrote to Sir George Airy, "that there is such a comet in the system, almost grazing the sun's surface in perihelion, and revolving in less than thirty-seven years? I confess I feel a difficulty in admitting it, notwithstanding the above extraordinary resemblance of orbits." 3

Mr. Hind's difficulty was shared by other astronomers. It would, indeed, be a violation of common sense to suppose that a celestial visitant so striking in appearance had been for centuries back an unnoticed frequenter of our skies. Various expedients accordingly were resorted to for getting rid of the anomaly. The most promising at first sight was that of the resisting medium. It was hard to believe that a body, largely vaporous, shooting past the sun at a distance of less than a hundred thousand miles from his surface, should have escaped powerful retardation. It must have passed through the very midst of the corona. It might easily have had an actual encounter with a prominence. Escape from such proximity might, indeed, very well have been

${ }^{1}$ Astr. Nach., No. 2307. $\quad$ 2 Ibid., No. 2304. $\quad 3$ Observatory, rol. iii., p. 390. 
judged beforehand to be impossible. Even admitting no other kind of opposition than that dubiously supposed to have affected Encke's comet, the result in shortening the period ought to be of the most marked kind. It was proved by Oppolzer ${ }^{1}$ that if the comet of 1843 had entered our system from stellar space with parabolic velocity, it would, by the action of a medium such as Encke postulated (varying in density inversely as the square of the distance from the sun), have been brought down, by its first perihelion passage, to elliptic movement in a period of twentyfour years, with such rapid diminution that its next return would be in about ten. But such restricted observations as were available on either occasion of its visibility, gave no sign of such a rapid progress towards engulfment.

Another form of the theory was advocated by Klinkerfues. $\mathrm{He}$ supposed that four returns of the same body had been witnessed within historical memory - the first in 37 I B.c., the next in 1668, besides those of I843 and I880; an original period of 2039 years being successively reduced by the withdrawal at each perihelion passage of $\frac{1}{1320}$ of the velocity acquired by falling from the far extremity of its orbit towards the sun, to 175 and 37 years. A continuance of the process would bring the comet of i 880 back in 1897.

Unfortunately, the earliest of these apparitions cannot be identified with the recent ones unless by doing violence to the plain meaning of Aristotle's words in describing it. He states that the comet was first seen "during the frosts and in the clear skies of winter," setting due west nearly at the same time as the sun. ${ }^{2}$ This implies some considerable north latitude. But the objects lately observed had practically no north latitude. They accomplished their entire course above the ecliptic in two hours and a quarter, during which space they were barely separated a hand's-breadth (one might say) from the sun's surface. For the purposes of the desired assimilation, Aristotle's comet should have appeared in March. It is not credible, however, that even a native of Thrace should have termed March "winter."

$$
1 \text { Astr. Nach., No. 2319: } 2 \text { Meteor., lib. i., cap. } 6 .
$$


With the comet of 1668 the case is more dubious. The circumstances of its appearance are barely reconcilable with the identity attributed to it, although too vaguely known to render certainty one way or the other attainable. It might, however, be expected that recent observations would at least decide the questions whether the comet of 1843 could have returned in less than thirty-seven years, and whether the comet of 1880 was to be looked for at the end of $17 \frac{1}{2}$. But the truth is that both these objects were observed over so small an arc $-8^{\circ}$ and $3^{\circ}$ respectively - that their periods remained virtually undetermined. For while the shape and position of their orbits could be and were fixed with a very close approach to accuracy, the length of those orbits might vary enọrmously without any very sensible difference being produced in the small part of the curves traced out near the sun. It is, however, remarkable that Dr. Wilhelm Meyer arrived, by an elaborate discussion, at a period of thirtyseven years for the comet of $1880,{ }^{1}$ while the observations of I 843 are admittedly best fitted by Hubbard's ellipse of 533 years; but these Dr. Meyer supposes to be affected by some constant source of error, such as would be produced by a mistaken estimate of the position of the comet's centre of gravity. He infers finally that, in spite of previous non-appearances, we really have to do with a regular denizen of our system, returning once in thirty-seven years along an orbit of such extreme eccentricity that its movement might be described as one of precipitation towards and rapid escape from the sun, rather than of sedate circulation round it.

The geometrical test of identity has hitherto been the only one which it was possible to apply to comets, and in the case before us it may fairly be said to have broken down. We may, then, tentatively, and with much hesitation, try a physical test, though scarcely yet, properly speaking, available. We have seen that the comets of I843 and I880 were strikingly alike in general appearance, though the absence of a formed nucleus in the latter, and its inferior brilliancy, detracted from the convincing effect of the resemblance. Nor was it maintained when tried

1 Mém. Soc. Phys. de Genève, t. xxviii., p. 23. 
by exact methods of inquiry. Professor Bredichin found that the gigantic ray emitted in 1843 belonged to his type No. I ; that of I880 to type No. 2. ${ }^{1}$ The particles forming the one were actuated by a repulsive force ten times as powerful as those forming the other. It is true that a second noticeably curved tail was seen in Chili, March I, and at Madras, March I I, I843; and M. Bredichin, accordingly, thinks the conjecture justified that the materials composing on that occasion the principal appendage having become exhausted, those of the secondary one remained predominant, and reappeared alone in the "hydrocarbon " train of I880. But the one known instance in point is against such a supposition. Halley's comet, the only great comet of which the returns have been securely authenticated and carefully observed, has preserved its "type" unchanged through many successive revolutions. The dilemma presented to astronomers by the Great Southern Comet of I880 was unexpectedly renewed in the following year.

On the 22nd of May I88I, Mr. John Tebbutt of Windsor, New South Wales, scanning the western sky, discerned a hazylooking object which he felt sure was a strange one. A marine telescope at once resolved it into two small stars and a comet, the latter of which quickly attracted the keen attention of astronomers; for Dr. Gould, computing its orbit from his first observations at Cordoba, found it to agree so closely with that arrived at by Bessel for the comet of $\mathrm{i} 807$, that he telegraphed to Europe, June I, announcing the unexpected return of that body. So unexpected, that theoretically it was not possible before the year 3346; and Bessel's investigation was one which inspired and eminently deserved confidence. Here then once more the perplexing choice had to be made between a premature and unaccountable re-appearance, and the admission of a plurality of comets moving nearly in the same path. But in this case facts proved decisive.

Tebbutt's comet passed the sun June I6, at a distance of sixty-eight millions of miles, and became visible in Europe six days later. It was, in the opinion of some, the finest object of

${ }^{1}$ Annales de l'Obs. de Moscou, t. vii., pt. i., p. 60. 
the kind since 186I. Jn traversing the constellation Auriga, on its debut in these latitudes, it outshone Capella. On June 24 and some subsequent nights, it was unmatched in brilliancy by any star in the heavens. In the telescope, the "two interlacing arcs of light" which had adorned the head of Coggia's comet were reproduced; while a curious dorsal spine of strong illumination formed the axis of the tail, which extended in clear skies over an arc of $20^{\circ}$. It belonged to the same "type" as Donati's great plume; the particles composing it being driven from the sun by a force twice as powerful as that urging them towards it. ${ }^{1}$ But the appendage was, for a few nights, and by two observers, perceived to be double. Tempel, on June 27, and Lewis Boss, at Albany (N.Y.), June 26 and 28, saw a long straight ray corresponding to a far higher rate of emission than the curved train, and shown by Bredichin to be a member of the (so-called) hydrogen class. It had vanished by July I, but made a temporary reappearance July $22 .^{2}$

The appendages of this comet were of remarkable transparency. Small stars shone wholly undimmed across the tail, and a very nearly central transit of the head over one of the seventh magnitude on the night of June 29, produced-if any change-an increase of brilliancy in the object of this spontaneous experiment. ${ }^{3}$ Yet Dr. Meyer, at the Geneva Observatory, found distinct evidence of refraction suffered by stellar rays under these circumstances. Three times he pursued with micrometric measurements the course of a star across the cometary surroundings; and on each occasion the uniformity of its progress was disturbed in a manner corresponding to the optical action of a gaseous mass increasing in density and refractive power as the square of the distance from the nucleus diminished. Supposing olefiant gas to be in question, its density, 102,000 kilometres from the nucleus, was estimated to be $\frac{7}{1000}$ that of our atmosphere at the sea-level. ${ }^{4}$ This was the

1 Bredichin, Annales, t. viii., p. 68. 2 Am. Jour. of Sc., vol. xxii., p. 305. 3 Messrs. Burton and Green nbserved a dilatation of the stellar image into a nebulous patch by the transmission of its rays through a nuclear jet of the comet. Am. Jour. of Sc., vol. xxii., p. 163. 4 Archives des Sciences, t. viii., p. 535. Meyer founded his conclusions on the theory of M. Gustave Cellérier. 
first successful attempt to measure the effects of cometary refraction, and will doubtless be renewed on a favourable opportunity.

The track pursued by this comet gave peculiar advantages for its observation. Ascending from Auriga through Camelopardus, it stood, July I9, on a line between the Pointers and the Pole, within $8^{\circ}$ of the latter, thus remaining for a considerable period constantly above the horizon of northern observers. Its brightness, too, was no transient blaze, but had a lasting quality which enabled it to be kept steadily in view during nearly nine months. Visible to the naked eye until the end of August, the last telescopic observation of it was made February 14, 1882, when its distance from the earth considerably exceeded 300 million miles. Under these circumstances, the knowledge acquired of its orbit was of more than usual accuracy, and showed conclusively that the comet was not a simple return of Bessel's ; for this would involve a period of seventy-four years, whereas 'Tebbutt's comet cannot revisit the sun until after the lapse of close upon three millenniums. Nevertheless, the two bodies move so nearly in the same path that an original connection of some kind is obvious; and the recent example of Biela readily suggested a conjecture as to what the nature of that connection might have been. The comets of I 807 and I88I are then regarded with much probability as fragments of a primitive disrupted body, one following in the wake of the other at an interval of seventy-four years.

Tebbutt's comet was the first of which a satisfactory photograph was obtained. The difficulties to be overcome were very great. The chemical intensity of cometary light is, to begin with, extraordinarily small. Janssen estimated it at $\frac{1}{30000}$ of moonlight. ${ }^{1}$ So that, if the ordinary process by which lunar photographs are taken had been applied to the comet of $188 \mathrm{i}$, an exposure of at least three days would have been required in order to get an impression of the head with about a tenth part of the tail. But by that time a new method of vastly increased sensitiveness had been rendered available, by which dry gelatine-

1 Annuaire, Paris, r882, p. 781. 
plates were substituted for the wet collodion-plates previously in use ; and this improvement alone reduced the necessary time of exposure to two hours. It was brought down to half an hour by Janssen's employment of a seflector specially adapted to give an image illuminated eight or ten times as strongly as that produced in the focus of an ordinary telescope. ${ }^{1}$

The photographic feebleness of cometary. rays was not the only obstacle in the way of success. The proper motion of these bodies is so rapid as to render the usual devices for keeping a heavenly body steadily in view quite inapplicable. The machinery by which the diurnal movement of the sphere is followed, must be specially modified to suit each eccentric career. This too was done, and on June 30, I 88 I, Janssen secured a perfect photograph of the brilliant object then visible, showing the structure of the tail with beautiful distinctness to a distance of $2 \frac{1}{2}^{\circ}$ from the head. An impression to nearly $10^{\circ}$ was obtained about the same time by Dr. Henry Draper at New York, with an exposure of 162 minutes. $^{2}$

'Tebbutt's (or comet I88 I iii.) was also the first. comet of which the spectrum was so much as attempted to be chemically recorded. Both Dr. Huggins and Dr. Draper were successful in this respect, but Dr. Huggins was more completely so. ${ }^{3}$ The importance of the feat consisted in its throwing open to investigation a part of the spectrum invisible to the eye, and so affording an additional test of cometary constitution. The result was fully to confirm the origin from carbon-compounds assigned to the visible rays, by disclosing additional bands belonging to the same series in the ultra-violet; as well as to establish unmistakably the presence of a not inconsiderable proportion of reflected solar light by the clear impression of some of the principal Fraunhofer lines. Thus the polariscope was found to have told the truth, though not the whole truth.

The photograph so satisfactorily communicative was taken by Dr. Huggins on the night of June 24; and on the 29th, at Greenwich, the tell-tale Fraunhofer lines were perceived to in-

${ }^{1}$ Annuaire, p. 776. ${ }^{2}$ Am. Jour. of Sc., vol. xxii., p. I34. ${ }^{3}$ Report Brit. Ass., p. 520. 
terrupt the visible range of the spectrum. This was at first so vividly continuous, that the characteristic cometary bands could scarcely be detached from their bright background. But as the nucleus faded, towards the end of June, they came out strongly, and were more and more clearly seen, both at Greenwich and at Princeton, to agree, not with the spectrum of hydro-carbons lit up in a vacuum tube by an electric discharge, but with that of the same substances burning in a Bunsen flame. ${ }^{1}$ Here we have an additional clue to the molecular condition of cometary materials. It need not, however, be inferred that they are really in a state of combustion. This, from all that we know, may be called an impossibility. The truth pointed to seems rather to be that the electricity by which comets are rendered luminous is of very low intensity. ${ }^{2}$

The spectrum of the tail was, in this comet, found to be not essentially different from that of the head. Professor Wright of Yale College ascertained a large, but probably variable percentage of its light to be polarised in a plane passing through the sun, and hence to be reflected sunlight. ${ }^{3}$ A faint continuous spectrum corresponded to this portion of its radiance; but gaseous emissions were also present. At Potsdam, on June 30, the hydro-carbon bands were traced by Vogel to the very end of the tail ; ${ }^{4}$ and they were kept in sight by Young at a greater distance from the nucleus than the more equably dispersed light. There seems little doubt that, as in the solar corona, the relative strength of the two orders of spectrum is subject to fluctuations.

The comet of I88 I iii. was thus of signal service to science. It afforded, when compared with the comet of 1807 , the first undeniable example of two such bodies travelling so nearly in the same orbit as to leave absolutely no doubt of the existence of a genetic tie between them. Cometary photography came to its earliest fruition with it; and cometary spectroscopy made a notable advance by means of it. Before it was yet out of sight, it was provided with a successor.

1 Month. Not., vol. xlii., p. I4; Am. Jour. of Sc., vol. xxii., p. 136. ${ }^{2}$ Piazzi Smyth, Nature, vol. xxiv., p. $430 . \quad{ }^{3}$ Astr. Nach., No. $2395 . \quad{ }^{4}$ Ibid. 
At Ann Arbor Observatory, Michigan, on July I4, a comet was discovered by Dr. Schaeberle, which, as his claim to priority is undisputed, is often allowed to bear his name. In strict scientific parlance, however, it is designated comet I88I iv. It was observed in Europe after three days, became just discernible with the naked eye at the end of July, and brightened consistently up to its perihelion passage, August 22, when it was still about fifty million miles from the sun. During many days of that month, the uncommon spectacle was presented of two bright comets circling together, though at widely different distances, round the north pole of the heavens. The newcomer, however, never approached the pristine lustre of its predecessor. Its nucleus, when brightest, was comparable to the star Cor Caroli, a narrow, perfectly straight ray proceeding from it to a distance of $10^{\circ}$. This was easily shown by Bredichin to belong to the hydrogen type of tails; ${ }^{1}$ while a "strange, faint second tail, or bifurcation of the first one," observed by Captain Noble, August $24,{ }^{2}$ fell into the hydro-carbon class of emanations. It was seen, August 22 and 24, by Dr. F. Terby of Louvain, ${ }^{3}$ as a short nebulous brush, like the abortive beginnings of a congeries of curving trains; but appeared no more. Its well-attested presence was, however, significant of the complex constitution of such bodies, and the manifold kinds of action progressing in them.

The only peculiarity in the spectrum of Schaeberle's comet consisted in the almost total absence of continuous light. The carbon-bands were nearly isolated and very bright. Barely from the nucleus proceeded a rainbow-tinted streak, indicative of solid or liquid matter, which, in this comet, must have been of very scanty amount. Its visit to the sun in I88I was, so far as is known, the first. The elements of its orbit showed no resemblance to those of any previous comet, nor any marked signs of periodicity. So that, although it may be considered probable, we do not know that it is moving in a closed curve, or will ever again penetrate the precincts of the solar system. It was last seen from the southern hemisphere, October I9, I88I.

1 Astr. Nach., No. 241 I.

2 Month. Not, vol. xlii., p. 49.

3 Astr. Nach., No. 2414. 
The third of a quartette of lucid comets visible within sixteen months, was discovered by Mr. C. S. Wells at the Dudley Observatory, Albany, March 17, I882. Two days later it was described by Mr. Lewis Boss as "a great comet in miniature," so well defined and regularly developed were its various parts and appendages. It was discernible without optical aid early in May; and on June 5 it was observed on the meridian at Albany just before noon-an astronomical event of extreme rarity. Comet Wells, however, never became an object so conspicuous as to attract general attention, owing to its immersion in the evening twilight of our northern June.

But the study of its spectrum revealed new facts of the utmost interest. All the comets till then examined had been found (with the two transiently observed exceptions already mentioned) to conform to one invariable type of luminous emission. Individual distinctions there had been, but no specific differences. Now all these bodies had kept at a respectful distance from the sun; for of the great comet of 1880 no spectroscopic inquiries had been made. Comet Wells, on the other hand, approached its surface within little more than five million miles on June IO, I882; and it is not doubtful that to this circumstance the novel feature in its incandescence was due.

During the first half of April its spectrum was of the normal type, though the carbon-bands were unusually weak; but with increasing vicinity to the sun they died out, and the entire light seemed to become concentrated into a narrow, unbroken, brilliant streak, hardly to be distinguished from the spectrum of a star. This unusual behaviour excited attention, and a strict watch was kept. It was rewarded at the Dunecht Observatory, May 27, by the discernment of what had never before been seen in a comet-the yellow ray of sodium. ${ }^{1}$ By June I, this had kindled into a blaze overpowering all other emissions. The light of the comet was practically monochromatic; and the image of the entire head, with the root of the tail, could be observed, like a solar prominence, depicted, in

1 Copernicus, vol. ii., p. 229. 
its new saffron vesture of vivid illumination, within the jaws of an open slit.

At Potsdam, the bright yellow line was perceived with astonishment by Vogel on May 3I, and was next evening identified with Fraunhofer's "D." Its character led him to infer a very considerable density in the glowing vapour emitting it. ${ }^{1}$ Hasselberg founded an additional argument in favour of the electrical origin of cometary light on the changes in the spectrum of comet Wells. ${ }^{2}$ For they were closely paralleled by some earlier experiments of Wiedemann, in which the gaseous spectra of vacuum tubes were at once effaced on the introduction of metallic vapours. It seemed as if the metal had no sooner been rendered volatile by heat, than it usurped the entire office of carrying the discharge, the resulting light being thus exclusively of its production. Had simple incandescence by heat been in question, the effect would have been different; the two spectra would have been superposed without prejudice to either. Similarly, the replacement of the hydro-carbon bands in the spectrum of the comet by the sodium line, proved electricity to be the exciting agent. For the increasing thermal power of the sun might, indeed, have ignited the sodium, but it could not have extinguished the hydro-carbons.

Dr. Huggins succeeded in photographing the spectrum of comet Wells by an exposure of one hour and a quarter. ${ }^{3}$ The result was to confirm the novelty of its character. None of the ultra-violet carbon groups were apparent; but certain bright rays, as yet unidentified, had imprinted themselves. Otherwise the spectrum was strongly continuous, uninterrupted even by the Fraunhofer lines detected in the spectrum of Tebbutt's comet. Hence it was concluded that a smaller proportion of reflected light was mingled with the native emissions of the later arival.

All that is certainly known about the extent of the orbit traversed by the first comet of $\mathrm{I} 882$ is that it came from, and

1 Astr. Nach., Nos. 2434, 2437.

2 Ibid., No. 244 I.

3 Report Brit. Ass., I882, p. 442. 
is now retreating towards, vastly remote depths of space. An American computer ${ }^{1}$ found a period indicated for it of no less than 400,000 years; A. Thraen of Dingelstädt arrived at one of 3617.2 Both are perhaps equally insecure.

We have now to give some brief account of one of the most remarkable cometary apparitions on record, and-with the single exception of that identified with the name of Halley-the most instructive to astronomers. The lessons learned from it were as varied and significant as its aspect was splendid; although from the circumstance of its being visible in general only before sunrise, the spectators of its splendour were comparatively few.

The discovery of a great comet at Rio Janeiro, September I I, I882, became known in Europe through a telegram from M. Cruls, director of the observatory at that place. It had, however (as appeared subsequently), been already seen on the 8th by Mr. Finlay of the Cape Observatory, and at Auckland as early as September 3. A later, but very singularly conditioned detection, quite unconnected with any of the preceding, was effected by Dr. Common at Ealing. Since the eclipse of May I7, when a comet-named "Tewfik" in honour of the Khedive of Egypt-was caught on Dr. Schuster's photographs, entangled, one might almost say, in the outer rays of the corona, he had scrutinised the neighbourhood of the sun on the infinitesimal chance of intercepting another such body on its rapid journey thence or thither. We record with wonder that, after an interval of exactly four months, that infinitesimal chance turned up in his favour.

On the forenoon of Sunday, September I7, he saw a great comet close to, and rapidly approaching the sun. It was, in fact, then within a few hours of perihelion. Some measures of position were promptly taken; but a cloud-veil covered the interesting spectacle before midday was long past. Mr. Finlay at the Cape was more completely fortunate. Divided from his fellow-observer by half the world, he unconsciously finished,

${ }^{1}$ J. J. Parsons, Am. Jour. of Science, vol. xxvii., p. 34. ${ }^{2}$ Astr. Nach., No. 244 I. 
under a clearer sky, his interrupted observation. The comet, of which the silvery radiance contrasted strikingly with the reddish-yellow glare of the sun's margin it drew near to, was followed "continuously right into the boiling of the limb"a circumstance without precedent in cometary history. ${ }^{1}$ Dr. Elkin, who watched the progress of the event with another instrument, thought the intrinsic brilliancy of the nucleus scarcely surpassed by that of the sun's surface. Nevertheless it had no sooner touched it than it vanished as if annihilated. So sudden was the disappearance (at 4h. 5om. 58s. Cape mean time), that the comet was at first believed to have passed behind the sun. But this proved not to have been the case. The observers at the Cape had witnessed a. genuine transit. Nor could non-visibility be explained by equality of lustre. For the gradations of light on the sun's disc are amply sufficient to bring out against the dusky background of the limb any object matching the brilliancy of the centre; while an object just equally luminous with the limb must inevitably show dark at the centre. The only practicable view, then, is that the bulk of the comet was of too filmy a texture, and its presumably solid nucleus too small, to intercept any noticeable part of the solar rays - a piece of information worth remembering.

On the following morning, the object of this unique observation showed (in Dr. Gill's words) "an astonishing brilliancy as it rose behind the mountains on the east of Table Bay, and seemed in no way diminished in brightness when the sun rose a few minutes afterward. It was only necessary to shade the eye from direct sunlight with the hand at arm's length, to see the comet, with its brilliant white nucleus and dense white, sharply-bordered tail of quite half a degree in length." 2 All over the world, wherever the sky was clear during that day, September I8, it was obvious to ordinary vision. Since I 843 nothing had been seen like it. From Spain, Italy, Algeria,

1 Observatory, vol. v., p. 355. The transit had been foreseen by Mr. Tebbutt, but it occurred after sunset in New South Wales. 2 Observatory, vol. v., p. 354 . 


\section{PLATE II.}
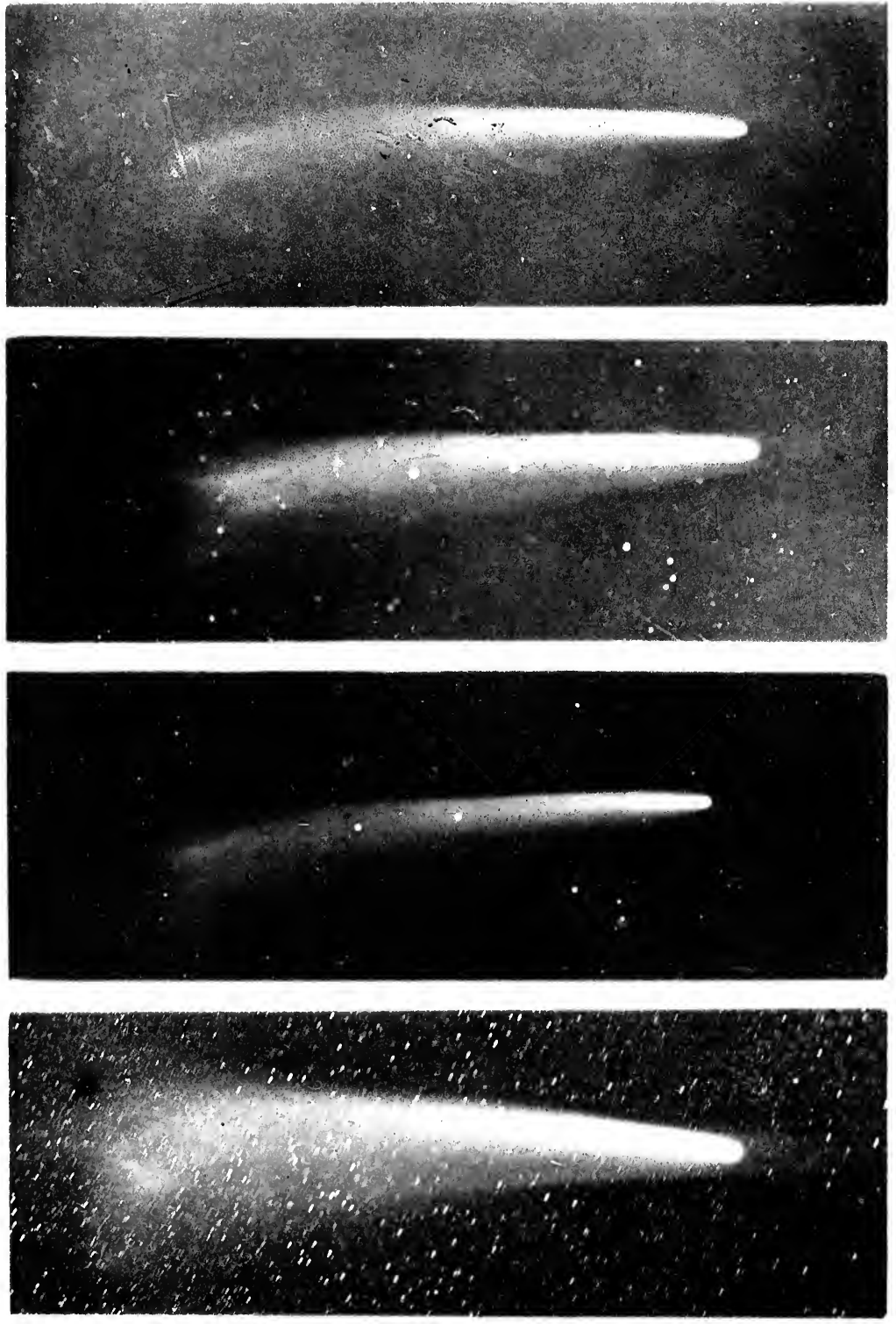

THE GREAT COMET OF SEPTEMBER I 882

Photographed at the Royal Observatory', Cape of Good Hope. 

Southern France, despatches came in announcing the extraordinary appearance. At Cordoba, in South America, the "blazing star near the sun" was the one topic of discourse. ${ }^{1}$ Moreover-and this is altogether extraordinary-the records of its daylight visibility to the naked eye extend over three days. At Reus, near Tarragona, it showed bright enough to be seen through a passing cloud when only three of the sun's diameters from his limb, just before its final rush past perihelion on September I7; while at Carthagena in Spain, on September I9, it was kept in view during two hours before and two hours after noon, and was similarly visible in Algeria on the same day. ${ }^{2}$

But still more surprising than the appearance of the body itself were the nature and relations of the path it moved in. The first rough elements computed for it by Mr. Tebbutt, Dr. Chandler of Harvard, and Mr. White, assistant at the Melbourne Observatory, showed at once a striking resemblance to those of the twin comets of 1843 and 1880 . This suggestive fact became known in this country, September 27, through the medium of a Dunecht Circular. It was fully confirmed by subsequent inquiries, for which ample opportunities were luckily provided. The likeness was not, indeed, so absolutely perfect as in the previous case ; it included some slight, though real differences; but it bore a strong and unmistakable stamp, broadly challenging explanation.

Two hypotheses only were really available. Either the comet of 1882 was an accelerated return of those of 1843 and I880, or it was a fragment of an original mass to which they also had belonged. For the purposes of the first view the "resisting medium "was brought into full play; the opinion invoking it was for some time both prevalent and popular, and formed the basis, moreover, of something of a sensational panic. For a comet which, at a single passage through the sun's atmosphere, encountered sufficient resistance to shorten its period from thirty-seven to two years and eight months, must, in the immediate future, be brought to rest on his surface; and the

1 Gould, Astr. Nach., No. 2481. 2 Flammarion; Comptes Rendus, t. xcv. p. $55^{8}$. 
solar conflagration thence ensuing was represented in some quarters, with more license of imagination than countenance from science, as likely to be of catastrophic import to the inhabitants of our little planet.

But there was a test available in I 882 which it had not been possible to apply either in I843 or in I880. The two bodies visible in those years had been observed only after they had already passed perihelion $;^{1}$ the third member of the group, on the other hand, was accurately followed for a week before that event, as well as during many months after it. Mr. Finlay's and Dr. Elkin's observation of its disappearance at the sun's edge formed, besides, a peculiarly delicate test of its motion. The opportunity was thus afforded, by directly comparing the comet's velocity before and after its critical plunge through the solar surroundings, of ascertaining with some approach to certainty whether any considerable retardation had been experienced in the course of that plunge. The answer distinctly given was that there had not. The computed and observed places on both sides of the sun fitted harmoniously together. The effect, if any were produced, was too small to be perceptible.

This result is, in itself, a memorable one. It seems to give the coup de grace to Encke's theory-discredited, in addition, by Backlund's investigation - of a resisting medium growing rapidly denser inwards. For the perihelion distance of the comet of I882, though somewhat greater than that of its predecessors, was nevertheless extremely small. It passed at less than 300,000 miles of the sun's surface. But the ethereal substance long supposed to obstruct the movement of Encke's comet would there be nearly 2000 times denser than at the perihelion of the smaller body, and must have exerted a conspicuous retarding influence. That none such could be detected seems to argue that no such medium exists.

Further evidence of a decisive kind was not wanting on the question of identity. The "Great September Comet" of I 882 was in no luurry to withdraw itself from curious terrestrial

1 Captain Ray's sextant-observation of the comet of 1843 , a few hours before perihelion, was too rough to be of use. 
scrutiny. It was discerned with the naked eye at Cordoba as late as March 7, I883, and still showed in the field of the great equatoreal on June I as an "excessively faint whiteness." 1 It was then about 480 millions of miles from the earth-a distance to which no other comet-not even excepting the peculiar one of I729-had been pursued. ${ }^{2}$ Moreover, an arc of 340 out of the entire 360 degrees of its circuit had been described under the eyes of astronomers ; so that its course came to be very well known. That its movement is in a very eccentric ellipse, traversed in several hundred years, was very soon ascertained. ${ }^{3}$ The later and exhaustive inquiries of Dr. H. Kreutz, of the Kiel observatory, ${ }^{4}$ have demonstrated that the period may be as long as rooo, but cannot fall short of 772 years. This unexpectedly wide range of doubt resulted from the impossibility of determining the comet's true centre of gravity. It closed every prospect of recognising its earlier apparitions.

The conclusion for a period to be counted by many centuries assures us positively that the comet of I882 was not a return of any of the three bodies so singularly connected with it. But it has little or no further application to them. ${ }^{5}$ For very slightly differing disturbances of each would suffice to develop a marked variety in their periods. A loss of velocity at perihelion, for instance, of only 49 metres a second (less than $\frac{1}{10000}$ of the whole), would bring a comet revolving in 175 years back in $37 .^{6}$ Yet the orbit would remain otherwise almost unchanged. A body moving in it would perceptibly diverge from its former track only at a considerable distance from the sun. Hence each of these four comets (I668-I 882) has doubtless-if they be in truth individually distinct-a period of its own.

A fifth has since come to be associated with them. On the I 8th of January, I887, M. Thome discovered at Cordoba a comet reproducing with curious fidelity the lineaments of that observed

1 Astr. Nach., No. 2538. $\quad 2$ Nature, vol. xxix., p. 135. $\quad{ }^{3}$ Astr. Nach., No. 2482. 4 Vierteljahrsschrift Astr. Ges., Jahrg. xxiv., p. 308 ; Bull. Astr., t. vii., p. 513. 5 The attention of the author was kindly directed to this point by Professor Young of Princeton (N.J.). $\quad{ }^{6}$ Rebeur-Paschwitz, Sirius, Bd. xvi., p. 233. This reasoning was designed to show the possible identity of the comets of 1668,1843 , and 1880 . 
in the same latitudes seven years previously. The narrow ribbon of light, contracting towards the sun, and running outward from it to a distance of thirty-five degrees; the unsubstantial head-a veiled nothingmess, as it appeared, since no distinct nucleus could be made out; the quick fading into invisibility, were all accordant peculiarities, and they were confirmed by some rough calculations of its orbit, showing geometrical affinity to be no less unmistakable than physical likeness. The observations secured were indeed, from the nature. of the apparition, neither numerous nor over-reliable; and the earliest of them dated from a week after perihelion, passed, almost by a touch-and-go escape, January I I. On January 27, this mysterious object could barely be discerned telescopically at Cordoba. ${ }^{1}$ That it belonged to the series of " southern comets" can scarcely be doubted; but the inference that it was an actual return of the comet of $\mathrm{I} 880$ is at present unsupported by any cogent evidence. It is worth noting that M. Meyer appends the "eclipse-comet" of I 882 to this extraordinary group. ${ }^{2}$

The idea of cometary systems was first suggested by Thomas Clausen in $1831 .^{3}$ It was developed by the acute inquiries of the late M. Hoek, director of the Utrecht Observatory, in I865 and some following years. ${ }^{4} \mathrm{He}$ found that in quite a considerable number of cases, the paths of two or three comets had a common point of intersection far out in space, indicating with much likelihood a community of origin. This consisted, according to his surmise, in the disruption of a parent mass during its sweep round the star latest visited. Be this as it may, the fact is undoubted, that numerous comets fall into groups, in which similar conditions of motion betray a pre-existent physical connection. Never before, however, had geometrical relationship been so notorious as between the three comets now under consideration; and never before, in a comet still, it might be said, in the prime of life, had physical peculiarities tending to account for that affinity been so obvious as in the chief member of the group.

${ }^{1}$ Oppenheim, Astr. Nach., No. 2902. ${ }^{2}$ Astr. Nach., No. 2717. ${ }^{3}$ Gruithuisen's Analekten, Heft vii., p. 48. Month. Not., vols. xxv., xxvi., xxviii. Cf. Plummer, Observatory, vol. xiii., p. 263. 
Observation of a granular structure in cometary nuclei dates far back into the seventeenth century, when Cysatus and Hevelius described the central parts of the comets of 16I8 and I652 respectively as made up of a congeries of minute stars. Analogous symptoms of a loose state of aggregation have of late been not unfrequently detected in telescopic comets, besides the instances of actual division offered by those connected with the names of Biela and Liais. The forces concerned in producing these effects seem to have been peculiarly energetic in the great comet of 1882 .

The segmentation of the nucleus was first noticed in the United States and at the Cape of Good Hope, September 30. It proceeded rapidly. At Kiel, on October 5 and 7, Professor Krüger perceived two centres of condensation. A definite and progressive separation into three masses was observed by Professor Holden, October I 3 and I $7 .^{1}$ A few days later, M. Tempel found the head to consist of four lucid aggregations, ranged nearly along the prolongation of the caudal axis; ${ }^{2}$ and Dr. Common, January 27, I883, saw five nuclei in a line "like pearls on a string:" ${ }^{3}$ This remarkable character was preserved to the last moment of the comet's distinct visibility. It was a consequence, according to Dr. Kreutz, of violent interior action in the comet itself while close to the sun.

There were, however, other curious proofs of a marked tendency in this body to disaggregation. On October 9, Schmidt discovered at Athens a nebulous object $4^{\circ}$ south-west of the great comet, and travelling in the same direction. It remained visible for a few days, and, from Oppenheim's and Hind's calculations, there can be little doubt that it was really the offspring by fission of the body it accompanied." This is rendered more probable by the unexampled spectacle offered, October I4, to Mr. E. E. Barnard, then of Nashville, Tennessee, of six or eight distinct cometary masses within $6^{\circ}$ south by west of the comet's head, none of which reappeared on the next opportunity for a search. ${ }^{5}$ A week later, however, one similar

1 Nature, vol. xxvii., p. 246. 2 Astr. Nach., No. 2468. 3 Athenaum, Feb. 3, 1883. 4 Astr. Nach., Nos. 2462, 2466. 5 1bid., No. 2489. 
object was discerned by Mr. W. R. Brooks, in the opposite direction from the comet. Thus, space appeared to be strewn with the filmy débris of this extraordinary body all along the track of its retreat from the sur.

Its tail was only equalled (if it were equalled) in length by that of the comet of 1843 . It extended in space to the vast distance of two hundred millions of miles from the head; but, so imperfectly were its proportions displayed to terrestrial observers, that it at no time covered an arc of the sky of more than $30^{\circ}$. This apparent extent was attained, during a few days previous to September 25, by a faint, thin, rigid streak, noticed only by a few observers-by Elkin at the Cape Observatory, Eddie at Grahamstown, and Cruls at Rio Janeiro. It diverged at a low angle from the denser curved train, and was produced, according to Bredichin, ${ }^{1}$ by the action of a repulsive force twelve times as strong as the counter-pull of gravity. It. belonged, that is, to type I ; while the great forked appendage, obvious to all eyes, corresponded to the lower rate of emission characteristic of type 2. This was remarkable for the perfect definiteness of its termination, for its strongly-forked shape, and for its unusual permanence. Down to the end of January I883, its length, according to Schmidt's observations, was still 93 million miles; and a week later it remained visible to the naked eye, without notable abridgment.

Most singular of all was an anomalous extension of the appendage towards the sun. During the greater part of October and November, a luminous tube or sheath, of prodigious dimensions, seemed to surround the head, and project in a direction nearly opposite to that of the usual outpourings of attenuated matter. (See Plate II.) Its diameter was computed by Schmidt to be, October I 5 , no less than four million miles, and it was described by Cruls as a "truncated cone of nebulosity," stretching $3^{\circ}$ or $4^{\circ}$ sunwards. ${ }^{2}$ This, and the entire anterior part of the comet, were again surrounded by a thin, but enormously voluminous paraboloidal envelope, observed by Schiaparelli for

1 Annales, Moscow, t. ix., pt. ii., p. 52. 2 Comptes Rendus, t xcvii., p. 797 . 
a full month from October 19. ${ }^{1}$ There can be little doubt that these abnormal effluxes were a consequence of the tremendous physical disturbance suffered at perihelion ; and it is worth remembering that something analogous was observed in the comet of I680 (Newton's), also noted for its excessively close approach to the sun. The only plausible hypothesis as to the mode of their production is that of an opposite state of electrification in the particles composing the ordinary and extraordinary appendages.

The spectrum of the great comet of 1882 was, in part, a repetition of that of its immediate predecessor, thus confirming the inference that the previously unexampled sodium-blaze was in both a direct result of the intense solar action to which they were exposed. But the D line was, this time, not seen alone. At Dunecht, on the morning of September i 8, Drs. Copeland and J. G. Lohse succeeded in identifying six brilliant rays in the green and yellow with as many prominent iron-lines; ${ }^{2}$ a very significant addition to our knowledge of cometary constitution, and one which goes far to justify Bredichin's assumption of various kinds of matter issuing from the nucleus with velocities inversely as their atomic weights. All the lines equally showed a slight displacement, indicating a recession from the earth of the radiating body at the rate of 37 to 46 miles a second. A similar observation, made by M. Thollon at Nice on the same day, gave emphatic sanction to the spectroscopic method of estimating movement in the line of sight. Before anything was as yet known of the comet's path or velocity, he announced, from the position of the double sodium-line alone, that at 3 P.M. on September 18 it was increasing its distance from our planet by from $6 \mathrm{I}$ to 76 kilometres per second. ${ }^{3}$ M. Bigourdan's subsequent calculations showed that its actual swiftness of recession was at that moment 73 kilometres.

Changes in the inverse order to those seen in the spectrum of comet Wells, soon became apparent. In the earlier body, carbon bands had died out with approach to perihelion, and had been replaced by sodium-emissions; in its successor, sodium

1 Astr. Nach., No. 2966. 2 Copernicus, vol. ii., p. 235. ${ }^{3}$ Comptes Rendus, t. xevi., p. 37 I. 
emissions became weakened and disappeared with retreat from perihelion, and found their substitute in carbon-bands. Professor Riccò was, in fact, able to infer, from the sequence of prismatic phenomena, that the comet had already passed the sun; thus establishing a novel criterion for determining the position of a comet in its orbit by the varying quality of its radiations.

Recapitulating what has been learnt from the five conspicuous comets of I880-82, we find that the leading facts acquired to science were these three. First, that comets may be met with pursuing each other, after intervals of many years, in the same, or nearly the same, track; so that identity of orbit can no longer be regarded as a sure test of individual identity. Secondly, that at least the outer corona may be traversed by such bodies with perfect apparent impunity. Finally, that their chemical constitution is a highly complex one, and that they possess, in some cases at least, a metallic core resembling the meteoric masses which occasionally reach the earth from planetary space.

A group of five comets, including Halley's, own a sort of cliental dependence upon the planet Neptune. They travel out from the sun just to about his distance from it, as if to pay homage to a powerful protector, who gets the credit of their establishment as periodical visitors to the solar system. The second of these bodies to effect a looked-for return was a comet - the sixteenth within ten years-discovered by Pons, July 20, I 8 I 2 , and found by Encke to revolve in an elliptic orbit, with a period of nearly 7 I years. It was not, however, until September I, I883, that Mr. Brooks caught its reappearance; it passed perihelion January 25, and was last seen June 2, I884. At its brightest, it had the appearance of a second-magnitude star furnished with a poorly-developed double tail, and was fairly conspicuous to the naked eye in southern Europe from December to March. One exceptional feature distinguished it: its fluctuations in form and luminosity were unprecedented in rapidity and extent. On September 2 I, Dr. Chandler ${ }^{1}$ observed 
it at Harvard as a very faint, diffused nebulosity, with slight central condensation. On the next night there was found in its place a bright star of the eighth magnitude, scarcely marked out, by a bare trace of environing haze, from the genuine stars it counterfeited. The change was attended by an eight-fold augmentation of light, and was proved by Schiaparellïs confirmatory observations ${ }^{1}$ to have been accomplished within a few hours. The stellar disguise was quickly cast aside. The comet appeared on September 23, as a wide nebulous disc, and soon after faded down to its original dimness. Its distance from the sun was then no less than 200 million miles, and its spectrum showed nothing unusual. These strange variations recurred slightly on October I5, and with marked emphasis January I, when they were witnessed with amazement, and photometrically studied by Dr. Müller of Potsdam. ${ }^{2}$ The entire cycle this time was run through in less than four hours - the comet having, in that brief space, condensed, with a vivid outburst of light, into a seeming star, and the seeming star having expanded back again into a comet. Scarcely less transient, though not altogether similar, changes of aspect were noted by M. Perrotin, January I 3 and I9, I884. ${ }^{3}$ On the latter date, the continuous spectrum given by a reddish-yellow disc surrounding the true nucleus, seemed intensified by bright knots corresponding to the rays of sodium.

A comet discovered by Mr. Sawerthal at the Royal Observatory, Cape of Good Hope, February 19, I888, distinguished itself by blazing up, on May I9, to four or five times its normal brilliancy, at the same time throwing out from the head two lustrous lateral branches. ${ }^{4}$ These had, on June I, spread backward so as to join the tail, with an effect like the playing of a fountain; ten or eleven days later, they had completely disappeared, leaving the comet in its former shape and insignificance. Its abrupt display of vitality occurred no less than two months after perihelion.

1 Astr. Nach., No. 2553. $\quad 2$ lbid., No. 2568. $\quad{ }^{3}$ Annales de l'Observatoire de Nice, t. ii., c. 53. $\quad$ Fényi, Astr. Nach., No. 2844; Kammermann, Ibid., No. 2849 . 
On the morning of July 7, I889, Mr. W. R. Brooks, of Geneva, New York, next to Barnard of Lick the most successful comet-hunter of our time, secured one of his customary trophies. The faint object in question was moving through the constellation Cetus, and turned out to be a member of Jupiter's numerous family of comets, revolving round the sun in a period of seven years. Its past history came then, to a certain extent, within the scope of investigation, and proved to have been singularly eventful; nor had the body escaped scatheless from the vicissitudes to which it had been exposed. Observing from Mount Hamilton, August 2 and 5, Professor Barnard noticed this comet $(\mathbf{8} 889, \mathbf{v}$.) to be attended in its progress through space by four outriders. "The two brighter companions" (the fainter pair survived a very short time) "were perfect miniatures," Professor" Barnard tells us," "of the larger comet, each having a small, fairly-defined head and nucleus, with a faint, hazy tail, the more distant one being the larger and less developed. The three comets were in a straight line, nearly east and west, their tails lying along this line. There was no connecting nebulosity between these objects, the tails of the two smaller not reaching each other, or the large comet. To all appearance they were absolutely independent comets." Nevertheless, Spitaler, at Vienna, in the early days of August, perceived, as it were, a thin cocoon of nebulosity woven round the entire trio. ${ }^{2}$ One of them faded from view September 5 ; the other actually ontshone the original comet on August 31, but was plainly of inferior vitality. It was last seen by Barnard on November 25, with the thirty-six inch refractor, while its primary afforded an observation for position with the twelve-inch, March 20, I890. ${ }^{3}$ A cause for the disruption it had presumably undergone had, before then, been plausibly assigned.

The adventures of Lexell's comet have long served to exemplify the effects of Jupiter's despotic sway over such bodies. Although bright enough in 1770 to be seen with the naked eye, and ascertained to be circulating in five and a half years, it had never

1 Publ. Astr. Pac. Soc., vol. i., p. 72. ${ }^{2}$ Annuaire, Paris, 189r, p. $30 \mathrm{I}$. Astr. Nach., No. 2989. 
previously been seen, and failed subsequently to present itself. The explanation of this anomaly, suggested by Lexell, and fully confirmed by the analytical inquiries both of Laplace and Leverrier, ${ }^{1}$ was that a very close approach to Jupiter in 1767 had completely changed the character of its orbit, and brought it within the range of terrestrial observation; while in I779, after having only twice traversed its new path (at its second return it was so circumstanced as to be invisible from the earth), it was, by a fresh encounter, diverted into one entirely different. Yet the possibility was not lost sight of that the great planet, by inverting its mode of action, might undo its own work, and fling the comet once more into the inner parts of the solar system. This possibility, it now seems, has been actually realised. The identification of Brooks's with Lexell's comet is due to the acumen of Dr. Chandler. ${ }^{2}$ He found that the former body had spent eight months in I 886 under Jupiter's immediate control-had, in fact, barely escaped being reduced to the position of his satellite-and had issued from the proximity with all the elements of its motion turned, so to speak, topsy-turvy. Moreover, its previous orbit proved singularly like that calculated by Leverrier for Lexell's comet after I779; and the pursuance backward from 1886 of its career in that orbit brought out the striking fact that it had encountered Jupiter in I779 at the same time and place with the lost comet of the last century. The inference that the two were one was irresistible, and was quickly ratified by Mr. Charles Lane Poor's more rigorous computations. ${ }^{3}$ They showed three revolutions, 'rendered of unequal length by Saturn's perturbing influence, to have been performed between 1779 and I886; and the approach to the Jovian surface in the latter year to have been within a single Jovian radius. So that the comet passed inside the orbit of the new inner satellite! The scene of encounter, moreover, coincides, according to Bredichin's determinations, ${ }^{4}$ with the point of intersection between the paths of the subordinate comets discovered by Barnard and that of the chief body, rendering it all but certain that the three had, until

Comptes Rendus, t. xxv., p. 564 . 2 Astr. Jour., No. 205.

3 Ibid., Nos. 228, 244. 4 Chandler, Ibid., No. 23 I. 
then, formed one mass. The agent of disruption was, by Chandler's conjecture, the fourth satellite of Jupiter. The next meeting of the Lexell-Brooks comet with the formidable vicegerent of the sun will be in $192{ }^{1},^{1}$ when the event of 1779 is likely to be repeated, with such modifications as the varied conditions may bring about.

On the morning of March 7, I892, Proféssor Lewis Swift, director of the Warner Observatory at Rochester, N.Y., discovered the brightest comet visible to northern observers since 1882. About the time of perihelion, which occurred on April 6, it was conspicuous, as it crossed the celestial equator from Aquarius towards Pegasus, with a nucleus equal to a third magnitude star, and a tail twenty degrees long. This tail was multiple, and multiple in a most curiously variable manner. It divided up into many thin nebulous streaks, the number and relative lustre of which underwent rapid and marked changes. Their permanent records on Professor Barnard's plates is one of the latest achievements of celestial photography. Plate iii. reproduces two of his pictures, taken with a six-inch camera, on April 5 and 7 respectively, with, in each case, an exposure of about one hour. The tail is in the first composed of three main branches, the middle one having sprung out since the previous morning, and the branches are, in their turn, split up into finer rays, to the number of perhaps a dozen in all. In the second, a very different state of things is exhibited. "The southern component," Professor Barnard remarks, "which was the brightest on the $5^{t h}$, had become diffused and fainter, while the middle tail was very bright and broad. Its southern side, which was the best defined, was wavy in numerous places, the tail appearing as if disturbing currents were flowing at right angles to it. At $42^{\circ}$ from the head the tail made an abrupt bend towards the south, as if its current was deflected by some obstacle. In the densest portion of the tail, at the point of deflection, are a couple of dark holes, similar to those seen in some of the nebulæ. The middle portion of the tail is brighter, and looks like crumpled silk in places. The width of the tail at $2^{\circ}$ from the head is

1 Barnard, Publ. Astr. Pac. Soc., vol. ii., p. 24. 
PLATE III.

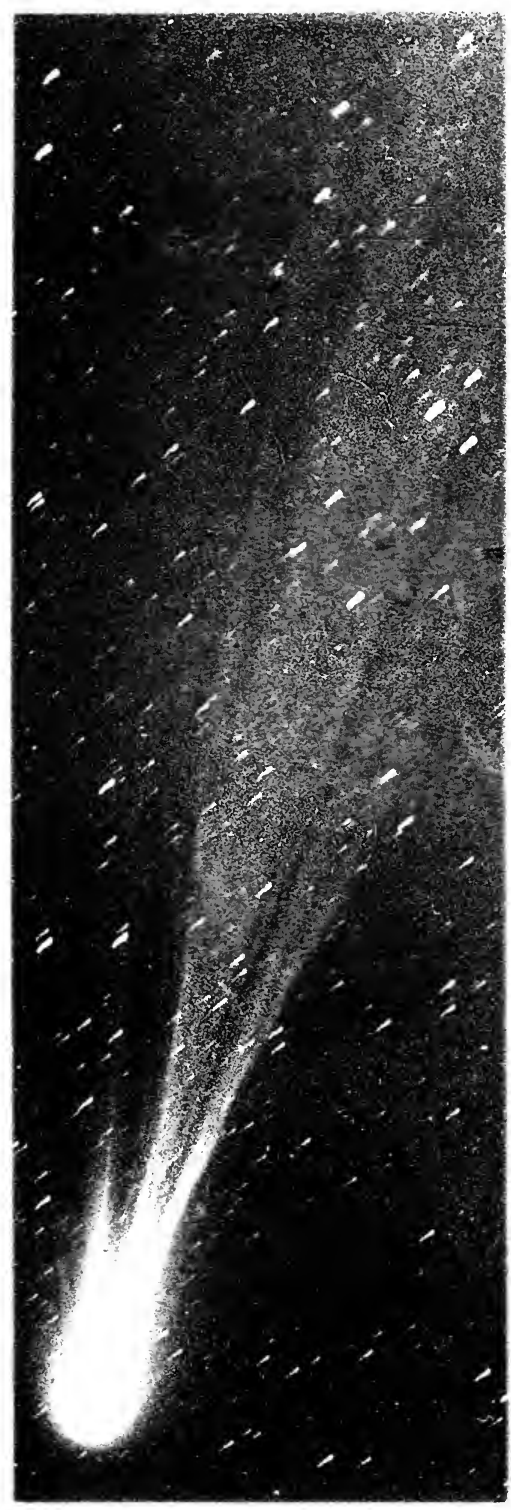

1.

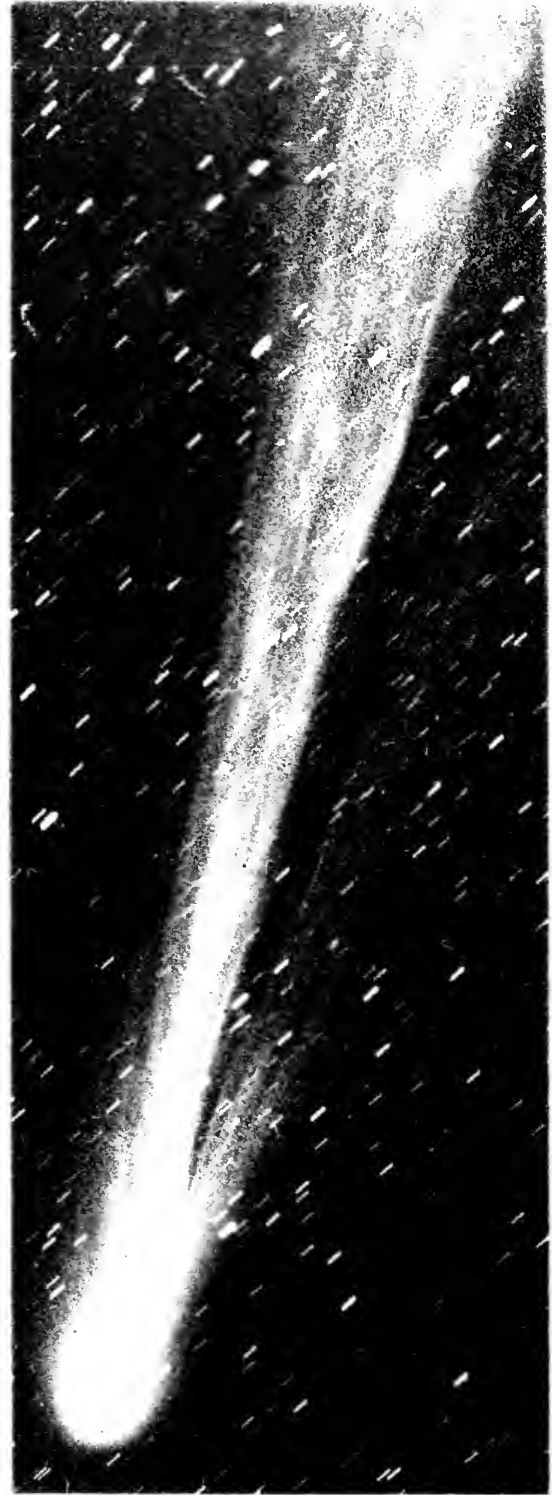

2.

PHOTOGRAPHS UF SWIFT'S COMET. By Professor E. E. BarNard. 
54." 1 Next morning the southern was the prominent branch, and it was loaded, at $I^{\circ} 42^{\prime}$ from the head, with a strange excrescence, suggesting the budding-out of a fresh comet in that incongruous situation. ${ }^{2}$ Some of these changes, Professor Barnard thought, might possibly be explained by a rotation of the tail on an axis passing through the nucleus; but moonlight conspired with clouds to prevent anything definite being learned on the point.

Seven comets were detected in 1892 , and all, strange to say, were visible together towards the close of the year. ${ }^{3}$ Among them was a faint object, which unexpectedly left a trail on a plate, exposed by Professor Barnard to the stars in Aquila ${ }^{4}$ on October 12. This was the first comet actually discovered by photography, the Sohag comet having been simultaneously seen and pictured. It has a period of about six years. Holmes's comet is likewise periodical, in rather less than seven years. Its path, which is wholly comprised between the orbits of Mars and Jupiter, is less eccentric than that of any other known comet. Since its discovery, on November 6, it has undergone some curious vicissitudes. At first bright and condensed, it expanded rapidly with increasing distance from the sun (to which it had made its nearest approach June 13), until, by the middle of December, "it was merely a great and feebly luminous mist on the face of the sky," ${ }^{5}$ barely discernible with powerful telescopes. But on January 16, I893, observers in Europe and America were bewildered to find, as if substituted for it, a yellow star of the seventh magnitude, slightly enveloped in a minute nebulous mist, within which lay the faint miniature of a tail. ${ }^{6}$ This condensation and recovery of light did not, however, last in its full intensity more than a couple of days. The spectrum of Holmes's comet was almost purely continuous. A mere trace of the carbon-bands was discernible in it.

The origin of comets has been long and eagerly inquired into,

3 Astr. and Astro-Physics, May, 1892, p. 387. 2 See Knowledge, Dec. I892. 3 H. C. Wilson, Astr. and Astro-Physics, Feb. I893, p. I21. 4 Observatory, vol. xvi., p. 92. $\quad 5$ Barnard, Astr. and Astro-Physics, Feb. 1893, p. I80. 6 Palisa, Astr. Nach., No. 3147.; Denning, Observatory, vol. xvi., p. I42. 
not altogether apart from the cheering guidance of ascertained facts. Sir William Herschel regarded them as fragments of nebulæ ${ }^{1}$ - scattered débris of embryo worlds; and Laplace approved of and adopted the idea. ${ }^{2}$ But there was a difficulty. No comet has yet been observed to travel in a decided hyperbola. The typical cometary orbit, apart from disturbance, is parabolic ; that is to say, it is indistinguishable from an enormously long ellipse. But this circumstance could only be reconciled with the view that the bodies thus moving were casual visitors from outer space, by making, as Laplace did, the tacit assumption that the solar system was at rest. His reasoning was indeed thereby completely vitiated, as Gauss pointed out in $1815 ;^{3}$ and his objections were reiterated by Schiaparelli, ${ }^{4}$ whe demonstrated in I 87 I that a large preponderance of well-marked hyperbolic orbits should result in comets picked up en route by a swiftly-advancing sun. The fact that their native movement is practically parabolic, shows it to have been wholly imparted from without. They passively obeyed the pull exerted upon them. In other words, their condition previous to being attracted by the sun was one of relative repose. ${ }^{5}$ They shared, accordingly, the movement of translation through space of the solar system.

This significant conclusion had been indicated, on other grounds, as the upshot of researches undertaken independently by Carrington ${ }^{6}$ and $\mathrm{Mohn}^{7}$ in $\mathrm{I} 860$, with a view to ascertaining the anticipated existence of a relationship between the general lie of the paths of comets and the direction of the sun's journey. It is tolerably obvious that, if they wander at haphazard through interstellar regions, a preponderance of their apparitions should seem to arrive from the vicinity of the constellation Hercules; that is to say, we should meet considerably more comets than would overtake us, for the very same reason that falling stars are more numerous. after than before midnight. Moreover, the comets met by us should be

1 Phil.Trans. vol. ci., p. 306. $\quad 2$ Conn.des Temps. 1816, p. 213. ${ }^{3}$ Euvres, t. vi., p. $58 \mathrm{r} . \quad 4 \mathrm{Mem}$. dell' Istit. Lombardo, t. xii., p. 164; Rendiconti, t. vii., p. 77, 1874. ${ }^{5}$ W. Förster, Pop. Mitth. 1879, p. 7. ${ }^{6} \mathrm{Mem}$. R. A. Soc., vol. xxix., p. 335. 7 Month. Not., vol. xxiii., p. 203. 
apparently swifter-moving objects than those coming up with us from behind; because, in the one case, our own real movement would be added to, in the other, subtracted from theirs. But nothing of all this can be detected. Comets approach the sun indifferently from all quarters, and with velocities quite independent of direction.

We conclude then that the "cosmical current" which bears the solar system towards its unknown goal, carries also with it nebulous masses of undefined extent, and at an undefined remoteness, fragments detached from which, continually entering the sphere of the sun's attraction, flit across our skies under the form of comets. These are, however, almost certainly so far strangers to our system that they had no part in the long processes of development by which its present condition was attained. They are, perhaps, survivals of an earlier, and by us scarcely and dimly conceivable state of things, when the chaos from which sun and planets were, by a supreme edict, to emerge, had not as yet separately begun to be. 


\section{CHAPTER XII.}

\section{STARS AND NEBULAE.}

'ГнAт a science of stellar chemistry should not only have become possible, but should already have made material advances, is assuredly one of the most amazing features in the swift progress of knowledge our age has witnessed. Custom can never blunt the wonder with which we must regard the achievement of compelling rays emanating from a source devoid of sensible magnitude through immeasurable distance, to reveal, by its peculiarities, the composition of that source. The discovery of revolving double stars assured us that the great governing force of the planetary movements, and of our own physical existence, sways equally the courses of the farthest suns in space; the application of prismatic analysis certified to the presence in the stars of the familiar materials, no less of the earth we tread, than of the human bodies built up out of its dust and circumambient vapours.

We have seen that, as early as 1823, Fraunhofer ascertained the generic participation of stellar light in the peculiarity by which sunlight, spread out by transmission through a prism, shows numerous transverse rulings of interrupting darkness. No sooner had Kirchhoff supplied the key to the hidden meaning of those ciphered characters, than it was eagerly turned to the interpretation of the dim scrolls unfolded in the spectra of the stars. Donati made at Florence, in $\mathrm{r} 860$, the first efforts in this direction; but with little result, owing to the imperfections of the instrumental means at his command. His comparative failure, however, was a prelude to others' success. Almost simultaneously, in 1862, the novel line of investigation 
was entered upon by Huggins and Miller near London, by Father Secchi at Rome, and by Lewis M. Rutherfurd in New York. Fraunhofer's device of using a cylindrical lens for the purpose of giving a second dimension to stellar spectra, was adopted by all, and was indeed indispensable. For a luminous point, such as a star appears, becomes, when viewed through a prism, a variegated line, which, until broadened into a band by the intervention of a cylindrical lens, is all but useless for purposes of research. This process of rolling out involves, it is true, much loss of light - a scanty and precious commodity, as coming from the stars; but the loss is an inevitable one. And so fully is it compensated by the great light-grasping power of modern telescopes, that important information can now be gained from the spectroscopic examination of stars far below the range of the unarmed eye.

The effective founders of stellar spectroscopy, then (since Rutherfurd shortly turned his efforts elsewhither), were Father Secchi, the eminent Jesuit astronomer of the Collegio Romano, where he died, February 26, I878, and Dr. Huggins, with whom the late Professor W. A. Miller was associated, The work of each was happily directed so as to supplement that of the other. With less perfect appliances, the Roman astronomer sought to render his extensive rather than precise; at Tulse Hill, searching accuracy over a narrow range was aimed at and attained. To Father Secchi is due the merit of having executed the first spectroscopic survey of the heavens. Above 4000 stars were in all passed in review by him, and classified according to the varying qualities of their light. His provisional establishment (1863-67) of four types of stellar spectra ${ }^{1}$ has proved a genuine aid to knowledge through the facilities afforded by it for the arrangement and comparison of rapidly accumulating facts. Moreover, it is scarcely doubtful that these spectral distinctions correspond to differences in physical condition of a marked kind.

1 Report Brit. Ass., I868, p. 166. Rutherford gave a rudimentary sketch of a classification of the kind in December 1862 , but based on imperfect observations. See Am. Jour. of Sc., vol. xxxv., p. 77. 
The first order comprises more than half the visible stars, and a still larger proportion of those eminently lustrous. Sirius, $\boldsymbol{a}$ Crucis, Vega, Regulus, Altair, are among its leading members. Their spectra are distinguished by the breadth and intensity of the four dark bars due to the absorption of hydrogen, and by the extreme faintness of the metallic lines, of which, nevertheless, hundreds are disclosed by careful examination. The light of these "Sirian" orbs is white or bluish; and it is found to be rich in ultra-violet rays.

Capella and Arcturus belong to the second, or solar type of stars, which is about one-sixth less numerously represented than the first. Their spectra are closely similar to that of sunlight, in being ruled throughout by innumerable fine dark lines; and they share its yellowish tinge.

The third class includes most red and variable stars (commonly synonymous), of which Betelgeux in the shoulder of Orion, and "Mira" in the Whale, are noted examples. Their characteristic spectrum is of the "fluted" description. It shows like a strongly illuminated range of seven or eight variously tinted columns seen in perspective, the light falling from the red end towards the violet. This kind of absorption is produced by the vapours of metalloids or of compound substances.

To the fourth order of stars belongs also a colonnaded spectrum, but reversed; the light is thrown the other way. The three broad zones of absorption which interrupt it are sharp towards the red, insensibly gradated towards the violet end. The individuals composing Class IV. are few, and apparently insignificant, the brightest of them not exceeding the fifth magnitude. They are commonly distinguished by a deep red tint, and gleam like rubies in the field of the telescope. Father Secchi, who detected the peculiarity of their analysed light, ascribed it to the presence of carbon in some form in their atmospheres; and this was confirmed by the researches of H. C. Vogel, ${ }^{1}$ director of the Astro-physical Observatory at Potsdam. The hydro-carbon bands, in fact, seen bright in comets, are dark

1 Publicationen, Potsdam, No. 14, 1884, p. 31 . 
in these singular objects-the only ones in the heavens (save one bright line star and a rare meteor) ${ }^{1}$ which display a cometary analogy of the fundamental sort revealed by the spectroscope.

The members of all four orders are, however, emphatically suns. They possess, it would appear, photospheres radiating all kinds of light, and differ from each other mainly in the varying qualities of their absorptive atmospheres. The principle that the colours of stars depend, not on the intrinsic nature of their light, but on the kinds of vapours surrounding them, and stopping out certain portions of that light, was laid down by Huggins in $1864 .^{2}$ Moreover, the phenomena of double stars seem to indicate a connection between the state of the investing atmospheres by the action of which their often brilliantly contrasted tints are produced, and their mutual physical relations. A remarkable tabular statement put forward by Professor Holden in June I $880^{3}$ made it, at any rate, clear that inequality of magnitude between the components of binary systems accompanies unlikeness in colour, and that stars more equally matched in one respect, are pretty sure to be so in the other. Besides, blue and green stars of a decided tinge are never (so far as is certainly known) solitary; they invariably form part of systems. So that association has undoubtedly a predominant influence upon colour.

Nevertheless, the crude notion thrown out by Zöllner in $1865,{ }^{4}$ that yellow and red stars are simply white stars in various stages of cooling, obtained for a time undeserved currency. D'Arrest indeed protested against it; and Àngström, in 1868, ${ }^{5}$ substituted for the mere criterion of colour ${ }^{6}$ as regards age and tem-

1 Von Konkoly once derived from a slow-moving meteor a hydro-carbon spectrum. A. S. Herschel, Nature, vol. xxiv., p. 507. 2 Phil. Trans., vol. cliv., p. 429. ${ }^{3}$ Am. Jour, of Sc., vol. xix., p. 467. ${ }^{4}$ Photom. Unters., p. 243. 5 Spectre Solaire, p. $38 .{ }^{6}$ Mr. J. Birmingham, in the Introduction to his Catalogue of Red Stars, adduces sundry instances of colour-change in a direction the opposite to that assumed by Zöllner to be the inevitable result of time. Trans., R. Irish Acad., vol. xxvi., p. 251. A learned discussion by Dr. T. J. J. See of Chicago, moreover, leaves little doubt that Sirius was genuinely red eighteen hundred years ago. Astr. and Astro-Physics, April and May, I892. 
perature, that of atmospheric quality and composition. His lead was followed by Lockyer in $1873,{ }^{1}$ and by Vogel in $1874 .^{2}$ The scheme of classification due to the Potsdam astro-physicist differed from Father Secchi's only in presenting his third and fourth types as subdivisions of the same order, and in inserting three subordinate categories; but their variety was "rationalised" by the addition of the seductive idea of progressive development. Thus, the white Sirian stars were represented as the youngest because the hottest of the sidereal family ; those of the solar pattern as having already wasted much of their store by radiation, and being well advanced in middle life; while the red stars with banded spectra figured as effete suns, hastening rapidly down the road to final extinction.

Vogel's scheme is, however, incomplete. It traces the downward curve of decay, but gives no account of the slow ascent to maturity. The present splendour of Vega, for instance, was prepared, according to all creative analogy, by almost endless processes of gradual change. What was its antecedent condition? The question has been variously answered. Dr. Johnstone Stoney advocated, in I867, the comparative youth of red stars $;^{3}$ A. Ritter, of Aix-la-Chapelle, divided them in $1883^{4}$ into two squadrons, posted, the one on the ascending, the other on the descending branch of the temperature curve, and corresponding, presumably, with Secchi's third and fourth orders of stars with banded spectra. Whether, in the interim, they should display spectra of the Sirian or of the solar type, was made to depend on their greater or less massiveness. ${ }^{5}$ This relation is, however, now certainly known to be non-existent. Indeed, Mr. Maunder has lately brought forward some evidence in favour of the opinion that the average solar star is a weightier body than the average Sirian star. ${ }^{6}$

On November I7, I 887, Professor Norman Lockyer communicated to the Royal Society the first of a series of papers embodying his "Meteoritic Hypothesis" of cosmical constitution,

1 Phil. Trans., vol. clxiv., p. 492. $\quad 2$ Astr. Nach., No. 2000. $\quad 3$ Proc. $R$. Soc., vols. xvi., p. 31, xvii., p. 48. 4 Annalen der Physik, Bd. xx. p. I55. Ibid., p. 153. ${ }^{6}$ Knouledge, vol. xiv., p. Iог. 
stated and supported more at large in a separate work bearing that name, published in $\mathbf{I} 890$. The fundamental proposition wrought out in it was that " all self-luminons bodies in the celestial space are composed either of swarms of meteorites, or of masses of meteoritic vapour produced by heat." 1 On the basis of this supposed community of origin, sidereal objects were distributed in seven groups along a temperature-curve ascending from nebulæ and gaseous or bright-line stars, through red stars of the third type, and a younger division of solar stars, to the high Sirian level; then descending through the more strictly solar stars to red stars of the fourth type ("carbon-stars"), below which lay only the caput mortuum entitled Group vii. The groundwork of this classification has not, it is true, proved solid. Certain spectroscopic coincidences, avowedly only approximate, suggesting that stars and nebulæ of every species might be formed out of variously aggregated meteorites, have not, on more critical inquiry, proved exact. And spectroscopic coincidences admit of no compromise. Either they are absolute, or they are worthless. The attendant evolutionary order is, however, capable of being supported on its own merits.

In his Presidential Address at the Cardiff Meeting of the British Association in I89I, Dr. Huggins adhered in the main to the line of advance traced by Vogel. The inconspicuousness of metallic lines in the spectra of the white stars, he attributed, not to the paucity, but to the high temperature of the vapours producing them, and the consequent deficiency of contrast between their absorption-rays and the continuous light of the photospheric background. " Such a state of things would more probably," in his opinion, "be found in conditions anterior to the solar stage," while "a considerable cooling of the sun would probably give rise to banded spectra due to compounds."

The strongest evidence for the primitive state of white stars is found in their nebular relations. The components of mixed groups, such as the Pleiades, show, perhaps invariably, spectra of the first type, occasionally crossed by bright rays. It is indeed not unlikely that all stars so circumstanced pass through

1 Meteoritic Hypothesis, p. 380. 
a bright-line stage in condensing from the surrounding nebulous matter into suns resembling Sirius and Vega. Relative density furnishes another important test of comparative age, and Sirian stars appear, ou the whole, to be more bulky proportionately to their mass than solar stars. But this is far from being an invariable rule; hence the change from one kind of spectrum to the other is not inevitably connected with the attainment of a particular degree of condensation. Nor is it to be supposed that all stars are identical in constitution, and present identical life-histories. ${ }^{1}$ Stellar types, may be the badges of species originally distinct, and destined to remain so. Their specialities of distribution in the heavens favour this view; nor is there any sign that the smaller, and therefore more rapidly cooling and condensing members of physical systems are any nearer to the solar stage than their large companions. From these, and other corresponding facts, Mr. Maunder infers "that spectrum type does not primarily or usually denote epoch of stellar life, but rather a fundamental difference of chemical constitution." 2

The first-known examples of the class of gaseous stars$\beta$ Lyræ and $\boldsymbol{\gamma}$ Cassiopeiæ-were noticed by Father Secchi at the outset of his spectroscopic inquiries. Both show bright lines of hydrogen and helium, so that the peculiarity of their condition probably consists in the intense ignition of their chromospheric surroundings. Their entire radiating surfaces might be described as faculous. That is to say, brilliant formations, such as have been photographed by Professor Hale on the sun's disc, ${ }^{3}$ cover perhaps the whole, instead of being limited to a small portion of the photospheric area. But this state of things is inconstant. The brilliant rays indicative of it fade and flash out again with very singular alternations. Dr. Vogel's observations at Bothkamp in I 87 I-2 already afforded him a suspicion of such vicissitudes ; ${ }^{4}$ but their ascertainment is due to M. Eugen von Gothard. After the completion of his new astrophysical observatory at Herény in

1 See the author's System of the Stars, p. 84. 2 Jour. Brit. Astr. Ass., vol. ii., p. 39; Astr. and Astro-Physics, Feb. 1892, p. I50. $\quad{ }^{3}$ See ante, p. 245.

4 Bothkamp Beobachtungen, Heft ii., p. 146. 
the autumn of I88I, he repeatedly observed the spectra of both stars without perceiving a trace of bright lines; and was thus taken quite by surprise when he caught a twinkling of the crimson C in $\gamma$ Cassiopeiæ, August I 3, I883. ${ }^{1}$ A few days later, the whole range (including $\mathrm{D}_{3}$ ) was lustrous. Duly apprised of the recurrence of a phenomenon he had himself vainly looked for during some years, M. von Konkoly took the opportunity of the great Vienna refractor being placed at his disposal to examine with it the relighted spectrum on August 27. ${ }^{2}$ In its wealth of light $\mathrm{C}$ was dazzling; $\mathrm{D}_{3}$, and the green and blue hydrogen rays, shone somewhat less vividly; D and the group $b$ showed faintly dark; while three broad absorption-bands, sharply terminated towards the red, diffuse towards the violet, shaded the spectrum near its opposite extremities. They thus agreed with the zones of "carbon-stars" in the plan of their structure, though not at all in position ; but proved significantly -what the spectrum of T Coronæ had already rendered apparent - the compatibility in stellar atmospheres of fluted absorption with a high state of incandescence.

The previous absence of bright lines from the.spectrum of this star was, however, by no means so protracted or complete as M. von Gothard supposed. At Dunecht, C was "superably visible" to Lord Lindsay, Drs. Copeland, and J. G. Lohse, December 20, I $879 ;{ }^{3} \mathrm{~F}$ was seen bright on October 28 of the same year, and frequently at Greenwich in I880-I, indeed much more conspicuously so than three years later. The curious fact has moreover been adverted to by Dr. Copeland, that $C$ is much more variable than $F$. 'To Vogel, June I 8, I872, the first was invisible, while the second was bright; at Dunecht, January I I, I887, the conditions were so far inverted that $\mathrm{C}$ was resplendent, $\mathrm{F}$ comparatively dim.

No spectral fluctuations were detected by Keeler in I 889; but even with the giant telescope of Mount Hamilton, the heliumray was completely invisible. ${ }^{4}$ Nor is there any record of its

1 Astr. Nach., No. 2539. $\quad 2$ Ibid., No. 2548; Observatory, vol. vi., p. 332. 3 Month. Not., vol. xlvii., p. $92 . \quad 4$ Publ. Astr. Pac. Soc., vol. i., p. 80; Observatory, vol. xiii., p. 46. 
appearance in this star since I883, save on September I9, I884, when it was faintly seen by Mr. Maunder.

The spectrum of $\beta$ Lyræ is subject to analogous transitions. Perfectly continuous, as observed at Herény, June I 7 and July 24 , it was interrupted by dark lines of hydrogen, September 5 , I 882. 1 A year later (August 26, I 883), Von Gothard first saw them in bright relief. The helium-ray was, thowever, found to vary independently of, and even more strikingly than, the hydrogen-lines. During I 884 it was followed through several complete cycles from dazzling brilliancy to total extinction, in a period of a few days. ${ }^{2}$ Now $\beta$ Lyræ is a "short-period variable." Its light changes with great regularity from 3.4 to 4.4 magnitude every twelve days and twenty-two hours, during which time it attains a twofold maximum, with an intervening secondary minimum. The question then is of singular interest, whether the changes of luminous quality visible in this object correspond to its changes in luminous quantity? A distinct answer in the affirmative has been supplied by photographic means. Mrs. M. Fleming, in examining the Harvard plates of the star's spectrum in I89r, found recorded upon them diverse complex changes of bright and dark lines, obviously connected with the phases of luminous variation, and obeying, in the long run, precisely the same period. ${ }^{3}$ Something more will be said presently as to the import of this discovery.

Bright hydrogen lines have so far been detected-for the most part photographically at Harvard College-in at least twenty-five stars, including Pleione, conjecturally identified by Pickering with the lost Pleiad, P Cygni, noted for instability of light in the seventeenth century, and the extraordinary southern variable, $\boldsymbol{\eta}$ Argûs. In some of, if not in all these objects, other vivid rays are associated with those due to hydrogen. A blaze of hydrogen, moreover, accompanies the recurring outbursts of about fifty "long-period variables," giving banded spectra of the third type. Professor Pickering discovered the first example of this class, towards the close of I886, in Mira Ceti ; further de-

${ }^{1}$ Astr. Nach., No. 258I. 2 Ibid., Nos. 265I-2. ${ }^{3}$ Ibid., No. 305 I Astr. and Astro-Physics, Jan. 1892, p. 25 ; Belopolsky, Astr. Nach., No. 3129. 
tections were made visually by Mr. Espin ; and the conjunction of bright hydrogen-lines with dusky bands has of late led to the recognition, through the Harvard photographs, of numerous stars subject to variations of lustre accomplished in some months.

A third variety of gaseous star is named after MM. Wolf and Rayet, who discovered, at Paris in $1867,{ }^{1}$ its three typical representatives, close together in the constellation Cygnus. The chief part of their light is concentrated in three or four brilliant lines or bands of unknown origin, united by a faint continuous spectrum. Vogel examined them at Bothkamp in 1873, and again after ten years with the twenty-seven inch Vienna equatoreal, but found no sign of change. ${ }^{2}$ The green line of hydrogen, however, identified by him in one of the objects in question, was vainly looked for by Dr. and Mrs. Huggins in $1890,{ }^{3}$ and may not improbably be variable. The latter observers established the curious fact that a diffuse, lustrous blue band, conspicuonsly present in all spectra of this description, is in some notably more refrangible than in others. Their measurements disproved its suggested origin from carbon-radiations, and its chemical relationship remains accordingly obscure. Six Wolf-Rayet stars were discovered by Dr. Copeland, five of them in the course of a trip for the exploration of visual facilities in the Andes in $1883 ;^{4}$ and a largenumber have been made known through spectral photographs taken in both hemispheres under Professor Pickering's direction. At the close of $\mathrm{r} 892$, forty-five such objects had in all been registered, ${ }^{5}$ their magnitudes ranging from the sixth to the eleventh; with the single exception of $\gamma$ Argûs, a secondmagnitude star, the resplendent continuons spectrum of which, first examined by Respighi and Lockyer in $187 \mathrm{I}$, is embellished with the yellow and blue rays distinctive of the type. Here then we have a stellar globe apparently at the highest point of sunlike incandescence, ${ }^{6}$ sharing the peculiarities of bodies verging towards the nebulous state. Professor Pickering indeed finds

1 Comptes Rendus, t. Ixv., p. 292. 2 Potsdam Publ., No. 14, p. 17. 3 Proc. R. Scc., vol. xlix., p. 33. $\quad{ }^{4}$ Copernicus, vol. iii., p. $207 . \quad{ }^{5}$ E. C. Pickering, Forty-seventh Ann. Report, p. 6; Mrs. Fleming, Astr. and Astro-Physics, Nov. 1892, p. 765. 6 System of the Stars, p. 70. 
the resemblance so close between the photographic spectra of the Wolf-Rayet stars on the one side, and of planetary nebulæ on the other, that he proposes to erect both species together into a single "fifth type." 1. But this scarcely seems advisable in view of the marked difference in the visual quality of their light. The mode of distribution of the Wolf-Rayet stars is very remarkable. They all, without exception, lie near the central line of the Milky Way. They tend also to gather into groups. Seven of them in Argo, eight in Cygnus, are met within a circle of four degrees radius.

The first spectroscopic star-catalogue was published by Dr. Vogel at Potsdam in $1883 .{ }^{2}$ It included $405 \mathrm{I}$ stars, distributed over a zone of the heavens extending from $20^{\circ}$ north to $2^{\circ}$ south of the celestial equator. ${ }^{3}$ More than half of these were white stars, while red stars with banded spectra occurred in the proportion of about one-thirteenth of the whole. To the latter genus, M. Dunér, then of Lund, now director of the Upsala Observatory, devoted a work of standard authority, issued at Stockholm in I 884. This was a catalogue with descriptive particulars of 352 stars showing banded spectra, 297 of which belonged to Secchi's third, 55 to his fourth class (Vogel's iii. $a$ and iii. $b$ ). Since then, discovery has progressed so rapidly, mainly through the telescopic reviews of Mr. Espin, and the photographic survey carried on at Harvard College, that considerablyover one thousand stars are at present recognised as of the family of Betelgeux and Mira, while about I 30 have so far exhibited the spectral pattern of I9 Piscium. (Secchi's Class IV.) One fact well ascertained as regards both species, is the invariability of the type. The prismatic flutings of the one and the broader zones of the other, are as if stereotyped-they undergo, in their fundamental outlines, no modification in passing from star to star. They are always accompanied by, or superposed upon, a spectrum of dark lines, in producing which sodium and iron have an obvious share; but particular examination has not been carried very far as

1 Astr. Nach., No. 3025. $\quad 2$ Potsdam Publ., No. ii. 3 The results of Von Konkoly's extension of Vogel's work to $15^{\circ}$ of $\mathrm{S}$. declination, were published in Bd. viii., Th. ii., of $O$ Gyalla Beobachtungen (1887). 
regards the first variety, and is totally wanting as regards the second.

A fairly complete answer to the question, What are the stars made of ? was given by Dr. Huggins in $1864 .{ }^{1}$ By laborious processes of comparison between stellar dark lines and the bright rays emitted by terrestrial substances, he made quite sure of his conclusions, though at much cost of time and pains. He averred, indeed, that-taking into account restrictions by weather and position-the thorough investigation of a single star-spectrum would be the work of some years. Of two, however-those of Betelgeux and Aldebaran-he was able to furnish detailed and accurate drawings. The dusky flutings in the prismatic light of the first of these stars have not been identified with the absorption of any particular substance; but associated with them are dark lines telling of the presence of sodium, iron, calcium, magnesium, and bismuth. Signs of absorption by silver, manganese, thallium, and tin, were also detected-though not with certainty -by Vogel in I87I ; and lines of antimony, mercury, and cadmium, were still more doubtfully recognised. ${ }^{2}$ Hydrogen rays are inconspicuously present. That an exalted temperature reigns, at least in the lower strata of the atmosphere, is certified by the vaporisation there of matter so refractory to heat as iron. ${ }^{3}$

Nine elements-those identified in Betelgeux, with the addition of tellurium, antimony, and mercury-were recognised by Dr. Huggins as having stamped their signature on the spectrum of Aldebaran; while the existence in Sirius, and nearly all the other stars inspected, of hydrogen, sodium, iron, and magnesium was rendered certain or highly probable. This was admitted to be a bare gleaning of results; nor is there reason to suppose any of his congeners inferior to our sun in complexity of constitution. Chemical interpretations of a positive kind have not yet, however, been carried in them much beyond the point to which they were brought by Dr. Huggins's pioneer-

1 Phil. Trans., vol. cliv., p. 413. Some preliminary results were embodied in a "note" communicated to the Royal Society, February 19, 1863 (Proc. Roy. Soc., vol. xii., p. 444). $\quad{ }^{2}$ Bothkamp Beob., Heft i., p. 25. $\quad{ }^{3}$ Phil. Trans., p. 429 , note. 
ing efforts. Far greater accuracy of measurement has been attained, but with results, in this respect, chiefly negative. It has rarely been possible to substitute genuine for certain spurious identifications most usefully coprected. Yet from ground so carefully prepared, a further crop of definite knowledge can scarcely fail to spring. The future of the science was indeed assured by the introduction of the photographic method.

In this, as in so many other directions, Dr. Huggins led the way. In March I 863 he obtained with his coadjutor, Dr. Miller, microscopic prints of the spectra of Sirius and Capella. ${ }^{1}$ But they told nothing. No lines were visible in them. They were mere characterless streaks of light. Nine years later Dr. Henry Draper of New York got an impression of four lines in the spectrum of Vega. Then Dr. Huggins attacked the subject again in 1876, when the r8-inch speculum of the Royal Society had come into his possession, using prisms of Iceland spar, and lenses of quartz; and this time with better success. A photograph of the spectrum of Vega showed seven strong lines. ${ }^{2}$ Still he was not satisfied. He waited and worked for three years longer. At length, on December 18, I879, he was able to communicate to the Royal Society ${ }^{3}$ results answering to his expectations. The delicacy of eye and hand needed to attain them may be estimated from the single fact, that the image of a star had to be kept, by continual minute adjustments, exactly projected upon a slit $\frac{1}{3 \frac{5}{5} 0}$ of an inch in width during nearly an hour, in order to give it time to imprint the characters of its analysed light upon a gelatine plate raised to the highest pitch of sensitiveness.

The ultra-violet spectrum of the white stars-of which Vega was taken as the type-was by this means shown to be a very remarkable one. Twelve strong lines, arranged at intervals diminishing regularly upwards, intersected it. They belonged presumably to one substance; and since the two least refrangible were known hydrogen rays, that substance could scarcely be any other than hydrogen. This was rendered certain by

1 Month. Not., vol. xxiii., p. I80. ${ }^{2}$ Proc. $R$. Soc., vol. xxv., p. 446.

3 Phil. Trans., vol. clxxi., p. 669. 
direct photographs of the hydrogen-spectrum taken by $\mathrm{H}$. W. Vogel at Berlin a few months earlier. ${ }^{1}$ In them seven of the white-star series of grouped lines were visible; and the full complement of twelve appeared on Cornu's plates in I886. ${ }^{2}$

In yellow stars, such as Capella and Arcturus, the same rhythmical series was partially represented, but associated with a great number of other lines; their state, as regards ultra-violet absorption, thus approximating to that of the sun; while the redder stars betrayed so marked a deficiency in actinic rays, that from Betelgeux, with an exposure forty times that required for Sirius, only a faint spectral impression could be obtained, and from Aldebaran, in the strictly invisible region, almost none at all.

Thus, by the means of stellar light-analysis, acquaintance was first made with the ultra-violet spectrum of hydrogen $;^{3}$ and its harmonic character, as expressed by "Balmer's Law," supplies a sure test for discriminating, among newly discovered lines, those that appertain from those that are unrelated to it. Deslandres's five additional prominence-rays, for instance, were at once seen to make part of the series, ${ }^{4}$ which is continued to its utmost known limit, by two still more refrangible dark rays, in the spectrum of the brilliant solar star Canopus. ${ }^{5}$ A group of six dusky bands, on the other hand, photographed by Dr. and Mrs. Huggins, April 4, 1890, ${ }^{6}$ near the extreme upper end of the spectrum of Sirius, were pronounced without hesitation, from their want of conformity to its law of radiation, to have nothing to do with hydrogen. Their true relationship must be sought elsewhere.

Dr. Scheiner's spectrographic researches at Potsdam exemplify the immense advantages of self-registration. In a restricted section of the spectrum of Capella, he was enabled to determine nearly three hundred lines with more precision than has yet been attained in the measurement of terrestrial spectra. This star appears to be virtually identical with the sun in physical constitution, although it emits, according to the best available data, about 250 times as much light, and is hence

${ }^{1}$ Astr. Nach., No. 2301 ; Monatsb., Berlin, I879, p. I19, I880, p. 192. 2 Jour. de Physique, t. v., p. $98 . \quad{ }^{3}$ System of the Stars, p. 39. ${ }^{4}$ See ante, p. 247. ${ }^{5}$ W. H. Pickering, Astr. and Astro-Physics, Feb. I893, p. 17 I. 6 Proc. $R$. Soc., vol. xlviii., p. 314. 
presumably 4000 times more massive. An equally close examination of the spectrum of Betelgeux showed the predominance in it of the linear absorption of iron $;^{1}$ but the bands differentiating this star from the near relations of our sun do not extend to the photographic region. Spectra of the second and third orders are for this reason not easily distinguished on the sensitive plate.

A spectrographic investigation of all the brighter northern stars was set on foot in I886 at the observatory of Harvard College, under the form of a memorial to Dr. H. Draper, whose promising work in that line was brought to a close by his premature death in I882. No individual exertions could however have realised a tithe of what has been and is being accomplished under Professor Pickering's able direction, with the aid of the Draper and other instruments, supplemented by Mrs. Draper's liberal provision of funds. A novel system was adopted, or rather, an old one-originally used by Fraunhofer-was revived. ${ }^{2}$ The use of a slit was discarded, as unnecessary for objects, like the stars, devoid of sensible dimensions, and giving hence a naturally pure spectrum; and a large prism, placed in front of the object-glass, analysed at once, with slight loss of light, the rays of all the stars in the field. Their spectra were taken, as it were, wholesale. As many as two hundred stars, down to the eighth magnitude, were occasionally printed on a single plate with a single exposure. No cylindrical lens was employed, the movement of the stars themselves being turned to account for giving the desirable width to their spectra. The star was allowed-by disconnecting, or suitably regulating the clock-to travel slowly across the line of its own dispersed light, so broadening it gradually into a band. Excellent results were thus secured. About fifty lines, for example, appeared in the photographed spectrum of Aldebaran, and eight in that of Vega. On January 26, I886, with an exposure of thirty-four minutes, a simultaneous impression was obtained of the spectra (among many others) of close upon forty Pleiades. With few and doubtful exceptions, they all proved to belong to the same type. The hydrogen-lines were 1887.

Die Spectralanalyse, p. 314. $\quad 2$ Henry Draper Memorial, First Ann. Report, 
predominant in all, alone in most. An additional argument for the common origin of the stars forming this beautiful group was thus provided. ${ }^{1}$

The "Draper Catalogue" of stellar spectra was published in I 890. ${ }^{2}$ It gives the results of a rapid analytical survey of the heavens north of $25^{\circ}$ of southern declination, and includes IO,35 I stars, down to about the eighth magnitude. The telescope used was of eight inches aperture, and forty-five focus, its field of view-owing to the "portrait-lens," or "doublet" form. given to it-embracing with fair definition no less than one. hundred square degrees. An objective prism eight inches square was attached, and exposures of a few minutes were given to the most sensitive plates that could be procured. In this way the sky was twice covered in duplicate, each star appearing, as a rule, on four plates. The registration of their spectra was sought to be made more distinctive than had previously been attempted-Secchi's first type being divided into four, his second into five subdivisions; but the differences regarded in them could be confidently established only for stars above the sixth magnitude. The work supplies none the less valuable materials for general inferences as to the distribution and relations of the spectral types. The labour of its actual preparation was borne by a staff of ladies under the direction of Mrs. Fleming. Materials for its completion to the southern pole are in course of accumulation with the identical instrument used in the north, transferred for the purpose in I889 to Peru. The progress of the Draper Memorial researches was marked by discoveries of an unexampled kind.

The principle upon which " motion in the line of sight" can be detected and measured with the spectroscope has already been explained. ${ }^{3}$ It depends, as our readers will remember, upon the removal of certain lines, dark or bright (it matters not which), from their normal places by almost infinitesimal amounts. The whole spectrum of the moving object, in fact, is very slightly shoved hither or thither, according as it is travelling

1 Mem. Amer. Acad., vol. xi., p. 215. 2 Harvard Annals, vol, xxvii.

3 See ante, p. 250. 
towards or from the eye; but, for convenience of measurement, one line is usually picked out from the rest, and attention concentrated upon it. The application of this method to the stars, however, is fraught with difficulties. It needs a powerfully dispersive spectroscope to show line-displacements of the minute order in question; and powerful dispersion involves a strictly proportionate enfeeblement of light. This, where the supply is already to a deplorable extent niggardly, can ill be afforded; and it ensues that the operation of determining a star's approach or recession is, even apart from atmospheric obstacles, an excessively delicate one.

It was first successfully executed by Dr. Huggins early in 1868. ${ }^{1}$ The brightest star in the heavens was selected as the most promising subject of experiment, and proved amenable. In the spectrum of Sirius, the F-line was considered to be just so much displaced towards the red as to indicate (the orbital motion of the earth being deducted) recession at the rate of twenty-nine miles a second; and the reality and direction of the movement were ratified by Vogel and Lohse's observation, March 22, I87 I, of a similar, but even more considerable displacement. $^{2}$ The inquiry was resumed by Dr. Huggins with improved apparatus in the following year, when the velocities of thirty stars were approximately determined. ${ }^{3}$ The retreat of Sirius seemed now slackened to about twenty miles per second, and it was announced to be shared, at rates varying from twelve to twenty-nine miles, by Betelgeux, Rigel, Castor, Regulus, and five of the principal stars in the Plough. Arcturus, on the contrary, gave signs of rapid approach, as well as Pollux, Vega, Deneb in the Swan, and the brightest of the Pointers.

Numerically, it is true, these results were entitled to little confidence. Thus, Arcturus is now fully ascertained to be travelling towards the sun at the comparatively slow pace of less than five miles a second; and Sirius is actually approaching, instead of retreating from him. The Greenwich observations from I 874 to 1886 seemed, indeed, to give evidence of regular

1 Phil. Trans., vol. clviii., p. 529. $\quad 2$ Schellen, Die Spectralanalyse, Bd. ii., p. 326 (ed. 1883). 3 Proc. Roy. Soc., vol. xx., p. 386. 
and alternating change in the radial movement of the Dog-star; yet possibly only through a chance combination of observational errors. The great difficulty of measuring so distended a line as the Sirian F might well account for some apparent anomalies. The scope of Dr. Huggins's achievement was not, however, to provide definitive data, but to establish as practicable the method of procuring them. In this he was thoronghly successful, and his success was of incalculable value. Spectroscopic investigations of stellar movements may confidently be expected to play a leading part in the unravelment of the vast and complex relations which we can dimly detect as prevailing among the innumerable orbs of the sidereal world; for it supplements the means which we possess of measuring by direct observation movements transverse to the line of sight, and thus completes our knowledge of the courses and velocities of stars at ascertained distances, while supplying for all a valuable index to the amount of perspective foreshortening of apparent movement. Thus some, even if an imperfect, knowledge may at length be gained of the revolutions of the stars-of the systems they unite to form, of the paths they respectively pursue, and of the forces under the compulsion of which they travel.

The applicability of the method to determining the orbital motions of double stars was pointed out by Fox Talbot in $187 \mathrm{I} ;{ }^{1}$ but its use for their discovery revealed itself spontaneously through the Harvard College photographs. In "spectrograms" of $\zeta$ Ursæ Majoris (Mizar), taken in 1887 , and again in 1889 , the K-line was seen to be double; while on other plates it appeared single. A careful study by Miss A. C. Maury of a series of seventy impressions proved that the doubling recurred in a period of fifty-two days, and was shown-though less evidently, owing to their less distinct nature-by all the remaining lines in the spectrum. ${ }^{2}$ The only available, and no doubt the true explanation of the phenomenon was that two similar and nearly equal stars are here merged into one telescopically indivisible; their combined light giving a single or double

1 System of the Stars, p. 199. '2 Pickering, Amer. Jour. of Science, vol. xxxix., p. 46; Vogel, Astr. Nach., No. 3017. 
spectrum, according as their orbital velocities are directed across or along our line of sight. The movements of a revolving pair of stars must always be opposite in sense and proportionate in amount. That is, they at all times travel with speeds in the inverse ratio of their masses. Hence, unless the plane of their orbits be perpendicular to a plane passing through the eye, there must be two opposite points where their velocities in the line of sight reach a maximum, and two diametrically opposite points where they touch zero. The lines in their common spectrum would thus appear alternately double and single twice in the course of each revolution. In the case of Mizar, this is evidently accomplished in about IO4 days, the relative velocity of the components coming out roughly one hundred miles a second. Assuming their paths to be circular, and to coincide with the line of sight, their distance apart is just 143,000 miles, or nearly thai of Mars and the sun. The corresponding joint mass of the circulating bodies would be forty times the solar mass. And this is a minimum estimate. For if the orbital plane be inclined, much or little, to the line of sight, the dimensions and mass of the system should be proportionately increased.

An analogous discovery was made by Miss Maury in I889. But in the spectrum of $\beta$ Aurigæ, the lines open out and close up on alternate days, indicating a relative orbit ${ }^{1}$ with a radius of less than eight million miles, traversed in about four days. This implies a rate of travel for each star of sixty-five miles a second, and a combined mass 4.7 times that of the sun. The components are approximately equal, both in mass and light, ${ }^{2}$ and the system formed by them is transported towards us with a speed of some sixteen miles a second. The line-shiftings so singularly communicative proceed, in this star, with perfect regularity. In $\zeta$ Ursæ, on the other hand, anomalies have become conspicuous, and suggest a considerably eccentric orbit, or possibly disturbance by otherwise unrecognised bodies. ${ }^{3}$

1 The "relative orbit" of a double star is that described by one round the other as a fixed point. Micrometrical measures are always thus executed. But in reality, both stars move in opposite directions, and at rates inversely as their masses, round their common centre of gravity. ${ }^{2}$ Vogel, Astr. Nach., Nos. 3017, 3039. $\quad 3$ Harvard Annals, vol, xxvi., pt. i., p. xvii. 
This new class of "spectroscopic binaries" could never have been visually disclosed. The distance of $\beta$ Aurigæ from the earth, as determined by Professor Pritchard, is nearly three and a third million times that of the earth from the sun (parallax $=$ $\left.0.06^{\prime \prime}\right)$; whence it has been calculated that the greatest angular separation of the revolving stars is only five thousandths of a second of arc. ${ }^{1}$ To make this evanescent interval perceptible, a telescope of eighty feet in aperture would be required.

The beautiful star, Spica ( $\boldsymbol{a}$ Virginis), was announced by Dr. Vogel, April 24, I890, ${ }^{2}$ to belong to the novel category, with the difference, however, of possessing a nearly dark, instead of a brilliantly lustrous companion. In this case, accordingly, the tell-tale spectroscopic variations consist merely in a slight swinging to and fro of single lines. No second spectrum leaves a legible trace on the plate. Spica revolves in four days at the rate of fifty-seven miles a second, or quicker, in proportion as its orbit is more inclined to the line of sight, round a centre at a minimum distance of three millions of miles. But the position of the second star being unknown, the mass of the system remains indeterminate. Now it is evident that if the plane of its motion made a very small angle with the line of sight, Spica would be a variable star. For, during a few hours of each revolution, some at least of its light should be cut off by a transit of its dusky companion. Such "eclipse-stars" are actually found in the heavens.

The best and longest-known member of the group is Algol in the Head of Medusa, the "Demon-star" of the Arabs." This remarkable object, normally of the second magnitude, loses and regains three-fifths of its light once in 68.8 hours, the change being completed in about ten hours. Its definite and limited nature, and punctual recurrence, suggested to Goodricke of York, by whom the periodicity of the star was discovered in

1 Huggins, Pres. Address, 1891 ; Cornu, Sur la Methode Doppler-Fizeau, p. D. 38. 2 Sitzungsb., Berlin, 1890, p. 401; Astr. Nach., No. 2995. 3 The derivation of the name Algol, or "El Ghoul," leaves little doubt that the Arab astronomers were acquainted with this star's variability. E. M. Clerke, Observatory, vol. xv., p. 271. 
$1783,{ }^{1}$ the interposition of a large dark satellite. But the conditions involved by the explanation were first seriously investigated by Pickering in $1880 .^{2}$ He found that the phenomena could be satisfactorily accounted for by supposing an obscure body 0.764 of the bright star's diameter to revolve round it in a period identical with that of its observed variation. This theoretical forecast was verified with singular exactitude at Potsdam in $1889 .^{3}$ A series of spectral photographs taken there showed each of Algol's minima to be preceded by a rapid recession from the earth, and succeeded by a rapid movement of approach towards it. They take place, accordingly, when the star is at the furthest point from ourselves of an orbit described round an invisible companion, the transits of which across its disc betray themselves to notice by the luminous vicissitudes they occasion. The diameter of this orbit, traversed at the rate of twenty-six miles a second, is just two million miles; and it is an easy further inference from the duration and extent of the phases exhibited, that Algol itself must be (in round numbers) one million, its attendant, 830,000 miles in diameter. Assuming both to be of the same density, Vogel found their respective masses to be four-ninths and two-ninths that of the sun, and their distance apart to be 3,230,000 miles.

This singularly assorted pair of stars probably form part of a larger system. Their period of revolution is shorter now by six seconds than it was in Goodricke's time; and Dr. Chandler has shown, by an exhaustive discussion, that its inequalities are comprised in a cycle of about 130 years: 4 They arise, in his view, from a common revolution, in that period, of the close couple about a third distant body, emitting little or no light, in an orbit inclined $20^{\circ}$ to our line of vision, and of approximately the size of that described by Uranus round the sun. The time spent by light in crossing this orbit causes an apparent delay in the phases of the variable, when Algol and its eclipsing satellite

1 Phil. Trans., vol. Ixxiii., p. 484. ${ }^{2}$ Proc. Amer. Acad. vol. xvi., p. I7 ; Observatory, vol. iv., p. I16. For a preliminary essay by T. S. Aldis, see Phil. Mag., vol. xxxix., p. 363, I870. ${ }^{3}$ Astr. Nach., No. 2947. ${ }^{4}$ Astr. Jour. Nos. 165-6, 255-6. See also Knowledge, vol. xv., p. 186. 
are on its further side from ourselves, balanced by acceleration while they traverse its hither side. Dr. Chandler derives confirmation for his plausible and ingenious theory from a supposed undulation in the line traced out by Algol's small proper motion ; but the fact cannot yet be taken as ascertained. It is remarkable, however, that the parallax for the star which it would imply $\left(0.07^{\prime \prime}\right)$ agrees very nearly with that measured photographically by Professor Pritchard. Algol is, on this showing, so remote that light takes nearly forty-seven years to travel thence to our eyes. Moreover, it radiates sixty-three times more powerfully than the sun; and since it presents only once and a third the sun's radiating surface, it must be forty-seven times more brilliant, area for area.

The variable in the Head of Medusa is the exemplar of a class including ten recognised members, all of which doubtless represent occulting combinations of stars. But their occultations result merely from the accident of their orbital planes passing through our line of sight; hence, the heavens must contain numerous similarly constituted systems, some of which, like Spica Virginis, will probably eventually become known through their spectroscopic changes, while others, because revolving in planes nearly tangent to the sphere, or at right angles to the visual line, may never disclose to us their true nature. No exception has so far been met with to the rule that spectroscopic doubles, whether occulting or non-occulting, belong to the first spectral order. In two as yet imperfectly investigated examples, however, a "white star" seems to be associated with a gaseous companion. One is the variable $\beta$ Lyræ, already mentioned, the alternating line-displacements in the spectrum of which suggest circulatory velocities of no less than three hundred miles a second. The other is I I Monocerotis, a fourthmagnitude star of steadfast lustre, but showing analogous spectral changes.

Gore's "Catalogue of Known Variables" 1 included, in I884, I90 entries, and the number was augmented to 243 on its

1 Proc. R. Irish. Ac., July 1884. 
revision in I 888. ${ }^{1}$ Chandler's list of 225 such objects ${ }^{2}$ was published about the same time, and many more have since been detected. Indeed, Dr. Gould is of opinion that most stars fluctuate slightly in brightnese through surface-alternations similar to, but on a larger scale than those of the sun. The solar analogy might, perhaps, be pushed somewhat further. It may be found to contain a clue to much that is perplexing in stellar behaviour. Wolf ${ }^{3}$ pointed out in 1852 the striking resemblance in character between curves representing sun-spot frequency, and curves representing the changing luminous intensity of many variable stars. There were the same steep ascent to maximum and more gradual decline to minimum, the same irregularities in heights and hollows, and, it may be added, the same tendency to a double maximum, and complexity of superposed periods. ${ }^{4}$ It is impossible to compare the two sets of phenomena thus graphically portrayed, without reaching the conclusion that they are of closely related origin. But the correspondence indicated is not, as has often been hastily assumed, between maxima of sun-spots and minima of stellar brightness, but just the reverse. The luminous outbursts, not the obscurations of variable stars, obey a law analogous to that governing the development of spots on the sun. Objects of the kind do not then gain light through the closing-up of dusky chasms in their photospheres, but by an immense growth of those brilliant formations-prominences and faculæ-which, in the sun, accompany, or are appended to spots. A comparison of light-curves with curves of spot-frequency leaves no doubt on this point, and the strongest corroborative evidence is derived from the kindling of bright lines in the spectra of long-period variables on the rise towards their recurring maxima.

Every kind and degree of variability is exemplified in the heavens. At the bottom of the scale are stars like the sun, of which the lustre is-tried by our instrumental means-sensibly steady. At the other extreme are ranged the astounding apparitions of "new," or "temporary" stars. Within the last

${ }^{1}$ Proc. Roy. Irish Ac., vol. i., p. 97. ${ }^{2}$ Astr. Jour., Nos. 179-180. $\quad{ }^{3}$ See ante, p. 159. ${ }^{4}$ System of the Stars, p. 125. 
twenty-seven years five of these stellar guests (as the Chinese call them) have presented themselves, and we meet with a sixth no farther back than April 27, I848. But of the "new star" in Ophiuchus found by Mr. Hind on that night, little more could be learnt than of the brilliant objects of the same kind observed by Tycho and Kepler. The spectroscope had not then been invented. Let us hear what it had to tell of later arrivals.

Between thirty and fifteen minutes before midnight of May I 2, I866, Mr. John Birmingham, of Millbrook, near Tuam, in Ireland, saw with astonishment a bright star of the second magnitude unfamiliarly situated in the constellation of the Northern Crown. Four hours earlier, Schmidt, of Athens, had been surveying the same part of the heavens, and was able to testify that it was not visibly there; that is to say, a few hours, or possibly a few minutes, sufficed to bring about a conflagration, the news of which may have occupied hundreds of years in travelling to us across space. The rays which were its messengers, admitted within the slit of Dr. Huggins's spectroscope, May 16, proved to be of a composition highly significant as to the nature of the catastrophe. The star-which had already declined below the third magnitude-showed what was described as a double spectrum. To the dusky flutings of Secchi's third type four brilliant rays were added. ${ }^{1}$ 'The chief of these agreed in position with lines of hydrogen; so that the immediate cause of the outburst was plainly perceived to have been the eruption, or ignition, of vast masses of that subtle kind of matter, the universal importance of which throughout the cosmos is one of the most curious facts revealed by the spectroscope.

T Coronæ (as the new star was called) quickly lost its adventitious splendour. Nine days after its discovery it was again invisible to the naked eye. It is now a pale yellow, slightly variable star near the tenth magnitude, and finds a place as such in Argelander's charts. It was thus obscurely known before it made its sudden leap into notoriety.

The next "temporary" discovered by Dr. Schmidt at Athens, November 24, I876, could lay no claim to previous recognition

1 Proc. Roy. Soc., vol. xv., p. 146 
even in that modest rank. It was strictly a parvenu. There was no record of its existence until it made its appearance as a star of nearly the third magnitude, in the constellation of the Swan. Its spectrum was examined December 2, by Cornu at Paris, ${ }^{1}$ and a few days later by Vogel and O. Lohse at Potsdam. ${ }^{2}$ It proved of a closely similar character to that of $T$ Coronæ. A range of bright lines, including those of hydrogen, helium (or sodium), and perhaps of coronium, stood out from a continuous background strongly "fluted" by absorption. It may be presumed that in reality the gaseous substances, which, by their sudden incandescence, had produced the apparent conflagration, lay comparatively near the surface of the star, while the screen of cooler materials rhythmically intercepting large portions of its light, was situated at a considerable elevation in its atmosphere.

The object, meanwhile, steadily faded. By the end of the year it was of no more than seventh magnitude. After the second week of March I877, strengthening twilight combined with the decline of its radiance to arrest further observation. It was resumed, September 2, at Dunecht, with a strange result. Practically the whole of its scanty light (it had then sunk below the tenth magnitude) was perceived to be gathered into a single bright line in the green, plausibly identified with the most characteristic line of gaseous nebulæ. ${ }^{3}$ The star had, in fact, so far as outward appearance was concerned, become transformed into a planetary nebula, many of which are so minute as to be distinguishable from smail stars only by the quality of their radiations. The nebular phase, however, seems to have been transient. In the course of I 880, Professor Pickering found that Nova Cygni gave an ordinary stellar spectrum of barely perceptible continuous light; ${ }^{4}$ and his observation was negatively confirmed at Dunecht, February I, I88 I.

This enigmatical object has now dropped to about the fourteenth magnitude, being thus entirely beyond the reach of spectroscopic scrutiny. The lesson learnt from its changes appears

1 Comptes Rendus, t. Ixxxiii., p. I172. ${ }^{2}$ Monatsb., Berlin, 1877, pp. 241, 826. 3 Copernicus, vol. ii., p. Ior. Annual Report, 1880, p. 7 . 
to be no less than this: That no clear dividing-line can be drawn between stars and nebulæ; but that in what are called "planetary nebulæ" on the one side, and in "gaseous stars" (those giving a spectrum of bright lines) on the other, we meet with transitional forms, serving to bridge the gap between such vast and highly finished orbs-if we may be permitted the expression-as Capella, and the inchoate, faintly-lucent stuff which curdles round the trapezium of Orion.

A supposed new star in Orion's Club (near $\chi^{\prime}$ Orionis), observed by Mr. J. E. Gore, December I3, r885, proved to be a till then unknown and highly interesting variable, closely akin to Mira. By the end of April it had declined from the sixth to below the ninth magnitude ${ }^{1}$ but rose to a second maximum (determined by Dr. Müller) on December I2, I886. Since then it has conformed to an average period of about 378 days, $^{2}$ or 45 days longer than that of the "wonderful" star in Cetus; and it shows a precisely similar colonnaded spectrum of great splendour and beauty, ${ }^{3}$ vivified by the same bright lines.

Perhaps none of the marvellous changes witnessed in the heavens has given a more significant hint as to their construction than the stellar blaze kindled in the heart of the great Andromeda nebula some undetermined number of years or centuries before its rays reached the earth in the month of August I885. The first published discovery was by Dr. Hartwig at Dorpat on August 3 I ; but it was found to have been already seen, on the I9th, by Mr. Isaac W. Ward of Belfast, and on the I7th by M. Ludovic Gully of Rouen. The negative observations, on the I6th, of Tempel ${ }^{4}$ and Max Wolf, limited very narrowly the epoch of the apparition. Nevertheless, it did not, like most temporaries, attain its maximum brightness all at once. When first detected, it was of the ninth; by September I it had risen to the seventh magnitude, from which it so rapidly fell off that in March it touched the limit of visibility (sixteenth magnitude) with the Washington 26-inch. Its light bleached very percep-

1 Müller, Astr. Nach., No. 2734. $\quad{ }^{2}$ Porro, Sulla Stella variabile U Orionis, p. 6. 3 C. Wolf, Comptes Rendus, t. ci., p. 1444. ${ }^{4}$ Astr. Nach., No. 2682. 
tibly as it faded. ${ }^{1}$ During the earlier stages of its decline, the contrast was striking between the sharply defined, ruddy disc of the star, and the hazy, greenish-white background upon which it was projected, ${ }^{2}$ and with which it was inevitably suggested to be in some sort of physical connection.

Let us consider what evidence was really available on this point. To begin with, the position of the star was not exactly central. It lay sixteen seconds of arc to the south-west of the true nebular nucleus. Its appearance did not then signify a sudden advance of the nebula towards condensation, nor was it attended by any visible change in it save the transient effect of partial effacement through superior brightness.

Equally indecisive information was derived from the spectroscope. To Vogel, Hasselberg, and Young, the light of the "Nova" seemed perfectly continuous; but Dr. Huggins caught traces of bright lines on September 2, confirmed on the 9 th $;^{3}$ and Dr. Copeland succeeded, on September 30, in measuring three bright bands with a special acute-angled prism constructed for the purpose. ${ }^{4}$ A shimmer of $\mathrm{F}$ was suspected, and had also been perceived by Mr. O. T. Sherman of Yale College. Still the effect was widely different from that of the characteristic blazing spectrum of a temporary star, and prompted the surmise that here too a variable might be under scrutiny. The star, however, was certainly so far "new" that its rays, until their sudden accession of strength, were too feeble to affect even our reinforced senses. Not one of the 1283 small stars recorded in charts of the nebula could be identified with it; and a photograph taken by Dr. Common, August 16, r884, on which a multitude of stars down to the fifteenth magnitude had imprinted themselves, showed the uniform, soft gradation of nebulous light to be absolutely unbroken by a stellar indication in the spot reserved for the future occupation of the "Nova." 5

So far then the view that its relation to the nebula was a merely optical one, might be justified; but it became altogether

1 A. Hall, Am. Jour. of Sc., vol. xxxi,, p. 301. ${ }^{2}$ Young, Sid. Messenger, vol. iv., p. 282 ; Hasselberg, Astr. Nach., No. 2690. ${ }^{3}$ Report Brit. Ass., 1885, p. 935. 4 Month. Not., vol. xlvii., p. 54. ${ }^{5}$ Nature, vol. xxxii., p. 522. 
untenable when it was found that what was taken to be a chance coincidence had repeated itself within living memory. On the 2 Ist of May I860, M. Auwers perceived at Königsberg a seventh magnitude star shining close to the centre of a nebula in Scorpio, numbered 80 in Messier's Catalogue. ${ }^{1}$ Three days earlier it certainly was not there, and three weeks later it had vanished. The effect to Mr. Pogson (who independently discovered the change, May 28) ${ }^{2}$ was as if the nebula had been replaced by a star, so entirely were its dim rays overpowered by the concentrated blaze in their midst. Now it is simply incredible that two outbursts of so uncommon a character should have accidentally occurred just on the line of sight between us and the central portions of two nebulæ; we must then conclude that they showed on these objects because they took place in them. The most favoured explanation is that they were what might be called effects of overcrowding-that some of the numerous small bodies, presumably composing the nebulæ, jostled together in their intricate circlings, and obtained compensation in heat for their sacrifice of motion. But this is scarcely more than a plausible makeshift of perplexed thought. Mr. W. H. S. Monck, on the other hand, has suggested that new stars appear when dark bodies are rendered luminous by rushing through the gaseous fields of space, ${ }^{3}$ just as meteors kindle in our atmosphere. The idea, although ingenious, does not (nor was it designed to) apply to our present case, Neither of the objects distinguished by the striking variations just described is of gaseous constitution. That in Scorpio appears under high magnifying powers as a "compressed cluster"; that in Andromeda is perhaps, as Sir J. Herschel suggested, "optically nebulous through the smallness of its constituent stars" 4 -if stars they deserve to be called.

On the 8th of December I89I, Dr. Max Wolf took a photograph of the region about $\chi$ Aurigæ. No stranger so bright as the ninth magnitude was among the stars depicted upon it. On the Ioth, nevertheless, a stellar object of the fifth magnitude, situated a couple of degrees to the north-east of $\beta$ Tauri, and

1 Astr. Nach., Nos. 1267, 2715. ${ }^{2}$ Month. Not., vol. xxi., p. 32. 3 Observatory, vol. viii., p. 335. 4 1bid., vol. viii., p. 325 (Maunder). 
previously unrecorded, where eleventh-magnitude stars appeared, stamped itself upon a Harvard negative. Subsequent photographs taken at the same place showed it to have gained about half a magnitude by the 2oth; but the plates were not then examined, and the discovery was left to be modestly appropriated by an amateur, the Rev. Dr. Anderson of Edinburgh, by whom it was announced, February I, I892, through the medium of an anonymous postcard, to Dr. Copeland, the Astronomer Royal for Scotland. ${ }^{1}$ By him and others, the engines of modern research were promptly set to work. And to good purpose. Nova Aurigæ was the first star of its kind studied by the universal chemical method. It is the first, accordingly, of which authentic records can be handed down to posterity. They are of a most remarkable character. The spectrum of the new object was photographed at Stonyhurst ${ }^{2}$ and South Kensington on February 3 ; a few days later, at Harvard and Lick in America, at Potsdam and Hérény on the continent of Europe. But by far the most complete impression was secured February 22, with an exposure of an hour and three-quarters, by Dr. and Mrs. Huggins, through whose kindness it is reproduced in Plate IV., Fig. I. The range of bright lines displayed in it is of astonishing vividness and extent. It includes all the hydrogen-rays dark in the spectrum of Sirius (printed below for comparison), besides many others still more refrangible, as yet unidentified. Very significant, too, is the marked character of the great prominence-lines, $H$ and $K$. The visual spectrum of the Nova was splendidly effective. A quartette of brilliant green rays caught the eye ; and they had companions too numerous to be easily counted. The hydrogen-lines were broad and bright; C blazed, as Mr. Espin said, "like a danger-signal on a dark night"; the sodium pair were recognised at Tulse Hill, and the helium-ray was suspected to lurk close beside them. Carbon-bands, on the other hand, were certainly, and magnesium-lines probably absent; nor could a strong band near the place of the chief nebular line be brought into agreement with it. Fig. 2 shows the spectrum as it was

1 Trans. R. Soc. of Edinburgh, vol, xxvii., p. 51; Astr. and Astro-Physics, Aug. 1892, p. 593. $\quad{ }^{2}$ Rev. W. Sidgreaves, Memoirs R. Astr. Soc., vol. li., p. 29. 

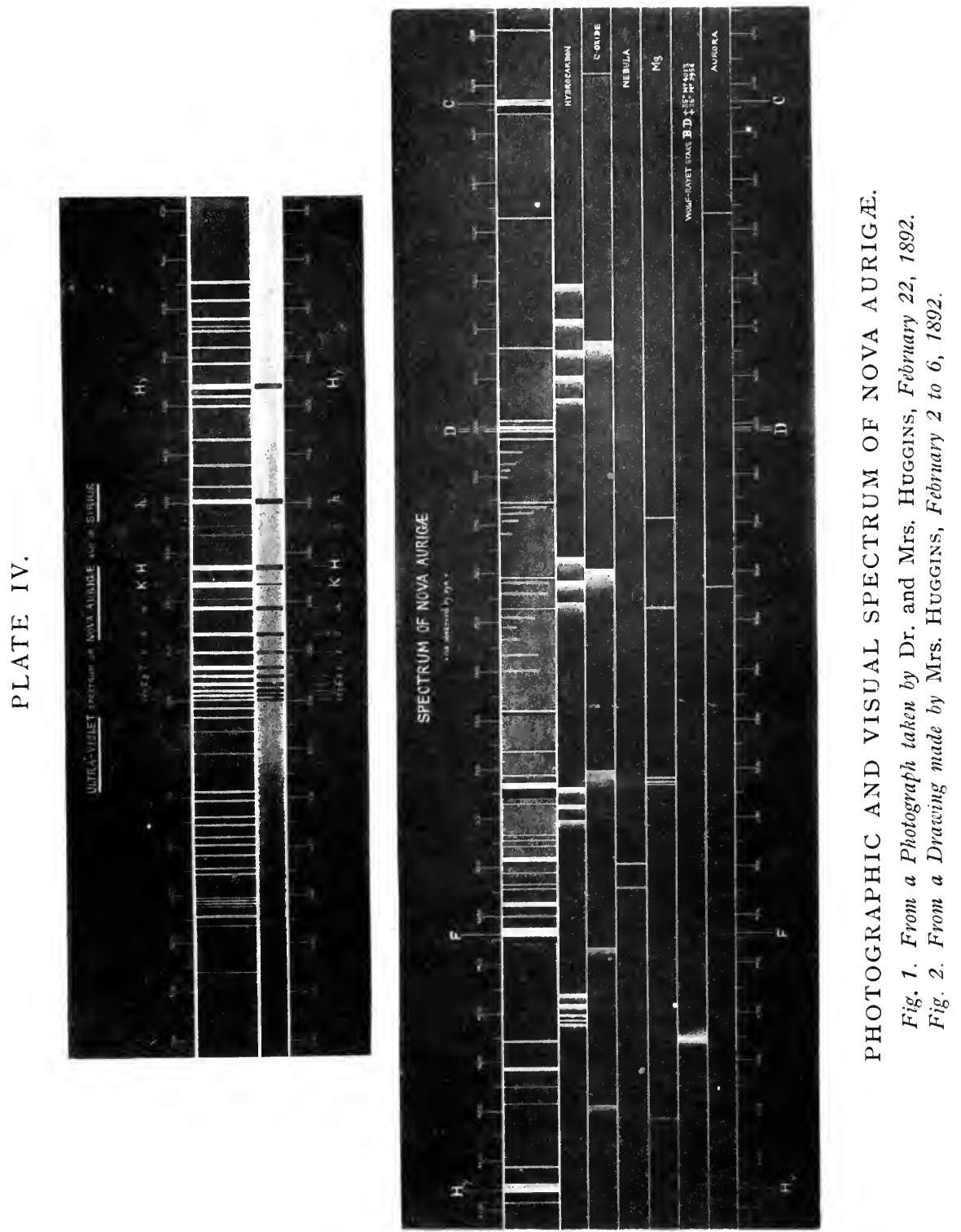

seen and mapped by Mrs. Huggins, February 2-6, together with the spectra employed to test the nature of the emissions dispersed in it. One striking feature will be at once remarked. It is that of the pairing of bright with dark lines. Both in the visible and the photographic regions, this singular peculiarity was unmistakable; and since the two series plainly owned the same chemical origin, their separate visibility implied large displacement. Otherwise, they would have been superposed, not juxtaposed. Measurements of the bright rays, accordingly, showed them to be considerably pushed down towards the red, while their dark companions were nearly as much pushed up towards the blue end. Thus the spectrum of Nova Aurigæ, like that of $\beta$ Lyræ, with which it had many points in common, appeared to be really double. It combined, by a reasonable supposition, the light of two distinct bodies, one, of a gaseous nature, moving rapidly away from the earth, the other, giving a more sun-like spectrum, approaching it with comparable speed. The relative velocity determined at Potsdam for these oppositely flying masses amounted to 550 miles a second. ${ }^{1}$ And this prodigious rate of separation was maintained during fully six weeks! It did not then represent a mere periastral rush-past. ${ }^{2}$ To the bodies exhibiting its effects, and parting company for ever under its stress, it must have belonged, with slight diminution, in perpetuity. The luminous outburst by which they became visible was explained by Dr. Huggins, in a lecture delivered at the Royal Institution, May I3, I892, on the tidal theory of Klinkerfues and Wilsing. Disturbances and deformations due to the mutual attraction of two bulky globes at a close approach would, he considered, "give rise to enormous eruptions of the hotter matters from within, immensely greater, but similar in kind, to solar eruptions, and accompanied, probably, by large electrical disturbances." The multiple aspect, and somewhat variable character of both bright and dark lines, were plausibly referred to processes of "reversal," such as are nearly always in progress above sun-spots; but the long duration of the star's

1 Vogel, Astr. Nach., No. 3079. 2 Observatory, vol. xv., p. 287 ; Seeliger, Astr. Nach., No. 3118; Astr. and Astro-Physics, Dec. 1892, p. 906. 
suddenly acquired lustre did not easily fit in with the adopted rationale. A direct collision, on the other hand, was out of the question, since there had obviously been little, if any, sacrifice of motion; and the substitution of a nebula for one of the "stars" 1 compelled recourse to scarcely conceivable modes of action for an explanation of the perplexing peculiarities of the compound spectrum.

An unexpected dénouement, however, threw all speculations off the track. The Nova retained most of its brightness, fluctuations notwithstanding, until March 9; after which date it ran swiftly and uniformly down towards what was apprehended to be its total extinction. No marked change of spectrum attended its decline. When last examined at Tulse Hill, March 24, all the more essential features of its prismatic light were still faintly recognisable. ${ }^{2}$ The object was steadily sinking on April 26, when a (supposed) final glimpse of it was caught with the Lick thirty-six inch. ${ }^{3}$ It was then of about the sixteenth magnitude. But on August 17 it had sprung up to the tenth, as Professors Holden, Schaeberle, and Campbell perceived with amazement on turning the same instrument upon its place. And to Professor Barnard it appeared, two nights later, not only revived, but transformed. ${ }^{4}$ No longer a star, it had assumed the guise of the nucleus of a planetary nebula, $3^{\prime \prime}$ across, and surrounded (on that night only) by a faint glow perhaps ten times as extensive. Its nebulous aspect was not indeed recognised elsewhere except at Pulkowa by Herr Renz. ${ }^{5}$ Mr. Newall, especially, found the object perfectly stellar with the Cambridge twenty-five inch refractor. The absence, however, of nebulosity in long-exposure photographs taken by Mr. Roberts and Dr. Max Wolf is inconclusive, its limits being overlapped by the distended nuclear image.

The rekindled Nova was detected in this country by $\mathrm{Mr} . \mathrm{H}$. Corder, on whose communication Mr. Espin, on August 21, examined its nearly monochromatic spectrum. ${ }^{6}$ The metamorphosis

1 Ranyard, Knowledge, vol. xv., p. I Io; Seeliger, Astr. Nach., No. 3 II 8. 2 Proc. Roy. Soc., vol. li., p. 492. ${ }^{3}$ Burnham, Month. Not., vol. liii., p. 58.

${ }^{4}$ Astr. Nach., No. 3118, 3143. ${ }^{5}$ Ibid., No. 31 I9. ${ }^{6}$ Ibid., No. 3 III. 
of Nova Cygni seemed repeated. ${ }^{1}$ The main part of the light of the new object, like that of its predecessor, was concentrated in a vivid green band, identified with the chief nebular line by Copeland, ${ }^{2}$ Von Gothard, ${ }^{3}$ and Campbell. ${ }^{4}$ The second nebular line was also represented. Indeed, the last-named observer recognised nearly all the eighteen lines measured by him in the Nova as characteristic of planetary nebulæ. ${ }^{5}$ Of particular interest is the registration in the star-spectrum photographed by Von Gothard of an ultra-violet line originally discovered by Dr. and Mrs. Huggins in the Orion nebula. It is also very strong in the Lyra annular nebula.

But before drawing the inference that Nova Aurigæ now shines as a genuine planetary, we must take into consideration some remarkable observations made by the eminent astrophysicists of Tulse Hill early in February, $1893 .{ }^{6}$ They succeeded in resolving the so-called first nebular line into a great group with a maximum of intensity near its blue end; and the second line appeared to be similarly composed, only with an inverted gradation of luminosity. The character of both is then totally different from that of the true nebular lines under ordinary conditions. The conditions, however, under which the Nova-spectrum originated in both its stages were evidently extraordinary, its constituent rays being, not only immensely broadened, but doubled or trebled. Their shiftings were thus difficult to determine. Professor Campbell deduced from those affecting the autumn-spectrum an approaching velocity of I 28 -miles a second on August 20, which increased to 192, then progressively diminished, after the first week in September, to less than one hundred miles a second in November. Orbital motion was thought to be concerned in producing these changes; but no orbital motion could have turned the recession at the rate of 300 miles a second, ascribed to the gaseous apparition in February and March, into the swift approach determined in Angust. Either the bodies emitting the rays analysed at the two epochs

1 Belopolsky, Astr. Nach., No. 3120. 2 Nature, Sept. 15, 1892. ${ }^{3}$ Astr. Nach., Nos. 31 22, 3129. $\quad$ 4 Ibid., No. 3133, Astr. and Astro-Physics, Oct. 1892, p. 715. 5 Publ. Astr. Pac. Soc., vol. iv., p. 244. ${ }^{6}$ Observatory, vol. xvi., p. I49. 
were not the same, or they did not possess the opposite velocities imputed to them. The latter alternative seems favoured by some recently published experiments. ${ }^{1} \quad$ M. Victor Schumann of Leipsic alleges evidence to show that hydrogen-lines derived from vacuum-tubes vary most curiously with changes of temperature and pressure, and in the mode of producing electrical excitement. They vary, according to him, in position no less than in aspect, and even transiently assume a multiple character.

There seems at any rate no doubt that the physical constitution of Nova Aurigæ became profoundly modified during the four months of its invisibility. The spectrum of February was or appeared compound; that of August was simple; it could reasonably be associated only with a single light-source. Many of the former brilliant lines, too, had vanished, and been replaced by others, previously inconspicuous or absent. As a result, the solar-prominence type, to which the earlier spectrum had seemed to conform, was completely effaced in the later. The cause, however, remains mysterious of alterations which remain for the present virtually suspended. Nova Aurigæ has secured a tolerably permanent footing among celestial objects. It is situated, like nearly all its congeners, in the full stream of the Milky Way. Hence, we learn without surprise that micrometrical measures by Burnham and Barnard ${ }^{2}$ failed to elicit from it any sign of parallactic shifting. It is certain then that the development of light, of which the news reached the earth in December, I89I, must have been on a vast scale and of ancient date. Nova Aurigæ at its maximum assuredly exceeded the sun many times in brightness; and its conflagration can scarcely have occurred less, and may have occurred much more, than a hundred years ago.

We have been compelled somewhat to anticipate our narrative as regards inquiries into the nature of nebulæ. The excursions of opinion on the point were abruptly restricted and defined by the application to them of the spectroscope. On August 29, 1864, Dr. Huggins sifted through his prisms the

1 Astr. and Astro-Physics, Feb. 1893, p. 159. ${ }^{2}$ Astr. Nach., No. 3143. 
rays of a bright planetary nebula in Draco. ${ }^{1}$ To his infinite surprise, they proved to be mainly of one colour. In other words, they avowed their origin from a mass of glowing vapour. As to what kind of vapour it might be by which Herschel's conjecture of a "shining fluid" variously diffused throughout the cosmos was thus unexpectedly verified, an answer only partially satisfactory could be afforded. The conspicuous bright line of the Draco nebula, although nearly accordant in position with one belonging to nitrogen, has since proved to be distinct from it; of its two fainter companions, one was unmistakably the $\mathrm{F}$ line of hydrogen, while the other, intermediate in situation, still remains unidentified.

By I 868, Dr. Huggins had satisfactorily examined the spectra of about seventy nebulæ, of which one-third displayed a gaseous character. $^{2}$ In all of these (and the rule has hitherto proved without exception) the simulated nitrogen line appeared; though in some cases-as "the Dumb-bell" nebula in Vulpecula -it appeared alone. On the other hand, a fourth line, the dark blue of hydrogen-in addition to the normal three, was subsequently detected in the light of the great Orion nebula. All bodies of this class, ${ }^{3}$ however, may be taken to be fundamentally alike in composition. Minor varieties have been disclosed by persevering inquiry; but the differences in their radiations at first perceived were mostly of intensity, not of kind. All planetary and annular nebulæ are gaseous, as well as those termed "irregular" which frequent the region of the Milky Way. Thus the signs of resolvability noted at Parsonstown and Cambridge (U.S.) in Orion and the "Dumb-bell," proved fallacious, so far, at least, as they had been taken to indicate a stellar constitution; though they may have quite faithfully corresponded to the existence in discrete masses of the glowing vapours elsewhere more equably diffused. An approximate coincidence between the chief nebular line and a "fluting" of magnesium having been alleged by Professor Lockyer in support

${ }^{1}$ Phil. Trans., vol. cliv., p. 437. ${ }^{2}$ Ibid., vol. clviii., p. 540. ${ }^{3}$ With the possible exception of the "looped" nebula in the southern constellation Dorado. Pickering, Forty-seventh Ann. Report, p. 7. 
of his meteoritic hypothesis of nebular constitution, it became of interest to ascertain its reality. The task was accomplished by Dr. and Mrs. Huggins in I 889 and I890, ${ }^{1}$ and by Professor Keeler, with the advantages of the Mount Hamilton apparatus and atmosphere, in I890-I. ${ }^{2}$ The upshot was to show a slight but sure discrepancy as to place, and a marked diversity as to character, between the two qualities of light. . The nebular ray (wave-length 5006 millionths of a millimetre) is slightly more refrangible than the magnesium fluting-edge, and it is sharp and fine with no trace of the unilateral haze necessarily clinging even to the last " remnant" of a banded formation.

The well-known nebula in Andromeda, and the great spiral in Canes Venatici are among the more remarkable of those giving a continuous spectrum; and, as a general rule, the emissions of all such nebulæ as present the appearance of starclusters grown misty through excessive distance, are of the same kind. It would, however, be eminently rash to conclude thence that they are really aggregations of sun-like bodies. The improbability of such an inference has been greatly enhanced by the occurrence, at an interval of a quarter of a century, of stellar outbursts in the midst of two of them. For it is practically certain that, however distant the nebulæ, the stars were equally remote; hence, if the constituent particles of the former be suns, the incomparably vaster orbs by which their feeble light was well-nigh obliterated must, as was argued by Mr. Proctor, have been on a scale of magnitude such as the imagination recoils from contemplating.

Among the ascertained analogies between the stellar and nebular systems is that of variability of light. On October I I, I852, Mr. Hind discovered a small nebula in Taurus. Chacornac observed it at Marseilles in I854, but was confounded four years later to find it vanished. D'Arrest missed it October 3, and re-detected it December 29, I86I. It was easily seen in 1865-66, but invisible in the most powerful

1 Proc. Roy. Soc., vols. xlvi., p. 40, xlviii., p. 202. "2 Publ. Astr. Pac. Soc., vol. ii., p. 265 ; Proc. Roy. Soc., vol. xlix., p. 399. 
instruments I877-80.1 Barnard, however, made out an almost evanescent trace of it, October I 5, I 890, with the great Lick telescope. ${ }^{2}$ This was the first undisputed instance of nebular variability. It has been confirmed by others of the same nature. Within sixteen years of the emergence to view of Hind's, two more temporary nebulæ were detected in the same region of the sky $;^{3}$ and many less startling instances of light-change in such objects have been more or less plausibly alleged.4 Professor Holden, moreover, having co-ordinated in his admirable "Monograph of the Nebula of Orion" 5 the results of all the more prominent inquiries since 1758 into the structure of that marvellous object, reached the conclusion that, while the figure of its various parts has (with only one possible exception) remained the same, their brightness has been and is in a state of continual fluctuation. This accords precisely with the conviction expressed by $O$. Struve in $1857,{ }^{6}$ and awaits only the ratification which it may be expected to obtain from a comparison of photographs taken at some years' interval, to be accepted as an ascertained fact.

Probably analogous is the case of the "trifid" nebula in Sagittarius, investigated by Professor Holden in $1877 .^{7}$ What is certain is, that a remarkable triple star, centrally situated, according to the observations of both the Herschels, 1784-1833, in a dark space between the three great lobes of the nebula, is now, and has been since I839, densely involved in one of them; and since the hypothesis of relative motion is on many grounds inadmissible, the change that has apparently taken place must be in the distribution of light. One no less conspicuous has been adduced by Mr. H. C. Russell, director of the Sydney Observatory. ${ }^{8} \quad$ A particularly bright part of the great Argo nebula, as drawn by Sir John Herschel, has, he asserts, totally disappeared. He noticed its absence in I87I, using a seven-inch telescope, failed equally later on to find it with an I $1 \frac{1}{2}$ inch, and his long-

${ }^{1}$ Astr. Nach., Nos. 1366, I391, 1689; Chambers, Descriptive Astr. (3rd ed.), p. 543; Flammarion, L'Univers Sidéral, p. 818. ${ }^{2}$ Month. Not., vol. li., p. 94 . s System of the Stars, p. 292. $\quad{ }^{4}$ Dreyer, Month. Not., vol. lii., p. Ioo. ${ }^{5}$ Wash. Obs., vol. xxv., App. I. ${ }^{6}$ Month. Not., vol. xvii., p. 230. ${ }^{7}$ Am. Jour. of Sc., vol. xiv., p. 433. Cf. Dreyer, Month. Not., vol. xlvii., p. 419. ${ }^{8}$ Month. Not., vol. li., p. 496. 
exposure photographs show no vestige of it. The same structure is missing from a splendid picture of the nebula ${ }^{1}$ taken by Dr. Gill in twelve hours distributed over four nights in March I892. An immense gaseous expanse has then, it would seem, sunk out of sight. Materially it is no doubt there; but the radiance has left it.

Nebulæ have no ascertained proper motions. No genuine change of place in the heavens has yet been recorded for any one of them. All equally hold aloof, so far as telescopic observation shows, from the busy journeyings of the stars. This seeming immobility is partly an effect of vast distance. Nebular parallax has, up to the present, proved evanescent, and nebular parallactic drift, in response to the sun's advance through space, remains likewise imperceptible. ${ }^{2}$ It may hence be presumed that no nebulæ occur within the sphere occupied by the nearer stars. But the difficulty of accurately measuring such objects inust also be taken into account. Displacements which would be conspicuous in stars might easily escape recognition in ill-defined, hazy masses. Thus the measures executed by d'Arrest in $1857^{3}$ have not yet proved effective for their designed purpose of contributing to the future detection of proper motions. Some determinations made by Mr. Burnham with the Lick refractor in I89I ${ }^{4}$ will ultimately afford a more critical test. He found that nearly all planetary nebulæ show a sharp stellar nucleus; the position of which with reference to neighbouring stars could be fixed no less precisely than if it were devoid of nebulous surroundings. Hence, the objects located by him cannot henceforward shift, were it only to the extent of a small fraction of a second, without the fact coming to the knowledge of astronomers.

The spectroscope, however, here as elsewhere, can supplement the telescope; and what it has to tell, it tells at once, without the necessity of waiting on time to ripen results. Dr. Huggins made, in $1874,{ }^{5}$ the earliest experiments on the radial movements

${ }^{1}$ Reproduced in Knowledge for April I893. 2 Unless an exception be found in the Pleiades nebulæ, which may be assumed to share the small apparent move ment of the stars they adhere to. ${ }^{3}$ Abhandl. Aliad. der Wiss., Leipzig, 1857, Bd .iii., p. 295. ${ }^{4}$ Month. Not., vol. lii., p. 31. ${ }^{5}$ Proc. Roy. Soc., 1874, p. 25 I. 
of nebulæ. But with only a negative upshot. None of the six objects examined gave signs of spectral alteration, and it was estimated that they must have done so had they been in course of recession from or approach towards the earth by as much as twenty-five miles a second. His inference has in only one case proved fallacious. Aided by far more powerful appliances, Professor Keeler renewed the attempt at Lick in r890-I ; and this time with unequivocal success. Ten planetary nebulæ yielded perfectly satisfactory evidence of line-of-sight motion, ${ }^{1}$ the swiftest traveller being the well-known shimmering globe in Draco, ${ }^{2}$ found to be hurrying towards the earth at the rate of forty miles a second. For the Orion nebula, a recession of about eleven miles was determined, ${ }^{3}$ the whole of which may, however, very well belong to the solar system itself, which, by its translation in the direction of Hercules or Lyra, is certainly leaving the great nebula pretty rapidly behind. The anomaly of seeming nebular fixity has nevertheless been removed; and the problem of nebular motion has begun to be solved through the demonstrated possibility of its spectroscopic investigation.

Professor Keeler's were the first trustworthy results of their kind obtained visually. That the similar work on the stars begun at Greenwich in 1874, and carried on for sixteen years, remained comparatively unfruitful, was only what might have been expected, the instruments available there being altogether inadequate for the attainment of a high degree of accuracy.

The various obstacles in the way of securing it were overcome by the substitution of the sensitive plate for the eye. Airtremors are thus rendered almost innocuous; and measurements of stellar lines displaced by motion with reference to fiducial lines from terrestrial sources, photographed on the same plates, can be depended upon within vastly reduced limits of error. Studies for the realisation of the "spectrographic" method were begun by Dr. Vogel and his able assistant Dr. Scheiner at Potsdam in J887. Their preliminary results,

1 Publ. Astr. Pac. Soc., vol. ii., p. 278. 2 The first gaseous nebula examined by Huggins in 1864. See System of the Stars, p. 257. ${ }^{3}$ Proc. Roy. Soc., vol. xlix., p. 399. 
communicated to the Berlin Academy of Sciences, March I 5, I 888, already showed that the requirements for effective research in this important branch were at last about to be complied with. An improved instrument was erected in the autumn of the same year, and the fifty-one stars, bright enough for determination with a refractor of eleven inches aperture, were promptly taken in hand. A list of their motions in the line of sight, published in $1892,{ }^{1}$ was of high value, both in itself and for what it promised. One noteworthy inference from the data it collected was that the eye tends, under unfavourable circumstances, to exaggerate the line-displacements it attempts to estimate. The velocities photographically arrived at were of much smaller amounts than those visually assigned. The average speed of the Potsdam stars came out only 10.4 miles a second, the quickest among them being Aldebaran with a recession of thirty miles a second. The hoped-for completion of a twenty-eight inch refractor will enable Dr. Togel to investigate spectrographically some hundreds of stars fainter than the second magnitude; and the data thus accumulated ought to provide the means for a definite and complete solution of the more than secular problem of the sun's advance through space. The solution should be complete, because including a genuine determination of the sun's velocity, apart from assumptions of any kind. M. Homann's attempt in $I 885,{ }^{2}$ to extract some provisional information on the subject from the radial movements of visually determined stars, gave a fair earnest of what might be done with materials of a better quality. He arrived at a goal for the sun's way shifted eastward to the constellation Cygnus-a result congruous with the marked tendency of recently determined apexes to collect in or near Lyra; and the most probable corresponding velocity seemed to be about nineteen miles a second, or just that of the earth in its orbit.

The first successful photograph of the nebular spectrum was taken by Dr. Huggins, March 7, I882. ${ }^{3}$ Five lines in all

1 Potsdam Publ. Bd. vii., Th. i. ${ }^{2}$ Astr. Nach., No. 2714 ; Schönfeld, V.J. S. Astr. Ges., Jahrg, xxi., p. 58. 3 Proc. R. Soc., vol. xxxiii., p. 425 ; Report Brit. Ass., I882, p. 444. The same feat was almost simultaneously 
stamped themselves upon the plate during forty-five minutes of exposure to the rays of the strange object in Orion. Of these, four were the known visible lines, and a fifth, high up in the ultra-violet, at wave-length 3724 , was apparently recorded in I 892 by Von Gothard ${ }^{1}$ in the spectra of the annular nebula in Lyra and of several planetaries, as well as in that of Nova Aurigæ in its later phase. Two additional hydrogen lines, making six in all, were photographed by Dr. and Mrs. Huggins from the Orion nebula in $1890 ;^{2}$ and the presence of two of the ultra-violet series agrees with the appearance of the yellow helium-ray detected by Dr. Copeland in $1886,{ }^{3}$ in suggesting that the tenuous matter composing this prodigious formation is in a high state of thermal or electrical excitement. Of its physical connection with the stars visually involved in it, there is convincing spectroscopic evidence. Dr. and Mrs. Huggins found a plate exposed February 5, I888, impressed with four groups of fine bright lines, originating in the continuous light of two of the trapezium-stars, but extending some way into the surrounding nebula. ${ }^{4}$ And Dr. Scheiner ${ }^{5}$ obtained proof of a wider relationship in the common possession, by the nebula and the chief stars in the constellation Orion, of a peculiar line, bright in the one case, dark in the others.

By direct photographic means, the structural unity of the stellar and nebular orders in this extensive region of the sky, has been independently made plain.

The first promising autographic picture of the Orion nebula was obtained by Draper, September 30, $1880 .^{6}$ The marked approach towards a still more perfectly satisfactory result shown by his plates of March I88I and I882, was unhappily frustrated by his death. Meanwhile, M. Janssen was at work in the same field from I88I, with his accustomed success. ${ }^{7}$ But Dr. A. Ainslie Common left all competitors far behind with an admirable

performed by Dr. Draper, who however failed to get the fifth line. Comptes Rendus, t. xciv., p. 1243. ${ }^{1}$ Astr. and Astro-Physics, Jan. 1893, p. 51. 2 Proc. Roy. Soc., vol. xlviii., p. 213. ${ }^{3}$ Month. Not., vol. xlviii., p. $360 .{ }^{4}$ Proc. Roy. Soc., vol. xlvi., p. 40 ; System of the Stars, p. 79. ${ }^{5}$ Sitzungsb., Berlin, Feb. 13, I890. ${ }^{6}$ Wash. Obs., vol. xxv., App. i., p. 226. $\quad$ 7 Comptes Rendus, t xcii., p. 26I. 
picture, taken January 30, I883, by means of an exposure of thirty-seven minutes in the focus of his three-foot silver-onglass mirror. ${ }^{1}$ Photography may thereby be said to have definitely assumed the office of historiographer to the nebulæ, since this one impression embodies a mass of facts hardly to be compassed by months of labour with the pencil, and affords a record of shape and relative brightness in the various parts of the stupendous object it delineates, which must prove invaluable to the students of its future condition. Its beauty and merit were officially recognised by the award of the Astronomical Society's Gold Medal in I 884 .

A second picture of equal merit, obtained by the same means, February 28, I883, with an exposure of one hour, is reproduced in the frontispiece. The vignette includes two specimens of planetary photography. The Jupiter, with the great red spot conspicuous in the southern hemisphere, is by Dr. Common. It dates from September 3, I879, and was accordingly one of the earliest results with his 36-inch, the direct image in which imprinted itself in a fraction of a second, and was subsequently enlarged on paper about twelve times. The exquisite little picture of Saturn was taken at Paris by MM. Paul and Prosper Henry, December 2I, I885, with their I2 $\frac{1}{2}$-inch photographic refractor. The telescopic image was in this case maguified eleven times previous to being photographed, an exposure of abont five seconds being allowed; and the total enlargement, as it now appears, is nimeteen times. A trace of the dusky ring perceptible on the original negative, is lost in the print.

A photograph of the Orion nebula taken by Mr. Roberts in 67 minutes, November 30, I886, made a striking disclosure of the extent of that prodigious object. More than six times the nebulous area depicted on Dr. Common's plates is covered by it, and it plainly shows an adjacent nebula, separately catalogued by Messier, to belong to the same vast formation.

This disposition to annex and appropriate has come out more strongly with every increase of photographic power. Plates exposed at Harvard College in March I888, with an eight-inch 
portrait-lens (the same used in the preparation of the Draper Catalogue) showed the old established, "Fish-mouth" nebula, not only to involve the stars of the sword-handle, but to be in tolerably evident connexion with the most easterly of the three belt-stars, from which a remarkable nebulous appendage was found to proceed. ${ }^{1}$ A still more curious discovery was made by W. H. Pickering in I 889. ${ }^{2}$ Photographs taken in three hours from the summit of Wilson's Peak in California, revealed the existence of an enormous, though faint spiral structure, enclosing: in its span of nearly seventeen degrees the entire stellar and nebulous group of the Belt and Sword, from which it most likely, although not quite traceably, issues as if from a nucleus. A positively startling glimpse is thus afforded of the cosmical importance of that strange "hiatus" in the heavens which excited the wonder of Huygens in 1656 . The inconceivable attenuation of the gaseous stuff composing it has been virtually demonstrated by Mr. Ranyard. ${ }^{3}$

In March I 885, Sir Howard Grubb mounted for Mr. Isaac Roberts, at Maghull, near Liverpool (his observatory has since been transferred to Crowborough in Sussex), a silver-on-glass reflector of twenty inches aperture, constructed expressly for use in celestial photography. A series of nebula-pictures, obtained with this fine instrument, have proved highly instructive both as to the structure and extent of these wonderful objects. Above all, one of the great Andromeda nebula, to which an exposure of three hours was given on October I, I888. ${ }^{4}$ In it, a convoluted structure replaced and rendered intelligible the anomalously rifted mass seen by Bond in I $847 .^{5}$ The effects of annular condensation appeared to have stamped themselves upon the plate, and two attendant nebulæ presented the aspect of satellites already separated from the parent body, and presumably revolving round it. The ring-nebula in Lyra was photographed at Paris in I886, and shortly afterwards by Von Gothard with a ten-inch reflector, ${ }^{6}$ and he similarly depicted in 1888 the two

1 Harvard Annals, vol. xviii., p. "I $16 . \quad{ }^{2}$ Sid. Mess., vol. ix., p. I. ${ }^{3}$ Knowledge, vol. xv., p. 191. * Month. Not., vol, xlix., p. 65. 5 System of the Stars, p. 269. ${ }^{6}$ Astr. Nach., Nos. 2749, 2754. 
chief spiral and other nebulæ. ${ }^{1}$ His representations are on a small scale, yet show a wonderful amount of detail. Photographs of the Lyre nebula taken at Algiers in $1890,{ }^{2}$ and at the Vatican observatory in $1892,{ }^{\mathbf{S}}$ are remarkable for the strong development of a central star, difficult of telescopic discernment, but evidently of primary importance to the surrounding annular structure.

The uses of photography in celestial investigations become every year more manifold and more apparent. The earliest chemical star-pictures were those of Castor and Vega, obtained with the Cambridge refractor in 1850 by Whipple of Boston under the direction of W. C. Bond. Double-star photography was inaugurated under the auspices of G. P. Bond, April 27, I857, with an impression, obtained in eight seconds, of Mizar, the middle star in the handle of the Plough. A series of measures, from sixty-two similar images, gave the distance and position angle of its companion with about the same accuracy attainable by ordinary micrometrical operations; and the method and upshot of these novel experiments were described in three papers remarkably forecasting the purposes to be served by stellar photography. ${ }^{4}$ The matter next fell into the able hands of Rutherfurd, who completed in I864 a fine object glass (of $\mathrm{I}_{1} \frac{1}{2}$ inches) corrected for the ultra-violet rays, consequently useless for visual purposes. The sacrifice was recompensed by conspicuous success. A set of measurements from his photographs of nearly fifty stars in the Pleiades, taken in 1872 and I874, enabled Dr. Gould in I 866 to ascertain, by comparison with Bessel's places for the same stars, that during the intervening third of a century no changes of importance had occurred in their relative positions. ${ }^{5}$ Mr. Harold Jacoby's reduction ${ }^{6}$ to the epoch 1873 of seventy-five stars originally measured from the plates under Rutherfurd's directions, and his comparison of their relative positions with

${ }^{1}$ Vogel, Astr. Nach., $2854 . \quad{ }^{2}$ Nature, vol. xliii., p. $419 . \quad{ }^{3}$ L'Astronomie, t. xl., p. I7 I. ${ }^{4}$ Astr. Nach., Bände xlvii., p. I, xlviii., p. I, xlix., p. 8I. Pickering, Mlem. $A m$. Ac., vol. xi., p. $180 .{ }^{5}$ Gould on Celestial Photography, $O b$. servatory, vol. ii., p. 16. ${ }^{6} A_{\text {Annals }}{ }^{N}$. 1 . Acad. of Éciences, vol. vi., p. 239, 1892 ; Elkin, Publ. Astr. Pac. Soc., vol. iv., p. 134. 
those derived from Dr. Elkin's heliometric triangulation of the cluster in $1886,{ }^{1}$ proved still more cogently the full adequacy of photographic observations to the most arduous tasks of exact astronomy. This is, however, only one among many results of the application of modern methods to that antique star-group.

A splendid photograph of I42 I stars in the Pleiades, taken by the MM. Henry with three hours' exposure, November I6, I 885, showed one of the brightest of them to have a small spiral nebula, somewhat resembling a strongly curved comet's tail, attached to it. The reappearance of this strange appurtenance on three subsequent plates left no doubt of its real existence, visually attested at Pulkowa, February 5, I 886, by one of the first observations made with the 30-inch equatoreal." Much smaller" apertures, however, sufficed to disclose the "Maia nebula," once it was known to be there. Not only did it appear. greatly extended in the Vienna 27-inch, ${ }^{3}$ but MM. Perrotin and Thollon saw it with the Nice I5-inch, and M. Kammermann of Geneva, employing special precautions, with a refractor of only ten inches aperture. ${ }^{4}$ The advantage derived by him for bringing it into view, from the insertion into the eye-piece of an uranium film, gives, with its photographic intensity, valid proof that a large proportion of the light of this remarkable object is of the ultra-violet kind.

This is not the only nebula in the Pleiades. On October I9, I859, Wilhelm Tempel, who, drawn by an overmastering impulse, had then recently exchanged his 'graver's tools for a small telescope, discovered an elliptical nebulosity, originating and stretching far to the southward from the star Merope. It has since been pretty constantly observed, though its extreme susceptibility to unfavourable aerial influences has led to a probably unfounded suspicion of variability. Nothing corresponding to this delicate object appeared on any of the Henry plates; hut in its stead some streaky nebulous patches in the same vicinity, never seen except by Dr. Common with his great reflector, February 8, I880..$^{5}$ A further mass near Alcyone,

1 Trans. Astr. Observatory of Yale Univ., vol. i., pt. i. ${ }^{2}$ Astr. Nach., No. 2719. ${ }^{3}$ Ibid., No. $2726 . \quad{ }^{4}$ Ibid., No. 2730. ${ }^{5}$ Month. Not., vol. xl., p. 376. 
perceived on the same occasion, received photographic confirmation elsewhere.

A picture of the Pleiades procured at Maghull in eighty-nine minutes, October 23, 1886 , revealed nebulous surroundings to no less than four leading stars of the group, namely, Alcyone, Electra, Merope, and Maia; and a second impression, taken in three hours on the following night, showed further "that the nebulosity extends in streamers and fleecy masses, till it seems almost to fill the spaces between tho stars, and to extend far beyond them." 1 The structural unity of the entire agglomeration was, moreover, placed beyond doubt by the visibly close relationship of the stars to the nebulous formations surrounding them in Mr. Roberts's striking pictures. Thus Goldschmidt's notion that all the clustered Pleiades constitute, as it were, a second Orion trapezium in the midst of a huge formation of which Tempel's nebula is but a fragment, ${ }^{2}$ has been to some extent verified. Yet it seemed fantastic enough in 1863 .

The next advance in this investigation was due to the MM. Henry. Early in I888 they gave exposures of four hours each to several plates, upon which were accordingly exhibited a crowd of 2326 stars, and some new features of the entangled nebulæ. The most curious of these was the threading together of stars by filmy processes. In one case, seven aligned stars appeared strung on a nebulous filament, "like beads on a rosary." 3 The "rows of stars," so often noticed in the sky, may then be concluded to have more than an imaginary existence.

The history of celestial photography at the Cape of Good Hope began with the appearance of the great comet of I882. No special apparatus was at hand; so Dr. Gill called in the services of a local artist, Mr. Allis of Mowbray, with whose camera, strapped to the Observatory equatoreal, pictures of conspicuous merit were obtained. But their particular distinction lay in the multitude of stars begemming the background. (See Plate II.) The sight of them at once opened to Dr. Gill a new prospect. He had already formed the project of extending Argelander's

1 Month. Not., vol. xlvii., p. 24. ' 2 Les Mondes, t. iii., p. 529.

3 Mouchez, Comptes Rendus, t. cvi., p. 912. 
"Durchmusterung" from the point where it was left by Schönfeld to the southern pole; and his ideas regarding the means of carrying it into execution crystallised at the needletouch of the cometary experiments. He resolved to employ photography for the purpose. The exposure of plates was accordingly begun, under the care of Mr. Ray Woods, in 1885 ; and in four years, the sky, from $19^{\circ}$ of south latitude to the pole, had been covered in duplicate. Their measurement, and the preparation of a catalogue of the stars imprinted upon them, were generously undertaken by Professor Kapteyn of Groningen, and his laborious task is now nearly completed. The Southern Durchmusterung will most likely be in the hands of astronomers in the course of a year. This first photographic census of the heavens will be fuller and surer than Argelander's. It will contain some 350,000 stars, nearly to the tenth magnitude; and their positions, derived from more than a million observations, can be depended upon to about one second of arc.

The production of this important work was thus a result of the Cape comet-pictures; yet not the most momentous one. They turned the scale in favour of recourse to the camera when the MM. Henry encountered, in their continuation of Chacornac's half-finished enterprise of ecliptical charting, sections of the Milky Way defying the enumerating efforts of eye and hand. The perfect success of some preliminary experiments made with an instrument constructed by them expressly for the purpose, was announced to the Academy of Sciences at Paris, May 2, 1885. By its means, stars estimated as of the sixteenth magnitude clearly recorded their presence and their places; and the enormous increase of knowledge involved may be judged of from the fact that, in a space of the Milky Way in Cygnus $2^{\circ} 15^{\prime}$ by $3^{\circ}$, where 170 stars had been mapped by the old laborious method, about five thousand stamped their images on a single Henry plate.

These results suggested the grand undertaking of a general photographic survey of the heavens, and Dr. Gill's proposal, June 4, 1886, of an International Congress for the purpose of setting it on foot, was received with acclamation, and promptly 
acted upon. Fifty-six delegates of seventeen different nationalities met in Paris, April 16, I887, under the presidentship of Admiral Monchez, to discuss measures and organise action. They resolved upon the construction of a Photographic Chart of the whole heavens, including stars of the fourteenth magnitude, to the surmised number of twenty millions; to be supplemented by a Catalogue, framed from plates of comparatively short exposure, giving stars to the eleventh magnitude. These will probably amount to about one million and a quarter. Both sets of plates, it was agreed, should be exposed with instruments precisely similar to that of the MM. Henry, which is a photographic refractor thirteen inches in aperture, and of eleven feet focus, attached to a guiding telescope of eleven inches aperture, corrected of course for the visual rays. Each plate will cover an area of four square degrees, and since the series must be duplicated to prevent mistakes, about 22,000 plates will be needed for the Chart alone. The task of procuring them has been apportioned among eighteen observatories in all parts of the world, ${ }^{1}$ except the United States, and ought to be completed in less than five years. The Atlas embodying the collected data will consist of copies on glass of the original negatives. It will form one of the most valuable bequests ever made by a generation of mankind to posterity. One of the most ardent promoters of the scheme it may be expected to realise was Admiral Mouchez, the successor of Leverrier in the direction of the Paris observatory. But it was not granted to him to see the fruition of his efforts. He died suddenly June 25, I892. ${ }^{2}$ Although not an astronomer by profession, he had been singularly successful in pushing forward the cause of the science he loved, while his genial and open nature won for him wide personal regard. He has been replaced by M. Tisserand, whose mathematical eminence fits him to continue the traditions of Delaunay and Leverrier.

The sublime problem of the construction of the heavens has not been neglected amid the multiplicity of tasks imposed upon the cultivators of astronomy by its rapid development. But

1 Miss A. Everett, Jour. Brit. Astr. Ass., vol. iii., p. 24. (See Appendix, Table vi.).

${ }^{2}$ D. Klumpke, Observatory, vol. xv., p. 305. 
data of a far higher order of precision, and indefinitely greater in amount, than those at the disposal of Herschel or Struve, must be accumulated before any definite conclusions on the subject are possible. The first organised effort towards realising this desideratum was made by the German Astronomical Society in 1865, two years after its foundation at Heidelberg. The scheme, as originally proposed, consisted in the exact determination of the places of about 100,000 of Argelander's stars from the re-observation of which, say, in the year 1950, astronomers of two or three generations hence may gather a vast store of knowledge-directly of the apparent motions, indirectly of the mutual relations binding together the suns and systems of space. Thirteen observatories in Europe and America joined in the work, now virtually terminated. Its scope was, after its inception, widened to include southern zones as far as the Tropic of Capricorn; this having been rendered feasible by Schönfeld's extension (1875-I 885) of Argelander's survey. Thirty thousand additional stars, thus taken in, were allotted in zones to five observatories. Another important undertaking of the same class is the re-observation of the 47,300 stars in Lalande's Histoire Céleste. Begun under Arago in 1855, its upshot, so far, has been the publication, in 1887 and 1891, of four volumes of the great Paris Catalogue, comprising nearly 15,000 stars. The proper motions of some hundreds of these have, moreover, been ascertained by diligent comparisons with the places assigned to them elsewhere.

Through Dr. Gould's unceasing labours during his fifteen years' residence at Cordoba, a detailed acquaintance with southern stars was brought about. His Uranometria Argentina (1879) enumerates the magnitudes of 8198 out of 10,649 stars visible to the naked eye under those transparent skies; 73, 160 down to $9 \frac{1}{2}$ magnitude are embraced in his "zones"; and the Argentine General Catalogue of 32,448 southern stars was published in 1886. Valuable work of the same kind has been done at Virginia by Professor 0 . Stone; while the present Radcliffe observer's "Cape Catalogue for I 880" affords an aid to the practical astronomer south of the line, of which it would be difficult to over- 
estimate the importance. Moreover, the gigantic task entered upon in 1860 by the late Dr. C. H. F. Peters, director of the Litchfield Observatory, Clinton (N.Y.), and of which a large instalment was finished in 1882, deserves honourable mention. It was nothing less than to map all stars down to, and even below, the fourteenth magnitude, situated within $30^{\circ}$ on either side of the ecliptic, and so to afford "a sure basis for drawing. conclusions with respect to the changes going on in the starry heavens." 1

It is tolerably safe to predict that no work of its kind, and for its purpose, will ever again be undertaken. In a fraction of one night more stars can now be got to register themselves, and more accurately, than the eye and hand of the most skilled observer could accomplish the record of in a year. Fundamental catalogues, constructed by the old time-honoured method, will continue to furnish indispensable starting-points for measurement; ${ }^{2}$ but the relative places of the small crowded stars-the sidereal oi $\pi o^{\prime} \lambda \lambda_{o}$-will henceforth be derived from their signatures on the sensitive plate. Even the secondary purpose - that of asteroidal discovery - served by detailed stellar enumeration, is more surely attained by photography than by laborious visual comparison. For planetary movement betrays itself tolerably quickly by turning the imprinted image of the object affected by it from a dot into a trail.

In the arduous matter of determining star distances, too, much progress has been made. Together, yet independently, Drs. Gill and Elkin carried out, at the Cape Observatory in I882-83, an investigation of remarkable accuracy into the parallaxes of nine southern stars. One of these was the famous a Centauri, the distance of which from the earth was ascertained to be just onethird greater than Henderson had made it. The parallax of Sirius, on the other hand, was doubled, or its distance halved; while Canopus was discovered to be quite immeasurably remotea circumstance which, considering that, among all the stellar

1 Gilbert, Sidereal Messenger, vol. i., p. 288. ${ }^{2}$ Mouchez, Comptes Rendus, t. cii., p. $15 \mathbf{I}$. 
multitude, it is outshone only by the radiant Dog-star, gives a stupendous idea of its real splendour and dimensions.

Inquiries of this kind were, during many years subsequent to I 867, successfully pursued at the observatory of Dunsink, near Dublin. Annual perspective displacements were by Dr. Brünnow detected in several stars, and in others re-measured with a care which inspired just confidence. His parallax for $a$ Lyræ (O. I $3^{\prime \prime}$ ) was confirmed by Hall in I 886 from an extended series of observations (giving $\left.\pi=0.134^{\prime \prime}\right)$; and the received value $\left(\pi=0.09^{\prime \prime}\right)$ for the parallax of the remarkable star "Groombridge I 830 "- the swiftest traveller, so far known, in the sidereal heavens-is that arrived at by him in I87I. His successor as Astronomer-Royal for Ireland, Sir Robert Stawell Ball (now Lowndean Professor of Astronomy in the University of Cambridge), has done good service in the same department. For besides verifying approximately Struve's parallax of half a second of arc for 6I Cygni, he refuted, in 188I, by a sweeping search for (so-called) "large" parallaxes, certain baseless conjectures of comparative nearness to the earth, in the case of red and temporary stars. ${ }^{1}$ Of 450 objects thus cursorily examined, only one star of the seventh magnitude, numbered 1618 in Groombridge's Circumpolar Catalogue, gave signs of measurable vicinity.

A second campaign in stellar parallax was undertaken by Drs. Gill and Elkin in I887. But this time, the two observers were in opposite hemispheres. Both used heliometers. Dr. Elkin had charge of the fine instrument then recently erected in Yale College Observatory; Dr. Gill employed one of seven inches, just constructed under his directions, in first-rate style, by the Repsolds of Hamburg. His results with it have not yet been made public. Dr. Elkin, however, completed in I 888 his share of the more immediate joint programme, which consisted in the determination, by direct measurement, of the average parallax of first magnitude stars. It came out, for the northern ones, '0.089", equivalent to a light-journey of more than thirty-six years. The deviations from this average were, indeed, exceedingly wide. Four of the stars, Betelgeux, Arcturus, Vega, and

1 Nature, vol. xxiv., p. 91 ; Dunsink Observations, pt. v., I884. 
a Cygni, gave no certain sign of any perspective shifting; of the rest, Procyon, with a parallax of $0^{\prime \prime} .266$, proved the nearest to our system. At the mean distance concluded for these ten brilliant stars, the sun would show as of only 6.5 magnitude; hence it claims a very subordinate rank among the suns of space. Further investigations of the same objects enabled Dr. Elkin to publish, in I 892, a revised list of their parallaxes, with greatly reduced probable errors. ${ }^{1}$ The upshot was, on the whole, thoroughly reassuring. An important change was, however, made by the assignment of a well-assured parallax of 0. "092 to Vega, while that of Procyon was increased to O".34I. Another valuable contribution to knowledge on this subject was Professor Kapteyn's determination, by meridian observations made from I 885 to I889, of the parallaxes of fifteen stars. ${ }^{2}$ His method seems capable of wide application.

The great inerit of having rendered photography available for the sounding of the celestial depths belongs to Professor Pritchard. The subject of his initial experiment was 6I Cygni. From measurements of 200 negatives taken in I 886 he derived for that classic star a parallax of $0.438^{\prime \prime}$, in satisfactory agreement with Ball's of $0.468^{\prime \prime}$. A detailed examination convinced the Astronomer-Royal(Mr.Christie) of its superior accuracy to Bessel's result with the heliometer. Since then the Savilian Professor has successfully executed his project of determining all secondmagnitude stars, to the number of about thirty, ${ }^{3}$ conveniently observable at Oxford, obtaining as the general outcome of the research an average parallax, for objects of that rank, of $0.056^{\prime \prime}$. This is in exact correspondence with Elkin's average for stars of the first magnitude. That is to say, it gives the "distance-ratio" theoretically derivable from the "light-ratio" of the two classes.

Observers of double stars are among the most meritorious, and need to be among the most patient and painstaking workers in sidereal astronomy. 'I'hey are scarcely as numerous as could be wished. Dr. Doberck, distinguished as a computer of stellar

1 Report Yale Coll. Obs., 1891-2. 2 Annalen der Sternwarte in Leiden, Bd. vii. ' 3 Researches in Stellar Parallax, pt. ii. 1892. 
orbits, complained in $1882^{1}$ that data sufficient for the purpose had not been collected for above 30 or 40 binaries out of between five and six hundred certainly or probably existing. The progress since made is illustrated by Mr. Gore's useful Catalogue of Computed Binaries, including fifty-nine entries, presented to the Royal Irish Academy, June 9, I890. ${ }^{2}$ Few have done more towards supplying the deficiency of materials than the late Baron Ercole Dembowski of Milan. He devoted the last thirty years of his life, which came to an end January I9, I 88 I, to the revision of the Dorpat Catalogue, and left behind him a store of micrometrical measures as numerous as they are precise.

Of living observers in this branch, Mr. S. W. Burnham is beyond question the foremost. While pursuing legal avocations at Chicago, he diverted his scanty leisure by exploring the skies with a six-inch telescope mounted in his back-yard; and had discovered, in May I882, one thousand close and mostly very difficult double stars. ${ }^{3}$ Summoned as chief assistant to the new Lick Observatory in I888, he resumed the work of his predilection with the thirty-six and twelve-inch refractors of that establishment. But although devoting most of his attention to much-needed remeasurements of known pairs, he incidentally divided no less than 274 stars, the majority of which lay beyond the resolving power of less keen and powerfully-aided eyesight. One of his many interesting discoveries was that of a minute companion to a Ursæ Majoris (the first Pointer), which already gives unmistakable signs of orbital movement round the shining orb it is attached to. Another pair, $\kappa$ Pegasi, detected in I880, was found in 1892 to have more than completed a circuit in the interim. ${ }^{4}$ Its period of a little over eleven years is probably the shortest attributable to a visible binary system; although $\delta$ Equulei, discovered by Otto Struve in I 852 , appears to be nearly as rapid a couple. Mr. Burnham brought his astronomical career to a pause in I892, having accepted an official appointment of the legal kind at Chicago. But his abilities as an observer will no doubt be turned to account in the new observa-

1 Nature, vol. xxvi., p. 177. ${ }^{2}$ Proc. R. Irish Acad., vol. i., p. 57 I, ser. iii. 3 Mem. R. A. Soc., vol. xlvii., p. 178. ${ }^{4}$ Astr. Nach., No. 3142 
tory there, just now in course of being equipped with instruments of unrivalled magnitude.

There is as yet no certainty that the stars of 6r Cygni form a true binary combination. It is tive that orbits were calculated for them, in $1883,{ }^{1}$ by Mr. Mann of Rochester, N.Y., and in I $885,{ }^{2}$ by Dr. C. F. W. Peters (now director of the Künigsberg Observatory), giving periods of II 59 and 783 years respectively; while the former concluded in I 890 for one of 462 years. Nevertheless, Mr. Burnham holds the components of the supposed pair to be in course of definitive separation ${ }^{3}$ and Professor Hall's observations at Washington, I879 to I89I, although favouring their physical connection, are far from decisive on the point. ${ }^{4}$ If their movements prove to be really devoid of relative curvature, the stars must form part of a more extended system, circulating in an indefinitely long period round some remote centre of attraction.

Important series of double-star observations were made by Perrotin at Nice in $1883-4 ;^{5}$ by Hall, with the 26 -inch Washington equatoreal, I874 to I89I ; ${ }^{6}$ above all, by Schiaparelli from I 875 to the present time, Burnham's most difficult and interesting pairs being picked out by preference for remeasurement with the exquisite achromatics of the Brera Observatory. ${ }^{7}$

A research of striking merit into the origin of binary stars was published in 1892 by Dr. T. J. J. See, of the Chicago University, in the form of an Inaugural Dissertation for his doctor's degree in the University of Berlin. ${ }^{8}$ The main result was to show the powerful effects of tidal friction in prescribing the course of their development from double nebulæ, revolving almost in contact, to double suns, far apart, yet inseparable. The high eccentricities of their eventual orbits were shown to result necessarily from this mode of action, which must operate with enormous strength on closely conjoined, nearly equal masses, such as the rapidly

1 Sidereal Messenger, vol.ii., p. 22. ${ }^{2}$ Astr. Nach., Nos.2708-9, 3157. ${ }^{3}$ Sid. Mess., Jan. 1891. ${ }^{4}$ Astr. Jour., No. $258 . \quad{ }^{5}$ Annales de l'Obs. de Nice, t. ii. 6 Wash. Observations, I888, App. i. 7 Milan Observations, vol. xxxiii., \&c. ${ }^{8}$ See also Observatory, vol. xiv., pp. 92, II5; Astr. and Astro-Physics, April I893, p. 289 . 
revolving pairs disclosed by the spectroscope. That these are still in an early stage of their life-history is probable in itself, and is further indicated by their invariable display-so far as is yet known-of the white-star pattern of spectrum.

Stellar photometry, initiated by the elder Herschel, and provided with exact methods by his son at the Cape, by Steinheil and Seidel at Munich, has of late years assumed the importance of a separate department of astronomical research. Two monumental works on the subject, compiled on opposite sides of the Atlantic, were thus appropriately coupled in the bestowal of the Royal Astronomical Society's Gold Medal in 1886. Harvard College Observatory led the way under the able direction of Professor E. C. Pickering. His photometric catalogue of 4260 stars, $^{1}$ constructed from nearly 95,000 observations during the years I879-82, constitutes a record of incalculable value for the detection and estimation of stellar variability. It was succeeded in 1885 by Professor Pritchard's "Uranometria Nova Oxoniensis," including photometric determinations of the magnitudes of all naked-eye stars, from the pole to ten degrees south of the equator, to the number of 2784 . The instrument employed was the "wedge photometer," which measures brightness by resistance to extinction. A wedge of neutral tint-glass, accurately divided to scale, is placed in the path of the stellar rays, when the thickness of it they have power to traverse furnishes a criterion of their intensity. Professor Pickering's "meridian photometer," on the other hand, is based upon Zöllner's principle of equalisation effected by a polarising apparatus. After all, however, as Professor Pritchard observed, "the eye is the real photometer," and its judgment can only be valid over a limited range. ${ }^{2}$ Absolute uniformity then, in estimates made by various means, under varying conditions, and by different observers, is not to be looked for; and it is satisfactory to find substantial agreement attainable and attained. Only in an insignificant fraction of the stars common to the Harvard and Oxford catalogues, discordances are found exceeding one-third of a magnitude; a large proportion (7 I per

\footnotetext{
${ }^{3}$ Harvard Annals, vol. xiv., pt. i., 1884. 2 Observatory, vol. viii., p. 309.
} 
cent.) agree within one fourth, a considerable minority (3 I per cent.) within one-tenth of a magnitude. ${ }^{1}$

Photographic photometry has meanwhile risen to an importance if anything exceeding that of visual photometry. For the usefulness of the great international star-chart now being prepared would be gravely compromised by systematic mistakes regarding the magnitudes of the stars registered upon it. No entirely trustworthy means of determining them have, however, yet been found. There is no certainty as to the relative times of exposure needed to get images of stars representative of successive photometric ranks. All that can be done is to measure the proportionate diameters of such images, and to infer, by the application of a law learned from experience, the varied intensities of light to which they correspond. The law is indeed neither simple nor constant. Different investigators have arrived at, different formulæ, which, since they are purely empirical, probably vary their nature with the conditions of experiment. Perhaps the best expedient for overcoming the difficulty is that devised by Pickering, of simultaneously photographing a star and its secondary image, reduced in brightness by a known amount. ${ }^{2}$ The results of its use will be exhibited in a catalogue of precisely ascertained ninth-magnitude stars, one for each square degree of the heavens. A photographic photometry of all the lucid stars, modelled on the visual photometry of 1884 , is promised from the same copious source of novelties. The magnitudes of the stars in the Draper Catalogue were determined, so to speak, spectrographically. The quantity measured in all cases was the photographic brightness belonging to a part of the spectrum adjacent to the hydrogen-line $G$. By the employment of this definite and uniform test, results were obtained, of special value indeed, but in strong disaccord with those given by less exclusive determinations.

Thought cannot, however, be held aloof from the great subject upon the future illustration of which so much patient industry is being expended. Nor are partial glimpses denied to us of

1 Month. Not., vol. xlvi., p. 277.

2 Carte Phot. du Ciel. Réunion du Comité Permanent, Paris, I891, p. 100. 
relations fully discoverable perhaps only by the slow efflux of time. Some important points in cosmical economy have, indeed, become quite clear within the last thirty years, and scarcely any longer admit of a difference of opinion. One of these is that of the true status of nebulæ.

This was virtually settled by Sir J. Herschel's description in I 847 of the structure of the Magellanic clouds; but it was not until Whewell in 1853 , and Herbert Spencer in $1858,{ }^{1}$ enforced the conclusions necessarily to be derived therefrom, that the conception of the nebulæ as remote galaxies, which Lord Rosse's resolution of many into stellar points had appeared to support, began to withdraw into the region of discarded and half-forgotten speculations. In the Nubeculæ, as Whewell insisted, ${ }^{2}$ "there co-exists, in a limited compass, and in indiscriminate position, stars, clusters of stars, nebulæ, regular and irregular, and nebulous streaks and patches. These, then, are different kinds of things in themselves, not merely different to us. There are such things as nebulæ side by side with stars and with clusters of stars. Nebulous matter resolvable occurs close to nebulous matter irresolvable."

This argument from co-existence in nearly the same region of space, reiterated and reinforced with others by Mr. Spencer, was urged with his accustomed force and freshness by $\mathrm{Mr}$. Proctor. It is unanswerable. There is no maintaining nebulæ to be simply remote worlds of stars in the face of an agglomeration like the Nubecula Major, containing in its (certainly capacious) bosom both stars and nebulæ. Add the evidence of the spectroscope to the effect that a large proportion of these perplexing objects are gaseous, with the intimate relation obviously subsisting between the mode of their scattering and the lie of the Milky Way, and it becomes impossible to resist the conclusion that both nebular and stellar systems are parts of a single scheme. ${ }^{3}$

As to the stars themselves, the presumption of their approximate uniformity in size and brightness has been effectually

1 Essays (2nd ser.), The Nebular Hypothesis. 2 On the Plurality of Worlds, p. 214 (2nd ed.). $\quad 3$ Proctor, Month. Not., vol. xxix., p. 342. 
dissipated. Differences of distance can no longer be invoked to account for dissimilarity in lustre. Minute orbs, altogether invisible without optical aid, are found to be indefinitely nearer to us than such radiant objects as Canopus, Arcturus, or Rigel. Moreover, intensity of light is perceived to be a very imperfect index to real magnitude. Brilliant suns are swayed from their courses by the attractive power of massive yet faint luminous companions, and suffer eclipse from obscure interpositions. Besides, effective lustre is now known to depend no less upon the qualities of the investing atmosphere, than upon the exient and radiative power of the stellar surface. Red stars must be far larger in proportion to the light diffused by them than white or yellow stars. ${ }^{1}$ There can be no doubt that our sun would at least double its brightness were the absorption suffered by its rays to be reduced to the Sirian standard; and, on the other hand, that it would lose half its present efficiency as a light-source, if the atmosphere partially veiling its splendours were rendered as dense as that of Aldebaran.

Thus, variety of all kinds is seen to abound in the heavens; and it must be admitted that the inevitable abolition of all hypotheses as to the relative distances of individual stars singularly complicates the question of their allocation in space. Nevertheless, something has been learnt even on that point; and the tendency of modern research is, on the whole, strongly confirmatory of the views expressed by Herschel in $1802 . \mathrm{He}$ then no longer regarded the Milky Way as the mere visual effect of an enormously extended stratum of stars, but as an actual aggregation, highly irregular in structure, made up of stellar clouds and groups and nodosities. All the facts since ascertained fit in with this conception; to which Mr. Proctor added reasons tending to show that the stars forming the galactic stream are not only crowded more closely together, but are also really, as well as apparently, of smaller dimensions than the lucid orbs studding our skies. By the laborious process of isographically charting the whole of Argelander's 324,000 stars,

1 This remark was first made by J. Michell, Fhil. 'T'rans., vol. lvii., p. 253 (1767). 
he brought out in $187 \mathrm{I}^{1}$ unmistakable signs of relationship between the distribution of the brighter stars and the complex branchings of the Milky Way. The stars, indeed, congregate rather towards a great circle inclined some twenty degrees to the galactic plane than towards that plane itself; and they were supposed by Gould to form with the sun a subordinate cluster, of which the components are seen projected upon the sky as a zone of stellar brilliants. ${ }^{2}$ But the zone displays obvious galactic affinities; and many - circumstances render it barely credible that the sun has any organic connection with it. Professor Kapteyn associates him with a very differently constituted group. $^{3}$ An elaborate comparison of the spectra and proper motions of 2357 stars elicited relations demonstrative, in his view, of the existence of a highly-compressed spherical cluster nearly concentric with the Milky Way. The sun is deeply immersed in the collection, the members of which show, in a large majority of cases, spectra of the solar type, But the rate and manner of their movements appear inconsistent with their dynamical coherence. ${ }^{4}$

A most suggestive delineation of the Milky Way, completed in I889, after five years of toil, by Dr. Otto Boeddicker, Lord Rosse's astronomer at Parsonstown, was published by lithography in I892. It shows a curiously intricate structure, composed of dimly luminous streams, and shreds, and patches, intermixed with dark gaps and channels. Ramifications from the main trunk run out towards the Andromeda nebula and the "Bee-hive" cluster in Cancer, involve the Pleiades and Hyades, and winding round the constellation of Orion, just attain the Sword-handle nebula. The last delicate touches had scarcely, however, been put to the picture, when the laborious eye-and-hand method was, in this quarter, as already in so many others, superseded by a more expeditious process. Professor Barnard took the first photographs ever secured of the true Milky Way, July 28, August I and 2, I889, at the Lick

1 Month. Not., vols. xxxi., p. 175 ; xxxii., p. I. p. 384 ; Ola and New Astronomy, p. 749 (Ranyard).

2 System of the Stars, Sciences, Jan. 28, 1893.

4 Ranyard, Knowledge, April i893, p. 68. 
Observatory. Special conditions were required for success; above all, a wide field and a strong light-grasp, both complied with through the use of a six-inch portrait-lens. Even thus, the sensitive plate needed some hours to pick out the exceedingly faint stars collected in the galactic clouds. These cannot be photographed under the nebulous aspect they wear to the eye ; the camera takes note of their real nature. and registers their constituent stars rank by rank. Hence the difficulty of disclosing them. "In the photographs made with the six-inch portrait lens," Professor Barnard wrote, "besides myriads of stars, there are shown, for the first time, the vast and wonderful cloud-forms, with all their remarkable structure of lanes, holes, and black gaps, and sprays of stars. They present to us these forms in all their delicacy and beanty, as no eye or telescope can ever hope to see them." 1 In Plate V. one of these strange galactic landscapes is reproduced. It occurs in the Bow of Sagittarius, not far from the Trifid nebula, where the aggregations of the Milky Way are more than usually varied and characteristic. One of their distinctive features comes out with particular prominence. It will be noticed that the bright mass near the centre of the plate is tunnelled with dark holes and furrowed by dusky lanes. Such interruptions recur perpetually in the Milky Way. They are exemplified on the largest scale in the great rift dividing it into two branches all the way from Cygnus to Crux; and they are reproduced in miniature in many clusters.

Mr. H. C. Russell, at Sydney in I890, successfully imitated Professor Barnard's example. ${ }^{2}$ His photographs of the southern Milky Way have many points of interest. They show the great rift, so black to the eye, as densely star-strewn to the perception of the chemical retina; while the "Coal-sack" appears absolutely dark only in its northern portion. His most remarkable discovery, however, was that of the spiral character of the two Nubeculæ. With an effective exposure of four and a half hours,

1 Publ. Astr: Pac. Soc., vol. ii., p. 242. 2 Month. Not., vol. li., pp. 40, 97. For reproductions of some of the photographs in question, see Knowledge, vol. xiv., p. 50 . 
PLATE V.

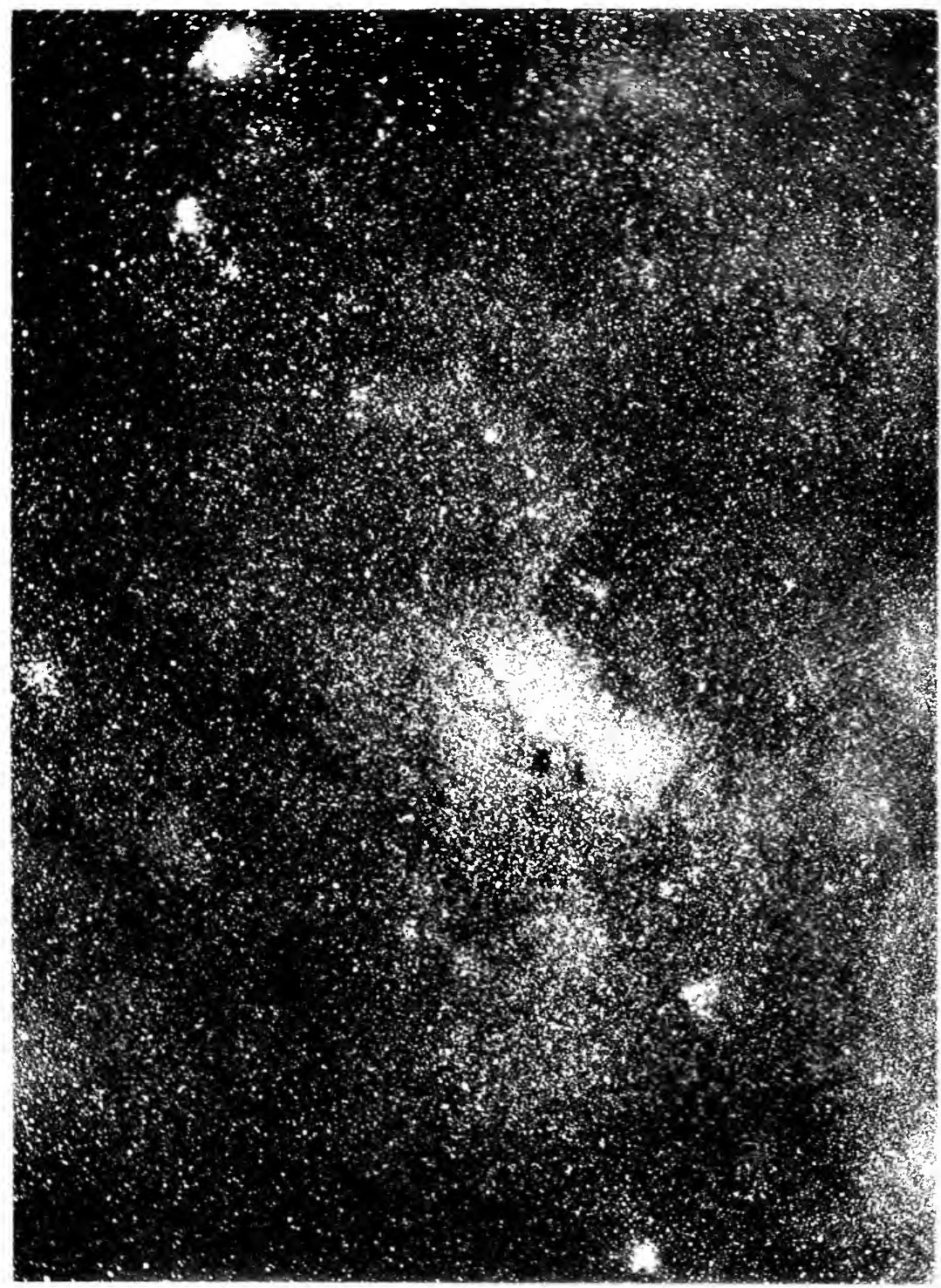

REGION OF THE MILKY WAY IN SAGITTARIUS,

SHOWING A NOUBLE BLACK APERTURE.

Photografhed by Professor E. E. BARNARD 

the Greater Cloud came out as "a complex spiral with two centres" ; while the similar conformation of its minor companion developed only after eight hours of persistent actinic action. The revelation is full of significance.

Scarcely less so, although after a different fashion, is the disclosure on plates exposed by Dr. Max Wolf with a five-inch lens, in June 1891, of a vastly extended nebula, condensing about $\boldsymbol{\alpha}$ and $\boldsymbol{\gamma}$ Cygni, and bringing them into apparently organic connection with the galactic collections also involved by it. ${ }^{1}$ The inference thus seems compulsory, that the Milky Way is in reality a prodigious mixed system, resembling that of the Pleiades in point of composition, though differing widely from it in plan of structure. Of corroborative testimony, moreover, is the discovery, independently resulting from Dr. Gill's and Professor Pickering's photographic reviews, that stars of the first type of spectrum largely prevail in the galactic zone of the heavens. ${ }^{2}$ For Sirian stars exhibit unquestionable nebulous affinities.

The first step towards the unravelment of the tangled web of stellar movements was taken when Herschel established the reality and indicated the direction of the sun's journey. But the gradual shifting backward of the whole of the celestial scenery amid which we advance, accounts for only a part of the observed displacements. The stars have motions of their own besides those reflected upon them from ours. All attempts, however, to grasp the general scheme of these motions, have hitherto failed. Yet they have not remained wholly fruitless. The community of slow movement in Taurus, upon which Mädler based his famous theory, has proved to be a fact, and one of very extended significance.

In I870 Mr. Proctor undertook to chart down the directions and proportionate amounts of about 1600 proper motions, as determined by Messrs. Stone and Main, with the result of bringing to light the remarkable phenomenon termed by him "stardrift." 3 Quite unmistakably, large groups of stars,

1 Astr. Nach., No. 3048 ; Observatory, vol. xiv., p. 301. 2 Proc. Roy. Inst., May 29, I891 (Gill). $\quad 3$ Proc. Roy Soc., vol. xviii., p. I69. 
otherwise apparently disconnected, were seen to be in progress together, in the same direction, and at the same rate, across the sky. An example of this kind of unanimity alleged by him in the five intermediate stars of the Plough, has not indeed fully maintained its authenticity. Dr. Auwers's researches show that an identical proper motion can be certainly ascribed to only two out of the five objects in question-namely, to $\epsilon$ and $\zeta$ Ursæ Majoris. That the agreement in thwartwise motion is no casual one, is practically demonstrated by the presence of a corresponding agreement in radial motion, the Potsdam measures giving to each star an approaching velocity of just eighteen miles a second. One of them, moreover, $\zeta$ Ursæ, alias Mizar, carries with it three other stars-Alcor, the Arab "Rider" of the horse, visible to the naked eye, besides a telescopic and a spectroscopic attendant. So that the system is, at the very least, quintuple. Now, Professor Pritchard has photographically determined a parallax of $0.08 \mathrm{I}^{\prime \prime}$ for $\epsilon$ Ursæ, whence its more than two hundredfold superiority, in point of light, to our sun, can be inferred. Hence, too, a minimum linear value can be assigned to the apparent interval separating it from Mizar. That is to say, if the line joining the two stars runs at right angles with the line of sight, they are (in round numbers) eighteen billions of miles apart, a distance which light would spend more than three years in crossing. But since this special arrangement is unlikely to prevail, the span of the quintuple system is almost certainly wider, and may be enormously, indefinitely wider. The law of its organisation must long remain mysterious.

This is by no means a solitary example. Particular association, indeed-as was surmised by Michell six-score years ago-appears to be the rule rather than an exception in the sidereal scheme. Stars are bound together by twos, by threes, by dozens, by hundreds. Our own sun is perhaps not exempt from this gregarious tendency. Many facts have been brought to light intimating its union with hundreds of other stars into a subordinate system within the confines of the Milky Way. ${ }^{1}$ Such another

1 Month. Not., vol. xl., p. 249. 
CHAP. XII.

would be the Pleiades. The laws and revolutions of such majestic communities lie, for the present, far beyond the range of possible knowledge; centuries may elapse before even a rudimentary acquaintance with them begins to develop; while the economy of the higher order of association, which we must reasonably believe that they unite to compose, will possibly continue to stimulate and baffle human curiosity to the end of time. 


\section{CHAPTER XIII.}

\section{METHODS OF RESEARCH.}

CoMPARING the methods now available for astronomical inquiries with those in use thirty years ago, we are at once struck with the fact that they have multiplied. The telescope has been supplemented by the spectroscope and the photographic camera. Now this really involves a whole world of change. It means that astronomy has left the place where she dwelt apart in rapt union with mathematics, indifferent to all things on earth save only to those mechanical improvements which should aid her to penetrate further into the heavens, and has descended into the forum of human knowledge, at once a suppliant and a patron, alternately invoking help from and promising it to each of the sciences, and patiently waiting upon the advance of all. The science of the heavenly bodies has, in a word, become a branch of terrestrial physics, or rather a higher kind of integration of all their results. It has, however, this leading peculiarity, that the materials for the whole of its inquiries are telescopically furnished. They are such as the unarmed eye takes no, or a very imperfect cognisance of.

Spectroscopic and photographic apparatus are simply additions to the telescope. They do not supersede, or render it of less importance. On the contrary, the efficacy of their action depends primarily upon the optical qualities of the instrument they are attached to. Hence the development, to their fullest extent, of the powers of the telescope is of vital moment to the progress of modern physical astronomy, while the older mathematical astronomy could afford to remain comparatively indifferent to it. 
The colossal Rosse reflector still marks, as to size, the ne plus ultra of performance in that line. A mirror, four feet in diameter was, however, sent out to Melbourne by the late Thomas Grubb of Dublin in I870. This is mounted in the Cassegrainian manner; so that the observer looks straight through it towards the object viewed, of which he really sees a twice-reflected image. The dust-laden atmosphere of Melbourne is said to impede very seriously the usefulness of this originally fine instrument.

It may be doubted whether so large a speculum will ever again be constructed. A new material for the mirrors of reflecting telescopes was proposed by Steinheil in 1856, and independently by Foucault in 1857,1 which has already in a great measure superseded the use of a metallic alloy. This is glass upon which a thin film of silver has been deposited by a chemical process invented by Liebig. It gives a peculiarly brilliant reflective surface, throwing back more light than a metallic mirror of the same area, in the proportion of about sixteen to nine. Resilvering, too, involves much less risk and trouble than repolishing a speculum. The first use of this plan on a large scale was in an instrument of thirty-six inches aperture, finished by Calver for Dr. Common in 1879 . To its excellent qualities, turned to account with rare skill, his triumphs in celestial photography were mainly due. A more daring experiment was the construction and mounting, by Dr. Common himself, of a five-foot reflector. But the first glass-disc ordered from France for the purpose proved radically defective. When figured, polished, and silvered, towards the close of 1888 , it gave elliptical instead of circular star-images. ${ }^{2} \quad$ A new one had to be procured, and was ready for astronomical use in I89r. The satisfactory nature of its performance is vouched for by the observations made with it upon Jupiter's new satellite in December 1892. This instrument, to which a Newtonian form has been given, concentrates more light than any telescope yet built. A refractor, to be its equal in this respect, should have more than fifty inches of aperture.

1 Comptes Rendus, t. xliv., p. 339. 2 A. A. Common, Memoirs R. Astr. Soc., vol. 1., p. I I 8 . 
It is, however, in the construction of refracting telescopes that the most conspicuous advances have recently been made. The Harvard College I5-inch achromatic was mounted and ready for work in June 1847. A simpilar instrument had already for some years been in its place at Pulkowa; but it was long before the possibility of surpassing these masterpieces of German skill presented itself to any optician. For fifteentyears it seemed as if a line had been drawn just there. It was first transgressed in America. A portrait-painter of Cambridgeport, Massachusetts, named Alvan Clark, had for some time amused his leisure with grinding lenses, the singular excellence of which was discovered in England by Mr. Dawes in I853. ${ }^{1}$ Seven years passed, and then an order came from the University of Mississippi for an object-glass of the unexampled size of eighteen inches. An experimental glance through it to test its definition resulted, as we have seon, in the detection of the companion of Sirius, January 31, 1862. It never reached its destination in the South. War troubles supervened; and it was eventually sent to Chicago, where it has served Professor Hough in his investigations of Jupiter, and Mr. Burnham in his scrutiny of double stars.

The next step was an even longer one, and it was again taken by a self-taught optician, Thomas Cooke, the son of a shoemaker at Allerthorpe, in the East Riding of Yorkshire. Mr. Newall of Gateshead ordered from him in 1863 a 25 -inch object-glass. It was finished early in 1868 , but at the cost of shortening the life of its maker, who died October 19, 1869, before the giant refractor he had toiled at for five years was completely mounted. This instrument, the excellent qualities of which had long been neutralised by an unfavourable situation, was presented by $\mathrm{Mr}$. Newall to the University of Cambridge a few weeks before his death, April 2 r, I 889. It is destined, under the care of his son, Mr. Frank Newall, for use in stellar physics.

Close upon its construction followed that of the Washington 26-inch, for which twenty thousand dollars were paid to Alvan Clark. Set to work in 1873, the most illustrious point in its career, so far, has been the discovery of the satellites of Mars.

${ }^{1}$ Newcomb, Pop. Astr., p. 137. 
Once known to be there, these were, indeed, found to be perceptible with very moderate optical means (Mr. Wentworth Erck saw Deimos with a 7-inch Clark); but the first detection of such minute objects is a feat of a very different order from their subsequent observation.

For a little over eight years the Washington refractor held the primacy. It had to yield the place of honour in December I880 to a giant achromatic, twenty-seven inches in aperture, built by Sir Howard Grubb (son and successor of Thomas Grubb) for the Vienna Observatory. This, in its turn, has been surpassed by two of respectively $29 \frac{1}{2}$ and 30 inches, sent by Gautier of Paris to Nice, and by Alvan Clark to Pulkowa; and an object-glass, three feet in diameter, was in I886 successfully turned out by the latier firm for the Lick Observatory in California. The difficulties, however, encountered in procuring discs of glass of the size and purity required for this last venture, seemed to indicate that a term to progress in this direction was not far off. The flint was indeed cast with comparative ease in the workshops of M. Feil at Paris. The flawless mass weighed I 70 kilogrammes, was over 38 inches across, and cost $£ 2,000$. But with the crown part of the designed achromatic combination things went less smoothly, The production of a perfect disc was only achieved after nineteen failures, involving a delay of more than two years; and the glass for a third lens, designed to render the telescope available at pleasure for photographic purposes, proved to be strained, and consequently went to pieces in the process of grinding. It has been replaced by one of thirty-three inches, with which a series of admirable lunar and other photographs have been taken.

Nor is the difficulty in obtaining suitable material the only obstacle to increasing the size of refractors. The "secondary spectrum," as it is called, also interposes a barrier troublesome to surmount. A truly achromatic combination cannot be obtained with ordinary flint and crown glass; and it has not yet been found possible to procure large castings of Professor Abbe's " Jena glass," by which outstanding colour is reduced to about one-sixth its usual amount. In the Lick telescope, accordingly, 
the differences of focal length for the various colours are counted by inches, ${ }^{1}$ and this not through any lack of skill in the makers, but by the necessity of the case. Embarrassing consequences follow. Only a small part of the spectrum of a heavenly body, for instance, can be distinctly seen at one time; and a focal adjustment of half-an-inch is required in passing from the observation of a planetary nebula to that of its stellar nucleus. A refracting telescope loses, besides, one of its chief advantages over a reflector when its size is increased beyond a certain limit. That advantage is the greater luminosity of the images given by it. Considerably more light is transmitted through a glass lens than is reflected from an equal metallic surface; but only so long as both are of moderate dimensions. For the glass necessarily grows in thickness as its area augments, and consequently stops a larger percentage of the rays it refracts. So that a point at length arrives-fixed by the late Dr. Robinson at a diameter a little short of three feet ${ }^{2}$-where the glass and the metal are, in this respect, on an equality; while above it, the metal has the advantage. And since silvered glass gives back considerably more light than speculum metal, the stage of equalisation with lenses is reached proportionately sooner where this material is employed.

The most distinctive faculty of reflectors, however, is that of bringing rays of all refrangibilities to a focus together. They are naturally achromatic. None of the beams they collect are thrown away in colour-fringes, obnoxious both in themselves and as a waste of the chief object of astro-physicists' greedlight. Reflectors, then, are in this respect specially adapted to photographic and spectrographic use. But they have a countervailing drawback. The penalties imposed by bigness are for them peculiarly heavy. Perfect definition becomes, with increasing size, more and more difficult. to attain; once attained, it becomes more and more difficult to keep; for the huge masses of material employed to form great object-glasses or mirrors tend with every movement to become deformed by their

1 Keeler, Publ. Astr. Pac. Soc., vol. ii., p. 160. Dub. Soc., vol. i. (new ser.), p. 2.

${ }^{2}$ H. Grubb, Trans. Roy. 
own weight. Now, the slightest bending of a mirror is fatal to its performance, the effect being doubled by reflection; while, in a lens, alteration of figure is compensated by the equal and contrary flexures of the opposing surfaces, so that the emergent beams pursue much the same paths as if the curves of the refracting medium had remained theoretically perfect. For this reason, work of precision must remain the province of refracting telescopes, although great reflectors retain the primacy in the portraiture of the heavenly bodies, as well as in certain branches of spectroscopy.

Ambition, as regards telescopic power, is by no means yet satisfied. Nor ought it to be. The advance of astro-physical researches of all kinds depends largely upon light-grasp. For the spectroscopic examination of stars, for the measurement of their motions in the line of sight, for the discovery and study of nebulæ, for stellar and nebular photography, the cry continually is, " more light." There is no enterprising head of an observatory but must feel cramped in his designs if he can command no more than fourteen or fifteen inches of aperture, and he aspires to greater instrumental capacity, not merely with a view to the chances of discovery, but for the steady prosecution of some legitimate line of inquiry. Thus projects of telescope-building on a large scale are rife, and some are in course of execution. Sir Howard Grubb has nearly finished a twenty-eight inch achromatic for Greenwich; one at least its equal ought ere long to be erected at Potsdam; and Mr. Alvan G. Clark, the sole survivor of the celebrated Cambridgeport firm, has undertaken what he expects will be his last arduous commission.

Mr. Yerkes of Chicago offered, in October I892, an unlimited sum for the provision of the University of that city with a "superlative" telescope. And it happened fortunately that a pair of glass discs, nearly forty-two inches in diarneter, and of perfect quality, were ready at hand. They had been cast by Mantois for the University of Southern California, when the erection of a great observatory on Wilson's Peak was under consideration. The Yerkes instrument may then be completed with relatively small delay; and a programme of work to be done 
with it has already been sketched out. ${ }^{1}$ And since, among those engaged in carrying it out will be Professor Hale, Dr. See, and Mr. Burnham, we may be sure that the coming implement of research will not be allowed to " rust unburnished."

Much vaguer is the prospect of seeing a gigantic reflector mounted in Paris by way of enhancement to the glories of the Exhibition year 1900. The mirror, of silvered glass, is to be ten feet in diameter, and will be contained in a tube I4O feet long; while magnifying powers are promised to be applied by which the moon will be brought within an insignificant number of kilometers of the amazed spectator. But the plan, as at present put forward, belongs to the realm rather of sensation than of science. Its realisation, regarded as possible by so high an authority as Dr. Common, would, none the less, be of great interest to optical astronomy.

These emulative efforts have without doubt been spurred on by the brilliant success of the Lick telescope. The results achieved with it are the best testimony to its excellence. The discovery, by Professors Holden and Schaeberle, of the helical forms of certain planetary nebulæ, Mr. Burnham's hair's-breadth star-divisions, Professor Keeler's spectroscopic determinations of nebular motion, Professor Barnard's detections and prolonged pursuit of faint comets, last, not least, his discovery of Jupiter's tiny moon-all this could only have been accomplished in four years, even by an exceptionally able and energetic staff, with the aid of an instrument of first-rate optical quality. But there was another condition which should not be overlooked.

The best telescope may be rendered useless by its situation. The larger it is, indeed, the more powerless is it to cope with atmospheric troubles. These are the worst plagues of all those that afflict the astronomer. No mechanical skill avails to neutralise or alleviate them. They augment with each increase of aperture; they grow with the magnifying powers applied. The rays from the heavenly bodies, when they can penetrate the cloud-veils that too often bar their path, reach us in an enfeebled,

1 Hale, Astr. and Astro-Physics, Nov. 1892, p. 291. ${ }^{2}$ Observatory, vol. xv., p. 391 . 
scattered, and disturbed condition. Hence the twinkling of stars, the "boiling" effects at the edges of sun, moon, and planets, hence distortions of bright, effacements of feeble telescopic images. Hence, too, the paucity of the results achieved with many powerful light-gathering machines.

No sooner had the Parsonstown telescope been built, than it became obvious that the limit of profitable augmentation of size had, under climatic conditions at all nearly resembling those prevailing there, been reached, if not overpassed; and Lord Rosse himself was foremost to discern the need of pausing to look round the world for a clearer and stiller air than was to be found within the bounds of the United Kingdom. With this express object Mr. Lassell transported his two-foot Newtonian to Malta in 1852 , and mounted there, in 1860 , a similar instrument of four-fold capacity, with which in the course of about two years 600 new nebulæ were discovered. Professor Piazzi Smyth's experiences during a trip to the Peak of Teneriffe in 1856 in search of astronomical opportunities, ${ }^{1}$ gave countenance to the most sanguine hopes of deliverance, at suitably elevated stations, from some of the oppressive conditions of low-level star-gazing; yet for a number of years nothing effectual was done for their realisation. Now at last, however, mountain observatories are not only an admitted necessity, but an accomplished fact; and Newton's long forecast of a time when astronomers would be compelled, by the developed powers of their telescopes, to mount high above the "grosser clouds" in order to use them, ${ }^{2}$ has been justified by the event.

Mr. James Lick, the millionaire of San Francisco, had already chosen when he died, October I, I876, a site for the new observatory, to the building and endowment of which he devoted a part of his large fortune. The situation of the establishment is exceptional and splendid. Planted on one of the three peaks of Mount Hamilton, a crowning summit of the Californian Coast Range, at an elevation of 4200 feet above the sea, in a climate scarce rivalled throughout the world, it commands views both celestial and terrestrial which the lover of

1 Phil. Trans., vol. cxlviii., p. $465 . \quad 2$ Optice, p. 107 (2nd ed., 1719). 
nature and astronomy may alike rejoice in. Impediments to observation are there found to be most materially reduced. Professor Holden, who was appointed in 1885 president of the University of California and director of the new observatory affiliated to it, stated that during six or seven months of the year an unbroken serenity prevails, and that half the remaining nights are clear. ${ }^{1}$ The power of continuous work thus afforded is of itself an inestimable advantage; and the high visual excellences testified to by Mr. Burnham's discovery, during a two months' trip to Mount Hamilton in the autumn of r879, of forty-two new double stars with a 6-inch achromatic, gave hopes, since fully realised, of a brilliant future for the Lick establishment. Its advantages, according to the generous design of Professor Holden, are shared by the whole astronomical world. ${ }^{2}$ A sort of appellate jurisdiction has been, by general consent, accorded to the great equatoreal, and more than one disputed point has been satisfactorily settled by recourse to it.

It is unlikely that its performances will be surpassed by outbidding it in size, unless the care expended upon the selection of its site be imitated. Professor Pickering has thus shown his customary prudence in reserving his efforts to procure a great telescope until Harvard College owned a dependent observatory where it could be employed to advantage. This has been found by Mr. W. H. Pickering, after many experiments in Colorado, California, and Peru, at Arequipa, on a slope of the Andes eight thousand feet above the sea-level. Here the post provided for by the "Boyden Fund" was established in I89I, under ideal meteorological conditions. Temperature preserves a "golden mean"; the barometer is almost absolutely steady; the yearly rainfall amounts to no more than three or four inches. No wonder then that the "seeing" there is of the extraordinary excellence attested by Mr. Pickering's observations. In the absence of bright moonlight, he tells us, ${ }^{3}$ eleven Pleiades can always be counted; the Andromeda nebula appears to the naked eye conspicuously bright, and larger than the full moon; third

1 Observatory, vol. viii., p. 85 .

2 Holden on Celestial Photography, Overland Monthly, Nov. I886. 3 Observatory, vol. xv., p. 283. 
magnitude stars have been followed to their disappearance at the true horizon; the zodiacal light spans the heavens as a complete arch, the "Gegenschein" forming a regular part of the scenery of the heavens. Corresponding telescopic facilities are enjoyed. The chief instrument at the station, a thirteen-inch equatoreal by Clark, shows the fainter parts of the Orion nebula, photographed at Harvard College in 1887 , by which the dimensions given to it in Bond's drawing are doubled; stars are at times seen encircled by half a dozen immovable diffractionrings, no less than twelve of which have been counted round a Centauri; while on many occasions no practicable increase of magnifying power availed to bring out any wavering in the limbs of the planets. Moreover, the series of fine nights is nearly unbroken from March to November.

In Professor E. C. Pickering's judgment, the advantages conferred, in many researches, by the climate of Arequipa are equivalent to a doubling of telescopic aperture. His appeal, ${ }^{1}$ then, for a colossal instrument, to be erected in a spot where its utmost powers could be turned to account with trifling interruption, will doubtless not be made in vain. Arequipa has the additional prerogative, owing to its position sixteen degrees below the line, of commanding the entire southern hemisphere. And at present, all the workable great telescopes in the world are located above the parallel of $35^{\circ}$ north latitude. The Melbourne reflector is the only instrument of more than fifteen inches aperture south of that limit; and it no longer counts for much, having probably suffered irreparable injury on the long sea-voyage from its place of origin to its destination.

Vapours and air-currents do not alone embarrass the use of giant telescopes. Mechanical difficulties also oppose a formidable barrier to much further growth in size. But what seems a barrier often proves to be only a fresh starting-point; and signs are not wanting that it may be found so in this case. It is possible that the monumental domes and huge movable tubes of our present observatories will, in a few decades, be as much

1 Astr. and Astro-Physics, Nov. 1892, p. 783. 
things of the past as Huygens's " aerial" telescopes. It is certain that the thin edge of the wedge of innovation has been driven into the old plan of equatoreal mounting.

M. Loewy, the present sub-director of the Paris Observatory, proposed to Delaunay in I87 I the erection of a telescope on a novel system. The design seemed feasible, and was adopted; but the death of Delaunay and the other untoward circumstances of the time interrupted its execution. Its resumption, after some years, was rendered possible by M. Bischoffsheim's gift of 25,000 francs for expenses, and the coudé or "bent" equatoreal has been, since I882, one of the leading instruments at the Paris establishment.

Its principle is briefly this. The telescope is, as it were, its own polar axis. The anterior part of the tube is supported at both ends, and is thus fixed in a direction pointing towards the pole, with only the power of twisting axially. The posterior section is joined on to it at right angles, and presents the objectglass accordingly to the celestial equator, in the plane of which it revolves. Stars in any other part of the heavens have their beams reflected upon the object-glass by means of a plane rotating mirror placed in front of it. The observer, meanwhile, is looking steadfastly down the bent tube towards the invisible southern pole. He would naturally see nothing whatever, were it not that a second plane mirror is fixed at the "elbow" of the instrument, so as to send the rays which have traversed the object-glass to his eye. He never needs to move from his place. He watches the stars seated in an arm-chair in a warm room, with as perfect convenience as if he were examining the seeds of a fungus with a microscope. Nor is this a mere gain of personal ease. The abolition of hardship includes a vast accession of power. ${ }^{1}$

Among other advantages of this method of construction are, first, that of added stability, the motion given to the ordinary equatoreal being transferred, in part, to an auxiliary mirror. Next, that of increased focal length. The fixed part of the tube can be made almost indefinitely long without inconvenience, and

${ }^{1}$ Loewy, Bull. Astr., t. i., p. 286 ; Nature, vol. xxix., p. 36. 
with enormous advantage to the optical qualities of a large instrument. Finally, the costly and unmanageable cupola is got rid of, a mere shed serving all purposes of protection required for the coudé.

The desirability of some such change as that which M. Loewy has realised, had been felt by others. Professor Pickering sketched in I88I a plan for fixing large refractors in a permanently horizontal position, and reflecting into them, by means of a shifting mirror, the objects desired to be observed. ${ }^{1}$ The observations for his photometric catalogue were, in fact, made with .a "broken transit," in which the line of sight remains permanently horizontal, whatever the altitude of the star examined. An instrument with "siderostatic" mounting by Sir Howard Grubb has been in use at the Crawford Observatory, Cork, since I882 ; in a paper read before the Royal Society, January 2I, I884, he proposed to carry out the principle on a more extended scale $;^{2}$ and shortly afterwards undertook its application to a telescope eighteen inches in aperture for the Armagh Observatory. ${ }^{3}$ The chief honours, however, remain to the Paris inventor. None of the prognosticated causes of failure have proved effective. The loss of light from the double reflection is insignificant. The menaced deformation of images is, through the exquisite skill of the MM. Henry in producing plane mirrors of all but absolute perfection, quite imperceptible. The definition of the novel $10 \frac{1}{2}$-inch equatoreal is admitted to be singularly good. Dr. Gill stated in I884 that he had never measured a double star so easily as he did $\gamma$ Leonis by its means. ${ }^{4}$ Professor Lockyer pronounced it to be " one of the instruments of the future "; and the principle of its construction was immediately adopted by the directors of the Besançon and Algiers Observatories, as well as for a I7-inch telescope destined for a new observatory at Buenos Ayres. At Paris, it has since been carried out on a larger scale. A coude, of $23 \frac{1}{2}$ inches aperture and sixty-two feet focal length, was in I890 installed at the National Observatory, and has served M. Loewy for his inge-

1 Nature, vol. xxiv., p. $389 .{ }^{2}$ lbid., vol. xxix., p. 470.

Dub. Soc., vol. iii., p. 6I. 4 Observatory, vol. vii., p. I67.

3 Trans. Roy. 
nious studies on refraction and aberration. A considerable number of orders for similar instruments are being executed; but the "bent" form, although suitable to reflectors as well as to refractors, ${ }^{1}$ has not yet been tipied with the former. The invention has, however, achieved a decisive success.

Celestial photography is not yet fifty years old ; yet its earliest beginnings already seem centuries behind itst.present performances. The details of its gradual yet rapid improvement are of too technical a nature to find a place in these pages. Suffice it to say that the " dry-plate" process, with which such wonderful results have been obtained, appears to have been first made available by Dr. Huggins in photographing the spectrum of Vega in 1876, and was then successively adopted by Common, Draper, and Janssen. Nor should Captain Abney's remarkable extension of the powers of the camera be forgotten. He began his experiments on the chemical action of red and infrared rays in 1874, and at length succeeded in obtaining a substance-the "blue" bromide of silver-highly sensitive to these slower vibrations of light. With its aid he explored a vast, unknown, and for ever invisible region of the solar spectrum, presenting to the Royal Society, December 5, I879, ${ }^{2}$ a detailed map of its infra-red portion (wave-lengths 7600 to 10,750), from which valuable inferences may yet be derived as to the condition of the various kinds of matter ignited in the solar atmosphere. Upon plates rendered "orthochromatic" by staining with erythrosin, or other dye-stuffs, the whole visible spectrum can now be photographed; but those with their maximum of sensitiveness near $G$, are found more practically available, except where the results of light-analysis are sought to be completely recorded. And since photographic refractors are corrected for the blue rays, exposures with them of orthochromatic surfaces would be entirely futile.

The chemical plate has two advantages over the human retina. ${ }^{3}$ First, it is sensitive to rays which are utterly powerless to produce any visual effect; next, it can accumulate impressions almost

1 Loewy, Bull. Astr., t. i., p. 265. 2 Phil. Trans., vol. clxxi., p. 653. 3 Janssen, L'Astronomie, t. ii., p. I21. 
indefinitely, while from the retina they fade after one-tenth part of a second, leaving it a continually renewed tabula rasa.

It is accordingly quite possible to photograph objects so faint as to be altogether beyond the power of any telescope to reveal ; and we may thas eventually learn whether a blank space in the sky truly represents the end of the stellar universe in that direction, or whether farther and farther worlds roll and shine beyond, veiled in the obscurity of immeasurable distance.

Of many ingenious improvements in spectroscopic appliances the most fundamentally important relate to what are known as "gratings." These are very finely striated surfaces, by which light-waves are brought to interfere, and are thus sifted out, strictly according to their different lengths, into " normal" spectra. Since no universally valid measures can be made in any others, their production is quite indispensable to spectroscopic science. Fraunhofer, who initiated the study of the diffraction spectrum, used a real grating of very fine wires; but rulings on glass were adopted by his successors, and were by Nobert executed with such consummate skill that a single square inch of surface was made to contain I00,000 hand-drawn lines. Such rare and costly triumphs of art, however, found their way into very few hands, and practical availability was first given to this kind of instrument by the inventiveness and mechanical dexterity of two American investigators. Both Rutherfurd's and Rowland's gratings are machine-ruled, and reflect, instead of transmitting the rays they analyse; but Rowland's present to them a very much larger diffractive surface, and consequently possess a higher resolving power. The first preliminary to his improvements was the production, in I882, of a faultless screw, those previously in use having been the inevitable source of periodical errors in striation, giving, in their turn, ghost-lines as subjects of spectroscopic study. ${ }^{1}$ Their abolition was not one of Rowland's least achievements. With his perfected machine a metallic area of $6 \frac{1}{4}$ by $4 \frac{1}{4}$ inches can be ruled with exquisite accuracy to almost any degree of fineness; he considers, however, 43,000

1 Rev. A. L. Cortie, Astr. and Astro-Physics, May I892, p. 400. 
lines to the inch to be the limit of usefulness. ${ }^{1}$. The ruled surface is moreover concave, and hence brings the spectrum to a focus without a telescope. A slit and an eyepiece are alone needed to view it, and absorption of light by glass lenses is obviatedan advantage especially sensible in dealing with the ultra- or infra-visible rays.

The high qualities of Professor Rowland's great photographic map of the solar spectrum were thus based upon his previous improvement of the instrumental means used in its execution. The amount of detail shown in it is illustrated by the appearance on the negatives of $\mathrm{I} 5 \mathrm{O}$ lines between $\mathrm{H}$ and $\mathrm{K}$; and many lines depict themselves as double which, until examined with a concave grating, had passed for one and indivisible. The corresponding hand-drawing for which M. Thollon received in 1886 the Lalande Prize, exhibits, not the diffractive, but the prismatic spectrum as obtained with bisulphide of carbon prisms of large dispersive power. About one-third of the visible gamut of the solar radiations (A to b) is covered by it; it includes 3200 lines, and is over ten metres long. ${ }^{2}$ The grating is an expensive tool in the way of light. Where there is none to spare, its advantages must be foregone. They could not, accordingly, be turned to account in stellar spectroscopy until the Lick telescope was at hand to supply more abundant material for research. By the use of Rowland's grating thus made possible, Professor Keeler was able to apply enormous dispersion to the rays of stars and nebulæ, and so to attain a previously unheard-of degree of accuracy in their measurement. His memorable detection of nebular movement in line of sight ensued as a consequence. Professor Campbell, his successor, has since obtained, by the same means, the first satisfactory photographs of stellar diffraction spectra.

The means at the disposal of astronomers have not multiplied faster than the tasks imposed upon them. Looking back to the year I 800 , we cannot fail to be astonished at the change. The comparatively simple and serene science of the heavenly bodies known to our predecessors, almost perfect so far as it went, in-

1 Plil. Mlag., vol. xiii., ı882, p. 469 . 2 Bull. Astr., t. iii., p. 33I. 
curious of what lay beyond its grasp, has developed into a body of manifold powers and parts, each with its separate mode and means of growth, full of strong vitality, but animated by a restless and unsatisfied spirit, haunted by the sense of problems unsolved, and tormented by conscious impotence to sound the immensities it perpetually confronts.

Knowledge might then be said to be bounded by the solar system; but even the solar system presented itself under an aspect strangely different from what it now wears. It consisted of the sun, seven planets, and twice as many satellites, all circling harmoniously in obedience to an universal law, by the compensating action of which the indefinite stability of their mutual relations was secured. The occasional incursion of a comet, or the periodical presence of a single such wanderer chained down from escape to outer space by planetary attraction, availed nothing to impair the symmetry of the majestic spectacle.

Now, not alone the ascertained limits of the system have been widened by a thousand millions of miles, with the addition of one more giant planet and seven satellites to the ancient classes of its members, but a complexity has been given to its constitution baffling description or thought. Three hundred and sixty circulating planetary bodies bridge the gap between Jupiter and Mars, the complete investigation of the movements of any one of which would overtask the energies of a lifetime. Meteorites, strangers apparently to the fundamental ordering of the solar household, swarm, nevertheless, by millions in every cranny of its space, returning at regular intervals like the comets so singularly associated with them, or sweeping across it with hyperbolic velocities, brought perhaps from some distant star. And each of these cosmical grains of dust has a theory far more complex than that of Jupiter; it bears within it the secret of its origin, and fulfils a function in the universe. The sun itself is no longer a semi-fabulous, fire-girt globe, but the vast scene of the play of forces as yet imperfectly known to us, offering a boundless field for the most arduous and inspiring researches. Among the planets the widest variety in physical habitudes is seen to prevail, and each is recognised as a world apart, inviting 
inquiries which, to be effective, must necessarily be special and detailed. Even our own moon threatens to break loose from the trammels of calculation, and commits "errors" which sap the very foundations of the Iunar theory, and suggest the formidable necessity for its complete revision. Nay, the steadfast earth has forfeited the implicit confidence placed in it as a time-keeper, and questions relating to the stability of the earth's axis, and the constancy of the earth's rate of rotation, are among those which it behoves the future to answer. Everywhere there is multiformity and change, stimulating a curiosity which the rapid development of methods of research offers the possibility of at least partially gratifying.

Outside the solar system, the problems which demand a practical solution are all but infinite in number and extent. And these have all arisen and crowded upon our thoughts within less than a hundred years. For sidereal science became a recognised branch of astronomy only through Herschel's discovery of the revolutions of double stars in I802. Yet already it may be, and has been called, "the astronomy of the future": so rapidly has the development of a keen and universal interest attended and stimulated the growth of power to investigate this sublime subject. What has been done is little-is scarcely a beginning; yet it is much in comparison with the total blank of a century past. And our knowledge will, we are easily persuaded, appear in turn the-merest ignorance to those who come after us. Yet it is not to be despised, since by it we reach up groping fingers to touch the hem of the garment of the Most High. 
A P P E N D I X. 



\section{TABLE I.}

\section{CHRONOLOGY, I774-IS93.}

I 774, March 4 . Herschel's first observation. Subject, the Orion Nebula.

I 774 . . . The depressed nature of sun-spots geometrically proved by Wilson.

1774 . . First experimental determination of the earth's mean density by Maskelyne.

I 781, March 13 . Discovery of Uranus.

$I_{7} 82$. . Herschel's first Catalogue of Double Stars.

I 783 . . . Herschel's first investigation of the sun's movement in space.

I783 . . . Goodricke's discovery of Algol's law of variation.

1784 . . Analogy between Mars and the Earth pointed out by Herschel.

I784 . . . Construction of the Heavens investigated by Herschel's method of star-gauging. "Clovendisk" plan of the Milky Way.

${ }_{1784}$. . . Discovery of binary stars anticipated by Michell.

${ }_{17} 86$. . . Herschel's first Catalogue of Nebulæ.

I 787 , January I I. Discovery by Herschel of two Uranian moons (Oberon and Titania.)

${ }_{17} 87$, Nov. 19 . Acceleration of the moon explained by Laplace. r 789 . . . Herschel's second Catalogue of Nebulæ, and classification of these objects as sidereal systems in more or less advanced stages of condensation.

I789 . . Completion of Herschel's forty-foot reflector. 
I 789 , August 28 and Sept. I 7$\}$

1789 $\times 789$

1790

I 79I

$179^{2}$

I 794

I 795

$179^{6}$

$179^{6}$

I 797

I 798

I 799

I 799, May 7

I799, Nov. I 2 1800 I 800

I80I, January I . I 801 I 80 I

I802, March 28. 1802 1802 I 802
His discovery with it of the two inner Saturnian satellites.

Repeating-circle invented by Borda.

Five-foot circle constructed by Ramsden for Piazzi.

Maskelyne's Catalogue of thirty-six fundamental stars.

Herschel retracts his opinion that all nebulæ are of sidereal nature, and admits the existence of a self-luminous fluid in space.

Presence of atmospheric refraction in Venus announced by Schröter.

Rotation-period of Saturn fixed by Herschel at Ioh. $16 \mathrm{~m}$.

Promulgation of Herschel's theory of the solar constitution.

Herschel's first measures of comparative stellar brightness.

Laplace's Nebular Hypothesis published in Exposition du Système du Monde.

Publication of Olbers's method of computing cometary orbits.

Retrograde motions of Uranian satellites. announced by Herschel.

Publication of first two volumes of Mécanique Céleste.

Transit of Mercury observed by Schröter.

Star-shower observed by Humboldt at Cumana. Monatliche Correspondenz started by Von Zach.

Invisible heat-rays detected in the solar spectrum by Herschel.

Discovery of Ceres by Piazzi.

Publication of Lalande's Histoire Céleste.

Investigation by Herschel of solar emissive variability in connection with spot-development.

Discovery of Pallas by Olbers.

Herschel's third Catalogue of Nebulæ.

Herschel's discovery of binary stars.

Marks of clustering in the Milky Way noted by Herschel. 
1802 . . . . Interruption of the solar spectrum by seven dark lines observed by Wollaston.

I 802, Nov. 9 . Transit of Mercury observed by Herschel.

I 804 , Sept. 2 . Discovery of Juno by Harding.

I804 . . . Foundation of Optical Institute at Munich.

I 805 . . . Herschel's second determination of the solar apex of motion.

I 807, March 29 . Discovery of Vesta by Olbers.

I8I I . .

I8I I, Feb. 9 . Death of Maskelyne. Pond appointed to succeed him as Astronomer Royal.

I8I I, Sept. I2 . Perihelion passage of great comet.

I8I2 . . . Theory of electrical repulsion in comets originated by Olbers.

I 8 I 2 , Sept. I 5 . Perihelion passage of Pons's comet.

1814 . . . Herschel demonstrates the irregular distribution of stars in space.

I8I5 . . Fraunhofer maps 324 dark lines in the solar spectrum.

I8I8 . . . Publication of Bessel's Fundamenta Astronomice.

I8r9 . . . Recognition by Encke of the first short-period comet.

I 8 I9, June 26 . Passage of the earth through the tail of a comet. 1820 . . . Foundation of the Royal Astronomical Society.

$182 \mathrm{I}$. . . Foundation of Paramatta Observatory.

I 82 I, September . First number of Astronomische Nachrichten.

I 822, May 24. First calculated return of Encke's comet.

I 822, August 25. Death of Herschel.

I823 . . . Bessel introduces the correction of observations for personal equation.

1823 . . Fraunhofer examines the spectra of fixed stars.

I824 . . . Distance of the sun concluded by Encke to be $95 \frac{1}{4}$ million miles.

I824 . . . Publication of Lohrmann's Lunar Chart.

1824 . . . Dorpat refractor mounted equatoreally with clock-work motion.

1826 . . Commencement of Schwabe's observations of sun-spots.

1826, Feb. 27 . Biela's discovery of the comet named after him. 
1827 . . Orbit of a binary star calculated by Savary.

1829 . . . Completion of the Royal Observatory at the Cape of Good Hope.

1829 . . . The Königsberg heliometer mounted.

I830 . . Publication of Bessel's Tabula Regiomontance.

1832 . . . Discovery by Brewster of "atmospheric lines" in the solar spectrum.

1833 . . The first magnetic observatory established at Göttingen.

I833, Nov. I2-I3 Star-shower visible in North America.

1833 . . Completion of Sir J. Herschel's survey of the northern heavens.

I 834, January 16. Sir J. Herschel's landing at the Cape.

1835, September . Airy appointed Astronomer-Royal in succession to Pond.

1835, Nov. I6 - Perihelion passage of Halley's comet.

I836, May I5 . Annular eclipse of the sun, and recognition of "Baily's Beads."

I837 . . Direction of the

I837 - . Bessel's application of the heliometer to the measurement of stellar parallax.

1837 . . . Publication of Beer and Mädler's Der Mond.

1837 . . Publication of Struve's Mensurce Micrometricce.

1837, Dec. I6 . Outburst of $\eta$ Argûs observed by Sir J. Herschel.

I837 . . . Thermal power of the sun measured by Herschel and Pouillet.

r838 . . Parallax of 6r Cygni determined by Bessel.

1839, January 9 . Parallax of $a$ Centauri announced by Henderson. I839 - . . Completion of Pulkowa Observatory and installation of Struve as its Director.

I839 . . . Solidity of the earth concluded by Hopkins.

I840, March 2 . Death of Olbers.

I840 . . First attempt to photograph the moon by J. W. Draper.

r842 . . . Doppler's principle of the change of refrangibility of light by motion enounced.

1842 . . Conclusion of Baily's experiments in weighing the Earth.

I842, July 8 . Total solar eclipse. Corona and prominences observed by Airy, Baily, Arago, and Struve. 
I 843, Feb. 27 . Perihelion-passage of great comet, visible to the naked eye at noon, February 28.

1845, February . Completion of Parsonstown reflector.

I845, April . . Discovery with it of spiral nebulæ.

1845, April 2 . Daguerreotype of the sun taken by Foucault and Fizeau.

I845, October 2 I . Place of Neptune assigned by Adams.

1845, Dec. 8 . Discovery of Astræa by Hencke.

I845, Dec. 29 . Duplication of Biela's comet observed at Yale College.

i846 . . . Melloni's detection of heating effects from moonlight.

I846, March I7 . Death of Bessel.

I 846, Sept. 23 . Discovery of Neptune by Galle.

I846, October Io. Neptune's Satellite discovered by Lassell.

1847 . : . Publication of Sir J. Herschel's Results of Observations at the Cape of Good Hope.

I847 . . Cyclonic theory of sun-spots stated by him.

I 848 . . . J. R. Mayer's meteoric hypothesis of solar conservation.

1848 . . . Motion-displacements of Fraunhofer-lines adverted to by Fizeau. .

I 848, April 27 . New Star in Ophiuchus observed by Hind.

I848, Sept. 19 . Simultaneous discovery of Hyperion by Bond and Lassell.

1849 . . . First experimental determination of the velocity of light (Fizeau).

I850, July I 7 . Vega photographed at Harvard College.

I 850 , Nov. I 5 . Discovery by Bond of Saturn's dusky ring.

I85 - . . O. Struve's first measurements of Saturn's ringsystem.

I85 I, July 28 . Total solar eclipse observed in Sweden.

I $85 \mathrm{I}$, October 24. Discovery by Lassell of two inner Uranian satellites.

I85I . . . Schwabe's discovery of sun-spot periodicity published by Humboldt.

I852, May 6 . Coincidence of magnetic and sun-spot periods announced by Sabine.

I 852, October I I . Variable nebula in Taurus discovered by Hind.

I852 - . Lassell's two-foot reflector transported to Malta. 
1853 . . . Adams shows Laplace's explanation of the moon's acceleration to be incomplete.

1854 . . Hansen infers from lunar theory the necessity of reducing Encke's value for the distance of the sun.

1854 . . . Helmholtz's "gravitation theory" of solar energy stated.

1856 . . Piazzi Smyth's observations on the Peak of Teneriffe.

1857 . . . Saturn's rings shown by Clerk Maxwell to be of meteoric formation.

1857, April 27 . Double-star photography initiated at Harvard College.

I 858 . 1858, Sept. 30 . Perihelion of Donati's comet.

I859.

- Spectrum analysis established on a secure foundation by Kirchhoff and Bunsen.

1859 . . - Carrington's discovery of the compound nature of the sun's rotation.

1859, March 26 . Lescarbault's supposed transit of Vulcan.

1859, Sept. I . Luminous solar outburst and magnetic storm.

I 859, October 19. Merope nebula discovered by Tempel.

1859, Dec. I5 . Chemical constitution of the sun described by Kirchhoff.

I 860, Feb. 27 . Discovery by Liais of a "double comet."

1860, May 21 . New star in Scorpio detected by Auwers.

1860, July 18 . Total solar eclipse observed in Spain. Prominences shown by photography to be solar appendages.

I86I, June 30 . The earth involved in the tail of a great comet.

1861-1862 . . Kirchhoff's map of the solar spectrum.

1862 . . Presence of hydrogen in the sun announced by Angström.

1862 . . Nasmyth's solar willow-leaves described.

1862, January 31 Discovery by Alvan G. Clark of the companion of Sirius.

1862 . . Foucault applies the velocity of light to the determination of the sun's distance.

1862 . . Opposition of Mars. Determination of solar parallax.

1862 . . Completion of Bonner Durchmusterung. 
I863 . . . Secchi's first classification of stellar spectra.

I863 . . Foundation of the German Astronomical Society. 1864, March 5 . Rotation period of Mars determined by Kaiser. r864 . . Huggins's first results in stellar spectrum -analysis. Spectra of Betelgeux and Aldebaran investigated.

1864, August 5. Application of the spectroscope to Tempel's comet by Donati. Found to be self-luminous, and of gaseous constitution.

I 864, August 29 . Discovery by Huggins of gaseous nebulæ.

I864 . . Reduction to 9r million miles of the received value of the sun's distance.

I 864 . . Croll's explanation of glacial epochs.

I 864, Nov. 23 . Death of Struve.

I 865, January 4. Spectroscopic observation by Huggins of the occultation of $\epsilon$ Piscium.

I 865 , January i 6 Faye propounds his theory of the solar constitution.

1865 . . First publication of results by Kew observers.

I865 . . . Zöllner insists upon the high internal temperature of the great planets.

I 866

Identity of the orbits of the August meteors, and of comet I 862 iii., demonstrated by Schiaparelli.

I866 . . Delaunay explains outstanding lunar acceleration by a lengthening of the day through tidal friction.

I 866, March 4 . Spectroscopic study of the sun's surface begun by Lockyer.

I866, May I2 . New star in Corona Borealis detected by Birmingham.

I866, October . Schmidt announces the disappearance of the lunar crater Linné.

I866, Nov. I3 - Meteoric shower visible in Europe. Predicted by H. A. Newton.

r867 . . Period of November meteors determined by Adams.

r 867, August 29 . Total solar eclipse. Minimum sun-spot type of corona observed by Grosch at Santiago.

Discovery of gaseous stars in Cygnus by Wolf and Rayet. 
I868, August I 8 . Great Indian eclipse. Spectrum of prominences observed.

1868, August 19 . First observations (by Janssen) of prominences without an eclipse.

1868, October 26. Announcement by Lockyer and Janssen of their independent discovery of a method of daylight spectroscopic observation of prominences.

1868 . . . Doppler's principle applied by Huggins to measure stellar movements in the line of sight.

I868 . . . Publication of Angström's map of the normal solar spectrum.

I868 . . . Analysis of the light of Winnecke's comet by Huggins. Spectrum found to agree with that of olefiant gas.

I869, Feb. I I . Lockyer and Frankland infer the extreme tenuity of chromospheric gases.

I869, Feb. I3 . Huggins observes a prominence with an "open slit."

I 869, August 7 . American eclipse. Detection of bright-line coronal spectrum.

1870 . . Mounting of Newall's 25-inch achromatic at Gateshead.

1870 . . Proctor indicates the prevalence of drifting movements among the stars.

r870 . . . A solar prominence photographed by Young.

I 870 , Dec. 22 . Sicilian eclipse. Young discovers reversing layer.

I87 I, May i I . Death of Sir J. Herschel.

I87 I, June 9 . Line displacements due to solar rotation detected by Vogel.

I 87 I, Dec. I 2 . Total eclipse visible in India. Janssen observes reflected Fraunhofer lines in spectrum of corona.

1872 . . . Conclusion of a three years' series of observations on lunar heat by Lord Rosse.

1872 . . . Spectrum of Vega photographed by H. Draper.

1872 . . . Cyclonic hypothesis of sun-spots enunciated by Faye.

1872 . . Young's solar-spectroscopic observations at Mount Sherman. 
1872 . . Cornu's experiments on the velocity of light.

I872, Nov. 27 . Meteoric shower connected with Biela's comet.

I873 . . . Determination of mean density of the earth by Cornu and Baille.

I 873 . . Solar photographic work begun at Greenwich.

I873 . . Erection of 26-inch Washington refractor.

I874 . . . Light-equation redetermined by Glasenapp.

I874 . . . Vogel's classification of stellar spectra.

I 874 , Dec. 8 . Transit of Venus.

. 1876 . . . Publication of Neison's The Moon.

I876, Nov. 24 . New star in Cygnus discovered by Schmidt.

1876 . . . Spectrum of Vega photographed by Huggins. First use of dry gelatine plates in celestial photography.

I877, May 19 . Klein observes a supposed new lunar crater (Hyginus N.)

I877 . . Measurement by Vogel of selective absorption in solar atmosphere.

1877, Aug. 16-17. Discovery of two satellites of Mars by Hall at Washington.

I 877 , Sept. 23 . Death of Leverrier.

I877 . . . Canals of Mars discovered by Schiaparelli.

1877 . . . Opposition of Mars observed by Gill at Ascension. Solar parallax deduced $=8^{\prime \prime} \cdot 78$.

I878, January . Stationary meteor-radiants described by Denning.

1878 . . Publication of Schmidt's Charte der Gebirge des Mondes.

1878

First observations of Great Red Spot on Jupiter.

1878

I 878 , May 6 I 878

Conclusion of Newcomb's researches on the lunar theory.

.1878 , July 29 . Total eclipse visible in America. Vast equatorial extension of the corona.

1878, October . Completion of Potsdam Astrophysical Observatory.

1878, Dec. 12 . Lockyer's theory of celestial dissociation communicated to the Royal Society.

I879 . . Michelson's experiments on the velocity of light. 
1879 . . Publication of Gould's Uranometria Argentina. 1879, November . Observations of the spectra of sun-spots begun at South Kensington.

I 879, December 5. Abney's map of the solar spectrum in the infrared presented to the Royal Society.

1879, Dec. I 8 . Ultra-violet spectra of white stars described by Huggins to the Royal Society.

I879, Dec. I8 . Communication of G. H. 'Darwin's researches into the early history of the moon.

I880, January 31. Discovery at Cordoba of a great southern comet.

I880 . . . Conditions of Algol's eclipses determined by Pickering.

r880 . . . Pickering computes mass-brightness of binary stars.

1880, Sept. 30 . Draper's photograph of the Orion Nebula.

I880 . . . The bolometer invented by Langley.

I88 I, January 20. G. H. Darwin's researches into the effects of tidal. friction on the evolution of the solar system, communicated to the Royal Society.

I88I . . . Langley's observations of atmospheric absorption on Mount Whitney.

I88I, June r6 . Perihelion of Tebbutt's comet.

I88I, June 24 . Its spectrum photographed by Huggins.

I88I, June . . Pnotographs of Tebbutt's comet by Janssen and Draper.

I88I, August I5 . Retirement of Sir George Airy. Succeeded as Astronomer Royal by Christie.

I88 I, August 22. Perihelion of Schaeberle's comet.

I88r . . Publication by Stone of the Cape Catalogue for I880.

1882 . . Struve's second measures of Saturn's ringsystem, showing no certain change since I 851 .

I882 . . Newcomb's determination of the velocity of light. Resulting solar parallax $=8 " .79$.

1882 . . Correction by Nyrén of Struve's constant of aberration.

1882, March 7 . Spectrum of Orion Nebula photographed by Huggins.

I882, May I 7 . Total solar eclipse observed at Sohag in Egypt. 
I882, May 27 . Sodium-rays observed at Dunecht in spectrum of Comet Wells.

I882, June ro . Perihelion of Comet Wells.

I882, Sept. I 7 . Perihelion of great comet. Daylight detection by Common. Disappearance in transiting the sun observed at the Cape.

I882, Sept. I 8 . Iron-lines identified in spectrum by Copeland and J. G. Lohse.

I882, September . Photographs of great comet taken with a portraitlens at the Cape Observatory, showing a background crowded with stars.

I882, Dec. 6 . Transit of Venus.

1882 . . Duplication of Martian canals observed by Schiaparelli.

1882 . . . Completion by Loewy at Paris of first.equatoreal Coudé.

I882 . . Rigidity of the earth concluded from tidal observations by G. H. Darwin.

1882 . . Foundation of the Liverpool Astronomical Society.

1882 . . Experiments by Huggins on photographing the corona without an eclipse.

I882 . . . Publication of Holden's Monograph of the Orion Nebula.

I 883, January 30. The Orion Nebula photographed by Common in 3 I minutes.

I883, May 6 . Caroline Island eclipse.

I883, June I . Great comet of I882 observed from Cordoba at a distance from the earth of 470 million miles.

I 883, August I3 . Variability in the bright-line spectrum of $\gamma$ Cassiopeiæ discovered by Von Gothard.

I883 . . Parallaxes of nine southern stars measured by Gill and Elkin.

I883 . . Catalogue of the spectra of $405^{\mathrm{I}}$ stars by Vogel.

1884, January 25. Perihelion of Pons's comet.

I884 . . Photometric Catalogue of 4260 stars by Pickering.

r884 . . Publication of Gore's Catalogue of Variable Stars. 
188 1884, October 4

Publication of Faye's Origine du Monde.

Eclipse of the moon. Heat-phases measured by Boeddicker at Parsonstown.

r884 . . Dunér's Catalogue of Stars with Banded Spectra.

1884 . . Backlund's researches into the movements of Encke's comet.

1885, February . Langley measures the lunar-heat-spectrum.

I 885 . 1885, August 17

1885, Sept. 5

I $88_{5}$, Sept. 9 I 885 , Nov. I 6

I 885 , Nov. 27 I 885 I 885

I 885 I 885 I 885 , Dec. I 3

I886, January 26 . I 886 , Feb. 5 1886, March I886, May 6 1886, June 4 1886, August 29. I 886 , October I

1886, Dec. 8
Publication of Urailometria Nova Oxoniensis.

New star in Andromeda nebula discerned by Gully.

Thollon's drawing of the solar spectrum presented to the Paris Academy.

Solar eclipse visible in New Zealand.

Photographic discovery by Paul and Prosper Henry of a nebula in the Pleiades.

Shower of Biela meteors.

Thirty-inch achromatic mounted at Pulkowa.

Publication of Rowland's photographic map of the normal solar spectrum.

Bakhuyzen's determination of the rotationperiod of Mars.

Stellar photographs by Paul and Prosper Henry.

Discovery by Gore of a remarkable new variable (U Orionis.)

Spectra of forty Pleiades simultaneously photographed at Harvard College.

First visual observation of the Maia nebula with the Pulkowa 30 -inch refractor.

Photographs by the Henrys of the Pleiades, showing 2326 stars with nebula intermixed.

Periodical changes in spectra of sun spots announced by Lockyer.

An international Photographic Congress proposed by Gill.

Total eclipse of the sun observed at Grenada.

Roberts's photograph showing annular structure of the Andromeda nebula.

Roberts's photograph of the Pleiades with dense masses of nebulosity. 
1886, Dec. 28 . Discovery by Copeland of helium-ray in spectrum of the Orion nebula.

r886 . . . Thirty-inch refractor mounted at Nice.

I886, May . . Photographic investigations of stellar parallax undertaken by Pritchard.

I 886 . . . Publication of Argentine General Catalogue.

r886 . . . Completion of Auwers's reduction of Bradley's observations.

r886 . . . Draper Memorial photographic work begun at Harvard College.

I886 . . . Photographic detection, at Harvard College, of bright hydrogen-lines in spectra of variables (Mira Ceti and U Orionis.)

1887, January I 8 Discovery by Thome at Cordoba of a great comet belonging to the group represented by the comet of 1882 .

1887 . . Publication of Lockyer's Chemistry of the Sun.

I887, April r6 . Meeting at Paris of the International Astrophotographic Congress. Construction of a general Photographic Chart and Catalogue resolved upon.

I887 . . Heliometric triangulation of the Pleiades by Elkin.

1887 . . L. Struve's investigation of the sun's motion, and re-determination of the constant of precession.

r887 . . Von Konkoly's extension to-r $5^{\circ}$ of Vogel's spectroscopic Catalogue.

1887 . . Auwers's investigation of the solar diameter.

1887 . . . Publication of Schiaparelli's Measures of Double - Stars (1875-85).

I 887, April 8 . Death of Thollon at Nice.

1887, August 19 . Total eclipse of the sun. Shadow-path crossed Russia. Observations marred by bad weather. I 887, November . Langley's Researches on the Temperature of the Moon.

I887, Nov. I7 . Lockyer's "Researches on Meteorites" communicated to the Royal Society.

r887 . . Stroobant's discussion of the observations relating to Venus's pseudo-satellite.

I887 . . Completion of 36-inch Lick refractor. 
I 888

1888

I 888

I 888

I 888

I 888

I 888 , June I

1888

I 888

I 888

I 888, January 28

1888

I 888 , Feb. 5

I888, Sept. 12 $\mathbf{1 8 8 9}$

I 889

1889

I889

I 889
Küstner's detection of variations in the latitude of Berlin brought before the International Geodetic Association.

Chandler's Catalogue of Variable Stars.

Mean paraltax of northern first-magnitude stars determined by Elkin.

- Publication of Dreyer's New General Catalogue of 7840 nebulæ. \&.

Vogel's first results in the spectrographic determination of stellar motion in line of sight.

Presence of carbon in the solar atmosphere ascertained by Trowbridge and Hutchins.

Activity of the Lick Observatory begun.

Completion of Dr. Common's five-foot reflector.

Heliometric measures of Iris for solar parallax at the Cape, Newhaven (U.S.A.), and Leipsic.

Loewy's comparative method of determining constant of aberration described.

Total eclipse of the moon. Heat-phases measured at Parsonstown.

Presentation of the Dunecht instrumental outfit to the nation by Lord Crawford. Dr. Copeland appointed Astronomer Royal for Scotland in succession to Professor Piazzi Smyth.

Photograph of the Orion nebula spectrum taken by Dr. and Mrs. Huggins, showing groups of bright lines common to the nebula and the trapezium-stars.

Death;of R. A. Proctor.

Photograph of the Orion nebula taken by W. H. Pickering showing it to be the nucleus of a vast spiral.

Discovery at Harvard College of the first known spectroscopic doubles, $\zeta$ Ursæ Majoris and Aurigæ.

Eclipses of Algol demonstrated spectrographic. ally by Vogel.

Completion of photographic work at the Cape Observatory for the SouthernDurchmusterung. Completion of Boeddicker's drawing of the Milky Way. 
1889 . . Photographs of southern star spectra taken at Chosica, Peru, in connexion with the Draper Memorial.

r889 - . . Pernter's experiments on scintillation from the Sonnblick.

I889 . . . H. Struve's researches on Saturn's satellites.

I889 . . Harkness's investigation of the masses of Mercury, Venus, and the Earth.

r889 . . Heliometric measures of Victoria and Sappho at the Cape.

r889, January I . Total solar eclipse visible in California.

I889, Feb. 7 . Foundation of the Astronomical Society of the Pacific.

r889, March . Investigation by Dr. and Mrs. Huggins of the spectrum of the Orion Nebula.

I889, July 7 . Re-discovery by Brooks of Lexell's lost comet.

r889, August 2 . Observation by Barnard of four companions to Lexell-Brooks comet.

I889, July-Aug. . First photographs of the Milky Way taken by Barnard.

I889, Nov. I . Passage of Japetus behind Saturn's dusky ring observed by Barnard.

I 889, December 8 Schiaparelli announces synchronous rotation and revolution of Mercury.

I889, Dec. 22 . Total eclipse of the sun visible in Guiana and on West African coast. Death of Father Perry, December 27.

1889 . . . Spectrum of Uranus investigated visually by Keeler, photographically by Dr. and Mrs. Huggins.

1890 . . . Long-exposure photographs of ring-nebula in Lyra bring out nebulous character of the central star.

I890 . . . Determinations of the solar translation by $\mathrm{L}$. Boss and O. Stumpe.

I 890 . . . Schiaparelli finds for Venus an identical period of rotation and revolution.

I890 . . Publication of Thollon's map of the solar spectrum.

I890 - . . Schaeberle's mechanical theory of the solar corona. 
I 890

Bigelow's mathematical theory of coronal structures.

I890 . . . Foundation of the British Astronomical Association.

1890 . . Measurements by Keeler at Lick of nebular movements in line of sight.

1890 . . Janssen's ascent of Mont Blanc, by which he ascertained the purely terrestrial origin of the oxygen-absorption in the solar spectrum.

1890

Newcomb's discussion of the transits of Venus of $x 76 \mathrm{x}$ and $\mathrm{x} 76 \mathrm{~g}$.

I890 . . . Spiral structure of Magellanic clouds displayed in photographs taken by H. C. Russell of Sydney with exposures up to eight hours.

I890 . . . Publication of the Draper Catalogue of Stellar Spectra.

I 890, March . Redetermination of chief nebular line by Dr. and Mrs. Huggins

I890, April 24 . Spica announced by Vogel to be a spectroscopic binary.

I890, June . . Gore's Catalogue of computed Binaries.

1890, November . Study by Dr. and Mrs. Huggins of the spectra of Wolf and Rayet's stars in Cygnus.

1890, November . Discovery by Barnard of a close nebulous companion to Merope in the Pleiades.

1890, November . Presentation to the R. Astronomical Society of F. McLean's spectrographs of the high and low sun.

r89I . . . Capture-theory of comets developed by Callandreau, Tisserand, and Newton.

I89I . . . Dunér's spectroscopic researches on the sun's rotation.

r89r . . . Preponderance of Sirian stars in the Milky Way concluded by Pickering, Gill, and Kapteyn.

I89I . . . . Detection by Mrs. Fleming of spectral variations corresponding to light-changes in $\beta$ Lyræ.

189I . . Establishment of a mountain-observatory at Arequipa in Peru (height, 8000 feet) in connexion with Harvard College.

r89 . . . Variations of latitude investigated by Chandler. 
1891 . . Prominence-photography set on foot by Hale at Chicago.

r89r, April . . Meeting at Paris of the Permanent Committee for the Photographic Charting of the Heavens.

r89r, May 9 . Transit of Mercury.

1891, August r9 . Presidential Address by Dr. Huggins at the Cardiff Meeting of the British Association.

I89 r, Dec. ro - Nova Aurigæ photographed at Harvard College. I891, Dec. 20 . Photographic maximum of Nova Aurigæ.

1891, Dec. 22 . First photographic discovery of a minor planet by Max Wolf at Heidelberg.

r892 . . Commencement of international photographic charting work.

r892 . . Photographic determination by Scheiner of 833 stars in the Hercules Cluster (M I 3.)

1892 . . . Publication by Vogel of spectrographic determinations of motions in the line of sight for $5 \mathrm{I}$ stars.

r892 . . Publication of Pritchard's photographic parallaxes for the second magnitude stars visible at Oxford.

1892, January 2 . Death of Sir George Airy.

1892, January 21 . Death of Professor Adams.

I 892 , Feb. I . Announcement by Anderson of the outburst of a new star in Auriga.

I 892, Feb. 5 . Appearance of the largest sunspot ever photographed at Greenwich.

1892, March 6 . Discovery of a bright comet by Swift.

1892, May 13 . Lecture by Dr. Huggins on Nova Aurigæ at the Royal Institution.

I892, June 29 . Death of Admiral Mouchez. Succeeded by Tisserand as director of the National Observatory, Paris.

1892, August 4 . Favourable Opposition of Mars.

r892, August 17 . Rediscovery at Lick of Nova Aurigæ.

r892, Sept. 9 . Discovery by Barnard of Jupiter's inner satellite.

1892, Oct. 12 . First photographic discovery of a comet by Barnard.

1892, Nov. 6 . Discovery of Holmes's comet. 
I892, Nov. 23 . Shower of Andromede meteors visible in America.

1892 . . . Photographic investigation by Deslandres of the spectra; of prominences.

1892 . . . Photographs of the sun with faculæ and chromospheric surroundings taken by Hale with a single exposure.

1892 . . Investigation by T. J. J. See of the ancient colour of Sirius.

1892 . . Publication of T. J. J. See's Thesis on the Evolution of Binary Systems.

1892 . . . Establishment of an observatory at Abastouman, Tiflis, 4600 feet above sea-level. Glasenapp appointed director.

I 892, March . Photograph of Argo Nebula taken by Dr. Gill at the Cape in twelve hours.

1892 . . Chandler accounts for the inequalities of Algol's light-period, by the revolution of the eclipsing pair round an obscure centre of attraction.

1892 . . . Nebulæ in Cygnus photographically discovered by Max Wolf, involving both bright stars and "star-dust."

I893, January 28 Kapteyn's investigation of the structure of the stellar universe.

1893, March ro . Dr. Gill announces to the Royal Astronomical Society his results from the Opposition of Victoria, among them a solar parallax = $8 . " 809$.

I893 . . . Observations begun at Bischoffsheim's Observatory on Mount Mounier, at an elevation of 9000 feet in the Maritime Alps.

I893, April r6 . Total solar eclipse observed in South America and West Africa. 


\section{TABLE II.}

\section{CHEMICAL ELEMENTS IN THE SUN (ROWLAND, I89I).}

Arranged according to the number of their representative Lines in the Solar Spectrum.

Iron $(2000+)$.

Nickel.

Titanium.

Manganese.

Chromium.

Cobalt.

Carbon $(200+)$.

Vanadium.

Zirconium.

Cerium.

Calcium $(75+)$.

Scandium.
Neodymium,

Lanthanum.

Yttrium.

Niobium.

Molybdenum.

Palladium.

Magnesium $(20+)$.

Sodium (II).

Silicon.

Strontium.

Barium.

Aluminium (4).
Cadmium.

Rhodium.

Erbium.

Zinc.

Copper (2).

Silver (2).

Glucinum (2).

Germanium.

Tin.

Lead (I).

Potassium (I).

Doubtful Elements.-Iridium, osmium, platinum, ruthenium, tantalum, thorium, tungsten, uranium.

Not in Solar Spectrum.-Antimony, arsenic, bismuth, boron, nitrogen vacuum tube), cæsium, gold, iridium, mercury, phosphorus, rubidium, selenium, sulphur, thallium, praseodymium.

\section{TABLE III.}

EPOCHS OF SUNSPOT MAXIMUM AND MINIMUM FROM I610 TO I893 (R. WOLF).

\begin{tabular}{|c|c|c|c|c|c|}
\hline Minima. & Maxima. & Minima. & Maxima. & Minima. & MaXIMA. \\
\hline I6Io .8 & $1615 \cdot 5$ & 1712.0 & I718.2 & 18 1о .6 & I8I6.4 \\
\hline I6I9 .o & 1626.0 & $1723 \cdot 5$ & $1727 \cdot 5$ & $1823 \cdot 3$ & I829.9 \\
\hline r634.o & I639.5 & I734.O & 1738.7 & $1833 \cdot 9$ & I837. 2 \\
\hline 1645.0 & 1649.0 & 1745.0 & $1750 \cdot 3$ & I843 5 & 1848 . I \\
\hline 1655.0 & 1660.0 & I755.2 & $1761 \cdot 5$ & 1856.0 & I860 . I \\
\hline 1666.0 & I675.O & $1766 \cdot 5$ & 1769.7 & 1867.2 & 1870.6 \\
\hline $1679 \cdot 5$ & 1685.0 & $1775 \cdot 5$ & 1778.4 & 1878.9 & I884. . \\
\hline $1689 \cdot 5$ & I693.0 & 1784.7 & I788. . I & I $890.2(?)$ & I893 (?) \\
\hline 1698 .9 & $1705 \cdot 5$ & I798 3 & $1804 \cdot 2$ & & \\
\hline
\end{tabular}




\section{TABLE IV.}

CONCLUSIONS AS TO THE, ¿DIRECTION OF THE SUN'S MOVEMENT IN SPACE, I783-1892.

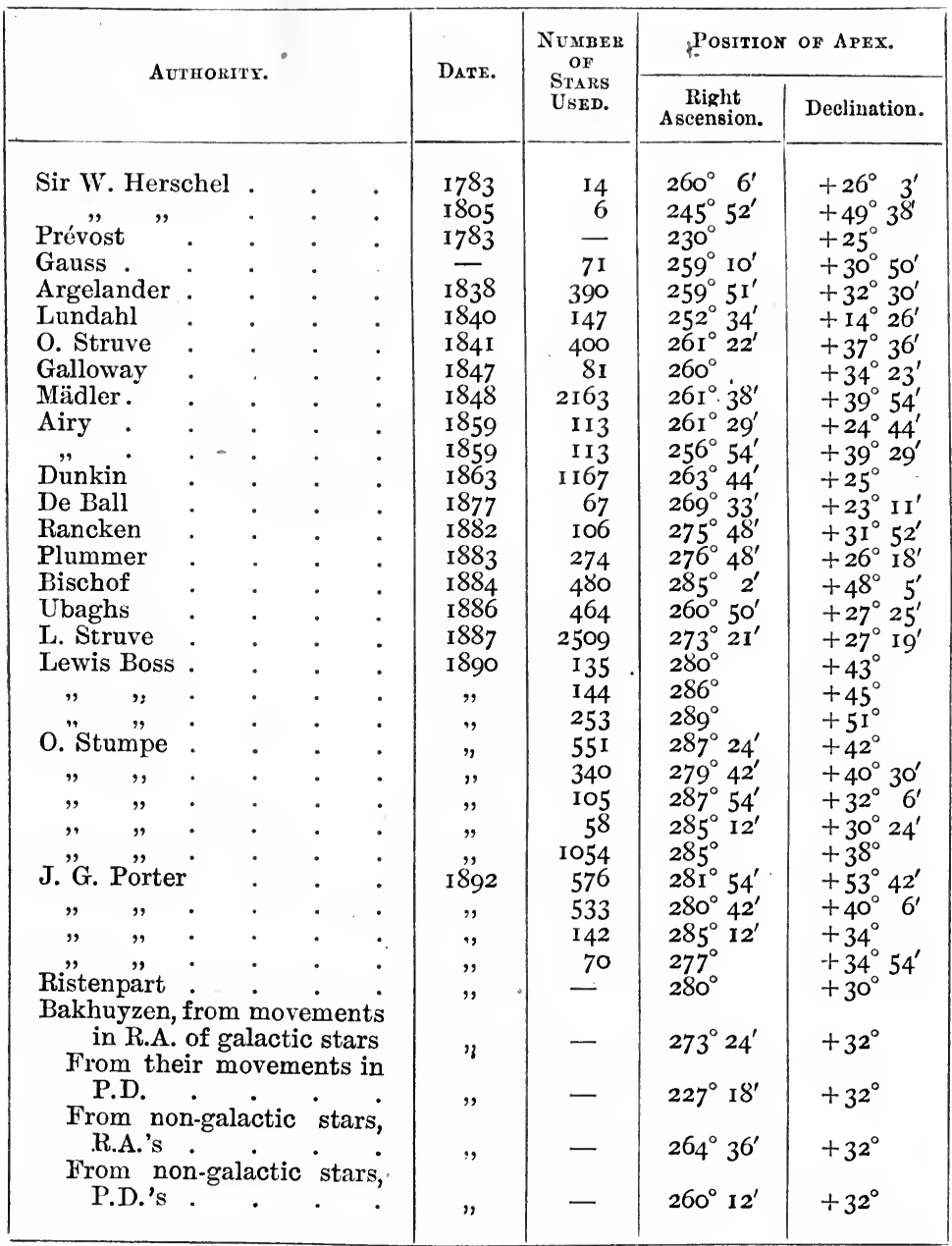




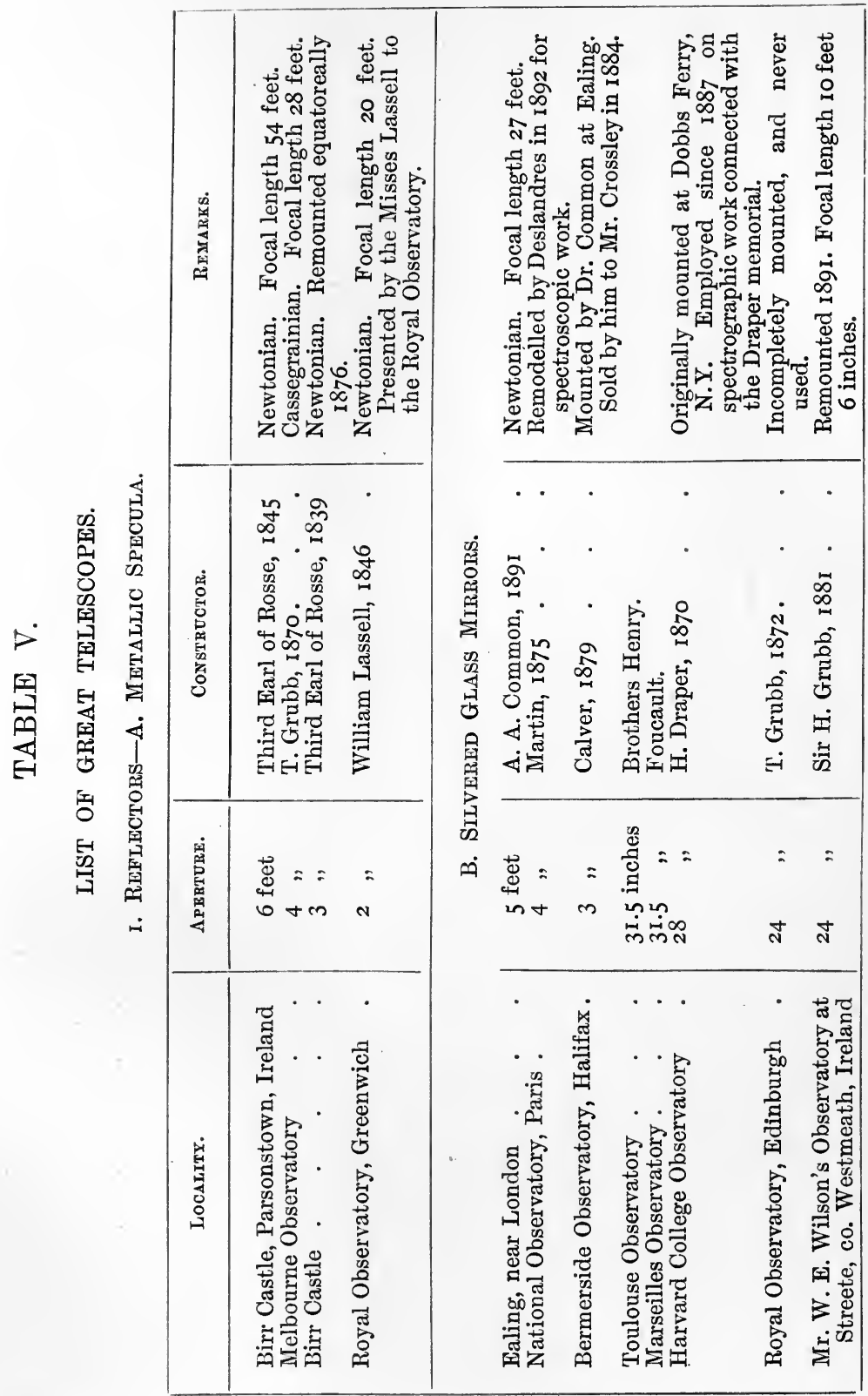




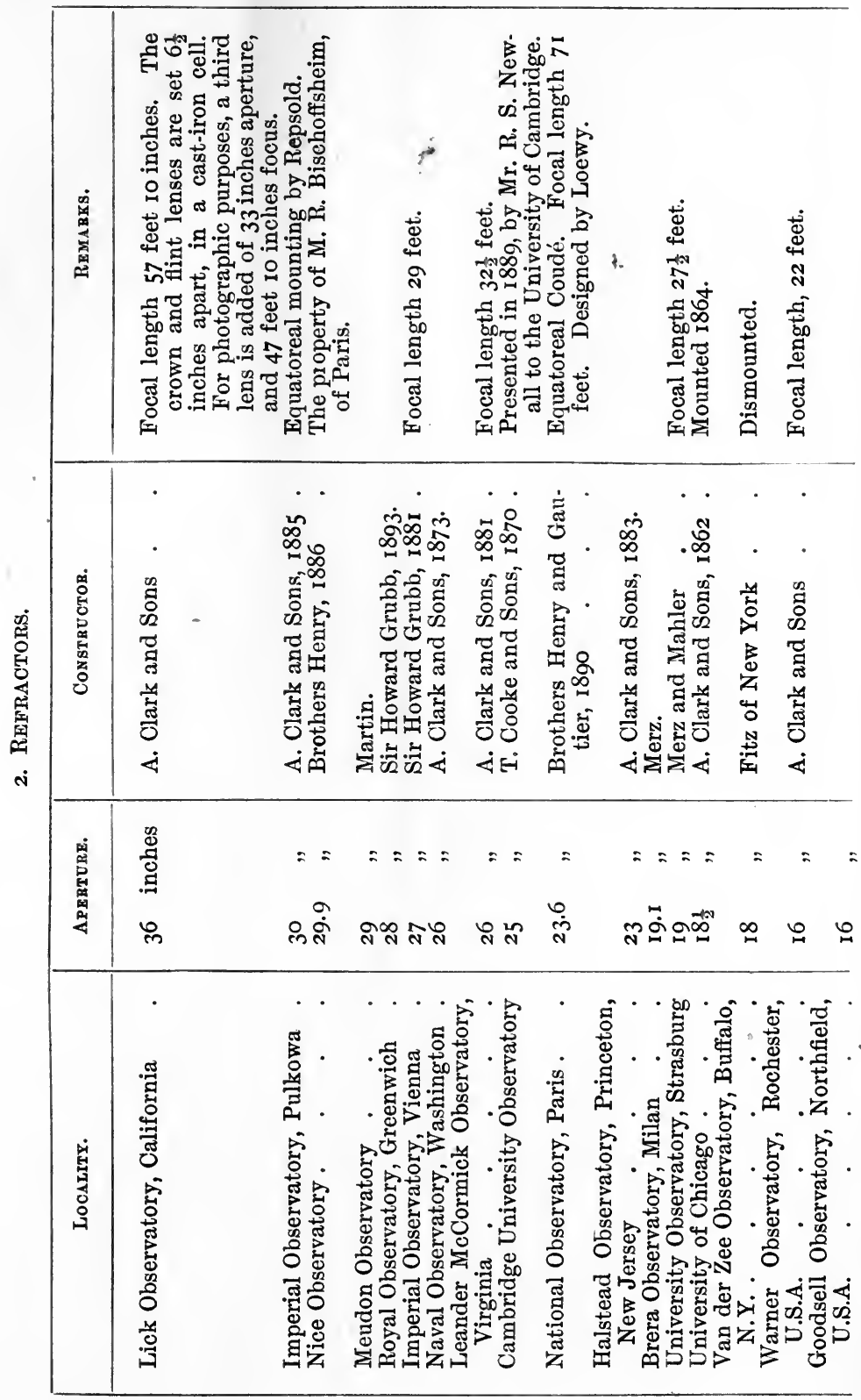




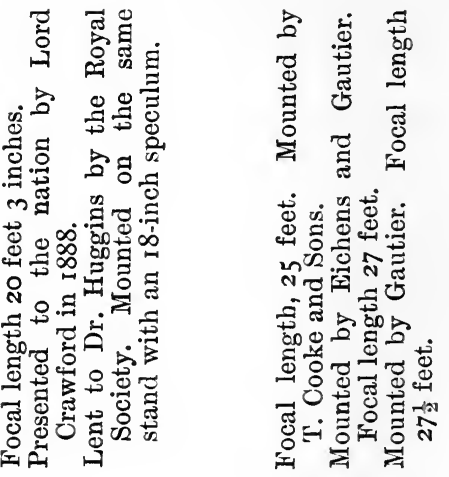

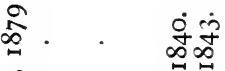

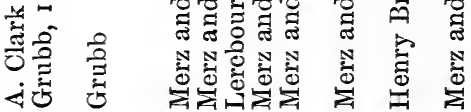

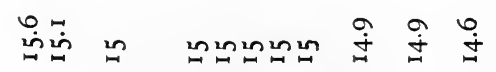

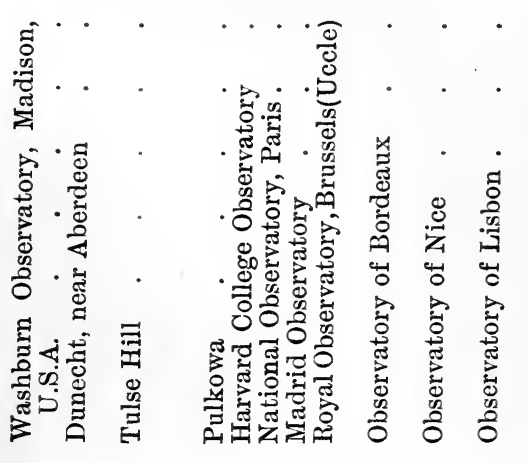

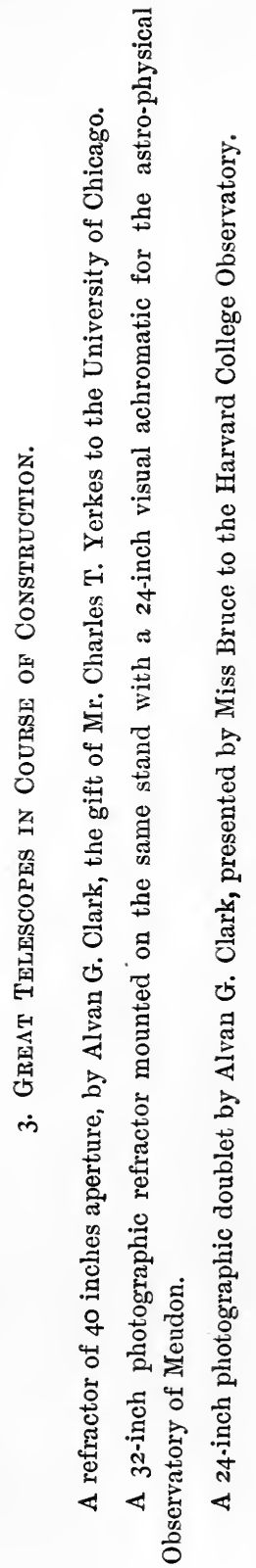




\section{TABLE VI.}

List of Observatories employed in the Construction of the Photographic Chart of the Heavens. All are provided with perfectly similar instruments, consisting of a thipteen-inch photographic coupled with an eleven-inch visual refractor.

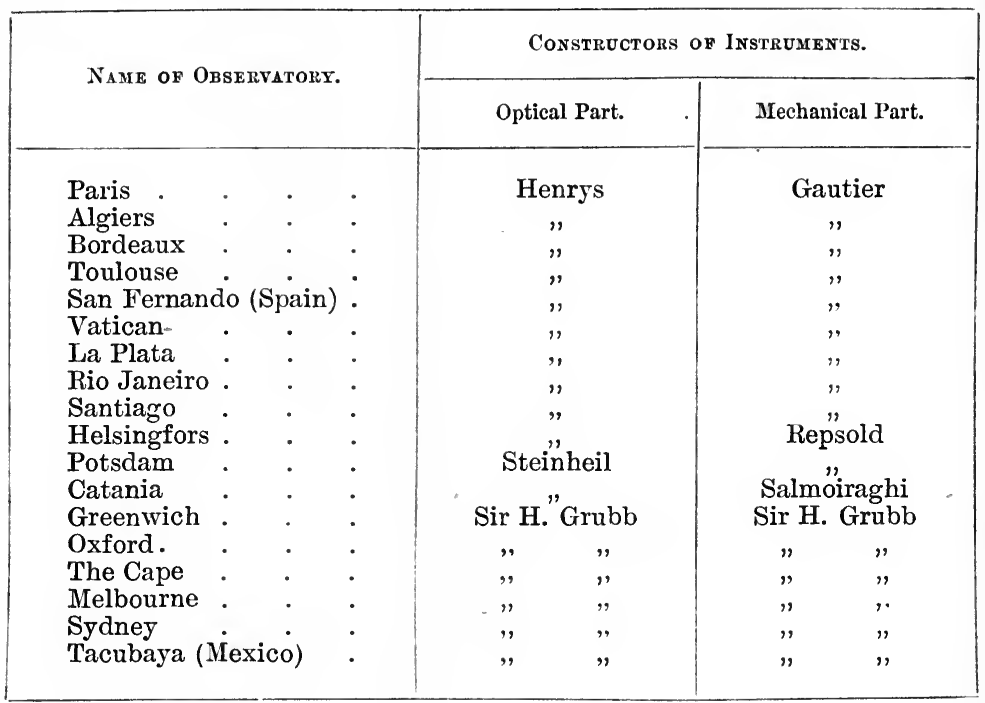




\section{N D E X.}

Aвbe, Cleveland, corona of 1878 , 220-I

Aberdour, Lord, solar chromosphere, 83

Aberration, discovered by Bradley, 4, I8; an uranographical correction, 37 ; distance of sun determined by, 285,297

Abney, daylight coronal photographs, 225 ; infra-red photography, 262, 277,524

Absorption, terrestrial atmospheric, I66, 262-3, 266-7, 268, 277, 339; solar, 167, 215-6, 265, 278 ; correlative with emission, I68-9, I 72

Adams, elements of Neptune, 97-8 ; lunar acceleration, 332 ; orbit of November meteors, $40 \mathrm{I}$

Aerolites during star-showers, 4 I I

Airy, solar translation, 47 ; prominences, 77 ; sierra, 85 ; Astronomer Royal, 97; search for Neptune, 98, 100; corona of 1851,219 ; solar parallax, 280, 29I ; transit of Venus, 287 ; Mercurian halo, 302 ; lunar atmosphere, 324

Albedo, of Mercury, 303 ; of Venus, 314 ; of Mars, 346 ; of minor planets, 350 ; of Jupiter, 354 ; of Uranus, $37 \mathrm{I}$

Alexander, spiral nebulæ, 147 ; observation during eclipse of 1860,302

Algol, variability of light, I2, 469; eclipses, 470; a ternary system, 470-I

Altitude and azimuth instrument, I49 note, $15 \mathrm{I}$

Amici, comet of 1843,128

Anderson, discovery of Nova Aurigæ, 478
Andrews, conditions of liquefaction, 188

Ångström, C. J., Optical Researches, 172; solar spectroscopy, 261, 263; age and temperature of stars, 453

Ångström, Knut, infra-red solar spectrum, 262

Arago, eclipse of $1842,75,78-9$; prominences, 78,84 ; polarisation in comets, I28 ; magnetic relations of auroræ, I6I ; nature of photosphere, I88 ; meteor-systems, 399

Arai, photographs of corona of $188_{7}$, 233

Arcturus, spectrum, 452, 463 ; radial movement, 466 ; remoteness, 499 , 506

Argelander, Bonn Durchmusterung, 39, 506; solar motion, 47 ; centre of Milky Way, 49 ; comet of r8II, 125

Aristotle, description of a comet, 423

Asten, movements of Encke's comet, I 16

Asteroids, minor planets so designated by Herschel, 92

Astronomical circles, I5I

Astronomical physics, 9, 175-7, 512

Astronomical Society, founded, 7 ; Herschel first President, 16

Astronomy, classification, I ; rapid progress, 6; in United States, 8 ; in Germany, 33 ; practical reform, 34 ; of the invisible, 50; physical, 175

Atmosphere, solar, Ir7, 229, 239, 274 ; of Venus, 29I, 3II-3; of Mercury, $302-3 ; 305$; of the moon, 323-5; of Mars, 339; of minor planets, $35^{1}$ 
Auroræ, periodicity, I60-1, 201-2 ; excited by meteors, 407

Auwers, reduction of Bradley's observations, 47 ; system of Procyon, 5I ; opposition of Victoria, 294; solar parallax, 296 ; new star in Scorpio, 477 ; proper motions, 509

BABINET, objection to nebular hypothesis, 382

Backlund, movements of Encke's comet, II6, 436

Baily, early life and career, 7I-3; observations of eclipses, 74-7; density of the earth, 73, 32 I

Baily's Beads, 74-5, 290

Bakhuyzen, rotation of Mars, 337-8

Ball, Sir Robert, parallaxes of stars, 43 note, 499; contacts in transits, 295

Balmer's Law, 247, 463

Barkowski, daguerreotype of eclipsed sun in 1851,207

Barnard, photographs of solar corona, 235 ; halo round Venus, 313; discovery of a fifth Jovian satellite, $357,5^{17}$; red spot, 361 ; eclipse of Japetus, 365 ; attendants on comet of 1882,439 ; on Lexell-Brooks comet, 443 ; observations of Swift's comet, 446 ; photographic discovery of a comet, 447 ; observations and measurements of Nova Aurigæ, 480,482 ; discernment of Hind's variable nebula, 485 ; photogr aphs of Milky Way, 507-8

Bartlett, photograph of a partial eclipse, 207

Basic lines, 256-7

Baxendell, meteors of 1866,402

Becker, drawings of solar spectrum, 263

Beckett, Sir E. (Lord Grimthorpe), value of solar parallax, 286

Beer and Mädler, survey of lunar surface, $325,326,327$; studies of Mars, 337

Belopolsky, photographs of corona (1887), 233

Berberich, mass of asteroids, 350 ; orbit of Holmes's comet, 409

Bessel, biographical sketch, 34-6 ; reduction of Bradley's observations, 38 ; zone observations, 39 ; parallax of 6I Cygni, 43; disturbed motion of Sirius and Procyon, 50 ; transUranian planet, 97 ; Halley's comet, 127; theory of instrumental errors,
152 ; personal equation, 153 ; rotation of Mercury, 304 ; lunar atmosphere, 324; opposite polarities in comets, 394 ; mathematical theory of cometary emanations, 417 ; multiple tails, 420 ; comet of I807, 425

Betelgeux, 452, 46r, 464; radial movement, 466 ; indefinite remoteness, 499

Bianchini, rotation of Venus, 308

Biela, discovery of comet, I 17

Bigelow, theory of solar corona, 238-9

Bigourdan, eclipse of I893, 237 ; movement of I882 comet, 44 I

Bird's quadrants, 4, I 5 I

Birmingham, colours of stars, 453 note; discovery of $\mathrm{T}$ Coronæ, 473

Birt, rotation of a sun-spot, I79; Selenographical Society, 326

" Black Ligament," 290-I

Bode, popular writings, 6 ; solar constitution, 68 ; a planet missed and found, 87,90

Bode's Law, 87-8, 90, 102. 348

Boeddicker, heat-phases during lunar eclipses, 330, 331; drawings of Jupiter, 36I; of the Milky Way, 507

Böhm, solar observations, 182, 184

Boguslawski, centre of sidereal revolutions, 49; observation of Halley's comet, I27

Bolometer described, 275-6

Bond, G. P., his father's successor, I06 ; light of Jupiter, 352 ; fluidity of Saturn's rings, 363 ; Donati's comet, 393-5 ; rifts in Andromeda nebula, 49I ; double-star photography, 492

Bond, W. C., observation of Neptune's satellite, 103; discovery of Hyperion, I05; of Saturn's dusky ring, 106 ; resolution of nebulæ, I48; celestial photography, 190, 492 ; satellite-transit on Jupiter, 355

Bonn Durchmusterung, 39

Borda, repeating circle, I5I

Boss, solar translation, 48 ; observations on comets, $426,43 \mathrm{I}$

Bouguer, solar atmospheric absorption, 274

Boulliaud, period of Mira, I2

Bouquet de la Grye, photographs of Venus on the Sun, 3 I4

Bouvard, Tables of Uranus, 96 ; observation of Encke's comet, I I 2

Bradley, observational faculties, 3 ; 
discoveries, 4; solar translation, I I ; star distances, I2, I8 ; observation on Castor, 20 ; instruments, 33, I 50 ; observations reduced by Bessel, 38 ; by Auwers, 47

Brahe, Tycho, star of 1572,29

Brandes, Andromede star-shower, 405

Brandes and Benzenberg, heights of meteors, 398

Braun, prominence-photography, 244

Brayley, meteoric origin of planets, 378

Bredichin, theory of comets' tails, I 24, 42I ; repulsive forces, 4I8-9; chemical constitution, 420 ; types of formation, $425,426,430,440$; structure of chromosphere, 248; red spot on Jupiter, 359 ; spectrum of Coggia's comet, 4I6 ; LexellBrooks and subordinate comets, 445

Bremiker, star-maps, 100

Brester, Théorie du Soleil, 189

Brewster,diffraction-theory of corona, $\mathrm{SI}$; telluric lines in solar spectrum, I66 ; absorption - spectra, I69

Brinkley, illusory stellar parallaxes, 39

Brisbane, observatory at Paramatta, 8, I 12

Brooks, fragment of 1882 comet, 440 ; rediscovery of Pons's comet, 442 ; of Lexell's, 444

Brünow, stellar parallax determinations, 499

Bruno, Giordano, motion of stars, I I

Buffham, rotation of Uranus, 369

Buffon, internal heat of Jupiter, 352

Bunsen, discovery of spectrum analysis, 164

Burnham, coronal photographs, 235 ; measures of Nova Aurigæ, 482 ; of planetary nebulæ, 486 ; discoveries of double stars, 50I, 514, 518, 520 ; 6I Cygni, 502

Burton, canals of Mars, 342 ; rotation of Jupiter's satellites, 356

Calandrelli, stellar parallaxes, 39

Callandreall, capture-theory of comets, 122

Campani, Saturn's dusky ring, Io7

Campbell, Lieutenant, polarisation of corona, 212

Campbell, Professor, spectrum of Nova Aurigæ, 48I ; photographs of stellar diffraction-spectra, 526

Canals of Mars, 34I-3
Canopus, spectrum, 463 ; immeasurable remoteness, 498

Cape Durchmusterung, 495

Capella, spectrum and light-power, 452,463

Carbon, absorption by, in solar atmosphere, 264 ; in stars, $45^{2}$

Carbonelle, origin of meteorites, $4 \mathrm{I} 2$

Carrington, astronomical career, I79$8 \mathrm{I}$; sunspot observations, I8I-2 ; solar rotation, $\mathrm{I} 83$; spot-distribution, I84; luminous outburst on sun, I98-9; Jovian and sunspot periods, 202; origin of comets, 448

Cassini, Domenico, discoveries of Saturnian satellites, r04; of division in ring, I05; solar rotationperiod, I82; solar parallax, 282; rotation of Venus, 308; of Mars, 336 ; of Jupiter, 353, 359; satellite of Venus, 315; satellite-transit on Jupiter, 355

Cassini, J. J., stellar proper motions, I I ; sun's limb notched by a spot, 64 ; theory of corona, 80 ; rotation of Venus, 308 ; structure of Saturn's rings, 364

Cavendish experiment, 73, 32I

Ceres, discovery, 89-9I ; diameter, 93 ; phases, 350

Chacornac, observation on a sunspot, I94; star-maps, 347, 495 ; variable nebula, 484

Challis, search for Neptune, I00-I ; duplication of Biela's comet, I I9

Chandler, variation of latitude, 318 ; changes in Pons's comet, 443; identification of Lexell-Brooks' comet, 445; system of Algol, 470-I; Catalogue of Variables, 472

Charlois, discoveries of minor planets, 347

Charropin, coronal photographs, 235

Chladni, origin of meteors, 398, 404

Christie, Mercurian halo, 301

Chromosphere, early indications, 83 ; distinct recognition, 84,208 ; depth, 217, 218; metallic injections, 242 ; eruptive character, 248

Clark, Alvan, large refractors, I4 I, 5I4-5

Clark, Alvan G., discovery of Sirian companion, 50, $5 \mathrm{I} 3$; forty-inch refractor, 517

Clarke, Colonel, figure of the earth, 322 
Clarke, F. W., celestial dissociation, 255

Clausen, period of I843 comet, I3I ; cometary systems, 438

Clerihew, secondary tail of 1843 comet, 129

Coggia, discovery of comet, $4 \mathrm{I}_{5}$ :

Comet, Halley's, return in 1759, 5, I09; orbit computed by Bessel, 35; capture by Neptune, I22, 442 ; return in 1835, 126-8, 417; type of tail, 419, 425; Newton's, Io9, 44I ; Encke's, I I 2 ; changes of volume, II 5 ; of brightness, II 7 ; acceleration, II5-7; possible capture by Mercury, I 22 ; Lexell's, I21, I32; rediscovered by Brooks, 444 ; approaches to Jupiter, 445 ; Winnecke's, II6, 4I4 ; Biela's, II7-20 ; star showers in connection with, 405-9 ; Haye's, I 2 I ; Brorsen's, I2I ; Vico's, I2I; of I8I1, I22-5, 419; of I807, 124, 420, 425, 427; of 1819, 125,128 ; of $1843,128-131$; type of tail, 419, 425 ; relationships, 422-4, 435 ; 'T'ewfik, 224, 433, 438; Donati's, 392-5; type of tail, 419, 420; of I86I, 395-7, 4I9; of the August meteors, 397,403 ; of the November meteors, 397, 403, 405, 415 ; Klinkerfues's, 400 ; Holmes's, 409, 4I 5 , 447 ; Coggia's, 415, 4I8, 4I9; of I880, 42I-2, 424, 425; Aristotle's, 423; Tebbutt's, 425-9; Schaeberle's, 430 ; Wells's, 42I-3; of September I882, 433-7, 439-42 ; Thome's, 437-8 ; Pons-Brooks, 442-3 ; Sawerthal's, 444 ; Swift's, 446

Cormets, subject to law of gravitation, I09; of short period, II2-3 ; contractions and expansions, I I4-5, I 27, 443, 447 ; translucency, I I 8, 131-2, 426; small masses, 1 20, 132; capture by planets, I22, 372, 442; polarisation of light, $128,428,429$; refraction by, I32, 426 ; photographs, 224, 427-8, 446, 447, 494 ; relation to meteor-systems, 403-5, 408-9; disintegration, 404, 409, 439 ; spectra, 4I4-6, 428-9, 431-2, 441 ; luminous by electricity, 416 , 429,432 ; systems, 427, 429, 437, 438,442 ; origin, $447-9$

Comets' tails, repulsive forces producing, I 23-4, I 27, 4I 7-2I ; velocity of projection, 124, 129, 419; multiple, I 24, 393, 41 7, 419-20, 426, 430,
440, 446 ; coruscations, I30; three types, 4I9-20, 425, 430

Common, reflectors for eclipse photography, 236; cbservations of Jupiter's inner satellite, $35^{8}$; daylight discovery of great comet, 433 ; five nuclei, 439 ; photograph of Andromeda nebula, 476 ; of Orion nebula and Jupiter, 489-90; nebulous patches in the Pleiades, 493; great reflectors, $5^{\mathrm{I}} 3$

Common, Miss, drawing of eclipsed sun, 236

Comte, celestial chemistry, I74 ; astronomy, 177

Cooke, 25-inch refractor, $5 \mathrm{I} 4$

Copeland, comets of 1843 and 1880 , 422 ; spectrum of comet of 1882 , 44I; of $\gamma$ Cassiopeiæ, 457 ; of Nova Andromedæ, 476 ; of Orion nebula, 489; gaseous stars, 459; Nova Aurigæ, 478

Copernicus, stellar parallax, 18

Cornu, telluric lines in solar spectrum, 25I; movements in promirences, 255; ultra-violet solar spectrum, 262, 267; solar parallax by light velocity, 286, 297; spectrum of hydrogen, 463; of Nova Cygni, 474

Cornu and Baille, density of the earth, $32 \mathrm{I}$

Corona, of $\mathrm{I} 842,76,78$; early records and theories, 79-82; photographs, 207, 21 7, 224, 228, 232-6; spectrum, 212, 217, 222-3, 228; constitution, $213,217,222-3,239-40$; varying types, $218,223,228,232-3$; of 1878 , 218-22; of 1867,221 ; of 1882, 223-4; of 1869,230 ; of 1886,232 ; of $1889,233-4,236$; photographing without an eclipse, 224-6; glaretheory, 229; mechanical theory, 237-8; mathematical theory, $238-9$ Coronium, 213, 217, 240

Cortie, movements within sunspots, I95; changes in spectra, $25^{8}$

Cotes, corona of 17 I 5,221

Croll, secular changes of climate, 319-20; source of solar energy, $38 \mathbf{I}$

Crookes, analysis of chemical elements, 260

Crova, solar constant, 278

Cruls, great comet of I882, 433, 440

Cusa, solar constitution, 68

Cysatus, Orion nebula, 25 ; comet of 1652, 439 
DAMOISEAU, theory of Halley's comet, 126

D'Arrest, orbits of minor planets, 347 ; Biela meteors, 405 ; ages of stars, 453 ; variable nebula, 484 ; measures of nebulæ, 486

Darwin, G. H., rigidity of the earth, 3I 7 ; Saturn's ring-system, 366-7; origin of the moon, 384-6 ; development of solar system, 387,391 ; solar tidal friction, 388

Daubrée, falls of aerolites, 4I I

Davidson, satellite-transit on Jupiter, 355

Dawes, prominences in 1851,85 ; Saturn's dusky ring, 106; a star behind a comet, I32 ; solar observations, I78, 204; colour of Mars, 339; drawings, 34I; ice-island, 343; satellite-transit on Jupiter, 355

De Ball, markings on Mercury, 305

Delambre, Greenwich observations, 3 ; solar rotation, 182 ; light-equation, 285

De la Roche, Newton's law of cooling, 269

De la Rue, celestial photography, I90-I, 329; solar investigations, 192 ; expedition to Spain, 207-8

De la Tour, experiments on liquefaction, 188

Delaunay, tidal friction, 332, 334 ; Coudé telescope, 522

Delisle, diffraction-theory of corona, 81 ; method of observing transits of Venus, 288, 295

Dembowski, measurements of double stars, 501

Denning, rotation of Mercury, 304; mountains of Venus, 311 ; rotation of Jupiter, 353; red spot, 359, 360; rotation of Saturn, 368 ; meteors of 1885, 408-9; of 1892, 410; with stationary radiants, 412

Denza, meteors of 1872,406

Derham, volcanic theory of sunspots, 63 ; ashen light of Venus, 314

Deslandres, daylight coronal photography, 226; eclipse expedition, 237; prominence-photography, 246; hydrogen spectrum in prominences, 247,463

Diffraction, corona explained by, $8 \mathrm{I}$, 85,228 ; spectrum, $173,261,276,525$

Dissociation, in the sun, $189,255-60$; in space, 380

Doberck, orbits of double stars, 46 , 500
Dollond, discovery of achromatic telescope, 4, I39

Donati, discovery of comet, 392 ; spectra of comets, 414; of stars, 450

Doppler, refrangibility of light changed by motion, 249

Draper, $\mathrm{H}$., ultra-violet solar spectrum, 262 ; oxygen in sun, 265 ; photographs of the moon, 329 ; of Jupiter's spectrum, 354; of 'Tebbutt's comet, 428; of spectrum of Vega, 462 ; of Orion nebula, 489

Draper, J. W., lunar photographs, I9o; distribution of energy in spectrum, 276 note

Draper Memorial, 464-5

Dreyer, New General Catalogue of nebulæ, 60

Dulong and Petit, law of radiation, 270,272

Dunér, spectra of sunspots, I95; spectroscopic determination of solar rotation, 252 ; spectroscopic starcatalogue, 460

Dunkin, solar translation, 47

Duponchel, sunspot period, 202

EARTH, mean density, 73, 32I ; body of science regarding, 316 ; rigidity, 317-9; variation of latitude, 318 ; figure, 32I-2 ; rotation checked by tidal friction, 333 ; possible inequalities, 335 ; bodily tides, 384 ; primitive disruption, 386

Eclipse, solar, of I836, 74 ; of 1842 , $75-9,82,86$; of $1851,84-6,207$; of $1860,207-8$; of $1868,209-10$; of 1869,212 ; of 1870,213 ; of 1871 , $216-7$; of $1878,218-22$; of 1882 , $222-4$; of $1883,226-8$; of 1885 , 231 ; of $1886,231-2$; of 1887,233 of Jan. I, I889, 233-5; of Dec. 22, I889, 235; of I893, 237

Eclipses, lunar, observations of heatphases, 330-I

Eclipses, solar, importance, $7 \mathbf{I}$; different classes, 73 ; results, 217 ; ancient, 334

Eddie, comet of 1880,421 ; of 1882 , 440

Edison, tasimeter, 222

Egoroff, telluric lines in solar spectrum, 266, 313

Elements, chemical, dissociation in sun, 255, 259-6I

Elkin, star parallaxes, 44, 498, 499500 ; transit of great comet, 434 , 
436 ; secondary tail, 440 ; measurement of Pleiades, 493

Elliot, opinions regarding the sun, 69

Elvins, red spot on Jupiter, 36I

Encke, star-maps, 95; a pupil jof Gauss, III ; identification of shortperiod comet, II 2 ; resisting medium, II 5 ; distance of the sun, 283,287 ; period of Pons's comet, 442

Engelmann, rotation of Jupiter's satellites, $35^{6}$

Ericsson, solar temperature, 27 I

Erman, meteoric rings, 400 ; method of computing meteoric orbits, $4 \mathrm{OI}$

Ertborn, mountain in Venus, 3 I I

Espin, bright lines in spectra of variable stars, 459 ; stars with banded spectra, 460; spectrum of Nova Aurigæ, 478 ; rediscovery, 480

Euler, resisting medium, I 5

Evolution of solar system, 374-6, $38 \mathrm{I}-3$, 39I ; of earth-moon system, $384-7$; of stellar systems, 502

Fabricius, David, discovery of Mira Ceti, II

Fabricius, John, discovery of sun. spots, 62

Faculæ, solar, relation to spots, 63 , I 93 ; photographed, 245,456 ; solar rotation from, 252

Faye, nature of prominences, 85 ; discovery of a comet, I2I ; cyclonic theory of sunspots, I79, 195-6 ; solar constitution, I86-90 ; maximum of $1883-4,203$; solar absorption, 2I 5 ; cometary appendages, 221 ; velocities in prominences, 255; distance of the sun, 296; planetary evolution, 383-4, 390

Feilitsch, solar appendages, 85

Ferrel, tidal friction, 334

Ferrer, nature of corona, 8I ; prominences, 84

Finlay, comet discovered by, I2I; transit of 1882 comet, 433,436

Fizeau, daguerreotype of the sun, I9I ; Doppler's principle, 250 ; velocity of light, 286

Flammarion, canals of Mars, 342 ; trans-Neptunian planet, 372

Flamsteed, nature of the sun, 68; distance, 282

Flaugergues, detection of 18 I I comet, I22 ; transit of Mercury, 301

Fleming, Mrs., spectrum of $\beta$ Lyræ,
458 ; preparation of Draper Catalogue, 465

Fontana, mountains of Venus, 3 Io; satellite, 315 ; spots on Mars, 336

Forbes, Prof. G., trans-Neptunian planets, 372-3

Forbes, James D., solar spectrum during annular eclipse, I67 ; solar constant, 278

Foucault, spectrum of voltaic arc, I7I; first. photograph of the sun, I 1 ; velocity of light, 286 ; silvered glass reflectors, $5^{1} 3$

Fraunhofer, early accident, 40 ; improvement of refractors, $4 \mathrm{I}$; death, 42 ; gave clockwork motion to telescopes, 150 ; spectra of flames, 163 ; of sun and stars, $165^{-6}, 450$; objective prism, 464 ; diffraction gratings, 525

Fraunhofer lines, mapped, 165 ; origin, 168-70, 216, 252 ; reflected in coronal spectrum, 216, 222, 223; in cometary spectra, 428,432 ; a criterion of radial motion, 250

Fritz, auroral periodicity, 20I

Frost, solar heat-radiation, 275

GALILEO, originated descriptive astronomy, 2; double-star method of parallaxes, 19; discovery of sunspots, 62; solar rotation, I82; planets and sun-spots, 202 ; darkening at sun's edge, 274

Galle, discovery of Neptune, IOo, IOI ; Saturn's dusky ring, 107; distance of the sun, 293 ; Biela's comet and meteors, 405, 406

Galloway, solar translation, 47

Gambart, discovery of Biela's comet, I 7

Gauss, orbits of minor planets, 90-I ; Theoria Motus, 95 ; magnetic observations, I 57 ; cometary orbits, 448

Gautier,sunspot and magnetic periods, I 56, 159 ; sunspots and weather, 160 German Astronomical Society, 7, 497 ; Gill, star parallaxes, 44, 5I, 498, 499 ; motion of $\zeta$ Toucanæ, 47 ; expedition to Ascension, 292 ; distance of the sun, 292-3, 294, 296, 298; measurements of minor planets 293-4, 296 ; great comet of I882, 434, 494; photograph of Argo nebula, 486; photographic survey of the heavens, 495; actinic intensity of Milky Way stars, 509; Coudé telescope, $5^{23}$ 
Gladstone, Dr. J. H., spectrum analysis, 166,169

Glaisher,occultation by Halley's comet, 132

Glasenapp, coronal photographs, 233 ; light equation, 285, 297

Glass, optical, excise duty on, I39, I43 ; Guinand's, I40-I ; Jena, 5 I 5

Gledhill, spot on Jupiter, 359

Goldschmidt, nebulæ in the Pleiades, 494

Goodricke, periodicity of Algol, 469

Gore, catalogue of variable stars, $47 \mathrm{I}$; of computed binaries, 501 ; discovery of U Orionis, 475

Gotha, astronomical congress at, 7

Gothard, bright-line stellar spectra, $456-7,45^{8}$; spectra of planetary nebulæ, 489; photographs of nebulæ, 49I

Gould, variation of latitude, 3I8; first photograph of Mars, 344; comets of 1881 and $18 \mathrm{c} 7,425$; fluctuations in stellar brightness, 472 ; measures of photographed Pleiades, 492 ; Uranometria Argentina, 497 ; solar cluster, 507

Graham, discovery of Metis, 94

Grant, solar envelope, 85,208 ; luminous effects attending transits of Venus, 3 I2

Green, N. E., observations of Mars, 343

Greenwich observations, 3, 33, 38

Gregory, David, acliromatic lenses, I39 note

Gregory, James, double-star method of parallaxes, 19 ; reflecting telescopes, $135^{-6}$

Groombridge, star catalogue, 37

Grosch, corona of 1867,22 I

Grubb, Sir Howard, photographic reflector, 49I ; Vienna and Greenwich refractors, 515,517 ; siderostat, 523

Grubb, Thomas, Melbourne reflector, $5 \mathrm{I} 3$

Grünwald, theory of spectra, 242

Gruithuisen, snow-caps of Venus, 3 I4 ; lunar inhabitants, 326

Gully, Nova Andromedæ, 475

Guthrie, nebulous glow round Venus, 312

HADLEY, Saturn's dusky ring, I07 ; reflecting telescope, I35

Haerdtl, Winnecke's comet, I 6

Hale, luminous outburst on sun,
200 ; daylight coronal photography, 226 ; spectrum of prominences, 242, 246 ; prominence - photography, 244-6

Hall, A saph, parallax of the sun, 298; discovery of Martian satellites, 345; rotation of Saturn, 367; parallax of Vega, 499; 6I Cygni, 502 ; double star measurements, 502

Hall, Chester More, invention of achromatic telescope, I39

Hall, Maxwell, rotation of Neptune, 371

Halley, stellar proper motions, II ; nebulæ, 26 ; eclipse of $1715,80,83$; predicted return of comet, IO9; magnetic theory of auroræ, 16I ; transits of Venus, 288; lunar acceleration, 332 ; origin of meteors, 397

Hansen, solar parallax from lunar theory, 284

Harding, discovery of Juno, 92 ; celestial Atlas, 95

Harkness, spectrum of corona, 212 ; corona of 1878,219 ; shadow of the moon in solar eclipses, 229 ; lightequation, 285 ; distance of the sun 292, 296, 297, 298

Harrington, variability of Vesta, 35I

Harriot, observations on Halley's comet, 35

Hartwig, Nova Andromedæ, 475

Hasselberg, metallic spectra, 262 spectra of comets, 414, 432; of Nova Andromedæ, 476

Hastings, composition of photo sphere, 189; reversing stratum, 215 ; observations at Caroline Island, 228 ; Saturn's dusky ring, 365

Hegel, number of the planets, 88

Heis, radiant of Andromedes, 405

Heliometer, 4I, 288, 296, 499

Helium, a constituent of prominences, 24I, 247; absence of absorptive action, 265; present in gaseous stars, $45^{6}$; in Orion nebula, 489

Helmholtz, gravitational theory of sun-heat, 378-9, 38 I

Hencke, discoveries of minor planets, 94

Henderson, parallax of a Centauri, 43 ; observation of chromosphere, 83

Henry, Paul and Prosper, lunar twilight, 325; minor planets, 347 ; markings on Uranus, 369 ; photo- 
graph of Saturn, 490; photographic discovery of nebulæ in Pleiades, 493, 494; plane mirrors, 523

Herrick and Bradley, duplication of Biela's comet, I I 9

Herschel, Alexander S., cometary and meteoric orbits, 403

Herschel, Caroline, her brother's assistant, I4; observation of Encke's comet, I 12

Herschel, Sir John, life and work, 54-6I ; expedition to the Cape, 56 ; Magellanic clouds, 56, 505 ; sunspots, 70-I, I79; solar flames, 82 ; anticipated discovery of Neptune, IOO; status of Hyperion, 105; Biela's comet, Ir8; Halley's, I27; comet of 1843,129 ; sixth star in trapezium, I4I ; grinding of specula, I44; spectrum analysis, I64; solar photography, I8I ; solar constitution, I88; shadow round eclipsed sun, 229; actinometrical experiments, 268; solar heat, 269 ; climate and eccentricity, 319 ; lunar-atmosphere, 324 ; surface of Mars, 338 ; Andromeda nebula, 477 ; observations of nebulæ, 485

Herschel, Colonel, spectrum of prominences, 209 ; of corona, 217

Herschel, Sir William, discovery of Uranus, 5 ; popular interest excited by his astronomical career, 5-6; founder of sidereal astronomy, IO ; biographical sketch, I2-16; sun's motion in space, $17,47,509$; revolutions of double stars, 21,528 ; structure of Milky Way, 22-4, 506 ; study of nebulæ, 25-30 ; results of astronomical labours, 30 ; centre of sidereal system, 49 ; theory of the sun, $65-7,86$; asteroids, 92, 93; discoveries of Saturnian and Uranian satellites, 104, 107-8, I37 ; comet of I8II, I23; reflecting telescopes, $135-8$; sunspots and weather, 16o; transit of Mercury, 301; refraction on Venus, 3II ; lunar volcanoes, 327 ; similarity of Mars to the earth, 336-7; Jovian trade-winds, 352 ; rotation of Jupiter's satellites, 356 ; ring of Saturn, 363 ; rotation of Saturn, 368 Herz, comets' tails, 42 I

Hevelius, acquaintance with "Mira," II ; contraction of comets, II4; granular structure of a comet, 439
Higgs, photographs of solar spectrum, 263

Hind, solar flames, 84 ; Iris and Flora discovered by, 94 ; distortion of Biela's comet, I19; transit of a comet, 125; earth in a comet's tail, 396 ; comets of 1843 and 188o, 422 ; computation of Schmidt's comet, 439 ; new star, 473 ; variable nebula, 484

Hirn, solar temperature, 273; resistance in space, $42 \mathrm{I}$

Hodgson, outburst on the sun, 199

Hoek, cometary systems, 438

Holden, Uranian satellites, I08 ; eclipse-expedition, 227; coronal extensions, 233,235 ; solar rotation, 252 ; transit of Mercury, 30I ; intra-Mercurian planets, 308 ; drawing of Venus, 3 ro ; canals on Mars, 342 ; surface of Mars, 344 ; transits of Jupiter's satellites, 355 ; markings on Uranus, 370; disintegration of great comet, 439 : colours of double stars, 453 ; Orion and Trifid nebulæ, 485 ; rediscovery of Nova Aurigæ, 486 ; director of Lick Observatory, 520

Holden and Schaeberle, helical nebulæ, $5 \mathrm{r} 8$

Holmes, discovery of a comet, 409

Homann, solar translation, 489

Hooke, solar translation, I I ; stellar parallax, I8; repulsive force in comets, 127 note; automatic movement of telescopes, 150 ; spots on Mars, 336, $33^{8}$

Hopkins, solidity of the earth, 316

Horrebow, sunspot periodicity, 155 ; satellite of Venus, 316

Hough, red spot on Jupiter, $35^{8}$, 360

Houzeau, solar parallax, 296

Hubbard, period of 1843 comet, I30, 424

Huggins, Dr., spectroscopic observations of prominences, 212, 243 ; daylight coronal photography, 224 6; hydrogen-spectrum in stars. 246 ; stellar motions in line of sight, 250, 466-7; transit of Mercury, 301 ; occultation of $\epsilon$ Piscium, 324 ; snowcaps on Mars, 338; spectrum of Mars, 340 ; of Jupiter, 354; Jovian markings and sunspots, 362 ; spectrum of Saturn's ring, 368; of Uranus, 370 ; of comets, 4I4-6 ; photographs, 428, 
432 ; stellar spectroscopy, 45I ; colours of stars, 453 ; Presidential Address at Cardiff, 455 ; chemical composition of stars, $46 \mathrm{I}$; photographs of stellar spectra, 462-3, 524; spectra of new stars, 473,476 ; theory of Nova Aurigæ, 479; spectra of nebulæ, 482-3; nebular radial movement, 486

Huggins, Dr. and Mrs., photograph of Uranian spectrum, 37 I ; spectra of Wolf-Rayet stars, 459; ultra-violet spectrum of Sirius, 463 ; spectrum of Nova Aurigæ, $478,48 \mathrm{I}-2$; of Orion nebula, 484,489

Humboldt, sunspot period, I 56 ; magnetic observations, I 57, I 58 ; starshower, 400

Hussey, search for Neptune, 97

Huygens, stellar parallax, I9; Orion nebula, 25 ; discovery of Titan, I04 ; Saturn's ring, I05, 366; spot on Mars, 337

Hydrogen, a constituent of prominences, 209, 24I, 247 ; spectrum, 246-7, 462-3; absorption in stars, 246, 452, 46I, 40́2 ; in sun, 263, 462 ; supposed material of first-type cometary tails, 420; bright lines of, in stellar spectra, 456-8, 473, 474, 478 ; in nebular spectra, 483,489

JACOBY, measurements of Rutherfurd's plates, 492

Janssen, photographs of the sun, 205 ; spectroscopic observations of prominences, 2 IO-I ; escape from Paris in a balloon, $2 \mathrm{I} 3$; coronal spectrum, 2I6-7, 22I ; photographs of corona of 1883,228 ; rarefaction of chromospheric gases, 229 ; oxygenabsorption in solar spectrum, 266 ; ascent of Mont Blanc, 267 ; transit of 1874,289 ; spectrum of Venus, 313 ; of Saturn, 368 ; photographs of Tebbutt's comet, $427-8$; of Orion nebula, 489

Japetus, eclipse of, 365 ; variability, 368

Joule, heat and motion, 376

Jupiter, mass corrected, 95, I I4 ; supposed influence on sunspot period, 202 ; physical condition, 351-3; spectrum, 354 ; satellite-transits, 355 ; discovery of inner satellite, 357 ; red spot, 357-6r ; photographs, 36I-2, 490 ; periodicity of markings, 362
KAISER, rotation of Mars, 337 ; map of Mars, 34I

Kammermann, observation of Maia nebula, 493

Kant, position of nebulæ, 16; Sirius the central sun, 48; planetary intervals, 87 ; tidal friction, 333 ; condition of Jupiter, 352 ; cosmogony, 374

Kapteyn, preparation of Cape Durch. musterung, 495 ; stellar parallaxes, 500 ; solar cluster, 507

Kayser and Runge, carbon in sun, 264 Keeler, red spot on Jupiter, 36r ; spectrum of Uranus, 37I ; of nebulæ, 484 ; radial movements of nebulæ, $487,518,526$

Kepler, star of 1604,29 ; solar corona, 79 ; missing planets, 87 ; cometary decay, II3, 4II; comet of I6I8, I I9; physical astronomy, I75

Kiaer, comets' tails, 421

Kirchhoff, foundation of spectrum analysis, 164, 167-168, 450 ; map of solar spectrum, I69; solar constitution, 186, 188, 215

Kirkwood, distribution of minor planets, 349 ; grouped orbits, 350 ; divisions in Saturn's rings, 367 ; origin of planets, 382 ; direction of their rotation, 390 ; comets and meteors, 404, 4I I

Kleiber, Perseid radiants, $4 \mathrm{I} 3$

Klein, Hyginus N., 328-9

Klinkerfues, comet predicted by, 407, 4 IO ; apparitions of southern comet, 423

Konkoly, spectrum of $\gamma$ Cassiopeiæ, 457

Kreil, lunar magnetic action, 16I

Kreutz, orbit of $186 \mathrm{I}$ comet, 397 ; period of great comet of 1882,437 ; multiple nucleus, 439

Krüger, segmentation of great comet, 439

Küstner, variation of latitude, 318

Kunowsky, spots on Mars 337

LACAILLE, southern nebulæ, 26

Lagrange, gravitational theory of solar system, 3; planetary disruption, 93

Lahire, diffraction-theory of corona, $8 \mathrm{I}$; distance of the sun, $2 \mathrm{S2}$; mountains of Venus, 3 Io

Lalande, popularised astronomy, 5 ; revolving stars, 2 I ; Histoire Céleste, 37,497 ; nature of sunspots, 63 ; observations of Neptune, IO2 
Lambert, solar motion, II ; construction of the universe, 16,48 ; missing planets, 87

Lamont, magnetic period, $157-8$

Lamp, ashen light of Venus, 315

Landerer, character of the light, of Venus, 3 I4

Langdon, mountains of Venus, $3 \mathbf{I}$ I

Langley, solar granules, 204 ; corona of 1878,220 ; spectroscopic effects of solar rotation, 251 ; experiments at Pittsburg, 273; bolometer, 275 ; distribution of energy in solar spectrum, 277-8; atmospheric absorption, 277-9, 339 ; colour of unveiled sun, 278 ; solar constant, 279 ; lunar heat-spectrum, 330 ; temperature of lunar surface, 331 ; age of the sun, 379

Laplace, lunar acceleration, 2, 332 ; Exposition du Système du Monde, 6; nebular hypothesis, 30, 374-6, 381-3, 391 ; stability of Saturn's rings, I05, 363 ; Lexell's comet, 132, 445 ; solar atmospheric absorption, 274; solar distance by lunar theory, 284 ; origin of meteors, 398 ; of comets, 448

Lassell, search for Neptune, 98 ; discovery of satellite, IO3; of Hyperion, 105; dusky ring of Saturn, I06; observations at Malta, 108, 519; reflectors, 142 ; equatoreal mounting, 150

Latitude, variation of, 318-9

Laugier, period of I843 comet, I3I ; solar rotation, 182

Le Chatelier, temperature of the sun, 272

Ledger, orbit of Aethra, 348

Lescarbault, pseudo - discovery of Vulcan, 306 ; halo round Venus in transit, 313

Lespiault, orbits of minor planets, 348

Le Sueur, spectrum of Jupiter, 354

Leverrier, discovery of Neptune, 99, IOO, IOI ; Lexell's comet, I2I, 445; distance of sun, 284, 296; movements of Mercury, 305; prediction of Vulcan, 306; supposed transits, 307 ; mass of asteroids, 350 ; orbit of November meteors, 403 ; Perseids and Leonids, 405

Lexell, comet of I 770, I 21,445

Liais, supposed transit of Vulcan, 306; comet of I86I, 396; division of a comet, 410
Librations, of Mercury, 305; of Venus, 310 ; of the moon, 327

Lick, foundation of observatory, 519

Light, velocity, 45, 285-6, 297 ; extinction in space, 54 ; refrangibility changed by movement, 249

Light-equation, 285,297

Lindsay, Lord, expedition to the Mauritius, 289

Line of sight, movements in, 249 ; spectroscopically determinable, 250 , 465; of solar limbs, 250-2 ; within prominences, $253,258-9$; of stars, $466-7$; serves for detection of close binaries, 467-70

Listing, dimensions of the globe, 322

Littrow, chromosphere, 85; sunspot periodicity, 156

Liveing and Dewar, numerical ratios of wave-lengths, 241 ; line-displacements in prominences, 259 ; spectrum of liquid oxygen, 266

Lockyer, solar spectroscopy, 194, 263; theory of sunspots, 197-8, 203 ; daylight observations of prominences, 2I I, 24I, 254 ; eclipse of 1870,213 ; reversals in solar atmosphere, 216, 242 ; slitless spectroscope, 217; corona of 1878, 219; coronal spectrum, 223 ; glare-theory of corona, 229; eclipse of I886, 231 ; classification of prominences, 244 ; motion-displacements in prominences, 252-3 ; celestial dissociation, 255-60; chemistry of sunspots, 257-8; carbon in sun, 264 ; spots on Mars, 337 ; meteoritic hypothesis, 454-5; chief nebular line, 483; equatoreal Coudé, 523

Loewy, constant of aberration, 298 ; equatoreal Coudé, 522

Lohrmann, lunar chart, 325 ; Linné, 328

Lohse, J. G., spectrum of great comet, 44I ; of $\gamma$ Cassiopeiæ, $457^{\prime}$

Lohse, O., daylight coronal photography, 224 note; red spot on Jupiter, 35I ; periodicity of Jupiter's markings, 362 ; recession of Sirius, 466; spectrum of Nova Cygni, 474, Louville, nature of corona, $8 \mathrm{I}$; chromosphere, 83

Lyman, atmosphere of Venus, 312

MCCLEAN, photographs of solar spectrum, 262, 263

Macdonnell, luminous ring round Venus, 313 
Maclaurin, eclipse of 1737,78

Maclear, Admiral, observations during eclipses, 214, 230

Maclear, sir Thomas, maximum of $\eta$ Argus, 59 ; observation of Halley's comet, 127

Mädler, central sun, 49 ; observations of Venus, 3I I, 3I2; lunar rills, 323 ; -aspect of Linné, 328 ; community of proper motions, 509

Magellanic clouds, 56, 505 ; spiral character, 508-9

Magnetism, terrestrial, international observations, I 57 ; periodicity, I 58 9; solar relations, I59, I99-200, 203, 254; lunar influence, I6I

Mann, N. M., period of 6I Cygni, 502

Mann, W., last observation of Donati's comet, 394

Maraldi, solar corona, 8I ; rotation of Mars, 336 ; satellite-transits on Jupiter, 355 ; spot on Jupiter, 359

Marius, Simon, Andromeda nebula, 25 ; sunspots, 62 ; origin of comets, 63 note

Mars, oppositions, 28I ; solar parallax from, 282, 285, 292, 296; polar spots, $336,338,340$; general stability of markings, 337,344 ; rotation, 337-8 ; atmosphere, 338-40; climate, 340 ; canals, 34I-3; photographs, 344 ; satellites, 344-6, 389-90, 5 I4

Marth, revolutions of Neptune's satellite, 372

Maskelyne, components of Castor, 21 ; Astronomer Royal, 33 ; experiment at Schehallien, 32I ; comets and meteors, 403

Maunder, photographs of 1886 corona, 232 ; stellar types, 454,456 ; spectrum of $\gamma$ Cassiopeiæ, 458

Maury, duplication of Biela's comet, I 19

Maury, Miss A. C., discoveries of spectroscopic binaries, 467,468

Maxwell, J. Clerk, structure of Saturn's rings, 364, 366

Mayer, Rev. C., star satellites, 20

Mayer, Julius R., tidal friction, 334 ; meteoric sustentation of sun's heat, 376-7

Mayer, Tobias, stellar motions, II ; solar translation, I7 ; repeating circle, I 5I ; solar distance by lunar theory, 284 ; satellite of Venus, 316 ; lunar surface, 323

Mazapil meteorite, 4I I
Meldrum, sunspots and cyclones, 204

Melloni, lunar heat, 329

Melvill, spectra of flames, 162

Mercury, mass, I I4 ; luminous phenomena during transits, $30 \mathrm{I}-2$; mountainous conformation, 303-4 ; rotation, 303-5 ; theory of movements, 305-6, 308

Mersenne, principle of reflecting telescope, 135

Messier, catalogue of nebulæ, 26

Meteoric hypothesis of solar sustentation, 376, 377 ; of planetary formation, 378

Meteorites, origin, 398; relation to shooting stars, 4I I-I2

Meteoritic hypothesis of cosmical constitution, 454-5, 484

Meteors, origin, 397-8 ; relationship to comets, 397, 403-5, 414; Leonids, 398-400, 40I-2 ; Perseids, 400, 403, 405, 4I3; Andromedes, 405; of I872, 406-7; of 1885, 408-9; of I892, 410; stationary radiants, 4I $2-3$

Meunier, canals of Mars, 342

Meyer, divisions of Saturn's rings, 367 ; comet of 1880,424 ; refraction by a comet, 426 ; comet Tewfik, 438

Michell, double stars, 20; torsion balance, $32 \mathrm{I}$; star systems, 5 IO

Michelson, velocity of light, 296

Milky Way, grindstone theory, I6; clustering power, 23, 3I ; structure, $24,50,54,56,506-7$; centre of gravity, 48-9; frequented by temporary stars, 482; drawings and photographs, 507-8

Miller, W. A., spectrum analysis, I64, I69, I70 ; stellar chemistry, 45I

Mira, light-changes, II ; spectrum, $45^{2}, 45^{8}$

Mitchel, lectures at Cincinnati, 8

Mohn, origin of comets, 448

Möller, theory of Faye's Comet, I2I

Moll, transit of Mercury, 301, 302

Monck, Perseid meteors, 4I3; new stars, 477

Moon, the, acceleration, 3, 332, 334 ; magnetic influence, I6I ; photographs, I90, 329; solar parallax from inequality of movement, 284 , 296 ; study of surface, 323 ; atmosphere, 323-5 ; charts, 325-6, 328 ; librations, 327 ; supposed changes, 328-9; thermal radiations, 329-3I; mode of rotation, 333 ; errors of tables, $334-5$; origin, $384-6$ 
Morinus, celestial chemistry, I74

Morstadt, Biela meteors, 404

Mouchez, photographic survey of the heavens, 496

Müller, phases of minor planets, 350, $35 \mathrm{I}$; variability of Neptune, 371 ; of Pons's comet, 443

Munich, Optical Institute, 34, 40

Myer, description of solar eclipse, 230

Naegamvala, Mercurian halo, 302

Nasmyth, assisted in construction of Lassell's reflector, IO3; solar willowleaves, 204 ; comparative lustre of Mercury and Venus, $3 I_{3} 3$; condition of Jupiter, $35^{2}$

Nasmyth and Carpenter, The Moon, 326

Nebula, Andromeda, early observations, 25; new star in, 475-6; photographs, 476, 49I ; structure, 477,491 ; visibility at Arequipa, 520

Nebula, Orion, observed by Herschel, I4; mentioned by Cysatus, 25; fallacious signs of resolvability, I 48,483 ; spectrum, $483,484,489$; monograph of, 485 : movement of recession, 487 ; photographs, 489-9I

Nebulæ, first discoveries, 25-6 ; catalogues, $26,55,60$; distribution, 27 , 58,505 ; composition, $29,57,483$; resolution, 57, 146, 148 ; donble, 58 ; spiral, I46-7, $484,49 \mathrm{I}-2$; new stars in, 475-7, 484; spectra, 482-4, 489 ; variability in light, $484-5$; radial movements, 486-7; photographs, 489-92, 509

Nebular hypothesis, Herschel's, 2930 ; Laplace's, 374-6, 391 ; objections, $38 \mathrm{I}-3$

Neison, atmosphere of Venus, 3I2 ; of the moon, 324; work on The Moon, 326

Neptune, discovery, 96-102 ; satellite, I03; density, I04; comets captured by, $122,372,442$; mode of rotation, $372,383,391$

Newall, F., stellar aspect of Nova Aurigæ, 470

Newall, R. S., 25-inch refractor, 514

Newcomb, origin of minor planets, 94; telescopic powers, 148 ; distance of the sun, 284, 287; velocity of light, 297 ; variation of latitude, 318 ; lunar atmosphere, 324 ; lunar theory, 334-5 ; disturbance of Neptune's satellite, 372 ; formation of planets, 382
Newton, H. A., capture of comets by planets, I22 ; falls of aerolites, 378 ; November meteors, 40I-2 ; meteors of $1885,408,409$; orbits of aerolites, 4I2

Newton, Sir Isaac, founder of theoretical astronomy, I, I75; law of gravitation obered by comets, I09; first speculum, I35; solar radiations, 268; law of cooling, 269, 27I, 272

Niesten, volume of asteroids, 350 ; red spot on Jupiter, 358

Nobert, diffraction-gratings, $\mathbf{5 2 5}$

Noble, observations of Mercury, 304 ; secondary tail of Schaeberle's comet, 430

Nolan, origin of the moon, 386 ; period of Phobos, 389

Norton, corona of I869, 220 note; expulsion-theory of solar appendages, 240 note; comets' tails, 4I7, 420

Nova Andromedæ, 475-6

Nova Aurigæ, 478-82

Nova Cygni, 473-4, 48 I

Nutation, discovered by Bradley, 4, I8; an uranographical correction, 37

OBSERVATORY, Greenwich, 3, 33 ; Cape of Good Hope, 8, 44 ; Paramatta, 8, I I2; Harvard College, 8, I06, 464 ; Königsberg, 36 ; Dorpat, 52 ; Pulkowa, 53; Palermo, 89; Berlin, I12 ; Anclam, I85; Potsdam, I85; Kew, I9I ; Arequipa, 325, 520-I ; Lick, 5 I9-20

Occultations, of stars by comets, i I8, I $31-2,426$; by the moon, 324 ; by Mars, 338 ; of Jupiter by the moon, 325

Olbers, Bessel's first patron, 35-6 ; discoveries of minor planets, $9 \mathrm{I}-2$; origin by explosion, 9I-4; career, I IO-I ; Biela's comet, i 8 ; comet of 1811, 123; electrical theory of comets, 123-4, I30, 393, 417 ; multiple tails, 124, 393, 420; comet of I819, I25; cometary coruscations, I30; a star behind a comet, 131 ; November meteors, 400

Olmsted, radiant of Leonids, 399 ; orbit, 400

Oppenheim, calculation of Schmidt's comet, 439

Oppolzer, E. von, theory of sunspots, I98

Oppolzer, Th. von, Winnecke's comet, 
II6; position of Vulcan, $30 \Omega$; comet of $\mathrm{IS}_{43}, 423$

Oxygen, no eridence of presence in sun, 265,267 ; telluric absorption, 266

PALISA, search for Vulcan, $30 \$$; discoreries of minor planets, 347

Pallas, discorery, 91 ; inclination of orbit, 92, 34S; diameter, 93,350

Pape, tails of Donati's comet, 417

Parallax, annual, of stars, 12, IS-19, $49 S-500$; illusory resuits, 39 ; of 61 Cygni, 43,500 ; of Vega, $43,499,500$; of a Centauri, 44, 49S; of Sirius, $5 \mathrm{I}, 49 \mathrm{~S}$; horizontal, of sun, $2 \mathrm{SO}$; Encke's result from transits of Venus, $2 S_{3}, 2 S_{7}$; found too large, 284 ; improred ralue from oppositions of Mars, 2S $5,292-3$; from light-relocity, $2 \$_{5}-6,297-\$$; from recent transits, 29I-2, 296; from obserrations of minor planets, 2934 ; general result, $29 \mathrm{~S}$

Paris Catalogue of Stars, 497

Pastorfi, drawings of the sun, 125

Peirce, structure of Saturn's rirgs, 363

Perrotin, rotation of Venus, 310 ; canals of Mars, 342 ; clouds on Mars, 344; striation of Saturn's rings, 364 ; rotation and compression of Uranus, 369,370 ; changes of Pons's comet, 443 ; Maia nebula, 493 ; measurements of double stars, 502

Perry, Father, eclipse of 1S86, 216; eclipse of Dec. ISS9 and death, 236

Personal equation, 153,290

Peters, C. A. F., parallax of 6r Cygni, 43 ; disturbed motion of Sirius, 50

Peters, C. F. W., orbit of Norember meteors and Tempel's comet, 403 ; orbit of 61 Cygni, 502

Peters, C. H. F., sunspot observations, $\mathrm{IS}_{3}, \mathrm{IS}_{4}$; discoreries of minor planets, 347 ; star-maps, 347,498

Peytal, description of chromosphere, $\dot{8}_{4}$

Phobos, rapid rerolution, 346, 382, $3^{\mathrm{S}} 9$; mode of origin, 390

Photography, solar, ISI, I9I-2, 205 ; of corona, 207, 216, 224, 22S, 230, 232-36; without an eclipse, 224-6; of prominences, $20 S, 244^{-6}$; of coronal spectrum, 223 ; of prominence spectrum, 242, 246; of solar spectrum, 262-3, 524, 526; of electric-are spectrum, 264 ; of Uranian spectrum, 371; of cometary spectra $42 \mathrm{~S}, 432$; of stellar and nebular spectra, 462-5, 47 $8,4 \mathrm{SI}_{1}, 4 \mathrm{~S}_{7}-9$; lunar, I90, 329; detection of comets by, 224, 447; of asteroids, 347; use of, in transits of Venus, 258, 291, 294, 314; Mars depicted br, 344 ; Jupiter, 361 ; comets, $427-\dot{S}$, 446, 494; nebulie, 4S6, 4S9-92, 494, 509 ; Milky War, 50 ; star-charting by, 495-6; star-parallaxes determined by, 500 ; rapid improvement, 524

Photometry, stellar, 59, 503; of planetary phases, 303, 350; of Saturn's rings, 364-5; photographic, 504

Photosphere, named by Schrüter, 66; structure, 19S, 204-5

Piazzi, star-catalogues, 37 ; parallaxes, 39 ; proper motion of 6I Cygni, 42 ; birth and training, $8 S-9$; discorery of Ceres, $S_{9}$; fire-foot circle, 89,151

Picard, Saturn's dark ring, 107 ; sun's distance, $2 \mathrm{~S}_{2}$

Pickering, E. C., satellites of Mars photometrically measured, 345 ; minor planets, 350; rariability of Japetus, 368 ; of Neptune, 371 ; the lost Pleiad, $45 \mathrm{~S}$; gaseous stars, 459 ; spectrographic results, 464 ; eclipses of Algol, 470; spectrum of Nova Crgni, 474; photometric catalogue, 503; photographic photometry, 504; preponderance of Sirian stars in the Milky Way, 509 ; climate of Arequipa, 520; horizontal telescope, 523

Pickering, W. H., corona of I856, 232-3; photographs of corona, Jan. I, ISS9, 235; lunar twilight, 325 ; lunar volcanic action, $32 \mathrm{~S}$; melting of snow on Mars, 340; snow-fall, 344 ; photograph of Orion nebula, 491 ; establishment of observatory at Arequipa, 520

Pingré, phenomena of comets, II4, I 9

Planets, influence on sunspots, 202-3 ; periods and distances, $2 S I$; inferior and superior, 351 ; origin, 375,378 ; relative ages, $382-4$; predictions of intra-Mercurian, 306 ; pseudo-discoreries, 306-S ; transNeptunian, 372-3

Planets, minor, existence anticipated, $\delta_{7}-\mathrm{S}$; discoreries, $89,91-2,94$, 
346-7 ; solar parallax from, 293-4, 296 ; distribution of orbits, 347-50 ; collective volume, 350 ; atmospheres, 351

Plantade, halo round Mercury, 301, 302

Pleiades, community of movement, 49 ; photographed spectra, 464; photographs, 492-4 ; measurements, 492-3; nebulæ, 493-4; systemic union, 5 I I

Pluicker, hydrogen in sun, 263

Plummer, solar translation, 47 ;

Encke's comet, 122

Plutarch, solar corona, 79

Pogson, prominence-spectrum, 209 ; reversing layer, 214 ; discovery of a comet, 407, 410; new star in Scorpio, 477

Pond, errors of Greenwich quadrant, 33 ; controversy with Brinkley, 39

Pons, discoveries of comets, I I2, I 6 , 442

Pontécoulant, return of Halley's comet, 126

Poor, C. Lane, identification of Lexell's comet, 445

Pouillet, solar constant, 268, 278 ; solar temperature, 270 ; temperature of space, 33I

Poynting, mean density of the earth, $32 \mathrm{I}$

Prince, glow round Venus, 312

Pritchard, parallax of Algol, 47I ; photographic determinations of stellar parallax, 500 ; photometric catalogue, 503 ; parallax of $\epsilon$ Ursæ, 5 Io

Pritchett, corona of Jan. I, I889, 234 ; red spot on Jupiter, $35^{8}$

Proctor, glare theory of corona, 229 ; velocity of projection in sun, 254 ; transit of Venus, 287 ; distance of sun, 292 ; atmosphere of Venus, 312; rotation of Mars, 338; map and canals of Mars, 34I, 342 ; condition of great planets, 353 ; Nova Andromedæ, 484 ; status of nebulæ, 505 ; structure of Milky Way, 506 ; star-drift, 509

Procyon, invisible companion, 50, 5I ; parallax, 500

Prominences, observed in $1842,76-7$, 84 ; described by Vassenius, 83 ; observed 1851, 85; photographed during eclipse, 208 ; without an eclipse, 244-6; spectrum, 209, 223, 24I-2, 246-7; spectroscopic method of observing, 210-12, 24I-3; white,
232, 245 ; two classes, 243 ; chemistry, 247 ; distribution, 247-8; cyclonic movements in, 253; velocities, 254-5

QueTelet, periodicity of August meteors, 400

RANYARD, drawing of a sunspot, 125 ; volume on. eclipses, 219; coronal types, 233 ; Jupiter's markings, 362 ; meteors from fixed radiants, 4I3; production of comets' tails, $42 \mathrm{I}$; tenuity of nebulæ, 49I

Rayet, spectrum of prominences, 209, 212 ; gaseous stars, 459

Red spot on Jupiter, 358-61

Reduction of observations, 37 ; Bessel's improvements, 38 ; Baily's, 72

Reed, observations of Jupiter's new satellite, $35^{8}$

Refraction, atmospheric, 37 ; in comets, 132, 426; in Venus, 29I, 3II-I3

Reichenbach, foundation of Optical Institute, 34, 40, I 5 I

Repsold, astronomical circles, 50, I 5 I ; Cape heliometer, 499

Resisting medium, I I 5-7, 435-6

Respighi, slitless spectroscope, 217 ; prominences and chromosphere, 24I, 244, 247-8; solar uprushes, 255 ; spectrum of $\gamma$ Argûs, 459

Reversing layer, detected, 213-4; nature and extent, 2I 5-6, 23I

Riccioli, secondary light of Venus, 3 I4

Riccò, distribution of prominences, 248 ; spectrum of Venus, 313 ; red spot on Jupiter, 359 ; spectrum of great comet, 442

Richer, distance of sun, 28I

Ritter, development of stars, 454

Roberts, photographs of Nova Aurigæ, 480 ; of Orion nebula, 490 ; of Andromeda nebula, 491; of the Pleiades, 494

Roberval, structure of Saturn's rings, 364

Robinson, reflectors and refractors, $5 \mathrm{I} 6$

Roche, inner limit of satellite-formation, 367 ; modification of nebular hypothesis, 390

Römer, star-places, II ; invention of equatoreal and transit-instrument. I 49 ; of altazimuth, I5I ; satellite. transit on Jupiter, 355 
Rosenberger, return of Halley's comet, I26

Rosetit, temperature of the sun, $271-2$

Rosse, third Earl of, biographical sketch, I42 ; great specula, I43-6 ; discovery of spiral nebulæ, I46; resolution of nebulæ, 147 ; climate and telescopes, 519

Rosse, fourth Earl of, experiments on lunar heat, 330

Rost, nature of sunspots, 64

Rowland, photographic maps of solar spectrum, 262, 526; carbon in sun, 264 ; metallic elements, 265 ; concave gratings, 525-6

Riimker, observation of Encke's comet, II 2

Russell, red spot on Jupiter, 359; change in Argo nebula, 485 ; photographs of Milky Way and nubeculæ, 508

Rutherfurd, lunar photography, 329 ; star-spectra, 45I ; photographs of the Pleiades, 492 ; diffraction-gratings, 525

SABINE, magnetic and sunspot periods, I 58 ; pendulum-experiments, 321

Safarik, secondary light of Venus, 315 ; compression of Uranus, 370

Satellites, discoveries, 103-5, 107-8, I37, 345, 357 ; transits, 355 ; variability, $355^{-6}, 368$; origin, 375 , $3^{8} 7$

Saturn, low specific gravity, 362-3; rotation, $367-8$; spectrum, 368

Saturn's rings, first disclosure of, I05; dusky ring, 106-7 ; stability, $105,363,366$; meteoric constitution, 364 ; eventual dispersal, 367

Savary, orbits of double stars, 55

Sawerthal, discovery of a comet, 443

Schaeberle, coronal photographs, 235 ; theory of corona, 237-8; discovery of a comet, 430

Schaeberle and Campbell, observations of Jupiter's satellites, 356, 357

Scheiner, nature of sunspots, 62, 64; helioscope, 18I ; solar rotation, I82; darkening of sun's edge, 274

Scheiner, Dr. J., spectrographic researches, 463, 487; stars and nebulæ in Orion, 489
Schiaparelli, rotation of Mercury, 304-5; of Venus, 309-10 ; spots on Mars, 338 ; snow-cap, 340 ; canals, 34I-3; compression of Uranus, 370; comets and meteors, 397, 402-3, 410; anomalous tail of great comet, 440; Pons's comet, 443; origin of comets, $44^{8}$; measures of double stars, 502

Schmidt, sunspot period, 156 ; lunar rills, 323 ; lunar maps, 326 ; disappearance of Linné, 328 ; discovery of comet, 439 ; appendages to great comet, 440 ; new stars, 473

Schönfeld, extension of Bonn Durchmusterung, 497

Schrader, construction of reflectors, 299

Schröter, a follower of Herschel, 6 ; biographical sketch, 299-300; observations on Mercury, 300-1, 303-4; on Venus, 308, 3II, 314; on the moon, 323 ; a lunar city, 326 ; Linné, 328 ; spots on Mars, 337,338 ; halo round Vesta, 35I ; Jovian markings, 353

Schülen, perspective effects in sunspots, 64

Schumann, spectrum of hydrogen, 482

Schuster, spectrum of corona, 223 ; photographs, 224, 232; spectra of oxygen, 266

Schwabe, discovery of sunspot periodicity, $155-7$

Secchi, chromosphere, 85 ; Biela's comet, 120 ; cyclonic movements in sunspots, I79; solar constitution, I88; depth of spots, I92; nature, I94, I97; eclipse-observations, 207-8 ; reversing layer, 214 ; observations of prominences, 24I, 244,247 ; absence of absorption by helium, 265 ; temperature of sun, 270 ; solar atmospheric absorption, 274 ; Martian canals, 342 ; spectrum of Uranus, 370 ; of Coggia's comet, 416 ; stellar spectral types, 451 ; carbon-stars, 452; gaseous stars, 456

See, colour of Sirius, 453 note ; evolution of stellar systems, 502

Seeliger, photometry of Saturn's rings, 364-5

Seidel, stellar photometry, 503

Sherman, spectrum of Nova Andromedæ, 476

Short, reflectors, 4, I35, I43, I50 ; 
chromosphere, 83 ; satellite of Venus, 316; striation of Saturn's rings, 364

Sidereal science, foundation, 10, 528 ; condition at opening: of present century, 12 ; progress, 61

Siemens, regenerative theory of the sun, 379-80

Simony, photographs of ultra-violet spectrum, 267

Sirius, a binary star, 50; mass, 5I ; parallax, 5I, 498 ; spectrum, I65, 452, 463; former redness, 453 note; radial movement, $466-7$

Smyth, Admiral, Donati's comet, 393

Smyth, Piazzi, lunar radiations, 329; expedition to Teneriffe, 5 I9

Solar constant, 268, 278-9

Solar spectrum, purified by use of a slit, I65; fixed lines, 165-9; maps by Fraunhofer, $165 ;$ Kirchhoff, 169 ; Lockyer, 256 ; Angström, 261 ; Cornu, 262; Rowland, 262, 526; Thollon, 262, 526 ; McClean, 262 ; Higgs, 263 ; distribution of energy, 276-7

Solar System, translation through space, 17, 47-8, 489; development, 374-6, 38I-3, 39I; complexity, 527

Soret, solar temperature, 270

South, Sir James, observations of double stars, 55 ; 12-inch lens, I4I ; Rosse reflector, 146 ; occultation by Mars, 338

Spectroscopic binaries, 467-70, 47 I

Spectrum analysis, defined, I6I ; first experiments, $162-4$; applied to the sun, I62-4; and stars, I65, 450-I ; Kirchhoff's theorem, I68; elementary principles, I 72-4; effects on science, I75-6; radial motion determined by, 250, 465 ; comets examined by, 4I4-6; new stars, 473; nebulæ, 482-3

Spencer, position of nebulæ, 505

Spitaler, attendants on Lexell-Brooks comet, 444

Spitta, transits of Jupiter's satellites, 355

Spörer, solar rotation, I84, I85; chromosphere, 248

Stannyan, early observation of chromosphere, 83

Star-catalogues, 33, 37, 39, 72, 497 ; spectroscopic, 460,465 ; photographic, 495-6; photometric, 503

Star-ärift, 509

Star-gauging, 23, 56
Star-maps, 95, I00, 347,498 ; photographic, 495-6

Stars, movements, II , 42, 47-8, 497, 509 ; in line of sight, 486-8; photometric estimates, I 5, 59-60, 503 ; distances, 42-6,498-500; chemistry, 450,461 ; spectroscopic orders, 452 ; colours, 453 ; stages of development, $453^{-6}$; wide range of real magnitude, 506; gregarious tendency, 5 Io

Stars, double, physical connexion anticipated, 20 ; proved, $21-2,528$; masses, 46, 51 ; catalogues, 52, 55, 60,501 ; orbits, 55,500 ; discoveries, 56, 57, 501, 520; photographs, 492 ; evolution, 502

Stars, gaseous, 456-6o

Stars, temporary, 29, 472-82

Stars, variable, first discoveries, I I-I 2; $\eta$ Argûs, 58-9, 458 ; sunspot analogy, I 59, 472 ; spectra, $45^{8}$; Algol class, 469-7I; catalogues, 47 I-2

Stefan, law of cooling, 272

Steinheil, stellar photometry, 503; silvered glass reflectors, $5^{1} 3$

Stewart, Balfour, Kirchhoff's principle I 68 note; solar investigations, 192-3, 204

Stewart, Matthew, solar distance by lunar theory, 284

Stokes, anticipation of spectrum analysis, I7 I

Stone, E. J., reversul of Fraunhofer spectrum, 214 ; distance of the sun, $285,287,29 I-2$; transit of Venus, 295; Cape Catalogue, 497

Stone, O., observation of Jupiter's inner satellite, 358; cataloguing stars, 497

Stoney, status of red stars, 454

Stroobant, satellite of Venus, 316

Struve, F. G. W., stellar parallax, 40, 43; career and investigations, $5 \mathbf{I}-4$; occultation by Halley's comet, I3 I ; Russo-Scandinavian arc, 321

Struve, Ludwig, solar translation, 48

Struve, Otto, solar velocity, 48 ; his father's successor at Pulkowa, 54; eclipse of $1842,75,78$; Neptune's satellite, I03; changes in Saturn's rings, 365-6; in Orion nebula, 485 Stumpe, solar translation, 48

Sun, the, Herschel's theory, 65-7, 86, I85; atmospheric circulation, 70-1 ; chemical composition, I68, 263-5; mode of rotation, 182-4 ; Kirchhoft's theory, I86; Faye's, I86-90; con- 
vection currents, I87, I90, 205 ; dissociation in, $189,255-60$; luminous outbursts, I98-200; explosions, 254-5 ; heat emission, 268-9, 274, 278-9; temperature, 270-3 ; problem of distance, 280 ; results from transits of last century, 283 , 287 ; from oppositions of Mars, 285, 293 ; from transit of $1874,29 \mathrm{I}-2$; from measurements of minorplanets, 293-4, 296; from transit of 1882 , 296; from light velocity, 297-8 ; concluded value, 298 ; maintenance of heat supply, 376-8I ; past and future duration, 379

Sunspots, first speculations regarding, 62-3; Wilson's demonstration, 64 ; distribution, 70, I84-5; cyclonic theory, 70, 179, I96; periodicity, I 56, I 59, 20 I-3; magnetic relations, I 58, 199-200, 202 ; meteorological, I60, 203-4; auroral, 16I, 199, 20I-2 ; photographs, I8I, I9I-2 ; spectra, 174-5, 257-8; volcanic hypothesis, 197 ; Lockyer's theory, 198 ; planetary influence, 202 ; relation to Jovian markings, 362

Swan, chromosphere, 85 ; sodiumline, 163

Swift, supposed detection of Vulcan, 227, 307-8; discovery of a comet, 446

TACCHINI, spectrum of corona, 223 ; eclipse of 1883,227 ; white prominences, 232; prominences and chromosphere, 248 ; spectrum of Venus, 313

Talbot, Fox, spectrum analysis, I63; spectroscopic method of determining movements of binaries, 467

Tarde, nature of sunspots, 62

Tajlor, eclipse-expedition, 236 ; spectrum of Uranus, 37 I

Tebbutt, comet of 1861, 396; comet discovered by, 425

Telescope, achromatic, 139; Rosse, I44-8, 513 ; equatoreal, I49-50 ; Common's five-foot, 513 ; Newall's 25-inch, 5I4; Lick 36-inch, 515, 518; Yerke's 40-inch, 5 I 7 ; proposed Paris ten-foot, 5 I8 ; Coudé, 522-4

Telescopes, reflecting, Short's, 4, I43, I 50 ; Herschel's, I 4, I35-8; Lassell's, I03, 142, I50; Newtonian, 135, I36; Cassegrainian, 136 ; Gregorian, 136; silvered glass, 513; achromatism, 516 ; refractors, development of power, 34, 5I7 ; difficulties, 5I 5 , 518, 521 ; Fraunhofer's, 40-I; Clark's, I4I, 514-5; distribution in latitude, 52 I

Tempel, red spot on Jupiter, 358; comets discovered by, 397, 4I4; observations on cumets, 426, 439; of Andromeda nebula, 475; discovery of Merope nebula, 493

Temperature, of the moon, 33I ; of space, 33I ; on Mars, 340

Teneriffe, Peak of, experimental observations from, $267,330,519$

Tennant, eclipse-observations, 209, 211,217

Terby, surface of Mars, 34I, 344 ; secondary tail of comet, 430

Thalén, basic lines, 256; map of solar spectrum, 26I ; solar elements, 263

Thollon, coronal spectrum, 223 ; linedisplacements by motion, 25I, 44I ; atlas of solar spectrum, 262, 526; death, 263 ; lunar atmospheric absorption, 324

Thome, comet discovered by, 437

Thomson, Sir William (Lord Kelvin), solar chemistry, I 7 I ; tidal strains, 316 ; rotation of the earth, 335; dynamical theory of solar heat, $377-8,3^{80}$

Thraen, period of Wells's comet, 433

Tidal friction, effects on moon's rotation, 333-4, 384 ; in lengthening month, 384-5; effects on planets, 388-9, 391; on development of binary systems, 502

Tietjen, asteroidal orbits, 347

Tisserand, capture of comets, 122; lunar acceleration, 334, 335; revolutions of Neptune's satellite, 372 ; director of Paris observatory, 496

Titius, law of planetary intervals, $87-8$, IO5

Todd, eclipse of 1887, 233; solar distance, 292, 297 ; trans-Neptunian planet, 373

Tornaghi, halo round Venus, 313

Transit-instrument, I49

Trépied, reversal of Fraunhofer spectrum, 214

Troughton, method of graduation, I5I

Trouvelot, veiled spots, I84 ; chromosphere, in 1878,220 ; intra-Mercurian planets, 227, 308; observations of prominences, 231, 244, 253; of Mercury, 301, 304; rotation of Venus, 310; mountains, 314; red spot on Jupiter, 36r 
Trowbridge and Hutchins, carbon in sun, 264

Tschermak, origin of meteorites, 4 I I

Tupman, transit-expedition, 290; results, 29I

Turner, observations during eclipses; 216, 233

ULLOA, eclipse of I778, 83

United States, observatories founded in, 8

Uranus, discovery, 5,88 , г 38 ; unexplained disturbances, 96-7, 373; satellites, 107-8, 369; equatoreal markings, 370; spectrum, 370-I ; retrograde rotation, 38I, 39I

VALERIUS, darkening of sun's limb, 274

Valle, corona of 1886,235

Vassenius, first description of prominences, 83

Venus, transits, $5,282-3,287$; transit of $1874,287-92$; of $1882,294-6$; atmosphere, 29I, 3II-3 ; rotation, 308-10; mountains, 310-I, 314; spectrum, 3I3; albedo, 3I4; secondary light, 315 ; pseudo-satellite, 315-6; effects upon, of solar tidal friction, 389

Very, lunar heat, 33I

Vesta, discovery, 92 ; diameter, 93, 350 ; spectrum, $35 \mathrm{I}$

Vicaire, solar temperature, 27 I

Vico, comet discovered by, 121 ; rotation of Venus, 309, 310 ; mountain, 3I I

Violle, solar temperature, 270, 27I ; solar constant, 278

Vogel, H. C., spectroscopic effects of solar rotation, 250 ; solar atmospheric absorption, 275,278 ; spectrum of Mercury, 303; of Venus, 313 ; of Vesta, 35I ; of Jupiter, 354 ; of Jupiter's satellites, 356 ; of Uranus, 370 ; rotation of Venus, 310 ; secondary light, 3 I5; cometary spectra, 414, 416, 429, 432 ; carbon in stars, $45^{2}$; stellar development, 454 ; spectrum of $\gamma$ Cassiopeiæ, 456; of Betelgeux, 461 ; of Nova Cygni, 474; of Nova Andromedæ, 476; spectroscopic starcatalogue, 460 ; radial motion of Sirius, 466 ; eclipses of Algol, 470 ; components of Nova Aurigæ, 479; spectrographic determinations of stellar radial motions, 487-8

Vogel, H. W., spectrum of hydrogen, 256 note, 463
Vulcan, existence predicted, 306 ; supposed discoveries, 306-8

WARD, Nova Andromedæ, 475

Wartmann, occultation by a comet, I32

Waterston, solar temperature, 270; meteoric infalls, 377

Watson, supposed discovery of Vulcan, $227,307-8$

Webb, comet of I 86 I, 395-6

Weber, illusory transit of Vulcan, 307

Weinek, discovery of a lunar crater, 329

Weiss, comets and meteors, 403, 405, 406

Wells, comet discovered by, 43 I

Wesley, drawings of corona, 219

Wheatstone, spectrum of electric arc, 164 ; method of determining light-velocity, 286

Whewell, stars and nebulæ, 506

Williams, A. Stanley, canals of Mars, 342 ; markings on Jupiter, 362

Williams, Mattieu, condition of major planets, 353

Wilsing, solar rotation from faculæ, I93; mean density of the earth, 321

Wilson, Alexander, perspective effects in sunspots, 64,192

Wilson, H. C., compression of Uranus, 370

Winnecke, comet discovered by, 116 ; albedo of Mercury, 303 ; Donati's comet, 393, 420

Wisniewski, last glimpse of I8I I comet, I22

Wolf, C., objections to Faye's cosmogony, 384 ; origin of Phobos, 390 ; gaseous stars, 459

Wolf, Max, photographic discovery of minor planets, 347 ; Nova Andromedæ, 475; Nova Aurigæ, 477, 480 ; nebulæ in Cygnus, 508

Wolf, R., sunspot and magnetic periodicity, 159, 201-2; sunspots and variable stars, I59, 472; auroræ, I60 ; suspicious transits, 307

Wollaston, ratio of moonlight to sunlight, 60 ; flame-spectra, 163 ; lines in solar spectrum, 165

Woods, C. Ray, coronal photography, 225, 227 ; Cape Durchmusterung, 495

Wrangel, auroræ and meteors, 407

Wright, G. F., Ice Age in North America, 320 
Wright, Prof., polarisation of cometary light, 429

Wright, Thomas, theory of Milky Way, I6 ; structure of Saturn's rings, 364

YERKES, donation of a superlative telescope, 5I7

Young, C. A., spectrum of sunspots, 195; origin, I96; spectrum of corona, 2I3; reversing layer, 213-4; corona of $1878,220,222$; eclipse of 1887,233 ; prominences and chromosphere, 24I-2 ; photograph of a prominence, 244; spectroscopic measurement of sun's rotation, 25I ; solar cyclones and explosions, 253-4 ; basic lines, 256 ; spectrum of Venus, 313 ; red spot on Jupiter, 359 ; observations on Uranus, 369-70; Andromedes of I892, 410; spectrum of Tebbutt's comet, 429 ; of Nova Aurigæ, 476

Young, Thomas, absorption-spectra, I69

$\mathrm{Z}_{\mathrm{ACH}}$, Baron von, promotion of astronomy, 6, 33; Baily's beads, 74 ; search for missing planet, 88 ; re-discovery of Ceres, 9I ; use of a heliostat, I 50

Zantedeschi, lines in solar spectrum, I66; lunar radiation, 329

Zenger, observations on Venus, 3II, 315

Zenker, mode of production of comet's tails, $42 \mathrm{I}$

Zezioli, observation of Andromedes, 406

Zodiacal light and resisting medium, I 7 ; relation to solar corona, 220, 239; meteoric constitution, 377

Zöllner, electrical theory of comets, I23, 4I6, 4I8, 420; solar constitution, 197 ; observations of prominences, 24I, 243 ; classification, 244; reversion-spectroscope, 256 ; solar temperatare, 273; Mercurian phases, 303; condition of Venus, 315; of great planets, 352 ; albedo of Mars, 346 ; of Jupiter, 354 ; of Uranus, 37 r ; Jovian markings, 362 ; ages of stars, 453 
$\because \ldots$

1. 
In Demy 8vo, 405 pp., Illustrated, Price 12s. 6d.

\title{
T Y C H O B R A E.
}

A PICTURE

OF

SCIENTIFIC LIFE AND WORK

IN THE

\section{SIXTEENTH CENTURY.}

J. L. E. DREYER, Ph.D., F.R.A.S., DIRECTOR OF THE ARMAGH OBSERVATORY.

Science in 羽laín Jlanguaạe.

\section{A S T R O N O M Y.}

SUN, MOON, STARS, ETC.

BY

WILLIAM DURHAM, F.R.S.E.

Crown 8vo, Cloth, Price 1s. 6 d.

\author{
A. AND C. BLACK, \\ SOHO SQUARE, LONDON, W.
}


Complete in 24, Volumes and Index.

\title{
$T \underset{r}{\mathrm{H}} \mathrm{E}$ \\ ENCYCLOPÆDIA \\ BRITANNICA.
}

NINTH EDITION.

A DICTIONARY OF ARTS, SCIENCES, AND

GENERAL LITERATURE.

ILLUSTRATED WITH PLATES, COLOURED MAPS,

AND WOOD ENGRAVINGS.

Price in Cloth Extra, Gilt Top, £37; and in Half-Morocco. or Half-Russia, $£ 456 s$.

\author{
A. AND C. BLACK, \\ SOHO SQUARE, LONDON, W.
}




\section{D'AY USE}

RETURN TO DESK FROM WHICH BORROWBD

\section{LOAN DEPT.}

This book is due on the last date stamped below, or on the date to which renewed. Renewals only: Tel. No. 642.3405

Renewals may be made 4 days prior to date due. Renewed books are subject to immediate recall.

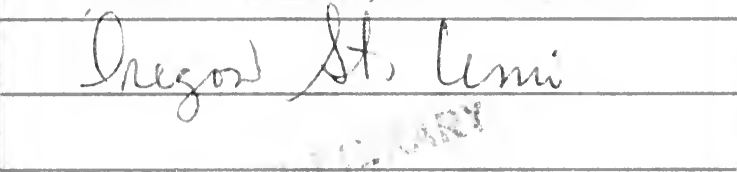


YC 22349 
